\title{
CONTRIBUIÇÃO AO ESTUDO DA ADERÊNCIA ENTRE BARRAS DE AÇO E CONCRETOS AUTO-ADENSÁVEIS
}

\author{
Fernando Menezes de Almeida Filho
}

\begin{abstract}
Tese apresentada à Escola de Engenharia de São Carlos, da Universidade de São Paulo, como parte integrante dos requisitos para obtenção do Título de Doutor em Engenharia de Estruturas.
\end{abstract}

ORIENTADORA: Profa. Dra. Ana Lúcia Homce de Cresce El Debs

São Carlos 

FOLHA DE JULGAMENTO

Candidato: Engenheiro FERNANDO MENEZES DE ALMEIDA FILHO

Tese defendida e julgada em 18/08/2006 perante a Comissão Julgadora:

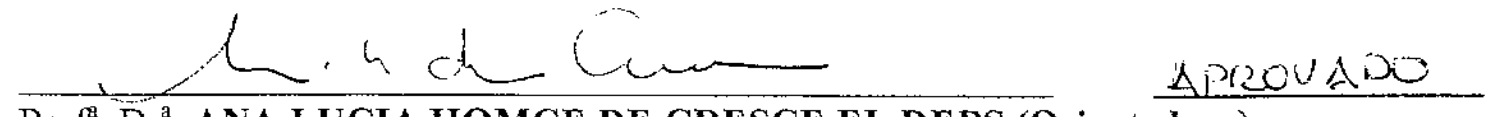
Prof ${ }^{\mathrm{a}}$. Dr $\mathrm{r}^{\mathrm{A}}$. ANA LUCIA HOMCE DE CRESCE EL DEBS (Orientadora)

(Escola de Engenharia de São Carlos/USP)

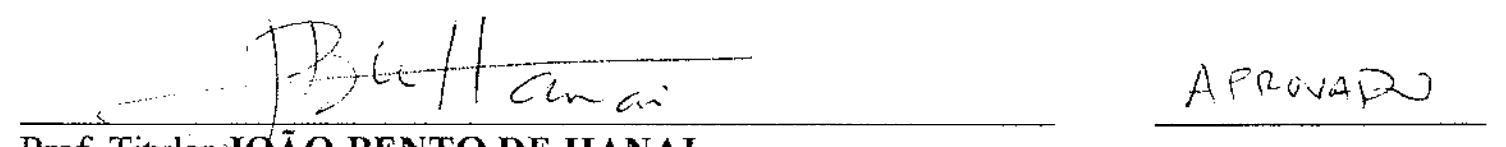

Prof. Titular JOÃO BENTO DE HANAI

(Escola de Engenharia de São Carlos/USP)

Wouic Sulw Bubosc.

Prof .Liv.Doc. MÔNICA PINTO BARBOSA

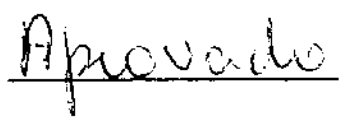

(Universidade Estadual Paulista "Júlio de Mesquita Filho"/UNESP - Campus de Itha Solteira)

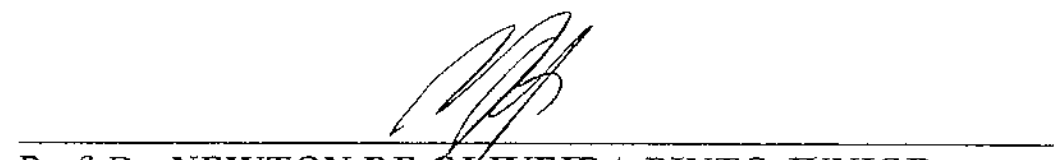

Prof. Dr. NEWTON DE OLIVEIRA PINTO JUNIOR

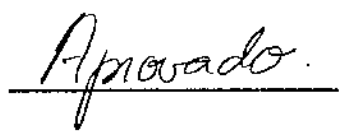

(Universidade Estadua/de Campinas/UNICAMP)

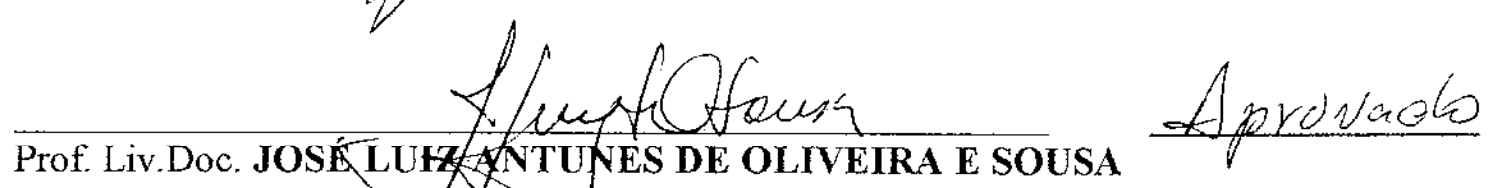

(Universidade Estadualde/Campina/UNICAMP)

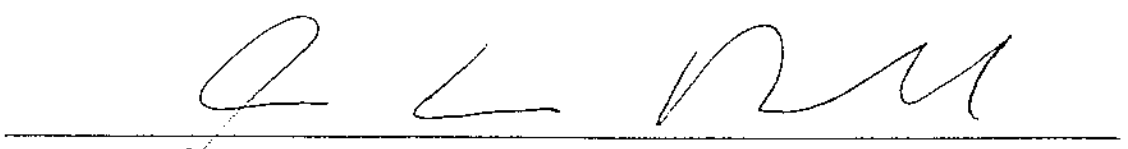

Prof: Associado MARCIO ANTONIO RAMALHO

Coordenador do Programa de Pós-Graduação em

Engenharia Civil (Engenharia de Estruturas)

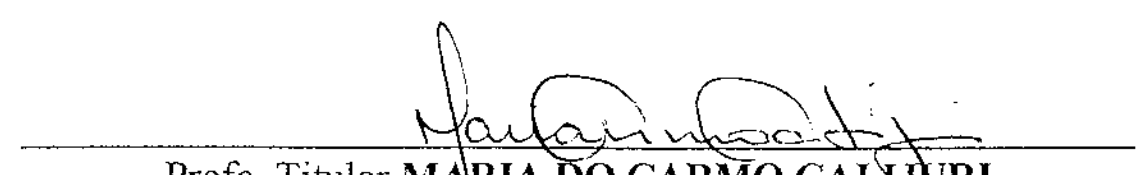

Profa. Titular MARIA Do CARMo CALIJIRI

Presidente da Comissão de Pós-Graduação 

A minha amada esposa, Andréa e ao nosso pequeno Pedro. 



\section{AGRADECIMENTOS}

À Deus, criador de tudo e de todos, por iluminar minha trilha com minha Família e meus Amigos.

A minha querida esposa Andréa Rocha Repenning, amor da minha vida, companheira e amiga incansável, pela sua enorme paciência, dedicação, carinho, apoio, incentivo e alegria, que se tornou junto com nosso pequeno Pedro, o maior objetivo e realização de minha vida.

Aos meus pais, em especial, minha querida mãe, Alanir, que sempre pensou anos-luz à frente de tudo e de todos, para me transformar no que sou.

A toda minha família, que sempre apoiou e acreditou em mim.

À minha orientadora, Professora Ana Lúcia, minha profunda gratidão por sua incansável e sempre bem humorada orientação e sua profunda sabedoria nos instantes de maior necessidade.

A FAPESP pelo auxílio financeiro que propiciou o desenvolvimento da pesquisa e a CAPES e ao CNPq, pelas bolsas de estudos para o doutorado no Brasil e no Exterior.

Ao meu grande amigo de Fortaleza, Ednardo, pessoa de valor ímpar e de inquestionável sabedoria a quem prezo e estimo muito.

Aos Professores Joaquim e Magnólia Mota, que foram fontes de minha inspiração para a engenharia de estruturas.

Aos meus inestimáveis amigos e companheiros do Departamento de Engenharia de Estruturas, em especial Rodrigo Gustavo Delalibera, Adilson Roberto Takeuti, Ricardo Carrazedo, João de Deus, Silvana De Nardin, Alex Sander Clemente, Caio Gorla Nogueira e Walter Luíz pelos momentos de grande alegria e apoio que, direta ou indiretamente, contribuíram para esta pesquisa.

Às empresas Holcim, Brasil Minas S.A., Elken e Grace Brasil, meu profundo agradecimento pelo material doado à pesquisa.

Aos meus amigos de Barcelona, Carlos Boneti, Bryan Barragán, José Ortiz, Joan Ramón Casas, Miguel Angel e Camilo Bernard, exemplos de pessoas com extrema competência e alegria, que foram fundamentais para minha estadia em Barcelona.

Aos professores e funcionários do Departamento de Engenharia de Estruturas, e aos técnicos do Laboratório de Estruturas, Fabiano, Amauri, Luís Vareda, Mário, Mauri e Valdir pela grande ajuda na elaboração dos ensaios e nas "infindáveis" concretagens realizadas, meu agradecimento e respeito. 



\section{Índice}

Resumo vii

$\begin{array}{ll}\text { Abstract ix } & \text { ix }\end{array}$

1. Introdução 1

1.1. Objetivos e justificativas 3

1.2. Metodología 4

1.3. Conteúdo do trabalho 5

2. Concreto auto-adensável 7

2.1. Considerações iniciais 7

2.2. Propriedades do CAA no estado fresco 8

2.2.1. Habilidade de passagem 9

2.2.2. Resistência à segregação 11

2.2.3. Habilidade de Preenchimento 11

2.2.4. Trabalhabilidade 11

2.3. Materiais 13

$\begin{array}{lll}\text { 2.3.1. } & \text { Agregado fino } & 13\end{array}$

$\begin{array}{lll}\text { 2.3.2. } & \text { Agregado graúdo } & 14\end{array}$

$\begin{array}{lll}\text { 2.3.3. Cimento } & 16\end{array}$

2.3.4. Aditivos e Adições Minerais 17

$\begin{array}{lll}\text { 2.3.4.1. Superplastificante } & 18\end{array}$

2.3.4.2. Sílica ativa 22

2.3.4.3. Finos (fillers) 23

2.4. Métodos de verificação e aprovação do traço da mistura de CAA 26

2.4.1. Ensaio de espalhamento (Slump flow test) 26

2.4.2. Ensaio de funil-V (V-funnel test) 28

2.4.3. Ensaio de caixa-L (L-Box test) 28

2.4.4. Ensaio de tubo-U (U-pipe test) 30

2.4.5. Ensaio de Anel-J (J ring) 32

2.4.6. Ensaio de Alto-adensamento do concreto 33

2.5. Considerações finais 33

3. Determinação da composição do CAA 35

3.1. Considerações iniciais 35

3.2. Proposta para determinação do concreto auto-adensável 40 
3.3. Materiais utilizados 42

3.4. Etapa Pasta 43

3.5. Etapa agregado 51

3.6. Etapa concreto 52

3.7. Considerações finais e resumo dos traços desenvolvidos 58

4. Aderência aço-concreto $\quad 61$

4.1. Considerações iniciais 61

4.2. Mecanismo de ruptura 63

4.3. Considerações sobre a avaliação da resistência de aderência 65

4.4. Considerações sobre os ensaios de aderência 67

4.5. Análise local da resistência de aderência 71

4.6. Considerações sobre investigações da resistência de aderência em concretos auto-adensáveis 73

4.7. Considerações finais $\quad 74$

5. Investigação experimental da aderência 77

$\begin{array}{ll}\text { 5.1. Programa experimental } & 77\end{array}$

5.2. Geometria dos modelos 79

5.2.1. Modelos de arrancamento 79

5.2.2. Modelos de viga 80

5.3. Instrumentação 83

5.3.1. Ensaios de arrancamento 83

5.3.2. Ensaios de viga 83

5.4. Aplicação do carregamento 84

5.5. Caracterização das barras de aço 85

5.6. Modelos de arrancamento 86

5.6.1. Série $1 \quad 86$

5.6.1.1. Modelos em CC 86

5.6.1.2. Modelos em CAA 89

$\begin{array}{lll}\text { 5.6.2. Série } 2 & 91\end{array}$

5.6.2.1. Modelos em CC 91

5.6.2.2. Modelos em CAA 93

5.6.3. Série complementar 96

5.7. Modelos de viga 99 
$\begin{array}{lll}\text { 5.7.1. } & \text { Série } 1 & 100\end{array}$

5.7.1.1. Modelos em CC 100

5.7.1.2. Modelos em CAA 104

$\begin{array}{lll}\text { 5.7.2. Série } 2 & 107\end{array}$

$\begin{array}{ll}\text { 5.7.2.1. Modelos em CC } & 107\end{array}$

$\begin{array}{lll}\text { 5.7.2.2. } & 111\end{array}$

5.8. Considerações finais 115

\section{Variabilidade das propriedades do CAA no estado fresco e} endurecido

6.1. Considerações iniciais 119

6.2. Objetivos 120

6.3. Materiais utilizados 121

6.4. Estudo da composição do traço 122

6.4.1. Etapa pasta 122

$\begin{array}{ll}\text { 6.4.2. } & 123\end{array}$

$\begin{array}{ll}\text { 6.4.3. Etapa concreto } & 124\end{array}$

6.5. Variabilidade do concreto auto-adensável no estado fresco 125

6.6. Variabilidade do concreto auto-adensável no estado endurecido 128

6.7. Variabilidade da aderência do concreto auto-adensável 133

6.7.1. Materiais e equipamentos utilizados 133

6.7.1.1. Aço 133

6.7.1.2. Concreto 133

6.7.1.3. Equipamentos utilizados 133

$\begin{array}{ll}\text { 6.7.2. Programa de ensaios } & 134\end{array}$

$\begin{array}{ll}\text { 6.7.3. Resultados } & 137\end{array}$

$\begin{array}{lll}\text { 6.7.3.1. Série C1 } & 137\end{array}$

6.7.3.2. Série C2 139

6.7.3.3. Série C3 142

6.8. Considerações finais 144

7. Simulação numérica 147

$\begin{array}{ll}\text { 7.1. } & \text { Considerações iniciais } \\ & 147\end{array}$

$\begin{array}{lll}\text { 7.1.1. } & \text { Materiais } & 150\end{array}$

$\begin{array}{lll}\text { 7.1.1.1. Concreto } & 150\end{array}$ 
7.1.1.2. Aço

7.1.1.3. Interface aço-concreto 151

7.2. Elementos utilizados 152

7.3. Simulação numérica 153

7.3.1. Modelos de arrancamento 153

$\begin{array}{ll}\text { 7.3.2. Modelos de viga } & 159\end{array}$

7.4. Considerações finais 165

8. Análise e discussão dos resultdos 167

8.1. Considerações iniciais 167

8.1.1. Critérios para análise da resistência de aderência 168

8.1.2. Critérios para previsão da resistência à tração e do módulo de $\begin{array}{ll}\text { elasticidade do concreto } & 171\end{array}$

8.1.3. Critérios para análise dos resultados 172

8.1.4. Parâmetros estatísticos analisados 172

$\begin{array}{ll}\text { 8.1.4.1. Média } & 173\end{array}$

8.1.4.2. Desvio Padrão 173

8.1.4.3. Coeficiente de Variação 173

8.1.4.4. Bias Factor $(\lambda) \quad 173$

8.1.4.5. Distribuição normal probabilística 174

$\begin{array}{ll}\text { 8.1.4.6. Intervalo de confiança } & 174\end{array}$

8.2. Comparação das propriedades mecânicas dos concretos desenvolvidos e as formulações 174

$\begin{array}{lll}\text { 8.3. Ensaios de arrancamento } & 178\end{array}$

$\begin{array}{lll}\text { 8.3.1. Série } 1 & 178\end{array}$

$\begin{array}{lll}\text { 8.3.2. Série } 2 & 183\end{array}$

$\begin{array}{ll}\text { 8.3.3. Série complementar } & 187\end{array}$

8.4. Ensaios de viga 191

8.4.1. Série $1 \quad 192$

8.4.2. Série $2 \quad 200$

8.5. Comparação entre os modelos de viga e de arrancamento e as formulações para previsão da resistência de aderência 207

8.5.1. Modelos de arrancamento 208

$\begin{array}{ll}\text { 8.5.2. Modelos de viga } & 209\end{array}$ 
8.5.3. Comparação dos resultados da resistência de aderência entre os modelos de arrancamento e de viga 210

8.5.4. Comparação com a previsão da resistência de aderência 213

8.6. Variabilidade do concreto auto-adensável 221

8.6.1. Estado fresco 221

$\begin{array}{ll}\text { 8.6.2. Estado endurecido } & 221\end{array}$

8.6.3. Variabilidade da aderência 231

8.7. Simulação numérica 238

$\begin{array}{lll}\text { 8.7.1. } & \text { Série } 1 & 239\end{array}$

8.7.1.1. Modelos de arrancamento 239

8.7.1.2. Modelos de viga 243

8.7.2. Série $2 \quad 250$

8.7.2.1. Modelos de arrancamento 250

8.7.2.2. Modelos de viga 253

9. Considerações finais 261

9.1. Comentários sobre os resultados obtidos 262

9.1.1. Investigação experimental do concreto auto-adensável 262

9.1.2. Investigação experimental da aderência 262

9.1.3. Simulação numérica dos ensaios de aderência 264

9.1.4. Comparação dos resultados com formulações de previsão do comportamento do CAA e da resistência de aderência 265

9.1.5. Variabilidade do concreto auto-adensável 265

9.2. Conclusões 269

9.3. Propostas de futuras pesquisas 270

$\begin{array}{ll}\text { Bibliografia } & 271\end{array}$ 



\section{Resumo}

Almeida Filho, F. M. (2006). Contribuição ao estudo da aderência entre barras de aço e concretos auto-adensáveis. Tese de doutorado, Escola de Engenharia de São Carlos, Universidade de São Paulo, 291 p., São Carlos-SP, Brasil.

A busca por novos materiais estruturais visa a melhoria da qualidade $\mathrm{e}$ desempenho das estruturas, impulsionando o desenvolvimento científico e tecnológico. O concreto auto-adensável surgiu da necessidade de se dispensar o difícil e oneroso trabalho de vibração do concreto, sendo definido como um material capaz de fluir dentro de uma fôrma, passando pelas armaduras e preenchendo a mesma, sem o uso de equipamentos de vibração.

Esta pesquisa caracteriza-se como um estudo teórico-experimental da aderência aço-concreto, utilizando concreto do tipo auto-adensável, mediante ensaios monotônicos de flexão em vigas e de arrancamento seguindo o modelo padrão do Rilem-Ceb-Fip (1973). O estudo considerou como parâmetros fundamentais o tipo de concreto (auto-adensável e convencional), a resistência à compressão do concreto e os diâmetros das barras. Ainda, realizou-se um estudo com relação à variabilidade do concreto auto-adensável nos estados fresco e endurecido, constatando que este possui pequena variação. De posse dos resultados, buscou-se verificar a previsão das formulações empregadas na literatura e pelos principais códigos internacionais.

De acordo com os resultados, o comportamento dos modelos de viga e de arrancamento para ambos os concretos foi similar, mostrando que o concreto autoadensável possui características semelhantes ao concreto convencional, com as vantagens da trabalhabilidade no estado fresco. Quanto à análise numérica, os modelos desenvolvidos representaram de forma satisfatória o comportamento dos ensaios, e forneceram uma idéia do comportamento da tensão de aderência na sua interface. Com relação às formulações teóricas, verificou-se que tanto para o concreto convencional quanto para o auto-adensável, ocorre uma superestimativa da resistência de aderência.

Palavras-chave: Aderência, concreto auto-adensável, concreto convencional, arrancamento, simulação numérica, análise experimental, flexão. 


\begin{abstract}
Almeida Filho, F. M. (2006). Contribution to the study of the bond between steel bars and self-compacting concrete. Doctoral thesis, Escola de Engenharia de São Carlos, Universidade de São Paulo, 291 p., São Carlos-SP, Brasil (in portuguese).
\end{abstract}

The search for new structural materials aims the improvement of the structures performance, pushing the scientific and technological development. Self-compacting concrete (SCC) origin was due to the need to avoid the difficult and expensive process of concrete vibration. It has been defined as a material capable to flow inside a formwork, passing through the reinforcement and filling it completely, without using of any special equipment.

This research is characterized as a theoretical and experimental study of steelconcrete bond, using SCC, through pull-out tests and beam tests standardized by Rilem-Ceb-Fip model. The study considered as main parameters the concrete type (ordinary concrete and SCC), its compressive strength and the steel bars diameters. Yet, a study of the variability of the properties of SCC, both in fresh and hardened state was also performed, showing that SCC is a very reliable material. The obtained results were compared with the ones established by the related bibliography and by the main International Codes.

According to the results, the behavior of the beams and pull-out tests were very similar for both concretes (SCC and OC), with the well know advantages for the SCC in fresh state. About the numerical approach, the developed models represented satisfactory the test behavior (beam and pull-out) and gave an idea of the bond stress behavior on the steel-concrete interface. About the theoretical formulations, it was verified the they usually overestimate the bond strength, for both types of concrete.

Keywords: Bond, self-compacting concrete, pull-out, flexure, ordinary concrete, numerical simulation, experimental analysis. 




\section{Introdução}

Desde o início da utilização do concreto armado, a aderência entre aço e concreto tem sido objeto de estudo de diversos pesquisadores. Essa interação entre os materiais é o mecanismo que caracteriza o concreto armado, pois a condição de que haja aderência entre a superfície da barra de aço e o concreto adjacente define o comportamento das estruturas obtidas. A aderência depende, além das características da barra de aço, das propriedades do concreto e, portanto, seu estudo passa pelo conhecimento dos materiais envolvidos na sua produção.

Com o passar dos anos, houve um grande desenvolvimento tecnológico dos materiais empregados na construção civil, dando origem aos concretos de alto desempenho e do tipo auto-adensável, que dispensa a etapa de vibração no canteiro de obras. No estudo da aderência, entretanto, pouco foi observado com relação ao comportamento dessa ligação com a utilização de concretos auto-adensáveis.

Segundo a literatura, dois modelos têm sido utilizados para se verificar o escorregamento da barra e as tensões de aderência na flexão, sendo eles: ensaios de arrancamento e o modelo de vigas com traspasse de barras.

Dentre as pesquisas existentes, muito sobre o comportamento da aderência açoconcreto precisa ser estudado, pois fatores como: resistência à compressão do concreto, a presença de fibras metálicas, o comprimento de ancoragem, o grau de confinamento e a quantidade de armadura utilizada são fatores que possuem uma infinidade de variáveis interdependentes que interferem na ligação aço-concreto (Tholen \& Darwin, 1998; Oragun et al. 1977; Hamad, 1995; Losberg \& Olsson, 1979; 
Fergunson \& Thompson, 1962; Hwang et al., 1996; Azizinamini et al., 1993; Azizinamini et al., 1999).

Atualmente, o concreto auto-adensável, ou CAA, pode ser classificado como um material de construção avançado. Sua composição inclui materiais inorgânicos de granulação fina, oferecendo a possibilidade de se utilizar pó de agregado, extremamente fino, o qual é considerado rejeito, sem qualquer aplicação na indústria e que demanda custo para seu descarte. Este concreto teve origem no Japão onde surgiu da necessidade de se dispensar o difícil e oneroso trabalho de vibração do concreto lançado às fôrmas, o que mostra que as principais causas de sua origem foram a economia de mão-de-obra (insumo que gera altos gastos em uma obra) e a durabilidade das estruturas. De acordo com Okamura (1997), um adensamento adequado do concreto por operários treinados era importante para obter estruturas duráveis; entretanto, tais operários seriam extremamente dispendiosos, pois, fora o correto treinamento, ainda haveria o custo da utilização de tal serviço.

Segundo Vachon (2003), a primeira publicação sobre o concreto auto-adensável (CAA) foi apresentado na EASEC-2 (East-Asia and Pacific Conference on Structural Engineering and Construction - 2) em 1989, e foi seguido de outra apresentação na CANMET (Energy Diversification Research Laboratories) e no ACl em 1992. Em 1997, o Comitê TC 174 do RILEM, em concreto auto-adensável, foi fundado.

De acordo com Bartos (2000), o princípio do concreto auto-adensável não é novo. Aplicações em fundações submersas requerem um concreto que seja fluido sem que necessite de adensamento, pois, freqüentemente, a vibração é impossível. No início dos anos 90 existiam pouquíssimas publicações a respeito do concreto autoadensável, e se concentravam no Japão. As indústrias que detinham o conhecimento e prática de sua construção mantinham em segredo tal concreto como uma vantagem comercial. A partir daí, diversos nomes para o concreto auto-adensável apareceram, de acordo com a empresa que o fabricava, tais como, NVC (Non-Vibrated Concrete), SQC (Super Quality Concrete) ou Biocrete.

Segundo Okamura (1997), o CAA é uma mistura que pode ser adensada em qualquer local na fôrma, apenas por meio da acomodação devida ao seu peso próprio e sem necessidade de vibração. Do mesmo modo, pode ser definido como um concreto capaz de fluir dentro de uma fôrma, passando pelas armaduras e preenchendo a mesma, sem o uso de equipamentos de vibração. Assim, o uso do CAA aumenta a produtividade, reduz a mão de obra exigida e melhora o ambiente de trabalho (Gomes, 2002). 


\subsection{Objetivos e justificativas}

O objetivo geral desta pesquisa é estudar o comportamento da aderência açoconcreto mediante ensaios de arrancamento de barras e de vigas submetidas à flexão, onde o concreto a ser estudado é do tipo auto-adensável.

Quanto aos objetivos específicos colocados, destacam-se: a) comparação do concreto auto-adensável com o concreto convencional utilizado no mercado; b) estudo da variabilidade das propriedades mecânicas e da aderência em concretos autoadensáveis; c) análise comparativa dos procedimentos dos dois ensaios em si, de suas vantagens e desvantagens na determinação do comportamento da aderência; d) desenvolvimento de modelo numérico consistente para a representação dos ensaios estudados, de forma a permitir uma análise paramétrica mais abrangente do fenômeno estudado; e) verificar a consistência das formulações empregadas na literatura corrente e pelos principais códigos internacionais, mediante sua comparação com os resultados obtidos experimentalmente.

O estudo da aderência entre o aço e o concreto envolve uma grande quantidade de variáveis, tais como: a resistência à compressão do concreto, diâmetro da barra, comprimento de ancoragem, adensamento e etc, onde cabe destacar que algumas dessas variáveis ainda não têm sua influência completamente estabelecida. Em função disso, surge a necessidade de maiores informações a respeito do comportamento da aderência em concretos de alta resistência e em vigas submetidas à flexão; e, por haver ausência de dados a respeito, da tecnologia de concretos autoadensáveis no país e de sua influência no comportamento da aderência aço-concreto.

A busca dessas informações motivou este projeto, do qual se esperam subsídios à futura normatização de ensaios de flexão e de arrancamento e para a utilização do concreto auto-adensável.

Outro fator que justifica esta pesquisa a utilização cada vez mais freqüente de concretos de alta resistência à compressão, em virtude da economia e da versatilidade provocada. Contudo, esse tipo de concreto torna necessária à utilização de grandes taxas de armadura para garantir uma ductilidade adequada à estrutura, e esta provoca uma grande dificuldade nas operações de vibração. Seria então desejável utilizar um concreto tal que a operação de vibração fosse dispensada, tal como o concreto autoadensável. Além disso, deve-se considerar que o tempo necessário para o adequado adensamento (por vibração) do concreto convencional, torna mais lento o andamento da obra. Assim, as vantagens do concreto auto-adensável podem ser descritas como: redução do tempo de construção e do custo da obra, aumento da qualidade do concreto lançado, aumento da segurança e da saúde dos operários, possibilidade de 
utilização de maiores taxas de armadura e aumento significativo da automação e da tecnologia do processo construtivo.

E desse modo, a necessidade de se conhecer o comportamento desse material, particularmente no que se refere à aderência, deu origem a este projeto.

\subsection{Metodología}

A pesquisa envolve um estudo teórico-experimental, e será dividida em três partes: revisão bibliográfica, análise experimental e análise teórica (incluindo a simulação numérica).

A primeira parte da pesquisa será composta de uma revisão bibliográfica abrangendo, principalmente, os seguintes temas: estudo da aderência aço-concreto, concretos de alto desempenho, estado da arte relacionada com ensaios de arrancamento e em vigas, estudo da utilização de concretos do tipo auto-adensáveis e o comportamento da aderência em concretos auto-adensáveis.

A segunda parte consiste no estudo experimental com o objetivo de se verificar o comportamento da aderência aço-concreto em concretos auto-adensáveis e compará-los com os modelos em concretos convencionais. Para isso, será realizado o estudo de um modelo de viga submetido à flexão e de um modelo de arrancamento, ambos padronizados pelo Rilem-Ceb-Fib (1973).

Além disso, o programa experimental compreendeu um estudo sobre a variabilidade do concreto auto-adensável em corpos-de-prova de $15 \times 30 \mathrm{~cm}$, ensaiados aos 28 dias. Os parâmetros observados foram: sua resistência à compressão, sua resistência à tração, seu módulo de elasticidade longitudinal e sua resistência de aderência.

A terceira parte consiste em uma simulação numérica, baseada no Método dos Elementos Finitos, com a finalidade de consolidar um modelo numérico e ainda, comparar os resultados numéricos e experimentais com as formulações empregadas na literatura corrente e pelos principais códigos internacionais. Com isso, seria possível avaliar a versatilidade das expressões propostas por estes modelos e determinar qual se aproxima mais dos modelos numéricos e experimentais. 


\subsection{Conteúdo do trabalho}

O capítulo 1 apresenta uma introdução ao estudo do concreto auto-adensável, aqui abreviado para CAA, citando algumas peculiaridades de sua origem e suas principais vantagens, além de, descrever os objetivos, justificativas e a metodologia da pesquisa.

O capítulo 2 ilustra as características do CAA com grande parte da revisão bibliográfica realizada, mostrando suas propriedades no estado fresco e a influência dos materiais utilizados na sua elaboração.

O capítulo 3 mostra a investigação experimental para o desenvolvimento do concreto auto-adensável de resistência à compressão normal e alta, mostrando a caracterização dos materiais utilizados, suas dosagens, equipamentos e métodos para avaliar as propriedades no estado fresco e endurecido dos CAA desenvolvidos.

O capítulo 4 mostra uma pequena revisão sobre a aderência aço-concreto e algumas de suas peculiaridades.

O capítulo 5 traz a investigação experimental realizada sobre a aderência açoconcreto (convencional e auto-adensável) em modelos de arrancamento e de viga.

O capítulo 6 mostra a investigação experimental sobre a variabilidade da resistência de aderência em concretos auto-adensáveis com diferentes tamanhos máximo de agregado graúdo e fluidez.

O capítulo 7 apresenta a simulação numérica desenvolvida para representar os ensaios de arrancamento e de viga realizados, mostrando a teoria utilizada e os modelos adotados para representar o comportamento da interface aço-concreto.

O capítulo 8 mostra a análise dos resultados obtidos na investigação experimental e simulação numérica e, além disso, traz uma comparação entre o comportamento das propriedades mecânicas do CAA (módulo de elasticidade, resistência à tração e resistência de aderência) em relação às formulações e recomendações normativas utilizadas para prever o comportamento do concreto no estado endurecido.

O capítulo 9 traz as conclusões e principais observações realizadas nesta pesquisa, além de sugestões para futuras pesquisas. 



\section{Concreto auto-adensável}

Este capítulo mostra o estado da arte do concreto auto-adensável desenvolvido por diversos pesquisadores, mostrando a suas propriedades no estado fresco, a influência das propriedades dos materiais que compõem sua mistura e os ensaios de verificação do CAA.

\subsection{Considerações iniciais}

Conforme comentado anteriormente, o concreto auto-adensável, ou CAA, surgiu da necessidade de se obter estruturas mais duráveis que dispensassem o trabalho de vibração ou adensamento mecânico no canteiro de obras, devido ao alto custo deste serviço e ainda, devido ao ganho de tempo de execução se fosse dispensado tal serviço.

A primeira mistura de CAA foi realizada em 1988 utilizando materiais existentes no mercado (Okamura \& Ouchi, 2003). Segundo os autores, o modelo comportou-se satisfatoriamente com atenção para a retração de secagem e a retração de endurecimento, calor de hidratação, densidade após o endurecimento entre outras. Naquela época, este concreto foi chamado de "concreto de alta performance", com os seguintes estágios:

- Fresco: alta adensabilidade;

- Idade recente: redução de defeitos iniciais, tais como, nichos;

- Após endurecimento: proteção contra agentes externos. 
Porém, o "concreto de alta performance" havia sido desenvolvido na Europa como um concreto de alta resistência à compressão e de alta durabilidade, por causa da pequena relação água-cimento. Assim, o nome foi mudado para "concreto de alta resistência auto-adensável".

Shindoh \& Matsuoka (2003) realizaram um breve histórico do desenvolvimento do CAA onde retratam o seu início no mercado e o crescente interesse de empresas neste novo material. Segundo os autores, o CAA é definido como um concreto com excelente deformabilidade, alta resistência à segregação e que pode ser lançado em estruturas densamente armadas sem a necessidade de adensamento e deformandose por meio do seu peso-próprio sem a segregação de nenhum de seus componentes. Com isso, o ensaio de abatimento (slump test) pode servir de referência para se medir a deformabilidade do CAA. Contudo, seriam necessários maiores estudos para o desenvolvimento de modelos de ensaio para se verificar a habilidade de passagem, resistência à segregação entre outras (Shindoh, 1990'; Tangermsirikul 1992²; Takenaka et al., 1998). Segundo Shindoh \& Matsuoka (2003), a primeira estrutura a utilizar o CAA foi uma torre de uma ponte estaiada em 1991.

Com a preocupação de se tornar o concreto altamente fluido mantendo as características de resistência à segregação entre outras, há a preocupação com relação às propriedades no estado endurecido, o que de acordo com literatura mundial mostra que as propriedades tanto do CAA quanto do CC, no estado endurecido, não são significantemente diferentes (Persson, 2000).

\subsection{Propriedades do CAA no estado fresco}

Existe uma série de pesquisas a respeito das características do CAA em seu estado fresco, tais como: trabalhabilidade, aplicações, métodos de dosagem. Porém, somente uma pequena parcela se refere à sua reologia.

As principais propriedades do CAA no estado fresco incluem a deformabilidade (pode-se traduzir como a trabalhabilidade), a resistência à segregação, a habilidade de passagem e a velocidade de fluidez. Assim, uma boa resistência à segregação significa uma boa distribuição de partículas de modo idêntico em todos os locais da

\footnotetext{
${ }^{1}$ SHINDOH, T.; MATSUOKA, Y.; SAKAMOTO, J.;TANGERMSIRIKUL, S. (1990). Properties of super workable concrete in fresh state. Proceedings of 45 th annual conference of Japan Society of Civil Engineers, 5, p. 228-229.

2 TANGERMSIRIKUL, S.; MATSUOKA, Y.; SHINDOH, T.; SAKAMOTO, J. (1992). A study of velocity of deformations of super workable concrete. Proceedings of Japan Concrete Institute, 14 (1), p. 1161-1166.
} 
mistura; uma boa habilidade de passagem significa que o concreto não sofrerá bloqueio ou obstruções quando fluir pelas armaduras existentes; uma boa velocidade de fluidez significa que a velocidade de lançamento do concreto será uniforme; a trabalhabilidade significa que o CAA apresentará uma boa fluidez e boa qualidade do concreto na retirada das fôrmas e, desse modo, a reologia do CAA depende de uma série de fatores, sendo eles (Bui et al., 2002): o volume de agregado com relação ao volume da pasta; a forma e tamanho dos agregados finos e graúdos; a relação entre a quantidade de agregado (fino e graúdo); a característica da superfície dos agregados e a diferença de densidade entre os agregados e a pasta.

As principais propriedades no estado fresco serão explicadas sucintamente a seguir.

\subsubsection{Habilidade de passagem}

A habilidade de passagem, ou fluidez, entre as barras de armadura presentes em elementos estruturais é a característica mais importante do concreto autoadensável (CAA) já que ela determina a capacidade de preenchimento das fôrmas, influenciando diretamente a resistência e a durabilidade do concreto.

Segundo Noguchi et al. (1999), a previsão da fluidez através das pequenas aberturas entre a armadura e do não bloqueio dos agregados por esses espaços para o concreto que é lançado às fôrmas é um dos itens mais importantes e fundamentais para a qualidade do elemento em concreto. Segundo os referidos autores, é importante avaliar a perda de velocidade e o bloqueio do concreto quando este passa através de pequenos espaços no elemento estrutural a ser concretado, especialmente para o CAA por não necessitar de adensamento. Diversas técnicas foram propostas e desenvolvidas em laboratório para avaliar a habilidade de passagem do CAA em pequenos espaços, porém, estas técnicas não foram adaptadas para utilização em um canteiro de obras.

Os referidos autores realizaram um estudo para solucionar o problema do concreto fresco passando através de aberturas, interpretando reologicamente os resultados de seus ensaios. Como hipótese inicial, os autores assumiram que o concreto fresco era um material de duas fases, sendo uma sólida e outra líquida, baseando-se na teoria de fluidos de fases múltiplas e, ainda, utilizando a teoria de excesso de espessura de argamassa e reologia ${ }^{3}$.

${ }^{3}$ OH, S.G.; KANEMATSU, M.; NOGUCHI, T.; TOMOSAWA, F. (1998). Evaluation of rheological properties of concrete by thickness of excess mortar. Sumaries of Technical Papers of Annual Meeting of Architectural Institute of Japan, 1998, A-1 Materials and Construction, pp. 985-988. 
Ainda, se a densidade relativa de pasta em excesso (consiste da densidade de pasta em excesso dividida pelo diâmetro dos círculos equivalentes para áreas projetadas de partículas de agregado) é determinada, então a fração de volume, correspondente ao acréscimo de agregado, pode ser obtida.

De acordo com os referidos os autores, quando o concreto fresco passa através de pequenas aberturas pode ser compreendido como uma redução da densidade relativa de pasta em excesso resultando em um aumento da fração de volume de agregado; o comportamento do concreto fresco passando pelas aberturas pode ser interpretado macroscopicamente como uma mudança nas suas propriedades reológicas e o aparato utilizado para medir a habilidade de passagem por um obstáculo com barras de aço foi adequado para se analisar, reologicamente, o comportamento do concreto fresco e, ainda, foram determinadas equações empíricas, resultando que a fração de volume de agregado pode ser calculada deste modo.

Shindoh \& Matsuoka (2003) avaliaram a deformabilidade do CAA utilizando o ensaio de abatimento ou espalhamento do concreto (slump flow test), onde a deformabilidade era medida a partir do diâmetro médio da base após o espalhamento.

O método proposto pelos referidos autores tem como idéia principal a simplicidade, não precisando de nenhum instrumento complicado para poder ser utilizado tanto em laboratórios quanto em canteiros de obra. Segundo o que foi visto, a velocidade de deformação varia conforme as condições de contorno, tais como a quantidade de armadura e a geometria das fôrmas. A velocidade de deformação pode ser definida como sendo a taxa de aumento no diâmetro de concreto que é permitido fluir sem qualquer obstrução. Por isso, foi utilizado o ensaio de abatimento. Esta velocidade foi medida a partir de gravação em vídeo do espalhamento, que se inicia quando o cone é retirado, e então, é verificada a velocidade em cada instante, com base na recomendação do JSCE de medir o tempo necessário para que o espalhamento atinja o diâmetro igual a $50 \mathrm{~cm}$.

Os autores concluíram em sua pesquisa que o ensaio de caixa-U pode ser bem complementado pelo ensaio de abatimento, pois o valor da altura $U_{h}$ cresce até que atinge um valor máximo e, a partir de então, começa a decrescer por causa da segregação do concreto. Assim, o melhor valor é aquele que é definido como ponto de adensabilidade máxima. Com relação à velocidade de deformação e à viscosidade da pasta, a pesquisa mostrou que existe uma relação linear entre a velocidade de deformação secante no ensaio de abatimento e a velocidade média de deformação. Assim, pode ser considerado que a medida de $T_{50}$ é apropriada para se avaliar a resistência à segregação do CAA. 


\subsubsection{Resistência à segregação}

A resistência à segregação, ou o afastamento dos componentes do CAA é uma propriedade que caracteriza a capacidade de manter o CAA uniforme durante seu transporte, lançamento e adensamento, sendo que, os mecanismos que governam esta propriedade são a coesão e a viscosidade (Gomes, 2002; Ferraris et al., 2000; Sedran, 2000).

De acordo com Bui et al (2002), as dimensões dos agregados têm um efeito significativo na resistência à segregação do CAA, bem como em sua trabalhabilidade.

\subsubsection{Habilidade de Preenchimento}

A habilidade de preenchimento do CAA está diretamente ligada à habilidade de passagem, sendo que esta característica é medida pela capacidade do CAA de fluir ao longo de fôrmas com armaduras e preencher os espaços entre elas.

Zhu et al. (2001) estudaram a uniformidade do CAA com relação ao CC em elementos estruturais, notadamente pilares e vigas. De acordo com os referidos autores, o CAA pode promover uma qualidade igual e até melhor que o do CC vibrado, fazendo com que as propriedades no local de lançamento do concreto permaneçam iguais às do concreto comum.

\subsubsection{Trabalhabilidade}

A trabalhabilidade é definida tanto qualitativamente, como no caso do lançamento do concreto, quanto quantitativamente por causa dos seus parâmetros reológicos. Segundo Ferraris et al. (2000), o teste mais comum para se determinar a trabalhabilidade na prática é o cone de abatimento, pois tanto a altura da mistura quanto o espalhamento desta podem ser medidos. Os parâmetros reológicos mais comuns para se classificar a trabalhabilidade são as tensões de escoamento e a viscosidade plástica, como as definidas por Bringham ${ }^{4}$ e, em alguns casos a formulação de Herschel-Bulkley ${ }^{5}$ é mais adequada para descrever a fluidez.

\footnotetext{
${ }^{4}$ TATTERSALL, G. H. (1976). The workability of concrete. A Viewpoint Publication, PCA, 1976. ${ }^{5}$ DE LARRARD, F.; FERRARIS, C. F.; SEDRAN, T. (1998). Fresh Concrete: a Herschel-Bukley material. Materials and Structures, Vol. 31, Issue 211, p. 494-498, 1998.
} 
Segundo Ferraris et al. (2000), um concreto altamente fluido não é necessariamente um concreto auto-adensável por que o CAA não deve somente fluir pela fôrma por causa da força da gravidade, mas também, deve preencher a fôrma inteiramente, promovendo uma compactação uniforme sem segregação. Em sua pesquisa, foram utilizados dois reômetros, o $\mathrm{IBB}^{6}$ e o $\mathrm{BTRHEOM}^{7}$, para medir as propriedades reológicas do CAA. Para se determinar os parâmetros para as equações de Bringham e de Herschel-Bukley, uma "caixa de trabalhabilidade" foi utilizada para determinar os parâmetros de viscosidade e de tensão de escoamento (yield stress).

Segundo os referidos autores, foram comparadas as misturas com ensaio de abatimento e de espalhamento e, de acordo com as informações obtidas, as misturas possuíam a mesma trabalhabilidade. Contudo, os ensaios utilizando os modelos de caixa-U, de funil-V e dos reômetros, mostraram que as misturas não apresentavam o mesmo comportamento para a capacidade de preenchimento, habilidade de passagem e de viscosidade. Seus resultados mostraram uma grande variação e isso levou a concluir que, do mesmo modo que Hayakawa et al. (1994) ${ }^{8}$, os modelos de abatimento e de espalhamento não são confiáveis para se medir a trabalhabilidade do CAA, pois não conseguem avaliar o comportamento do CAA durante o seu lançamento, mostrando que, para um mesmo resultado de espalhamento ou de abatimento, diversas habilidades de preenchimento, de passagem ou de viscosidade podem ser obtidas e, por isso, não é possível se estabelecer uma correlação entre os resultados de funil $\mathrm{V}$ e caixa $\mathrm{U}$ com os modelos de abatimento e de espalhamento.

De acordo com Beaupré (1994), o melhor método para se avaliar o concreto com uma determinada habilidade seria obter os valores para a tensão de escoamento e da viscosidade e traçar uma curva com esses valores. Na pesquisa de Ferraris et al. (2000) foi visto que não é possível se estabelecer uma relação entre as propriedades reológicas de escoamento e da viscosidade com os ensaios de funil-V e de caixa-U.

Do mesmo modo que Beaupré (1994), Sedran \& De Larrard (1999) ${ }^{9}$, apud Gomes (2002), realizaram um estudo sobre a reologia do CAA com relação ao ensaio de espalhamento onde o tempo $T_{50}$ era relacionado com a viscosidade do CAA.

${ }^{6}$ BEAUPRÉ, D. (1994). Rheology of high performance shotcrete. Ph. D. Thesis, University of British Columbia, Canada, 1994;

${ }^{7}$ DE LARRARD, F.; HU, C.; SZITKAR, J. C.; JOLY, M.; CLAUX, F.; SEDRAN, T. (1995). A new rheometer for soft-to-fluid fresch concrete. LCPC internal report, Paris, France, 1995;

${ }^{8}$ HAYAKAWA, M.; MATSUOKA, Y.; SHINDOH, T. (1994). Development and application of super workable concrete. Special concretes: "workability and mixing", Ed. by P. J. Bartos, RILEM, p. 183-190, 1994.

${ }^{9}$ SEDRAN, T.; DE LARRARD, F. (1999). Optimization of self-compacting concrete thanks to packing model. Proceedings of $1^{\text {st }}$ International RILEM Symposium on Self-Compactring Concrete. Editores: A. Skarendahl e Ö Petersson, Estocolmo, Suécia, p. 321-332, 1999. 
Sedran (2000) realizou um estudo de caracterização do comportamento reológico do CAA no estado fresco utilizando reômetros disponíveis no mercado com a finalidade de encontrar relações entre os ensaios de trabalhabilidade e de abatimento (slump flow test), com o objetivo de verificar se as propriedades reológicas do concreto poderiam ser avaliadas por um simples ensaio como o de abatimento. Com isso, poderiam ser determinados os parâmetros de viscosidade e de tensão de escoamento para diferentes misturas de CAA, como por exemplo, variação dos agregados, superplastificantes, agentes viscosos, entre outros. Ainda, foi determinada em sua pesquisa uma relação entre efeito do tipo do cimento e do superplastificante.

Como resultados, os referidos autores verificaram que o ensaio de abatimento é simples, mas descreve com menor precisão o comportamento da mistura, ao passo que o reômetro fornece resultados muito precisos. Porém, os limites para a tensão de escoamento (yield stress) e da viscosidade não são bem definidos por causa da falta de uma relação que inclua estas propriedades reológicas para o concreto em seu estado fresco. Assim, mais pesquisas são necessárias para se fornecer maiores informações sobre este estudo.

Os autores recomendaram então que o ensaio de caixa-L está mais apto para se estudar o efeito do confinamento no risco de bloqueio, quando o concreto fresco flui através da armadura.

\subsection{Materiais}

A seguir, tem-se uma breve apresentação sobre os materiais utilizados na elaboração do CAA.

\subsubsection{Agregado fino}

O Código EFNARC (2002) cita que qualquer tipo de areia pode ser utilizado, tanto o britado como o natural. A quantidade de areia na mistura do CAA é importante, uma vez que a razão areia/agregados (AF/AT), onde a parcela de agregados representa a soma da massa dos agregados finos (areia) e graúdos (brita), influencia o módulo de elasticidade longitudinal do concreto. De acordo com Hirsch (1962), o módulo de elasticidade longitudinal da pasta é influenciado pela relação água/cimento e a sua idade na hora do ensaio. Ainda, diversos pesquisadores, tais como Hashin \& 
Shtrikman $(1962)^{10}$, Mori \& Tanaka $(1973)^{11}$, Eshelby $(1957)^{12}$ e Yang \& Huang (1996, $\left.1998^{13}\right)$, discutiram a variação desse módulo, realizando estudos teóricos e experimentais.

A utilização de agregados miúdos de pequena granulometria melhora a trabalhabilidade e aumenta a viscosidade do CAA, pois reduz o conteúdo de vazios. De acordo com Hibino \& Maruyama (2002), a determinação do teor de umidade no agregado miúdo é de grande importância, pois este possui grande influência na adensabilidade do CAA. Desse modo, é muito importante determinar a umidade da areia no instante da concretagem, o que leva a perda de tempo e, além disso, pode estar sujeito a erros. Assim, para se evitar qualquer tipo de erro decorrente da variação da umidade do agregado miúdo, a utilização de AMV's (agentes modificadores de viscosidade, que serão vistos mais adiante) ajudam a estabilizar a qualidade do concreto.

Su et al. (2002) realizaram pesquisa experimental sobre a relação AF/AT (relação agregado fino / agregado fino + graúdo) para o CAA comparando-o com o concreto convencional com relação à variação do módulo de elasticidade e ainda, avaliando a habilidade de fluir e preencher espaços do CAA. De acordo com as observações dos resultados, a razão AF/AT é importante para o CAA, pois as propriedades reológicas aumentam com o crescimento desta razão. Foi observado na pesquisa que uma razão AF/AT ideal seria igual a 47,5\%. Ainda, o módulo de elasticidade do concreto foi principalmente influenciado pelo módulo de elasticidade da matriz, ou seja, da pasta. Entretanto, o módulo de elasticidade do CAA não é significantemente afetado pela razão AF/AT quando o volume de agregado for constante e quando o módulo de elasticidade dos agregados fino e graúdo não forem muito diferentes.

\subsubsection{Agregado graúdo}

O agregado graúdo, natural e britado, pode ser utilizado para o CAA. A brita necessita, normalmente, de uma quantidade maior de pasta, especificamente se a mistura tem a razão de bloqueio crítica.

\footnotetext{
${ }^{10} \mathrm{HIRSCH}, \mathrm{T}$. J. (1962). Modulus of elasticity of concrete affected by elastic moduli of cement paste matrix and aggregate. ACl Material Journal, p. 427-451, 1962;

${ }^{11}$ MORI, T.; TANAKA, K. (1973). Average stress in matrix and average energy of materials with misfitting inclusions. Acta Metall., Vol. 21, p. 571-574, 1973;

12 ESHELBY, J. D. (1957). The determination of the elastic field of ellipsoidal inclusion, and related problems. Proceedings of Roy. Soc., A241, p. 376-396, 1957;

${ }^{13}$ YANG, C. C.; HUANG, R. (1998). Effect of S/A ratio on the elastic modulus of cement-based materials. Journal of the Chinese Institute of Engineers, Vol. 21, No. 3, p. 357-364, 1998.
} 
Os agregados britados tendem a possuir maior resistência por causa do travamento existente entre os ângulos das partículas, enquanto os agregados naturais, que não possuem ângulos agudos, por serem mais arredondados aumentam a capacidade de fluidez da pasta em função do menor atrito interno entre partículas.

Segundo a literatura mundial, a maior dimensão do agregado graúdo é da ordem de 16 a $20 \mathrm{~mm}$. É importante frisar que investigações com dimensões do agregado graúdo de até $10 \mathrm{~mm}$ têm problemas na medição da estabilidade da mistura, pois estudos mostraram segregação dentro de estruturas onde os ensaios de abatimento e de trabalhabilidade não mostraram nenhuma segregação. Assim, maiores estudos devem ser realizados em função do aumento das taxas de armadura em elementos estruturais para se aferir as dimensões máximas para o agregado graúdo (Bui et al., 2002).

Entretanto, ainda que haja a recomendação de se utilizar agregado graúdo com dimensão máxima de $20 \mathrm{~mm}$, o código EFNARC (2002) comenta que é possível se desenvolver um CAA com agregado graúdo de dimensão de $40 \mathrm{~mm}$ ou maior. $\mathrm{O}$ importante é se ter uma consistência gradual da passagem de agregado graúdo pelas peneiras.

Bui et al. (2002) relacionaram a reología do CAA com o espaçamento médio entre agregados e o diâmetro médio dos mesmos (assumindo que estes são esféricos) para avaliar sua influência no CAA. Desse modo, o volume da pasta tem que ser alto o bastante para preencher os vazios entre os agregados e garantir que haja uma camada que envolva as partículas de agregado para aumentar a deformabilidade e proporcionar uma boa resistência à segregação.

Sedran (2000) avaliou a reología do CAA em sua pesquisa variando o tipo de cimento, superplastificante e filler. Utilizou agregados graúdos com diferentes formas (brita e natural), dimensões (0-8mm e 8-16mm) e quantidade (39, 42 e $45 \%$ da quantidade total de agregados) em ensaios com reômetros e viscômetros, estabelecendo relações com os ensaios de abatimento. O referido autor, do mesmo modo que Emborg (2000), encontrou dificuldades em relacionar os valores em função de alguns fatores, como por exemplo o teor de umidade na superfície do agregado e a umidade do local de ensaios, e observou ainda que a ausência de um agente viscoso faz com que o CAA seja sensível a variações do conteúdo de água.

Sakai et al. (1994) ${ }^{14}$ e Ushijima et al. (1995) ${ }^{15}$, apud Emborg (2000), mostraram que aumentando a quantidade de água para simular a variação do teor de umidade no

${ }^{14}$ SAKAI, G.; SHIGEMATSU, K.; YURUGUI, M.; SAKATA, N. (1994). Flow stabilizing properties of special viscosity agent. The $37^{\text {th }}$ Japan Congress on Material Research. 
agregado entre $\pm 5 \%$ e $-1 \%$ e $+1,5 \%$, respectivamente, existe uma grande influência no ensaio de abatimento.

O efeito da fração e do tamanho do agregado também é importante quando se tem como objetivo avaliar a fluidez e a capacidade de preenchimento do concreto, porém as propriedades reológicas não dependem somente disso, mas também da sua forma e da sua textura (Geiker et al., 2002). Desse modo, o nível de rugosidade do agregado graúdo é diretamente proporcional ao nível de tensão de aderência entre este agregado e a argamassa (Rao \& Prasad, 2002; Geiker et al., 2002).

\subsubsection{Cimento}

Os cimentos do tipo Portland apresentam um bom comportamento (aumento da trabalhabilidade) com a adição de superplastificantes, porém esse valor depende da composição química deste. Assim, quanto maior a finura do cimento, menor a eficiência do superplastificante, pois ocorre uma redução na concentração das moléculas adsorvidas aos grãos de cimento.

De acordo com o EFNARC (2002), um cimento com conteúdo de $\mathrm{C}_{3} \mathrm{~A}$ maior que $10 \%$ pode causar problemas de trabalhabilidade.

A Tabela 2.1 ilustra a composição mineralógica típica do cimento Portland.

Tabela 2.1 Composição mineralógica do cimento

\begin{tabular}{|c|c|c|c|c|}
\hline Composto & Fórmula química & Abrev. & $\begin{array}{c}\% \text { no } \\
\text { cimento }\end{array}$ & Propriedades \\
\hline $\begin{array}{c}\text { Silicato tricálcico } \\
\text { (alita) }\end{array}$ & $3 \mathrm{CaO} . \mathrm{SiO}_{2}$ & $\mathrm{C}_{3} \mathrm{~S}$ & $50-65$ & $\begin{array}{l}\text { Rápido endurecimento; } \\
\text { Alto calor de hidratação; } \\
\text { Alta resistência inicial. }\end{array}$ \\
\hline $\begin{array}{l}\text { Silicato dicálcico } \\
\text { (belita) }\end{array}$ & $2 \mathrm{CaO} . \mathrm{SiO}_{2}$ & $\mathrm{C}_{2} \mathrm{~S}$ & $15-25$ & $\begin{array}{l}\text { Lento endurecimento; } \\
\text { Baixo calor de hidratação; } \\
\text { Baixa resistência inicial. }\end{array}$ \\
\hline $\begin{array}{l}\text { Aluminato } \\
\text { tricálcico } \\
\text { (Aluminato) }\end{array}$ & $3 \mathrm{CaO} \cdot \mathrm{Al}_{2} \mathrm{O}_{3}$ & $\mathrm{C}_{3} \mathrm{~A}$ & $6-10$ & $\begin{array}{c}\text { Pega rápida (controle por gesso); } \\
\text { Suscetível a ataque em meios } \\
\text { sulfatados; } \\
\text { Alto calor de hidratação; } \\
\text { Baixa resistência final. }\end{array}$ \\
\hline $\begin{array}{l}\text { Ferro aluminato } \\
\text { tetracálcico } \\
\text { (ferrita) }\end{array}$ & $4 \mathrm{CaO} \cdot \mathrm{Al}_{2} \mathrm{O}_{3} \cdot \mathrm{Fe}_{2} \mathrm{O}_{3}$ & $\mathrm{C}_{4} \mathrm{AF}$ & $3-8$ & $\begin{array}{c}\text { Endurecimento lento; } \\
\text { Resistente a meios sulfatados; } \\
\text { Não contribui para a resistência. } \\
\text { Aceitável em pequenas }\end{array}$ \\
\hline Cal livre & $\mathrm{CaO}$ & C & $0,5-1,5$ & $\begin{array}{l}\text { quantidades; } \\
\text { Quantidades maiores acarretam } \\
\text { aumento do volume e fissuração. }\end{array}$ \\
\hline
\end{tabular}

\footnotetext{
${ }^{15}$ USHIJIMA, S.; HARADA, K.; TANIGUCHI, H. (1995). Fundamental study in the practical use of high performance concrete, concrete under severe conditions 2 (ch 99), E \& FN Spon.
} 
O aumento da resistência à compressão do concreto feito com cimento portland comum é determinado pela taxa de hidratação dos seus quatro constituintes, alita, belita, aluminato e ferrita, sendo que os dois últimos têm pequena participação no aumento da resistência em comparação com as duas fases de silicato, principalmente alita. De acordo com Copeland \& Kantro $^{16}$ (1969) e Ash et al ${ }^{17}$. (1993), apud Wild et al. (1995), a alita e a belita hidratam em taxas muito diferentes, sendo que, a belita é mais lenta que a alita.

Vários pesquisadores estudaram a hidratação dos componentes individuais do cimento e, foi observado que a hidratação dos componentes de cimento puro é mais lenta do que os mesmos componentes na pasta de cimento (Wild et al., 1995), e a relação A/C influencia a taxa de hidratação, pois quanto maior for essa relação, maior será a taxa de hidratação. Ainda, dentre os fatores que podem influenciar a taxa de hidratação, tem-se a temperatura e a adição de pozolanas. De acordo com Copeland \& Kantro (1969) apud Wild et al. (1995), a temperatura é um grande acelerador de hidratação da alita. Quanto à belita, esta também tem acréscimo em sua hidratação por causa do aumento da temperatura, mas, esse aumento tem um atraso por causa do efeito da hidratação da alita e por causa de diferenças significativas no grau de hidratação ocorrerem em datas mais avançadas. Com relação à adição de pozolanas, esse material tem um efeito acelerador na hidratação tanto da alita quanto da belita (Huang \& Feldman, 1985).

\subsubsection{Aditivos e Adições Minerais}

Desde a criação do concreto, existe uma grande procura por subprodutos que melhorem suas propriedades reológicas, tanto no estado fresco quanto no estado endurecido. Segundo Metha \& Monteiro (1994), em alguns países, 70\% do volume total de concreto produzido apresenta em sua composição um ou mais aditivos.

A NBR 11768 (1992) define o aditivo como sendo um material que, desde que adicionado em pequenas quantidades ao concreto com cimento Portland, melhora algumas de suas propriedades, tornando este mais adequado aos diversos tipos de situação existentes em projetos, seja garantir a coesão, a trabalhabilidade, a fluidez ou a durabilidade.

${ }^{16}$ COPELAND, L. E.; KANTRO, D. L. (1969). Proceedings of $5^{\text {th }}$ International Symposium Cement Chemicals, Proceedings, 2, 387.

${ }_{17}$ ASH, J. E.; HALL. M. G.; LANGFORD, J. I.; MELLAS, M. (1993). Cement and Concrete Research, V. 24, No. 5, p. 966. 
De acordo com EFNARC (2002), os fillers são partículas com dimensões inferiores a 0,125 $\mathrm{mm}$ e podem ser divididos em calcário e cinza volante.

Dentre os aditivos e adições minerais existentes, os mais utilizados para a elaboração do CAA são o superplastificante, a sílica ativa e os fillers.

\subsubsection{Superplastificante}

O superplastificante ou aditivo redutor de água é incorporado ao concreto com a finalidade de reduzir a quantidade de água na mistura mantendo a trabalhabilidade ou aumentando-a (Aïtcin et al., 1994). Essa redução da quantidade de água resultou em menores relações água/cimento $(\leq 0,35)$, o que possibilitou o desenvolvimento de concretos de alta resistência, mantendo sua consistência e fluidez adequadas (Hanna et al., 1989; Khayat, 1999). Mas, diversos estudos têm mostrado que nem todos os superplastificantes comerciais possuem a mesma eficiência na dispersão das partículas de cimento, seja na redução da quantidade de água ou no controle de qualidade da reología do concreto (Aïtcin, 2000). Isso pode ocorrer por causa de problemas de compatibilidade da etringita, o qual depende do tipo, da quantidade e da reatividade da fase intersticial, do tipo e da solubilidade dos sulfatos no cimento e da reatividade inicial do aluminato.

O aumento da fluidez é atribuído ao aumento da dispersão das partículas de cimento resultando na adsorção do superplastificante na superfície do cimento seco ou hidratado por causa da mudança da carga elétrica que ocasiona a repulsão entre partículas. Essa dispersão, que gera a fluidez, varia em função de uma série de fatores inter-relacionados, que são: a natureza química e da concentração de superplastificante; a finura e a mineralogia do cimento; a relação $A / C$; o tempo de cura e o método de mistura do concreto (Hanna et al., 1989).

Os plastificantes foram os primeiros aditivos redutores de água a serem utilizados, porém, sua utilização permitia apenas uma pequena redução da quantidade de água. Assim, diversas pesquisas convergiram para os aditivos superplastificantes, os quais possibilitam uma redução de até $30 \%$ da água na mistura.

De acordo com Malhotra (1989), o modo de atuação do superplastificante se baseia em uma adsorção das partículas de cimento e por mostrar uma repulsão eletrostática. Isso resulta na dissociação dos aglomerados de cimento em partículas com uma significativa redução na viscosidade do sistema superplastificante-águacimento, resultando ainda em uma redução na tensão superficial das partículas de água, produzindo assim um lubrificante que aumenta o escoamento do sistema. 
Porém, sabe-se que diferentes tipos de superplastificante não produzem a mesma fluidez para o mesmo tipo de cimento, ou seja, o mesmo superplastificante pode não gerar a mesma fluidez para vários tipos de cimento. De acordo com investigações experimentais, a fluidez varia de um tipo de cimento para outro, utilizando o mesmo tipo e concentração de superplastificante. Essa diferença se devia à quantidade de aluminato e à finura do cimento, e vários estudos mostram que as diferentes quantidades de aluminato $\left(\mathrm{C}_{3} \mathrm{~A}\right)$ ou os álcalis presentes no cimento possam originar tais diferenças (Hanna et al., 1989).

A utilização de agentes redutores de água e de superplastificantes teve especial atenção por parte dos pesquisadores para o beneficiamento da trabalhabilidade e do bombeamento, com a possibilidade de economia de cimento e aumento da resistência à compressão do concreto. Atualmente existe uma grande preocupação no que se refere à qualidade das estruturas, o que implica em garantia de durabilidade,e que pode ser associada a uma menor permeabilidade e porosidade (Swamy, 1989). Desse modo, a utilização de partículas finas, como os fillers, ajuda a reduzir a porosidade e a permeabilidade de uma estrutura, implicando em uma maior durabilidade. Entretando, os fillers prejudicam a trabalhabilidade do CAA, sendo necessária a determinação de um ponto de dosagem ótima para os fillers com os superplastificantes. Essas características aumentam a resistência aos agentes químicos externos que possam atacar o elemento estrutural, além da resistência à carbonatação, e previnem a penetração de íons de cloro; para obtê-las é necessária uma pequena relação $A / C$ (Swamy, 1989).

Os principais polímeros solúveis em água são caracterizados nos seguintes grupos: carboxila (COO-); sulfonatos $\left(\mathrm{SO}_{3}^{-}\right)$e fosfonatos $\left(\mathrm{PO}_{3}{ }^{-}\right)$. Em geral, os superplastificantes utilizados são sulfactanes poliméricos com um alto peso molecular e um grande número de unidades moleculares que se repetem em uma certa seqüência (Roncero, 2000).

Os primeiros superplastificantes foram classificados como lignosulfonatos modificados (modified lignosulfonates) ou LSM; sais de formaldeído de melamina sulfonada condensada (salts of sulfonated melamine-formaldehyde condensates) ou SMF; e, sais de formaldeído de naftaleno sulfonado condensado (salts of sulfonated naphthalene-formaldehyde condensates) ou SNF. Todos esses superplastificantes apresentam o mesmo grupo funcional de sulfonato, mesmo aqueles com origem diferente (Roncero, 2000; Aïtcin, 2000)

Nos últimos anos, vários sulfactantes poliméricos de grupos funcionais com carboxila, hidroxila ou fosfonato, têm sido introduzidos no mercado como superplastificantes. Essas formulações são chamadas de comb-polymers, e são 
caracterizados por longas cadeias onde grupos hidrofóbicos e hidrófilos são combinados (Roncero, 2000).

Essas formulações podem ser modificadas para se obter desempenhos específicos com relação à dispersão de partículas, retardador de pega e retenção de abatimento, modificando o tamanho dos grupos, sua composição e o peso molecular da cadeia principal.

A interação entre o superplastificante e o cimento pode ser classificada em duas categorias:

- Interação física: a adsorção das moléculas de superplastificante pelas partículas de cimento impede sua floculação por causa da geração de uma força repulsiva de origem eletrostática e/ou por causa de simples obstáculos. Assim, as partículas são distribuídas uniformemente na solução aquosa, minimizando a quantidade de água necessária para a dispersão das partículas, o que resulta em uma maior trabalhabilidade/fluidez do concreto.

- Interação química: Inclui a absorção química, interação com locais mais reativos da partícula de cimento e interações com a morfologia dos hidratos formados.

A quantidade de água adsorvida depende do instante em que o superplastificante é adicionado à mistura, pois a quantidade de água é menor quando o superplastificante é lançado após a mistura do cimento com a água, aumentando significativamente a sua trabalhabilidade (Roncero, 2000). Existem recomendações para se adicionar o superplastificante dois minutos após a mistura de cimento com a água, pois esse seria o período em que os íons de $\mathrm{Ca}^{2+}$ alteram a superfície da partícula de cimento, reduzindo a adsorção de superplastificante e aumentando a quantidade de superplastificante livre na solução aquosa.

Existe então a necessidade de se determinar o teor máximo de superplastificante na dosagem para garantir a trabalhabilidade/fluidez da mistura (Roncero, 2000; Gomes, 2002). O método de se obter esse parâmetro de trabalhabilidade é baseado na utilização do ensaio de funil Marsh em pastas e argamassas, o qual determina o seu ponto de saturação (De Larrard et al., 1996; Roncero, 2000; Gomes 2002). Esse ponto de saturação de uma dosagem de superplastificante corresponde ao grau máximo de dispersão entre as partículas de cimento (Roncero, 2000; Gomes, 2002), e é adotado como a dosagem máxima de superplastificante no concreto, podendo ser utilizado com diferentes tipos de superplastificantes; pode ainda determinar a perda de fluidez com o tempo. 
Com o ponto de saturação determinado, isso significa que uma camada completa de moléculas foi adsorvida e que as propriedades da superfície estão em seu grau ótimo de aproveitamento. De acordo com Roncero (2000), dosagens de superplastificantes acima do ponto de saturação não aumentam a fluidez, e podem causar efeitos nocivos, tais como problemas de estabilidade da mistura (segregação e exsudação).

O efeito do superplastificante no concreto fresco é diretamente ligado ao seu efeito dispersivo, e vários fatores podem interferir em seu comportamento, como por exemplo: a finura do cimento; a quantidade de $\mathrm{C}_{3} \mathrm{~A}$ e $\mathrm{C}_{4} \mathrm{AF}$ (Hanna et al., 1989); a quantidade de sulfatos (Nawa et al., 1989); a natureza do superplastificante e o seu peso molecular (Basile et al., 1989); e a seqüência e o tipo de misturador do concreto.

A exsudação acontece no concreto em seu estado fresco quando são utilizadas altas dosagens de superplastificante, e a interação entre o superplastificante e o sulfato interfere na estabilidade do concreto (Suhr \& Schöner ${ }^{18}$, 1990; apud Roncero, 2000)

Com relação ao efeito do superplastificante em concretos em seu estado endurecido, sua incorporação afeta a estrutura interna do concreto, sendo que os poros capilares são menores e os vazios são menos conectados (Roncero, 2000). Tal mudança microestrutural afeta a distribuição dos poros, e isso contribui para a retração do concreto (Ramachandran ${ }^{19}$, 1984, apud Roncero, 2000).

Esse efeito do superplastificante na retração é difícil de ser analisado, pois estudos anteriores consideraram diferentes condições de ensaio, tais como o tipo de amostra, condições de cura e dosagem. Diversos pesquisadores mediram a retração variando as condições de cura e tipos de amostras, e concluíram que a incorporação do superplastificante aumenta a retração do concreto (Feldman \& Swenson ${ }^{20}, 1975$; Dhir \& Yap ${ }^{21}$, 1983; Beaudoin \& Ramachandran ${ }^{22}$, 1989; Cabrera et al. ${ }^{23}$, 1993, apud

18 SUHR, S.; SCHÖNER, W. (1990). Bleeding of cement pastes. IN: Properties of Fresh Concrete, (International RILEM Symposium), Proceedings, Hanover, Germany, Ed. H. J. Wierig, Chapman and Hall, London, U.K., p. 33-40.

${ }^{19}$ RAMACHANDRAN, V. S. (1984). Concrete admixtures handbook. Noyes Publications, New Jersey, USA.

${ }^{20}$ FELDMAN, R. F.; SWENSON, E. G. (1975). Volume change on first drying of hydrated Portland cement with and without admixtures. Cement and Concrete Research, V. 5, No. 1, pp. 25-35.

${ }^{21}$ DHIR, R. K.; YAP, A. W. F. (1983). Superplasticized high-workability concrete: some properties in the fresh and hardened states. Magazine of Concrete Research, V. 35, No. 125, pp. 214-228.

${ }^{22}$ BEAUDOIN, J. J.; RAMACHANDRAN, V. S. (1989). Effect of water dispersible polymers on the properties of superplasticized cement paste, mortar and concrete. IN: Third International Conference on Superplasticizers and Other Chemical Admixtures in Concrete (SP-119), Proceedings, Otawa-Canadá, Ed. Por V. M. Malhotra, ACI Publication, Detroit-USA, pp. 221242. 
Roncero, 2000). Segundo Cabrera et al. (1993) apud Roncero (2000), os superplastificantes baseados em SNF e SMF não afetaram significativamente a retração, mas os baseados em LSM e copolímeros aumentaram de 15 a $20 \%$ a retração do concreto.

\subsubsection{Sílica ativa}

A sílica ativa consiste de um aditivo mineral aplicado no concreto reduzindo a porosidade e a permeabilidade de sua superfície.

A sílica ativa foi utilizada pela primeira vez em 1969 na Noruega e foi usada na América do Norte e Europa nos anos 80. Esta, adicionada à mistura em substituição a uma parcela igual de cimento, combinada com a utilização de superplastificantes, aumenta significativamente a resistência do concreto (Toutanji \& El-Korchi, 1995).

Uma das atuais pesquisas sendo desenvolvida é a de otimizar a utilização de sílica ativa na mistura. Diversos pesquisadores ainda estudam a percentagem de substituição de sílica para com o cimento, e essas pesquisas levaram a diversos valores para obter a máxima resistência do concreto (Wild et al., 1995). Esse valor otimizado de sílica depende de uma série de fatores, tais como tipo e quantidade de cimento; tipo e dosagem dos aditivos; e, da idade de ensaio da amostra. Esse aumento da resistência do concreto eleva a sua qualidade por causa da melhora nas demais propriedades do concreto, e a maioria dos trabalhos referentes à otimização da quantidade de sílica a ser adicionada ao concreto tem objetivo por aumentar a sua resistência à compressão, mas essa avaliação da durabilidade e resistência ainda são pesquisas longe de serem totalmente compreendidas (Bhanja \& Segupta, 2003).

O aumento da resistência por causa da adição de sílica ativa no concreto ocorre em função de um processo físico e outro químico. O processo químico ocorre por causa da pozolana e o processo físico ocorre por causa da ação de microfiller existente. Assim, esse aumento da resistência ocorre como resultado do acréscimo de resistência zona de transição entre o agregado e a pasta, que se torna menos porosa e mais compacta. Um exemplo disso é que concreto com sílica ativa é mais resistente que a pasta com sílica ativa, pois, a resistência do agregado é maior que a resistência da pasta. No concreto sem sílica ativa, os agregados funcionam como fillers inertes por causa da presença de zona interfacial pouco resistente. Já no concreto com sílica

${ }^{23}$ CABRERA, J. G.; BROOKS, J J.; BERENJIAN, J. (1993). The effect of creep and drying shrinkage on the micromorphology of cement paste containing superplasticizers. IN: Creep and Shrinkage of Concrete, Fifth International RILEM Symposium, ConCreep 5, Proceedings, Barcelona-Espanha, Ed. Z. P. Bazant; I. Carol, E \& FN Spon, pp. 115-120. 
ativa, a presença desta sílica reforça a ligação entre a pasta e o agregado, formando menos poros e uma microestrutura da região interfacial mais homogênea (Toutanji \& El-Korchi, 1995). Assim, a interação da sílica ativa na interface do agregado com a argamassa é bastante evidente, pois uma substituição de $20 \%$ da massa de cimento por sílica ativa aumenta a quantidade de $\mathrm{SiO}_{2}$ na zona interfacial entre agregados cilíndricos e a matriz de argamassa, aumentando a resistência de aderência em relação a modelos similares utilizado somente matrizes de cimento (Caliskan, 2003).

Embora a utilização de sílica ativa garanta o aumento da resistência à compressão do concreto (dependendo de sua dosagem), deve-se observar que a sílica ativa não afeta a retração total e a retração por secagem sofre uma redução à medida que se aumenta sua concentração; entretanto, a retração autógena para concretos de alta resistência aumenta. Com relação à fluência, ocorre que, à medida que se aumenta a concentração de sílica ativa, ocorre a redução da fluência da estrutura de concreto (Mazloom et al., 2004).

\subsubsection{Finos (fillers)}

De acordo com a literatura mundial, os principais fillers utilizados para o CAA são:

- Pó de calcário (limestone filler);

- Cinza volante (fly ash);

- Pó de pedra (quarry dust) ou finos de pedra britada (crushed rock fines);

- Pó de quartzo (quartz filler);

- Cinza de casca de arroz;

- Finos basálticos e etc.

A utilização de um fino (filler) promove o aumento da trabalhabilidade e da durabilidade das estruturas. A função desta adição é garantir a coesão da pasta (resistência à segregação) e reduzir a abertura de poros no elemento estrutural.

Em geral, o fino é referenciado como uma partícula com diâmetro inferior a 0,125 mm (Efnarc, 2002). De acordo com Bilberg ${ }^{24}$ (1999) apud Ho et al. (2001), a reología do concreto só pode ser otimizada se a parte fina da argamassa do concreto é projetada com a finalidade de se otimizar sua reologia.

${ }^{24}$ BILLBERG, P. (1999). Fine mortar rheology in mix design of SCC. IN: Proceedings of First International RILEM Symposium of Self-Compacting Concrete, Proceedings, RILEM Publications, S.A.R.L., Estocolmo, Japan, 1999, pp. 47-58. 
Para se evitar a segregação quando da adição do superplastificante, um método simples é o de aumentar a quantidade de areia e de reduzir na mesma proporção a quantidade de agregado graúdo de $4 \%$ a $5 \%$. Entretanto, a redução na quantidade de agregados acarreta um alto consumo de cimento, que leva ao aumento da temperatura e ao aumento do custo. Uma alternativa para isso consiste em incorporar agentes modificadores de viscosidade (AMV) para aumentar a estabilidade da mistura. Porém, esses aditivos químicos são caros e sua utilização aumentará o custo da mistura de CAA. Assim, uma boa alternativa para isso é a utilização de aditivos minerais como a cinza volante, pó de calcário entre outros finos, que podem melhorar o abatimento do CAA sem aumentar seu custo (Bouzoubaâ \& Lachemi, 2001).

Com relação à viscosidade do CAA, outro modo de ser aumentada é reduzir a relação A/MC (água/material cimentício) para manter uma coesão adequada entre o agregado graúdo e a argamassa e garantir fluidez uniforme para o CAA através de seções transversais com altas taxas de armadura; e uma outra maneira de se obter a viscosidade adequada do CAA é a de acrescentar AMV's sem diminuir a relação $\mathrm{A} / \mathrm{MC}$.

A finura do filler é objeto de estudo de muitos pesquisadores, que propõem inclusive materiais ultrafinos para otimizar o CAA, aumentando a viscosidade do concreto no estado fresco, e funcionando como se fosse um agente viscoso, mas sem aumentar a fluidez do concreto (Xie et al., 2001). A utilização de cinza volante ultrafina leva o CAA a propriedades mecânicas otimizadas, como baixa permeabilidade, pouca retração e alta durabilidade.

A quantidade de fino a ser adicionado ao CAA também é objeto de muitos estudos, onde se verifica que à medida que se aumenta a quantidade de finos existe uma melhoria das propriedades mecânicas do CAA no estado endurecido, mas ocorre um grande aumento no consumo de superplastificantes e de água em virtude da finura do filler adicionado em excesso (Bouzoubaâ \& Lachemi, 2001; Gomes, 2002), porém, pode ser obtida uma economia na produção de CAA incorporando altas quantidades de cinza volante (Bouzoubaâ \& Lachemi, 2001).

A cinza volante pode substituir grandes quantidades de cimento (até 70\%) levando a elevadas resistências à compressão do concreto, o que pode ser explicado pelas reações pozolânicas da cinza volante, principalmente quando se avalia a resistência à compressão acima de 91 dias. Entretanto, existe um valor ótimo de teor de cinza volante para o concreto e, este varia em torno de 30 a $50 \%$ em relação a massa de cimento (Kawaguchi et al., 1998). Ainda, a cinza volante leva a menor retração por secagem em relação ao concreto convencional (Lee et al., 2002). 
Nishio et al. (1998) avaliaram a utilização de finos de pedra britada em CAA's mostrando que havia a necessidade de se estudar sua utilização, pois algumas amostras estudadas resultaram em módulos de elasticidade menores em relação ao CC e não houve boa uniformidade no lançamento do CAA em pilares, o que de acordo com os referidos autores seria contornado se fosse realizada uma reversão na direção de lançamento do concreto; porém os autores não deixaram claro como isso seria realizado. Do mesmo modo, Ho et al. (2001), estudaram o efeito da adição de pó de pedra na composição do CAA, comparando as misturas com traços semelhantes utilizando pó de calcário. De acordo com os referidos autores, o pó de pedra é uma alternativa interessante para o CAA, sendo que o maior aliado para sua utilização se reside em seu baixo custo, porém, por causa de sua grande finura, este exige um volume maior de água e de superplastificante para o concreto fresco, o que, conseqüentemente, exigirá um aumento no consumo de cimento para garantir as mesmas propriedades de fluidez com relação às misturas semelhantes com pó de calcário.

Com relação ao comportamento do CAA no estado endurecido, percebe-se que embora a maioria dos resultados esteja dentro dos limites estabelecidos pelo modelo do Ceb-Fib (1990), em alguns casos o comportamento do CAA é melhor que o CC (Holshemachser \& Klug, 2002).

Aditivos modificadores de viscosidade (AMV) são polímeros solúveis em água que aumentam a viscosidade e a coesão de materiais cimentícios. Este incremento na viscosidade é essencial em sistemas fluidos no sentido de reduzir a separação dos materiais constituintes da mistura e melhorar a homogeneidade e propriedades mecânicas do concreto no estado endurecido. Esses aditivos modificadores de viscosidade recebem o nome de VEA (viscosity-enhancing admixture) e são geralmente utilizados com superplastificantes para obter maior fluidez, mantendo a coesão dos materiais cimentícios e garantindo mínima separação dos seus constituintes de densidades diferentes (Khayat, 1998).

A combinação de uma adição inorgânica (sílica ativa) com um aditivo orgânico (um polissacarídeo) obtém resultados satisfatórios, com um CAA com custo razoável e ausência de exsudação e segregação e, além disso, obtendo características como: alta resistência à compressão (se comparado com os valores usuais para uma relação $\mathrm{A} / \mathrm{C}$ de 0,43 a 0,45 ), superfície homogênea e suave para o concreto endurecido com excelente aspecto e um tempo para desfôrma inferior ao tempo necessário para o CAA comum (Sari et al., 1999).

O welan gum, um polissacarídeo natural solúvel em água, de acordo com a literatura mundial, é bastante eficiente na estabilização da reología do CAA, porém, o 
maior empecilho para sua utilização é o seu custo. Assim, diversos pesquisadores estão desenvolvendo agentes viscosos com custos inferiores ao welan gum, tais como: a goma (starch), sílica precipitada e escória de goma industrial (by-product) (Rols et al., 1999).

Sonebi (2004) estudou a variação do tipo de aditivo mineral utilizado no desenvolvimento do CAA, onde utilizou cinza de combustível pulverizado (pulverized fuel ash), e verificou que sua utilização leva a CAA de média resistência (que era objetivo da pesquisa) com baixo consumo de cimento, e desse modo produz um CAA de baixo custo mantendo sua qualidade final.

O nível de dosagem para o AMV depende do seu tipo; assim, uma dosagem para um AMV da classe $A$ varia de $0,2-0,5 \%$, os da classe $B$ variam de $0,01-0,1 \%$ e os da classe $C$ entre $0,1-0,15 \%$, sendo que todos são representados em porcentagem de resíduo seco em relação ao peso de cimento (Gettu \& Agulló, 2004a).

\subsection{Métodos de verificação e aprovação do traço da mistura de CAA}

Para a determinação da mistura, isto é, se esta atende a premissa do concreto ser do tipo auto-adensável, é necessário que esta passe por uma série de etapas, descritas a seguir, com o objetivo de comprovar a fluidez do concreto.

Para se comprovar a fluidez do concreto auto-adensável, existem os ensaios de abatimento (slump flow) e do funil-V (V-funnel) que serão descritos a seguir. Para se comprovar a habilidade de passagem do concreto existe o método da caixa-L ( $L$ box). Para se determinar a segregação do concreto utiliza-se um perfil de cano em forma de $U$ (U-pipe).

\subsubsection{Ensaio de espalhamento (Slump flow test)}

É um método simples e fácil de executar e fornece a habilidade de fluidez do concreto. Este consiste de uma fôrma de abatimento (slump test) onde a massa de concreto deve se espalhar sobre uma placa de previamente marcada com as distâncias referentes a 50, 60 e $75 \mathrm{~cm}$. Deve ser tomado o tempo necessário para que a extensão do espalhamento do concreto atinja a marca de $50 \mathrm{~cm}$ e, essa marca deve ser obtida em um tempo igual a $5 \pm 2 \mathrm{~s}$.

Os procedimentos para este ensaio, segundo Tviksta (2000), são: 
- Ter certeza que a base está na horizontal, ter uma superfície suave e que haja uma marcação concêntrica de diâmetro de $50 \mathrm{~cm}$. Vale salientar que o material da superfície da base seja a mesma utilizada na fôrma dos modelos experimentais, pois pode haver alguma influência e, portanto, o mesmo tipo de material deverá ser utilizado;

- Limpar a superfície da base e cone de abatimento com água e secar com pano seca, assim, as superfícies estarão úmidas, mas sem água livre;

- Colocar o cone na marcação central da base e enchê-lo com concreto pressionado o cone contra a base para não haver derramamento de concreto pela base do cone;

- Deve-se então puxar o cone e, assim que iniciar a distribuição do concreto pela base, iniciar a contagem do tempo necessário para se obter $\mathrm{T}_{50}$;

- Quando o concreto parar de fluir, deve-se medir o diâmetro final do concreto (D-final) medindo dois diâmetros perpendiculares e a borda segregada na periferia do concreto. Deve-se observar de agregados foram levados para a periferia e, se houver uma borda de segregação, isso pode indicar segregação na mistura.

A Figura 2.1 abaixo ilustra o modelo do ensaio.
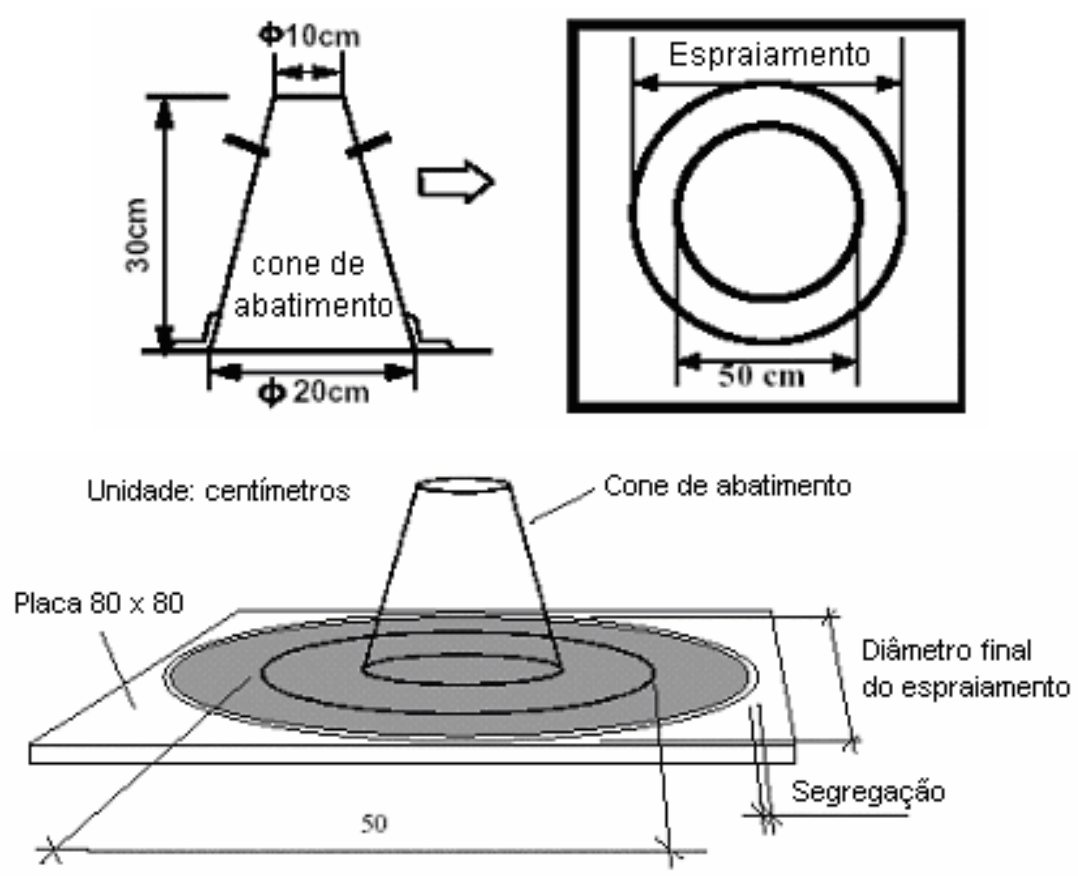

Figura 2.1 Ensaio de abatimento (Slump flow) (Gomes, 2002; Tviksta, 2000) 


\subsubsection{Ensaio de funil-V (V-funnel test)}

É um método simples e fácil de executar e fornece a habilidade de fluidez do concreto. Este consiste de uma fôrma em forma de funil (ver Figura 2.2) onde a massa de concreto deve ser colocada (aproximadamente 10 litros). Deve ser tomado o tempo necessário para que o volume de concreto passe pela boca do funil e, essa marca deve ser obtida em um tempo igual a $10 \pm 3 \mathrm{~s}$.

Os procedimentos para que haja a correta aferição da mistura são descritos abaixo.

- Inicialmente, deve-se limpar com água o funil e secá-lo com um pano, de modo que a superfície fique apenas úmida, não havendo acúmulo de água;

- Após, deve-se fechar a boca de saída do funil para se lançar o concreto neste;

- Então, após o lançamento do concreto no funil, espera-se um total de 15 s e então se retira o lacre da boca do funil, para então este escoar para um recipiente logo abaixo do aparato;

- Mede-se então o tempo necessário para a passagem do volume de concreto e, esse deve apresentar um tempo igual a $10 \pm 3 \mathrm{~s}$.

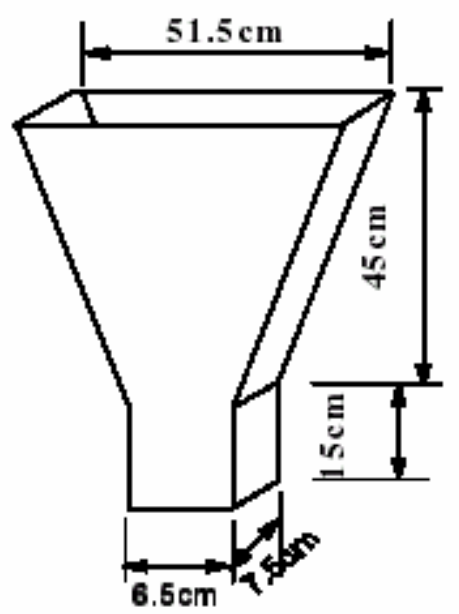

Figura 2.2 Modelo de ensaio do funil V (Gomes, 2002)

\subsubsection{Ensaio de caixa-L (L-Box test)}

Este método mede a fluidez do concreto e sua capacidade de passar por obstáculos, como por exemplo, armaduras. O princípio deste processo está na parte 
vertical do aparato, pois, quando o portão é aberto, a força da gravidade faz com que o concreto deslize pela caixa e, então, são medidos os tempos para se determinar a capacidade de transpor obstáculos do concreto auto-adensável.

Os procedimentos para este ensaio, segundo o Tviksta (2000) são:

- Inicialmente, a caixa-L deve ser feita de um material não absorvente e rígido. A abertura entre as barras é de $34 \mathrm{~mm}$, mas pode ser modificado para outros tamanhos de aberturas devido a espaçamentos de armadura na construção. Vale salientar que a caixa $L$ deve ser de montagem e desmontagem fáceis de modo a se limpar de modo eficiente à superfície da caixa. Entretanto, é importante que se usem agentes desmoldantes nas superfícies em contato com o concreto. A vantagem de se desmontar a caixa- $L$ após a concretagem consiste em poder conseguir informações importantes com o concreto endurecido, para isso, faz-se um corte no volume de concreto e vêem-se as superfícies das seções;

- Antes de se iniciar o lançamento do concreto na parte vertical da caixa-L, devem-se marcar as posições de referência para se tomar os tempos para medir a fluidez do concreto, sendo a primeira a $200 \mathrm{~mm}\left(\mathrm{~T}_{20}\right)$ e a segunda a $400 \mathrm{~mm}\left(\mathrm{~T}_{40}\right)$;

- Após o lançamento do concreto na fôrma vertical da caixa-L, cerca de 12,7 litros, deve-se esperar um total de 1 minuto antes de se levantar o portão deslizante. Assim, o concreto vai fluir da parte vertical para a parte horizontal passada pelas barras verticais posicionadas;

- Quando se levantar a porta deslizante, deve iniciar a contagem de tempo até atingir a marca de $\mathrm{T}_{\mathrm{L} 20}$ e então, a partir daí, medir o tempo necessário para atingir a marca referente à $T_{\llcorner 40}$;

- O tempo requerido para se obter a marca $T_{L 20}$ é de $1 \pm 0,5 \mathrm{~s}$ e, o tempo necessário para fluir $T_{\llcorner 40}$ é de 2,5 $\pm 1 \mathrm{~s}$ (quando a abertura entre as armaduras é maior ou igual a três vezes a maior dimensão de agregado da mistura);

- Quando o concreto parar de fluir, devem-se medir as alturas $\mathrm{H}_{1}$ e $\mathrm{H}_{2}$;

- Com a medida das alturas $\mathrm{H}_{1}$ e $\mathrm{H}_{2}$, calcula-se a razão e, $\mathrm{H}_{2} / \mathrm{H}_{1} \geq 0,80$, que é denominada de razão ou coeficiente de bloqueio;

- Uma coisa que pode ser observada durante o ensaio é a resistência a segregação do concreto. Se o concreto construir uma placa nas barras de aço, o concreto está bloqueado ou segregado. A habilidade de transpor obstáculos normalmente mostra-se por agregados graúdos 
distribuídos em toda a superfície até o final da parte horizontal, assim, o concreto pode ser visto como homogêneo.

Segundo TVRISKA (2000), o valor aceitável para a razão de bloqueio, $\mathrm{H}_{2} / \mathrm{H}_{1}$, é normalmente situado entre 0,80 a 0,85 , e, valores inferiores como 0,6 , às vezes, mostram valores aceitáveis para a estrutura. Entretanto, valores entre 0,8 e 1,0 são considerados aceitáveis, desde que seja verificada a resistência à segregação do concreto. A Figura 2.3 ilustra o modelo de caixa-L.

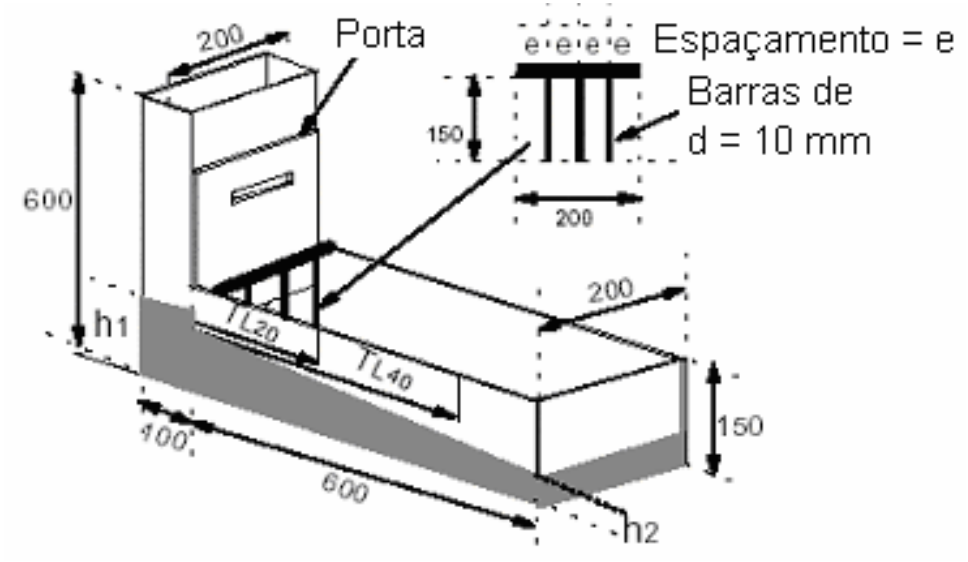

Figura 2.3 Representação esquemática do ensaio de caixa L (Gomes, 2002)

No caso desta pesquisa, a medição do valor do tempo $T_{20}$ era muito difícil e sujeita a muito erro por causa do pequeno valor medido e, por isso, foi adotado nesta pesquisa a aferição somente do valor de $T_{60}$ (tempo que o concreto leva para tocar a outra extremidade da caixa-L) conforme experiência adquirida no Estágio de Doutorado no Exterior.

\subsubsection{Ensaio de tubo-U (U-pipe test)}

É um processo simples e mede a segregação do concreto. O princípio deste ensaio está na fluidez do concreto que passa de lado a outro do tubo em forma de $U$. A vantagem deste processo é que o aparato para ensaio é barato e de fácil manutenção. O ensaio, entretanto, é limitado a concretos altamente fluidos, envolve uma grande quantidade de material e a duração depende da pega do concreto.

$\mathrm{O}$ aparato consiste em três tubos de PVC retos e dois tubos de PVC curvos (900), onde todos apresentam o diâmetro igual a 156 mm (ver Figura 2.4). Todos os tubos são cortados ao meio a fim de que o tubo, que funciona como uma fôrma, possa 
ser retirada sem danificar o concreto e assim verificar a distribuição de agregado graúdo no concreto.
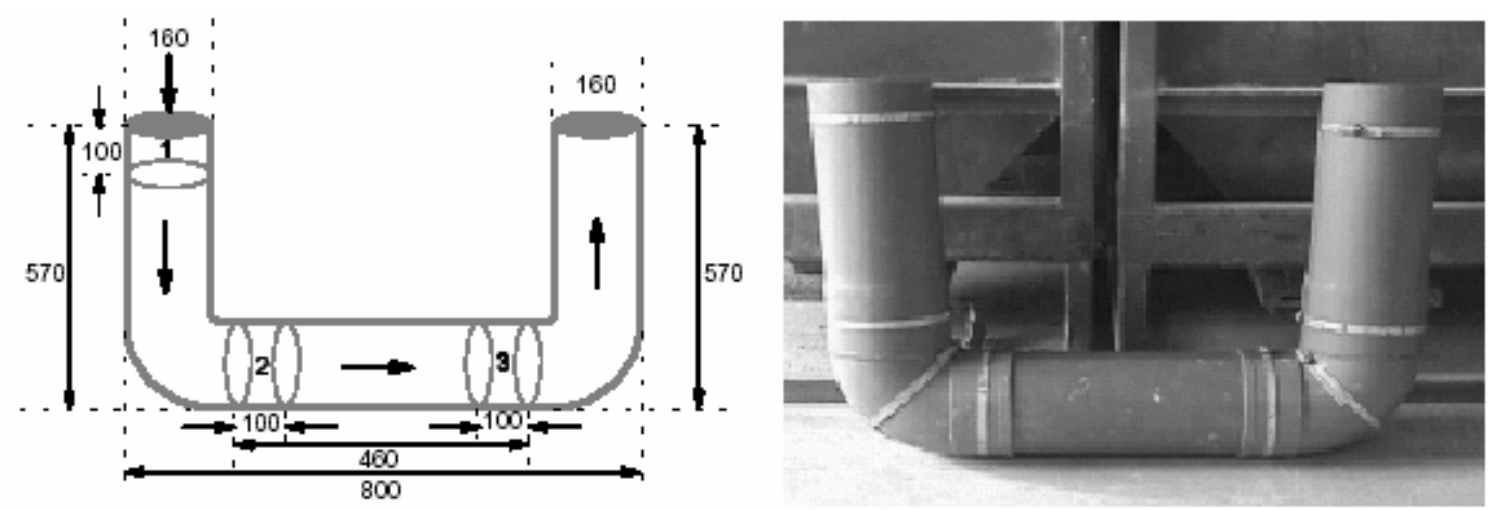

Figura 2.4 Modelo de tubo-U (U-pipe) (Gomes, 2002)

Segundo Gomes (2002), o procedimento de ensaio utilizando o tubo-U é o seguinte:

- Devem ser adquiridos três tubos de PVC retos e dois outros tubos de PVC curtos com diâmetro igual a $156 \mathrm{~mm}$. Eles devem ser cortados ao meio, ao longo de sua seção longitudinal;

- O concreto então deverá ser lançado no tubo em um lado até que o concreto apareça na outra extremidade, onde, são utilizados aproximadamente 32 litros de concreto;

- Após lançado o concreto e este iniciado a pega em aproximadamente três horas, o tubo é colocado na posição horizontal e a parte superior do tubo é retirada. Vale salientar que o concreto deve estar rígido o bastante para manter sua forma, mas não deve estar endurecido;

- Devem ser retiradas três amostras de $10 \mathrm{~cm}$ em três locais diferentes. A amostra deverá ser limpa com água para remover a argamassa e obter uma visão clara dos agregados graúdos em cima de uma tela de metal;

- Os agregados deverão ser secos com papéis-toalha e seu peso deverá ser medido. O agregado graúdo das amostras 2 e 3 deverão ser comparados com os da amostra 1, o qual é o padrão de referência. A razão de segregação (RS) é tomada como o menor dos dois valores obtidos.

$O$ valor da razão de segregação é o menor valor das relações $P_{d 1} / P_{d 2}$ e $P_{d 1} / P_{d 3}$, onde $P_{d 1}, P_{d 2}$ e $P_{d 3}$ são as massas medidas referentes aos agregados graúdos nas 
posições 1, 2 e 3, respectivamente. A segregação é considerada desprezível se RS $\geq$ 0,90 .

Após a verificação do RS, pode-se deixar o concreto das demais regiões endurecer e fazer um corte longitudinal de modo a verificar a distribuição de agregados pelos volumes remanescentes de concreto (ver Figura 2.5).

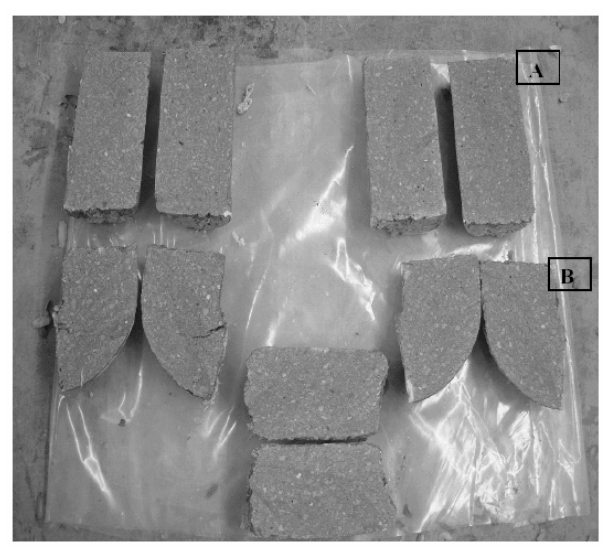

Figura 2.5 Cortes no concreto após o ensaio de tubo-U (Gomes, 2002)

\subsubsection{Ensaio de Anel-J (J ring)}

O ensaio de anel-J foi criado como forma de se avaliar diretamente a capacidade de passagem através de uma armadura, combinando o ensaio de abatimento com um anel de aço com barras de aço (Groth \& Nemegger, 1999).

Esse anel sofre variações do mesmo modo que no caso do ensaio de caixa-L, onde o espaçamento entre as barras é maior à medida que se aumenta o tamanho máximo do agregado graúdo.

A Figura 2.6 mostra o modelo de anel-J.

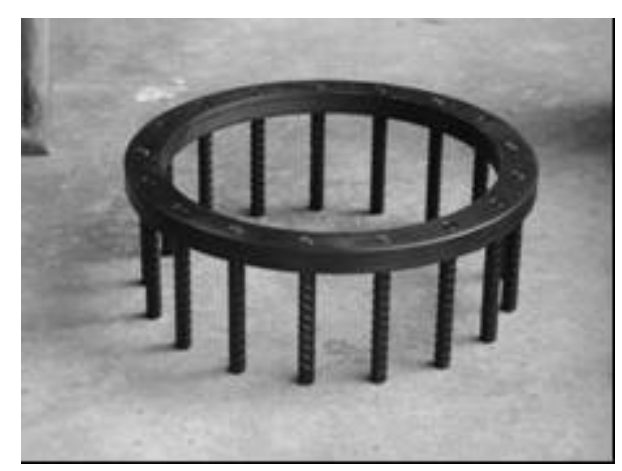

Figura 2.6 Modelo de anel-J 


\subsubsection{Ensaio de Alto-adensamento do concreto}

Este modelo de ensaio para se determinar a adensabilidade do CAA foi apresentado por OUCHI et al. (1995). A idéia deste ensaio é verificar a performance do concreto quando está passando através de aberturas em um malha de armadura. $A$ Figura 2.7 ilustra esse modelo.

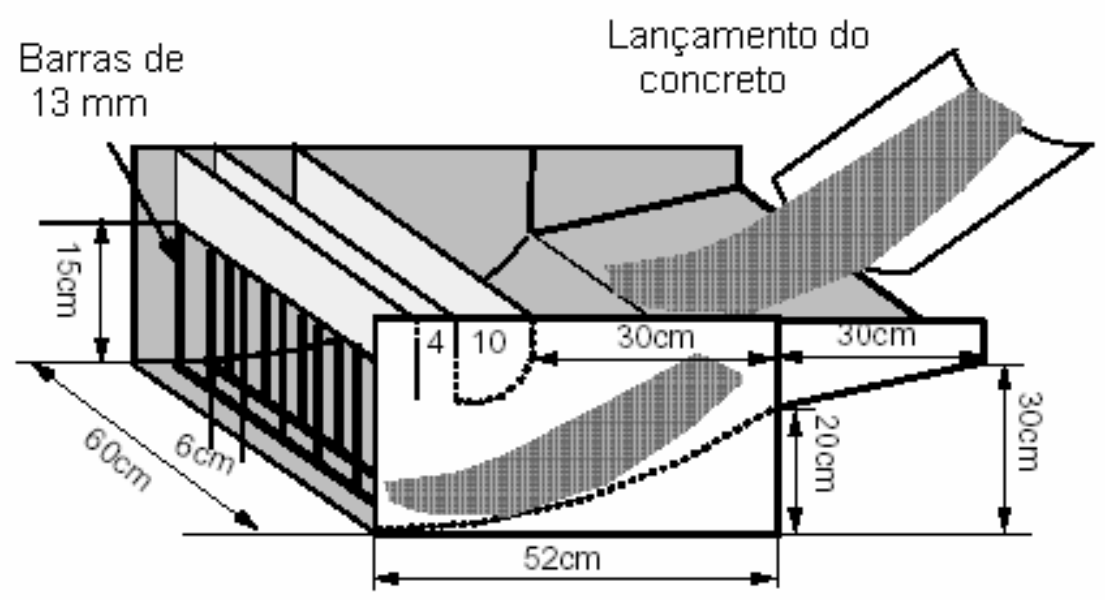

Figura 2.7 Ensaio de alto-adensamento do concreto (Gomes, 2002)

\subsection{Considerações finais}

Neste capítulo foi mostrado um panorama sobre o concreto auto-adensável, no que se refere às suas propriedades no estado fresco, seus materiais componentes e os ensaios de verificação para aceitação do CAA. Conforme o que foi visto, viu-se que há preocupação por parte dos pesquisadores sobre a trabalhabilidade do CAA, porém a adoção deste material necessita ensaios práticos para aceitação na construção e, em alguns processos para determinação da auto-adensabilidade do CAA requerem a utilização de equipamentos sofisticados ou de calibração complicada, que torna difícil sua aplicação.

O controle tecnológico dos materiais utilizados tem grande importância na qualidade do CAA, o que pode ser um fator que, inicialmente, afaste sua utilização na construção civil; entretanto espera-se que sua utilização se torne mais freqüente em virtude das altas exigências de qualidade e durabilidade das construções em concreto.

Com relação aos processos de verificação do CAA, os modelos mostrados são os mais comumente utilizados, por serem de fácil aplicação, transporte e calibração, sendo adequados para utilização no canteiro de obras. 



\section{Determinação da composição do CAA}

Neste capítulo são apresentadas as composições do traço para os concretos auto-adensáveis, mostrando cada etapa para sua determinação e as principais observações feitas no decorrer do seu desenvolvimento.

\subsection{Considerações iniciais}

Segundo Okamura \& Ouchi (2003), o método para se determinar o CAA não envolve apenas a alta deformabilidade da pasta ou da argamassa, mas também da resistência à segregação entre o agregado graúdo e da argamassa quando o concreto flui através de uma abertura de uma malha de armadura.

Então, o contato entre os agregados poderia ser aumentado, assim como a redução distância relativa entre as partículas, levando à conclusão de que as tensões internas poderiam aumentar quando o concreto está deformado, principalmente próximo a obstáculos.

Assim, quando se limitava à quantidade de agregados, a fluidez necessária era maior que no caso de se ter quantidade normal de agregados, e com isso não haveria nenhum tipo de bloqueio para a passagem da mistura; logo, o consumo de energia, que se pode traduzir como as perdas de pasta por causa de algum obstáculo, seria menor.

A Figura 3.1a mostra que, quando o concreto está fluindo através de uma abertura, uma pasta com alta viscosidade pode prevenir o aumento de tensões localizadas em virtude da aproximação de algum obstáculo. Esta alta deformabilidade 
somente pode ser obtida se forem utilizados superplastificantes, para assim poder manter pequena a relação água-finos.

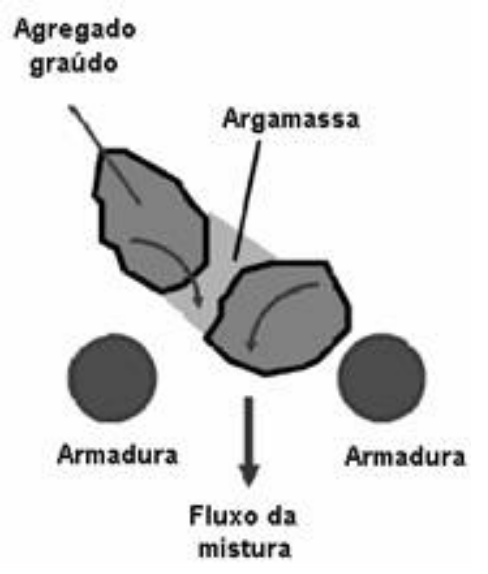

(a)

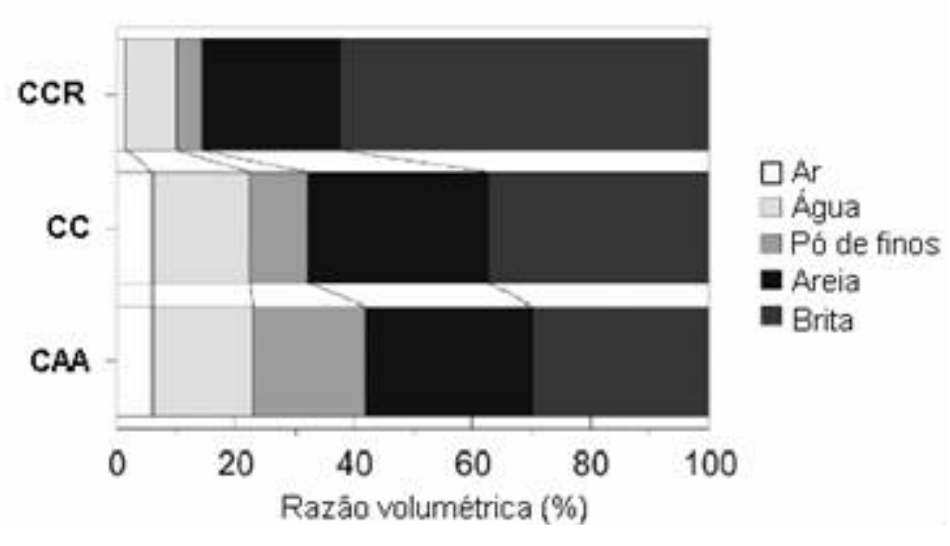

(b)

Figura 3.1 a) Mecanismo do CAA e (b) Comparação entre CAA, CC e CCR (Okamura \& Ouchi, 2003)

De acordo com os referidos autores, foi feita uma comparação das quantidades de volume de material entre concreto convencional (CC), concreto compactado com rolo para represas (CCR) e concreto auto-adensável (CAA).

Segundo Gomes (2002), a alta fluidez, estabilidade e baixo bloqueio de partículas são as características básicas de um CAA. Os materiais a serem empregados na dosagem de CAA apresentam a seguinte distribuição:

- Alto volume de pasta (cerca de 35 a $40 \%$ do volume de concreto). Esse alto volume de pasta é necessário para garantir a fluidez;

- Altas quantidades de finos (fillers), cerca de 400 a $650 \mathrm{~kg} / \mathrm{m}^{3}$, onde, este compreende partículas com dimensões inferiores a $100 \mu \mathrm{m}$, e consistem de cimento $\left(200\right.$ a $\left.400 \mathrm{~kg} / \mathrm{m}^{3}\right)$ e fillers minerais, sendo esses feitos de pozolana (cinza volante (fly ash), sílica ativa (silica fume), refugo de fornos (blast furnance slag) e finos naturais (calcário, quartzo, etc.)). A alta quantidade de finos se justifica para se evitar a segregação dos agregados e para reduzir o atrito entre os agregados graúdos. Porém, a alta quantidade de cimento gera um alto calor de hidratação da pasta e, conseqüentemente, um alto custo financeiro. Assim, a utilização de pozolanas e/ou fillers têm sido utilizadas para reduzir a quantidade de cimento; 
- A quantidade de água varia de 150 a $180 \mathrm{~kg} / \mathrm{m}^{3}$, com a relação entre peso da água e o peso dos fillers (A/F) variando de 0,25 a 0,4 e, com a relação peso de água e peso de finos mais agregados finos $(A / F+A F)$ variando de 0,11 a 0,14 ;

- Com agentes viscosos presentes em algumas misturas o volume de água pode ser de $200 \mathrm{l} / \mathrm{m}^{3}$ para relação $A / F+A F$ variando de 0,12 a 0,16 ;

- Com relação ao volume de agregado graúdo, o seu volume varia entre 30 a $35 \%$ do volume total de concreto, e a razão entre o peso do agregado graúdo com o peso da mistura, varia entre 32 a $40 \%$;

- A dimensão do agregado graúdo deverá ser pequena em função do bloqueio na passagem por pequenas aberturas, e é recomendado que esta dimensão máxima esteja entre 10 a $20 \mathrm{~mm}$;

- O volume do agregado fino varia de 40 a $50 \%$ do volume da argamassa, com valores oscilando entre 710 a $900 \mathrm{~kg} / \mathrm{m}^{3}$. A relação entre o volume de agregado graúdo e o volume total de agregados varia entre 0,44 a 0,64.

Superplastificantes e redutores de água tais como policarboxilatos e copolímeros podem ser utilizados, e para a determinação de sua quantidade deverão ser utilizados os procedimentos de ensaios de espalhamento e de fluidez.

A quantidade típica de cimento para um CAA, é de $350-450 \mathrm{~kg} / \mathrm{m}^{3}$. Uma quantidade superior a $500 \mathrm{~kg} / \mathrm{m}^{3}$ pode ser perigosa e aumentar a retração, e quantidade inferior a $350 \mathrm{~kg} / \mathrm{m}^{3}$ somente poderá ser adotada se houver a inclusão de algum filler (EFNARC, 2002).

Agentes viscosos solúveis em água, baseados em polissacarídeos e celulose, podem substituir fillers minerais.

Segundo o Gomes (2002), para CAA de alto desempenho, isto é, CAAAD, temse pequenos valores para a relação $A / C(0,35$ a 0,45$)$, alta quantidade de cimento (400 a $550 \mathrm{~kg} / \mathrm{m}^{3}$ ) e a quantidade de agregado graúdo é, em geral, menor que o convencional.

De acordo com Nunes et al. (2003), a primeira proposta para um método para definir o traço do CAA tratava-se de um processo relativamente simples, porém limitado a um conjunto de materiais de origem japonesa, como por exemplo agregados com dimensões entre 5 a $20 \mathrm{~mm}$, cimento com baixo calor de hidratação e ausência de aditivos como o agente de viscosidade.

O método de Okamura et al. (2000) define o CAA, ao contrário do CC, em termos volumétricos. O primeiro passo do processo é fixar o teor de ar $\left(V_{a}\right)$ em função do ambiente ao qual a estrutura está exposta. $\mathrm{O}$ volume real de agregado graúdo $\left(\mathrm{V}_{\mathrm{g}}\right)$ 
corresponde ao volume aparente de $0,5 \mathrm{~m}^{3}$, por unidade de volume de concreto. Assim, o volume da pasta corresponde ao volume total menos o volume do agregado graúdo. Desse volume, $40 \%$ será ocupado por materiais de granulometria fina $\left(V_{s}\right)$, onde esta granulometria tem dimensão superior a $90 \mu \mathrm{m}$, e o restante deverá ser ocupado por materiais de granulometria muito fina com dimensão inferior a $90 \mu \mathrm{m}$.

Após a definição da composição da mistura, deve-se determinar a razão volumétrica água/finos $\left(\mathrm{V}_{\mathrm{w}} / \mathrm{V}_{\mathrm{p}}\right)$ e a dosagem do superplastificante. $\mathrm{O}$ processo para se determinar a razão volumétrica correta e a quantidade de superplastificante é empírico, ou seja, é necessária a utilização de dois ensaios, onde um mede o espalhamento e o outro mede a fluidez da pasta, verificando sua deformabilidade e sua viscosidade.

Porém, somente os ensaios de fluidez e de consistência não são suficientes para se avaliar corretamente a adensabilidade do concreto e, assim deve-se recorrer a outros ensaios, como por exemplo, o de caixa-U, caixa-L, entre outros.

Billberg (1999) ${ }^{25}$, apud Gomes et al. (2003) e Petersson et al. (1996), propuseram um método que consistia da determinação do esqueleto granular e o volume mínimo da pasta para garantir as características básicas do CAA no ensaio de caixa-L. De acordo com a pesquisa desenvolvida por esses autores, a quantidade de finos, de água e de superplastificante foram ajustadas para se obter a resistência à compressão do concreto, e ainda conseguir viscosidade suficiente e uma pequena tensão de escoamento (yield stress).

Sedran et al. (1996), propuseram um modelo computacional para determinar o esqueleto granular da mistura, considerando o efeito parede e a viscosidade da mistura. De acordo com a pesquisa desenvolvida pelos referidos autores, a dosagem de finos serviu para determinar a resistência à compressão do concreto, a quantidade de superplastificante foi definida utilizando o ensaio de funil Marsh; e a quantidade de água e de superplastificante era determinada com o objetivo de se obter uma viscosidade aceitável utilizando um reômetro e o ensaio de espalhamento.

Segundo Nunes et al. (2003), as primeiras misturas utilizando esse processo resultaram em concretos com elevado conteúdo de pasta. Assim, foi necessário adaptar os parâmetros do método de Okamura et al. (2000). Desse jeito, o valor do volume aparente de agregado graúdo corresponde $0,5 \mathrm{~m}^{3}$ para alcançar um nível de alta adensabilidade, mas esse valor somente é recomendado para misturas em que o

${ }^{25}$ BILLBERG, P.; PETERSSON, Ö; NORBERG, J. (1999). Full scale casting of bridges with self-compacting concrete. Proceedings, 1st International RILEM Symposium on SelfCompacting Concrete (Stockholm, Sweden), A. Skarendahl and Ö. Petersson (editors), RILEM Publications S.A.R.L, p. 639-650; 
diâmetro máximo do agregado graúdo é próximo de $20 \mathrm{~mm}$, já que para diâmetros menores o volume aparente de agregado graúdo pode ser reduzido.

Outro problema encontrado foi que a razão $V_{w} / V_{p}$ obtida nos ensaios conduziu a concretos extremamente viscosos e com sua trabalhabilidade comprometida. Então foi adotado um fator $\alpha$ a ser aplicado na relação água/finos na equação Eq. 3.2).

$$
\begin{aligned}
& \mathrm{V}_{\mathrm{p}}+\mathrm{V}_{\mathrm{s}}+\mathrm{V}_{\mathrm{g}}+\mathrm{V}_{\mathrm{w}}+\mathrm{V}_{\mathrm{a}}=1 \\
& \mathrm{~V}_{\mathrm{p}}+\mathrm{S} \cdot\left(1-\mathrm{V}_{\mathrm{a}}-\mathrm{V}_{\mathrm{g}}\right)+\mathrm{V}_{\mathrm{ap}} \cdot \mathrm{V}_{\mathrm{g}, \lim } \cdot\left(1-\mathrm{V}_{\mathrm{a}}\right)+\alpha \cdot\left(\mathrm{V}_{\mathrm{w}} / \mathrm{V}_{\mathrm{p}}\right) \cdot \mathrm{V}_{\mathrm{p}}+\mathrm{V}_{\mathrm{a}}=1
\end{aligned}
$$

Onde, "S" corresponde à percentagem do volume de agregado fino em relação ao volume de argamassa, " $\mathrm{V}_{\mathrm{ap}}$ " corresponde ao volume aparente que serve de referência para a definição do volume de agregado graúdo, e " $\alpha$ " é o fator de aumenta a relação água/finos.

Vale salientar que esses parâmetros assumem os valores de $S=40 \%, V_{a p}=0,5$ $\mathrm{m}^{3}, \alpha=1,0$ (Okamura et al., 2000; Nunes et al., 2003).

Embora a formulação pareça simples e seja possível o desenvolvimento de um traço para um CAA adequado, é importante levar em consideração a relação AF/AG, isto é, agregado fino/agregado graúdo, de modo a minimizar a presença de vazios na mistura.

Outro ponto observado pelos pesquisadores, é que a utilização de cimento portland fornece a mistura com relações $\mathrm{A} / \mathrm{C}$ muito baixas, o que leva a concluir que existem dificuldades em se obter um CAA com baixa resistência à compressão.

Assim, de acordo com Gomes (2002), o traço do CAA não está totalmente estabelecido em função da complexidade de se obter uma otimização na mistura de seus componentes e das diferentes propriedades requeridas para o CAA. Por isso, a caracterização do CAA necessita de métodos mais simples, pois os atuais procedimentos necessitam de equipamentos sofisticados, tais como o reômetro, ou de calibração complicada.

De acordo com Tviksta (2000a), experimentos realizados em CAA mostraram que a resistência à compressão e o módulo de elasticidade longitudinal do concreto são similares ao CC. 


\subsection{Proposta para determinação do concreto auto-adensável}

Existem muitas propostas para se determinar a composição do CAA, dentre elas a proposta de Tutikian et al. (2004), Saak et al. (2001), Arima et al. (2002) e da UPC (Gettu \& Agulló, 2004). A proposta para se desenvolver o CAA foi baseada na pesquisa de Gomes (2002) a qual se baseia no método de dosagem desenvolvido na UPC (Universidade Politécnica da Catalunha). Segundo sua análise, o CAA pode ser determinado a partir da otimização de três etapas, sendo elas: pasta, agregado (esqueleto granular) e concreto.

O método de dosagem da UPC se baseia na otimização separada da composição da pasta e do esqueleto granular dos agregados. A pasta é composta de cimento, sílica ativa, filler, água e superplastificante, enquanto o esqueleto granular é composto da otimização entre o agregado miúdo e o graúdo de modo a se obter a maior compactação seca sem haver a necessidade de compactar os agregados; desse modo, há a redução de vazios no esqueleto granular.

Para a determinação da composição da pasta se utilizam relações em peso $A / C$, SA/C, SP/C e F/C. No caso de concretos de alta resistência se utiliza a relação $S A / C=0,1$, a relação $A / C$ é fixada em 0,4 e, a partir daí, esse valor é reduzido até que se obtenha a resistência requerida (Gettu \& Agulló, 2004a).

Com a determinação das relações $A / C$ e SA/C, passa-se à determinação da dosagem tanto do superplastificante quanto da adição de filler, sendo que este pode ter ou não efeito pozolânico (filler calcário e filler quartzo, por exemplo).

A relação SP/C é determinada a partir do ensaio de cone Marsh, que representa o ensaio de fluidez e otimização do teor de superplastificante na pasta. O cone Marsh utilizado tem abertura de $8 \mathrm{~mm}$ para pastas e $12,5 \mathrm{~mm}$ para argamassas. 0 procedimento para o cone Marsh é mostrado em segmentos posteriores deste mesmo capítulo. Quando se obtém a curva log $\left(T_{m}\right)$ - SP/C (\%), pode-se determinar o teor ótimo de superplastificante para um determinado tempo no qual foi realizado o ensaio (no caso desta pesquisa, foram realizados ensaios para 10, 15 e 30 minutos após a mistura da água com o cimento e verificar a perda de fluidez com o tempo). O teor ótimo é determinado a partir de um ângulo interno de $140^{\circ} \pm 10^{\circ}$ na curva log $\left(T_{m}\right)-$ $\mathrm{SP} / \mathrm{C}(\%)$.

Com o teor ótimo de superplastificante determinado, passa-se à determinação do teor ótimo de adição, onde esta varia em adição ao cimento ou em substituição de cimento (este último utilizado nesta pesquisa). Essa dosagem de filler se faz a partir do ensaio de mini-abatimento ou mini-espalhamento (Aïtcin, 2000). Esse ensaio se resume em medir o diâmetro do espalhamento, que deve estar dentro do limite de $18 \pm$ 
$1 \mathrm{~cm}$ e de medir o tempo que a pasta leva para ultrapassar o diâmetro de $115 \mathrm{~mm}$ ( $\left.T_{115}\right)$, que deve estar dentro do limite de $3 \pm 1 \mathrm{~cm}$. Assim, a pasta que respeitar os limites estabelecidos terá a relação de filler com relação ao cimento ótima (Gettu \& Agulló, 2004a, Gomes, 2002).

Conteúdo ótimo de pasta tem grande importância na fluidez e coesão do CAA, pois esta tem como função preencher os vazios existentes entre os agregados, propiciando assim a auto-adensabilidade no estado fresco e a resistência à compressão no estado endurecido (Gomes 2002; Gettu \& Agulló, 2004a). Esse conteúdo ótimo de pasta pode ser avaliado por ensaios de abatimento ou espalhamento do tronco de cone de Abrams, e para avaliar a capacidade de passar por armaduras, o ensaio de caixa $L$ é adotado.

A Figura 3.2 ilustra o esquema de otimização da dosagem do CAA (Gomes, 2002).

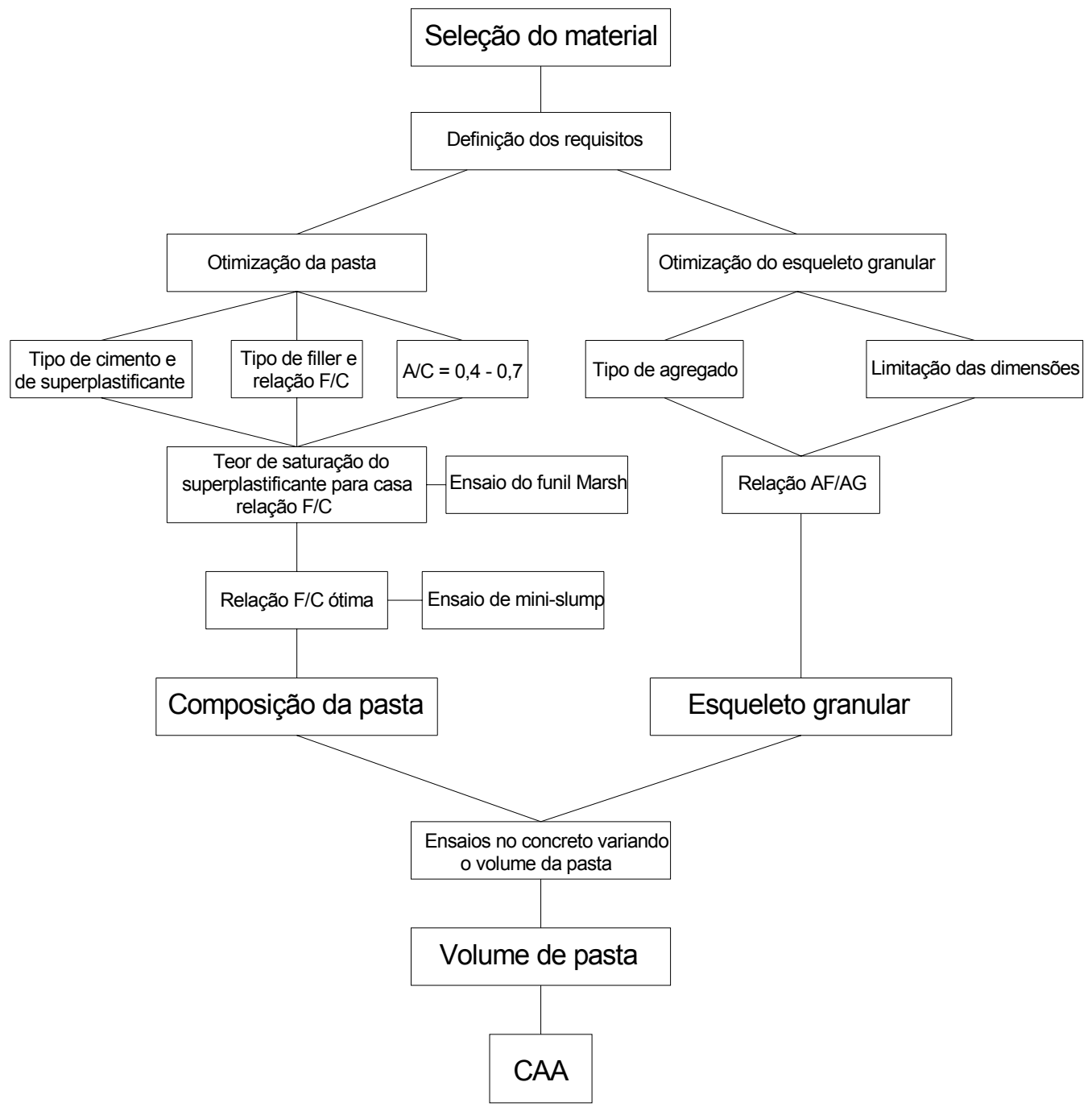

Figura 3.2 Esquema de otimização para o CAA (Gomes, 2002) 


\subsection{Materiais utilizados}

O agregado miúdo e graúdo utilizados nesta pesquisa foi classificado de acordo com a NBR 7211 (1983). A Figura 3.3 ilustra suas granulometrias.
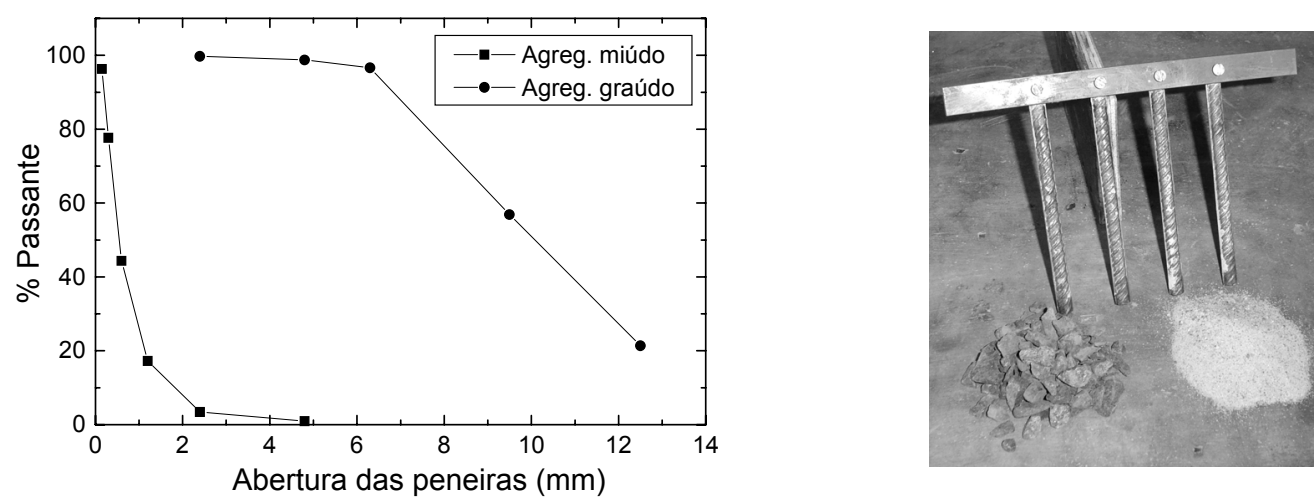

Figura 3.3 Distribuição granulométrica dos agregados e tamanho dos agregados em relação ao espaçamento das armaduras para o ensaio de caixa-L

O valor da massa específica da areia analisada foi de $2,630 \mathrm{~g} / \mathrm{cm}^{3}$ (NBR 9776, 1987) e o módulo de finura médio foi de 1,92 e diâmetro máximo de 1,2 mm.

Para o agregado graúdo, a NBR 9937 (1987) estabelece o ensaio de determinação da massa específica do agregado graúdo tanto na condição seca $\left(\gamma_{\mathrm{s}}\right)$ quanto na condição saturada e superfície seca $\left(\gamma_{s s s}\right)$ e, a partir daí, determina-se o índice de absorção do agregado (a). A Tabela 3.1 ilustra os valores obtidos.

Tabela 3.1 Características do agregado graúdo utilizado

\begin{tabular}{cc}
\hline Característica & Valores obtidos \\
\hline$\gamma_{\mathrm{s}}$ & $2,828 \mathrm{~g} / \mathrm{cm}^{3}$ \\
$\gamma_{\mathrm{sss}}$ & $2,876 \mathrm{~g} / \mathrm{cm}^{3}$ \\
$\mathrm{a}$ & $1,71 \%$ \\
\hline
\end{tabular}

O cimento utilizado na pesquisa foi o Ciminas CP V ARI Plus cujas características físico-químicas são mostradas na Tabela 3.2.

Tabela 3.2 Características físicas e químicas do cimento

\begin{tabular}{cc}
\hline Parâmetro & Valores obtidos \\
\hline$\# 325$ & $3 \%$ \\
Superfície Blaine & 4500 \\
Tempo de pega & $130 \mathrm{~min}$. \\
Resistência à compressão & $1 \mathrm{dia}=26 \mathrm{MPa} / 28$ dias $=53 \mathrm{MPa}$ \\
Coloração & Clara e uniforme \\
\hline
\end{tabular}


O superplastificante utilizado foi o GRACE ADVA@CAST baseado em carboxilato, com massa específica de $1,08 \mathrm{~kg} / \mathrm{dm}^{3}$ e conteúdo de $30 \%$ de partículas sólidas e $70 \%$ de água, doado pela GRACE Brasil.

Sílica ativa utilizada na pesquisa foi a Microsílica 920-U, marca ELKEM, doada por esta empresa. De acordo com o certificado de conformidade, a Tabela 3.3 mostra suas características.

Tabela 3.3 Características físico-químicas da sílica ativa

\begin{tabular}{ccc}
\hline Parâmetro & Limites & Resultado da análise \\
\hline Exigências químicas & mín. $85 \%$ & $94,3 \%$ \\
$\mathrm{SiO}_{2}$ & máx. 3\% & $0,4 \%$ \\
Umidade & máx. $6 \%$ & $1,7 \%$ \\
Perda ao fogo & máx. $1,5 \%$ & $0 \%$ \\
Eq. Alcalino em $\mathrm{Na}_{2} \mathrm{O}$ & & \\
Exigências físicas & & $6,3 \%$ \\
Resíduos na peneira $45 \mu \mathrm{m}$ & máx. $10 \%$ & $270 \mathrm{~kg} / \mathrm{m}^{3}$ \\
Densidade aparente & $<350 \mathrm{~kg} / \mathrm{m}^{3}$ & \\
\hline \multicolumn{2}{l}{ Lote: $307 ;$ Referência: MF-307 }
\end{tabular}

A Tabela 3.4 ilustra as características físico-químicas do filler (pó de calcário) utilizado.

Tabela 3.4 Características físico-químicas do fíller calcário

\begin{tabular}{lc}
\hline \multicolumn{1}{c}{ Parâmetro } & Resultados \\
\hline Cor & Cinza \\
Diâmetro médio & $45 \mu \mathrm{m}$ \\
Características químicas & \\
$\mathrm{CaO}$ & $55,17 \%$ \\
$\mathrm{MgO}$ & $0,13 \%$ \\
$\mathrm{Fe}_{2} \mathrm{O}_{3}$ & $0,07 \%$ \\
$\mathrm{Al}_{2} \mathrm{O}_{3}$ & $0,30 \%$ \\
$\mathrm{SiO}_{2}$ & $0,77 \%$ \\
$\mathrm{Caracrterísticas} \mathrm{Físicas}_{\mathrm{Absorção} \mathrm{DOP}(\%)}$ & $28-32$ \\
$\mathrm{pH}($ sol. aqu. $5 \%)$ & $10-11$ \\
Densidade aparente $\left(\mathrm{g} / \mathrm{cm}^{3}\right)$ & $1-1,2$ \\
Perda ao fogo $\left(850^{\circ} \mathrm{C}\right)$ & $45 \%$ máx. \\
Absorção óleo de linhaça (\%) & $23-27$ \\
\hline
\end{tabular}

\subsection{Etapa Pasta}

O CAA necessita de alta fluidez com uma pequena segregação dos agregados, o que requer uma otimização da quantidade de material nas fases de pasta e agregado (Gomes, 2002). 
Neste segmento, apresenta-se a teoria para se obter uma pasta com alta fluidez e boa coesão entre suas partículas. Essa teoria envolve a aplicação de dosagens de superplastificantes e de fillers para garantir a fluidez e a coesão, respectivamente.

Existem dois processos para se formular um critério baseado no ensaio de minislump (Gomes, 2002), que pode ser chamado de mini-abatimento (Aïtcin, 2000) sendo eles:

- Comparação dos resultados entre pasta e argamassa utilizando o ensaio de mini-abatimento e o de truncaded cone, aqui chamado de ensaio de tronco de cone parcial de abatimento;

- Comparação da adensabilidade do concreto com os ensaios de miniabatimento da pasta.

Para a elaboração da pasta de CAA, deve-se inicialmente determinar as características dos materiais utilizados para sua elaboração, uma vez que o ponto de saturação depende do tipo do cimento, da relação $A / C$, do tipo de superplastificante, do tipo de adição mineral e de sua dosagem, e da seqüência da mistura dos materiais (Gomes, 2002; Roncero, 2000).

A dosagem da pasta é definida pelo ponto de saturação ou ponto ótimo de dosagem. O procedimento de ensaio da fluidez da pasta é importante para se determinar se a pasta possui fluidez suficiente, e quanto maior a fluidez da pasta a sua perda de fluidez por um tempo superior a 30 minutos é desprezada (Gomes, 2002).

O ensaio de funil Marsh foi criado na década de 60 como um método simples e prático para se avaliar a fluidez de misturas, principalmente na indústria petrolífera. $A$ aplicação deste método na construção civil se deu em virtude da utilização do concreto de alto desempenho, com alta resistência à compressão e elevada trabalhabilidade, como parte do projeto para a mistura do concreto (Gomes, 2002).

As vantagens da utilização deste método envolvem o uso de um aparato simples para sustentação do funil, uma pequena quantidade de material e um procedimento de ensaio simples e de fácil repetição. A desvantagem deste método está na utilização de pastas com pouca fluidez e na rugosidade da superfície do cone, que pode interferir nos resultados.

Segundo Roncero (2000) a temperatura ambiente (variando de 5 a $45^{\circ} \mathrm{C}$ ) não altera o ponto de saturação de uma mistura.

Para a determinação do índice de fluidez da pasta será utilizada a NBR 7682 (1983) que prescreve o método para determinação do índice de fluidez de calda de cimento para injeção utilizando o funil Marsh. 
Na presente pesquisa foi utilizado o funil Marsh mostrado na Figura 3.4a. Para a mistura da pasta foi utilizado um funil com diâmetro igual a $8 \mathrm{~mm}$ (NBR 7682, 1983). O procedimento consiste de medir o tempo para que certo volume de pasta flua para um recipiente. Assim, quanto menor o tempo de fluidez da pasta mais fluida será a mistura. A Figura 3.4b ilustra a argamassadeira marca "Controls" de 10 velocidades com capacidade de cuba de 10 litros utilizada para a pesquisa.

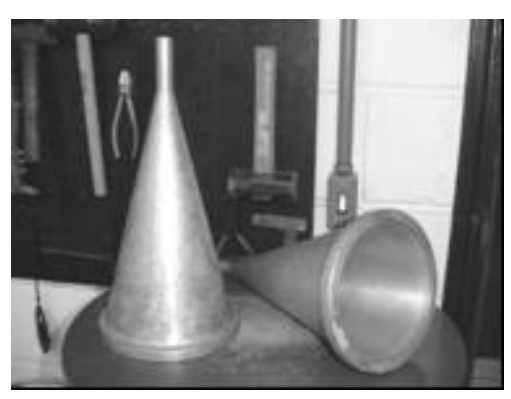

a)

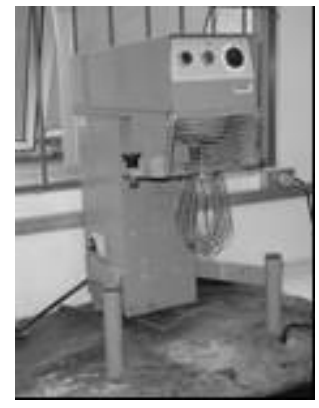

b)

Figura 3.4 a) Funil Marsh utilizado para o ensaio de fluidez e b) argamassadeira utilizada na etapa pasta

Para se determinar o ponto de saturação de uma pasta foi utilizado o procedimento semelhante ao utilizado por Gomes (2002) que se baseia no Método AFREM (De Larrard et al., 1997). Este procedimento consiste em montar a curva em escala logarítmica do tempo de fluidez $\left(T_{m}\right)$ vs. a relação SP/C e considerar a tangente para a menor razão SP/C com uma inclinação 2/5. A Figura 3.5 ilustra os processos para determinação do ponto de saturação de uma pasta.

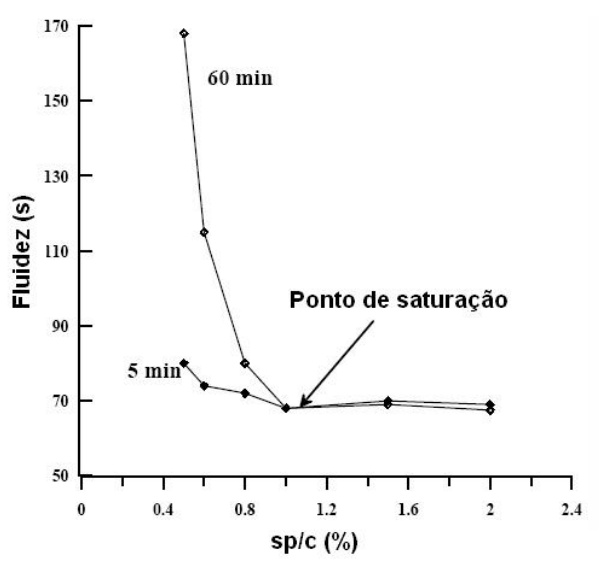

(a)

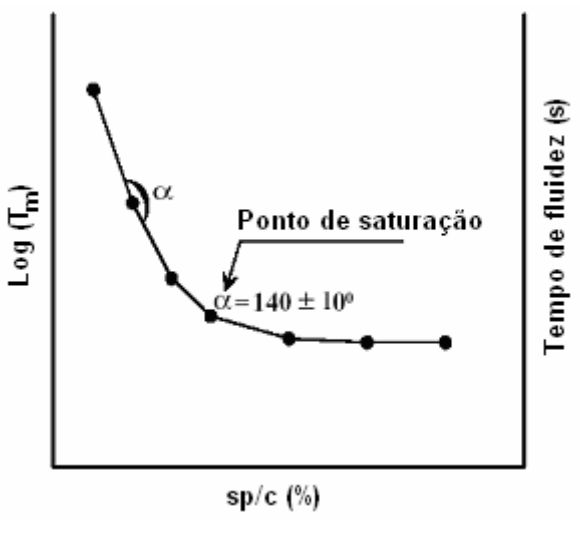

(b)

Figura 3.5 Modelos para determinação do pronto de saturação (a) Método de Aïtcin, (b) Método AFREM (Gomes, 2002) 
Avaliando-se o teor ótimo de superplastificante para a composição da pasta, pode-se perceber que, à medida que se aumenta a quantidade de finos na mistura, a quantidade de superplastificante ou de água é maior, para permitir uma melhor hidratação do cimento, pois foi observado que a falta de água ou superplastificante acarreta a formação de aglomerados de cimento com finos, que provocam uma má avaliação da fluidez da pasta, pois diversas misturas apresentaram excelente fluidez, porém a formação de aglomerados de cimento com finos obstruía a passagem da pasta no funil.

Com relação ao procedimento de mistura, a reología do cimento é sensível à forma de adição dos materiais (Gomes, 2002), assim, o efeito da seqüência do lançamento dos materiais foi estudado primeiramente com o objetivo de se obter a seqüência que promovesse a maior fluidez. A Tabela 3.5 ilustra a seqüência de lançamento dos materiais que apresentou menor tempo de fluidez.

Tabela 3.5 Seqüência de lançamento dos materiais

\begin{tabular}{cccccc}
\hline Seqüência & Passo & Material & $\begin{array}{c}\text { Tempo de } \\
\text { mistura }\end{array}$ & $\begin{array}{c}\text { Velocidade } \\
\text { de mistura }\end{array}$ & $\begin{array}{c}\text { Fempo (s) no } \\
\text { Funil Marsh }\end{array}$ \\
SP/C = 1,0\%
\end{tabular}

Para cada teor de saturação foi realizado o mesmo ensaio três vezes para assim se ter uma idéia da variabilidade das propriedades do CAA e desse modo promover uma confiabilidade dos resultados. Para esse procedimento foi adotado um coeficiente de variação de no máximo $5 \%$, onde, se este fosse ultrapassado, o ensaio seria refeito.

O teor ótimo de superplastificante foi considerado para o tempo de 10 minutos após a mistura do cimento com a água. Com isso, os teores de superplastificantes foram de $0,48 \%$ para $A / C=0,4$ e de $0,42 \%$ para $A / C=0,6$.

No estudo da fluidez da pasta, a temperatura variou de 22 a $26^{\circ} \mathrm{C}$, com umidade relativa do ar entre 63 e $89 \%$, para todos os ensaios.

Na Figura 3.6 ilustra-se a variação do tempo de escoamento, conforme o método AFREM discutido anteriormente. 


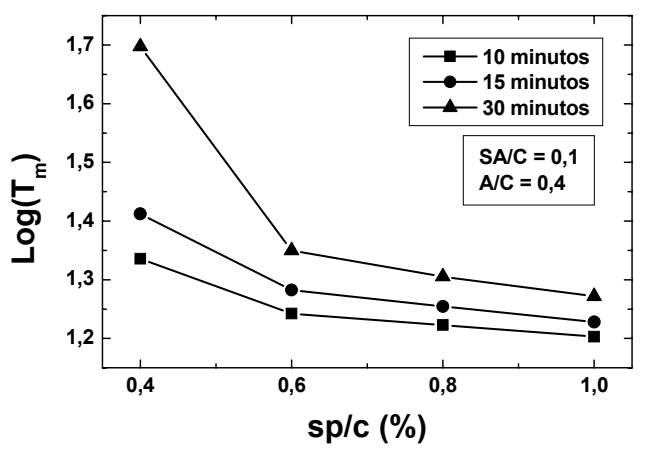

Figura 3.6 Curvas de fluidez para os ensaios com o funil Marsh com A/C = 0,4

O teor ótimo de superplastificante foi considerado para o tempo de 10 minutos após a mistura do cimento com a água. De acordo com Gomes (2002), quando não for fornecido um ponto com o ângulo entre $140^{\circ} \pm 10^{\circ}$, ou uma determinação mais acurada for necessária, pode-se interpolar os pontos existentes pata obter o ângulo correspondente para o ponto de saturação. Assim, os teores de superplastificantes foram de $0,64 \%(A / C=0,4)$ e $0,67 \%(A / C=0,6)$. Entretanto, a relação $A / C=0,6 \mathrm{com}$ adição de sílica ativa não foi utilizada, pois se procurava obter uma resistência à compressão do concreto em torno de $30 \mathrm{MPa}$.

Para se avaliar se houve ou não segregação da pasta, é necessário realizar o ensaio de mini-abatimento (Aïtcin, 2000; Gomes, 2002)

Com relação ao tempo de espalhamento da pasta no ensaio de mini-abatimento, as misturas possuíam altíssima fluidez, impossibilitando a aferição do tempo de escoamento das pastas. De acordo com a literatura a respeito da reología das pastas de cimento e por esta pesquisa preliminar, foi constado que não é possível medir $T_{115}$ para pastas com relação $A / C$ superiores a 0,4 , a não ser que estas sejam bastante rígidas por causa da adição de finos, o que levou à conclusão que seria necessária a utilização de um filler para aumentar a rigidez da pasta, mesmo não sendo observada qualquer segregação nesta, tornando-se assim uma medida preventiva para o caso de se ter exsudação por falta de rigidez da pasta.

Com isso foi realizado um estudo para otimizar o conteúdo de partículas de finos com relação ao teor de superplastificante. Foram adotados quatro teores de adição de filler calcário $(10,20,30$ e 40\%) em substituição da massa de cimento, além da substituição do teor de sílica ativa (10\%). A Figura 3.7 ilustra a variação do teor ótimo de saturação para a relação $A / C=0,4$. 


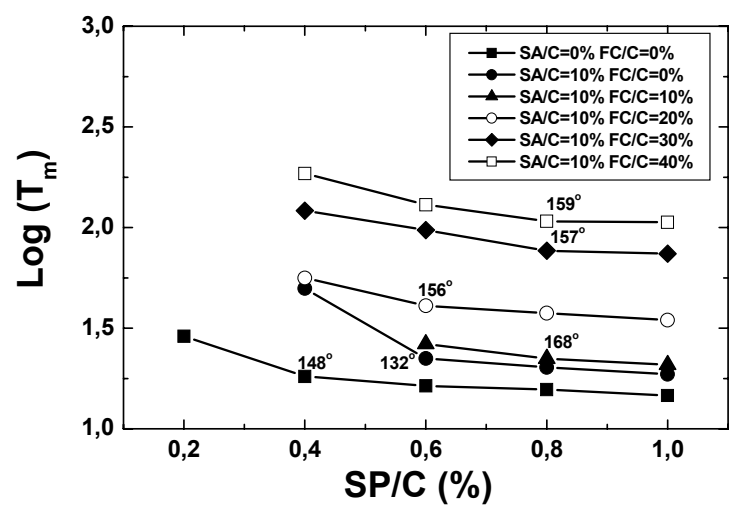

Figura 3.7 Variação do teor ótimo de superplastificante para $A / C=0,4$

Vale salientar que este estudo minucioso foi realizado apenas para a relação $A / C=0,4$. No caso da relação $A / C=0,6$, o estudo foi mais objetivo, uma vez que a metodologia já estava consolidada.

A Tabela 3.6 ilustra os teores de filler calcário e sílica ativa para a pasta. Os valores para o teor ótimo de superplastificante observados na Tabela 3.6 foram tomados para o tempo de 10 minutos e, quando não foi possível determinar um ponto de saturação, era realizada a interpolação (Gomes, 2002).

Tabela 3.6 Valores observados para os ensaios de fluidez e de mini-abatimemto $(\mathrm{A} / \mathrm{C}=\mathbf{0}, \mathbf{4})$

\begin{tabular}{lccccc}
\hline SA/C (\%) & 10 & 10 & 10 & 10 & 10 \\
FC/C (\%) & 0 & 10 & 20 & 30 & 40 \\
\hline SP/F (\%) - Saturação & 0,60 & 0,78 & 0,55 & 0,65 & 0,75 \\
Espalhamento (cm) & 13,0 & 17,8 & 14,5 & 16,9 & 18,0 \\
$\mathbf{T}_{115}(\mathbf{s})$ & 0,4 & 0,3 & 0,7 & 0,5 & 0,5 \\
Densidade $\left(\mathbf{g} / \mathbf{c m}^{\mathbf{3}}\right)$ & 1,963 & 1,898 & 1,890 & 1,875 & 1,843 \\
\hline
\end{tabular}

Os valores medidos para $T_{115}$ mostrados na Tabela 3.6 são muito baixos e suscetíveis a erro de medição, e, portanto não devem ser levados em consideração para efeito de verificação da pasta.

Para a verificação da quantidade de filler a ser utilizado na substituição de cimento, foi realizado um estudo do comportamento da pasta variando a quantidade de filler calcário, no caso, foi variado de 0 a 40\% (Tabela 3.6). O ensaio de miniabatimento serve para determinar se o teor de filler presente na mistura é ideal para promover a coesão sem comprometer a fluidez.

Nas amostras de mini-espalhamento, não foi observado qualquer segregação da mistura, conforme pode ser visto na Figura 3.8. 

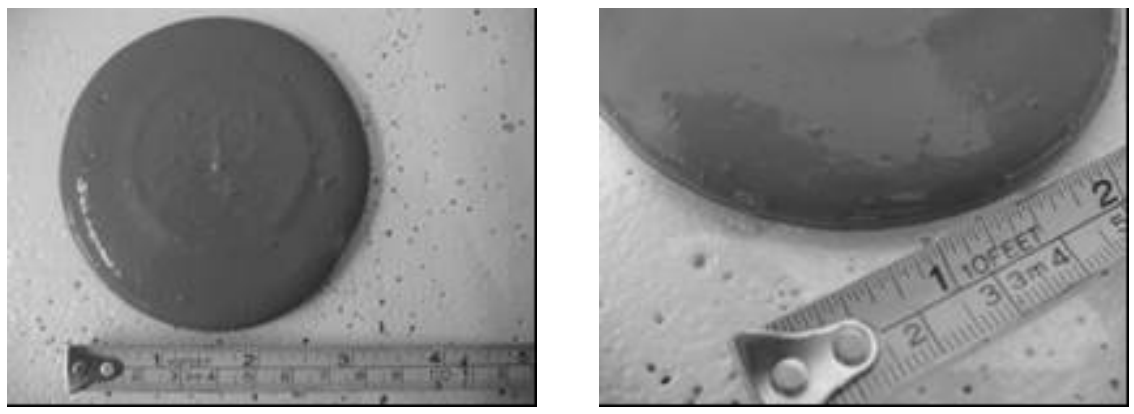

Figura 3.8 Ensaios de mini-espalhamento para relação $A / C=0,4, F / C=0,3$ e $S A / C=0,1$

De acordo com os critérios para o teor ótimo de filler na mistura, o critério estabelece que o diâmetro de espalhamento deva estar no intervalo de 18,0 $\pm 1,0 \mathrm{~cm}$ e que o tempo $T_{115}$ tem que estar no intervalo de $3 \pm 1$ s (Gettu \& Agulló, 2004a; Gomes, 2002). Para valores elevados de A/F (água/finos), maiores que 0,4, o tempo $T_{115}$ fica muito difícil de se medir (Gomes, 2002), em função da alta fluidez da pasta; assim, o critério para determinar o teor ótimo de filler será o diâmetro final de espalhamento, que, no caso, foi obedecido por duas misturas, sendo elas a $\mathrm{FC} / \mathrm{C}=0,1$ e a $F C / C=0,4$. No sentido de se otimizar o consumo de cimento no $C A A$, optou-se pela segunda mistura $(\mathrm{FC} / \mathrm{C}=0,4)$. A Figura 3.9 ilustra o comportamento do teor de filler calcário e de superplastificante nas pastas estudadas.
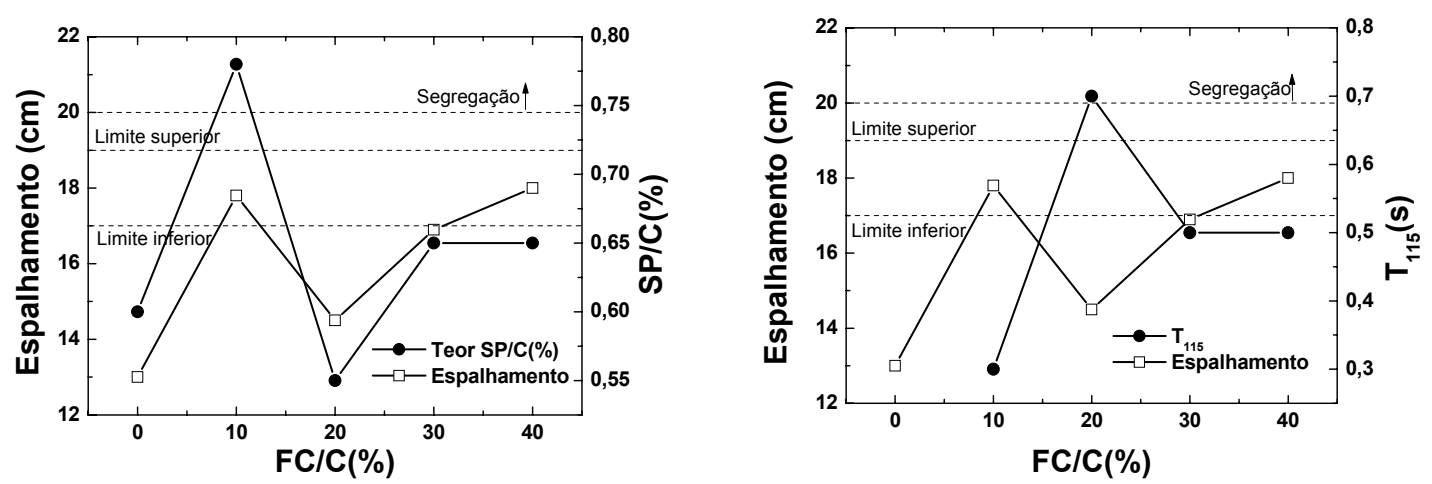

Figura 3.9 Resultados para os ensaios com pasta $(A / C=0,4)$

Com relação à segunda pasta, com $A / C=0,6$, optou-se por se fazer um estudo de composição do traço mais simplificado, depois das considerações realizadas para a relação $A / C=0,4$. Assim, a relação $A / C=0,6$ adotou a relação $F C / C=0,3$ e $S A / C=0$. $A$ Figura 3.10 mostra a variação do teor ótimo de saturação para a relação $A / C=0,6$ sem adição de filler. 


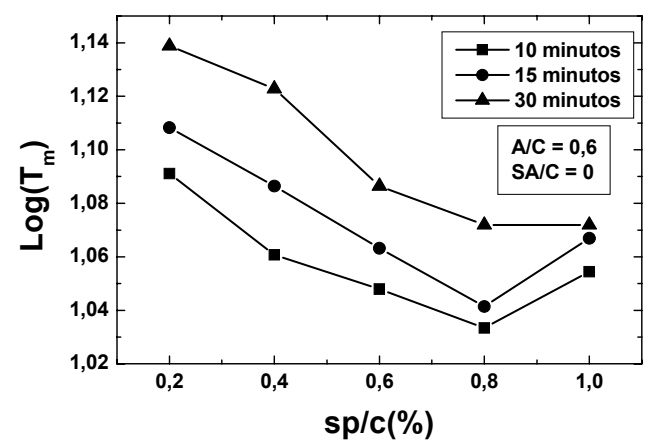

Figura 3.10 Curvas de fluidez para os ensaios com o funil Marsh com $A / C=0,6$

A Figura 3.11 mostra a variação do teor ótimo de saturação para a relação $\mathrm{A} / \mathrm{C}=0,6$ e $\mathrm{FC} / \mathrm{C}=0,3$.

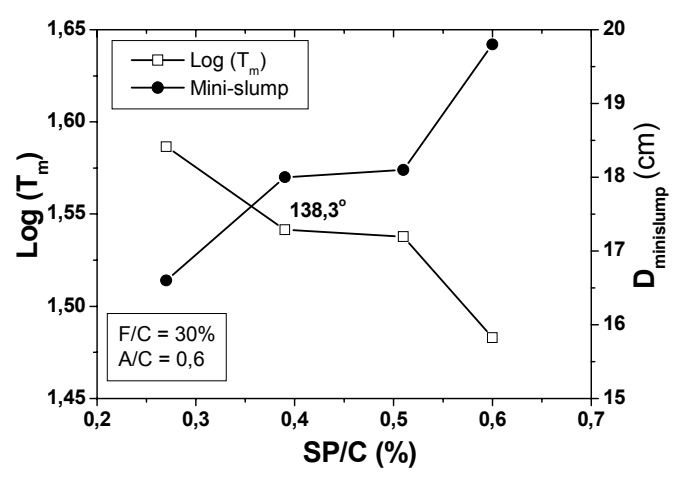

Figura 3.11 Variação do teor ótimo de superplastificante para $A / C=0,6$ e $F C / C=0,3$

A Figura 3.12 mostra os ensaios de mini-espalhamento para a relação $A / C=0,6$ com adição de $30 \%$ de filler em substituição.
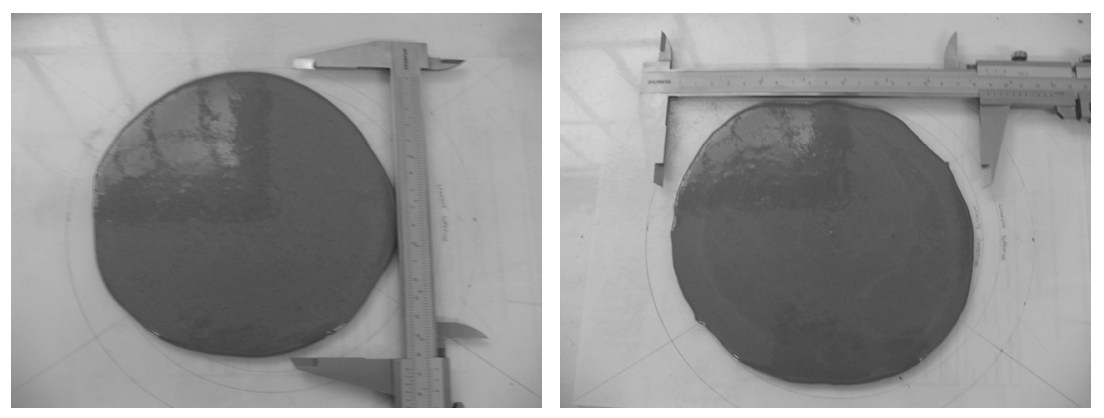

Figura 3.12 Ensaios de mini-espalhamento para relação $A / C=0,6$ e $F / C=0,3$

Com a determinação dos teores ótimos de superplastificante para as relações $\mathrm{A} / \mathrm{C}$ de 0,4 e 0,6, pode-se dar início à segunda etapa que consiste da otimização do esqueleto granular. 


\subsection{Etapa agregado}

Nesta etapa é otimizada a quantidade de agregados utilizados na elaboração do CAA. Após a caracterização dos agregados, devem-se determinar as relações entre os agregados, o teor de vazios existentes e a relação entre a quantidade de agregado miúdo e total de agregados (Su et al., 2001).

Com a determinação dos agregados a serem utilizados na mistura, deve-se verificar a influência da quantidade de vazios existentes no esqueleto granular; para isso, deve-se realizar o ensaio de mistura dos teores dos agregados de modo a se obter a mistura com menor quantidade de vazios. Esse procedimento tem como base a idéia de que a combinação dos agregados com uma mínima quantidade de vazios levava a um menor consumo de pasta, porosidade e retração (Gomes, 2002; Goltermann et al., 1997).

Assim, para esta pesquisa foi utilizado o mesmo procedimento de Gomes (2002) e Gettu \& Agulló (2004) para a determinação do teor ótimo de agregados levando em consideração que a relação AF/AT é igual a 47,5\% (Sue t al., 2001).

Para esse ensaio, utiliza-se um recipiente cilíndrico com capacidade de 3 litros com altura e diâmetro de 17 e $15 \mathrm{~cm}$, respectivamente, e uma haste metálica com 16 $\mathrm{mm}$ de diâmetro e $60 \mathrm{~cm}$ de altura. De acordo com Gomes (2002), não há sentido em realizar os 25 golpes por camada (três no total), pois este adensamento não existe no CAA, logo, as misturas de areia e brita serão somente colocadas no recipiente e posteriormente pesadas. Com isso, a determinação do teor de vazios segue o seguinte procedimento (Gomes, 2002; Silveira et al., 2004):

$$
\rho_{u}=\frac{\omega_{t}}{V_{t}} \text { e } V_{\text {solid }}=\frac{\omega_{s}}{\rho_{s d}}+\frac{\omega_{g}}{\rho_{g d}}
$$

Onde, $\omega_{\mathrm{t}}$ e $V_{\mathrm{t}}$ representam o peso e o volume total da mistura, respectivamente, e $\omega_{\mathrm{s}}$ e $\omega_{\mathrm{g}}$ representam o peso (em $\mathrm{kg}$ ) e $\rho_{\mathrm{sd}}$ e $\rho_{\mathrm{gd}}$ representam as densidades secas para o agregado miúdo e graúdo, respectivamente. $V_{\text {solid }}$ é o volume sólido do esqueleto granular.

Assim, o conteúdo de vazios, V(\%), é obtido por:

$$
V(\%)=100 \cdot\left(\frac{V_{t}-V_{\text {solid }}}{V_{t}}\right)
$$


Para a presente pesquisa, foram adotados os conteúdos de areia iguais a 0,30 , 40, 50, 60, 70 e 100\% em relação ao volume de agregados, pois, para cada amostra de material ocorrem mudanças significativas, comprovando a necessidade de se fazer este ensaio para cada bateria de material (Gomes, 2002).

A Figura 3.13 ilustra a composição do esqueleto granular.
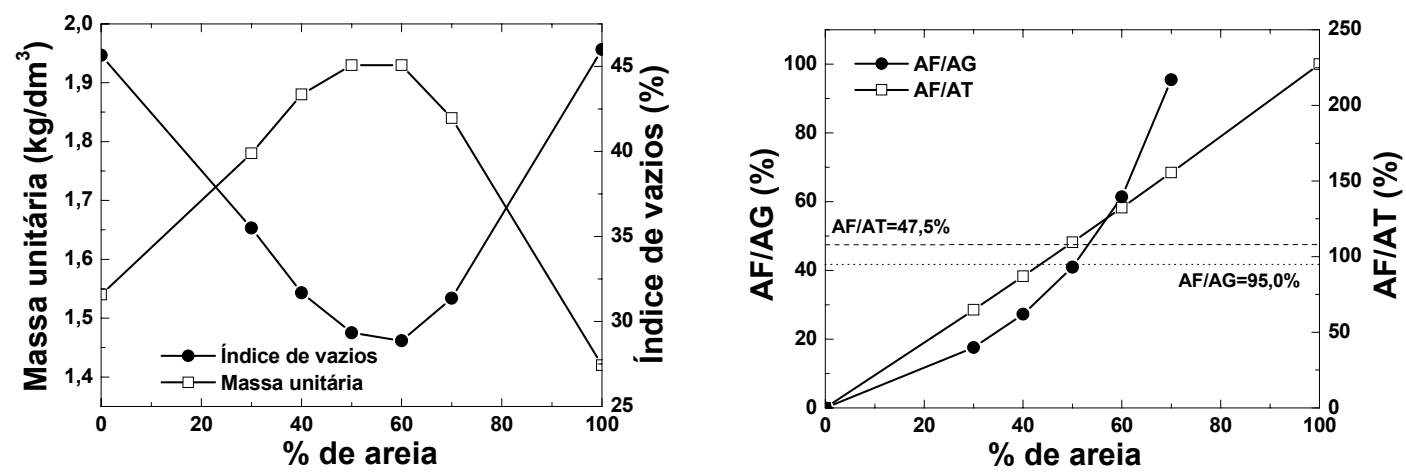

Figura 3.13 Composição do esqueleto granular e relações AF/AG e AF/AT

Assim, foi adotado o teor de agregado miúdo de $50 \%$, embora este não tenha fornecido o menor teor de vazios (mesmo o valor para o teor de $60 \%$ de areia sendo $1,6 \%$ menor que este), mas teve a maior massa unitária, forneceu a melhor relação AF/AT (agregado fino / total de agregados), se aproxima mais do teor ideal de $47,5 \%$ para a relação AF/AT (Su et al., 2001), e ainda o teor de $50 \%$ de areia leva a uma relação AF/AG (Agregado fino / Agregado graúdo) igual a 0,93 em peso que permite menor teor de vazios (Gomes, 2002; Bouzoubaâ \& Lachemi, 2000; Su et al., 2001).

\subsection{Etapa concreto}

Com a determinação dos teores aditivos e adições, bem como do esqueleto granular, passa-se para determinação da composição do traço do CAA. O processo para se determinar a composição do CAA foi o Método da UPC (Okamura et al. , 1997; Nunes et al., 2003; Gomes, 2002).

O procedimento para a determinação da quantidade de cada material, para se obter $1 \mathrm{~m}^{3}$ de CAA, é visto a seguir.

Volume da argamassa:

$\mathrm{V}_{\mathrm{s}}+\mathrm{V}_{\mathrm{p}}=1$ 
Como o valor de $\mathrm{V}_{\mathrm{s}}$ corresponde a $40 \%$ do volume total de argamassa, o volume de pasta $\left(V_{p}\right)$ é igual a $60 \%$, logo:

$$
\omega_{s d}=0,4 \cdot \rho_{s d} \text { e } \omega_{p}=0,6 \cdot \rho_{p}
$$

Onde,

$$
\omega_{p}=\omega_{c}+\omega_{f}+\omega_{w}+\omega_{s p}
$$

Tem-se que:

$$
\omega_{w}=(\mathrm{a} / \mathrm{c}) \cdot \omega_{\mathrm{c}}, \omega_{\mathrm{f}}=\frac{(\mathrm{sa} / \mathrm{c}+\mathrm{f} / \mathrm{c})}{100} \cdot \omega_{\mathrm{c}} \text { e } \omega_{\mathrm{sp}}=\frac{(\mathrm{sp} / \mathrm{c})}{100} \cdot \omega_{\mathrm{c}}
$$

Substituindo as relações das equações Eq. 3.7 e Eq. 3.8, tem-se:

$$
\omega_{c}=0,6 \cdot\left[\frac{\rho_{p}}{1+a / c+0,01 \cdot(s a / c+f / c)+0,01 \cdot s p / c}\right]
$$

Para os agregados, tem-se:

$$
\omega_{g}=\frac{\left(1-V_{p}\right)}{\frac{A F / A G}{\rho_{s d}}+\frac{1}{\rho_{g d}}} \text { e } \omega_{s}=\frac{(A F / A G) \cdot\left(1-V_{p}\right)}{\frac{A F / A G}{\rho_{s d}}+\frac{1}{\rho_{g d}}}
$$

Onde,

$\omega_{\mathrm{sd}}=$ massa de areia seca por $\mathrm{m}^{3}(\mathrm{~kg})$;

$\omega_{\mathrm{p}}=$ massa de pasta por $\mathrm{m}^{3}(\mathrm{~kg})$;

$\omega_{\mathrm{w}}=$ massa de água por $\mathrm{m}^{3}(\mathrm{~kg})$;

$\omega_{\mathrm{c}}=$ massa de cimento por $\mathrm{m}^{3}(\mathrm{~kg})$;

$\omega_{\mathrm{f}}=$ massa de filler por $\mathrm{m}^{3}(\mathrm{~kg})$

$\omega_{\mathrm{sp}}=$ massa de superplastificante $(\mathrm{kg})$

$\omega_{\mathrm{g}}=$ massa de brita por $\mathrm{m}^{3}(\mathrm{~kg})$

$\mathrm{a} / \mathrm{c}=$ relação água/cimento;

sa/c = relação sílica ativa/cimento;

$\mathrm{f} / \mathrm{c}=$ relação filler/cimento;

$\mathrm{sp} / \mathrm{c}=$ relação superplastificante/cimento;

$\mathrm{AF} / \mathrm{AG}=$ relação areia/brita;

$\rho_{\mathrm{p}}=$ massa unitária da pasta $(\mathrm{kg} / \mathrm{l})$;

$\rho_{\mathrm{sd}}=$ massa específica da areia seca $(\mathrm{kg})$;

$\rho_{\mathrm{gd}}=$ massa específica da brita seca $(\mathrm{kg})$;

Vale salientar que se os agregados estiverem úmidos deve ser feita a compensação com relação à água lançada ao concreto.

Com relação à mistura dos componentes do CAA, diversos modelos para mistura do CAA foram desenvolvidos, e para esta pesquisa foi adotado o procedimento visto a seguir: 
- Adiciona-se o agregado graúdo mais $3 / 4$ da água total (água para a pasta e água para saturar os agregados) e mistura-se por $30 \mathrm{~s}$;

- Adicionam-se o cimento, a sílica ativa e o pó de calcário com o superplastificante e o restante da água e mistura por $120 \mathrm{~s}$;

- Adiciona-se o agregado miúdo e mistura-se por $120 \mathrm{~s}$.

Este processo se baseia em processos de mistura adotados no Laboratório de Materiais Avançados à Base de Cimento $(\mathrm{LMABC})$ e o tempo total gasto para a mistura é de 270 s. A Figura 3.14 ilustra o aparato de caixa-L.

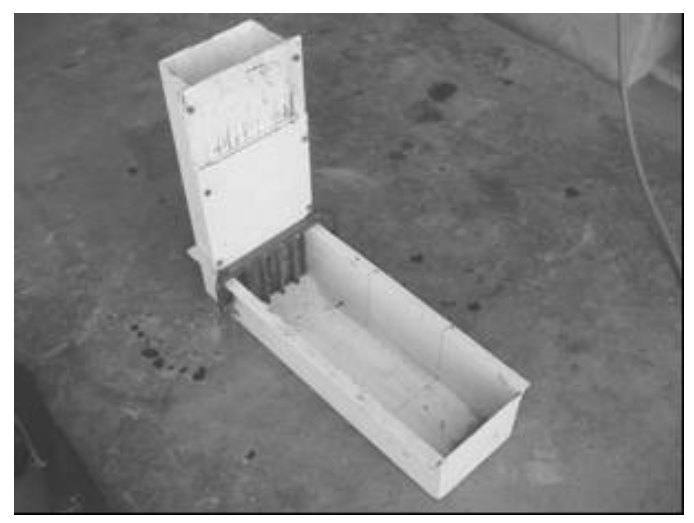

Figura 3.14 Caixa-L utilizada

O ensaio de espalhamento fornece resultados importantes com relação à fluidez do CAA e sua coesão. Além disso, pode-se observar a sua resistência à segregação. A Figura 3.15 ilustra o ensaio de espalhamento do CAA onde se visualiza um detalhe da distribuição dos agregados graúdos no CAA onde, pode-se observar que não houve segregação ou exsudação.
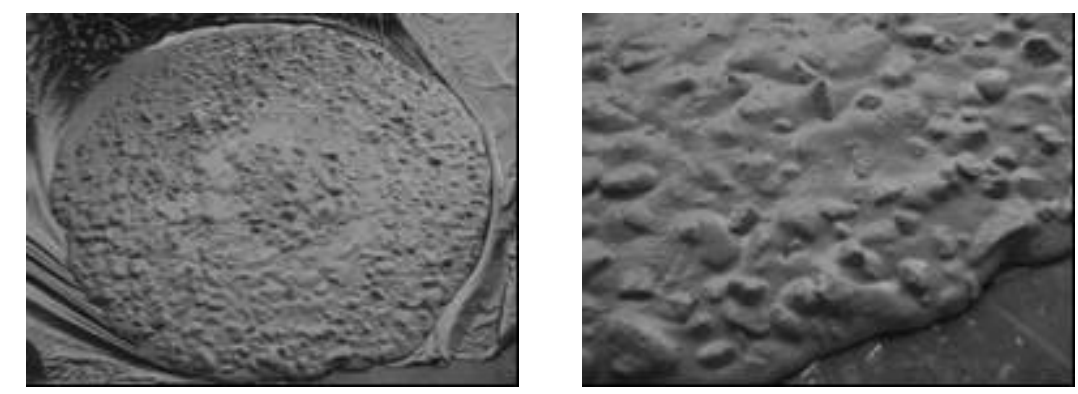

Figura 3.15 Ensaio de abatimento ou espalhamento para o CAA com relação $A / C=0,4$

Inicialmente, o ensaio para o CAA teve algumas dificuldades em função do agregado miúdo utilizado, pois este possuía uma finura muito elevada e demandava uma quantidade de água para hidratação em torno de 10\%. O ensaio de determinação 
do teor de água absorvida pela areia foi inicialmente realizado, porém, por causa de alta finura da areia, não era possível realizá-lo. Foram adotados valores de teor de água para hidratar a areia de 3,3\%,6,6\%, 9,9\% e 11,6\%. Essas tentativas mostraram que o teor era superior a $9,9 \%$ e inferior a $11,6 \%$. Desse modo, foram adotados os valores de 9,9 e $11,6 \%$ e estes foram ensaiados para se determinar o teor ideal de água para hidratar a areia. A Tabela 3.7 demonstra as tentativas realizadas.

Tabela 3.7 Variação das propriedades do CAA $(A / C=0,4)$

\begin{tabular}{|c|c|c|c|c|c|c|c|c|}
\hline Material & $\begin{array}{c}1^{\mathrm{a}} \\
\text { tent. }\end{array}$ & $\begin{array}{c}2^{\mathrm{a}} \\
\text { tent. }\end{array}$ & $\begin{array}{c}3^{\mathrm{a}} \\
\text { tent. }\end{array}$ & $\begin{array}{c}4^{\mathrm{a}} \\
\text { tent. }\end{array}$ & $\begin{array}{c}5^{\mathrm{a}} \\
\text { tent. }\end{array}$ & $\begin{array}{c}6^{\mathrm{a}} \\
\text { tent. }\end{array}$ & $\begin{array}{c}7^{\mathrm{a}} \\
\text { tent. }\end{array}$ & $\begin{array}{c}8^{\mathrm{a}} \\
\text { tent. }\end{array}$ \\
\hline Cimento $(\mathrm{kg})$ & 368,6 & 368,6 & 368,6 & 368,6 & 368,6 & 368,6 & 368,6 & 368,6 \\
\hline $\mathrm{FC} / \mathrm{C}(\%)$ & 40 & 40 & 40 & 40 & 40 & 40 & 40 & 40 \\
\hline $\mathrm{SA} / \mathrm{C}(\%)$ & 10 & 10 & 10 & 10 & 10 & 10 & 10 & 10 \\
\hline Areia $(\mathrm{kg})$ & 815,3 & 815,3 & 815,3 & 815,3 & 815,3 & 815,3 & 918,5 & 1006,5 \\
\hline Brita $(\mathrm{kg})$ & 876,7 & 876,7 & 876,7 & 876,7 & 876,7 & 876,7 & 765,5 & 671 \\
\hline SP/C (\%) & 0,65 & 0,65 & 0,75 & 0,75 & 0,70 & 0,70 & 0,75 & 0,75 \\
\hline Água p/ brita (\%) & 1,71 & 1,71 & 1,71 & 1,71 & 1,71 & 1,71 & 1,71 & 1,71 \\
\hline Água p/ areia (\%) & 9,9 & 11,6 & 11,6 & 9,9 & 11,6 & 9,9 & 9,9 & 9,9 \\
\hline \multicolumn{9}{|l|}{ Critérios } \\
\hline \multicolumn{9}{|c|}{ Ensaio de espalhamento } \\
\hline$T_{50}(\mathrm{~s})$ & 2,2 & 1,0 & 0,3 & 1,0 & 0,6 & 0,7 & 0,9 & 0,6 \\
\hline \multicolumn{9}{|l|}{ Ensaio de caixa-L } \\
\hline $\mathrm{T}_{40}(\mathrm{~s})$ & 2,0 & 1,2 & ---- & 1,0 & 0,6 & 0,9 & 0,6 & 1,2 \\
\hline RB & 0,1 & 0,4 & ---- & 0,8 & 0,28 & 0,05 & 0,84 & 0,8 \\
\hline \multicolumn{9}{|c|}{ Resistência à compressão (MPa) } \\
\hline 2 dias & ---- & $38,3^{*}$ & ---- & 31,8 & 25,1 & 27,0 & $32,3^{* *}$ & $32,8^{* *}$ \\
\hline 7 dias & ---- & 40,9 & ---- & 45,2 & 36,8 & 40,5 & 38,1 & 40,3 \\
\hline D.P. (7 dias) & & 0,6 & & 1,5 & 0,4 & 0,15 & 0,9 & 0,2 \\
\hline \multicolumn{9}{|c|}{ Resistência à tração (MPa) } \\
\hline 2 dias & ---- & $3,2^{*}$ & ---- & 2,3 & 2,2 & 2,3 & $2,9^{*}$ & $3,4^{*}$ \\
\hline
\end{tabular}

${ }^{*}$ Realizado aos 5 dias ${ }^{* *}$ Realizado aos 3 dias ${ }^{*}$ Realizado aos 7 dias - D.P. = Desvio padrão

Vale salientar que o volume de pasta calculado para a composição do traço do CAA foi de $38 \%$.

Assim, a melhor dosagem foi a $4^{\text {a }}$ tentativa, pois apresentou uma razão de bloqueio e espalhamento dentro dos limites estabelecidos, mas uma fluidez muito elevada. Isso significa que é necessário aumentar a massa específica do concreto para aumentar a coesão, e assim aumentar o tempo de fluidez, tornando a mistura mais densa. Assim é possível tomar dois caminhos, sendo eles: o primeiro seria reduzir o consumo de fíller calcário para 10 e $30 \%$, o que acarretaria um aumento na massa específica da pasta e, conseqüentemente, aumentaria a sua coesão, e o segundo seria colocar mais um aditivo para reduzir a pega falsa do cimento. A segunda opção torna necessário realizar mais um estudo de mini-abatimento para se determinar um valor para $T_{115}$ mais interessante (uma vez que os valores de $T_{115}$ obtidos anteriormente estão fora dos limites estabelecidos para este ensaio). 
Com a determinação correta do teor ótimo de água para hidratar a areia, foram realizadas outras concretagens com os valores para o teor de filler calcário de $10 \%$, porém houve segregação na mistura.

Assim, foram realizados ensaios de compressão diametral para se verificar se as concretagens outrora realizadas na Tabela 3.7 possuíam segregação nos corpos-deprova, mesmo com a verificação visual de sua não existência nos ensaios de abatimento. A Figura 3.16 ilustra os corpos-de-prova ensaiados à compressão diametral abertos para visualização da distribuição dos agregados graúdos para as tentativas $2,4,5$ e 6 .

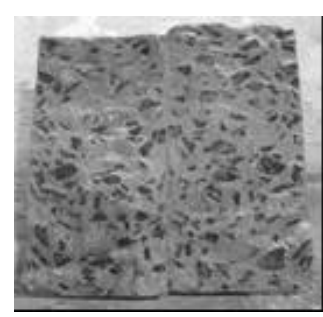

$2^{\mathrm{a}}$ Tentativa

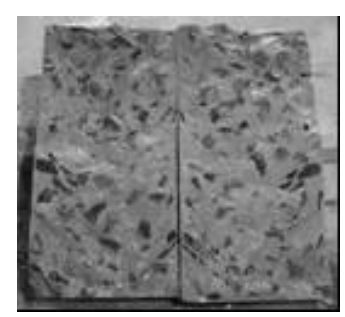

$4^{\mathrm{a}}$ Tentativa

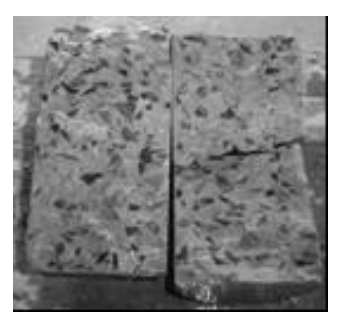

$5^{\mathrm{a}}$ Tentativa

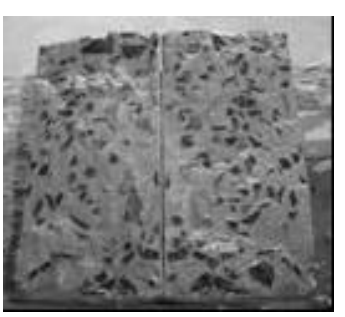

$6^{\mathrm{a}}$ Tentativa

Figura 3.16 Distribuição do agregado graúdo nas concretagens

Desse modo, as concretagens obedeceram aos requisitos necessários para os ensaios de abatimento e de caixa $L$, com exceção dos tempos de medição $\left(T_{50}\right.$ e $T_{40}$, respectivamente); porém sendo garantida a resistência à segregação e à exsudação, o CAA está aprovado para o ensaio.

O acréscimo de areia na mistura trouxe maior coesão sem perda de fluidez para a mistura, conforme a Figura 3.17. Também, não houve perda da resistência à compressão do CAA em relação aos CAA's sem acréscimo de areia.

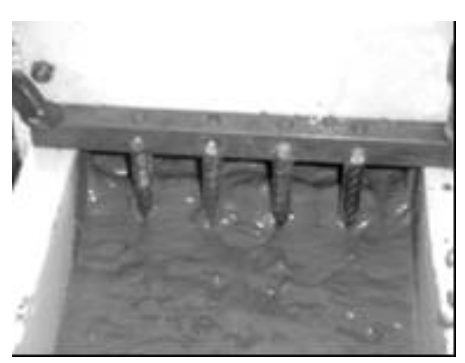

$\mathrm{AF} / \mathrm{AG}=1,2$

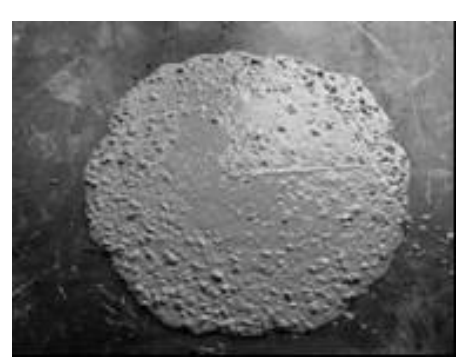

$\mathrm{AF} / \mathrm{AG}=1,2$

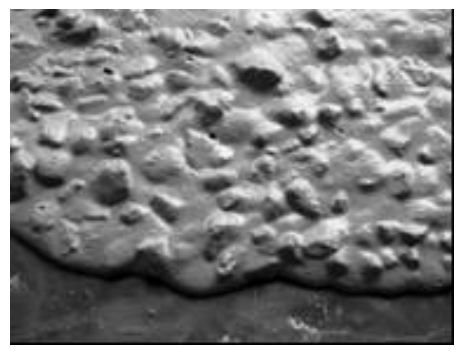

$\mathrm{AF} / \mathrm{AG}=1,5$

Figura 3.17 Comportamento do CAA com acréscimo de areia

A causa dos pequenos tempos medidos para os ensaios de validação se dá em função do tipo de superplastificante utilizado, que não possui um agente redutor de pega para o cimento, o que não traz viscosidade para a mistura. Assim, para 
solucionar esse problema, foi realizado um estudo variando o teor de areia na mistura de acordo com a Tabela 3.7 onde a $7^{\mathrm{a}}$ e a $8^{\mathrm{a}}$ tentativa correspondem ao aumento da relação AF/AG iguais a 1,2 e a 1,5 , respectivamente.

Com relação à segunda pasta a ser desenvolvida, com relação $A / C=0,6$ e $\mathrm{FC} / \mathrm{C}=0,3$, do mesmo modo que na etapa pasta, objetivou-se elaborar a composição deste CAA tomando como referências as observações realizadas na elaboração da relação $A / C=0,4$.

Assim, a Tabela 3.8 mostra a composição do traço para esta relação e a correspondente variação de suas propriedades no estado fresco e endurecido.

Tabela 3.8 Variação das propriedades do CAA $(A / C=0,6)$

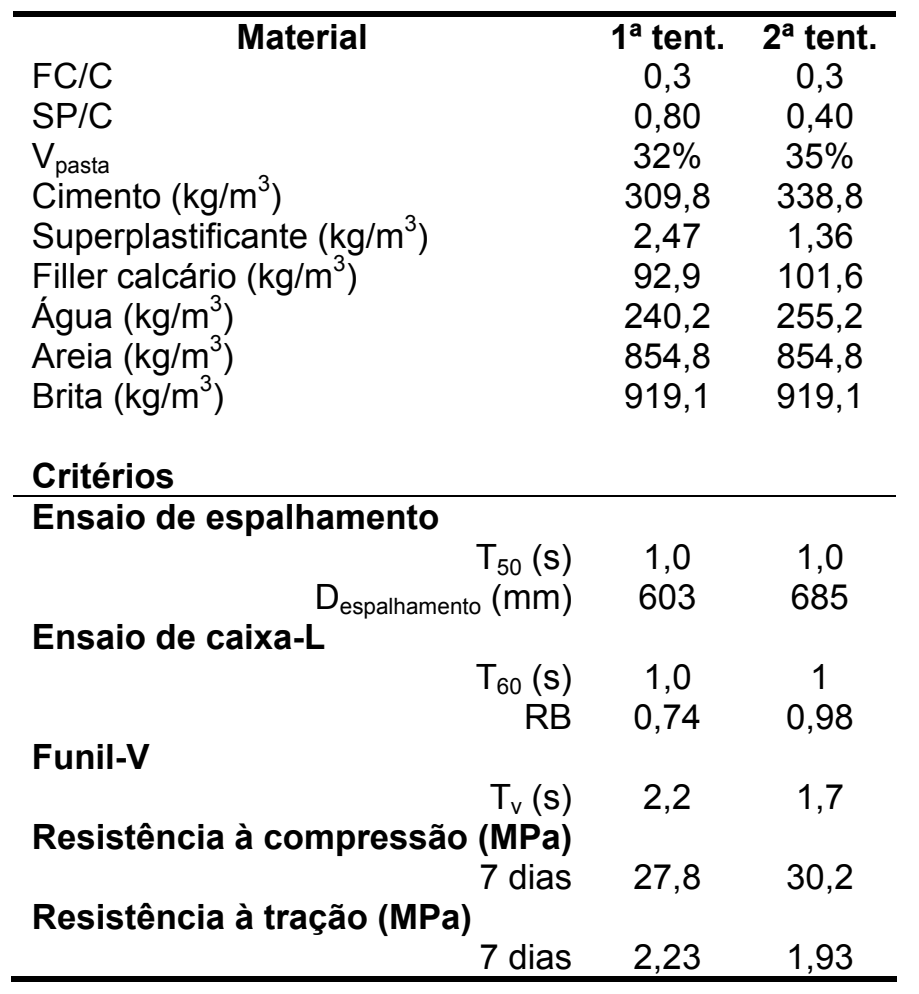

A Figura 3.18 mostra os ensaios de verificação para o $\mathrm{CAA}$ com relação $\mathrm{A} / \mathrm{C}=$ 0,6 .
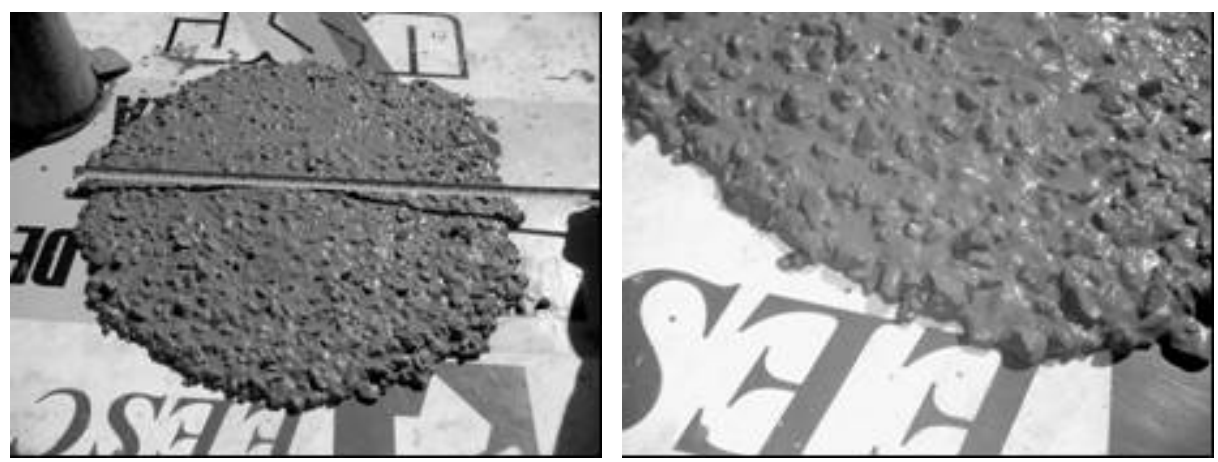

Figura 3.18 Ensaios de verificação do CAA com $V_{p}=35 \%$ 
A Figura 3.19 ilustra os corpos-de-prova ensaiados à compressão diametral abertos para visualização da distribuição dos agregados graúdos para as tentativas da Tabela 3.8.

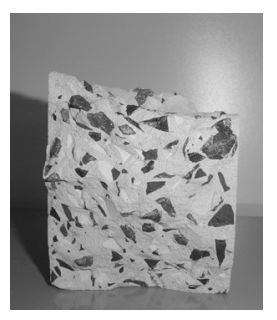

$V_{p}=32 \%$

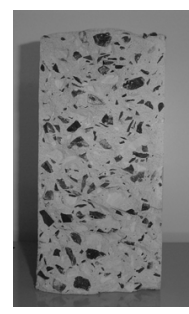

$V_{p}=35 \%$

Figura 3.19 Distribuição do agregado graúdo nas concretagens

Desse modo, com a resistência à compressão do concreto de $30 \mathrm{MPa}$ aos 7 dias, foi adotado o traço com $35 \%$ de volume de pasta. Essa medida foi adotada por motivo de adequação às atividades no Laboratório de Estruturas.

\subsection{Considerações finais e resumo dos traços desenvolvidos}

Com base nos resultados obtidos, pode-se concluir que:

- A utilização da metodologia adotada por Gomes (2002) é adequada para a determinação da composição do traço para concretos auto-adensáveis;

- A utilização de relações $A / C$ maiores que 0,4 conduzem a dosagens com menor consumo de cimento e de superplastificante, constituindo material de construção interessante e de fácil utilização em construções em concreto armado em face da economia de material obtida;

- Embora a metodologia para determinação da composição do traço do CAA necessite um rígido controle tecnológico dos materiais envolvidos em sua elaboração, o que requer maiores investimentos na parte de capacitação profissional e de equipamentos, pode ser compensada pela alta qualidade final e durabilidade das construções em CAA, além do fato do ganho de produtividade durante a construção.

A Tabela 3.9 ilustra os traços desenvolvidos e os ensaios de verificação para o concreto auto-adensável. 
Tabela 3.9 Composição do traço dos CAA's desenvolvidos

\begin{tabular}{|c|c|c|}
\hline Material & $\overline{\text { CAA1 }}$ & $\overline{\text { CAA2 }}$ \\
\hline $\mathrm{A} / \mathrm{C}$ & 0,4 & 0,6 \\
\hline $\mathrm{FC} / \mathrm{C}$ & 0,4 & 0,3 \\
\hline $\mathrm{SA} / \mathrm{C}$ & 0,1 & 0,0 \\
\hline $\mathrm{SP} / \mathrm{C}$ & 0,75 & 0,4 \\
\hline$V_{\text {pasta }}$ & $38 \%$ & $35 \%$ \\
\hline Cimento $\left(\mathrm{kg} / \mathrm{m}^{3}\right)$ & 368,6 & 338,8 \\
\hline Superplastificante $\left(\mathrm{kg} / \mathrm{m}^{3}\right)$ & 2,76 & 1,36 \\
\hline Filler calcário $\left(\mathrm{kg} / \mathrm{m}^{3}\right)$ & 146,9 & 101,6 \\
\hline Sílica ativa $\left(\mathrm{kg} / \mathrm{m}^{3}\right)$ & 36,9 & 0,0 \\
\hline Água $\left(\mathrm{kg} / \mathrm{m}^{3}\right)$ & 214,3 & 255,2 \\
\hline Areia $\left(\mathrm{kg} / \mathrm{m}^{3}\right)$ & 815,3 & 854,8 \\
\hline $\begin{array}{l}\text { Brita }\left(\mathrm{kg} / \mathrm{m}^{3}\right) \\
\text { Critérios }\end{array}$ & 876,7 & 919,1 \\
\hline Ensaio de espalhamento & & \\
\hline $\mathrm{T}_{50}(\mathrm{~s})$ & 1,0 & 1,0 \\
\hline $\begin{array}{l}\mathrm{D}_{\text {espalhamento }}(\mathrm{mm}) \\
\text { Ensaio de caixa-L }\end{array}$ & 740 & 685 \\
\hline $\mathrm{T}_{40}(\mathrm{~s})$ & 1.0 & 1 \\
\hline $\mathrm{RB}$ & 0,8 & 0,98 \\
\hline Funil-V & & \\
\hline $\begin{array}{l}\mathrm{T}_{\mathrm{v}}(\mathrm{s}) \\
\text { Ensaio de anel-J }\end{array}$ & - & 1,7 \\
\hline $\mathrm{T}_{50}(\mathrm{~s})$ & - & 2,0 \\
\hline $\mathrm{D}_{\text {espalhamento }}(\mathrm{mm})$ & - & 685 \\
\hline RB & - & 1,0 \\
\hline Resistência à compressão (MPa) & & \\
\hline $\begin{array}{l}7 \text { dias } \\
\text { Resistência à tracão }(\mathrm{MPa})\end{array}$ & 45,2 & 30,2 \\
\hline 7 dias & $2,3^{*}$ & 2,45 \\
\hline
\end{tabular}





\section{Aderência aço-concreto}

Este capítulo faz um resumo do estudo da aderência aço-concreto, em ensaios de arrancamento e de viga, ambos padronizados pelo Rilem-Ceb-Fip (1973), mostrando os tipos de aderência e os fatores que a influenciam. Não é objetivo deste capítulo reescrever a influência de cada parâmetro na resistência de aderência, para isso, Fernandes (2000), Barbosa (2001) e Castro (2002) realizaram uma ampla revisão bibliográfica sobre esse assunto. Assim, o objetivo deste capítulo é fazer comentários sobre diversos estudos realizados e procedimentos adotados.

\subsection{Considerações iniciais}

A aderência entre os materiais aço e concreto é um dos problemas mais difíceis no estudo do concreto e ainda não está completamente entendido. Isso se dá em função do grande número de dificuldades teóricas e experimentais encontradas para se estudar a aderência.

O arrancamento de uma barra de aço de um prisma de concreto envolve a ruptura do concreto adjacente à barra e, de acordo com Nielsen (1984), um mecanismo com escorregamento puro não seria possível. Isso ocorre em função da dilatação do concreto, pois, a transferência de esforços para o deslocamento longitudinal da barra faz com que surjam deformações radiais no concreto. As tensões na barra fazem com que haja componentes inclinadas no concreto, fazendo com que apareçam tensões de tração circunferenciais. Logo, se uma barra se localiza próxima da superfície do prisma de concreto, ocorrerá o fendilhamento do concreto. Assim, se 
nenhum tipo de armadura for adicionada ao prisma de concreto, a resistência de aderência dependerá, quase totalmente, da resistência do concreto.

De acordo com Bangash (1989), a aderência varia em função de três parcelas, sendo elas: a adesão, que consiste da resistência ao esforço cisalhante entre as partículas de concreto e de aço; o atrito, que é fator determinante para a resistência de aderência para peças no estado limite último; e a interação do contato entre os materiais (bearing action), que é causada pela deformação das barras em contato com o concreto.

Esses parâmetros são fortemente influenciados por variáveis como:

- Mistura do concreto, temperatura de umidade;

- A idade e os valores para resistência à compressão e à tração;

- Tipo da barra e o comprimento de ancoragem;

- A velocidade de carregamento e sua repetição.

Entre os tipos de aderência, esta é composta de três parcelas distintas, que são a aderência química, a aderência por atrito e a aderência mecânica.

A aderência química, ou adesão, oriunda das ligações físico-químicas que existem na zona de contato entre os dois materiais aço e concreto durante a pega do cimento. Essa parcela tem um valor pequeno se comparado com os demais tipos de aderência (Eligehausen et al., 1983).

A aderência por atrito depende do coeficiente de atrito existente na interface aço-concreto, da rugosidade superficial da barra de aço, proveniente por sua vez de pressões transversais que a barra sofre por causa de retração do concreto (Fusco, 1995) ou por ações externas de compressão. A parcela de resistência ao deslizamento por atrito é maior que a referente à adesão (Eligehausen et al., 1983; Fernandes, 2000; Castro, 2002; Dumêt, 2003).

A aderência mecânica depende da irregularidade da superfície da barra de aço. Isto significa que quanto mais irregular for a conformação superficial da barra, maior será a aderência mecânica, pois ocorrerá o chamado "efeito de cunha" (Fusco, 1995).

A parcela referente à aderência mecânica é a grande responsável pela ancoragem da barra de aço e, esta promove certa resistência de pós-pico (depois de atingida a tensão máxima de aderência). 


\subsection{Mecanismo de ruptura}

Existem diversos tipos de modos de ruptura para a perda de aderência dentre as quais, as que mais se destacam são a ruptura por arrancamento e a ruptura por fendilhamento. Estes modos de ruptura são fortemente influenciados por diversos fatores (Dumêt, 2003), sendo eles: o tipo de armadura (barra, fio e cordoalha), a conformação superficial (lisa ou nervurada), o diâmetro da barra, a presença de armadura de confinamento, a distância entre as barras, o cobrimento, a tensão na barra, a qualidade do concreto e etc.

De acordo com Rots (1989), existiriam quatro tipos de mecanismos distintos para o fenômeno da aderência, sendo elas: a deformação elástica, a fissuração secundária, a fissuração por fendilhamento longitudinal, e o esmagamento do concreto nas nervuras da barra de aço. A Figura 4.1 ilustra esses mecanismos.

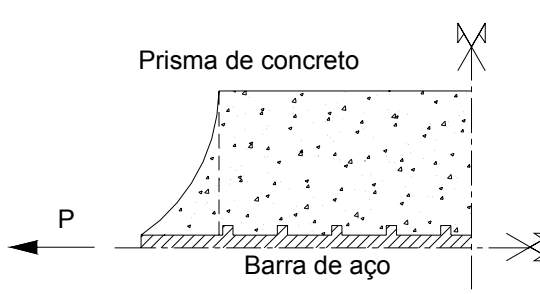

Deformação elástica

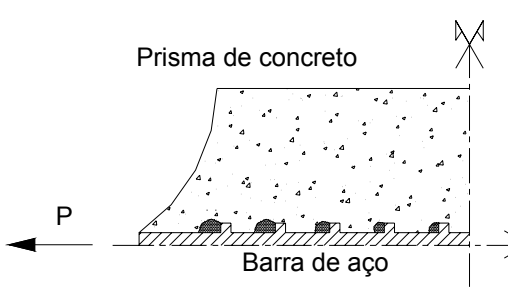

Esmagamento do concreto

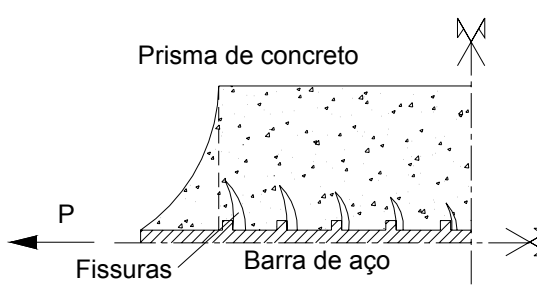

Fissuração secundária

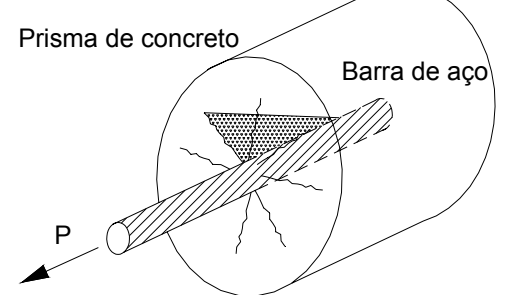

Fissuração longitudinal

Figura 4.1 Mecanismos de ruptura da aderência (Rots, 1989)

Segundo Ferguson (1979), quando o escorregamento da barra atinge toda a extensão do comprimento de ancoragem, podem ocorrer, em ensaios de arrancamento, três tipos de ruptura: o fendilhamento longitudinal do concreto, o arrancamento da barra, no caso de pequenos diâmetros ou utilizar concreto leve, e o escoamento da barra, caso o comprimento de ancoragem seja suficiente.

Assim, a ruptura por arrancamento da barra de aço ocorre quando não há suficiente resistência à compressão do concreto tal que, se permite o cisalhamento do concreto entre as nervuras da barra de aço. Caso contrário se há suficiente resistência 
à compressão do concreto, ocorrerá o fendilhamento do prisma de concreto. Se há armadura de confinamento, ocorre à redução da propagação de fissuras, proporcionando o arrancamento da barra.

Esse fendilhamento pode ser definido como o efeito da tração circunferencial ocasionado pelas componentes radiais das tensões de compressão que transferem o esforço da barra para o concreto. Esse tipo de ruptura ocorre quando o confinamento é insuficiente para garantir o deslizamento da barra. As tensões radiais de tração, originadas das tensões diagonais de compressão causam uma pressão no concreto adjacente a barra de aço, tornando essa região microfissurada e sujeita ao fendilhamento paralelo ao eixo da barra. As fissuras de fendilhamento que surgem por causa das tensões circunferenciais de tração se propagam em direção as bordas do elemento estrutural, causando perda de resistência de aderência e de cobrimento.

De acordo com o referido autor, fica faltando à parcela referente à barra de aço, que é discutido por Al-Jahdali et al. (1994).

Assim, em um ensaio simples de arrancamento de uma barra de aço em um prisma de concreto simples, isto é, sem adição de armadura de confinamento ou de fibras metálicas, podem ocorrer quatro modos de ruptura, sendo:

- Arrancamento: consiste do escorregamento da barra no prisma de concreto, pois o cobrimento do concreto adjacente à barra de aço promove um confinamento adequado prevenindo o fendilhamento do modelo, caracterizando, então, uma ruptura dúctil.

- Fendilhamento: consiste da ruptura no prisma de concreto do concreto adjacente à barra de aço. Isso ocorre em virtude do aumento das tensões que superam a capacidade resistente da peça, originando uma fissuração intensa na direção transversal e longitudinal. Este tipo de ruptura é caracterizado como frágil ou súbita.

- Tração: consiste da formação de fissuras perpendiculares à direção da aplicação da força e localiza-se na extremidade da barra de aço envolvida pelo prisma de concreto.

- Ruptura do aço: consiste do escoamento da barra de aço antes que seja atingida a capacidade resistente da ligação entre o aço e o concreto, ou seja, a aderência entre os dois materiais excedeu a limite de escoamento do aço. 


\subsection{Considerações sobre a avaliação da resistência de aderência}

A tensão ou resistência de aderência é equivalente à tensão devida à força cortante que atua paralela à barra de aço na zona de contato entre a barra de aço e concreto adjacente. Por causa da transferência de esforços entre a barra de aço e o concreto adjacente, a força varia ao longo da barra. Essa força aplicada na barra é transferida para o concreto por meio de forças radiais inclinadas ao longo da barra. A resistência de aderência vai variar conforme o valor da força pela unidade de área da superfície da barra em contato com o concreto, assim, para existir a resistência de aderência, é necessário que exista mudança de tensão ao longo da barra.

No modelo de arrancamento de barras utilizando concretos auto-adensáveis, a bibliografia internacional mostra pesquisas ainda incipientes a respeito do seu comportamento.

A capacidade resistente de uma peça de concreto depende da aderência entre os materiais aço e concreto. Em virtude disso, várias pesquisas foram realizadas com a intenção de se entender o fenômeno da aderência para concretos convencionais26, e foi visto que os fatores que mais influenciaram este fenômeno foram: a superfície de contato entre a barra de aço e o concreto adjacente, o número de ciclos de carregamento, o traço da mistura de concreto, a direção do lançamento do concreto e a geometria do modelo a ser estudado, que em nosso caso se baseia em um ensaio de arrancamento.

Nesta pesquisa, será avaliada a influência do sentido da concretagem em relação ao sentido de carregamento de arrancamento da barra, pois, de acordo com Alcântara et al. (2004), dependendo da posição da barra haverá perda de tensão de aderência, onde estas podem ser classificadas da ordem decrescente de resistência de aderência:

- Barras posicionadas verticalmente e carregadas no sentido contrário ao de lançamento do concreto;

- Barras posicionadas horizontalmente;

- Barras posicionadas verticalmente e carregadas no mesmo sentido ao de lançamento do concreto.

${ }^{26}$ Entendem-se concretos convencionais como os concretos adensados mecanicamente com adensadores (vibradores) mecânicos. 
Nas peças de concreto armado, as armaduras sofrem variação de tensão ao longo do comprimento, especialmente nas zonas de ancoragem e de variação do momento fletor. Para que não haja o escorregamento da armadura e a peça permaneça em equilíbrio, é necessário que surjam as tensões de aderência. A Figura 4.2 ilustra esse comportamento.

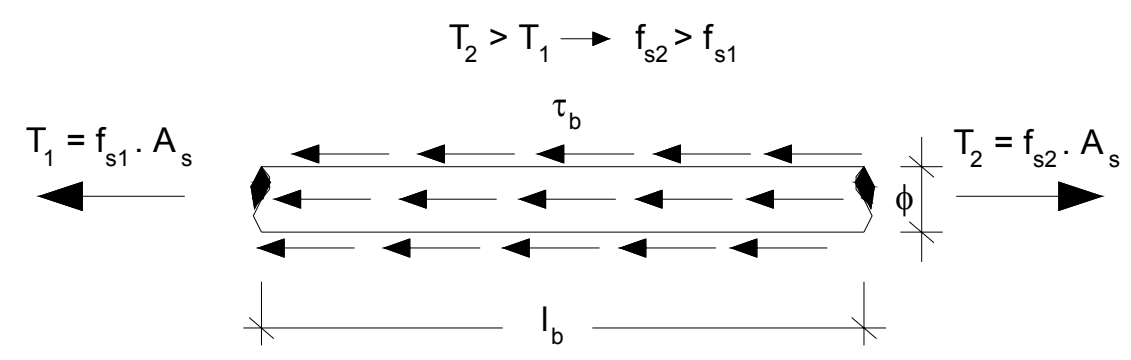

Figura 4.2 Resistência de aderência na barra de aço tracionada no concreto (Dumêt, 2003)

Para que a barra de aço não escorregue é preciso que surja uma resistência de aderência que se opõe ao movimento de tracionamento da barra, e esta equilibra a diferença entre as forças $T_{1}$ e $T_{2}$. Desse modo, é possível escrever uma equação de equilíbrio.

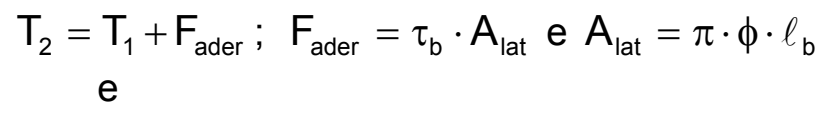

$$
f_{s e} \cdot A_{s}=f_{s 1} \cdot A_{s}+\tau_{b} \cdot \pi \cdot \phi \cdot \ell_{b}, \operatorname{com} A_{s}=\pi \cdot \phi^{2} / 4
$$

Substituindo, tem-se:

$$
\Delta \mathrm{f}_{\mathrm{s}}=\mathrm{f}_{\mathrm{s} 2}-\mathrm{f}_{\mathrm{s} 1}=\frac{4 \cdot \pi \cdot \phi \cdot \ell_{\mathrm{b}} \cdot \tau_{\mathrm{b}}}{\pi \cdot \phi^{2}}=\frac{4 \cdot \ell_{\mathrm{b}} \cdot \tau_{\mathrm{b}}}{\phi}
$$

Onde, " $\mathrm{f}_{\mathrm{s}}$ " é a tensão na armadura, " $\mathrm{A}_{\mathrm{s}}$ " é a área da seção transversal da barra de aço, " $\tau_{b}$ " é a resistência de aderência, " $\phi$ " é o diâmetro da barra de aço e " $A_{\text {lat }}$ " é a área de atuação da resistência de aderência. 


\subsection{Considerações sobre os ensaios de aderência}

Para o ensaio de avaliação da tensão de aderência, existe uma série de procedimentos para sua análise através de três modelos distintos: o de flexão, o de prisma carregado axialmente (tirante) e o de arrancamento.

O ensaio de arrancamento padrão (Rilem-Ceb-Fip, 1973), embora seja de simples execução, possui uma série de desvantagens, pois o concreto fica confinado na base de apoio para a execução do ensaio, este não permitindo nem a fissuração nem a expansão transversal do prisma de concreto (atrito com a placa de apoio) e promovendo um confinamento na armadura, o que faz com que os resultados não sejam representativos para outros elementos estruturais, como as vigas, por exemplo. Porém, esses ensaios fornecem resultados satisfatórios, tanto quantitativos quanto qualitativos para a pesquisa, pois este permite uma observação simples e precisa dos fenômenos que influenciam a aderência. A Figura 4.3 mostra as tensões principais no ensaio de arrancamento padrão (Leonhardt \& Mönnig, 1977).

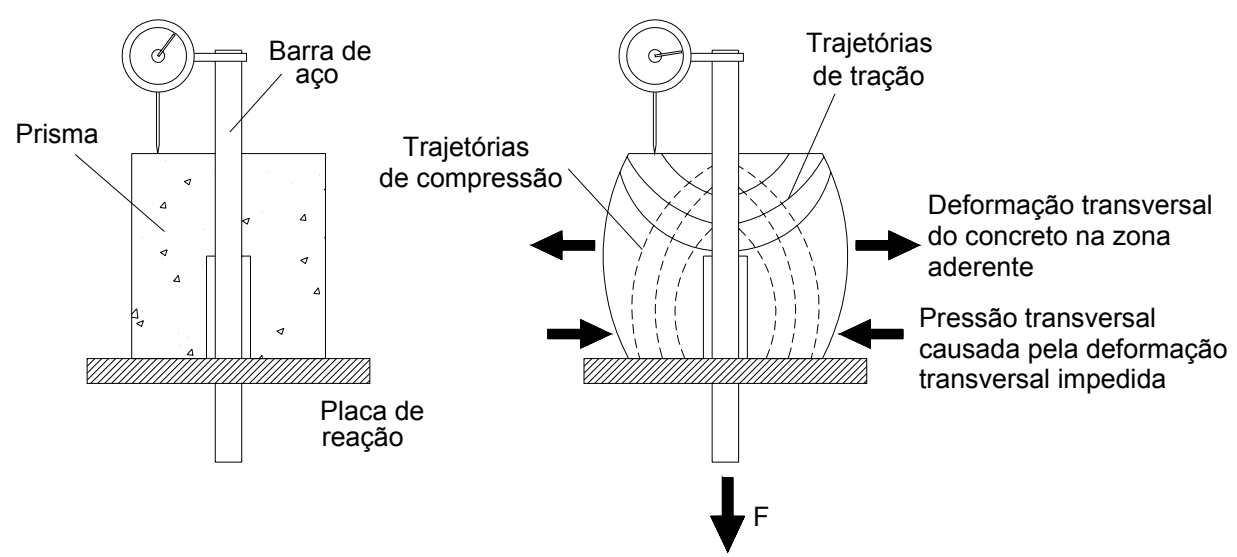

Figura 4.3 Tensões principias no ensaio de arrancamento padrão (Leonhardt \& Mönnig, 1977)

A Figura 4.4 mostra a variação da resistência de aderência, do deslizamento, das tensões na barra de aço e os limites para adesão, resistência ao atrito e o póspico até o arrancamento da barra do comportamento do ensaio para concretos de baixa resistência à compressão. 


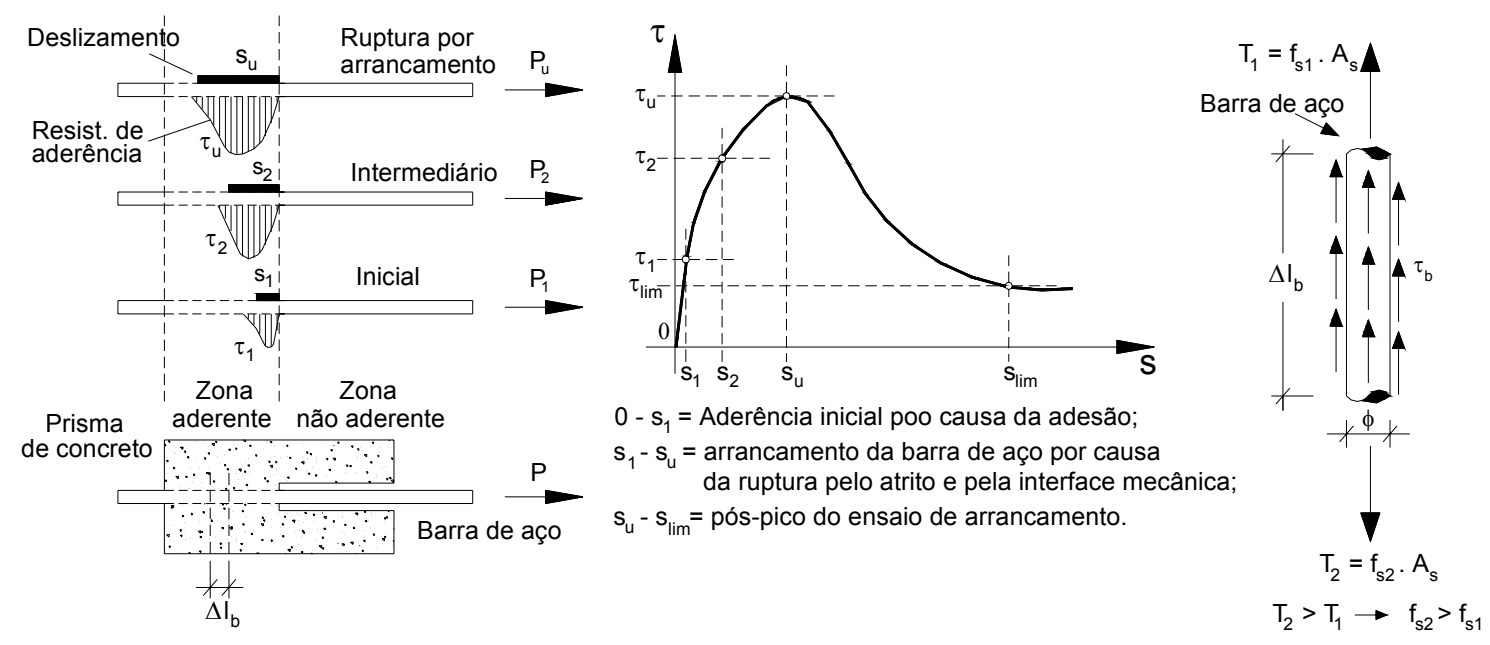

Figura 4.4 Comportamento da resistência de aderência e do deslizamento no ensaio de arrancamento

Por causa das limitações que o modelo de arrancamento padrão oferece, diversos autores propuseram modelos diferentes, com o objetivo de avaliar o comportamento da aderência quando o concreto se encontra tracionado (Oragun et al., 1977; Elzedin \& Balaguru, 1989; Al-Jahdali et al., 1994). Esses ensaios adotam um critério comum, que é o de posicionar duas barras nas extremidades do prisma de concreto e arrancar um das barras, que terá menor comprimento aderente, e assim avaliar o comportamento da ligação.

Com relação ao ensaio de vigas, de acordo com a literatura encontrada pode-se ver claramente a preocupação de vários pesquisadores com relação ao comportamento da aderência aço-concreto em ensaios de flexão, porém, essa preocupação se restringe às variáveis comprimento de ancoragem, diâmetro das barras, tipo de carregamento (monotônico ou cíclico), variação do cobrimento, presença ou não de armadura de confinamento, resistência à compressão do concreto (entre 30 e $100 \mathrm{MPa}$ ), variação da amplitude de carregamento aplicado ao modelo e, na última década do século $X X$, a presença ou não de fibras. Dentre os modelos de vigas, dois modelos foram mais utilizados para se verificar o escorregamento da barra e as tensões de aderência, sendo eles o ensaio padrão da Rilem-Ceb-Fib (1973) e o modelo de vigas com traspasse de barras. Sendo que o estudo realizado se baseou na primeira referência (Figura 4.5).

Existem ensaios que tentam simular o efeito da excentricidade da barra de aço na viga. Esse procedimento foi chamando de ensaio de meia-viga (half-beam test) pois consiste de um prisma de concreto com uma barra de aço posicionada excentricamente ao eixo normal da peça (Ferguson, 1979, Kemp \& Wilhelm, 1979). 
Soretz (1972) e Bony et al. (1973) realizaram um estudo comparativo entre a resistência de aderência entre ensaios de viga e de arrancamento padronizados pelo Rilem-Ceb-Fib (1973) e foi observado que, quanto maior o diâmetro da barra de aço, menor a resistência de aderência.

A Figura 4.5 mostra o modelo de viga de acordo com o Rilem-Ceb-Fib (1973) para diâmetro de barra inferior a $16 \mathrm{~mm}$.

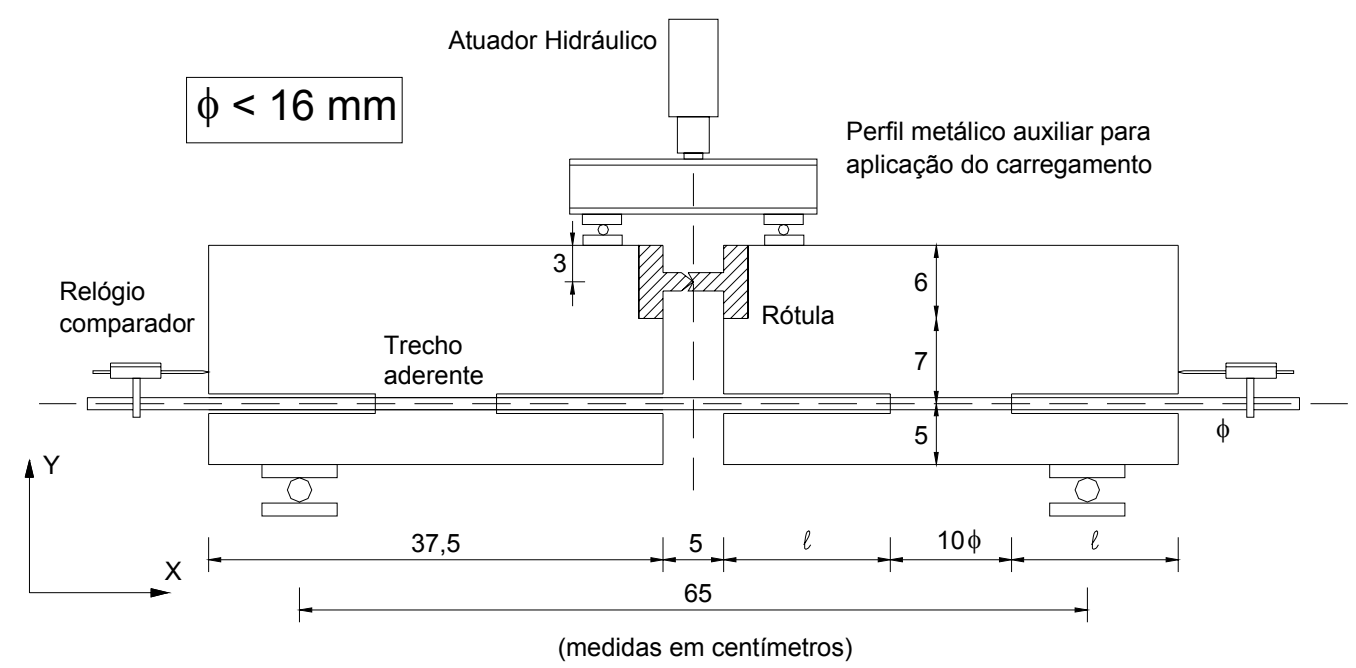

Figura 4.5 Modelo de viga padronizado (Rilem-Ceb-Fib, 1973)

Dentre as investigações realizadas com o modelo de viga do Rilem-Ceb-Fib (1973), podem-se destacar as pesquisas de Jimenez et al. (1979), Hamza \& Naaman (1996) Moreno Jr. \& Rossi (2002), Kemp \& Wilhelm (1979) e De Larrad et al. (1993). Vale comentar que em todos os casos a aplicação do carregamento foi do tipo monotônico.

Segundo Jimenez et al. (1979), a presença de armadura de confinamento aumenta a tensão requerida para a ruptura por escorregamento e, ainda, ajuda no controle da propagação de fissuras. O mesmo foi observado por De Larrad et al. (1993) que, para concretos de elevada resistência, a presença de armadura de confinamento (armadura transversal) proveu um comportamento dúctil, mesmo para barras de diâmetros elevados. A Figura 4.6 mostra o modelo de Jimenez et al. (1979). 

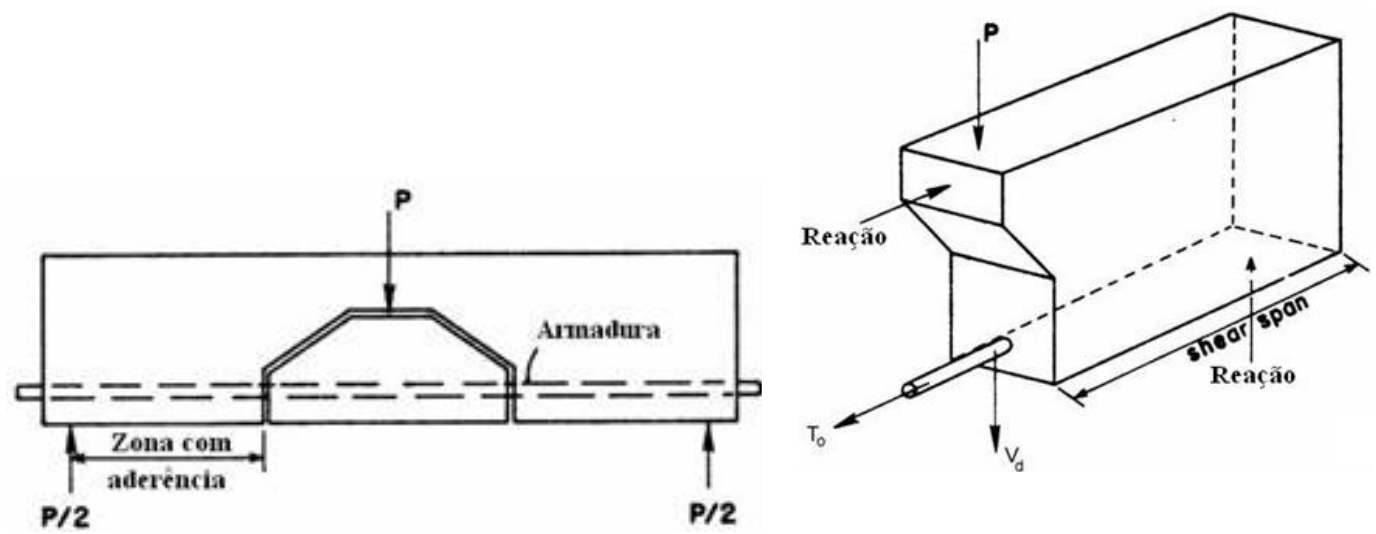

Figura 4.6 Modelo de viga estudado por Jimerez et al. (1979)

A presença de fibras metálicas melhora a resistência de aderência, especialmente na após a fissuração. Isso resulta em um arrancamento da barra de aço de uma forma mais dúctil e estável, o que contribui para um comportamento mais dúctil do elemento estrutural. Com relação ao volume de fibras no concreto, quanto maior sua quantidade, maior a capacidade dúctil da estrutura, sem mencionar o fato do acréscimo na resistência à tração do concreto (Dumêt, 2003; Hamza \& Naaman, 1996). A Figura 4.7 mostra o modelo de viga estudado por Hamza \& Naaman (1996) com matriz de SIFCON (Slurry-Infiltrated Fiber Concrete).

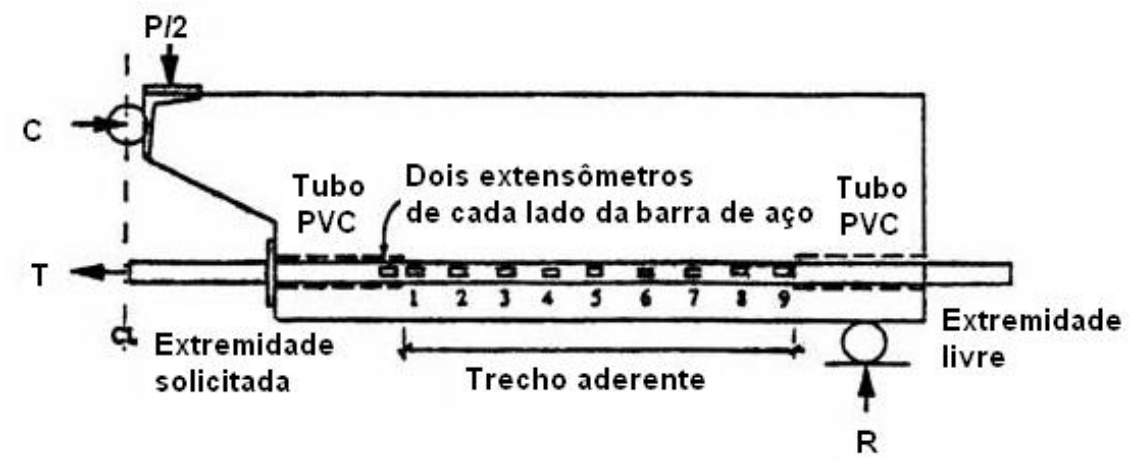

Figura 4.7 Modelo experimental estudado por Hamza \& Naaman (1996)

Vale salientar que a utilização de extensômetros elétricos de resistência posicionados na zona aderente da barra de aço pode comprometer o resultado esperado, pois nessa região de posicionamento do extensômetro, ocorre perda de trecho aderente.

Segundo Kemp \& Wilhelm (1979), o escorregamento da barra na aderência açoconcreto é um fenômeno complexo que envolve interação entre o esforço cortante e a flexão e estão ainda são influenciadas pelo: cobrimento, espaçamento entre barras, 
número de barras, espessura do modelo, forças de aderência, e outros efeitos secundários. A Figura 4.8 mostra o modelo de meia-viga.

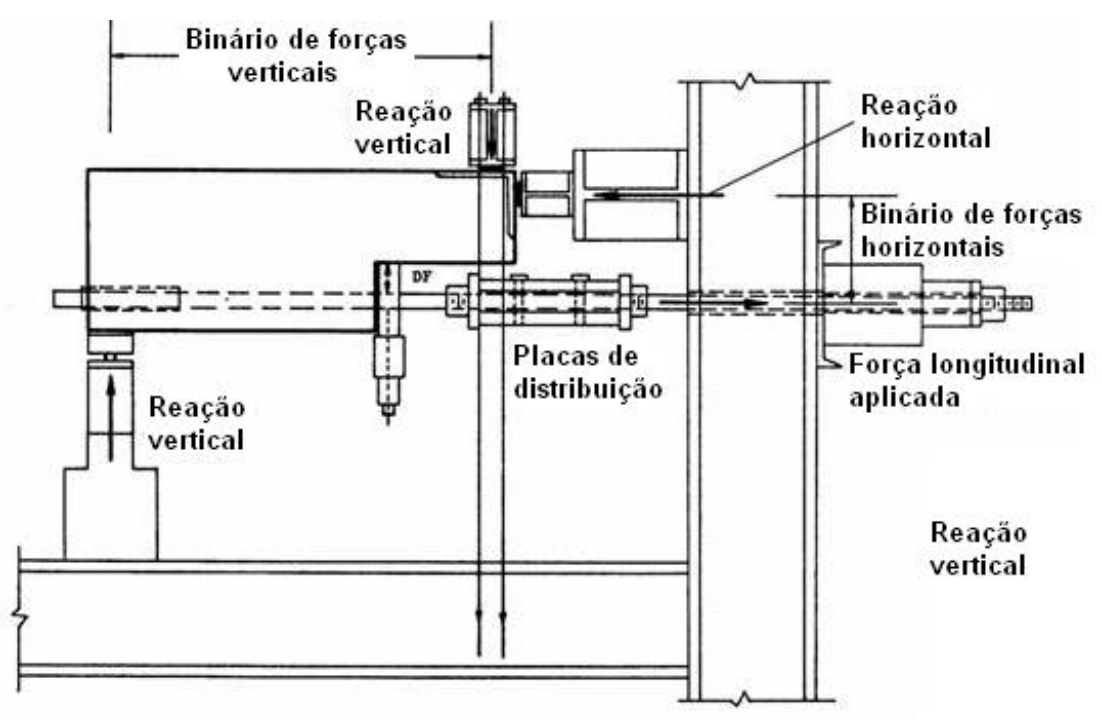

Figura 4.8 Modelo de meia-viga (half-beam test) de Kemp \& Wilhelm (1979)

De acordo com Moreno Jr. \& Rossi (2002), ocorre um aumento da resistência de aderência com o incremento da resistência à compressão do concreto. No entanto, os comprimentos de ancoragem de 5 e 10 diâmetros de barra podem não ser suficientes para garantir um deslizamento da barra de aço antes do seu escoamento.

\subsection{Análise local da resistência de aderência}

Segundo NIELSEN (1984), para uma barra com nervuras com altura "e" e espaçamento entre elas igual a "a". O mecanismo de ruptura geometricamente possível consiste de um escorregamento formando um cone, como pode ser visto na Figura 4.9.

A barra desloca-se de uma distância " $u_{s}$ " e o concreto adjacente move-se, axisimetricamente de uma distância " $\mathrm{u}_{\mathrm{c}}$ " na direção perpendicular à força aplicada $\mathrm{P}$. Esses vetores de deslocamento formam com o vetor resultante de deslocamento " $\mathrm{u}_{\mathrm{cs}}$ ", um ângulo $\alpha$. Assim, o trabalho virtual é dado por:

$$
\mathrm{W}_{\mathrm{E}}=\mathrm{P} \cdot \mathrm{u}_{\mathrm{cs}} \cdot \cos \alpha
$$

Desse modo, o valor da tensão será dado em função do ângulo $\gamma$ da superfície de ruptura entre as mossas, e, este valor pode ter duas representações: 
Para $\gamma \geq \gamma_{0}$, tem-se:

$\frac{\tau}{f_{c}}=\frac{(d+e) \cdot e}{d \cdot a \cdot \cos \alpha \cdot \cos \gamma} \cdot\left[\frac{1-\operatorname{sen}(\alpha-\gamma)}{2}+\left(\frac{f_{t}}{f_{c}}\right) \cdot \frac{\operatorname{sen}(\alpha-\gamma)-\operatorname{sen} \varphi}{1-\operatorname{sen} \varphi}\right]$

Para $0 \leq \gamma \leq \gamma_{0}$, tem-se:

$$
\frac{\tau}{f_{c}}=\frac{(d+2 \cdot e-a \cdot \tan \gamma)}{d \cdot \cos \alpha \cdot \cos \gamma} \cdot\left[\frac{1-\operatorname{sen}(\alpha-\gamma)}{2}+\left(\frac{f_{t}}{f_{c}}\right) \cdot \frac{\operatorname{sen}(\alpha-\gamma)-\operatorname{sen} \varphi}{1-\operatorname{sen} \varphi}\right]
$$

Onde, "I" corresponde ao comprimento de ancoragem; "d" é o diâmetro da barra; "e" altura das mossas; "a" distância entre mossas; " $\mathrm{f}_{\mathrm{t}}$ " é a é a resistência à tração do concreto; " $f_{c}$ " resistência à compressão do concreto; " $\tau$ " é a resistência de aderência.

O autor não fez qualquer comentário com relação à variável $\varphi$, fazendo supor que este corresponda ao ângulo de coesão entre as partículas de concreto.

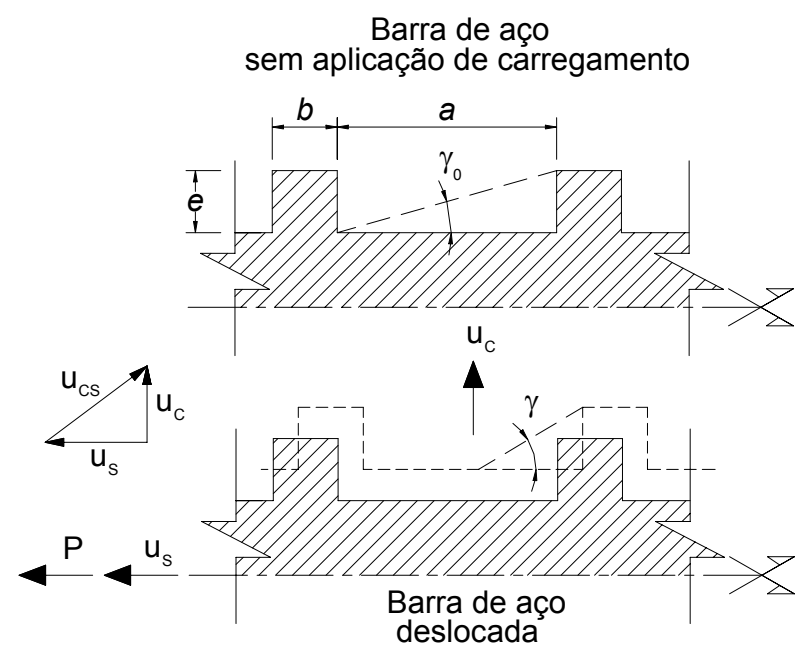

Figura 4.9 Mecanismo de ruptura local em uma barra de aço (Nielsen, 1984)

Para estas expressões é necessário adicionar a parcela referente à dissipação de energia no concreto e na armadura. Segundo o referido autor, para casos normais que ocorrem na prática, o valor de $\gamma$ é igual a zero e, estas equações são estritamente corretas somente se o concreto adjacente for deslocado axisimetricamente, o que corresponderia ao concreto ter uma distribuição de fissuras uniforme e de forma radial. 


\subsection{Considerações sobre investigações da resistência de aderência em concretos auto-adensáveis}

De acordo com as análises experimentais do CAA de resistência normal à compressão, espera-se que a sua utilização melhore o comportamento na flexão e a capacidade de carregamento de elementos estruturais por causa de melhor capacidade de preenchimento do CAA que aumenta, diretamente, a aderência entre os materiais aço e concreto e, indiretamente, o efeito do confinamento das armaduras laterais ou estribos.

Dehn et al. (2000) e Holshemachser \& Klug (2002) realizaram estudos experimentais a respeito da aderência entre barras de aço e CAA's em modelos de arrancamento de barras comparando-os com modelos em CC de mesmas características. Como resultados, os referidos autores avaliaram que existe certa ductilidade no comportamento pós-pico da tensão de aderência, sendo esta caracterizada por um deslizamento acompanhando de uma perda de tensão de aderência muito pequena.

Isa \& Aguado (2003), estudaram o fenômeno da aderência em vigas com concreto auto-adensável comparadas a concretos convencionais de mesma resistência à compressão. Foi utilizada como modelo de viga, uma adaptação do modelo de viga do Rilem-Ceb-Fib (1973), para barras de armadura inferiores a $16 \mathrm{~mm}$ de diâmetro. Segundo os autores, esta opção foi em função de se adequar às fôrmas existentes em laboratório. De acordo com os referidos autores, a principal conclusão foi que os modelos de viga tinham ruptura devido à força cortante e, dessa forma, a ruptura do modelo era do tipo frágil (Figura 4.10).

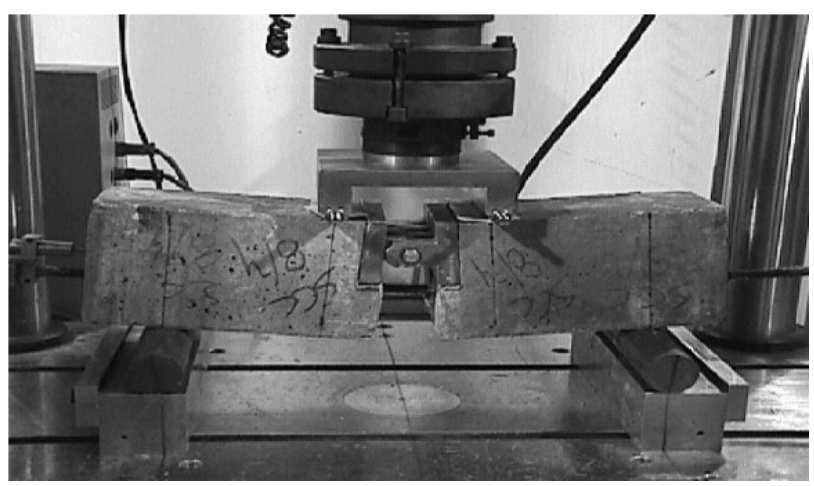

Figura 4.10 Modelo de viga utilizado por Isa \& Aguado (2003)

De acordo com os autores, a característica observada por Konig et al. (2001), ocorre por causa da alta quantidade de finos presentes na mistura, o que, diminui a 
resistência de aderência. Ainda, os CAA quando corretamente dosados, apresentam valores de resistência de aderência da mesma ordem de grandeza que o concreto comum e, o CAA apresenta ruptura do tipo frágil, necessitando então de uma normatização. Como recomendações, os referidos autores comentam a necessidade de estimular a utilização de CAA para aumentar a durabilidade das estruturas, bem como sua utilização no reparo de estruturas degradadas.

Alcântara et al. (2004) observaram a influência da posição da armadura na interface aço-CAA, onde, avaliaram barras na direção vertical e horizontal, mostrando que o CAA apresenta melhor adesão em relação ao $\mathrm{CC}$, e o desempenho quando lançado na direção vertical é similar ao CC.

De acordo com observações realizadas, percebe-se que quando da utilização de concretos de alta resistência à compressão, poderá ocorrer ruptura frágil na interface aço-concreto. O que ocorre é que, como o CAA possui uma capacidade de melhor preenchimento das fôrmas e, conseqüentemente, melhor envolvimento das barras de aço da estrutura, isso melhoraria diretamente a resistência de aderência, pois ocorreria um acréscimo na adesão e no atrito da barra de aço com o concreto e, portanto, aumentaria a probabilidade de ruptura brusca da interface aço-concreto.

\subsection{Considerações finais}

De acordo com o que foi exposto, a literatura técnica mostra que o estudo do comportamento da aderência aço-concreto ainda possui muitas lacunas a serem preenchidas e a quantidade de parâmetros que influem em seu comportamento é muito grande.

Por exemplo, o aumento da resistência à compressão do concreto aumenta a resistência de aderência, porém o aumento do diâmetro da barra de aço reduz a resistência de aderência.

Os ensaios de resistência de aderência realizados por diversos pesquisadores, muitas vezes não representam de forma adequada o comportamento da aderência, pois alguns ensaios possuem limitações que provocam ou uma superestimativa ou subestimativa da resistência de aderência, tornando necessário o desenvolvimento de um ensaio padronizado, para se avaliar adequadamente a resistência de aderência, e de ensaios em elementos estruturais para obter uma correlação entre o desempenho do elemento e o ensaio de aderência padronizado (Cairns \& Plizzari, 2003).

A Tabela 4.1 mostra um resumo das propriedades que influem no comportamento da aderência aço-concreto. 
Tabela 4.1 Fatores que influenciam a resistência de aderência (Barbosa, 2001)

\begin{tabular}{ccc}
\hline Parâmetro & $\begin{array}{c}\text { Comportamento do } \\
\text { parâmetro }\end{array}$ & $\begin{array}{c}\text { Comportamento da } \\
\text { aderência }\end{array}$ \\
\hline Resistência à compressão & Aumento & Aumento \\
Superfície da barra & Aumento & Aumento \\
Diâmetro da barra & Aumento & Diminui \\
Área relativa da nervura & Aumento & Aumento \\
Posição da barra na & Horizontal (superior) & Diminui \\
concretagem & Aumento & Aumento \\
Idade do ensaio & Aumento & Aumento \\
Adensamento & Aumento & Diminui \\
Carregamento cíclico & & \\
\hline
\end{tabular}





\section{Investigação experimental da aderência}

Neste capítulo se apresenta a investigação experimental desenvolvida para o estudo da aderência aço-concreto com modelos de arrancamento e de viga, ambos padronizados pelo Rilem-Ceb-Fip (1973), utilizando concretos convencionais e autoadensáveis com resistência à compressão do concreto de 30 e $60 \mathrm{MPa}$. Os ensaios foram conduzidos no Laboratório de Estruturas utilizando uma máquina de ensaios universal (Instron). Foram utilizados transdutores de deslocamento e extensômetros elétricos de resistência para se aferir os deslizamentos e as deformações na barra de aço. De acordo com os resultados, o comportamento dos modelos de arrancamento e de viga demonstrou que o concreto auto-adensável possui propriedades mecânicas similares ao CC e ainda, possui as vantagens de trabalhabilidade no estado fresco.

\subsection{Programa experimental}

O programa experimental compreendeu o estudo da resistência de aderência em modelos de arrancamento de barras de aço e de vigas submetidas à flexão pura. Nesta etapa foram moldados os modelos para estudo da aderência aço-concreto e a verificação da variabilidade da resposta do modelo de arrancamento e de viga utilizando tanto para o CC quanto para o CAA.

A quantidade dos modelos foi estabelecida da seguinte forma: para os modelos de arrancamento seriam realizadas, por variável, 5 amostras e para os modelos de viga, antes planejado o valor de 5 amostras, foi reduzido para 2 em função da grande quantidade de atividades no Laboratório de Estruturas. 
Os concretos auto-adensáveis utilizados nos modelos de viga e de arrancamento são os mesmos desenvolvidos no Capítulo 3.

A Tabela 5.1 e a Tabela 1.3 mostram a nomenclatura para os modelos de arrancamento e de viga, respectivamente.

Tabela 5.1 Nomenclatura dos modelos de arrancamento

\begin{tabular}{ccc}
\hline Modelo & Série & Quantidade de modelos \\
\hline A-CAA-C30-B10 & & 5 \\
A-CAA-C30-B16 & 1 & 5 \\
A-CC-C30-B10 & & 5 \\
A-CC-C30-B16 & & 5 \\
\hline A-CAA-C60-B10 & & 5 \\
A-CAA-C60-B16 & 2 & 5 \\
A-CC-C60-B10 & & 5 \\
A-CC-C60-B16 & & 5 \\
\hline A10 & & 5 \\
A12,5 & Complementar & 5 \\
A16 & & 5 \\
\hline
\end{tabular}

Onde A corresponde ao modelo de arrancamento, CC e CAA correspondem ao concreto convencional e ao concreto auto-adensável, C30 e C60 correspondem a classe de resistência à compressão do concreto (30 e $60 \mathrm{MPa})$ e B10 e B16, correspondem ao diâmetro da barra, 10 e $16 \mathrm{~mm}$, respectivamente. O total de prismas de arrancamento ensaiados foi de 55 modelos.

Com relação à série complementar de ensaios, esta somente utilizou o concreto auto-adensável com diferentes diâmetros de barra de aço. Com isso, ao final do item 5.6, se apresentam os resultados obtidos.

Tabela 5.2 Nomenclatura dos modelos de viga

\begin{tabular}{ccc}
\hline Modelo & Série & Quantidade de modelos \\
\hline V-CAA-C30-B10 & & 2 \\
V-CAA-C30-B16 & 1 & 2 \\
V-CC-C30-B10 & & 2 \\
V-CC-C30-B16 & & 2 \\
\hline V-CAA-C60-B10 & & 2 \\
V-CAA-C60-B16 & 2 & 2 \\
V-CC-C60-B10 & 2 \\
V-CC-C60-B16 & 2 \\
\hline
\end{tabular}

Onde $\mathrm{V}$ corresponde ao modelo de viga, CC e CAA correspondem ao concreto convencional e ao concreto auto-adensável, C30 e C60 correspondem a classe de resistência à compressão do concreto (30 e $60 \mathrm{MPa})$ e B10 e B16, correspondem ao diâmetro da barra, 10 e $16 \mathrm{~mm}$, respectivamente. O total de vigas ensaiadas foi de 16 modelos. 


\subsection{Geometria dos modelos}

Aqui se apresenta a geometria dos modelos utilizados.

\subsubsection{Modelos de arrancamento}

Conforme comentado anteriormente o modelo de arrancamento adotado foi o estabelecido pelo Rilem-Ceb-Fip (1973). Na Figura 5.1 ilustra-se a geometria para os modelos de arrancamento para as barras de 10, 12,5 e $16 \mathrm{~mm}$.

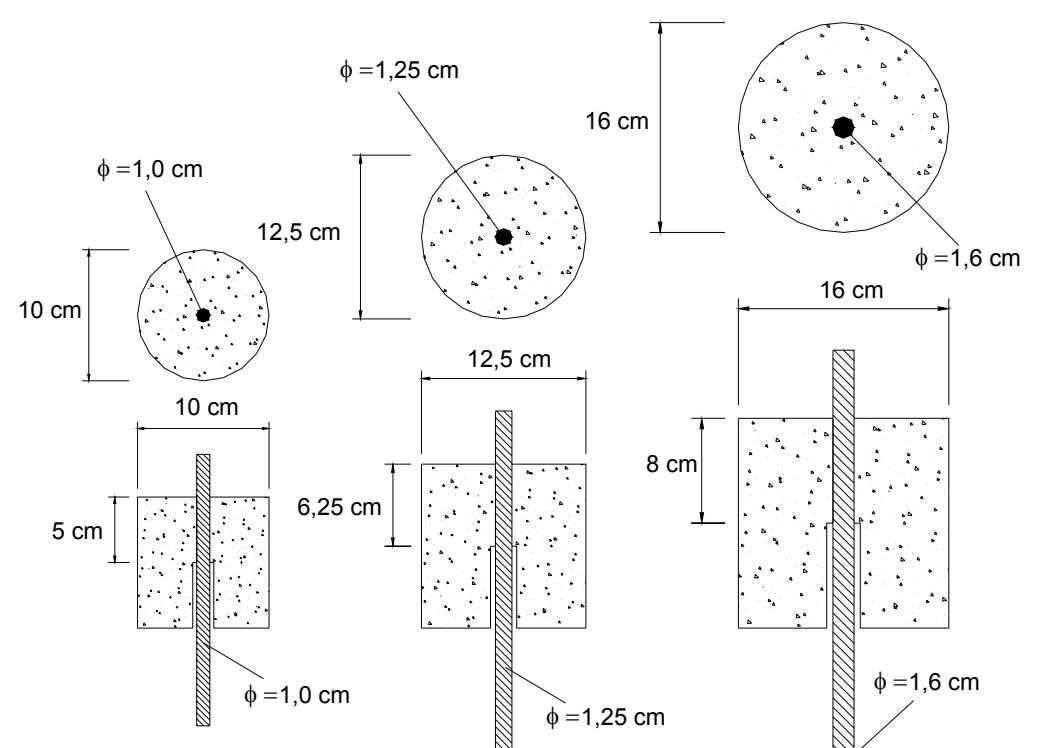

Figura 5.1 Fôrmas do modelo de arrancamento com barras de 10, 12,5 e $16 \mathrm{~mm}$

A posição e a inclinação das barras durante a concretagem têm comportamento significativo na resistência de aderência. Os prismas concretados na direção vertical apresentam maior resistência de aderência que os prismas concretados na posição horizontal. Assim, os modelos de arrancamento foram concretados na posição vertical.

As fôrmas eram compostas de um tubo de PVC com o diâmetro equivalente a dez vezes o diâmetro da barra. A extremidade inferior do tubo era fechada com uma fôrma de madeirit com um furo central que permitiria a passagem da barra de aço. $\mathrm{Na}$ extremidade superior, havia outra placa de madeirit para posicionar adequadamente a barra de aço no centro geométrico da seção transversal do modelo. O trecho nãoaderente era constituído de uma mangueira plástica posicionada manualmente e esta era medida de forma que o comprimento de ancoragem fosse respeitado. A Figura 5.2 ilustra as fôrmas utilizadas. 

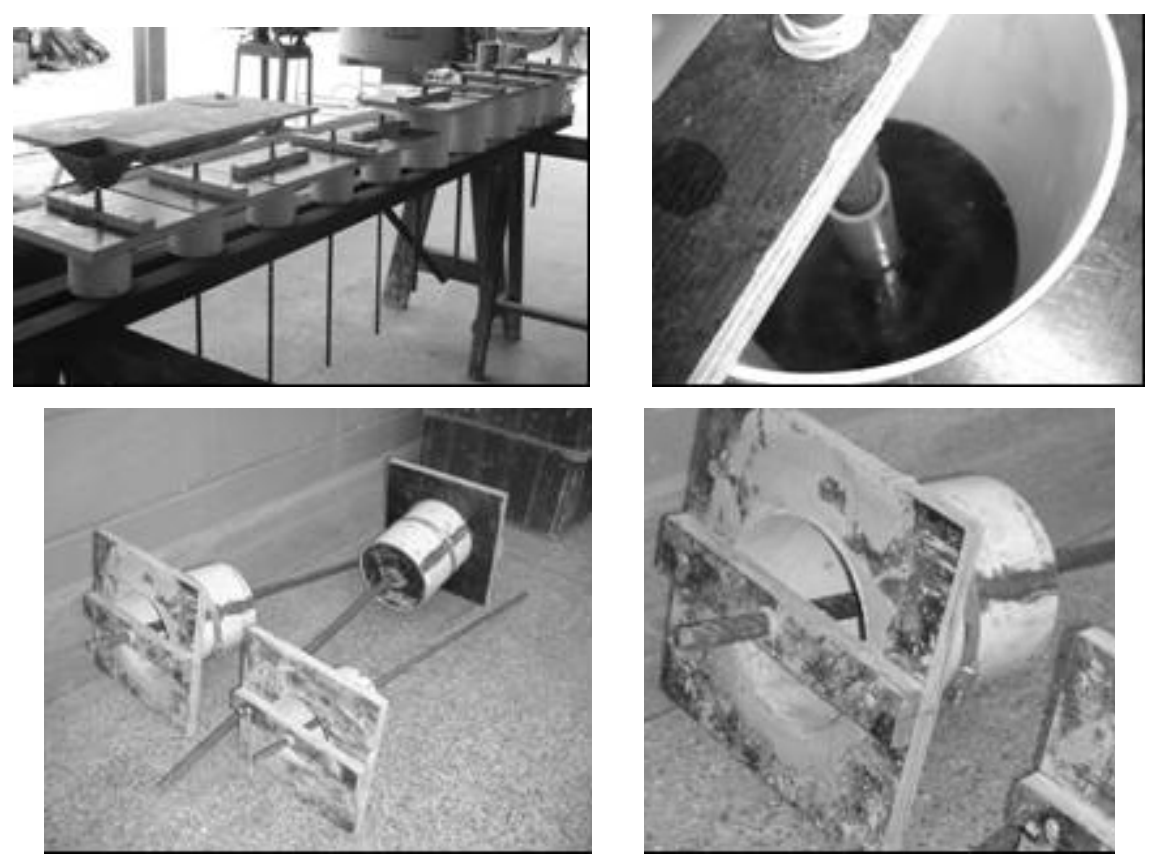

Figura 5.2 Fôrmas de arrancamento utilizadas

Vale ressaltar que esse tipo de fôrma permite várias repetições da concretagem sem perda de qualidade do modelo moldado.

\subsubsection{Modelos de viga}

$\mathrm{Na}$ Figura 5.3 ilustra-se a geometria para os modelos de viga para as barras de 10 e $16 \mathrm{~mm}$.
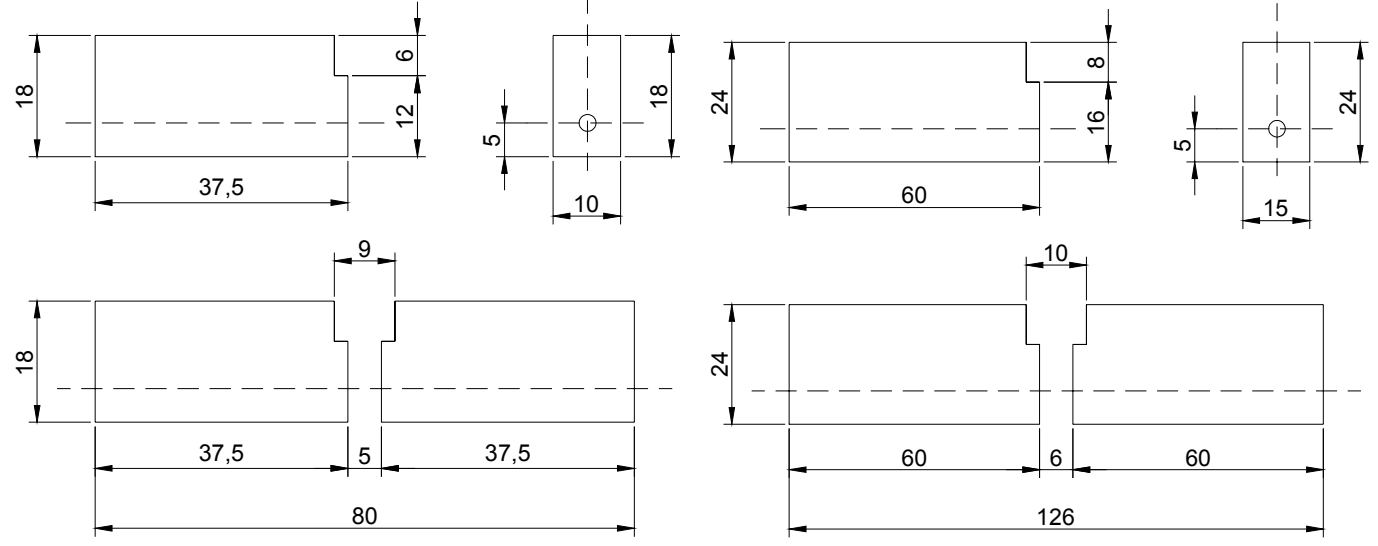

Fôrmas para modelo de viga com barra de $10 \mathrm{~mm}$ de diâmetro

Fôrmas para modelo de viga com barra de $16 \mathrm{~mm}$ de diâmetro

Figura 5.3 Fôrmas para o modelo de viga com barra de 10 e 16 mm 
As fôrmas eram feitas em folhas de madeirit recortadas para permitir o posicionamento posterior da rótula. Vale comentar que esse tipo de fôrma é de fácil execução, porém é de difícil desfôrma por causa do detalhe existente na mesma que se refere à posição da rótula. O trecho não-aderente era feito constituído de mangueira plástica posicionada manualmente e esta era medida de forma que o comprimento de ancoragem fosse respeitado em ambos os lados da viga. Após o posicionamento da barra de aço, esta era então lacrada nos pontos onde se passava a barra de aço de modo a impedir a perda de argamassa. A Figura 5.4 mostra as fôrmas dos modelos de viga com barra de 10 e $16 \mathrm{~mm}$ preparados para concretagem.
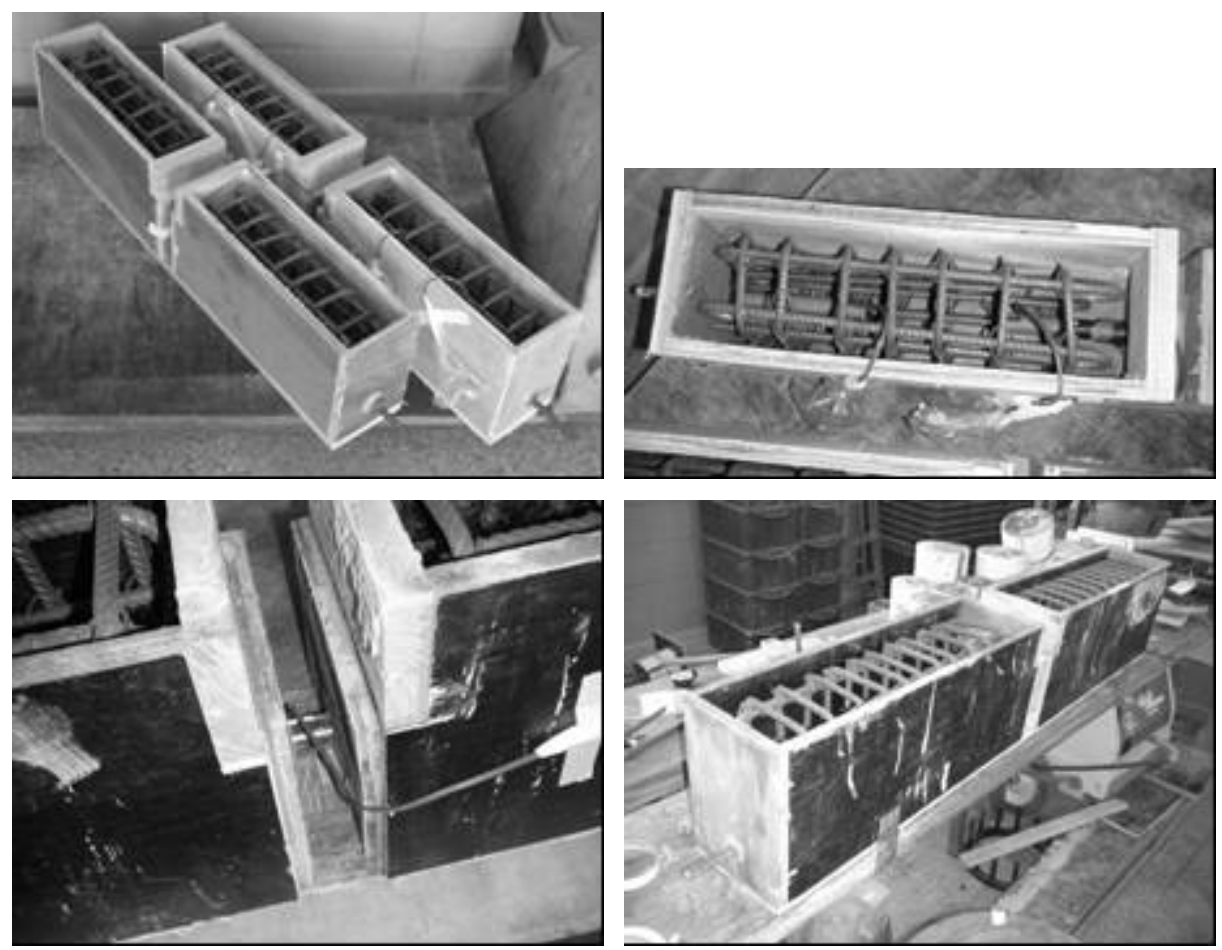

Figura 5.4 Fôrmas de viga prontas para concretagem

A Figura 5.5 mostra as rótula desenvolvidas para os ensaios de viga, conforme estabelecido pelo Rilem-Ceb-Fip (1973).
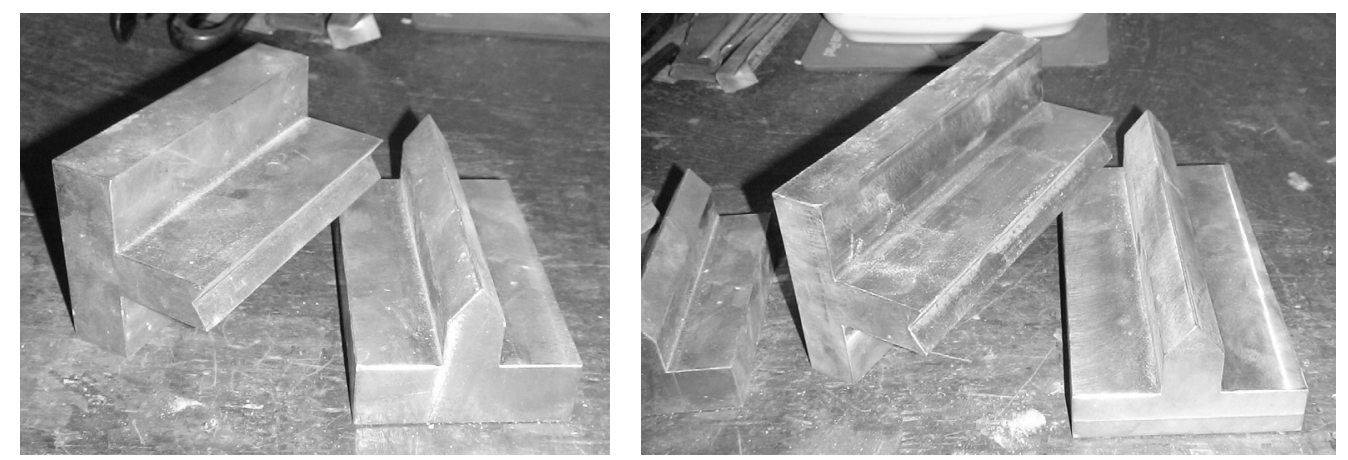

Figura 5.5 Fôrmas para a rótula do modelo de viga com barra de 10 e $16 \mathrm{~mm}$ 
A Figura 5.6 e Figura 5.7 mostram o detalhe das armaduras utilizadas em cada modelo de viga, conforme estabelecido pelo Rilem-Ceb-Fip (1973).
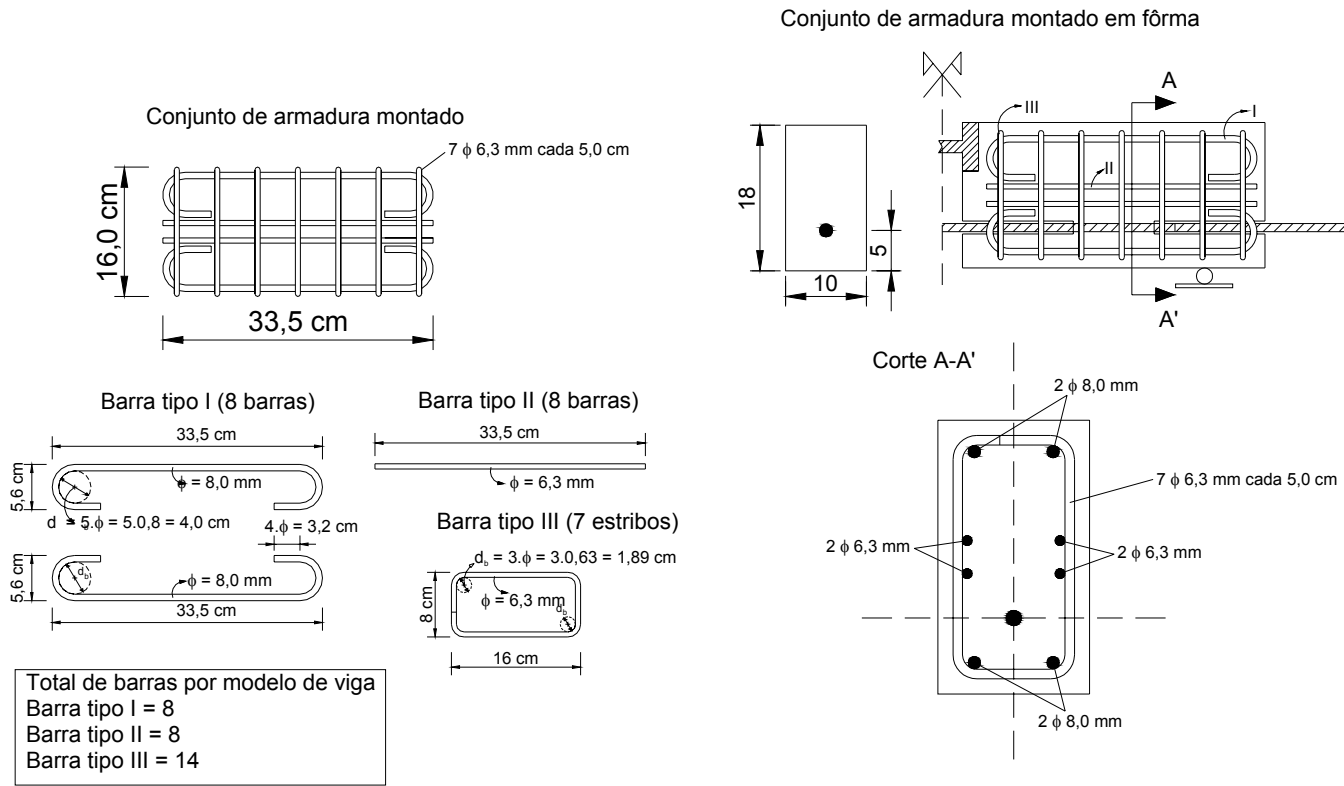

Figura 5.6 Detalhe da armadura do modelo de viga com barra de $10 \mathrm{~mm}$

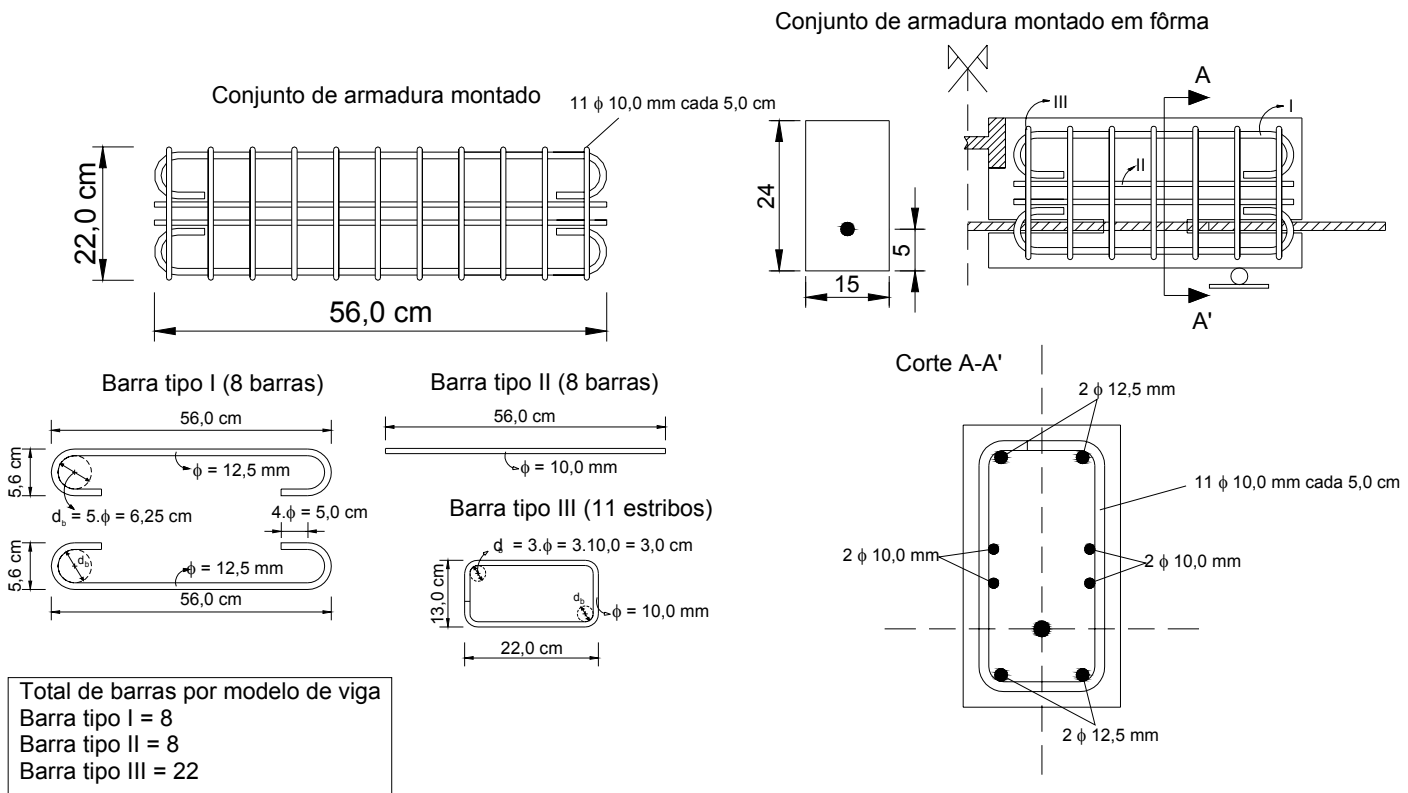

Figura 5.7 Detalhe da armadura do modelo de viga com barra de $16 \mathrm{~mm}$

Vale comentar que a armadura da Figura 5.6 e Figura 5.7 eram de difícil execução por causa de seu tamanho reduzido. 


\subsection{Instrumentação}

Aqui se apresenta a instrumentação utilizada. Vale salientar que a instrumentação utilizou transdutores de $20 \mathrm{~mm}$ de curso e extensômetros elétricos de resistência de $10 \mathrm{~mm}$.

\subsubsection{Ensaios de arrancamento}

A instrumentação vai seguir o modelo da Figura 5.8. Embora alguns autores tenham obtido valores para a tensão de aderência utilizando extensômetros elétricos de resistência presos à barra de aço e, em alguns casos dentro da barra de aço (Mirza \& Houde, 1978; Fernandes, 2000; Castro, 2002), o primeiro procedimento acarreta a perda de trechos aderentes que podem comprometer os resultados, enquanto o segundo é de difícil execução.

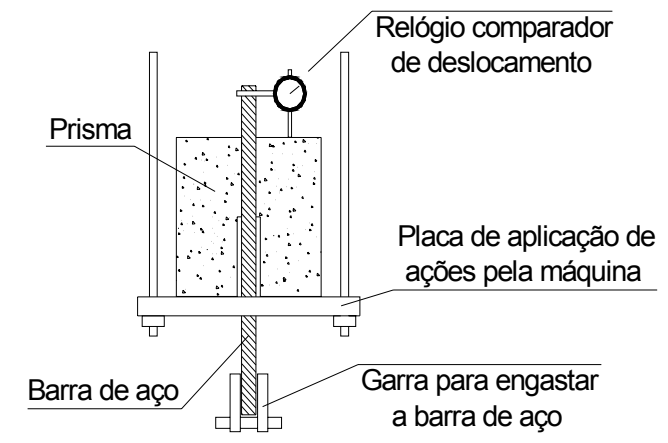

Figura 5.8 Instrumentação do modelo de arrancamento

\subsubsection{Ensaios de viga}

Os ensaios de viga seguiram a mesma orientação adotada para o modelo de arrancamento que consistia de não posicionar extensômetros elétricos de resistência no trecho aderente. Assim, foram utilizados dois transdutores de deslocamento (LVDT) posicionados nas extremidades livres da barra de aço e mais um LVDT posicionado junto no pistão da máquina de ensaios (Figura 5.9) para se determinar o deslocamento máximo da viga (flecha) e, ainda foram posicionados cinco extensômetros por barra de acordo com a Figura 5.10. Os extensômetros foram posicionados antes e logo depois do trecho aderente e um outro foi posicionado no centro da barra de modo a se verificar o escoamento da mesma. 


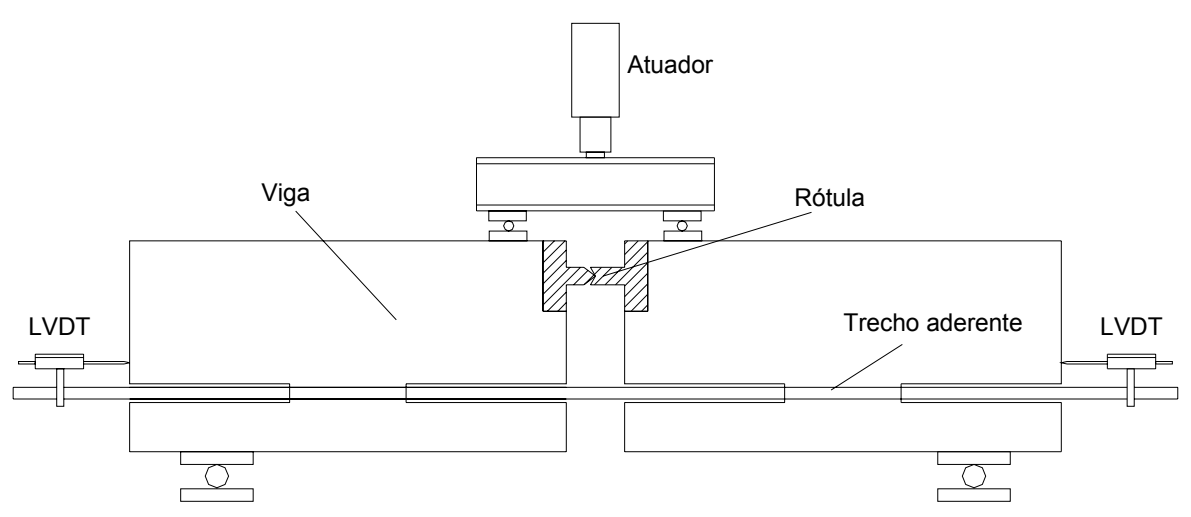

Figura 5.9 Instrumentação do modelo de viga

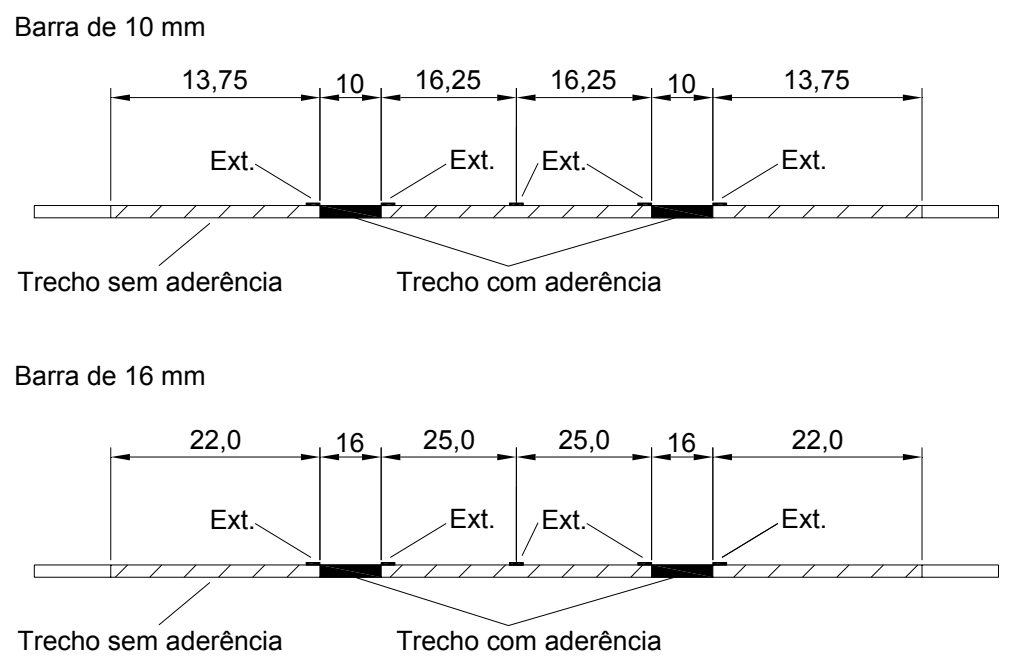

Figura 5.10 Instrumentação da barra de aço para o modelo de viga

Vale salientar que a quantidade de barras instrumentadas por série se limitou a uma barra, por motivos de adequação a programação das atividades do Laboratório de Estruturas.

\subsection{Aplicação do carregamento}

O carregamento aplicado aos modelos de viga e de arrancamento foi calculado de acordo com o diâmetro da barra ensaiada, onde para o caso de barras de $10 \mathrm{~mm}$ e $16 \mathrm{~mm}$, a velocidade de carregamento foi de 0,05 e $0,08 \mathrm{~mm} / \mathrm{s}$, respectivamente (Fernandes, 2000; Castro, 2002). A Figura 5.11 mostra o procedimento de ensaio, onde, a aplicação do carregamento é realizada pela placa que apóia o prisma de concreto e a barra que é presa à máquina de ensaios, no caso dos modelos de arrancamento, e no caso dos modelos de viga, utilizou-se um perfil metálico de modo 
a se distribuir o deslocamento aplicado pelo pistão à viga, que era apoiada na própria máquina.
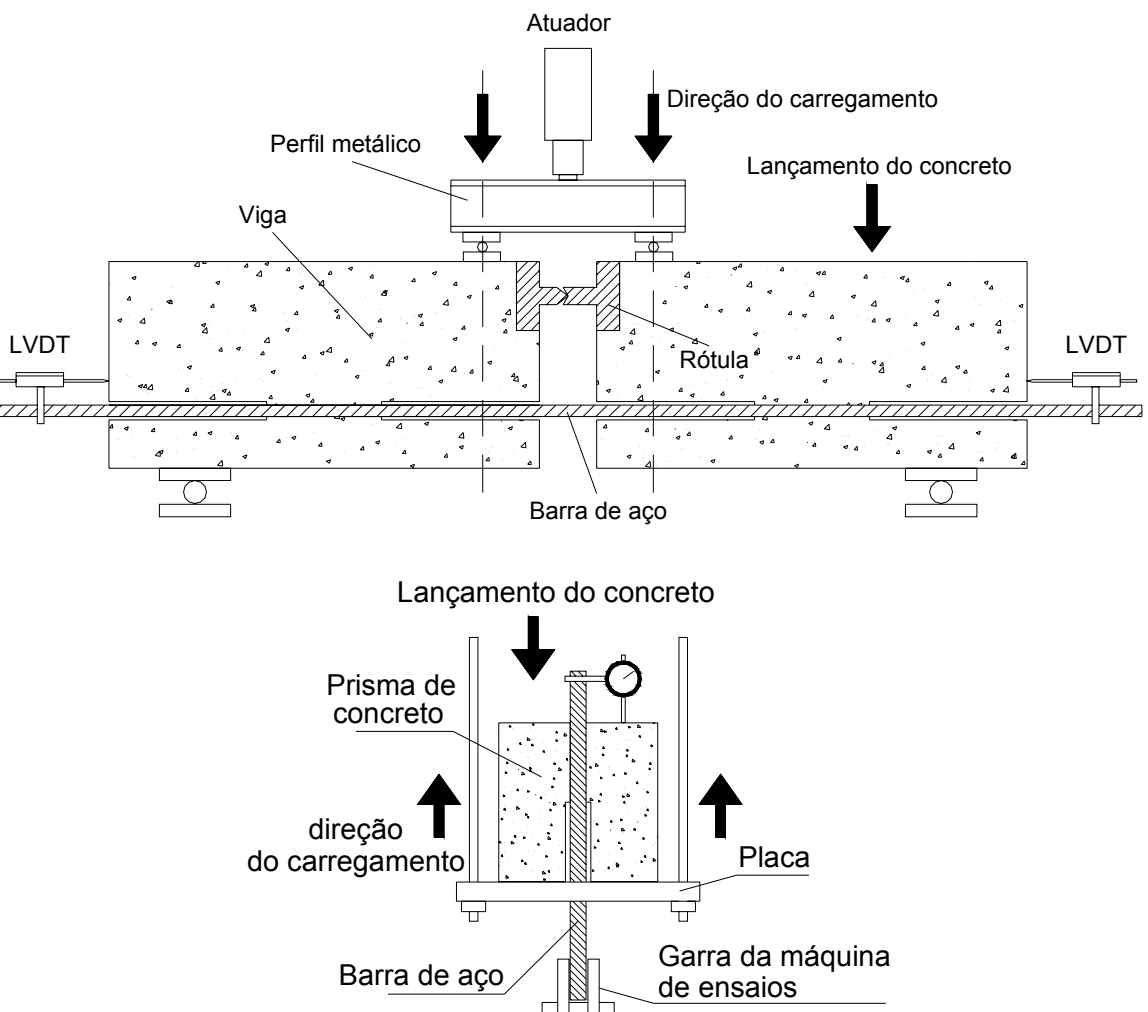

Figura 5.11 Aplicação do carregamento para o modelo de viga e de arrancamento

\subsection{Caracterização das barras de aço}

As barras de aço foram caracterizadas de acordo com a NBR 6152 (1992) e a NBR 7480 (1996). A Figura 5.12 mostra o comportamento das barras de 10 e $16 \mathrm{~mm}$ utilizadas nos ensaios de viga e de arrancamento.

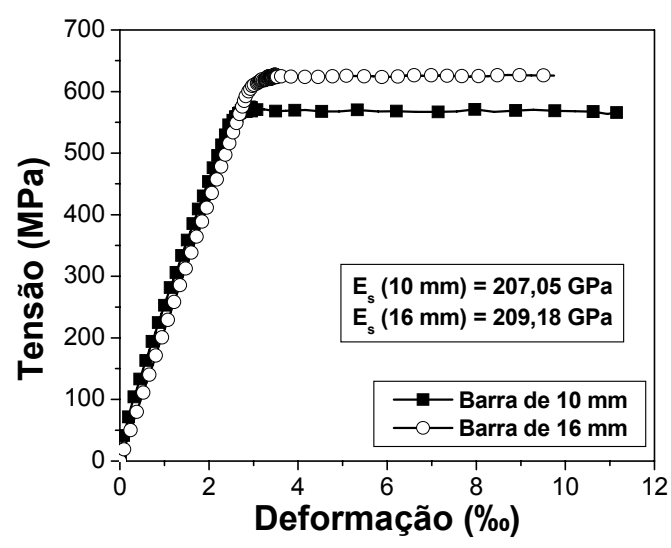

Figura 5.12 Comportamento das barras de aço de 10 e $16 \mathrm{~mm}$ 


\subsection{Modelos de arrancamento}

Os modelos de arrancamento foram divididos com base em sua resistência à compressão e o diâmetro da barra de aço utilizada. Assim, a primeira série de ensaios envolveu os concretos com resistência à compressão de $30 \mathrm{MPa}$ e a segunda série consiste dos concretos com resistência à compressão de $60 \mathrm{MPa}$. Ainda, foi realizada uma série complementar com concreto auto-adensável de alta resistência à compressão e com elevada coesão com diâmetros de barra de 10, 12,5 e 16 mm.

Os modelos de referência em concreto convencional (CC) utilizaram os mesmos materiais usados na elaboração do CAA, no caso cimento e agregados. As dosagens foram determinadas a partir de ensaios previamente realizados no Laboratório de Estruturas e atendem aos requisitos de resistência à compressão do concreto (30 e 60 $\mathrm{MPa}$ ), conforme mostrado anteriormente.

\subsubsection{Série 1}

Aqui se apresentam os resultados referentes aos modelos de arrancamento em concreto convencional $(\mathrm{CC})$ e em concreto auto-adensável (CAA) com resistência à compressão de $30 \mathrm{MPa}$ aos 7 dias.

\subsubsection{Modelos em CC}

A Tabela 5.3 mostra a composição do traço para o concreto convencional com resistência à compressão de $30 \mathrm{MPa}$.

Tabela 5.3 Composição do traço do CC da série 1

\begin{tabular}{lc}
\hline Material & Quant. (kg) \\
\hline Cimento & 365,3 \\
Água & 260,8 \\
Areia & 883,9 \\
Brita & 942,3 \\
\hline
\end{tabular}

\begin{tabular}{l}
\hline Ensaios \\
\hline Abatimento \\
$24,0 \mathrm{~cm}$ \\
\end{tabular}

A Tabela 5.4 ilustra as propriedades no estado endurecido para o CC de 30 MPa. Vale salientar que conforme adequação às atividades do Laboratório de Estruturas, os ensaios foram realizados aos 7 dias. Embora o abatimento do concreto tenha sido elevado, era necessário o adensamento mecânico para um preenchimento adequado dos modelos. 
Tabela 5.4 Propriedades do CC aos 7 dias

\begin{tabular}{cccc}
\hline & Média (MPa) & D.P. (MPa) & C.V. \\
\hline $\mathbf{f}_{\mathrm{c}, 7}$ & 32,02 & 0,70 & $2,19 \%$ \\
$\mathbf{E}_{\mathrm{c}, 7}$ & 27237,00 & 631,00 & $2,32 \%$ \\
$\mathbf{f}_{\mathrm{ct}, \mathbf{s p}, 7}$ & 2,182 & 0,52 & $9,17 \%$ \\
\hline
\end{tabular}

Onde, $\mathrm{f}_{\mathrm{ct} \text { sp }}$ é a resistência à tração indireta, $\mathrm{E}_{\mathrm{c}}$ é o módulo de elasticidade longitudinal e $\mathrm{f}_{\mathrm{c}, 7}$ é a resistência à compressão do concreto, todos ensaiados aos 7 dias. A Figura 5.13 mostra o módulo de elasticidade dos modelos em CC da série 1.
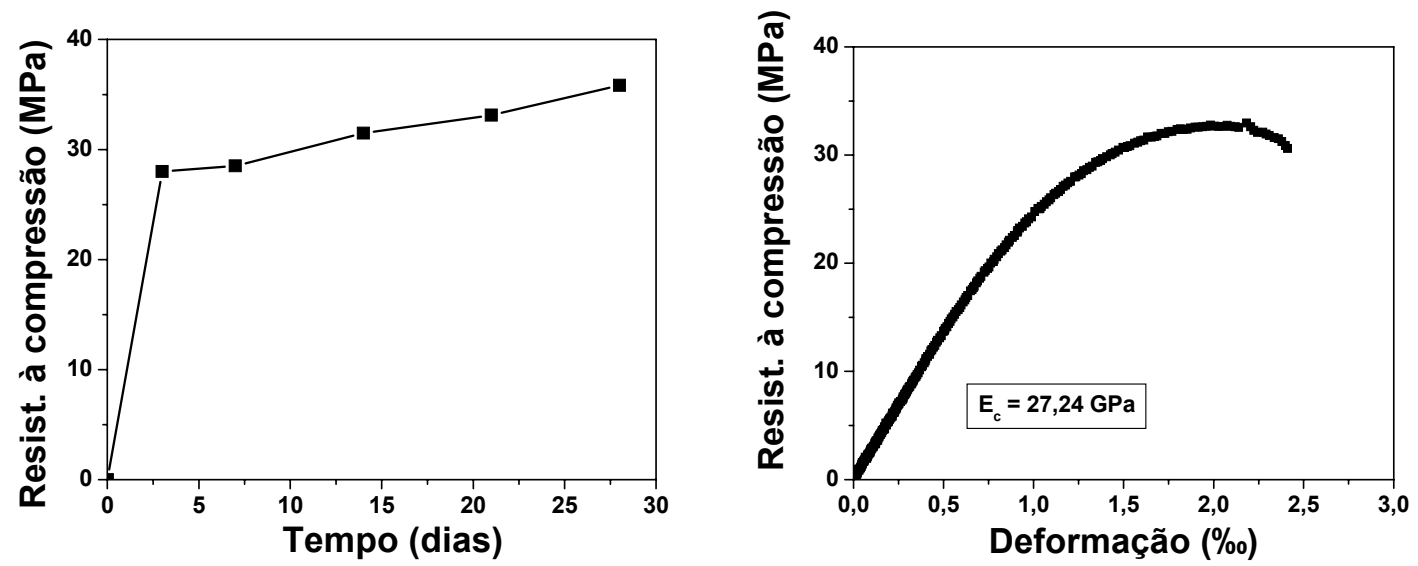

Figura 5.13 Variação da resistência à compressão e módulo de elasticidade longitudinal para os modelos em CC

Os modelos de referência foram ensaiados em baterias de 5 modelos por diâmetro de barra onde o objetivo era fornecer uma representatividade dos resultados obtidos. Os prismas foram concretados com o auxílio de uma mesa vibratória conforme a Figura 5.14.
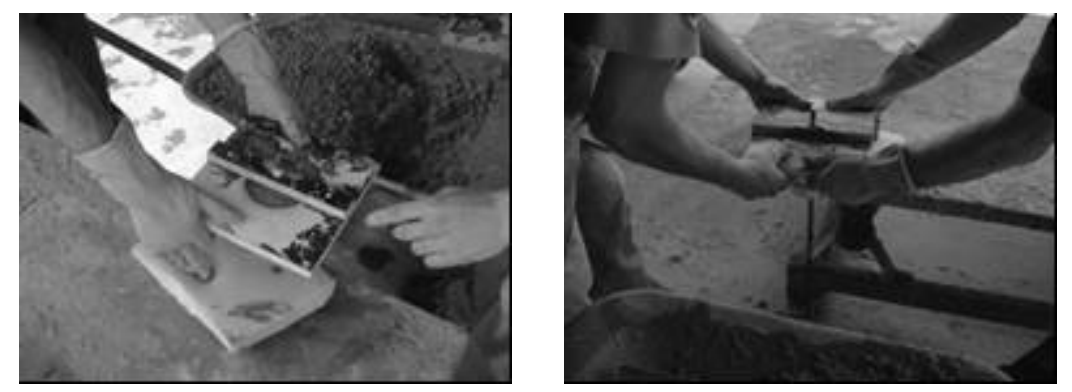

Figura 5.14 Concretagem dos modelos de arrancamento em CC

Para os modelos de referência a aplicação da vibração é essencial. A falta de adensamento pode resultar em perda de resistência de aderência conduzindo a problemas no desempenho estrutural do elemento. Para o CC, o adensamento exagerado (com cuidado de não causar segregação) ou adensamento inadequado não 
afeta a tensão de aderência, mostrando que a prática de adensamento é importante, mas não crucial para concreto com pequeno abatimento, pois a coesão do concreto com pequeno abatimento previne segregação ou a exsudação; entretanto, para concretos de alta resistência, o adensamento exagerado ou inadequado pode acarretar a uma perda de até $30 \%$ da tensão de aderência (Chan et al., 2003).

A Figura 5.15 ilustra o comportamento dos modelos de arrancamento em CC.
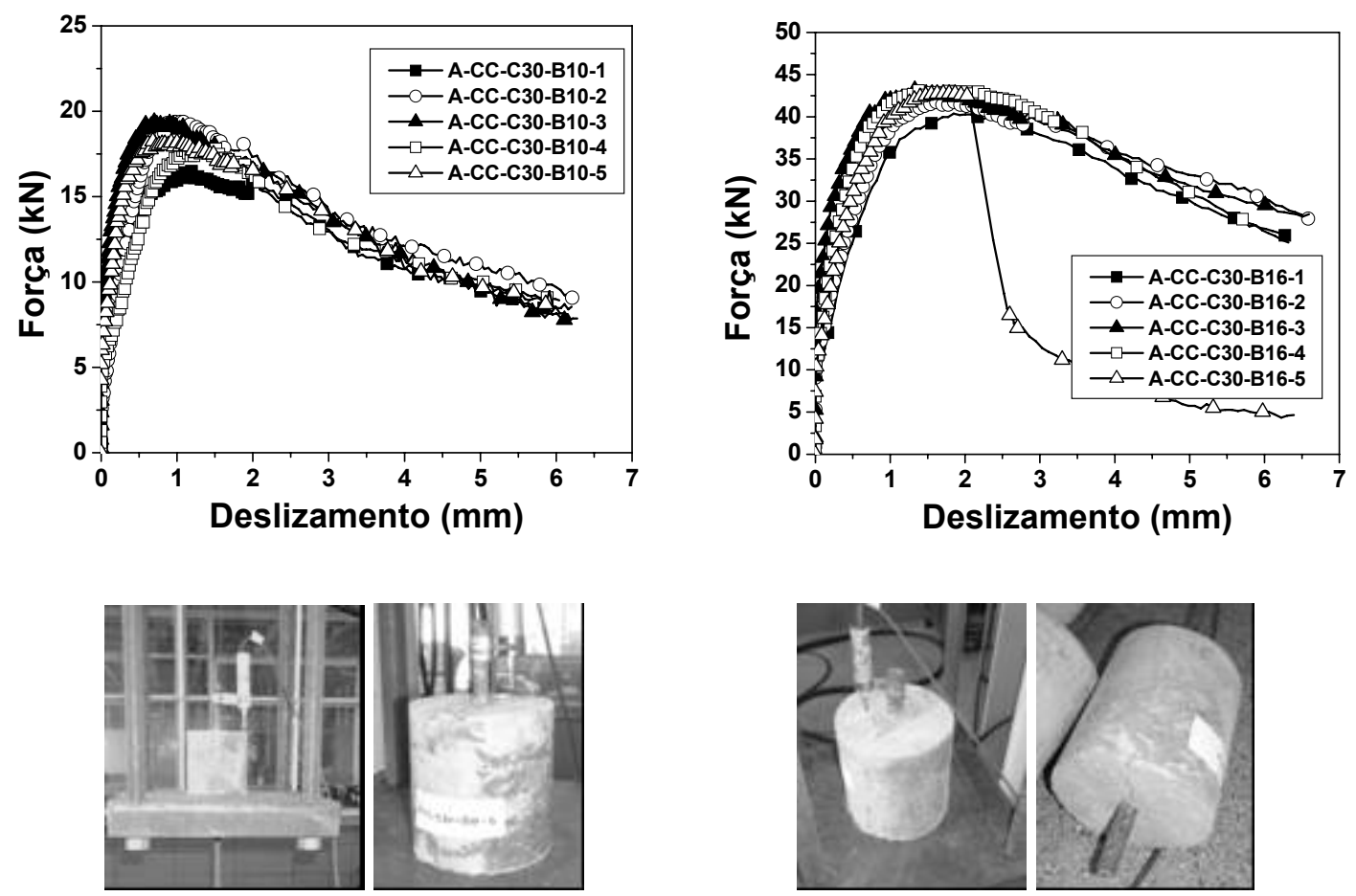

Figura 5.15 Comportamento dos modelos de arrancamento em CC da série 1

A Figura 5.16 ilustra os modelos de arrancamento em CC.

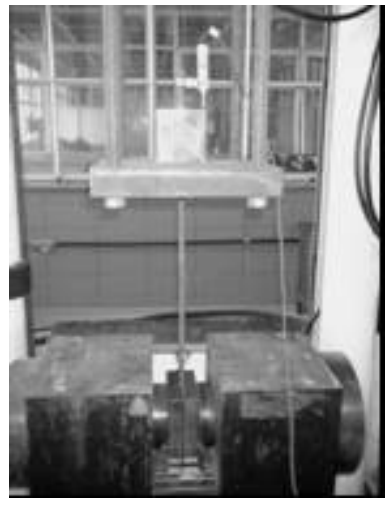

$\phi=10 \mathrm{~mm}$

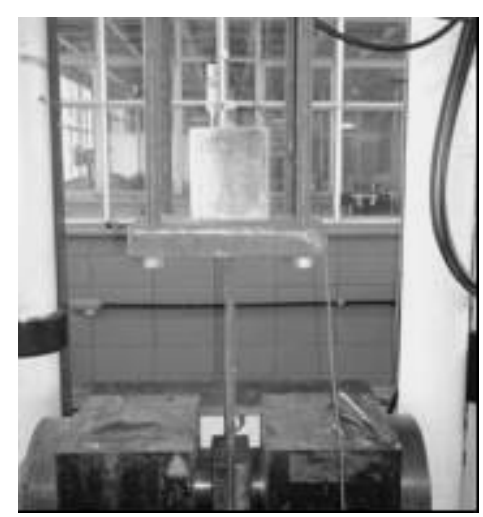

$\phi=16 \mathrm{~mm}$

Figura 5.16 Modelos de arrancamento em CC 
Todos os modelos de arrancamento, para ambos os diâmetros de barra, tiveram ruptura por arrancamento da barra de aço no prisma de concreto. Somente um dos modelos com barra de $16 \mathrm{~mm}$ apresentou ruptura por fendilhamento do prisma de concreto.

\subsubsection{Modelos em CAA}

Os modelos em CAA foram moldados após a verificação das propriedades de habilidade de passagem (ensaio da caixa-L), coesão (ensaio de espalhamento e funilV) e de fluidez (ensaio de espalhamento). A Tabela 5.5 mostra a composição do traço para o CAA utilizado na confecção dos modelos de arrancamento desta série.

Tabela 5.5 Composição do traço do CAA da série 1 e resultados do estado fresco

\begin{tabular}{lc}
\hline Material & Quant. (kg) \\
\hline Cimento & 338,8 \\
Água & 273,6 \\
Filler & 101,6 \\
Areia & 854,8 \\
Brita & 919,1 \\
Superplast. & $0,4 \%$ \\
V pasta & $35,0 \%$ \\
&
\end{tabular}

\begin{tabular}{lc}
\hline Ensaios & \\
\hline Espalhamento & \\
$\mathrm{T}_{50}(\mathrm{~s})=$ & 1,0 \\
$\mathrm{D}_{\text {esp. }}(\mathrm{cm})=$ & 67,5 \\
Caixa-L & \\
$\mathrm{T}_{60}(\mathrm{~s})=$ & 1,0 \\
$\mathrm{CB}=$ & 0,95 \\
Funil-V & \\
$\mathrm{T}_{\mathrm{v}}(\mathrm{s})=$ & 1,25 \\
\hline
\end{tabular}

Para esta etapa foram concretados três cp's para ensaio à compressão e três cp's para ensaio à tração, ambos com dimensões de $10 \times 20 \mathrm{~cm}$. Ainda, foram concretados mais três cp's de $10 \times 20 \mathrm{~cm}$ para ensaio de módulo de elasticidade longitudinal. A Figura 5.17 mostra o módulo de elasticidade longitudinal dos modelos em CAA da série 1.
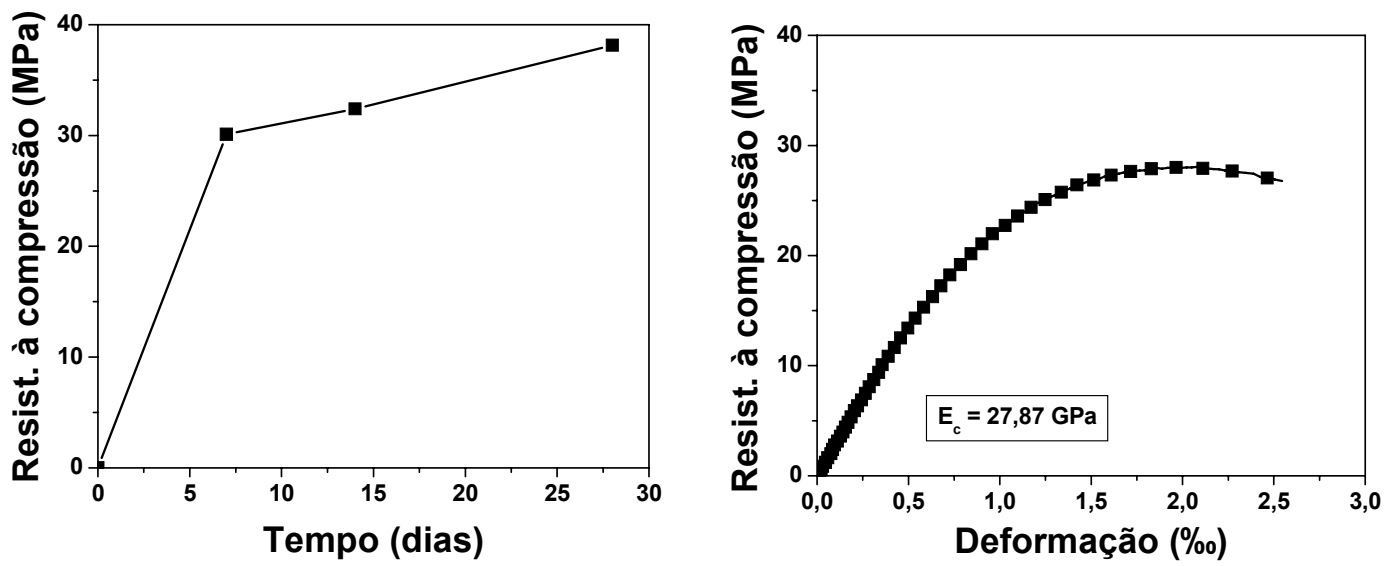

Figura 5.17 Módulo de elasticidade longitudinal para os modelos de referência da série 1 
A Tabela 5.17 ilustra as propriedades no estado endurecido para o CAA de 30 MPa. Vale salientar que conforme adequação às atividades do Laboratório de Estruturas, os ensaios foram realizados aos 7 dias.

Tabela 5.6 Propriedades do CAA aos 7 dias

\begin{tabular}{cccc}
\hline & Média (MPa) & D.P. (MPa) & C.V. \\
\hline $\mathbf{f}_{\mathrm{c}, 7}$ & 30,10 & 1,297 & $4,31 \%$ \\
$\mathbf{E}_{\mathrm{c}, 7}$ & 27873,00 & 775,40 & $2,78 \%$ \\
$\mathbf{f}_{\mathrm{ct}, \mathbf{s p}}$ & 2,45 & 0,61 & $24,88 \%$ \\
\hline
\end{tabular}

A Figura 5.18 mostra o comportamento do ensaio de arrancamento da série 1 em concreto auto-adensável.
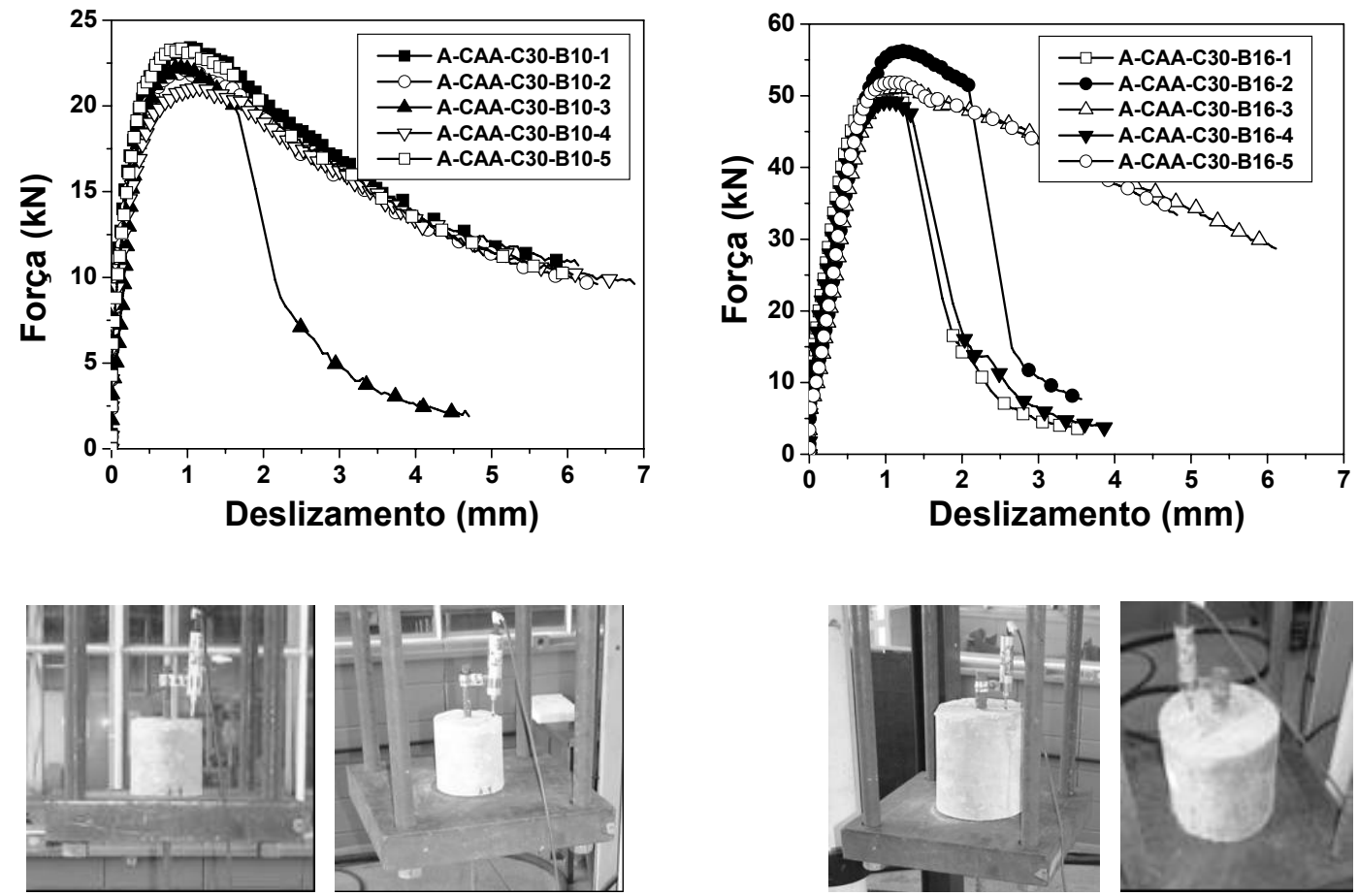

Figura 5.18 Comportamento dos modelos de arrancamento em CAA da série 1

Todos os modelos de arrancamento para ambos os diâmetros de barra tiveram ruptura por arrancamento da barra de aço no prisma de concreto, com exceção de três modelos com barra de $16 \mathrm{~mm}$, que apresentaram ruptura por fendilhamento do concreto (A-CAA-C30-B16-1 e 4).

A Figura 5.19 ilustra os modelos de arrancamento de barras com diâmetro da barra de aço de 10 e de $16 \mathrm{~mm}$. 


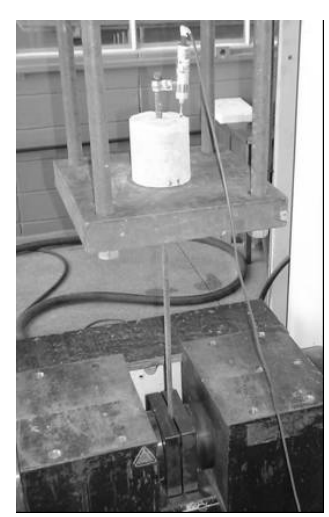

$\phi=10 \mathrm{~mm}$

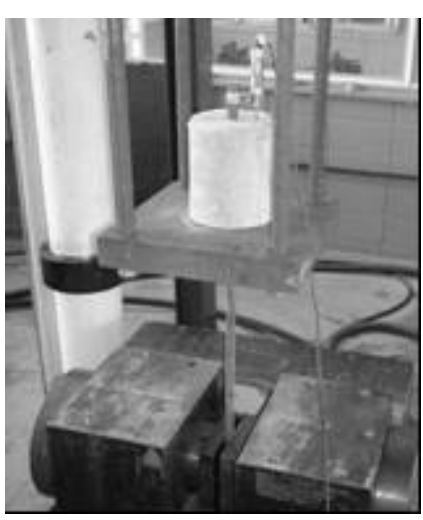

$\phi=16 \mathrm{~mm}$

Figura 5.19 Modelos de arrancamento em CAA ensaiados

\subsubsection{Série 2}

Aqui se apresentam os resultados referentes aos modelos de arrancamento em concreto convencional $(\mathrm{CC})$ e em concreto auto-adensável (CAA) com resistência à compressão de $60 \mathrm{MPa}$.

\subsubsection{Modelos em CC}

Os modelos de referência foram chamados de A-CC-C60-B10 e A-CC-C60-B16, onde A corresponde ao modelo de arrancamento, CC corresponde ao concreto convencional, C60 corresponde a classe de resistência à compressão do concreto (60 MPa) e B10 e B16, correspondem ao diâmetro da barra de 10 e 16 mm, respectivamente. A Tabela 5.7 mostra a composição do traço para o CC da série 2 .

Tabela 5.7 Composição do traço do CC da série 2

\begin{tabular}{lc}
\hline Material & Quant. (kg) \\
\hline Cimento & 488,3 \\
Água & 227,0 \\
Areia & 766,6 \\
Brita & 942,4 \\
\hline
\end{tabular}

\begin{tabular}{l}
\hline Ensaios \\
\hline Abatimento \\
$9 \mathrm{~cm}$ \\
\\
\hline
\end{tabular}

Com relação à resistência à tração diametral, foram ensaiados três cp's de $10 \times 20 \mathrm{~cm}$ na data ou no dia posterior do ensaio de arrancamento ou de viga juntamente com os ensaios de módulo de elasticidade longitudinal (três cp's). A Figura $5.20 \mathrm{~b}$ mostra o módulo de elasticidade longitudinal dos modelos de referência. 

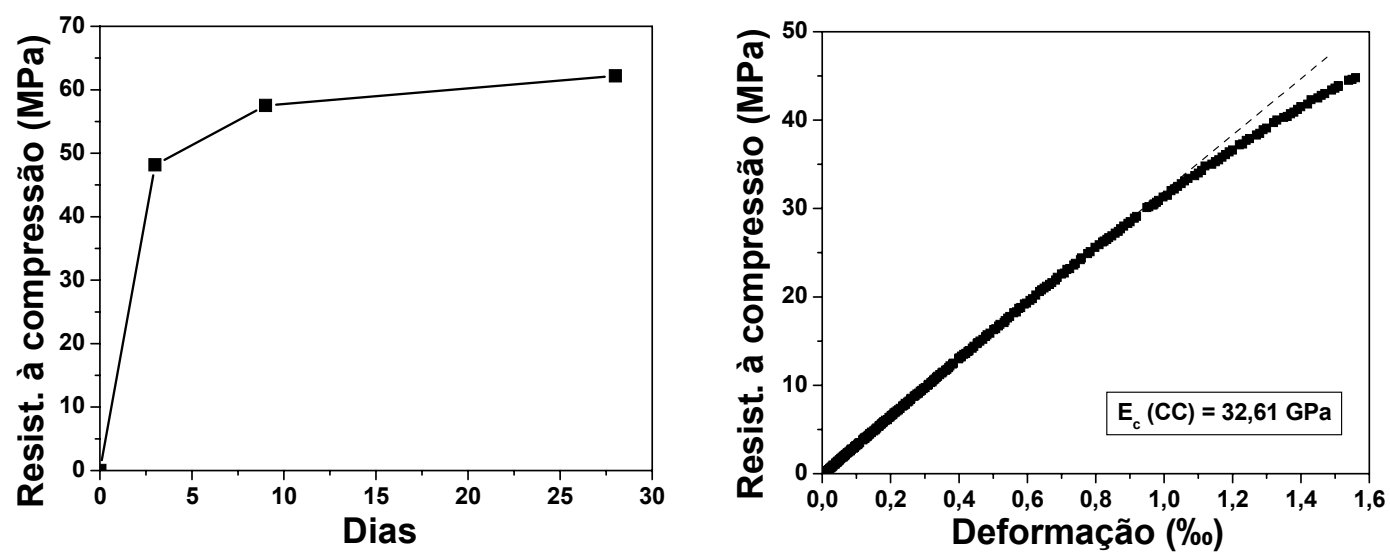

Figura 5.20 Variação da resistência à compressão e módulo de elasticidade longitudinal para os modelos de referência

A Tabela 5.8 ilustra as propriedades no estado endurecido para o CC de 60 MPa. Vale salientar que conforme adequação às atividades do Laboratório de Estruturas, os ensaios foram realizados aos 14 dias.

Tabela 5.8 Propriedades do CC aos 14 dias

\begin{tabular}{cccc}
\hline & Média (MPa) & D.P. (MPa) & C.V. \\
\hline $\mathbf{f}_{\mathbf{c}, 14}$ & 61,0 & 1,4 & $2,33 \%$ \\
$\mathbf{E}_{\mathbf{c}}$ & 32614,0 & 68,0 & $0,21 \%$ \\
$\mathbf{f}_{\mathrm{ct}, \mathbf{s p}}$ & 3,45 & 0,02 & $0,53 \%$ \\
$\mathbf{f}_{\mathrm{ct}, \mathrm{f}}$ & 4,82 & 0,16 & $3,27 \%$ \\
\hline
\end{tabular}

Onde, $\mathrm{f}_{\mathrm{ct}, \mathrm{sp}}$ é a resistência à tração indireta, $\mathrm{f}_{\mathrm{ct}, \mathrm{f}}$ é a resistência à tração na flexão, $E_{c}$ é o módulo de elasticidade longitudinal e $f_{c, 14}$ é a resistência à compressão do concreto aos 14 dias. A Figura 5.21 ilustra os modelos de arrancamento em CC.

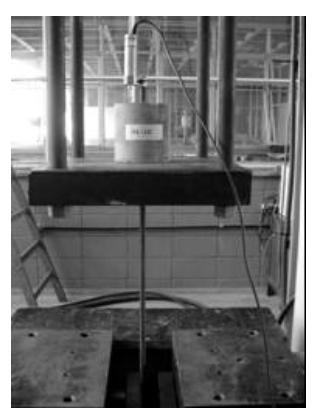

$\phi=10 \mathrm{~mm}$

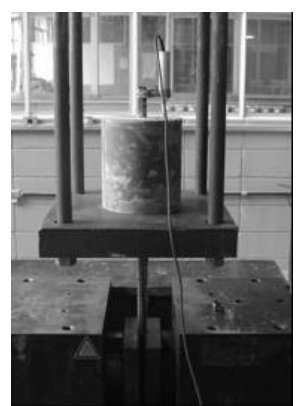

$\phi=16 \mathrm{~mm}$

Figura 5.21 Modelos de arrancamento com CC ensaiados

A Figura 5.22 ilustra o comportamento dos modelos de arrancamento. 

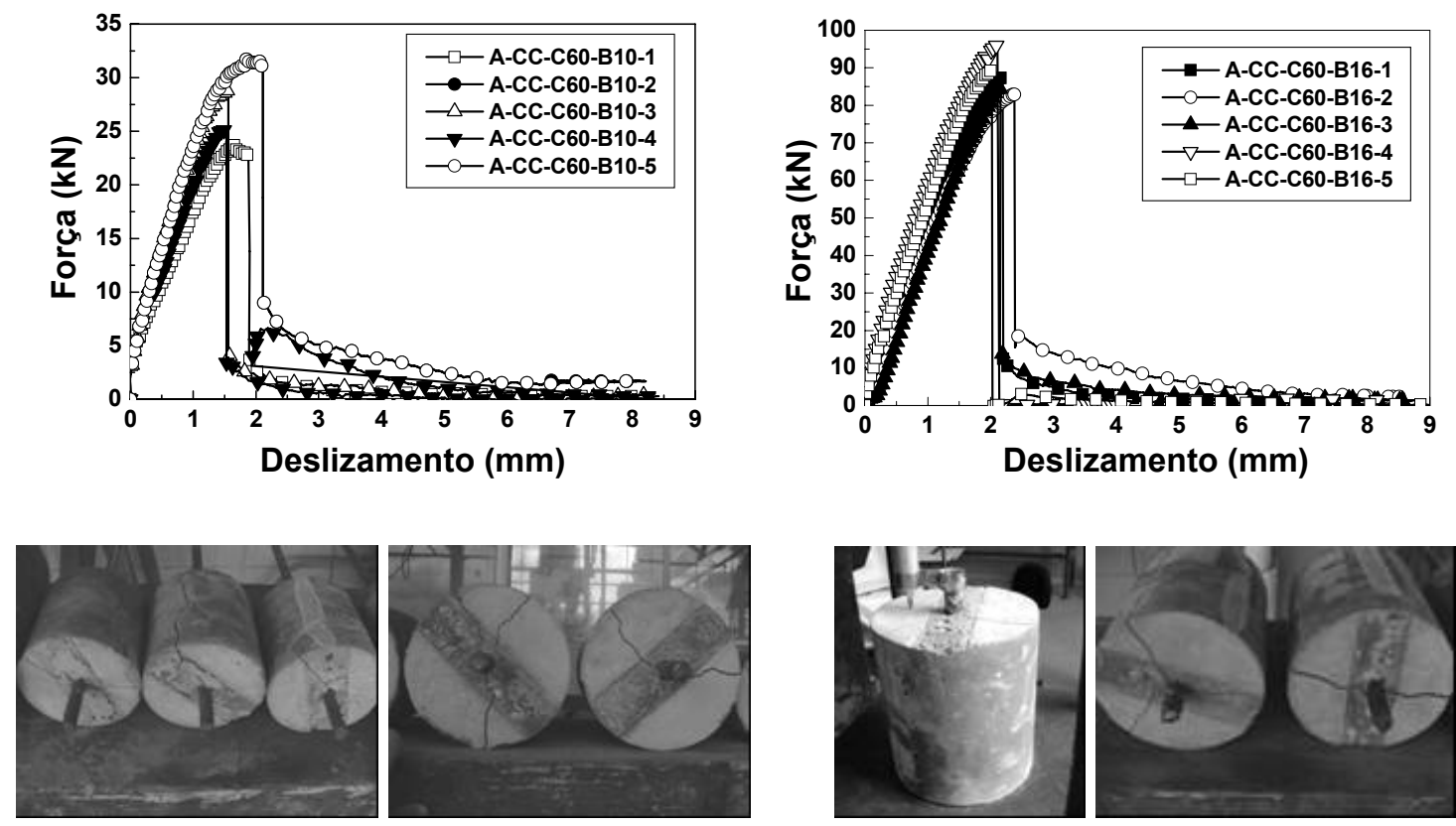

Figura 5.22 Comportamento dos modelos de arrancamento em CC da série 2

Todos os modelos de arrancamento, para ambos os diâmetros de barra, tiveram ruptura brusca por fendilhamento do concreto, por causa da alta resistência à compressão do concreto.

\subsubsection{Modelos em CAA}

Os modelos em CAA foram moldados após a verificação das propriedades de habilidade de passagem (ensaio da caixa L), coesão (ensaio de espalhamento) e de fluidez (ensaio de espalhamento).

A Tabela 5.9 mostra a composição do traço para o CAA utilizado na confecção dos modelos de arrancamento desta série.

Tabela 5.9 Composição do traço do CAA da série 2 e resultados do estado fresco

\begin{tabular}{lc}
\hline Material & Quant. (kg) \\
\hline Cimento & 368,6 \\
Água & 147,5 \\
Filler & 147,5 \\
Sílica ativa & 36,9 \\
Areia & 815,3 \\
Brita & 876,7 \\
Superplast. & $0,75 \%$ \\
V & $38,0 \%$ \\
\hline
\end{tabular}

\begin{tabular}{lc}
\hline Ensaios & \\
\hline Espalhamento & \\
$\mathrm{T}_{50}(\mathrm{~s})=$ & 1,0 \\
$\mathrm{D}_{\text {esp. }}(\mathrm{cm})=$ & 74,0 \\
Caixa-L & \\
$\mathrm{T}_{20}(\mathrm{~s})=$ & $<1,0$ \\
$\mathrm{~T}_{40}(\mathrm{~s})=$ & 1,0 \\
$\mathrm{CB}=$ & 0,85 \\
& \\
\hline
\end{tabular}


Com relação aos modelos de arrancamento, a aplicação de qualquer tipo de vibração deve ser evitada em concretos auto-adensáveis, pois esta pode acarretar a perda de $10 \%$ ou mais de resistência de aderência (Chan et al., 2003).

A Figura 5.23 ilustra a concretagem dos modelos de arrancamento. Para esta etapa foram concretados três cp's para ensaio à compressão e três cp's para ensaio à tração, ambos com dimensões de $10 \times 20 \mathrm{~cm}$. Além deles, foram concretados mais três cp's de 10x20 cm para ensaio de módulo de elasticidade longitudinal. Esses cp's foram ensaiados no dia do ensaio dos modelos de arrancamento.
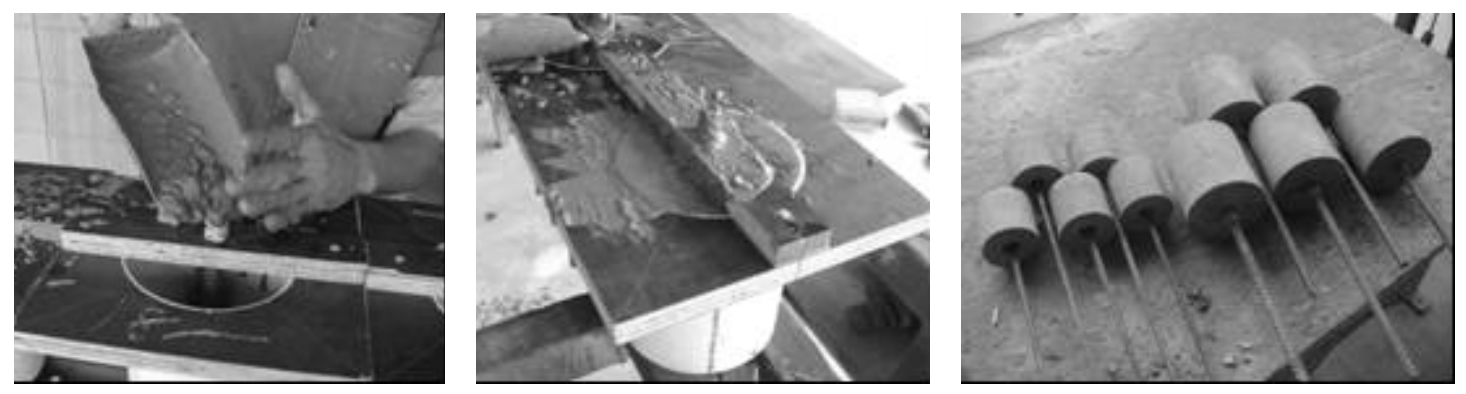

Figura 5.23 Concretagem dos modelos de arrancamento em CAA

Os modelos de referência foram chamados de A-CAA-C60-B10 e A-CAA-C60$\mathrm{B} 16$, onde A corresponde ao modelo de arrancamento, CAA corresponde ao concreto auto-adensável, C60 corresponde a classe de resistência à compressão do concreto (60 MPa) e B10 e B16, correspondem ao diâmetro da barra, 10 e 16 mm, respectivamente.

Durante a concretagem ilustrada na Figura 5.23 houve a preocupação em realizá-la em uma superfície plana e lisa, para prevenir desníveis que pudessem interferir nos resultados.

A Figura 5.24 ilustra os modelos de arrancamento de barras com diâmetro da barra de aço de 10 e de 16 mm para a resistência à compressão do concreto de 60 $\mathrm{MPa}$, respectivamente.

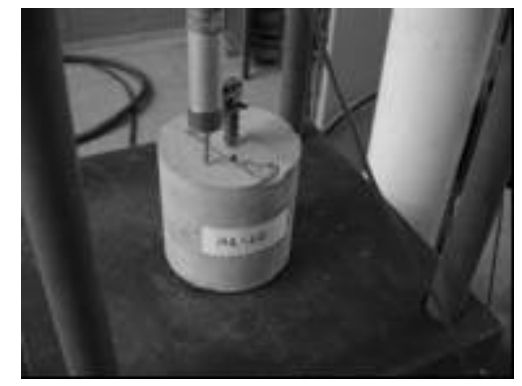

$\phi=10 \mathrm{~mm}$

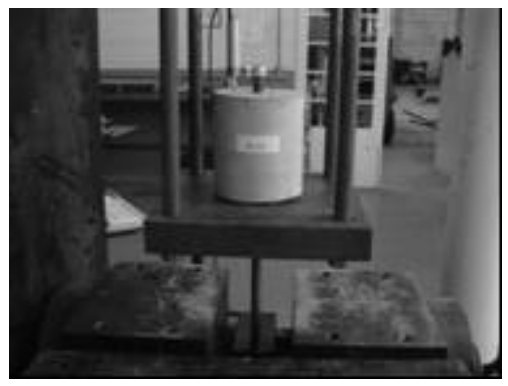

$\phi=16 \mathrm{~mm}$

Figura 5.24 Modelos de arrancamento em CAA ensaiados 
A Figura 5.25 ilustra a variação da resistência à compressão do CAA até a data do ensaio e o módulo de elasticidade longitudinal dos modelos em CAA.
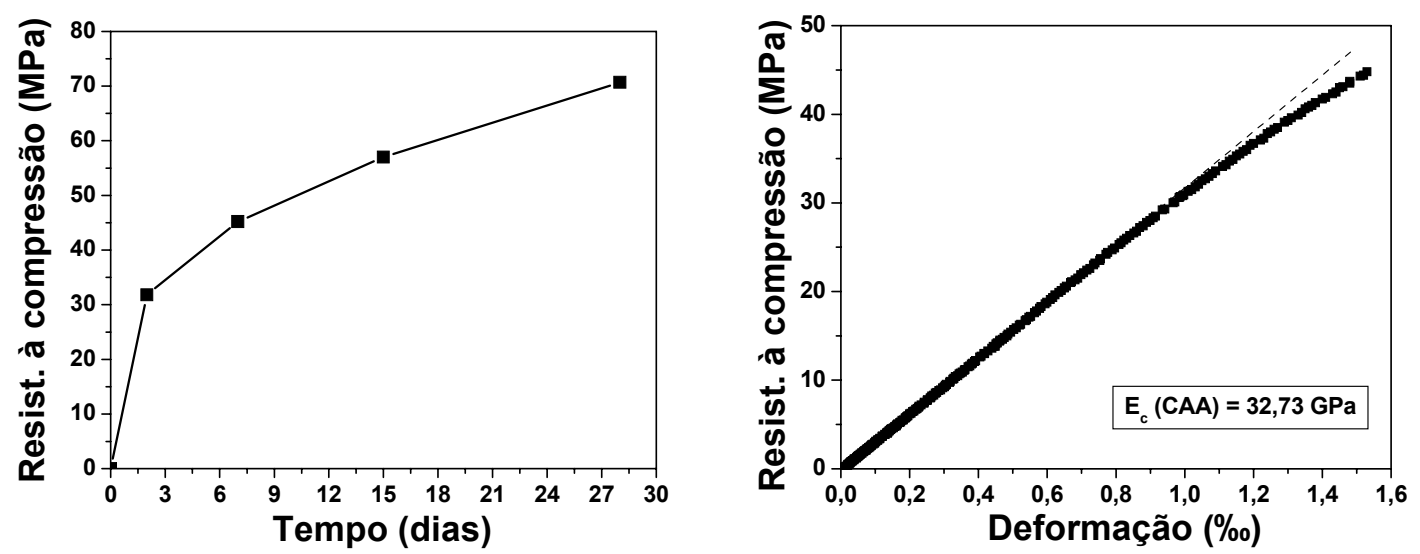

Figura 5.25 Variação da resistência à compressão e módulo de elasticidade longitudinal para os modelos em CAA

A Tabela 5.10 ilustra as propriedades no estado endurecido para o CAA de 60 MPa.

Tabela 5.10 Propriedades do CAA aos 15 dias

\begin{tabular}{cccc}
\hline & Média (MPa) & D.P. (MPa) & C.V. \\
\hline $\mathbf{f}_{\mathrm{c}, 15}$ & 57,0 & 2,1 & $3,72 \%$ \\
$\mathbf{E}_{\mathrm{c}}$ & 32728,0 & 522,6 & $1,61 \%$ \\
$\mathbf{f}_{\mathrm{ct}, \mathbf{s p}}$ & 3,71 & 0,36 & $9,91 \%$ \\
$\mathbf{f}_{\mathrm{ct}, \mathrm{f}}$ & 4,82 & 0,24 & $5,06 \%$ \\
\hline
\end{tabular}

Onde, $\mathrm{f}_{\mathrm{ct}, \mathrm{sp}}$ é a resistência à tração indireta, $\mathrm{f}_{\mathrm{ct}, \mathrm{f}}$ é a resistência à tração na flexão, $E_{c}$ é o módulo de elasticidade longitudinal e $f_{c, 15}$ é a resistência à compressão do concreto aos 15 dias.

A Figura 5.26 ilustra o comportamento dos modelos de arrancamento. 

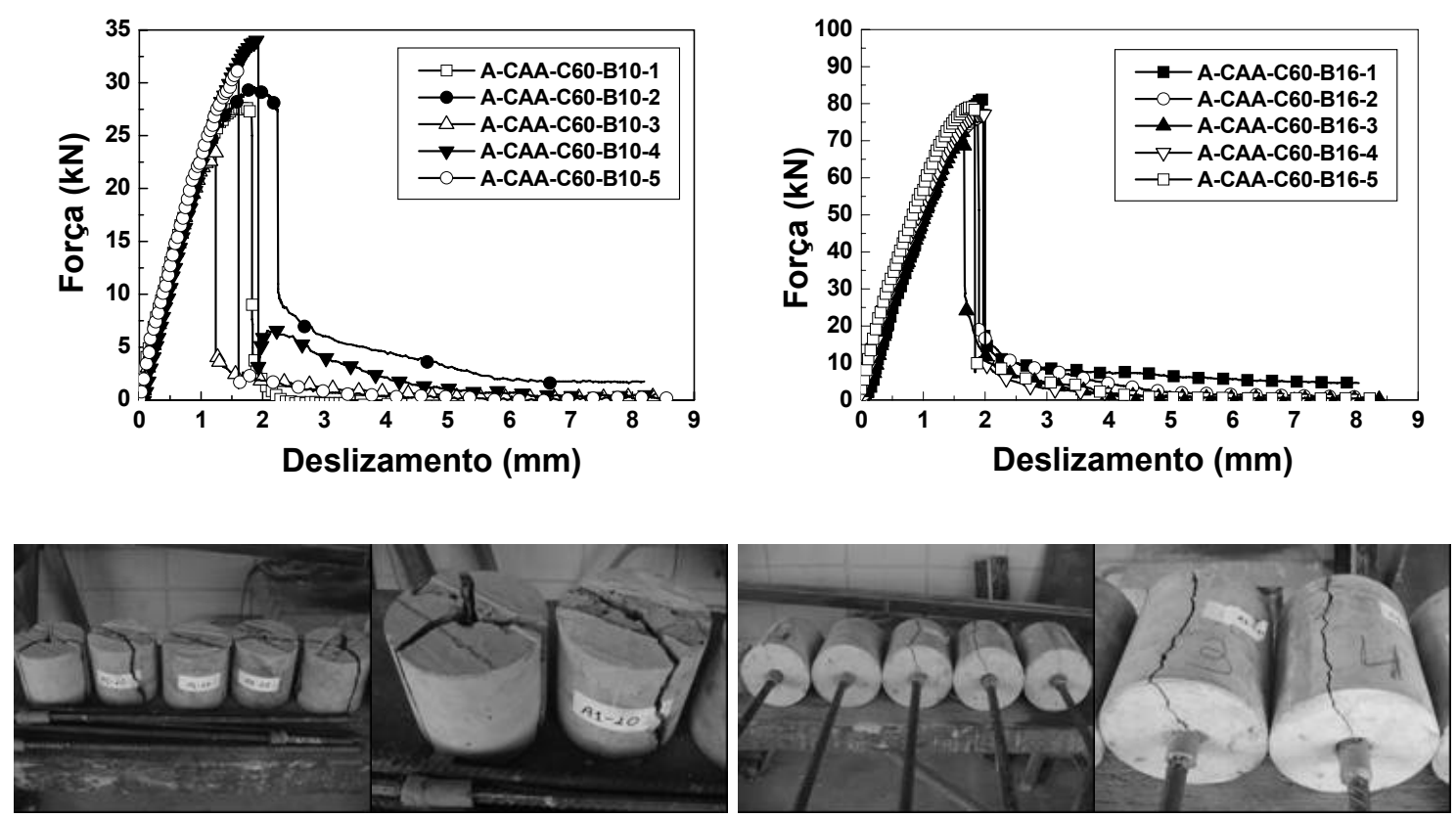

Figura 5.26 Comportamento dos modelos de arrancamento em CAA da série 2

Da mesma forma dos modelos de arrancamento com concreto convencional, todos os modelos de arrancamento em CAA, para ambos os diâmetros de barra, tiveram ruptura brusca por fendilhamento do concreto, por causa da alta resistência à compressão do concreto.

\subsubsection{Série complementar}

Aqui se apresentam os resultados referentes aos modelos de arrancamento em concreto auto-adensável (CAA) com resistência à compressão de $50 \mathrm{MPa}$ aos 7 dias e com elevada coesão.

Os modelos foram chamados de $\mathrm{A} 10, \mathrm{~A} 12,5$ e $\mathrm{A} 16$, onde $\mathrm{A}$ corresponde ao modelo de arrancamento e 10, 12,5 e 16 correspondem ao diâmetro da barra (em milímetros).

Do mesmo modo que nas séries anteriores de arrancamento, foi estabelecido uma quantidade de cinco amostras por modelo, isto é, foram ensaiados quinze modelos de arrancamento onde, cinco eram do modelo A10, cinco do modelo A12,5 e cinco do modelo A16.

Nesta série de ensaios, foi adotado um superplastificante baseado em cadeias de policarboxilatos, com o objetivo de se verificar sua influência no comportamento da resistência de aderência. O aditivo superplastificante utilizado foi o Glenuim $^{\circledR} 51$, baseado em cadeia de éter carboxílico modificado que permite, de acordo com o 
fabricante, a confecção de CAA para peças com altas taxas de armadura. A Tabela 5.11 mostra as características deste superplastificante.

Tabela 5.11 Dados técnicos do superplastificante Glenium ${ }^{\circledR} 51$

\begin{tabular}{lc}
\hline Função principal & Superplastificante de $\mathbf{3}^{\mathrm{a}}$ geração \\
\hline Base química & Policarboxilatos \\
Aspecto & Líquido viscoso \\
Cor & Marrom \\
Densidade & 1,067 à $1,107 \mathrm{~g} / \mathrm{cm}^{3}$ \\
pH & 5 à 7 \\
Conteúdo de sólidos & 28,5 à $31,5 \%$ \\
Viscosidade & 95 à $160 \mathrm{cps}$ \\
\hline
\end{tabular}

A Tabela 5.12 mostra a composição do traço para o CAA utilizado na confecção dos modelos de arrancamento desta série.

Tabela 5.12 Composição do traço do CAA da série complementar e resultados do estado fresco

\begin{tabular}{lc}
\hline Material & Quantidade (kg) \\
\hline Cimento & 373,0 \\
Água & 149,2 \\
Filler & 111,9 \\
Sílica ativa & 0 \\
Areia & 815,3 \\
Brita & 876,7 \\
Superplast. & $1,7 \%$ \\
Vpasta & $38 \%$ \\
\hline
\end{tabular}

\begin{tabular}{lc}
\hline Ensaios & \\
\hline Espalhamento & \\
$\mathrm{T}_{50}(\mathrm{~s})=$ & 2,5 \\
$\mathrm{D}_{\text {esp. }}(\mathrm{cm})=$ & 69,5 \\
Caixa-L & \\
$\mathrm{T}_{40}(\mathrm{~s})=$ & 5,0 \\
$\mathrm{CB}=$ & 0,8 \\
Funil-V & \\
$\mathrm{T}_{\mathrm{v}}(\mathrm{s})=$ & 17,5 \\
\hline
\end{tabular}

A Figura 5.27 ilustra os modelos de arrancamento de barras com diâmetro da barra de aço de 10 , de 12,5 e de 16 mm para a resistência à compressão do concreto de $50 \mathrm{MPa}$, respectivamente.

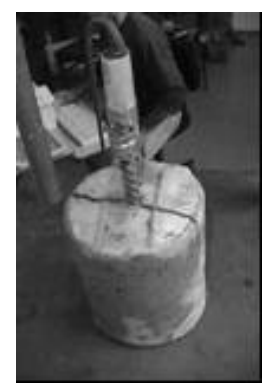

$\phi=10 \mathrm{~mm}$

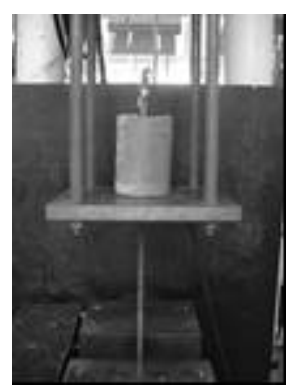

$\phi=12,5 \mathrm{~mm}$

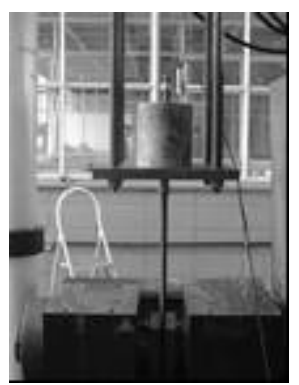

$\phi=16 \mathrm{~mm}$

Figura 5.27 Modelos de arrancamento da série complementar

A Tabela 5.13 ilustra as propriedades no estado endurecido para o CAA de 50 $\mathrm{MPa}$. 
Tabela 5.13 Propriedades do CAA aos 7 dias

\begin{tabular}{cccc}
\hline & Média (MPa) & D.P. (MPa) & C.V. \\
\hline $\mathbf{f}_{\mathrm{c}, 7}$ & 53,0 & 1,86 & $3,51 \%$ \\
$\mathbf{E}_{\mathbf{c}}$ & 34621,84 & 475,36 & $1,37 \%$ \\
$\mathbf{f}_{\mathrm{ct}, \mathbf{s p}, 7}$ & 3,07 & 0,13 & $4,35 \%$ \\
\hline
\end{tabular}

Onde, $\mathrm{f}_{\mathrm{ct}, \mathrm{sp}}$ é a resistência à tração indireta aos 7 dias, $E_{c}$ é o módulo de elasticidade longitudinal e $\mathrm{f}_{\mathrm{c}, 7}$ é a resistência à compressão do concreto aos 7 dias.

A Figura 5.28 ilustra o comportamento dos modelos de arrancamento.
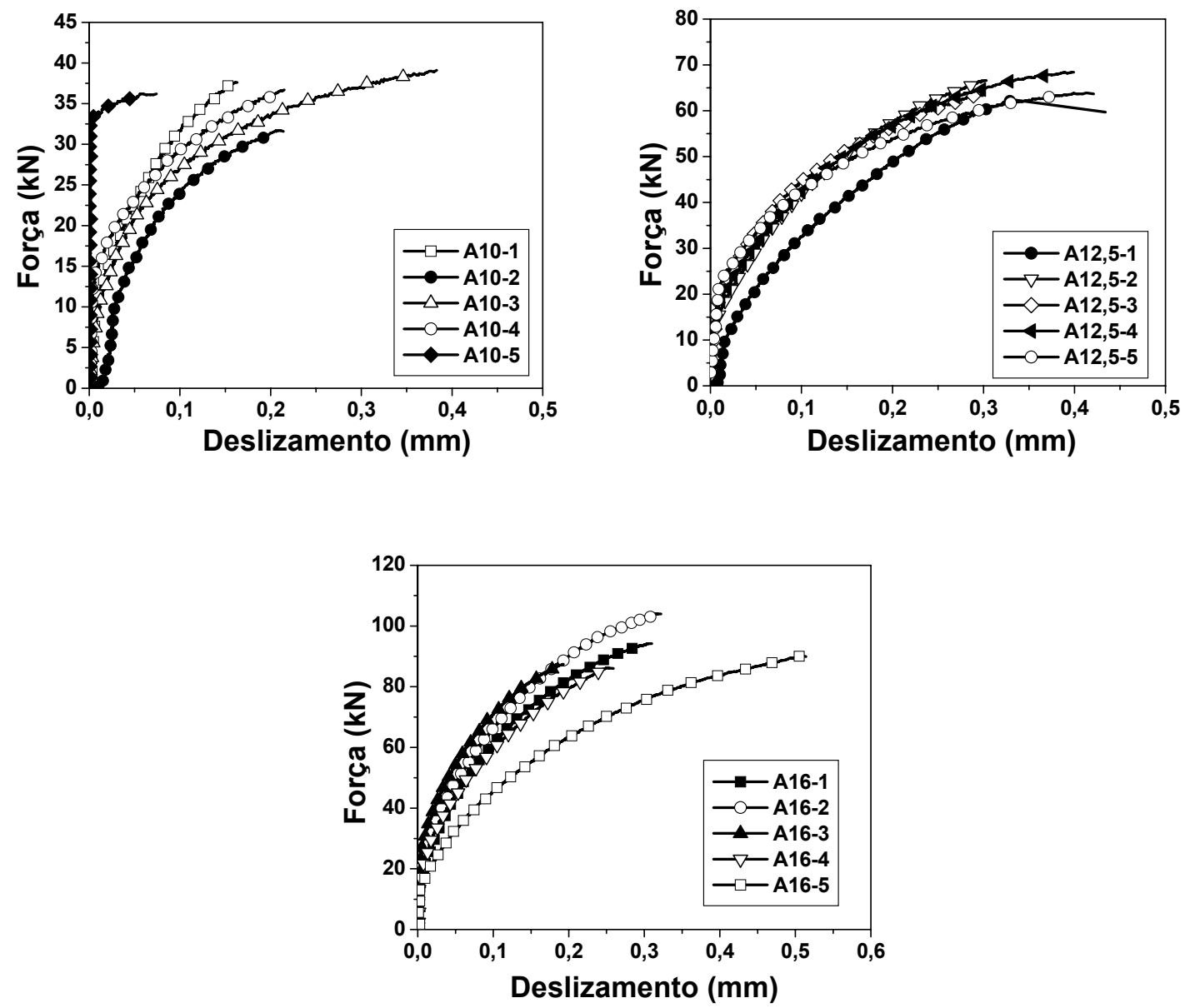

Figura 5.28 Resultados dos modelos de arrancamento da série complementar

A Figura 5.29 ilustra o comportamento do CAA da série complementar. 


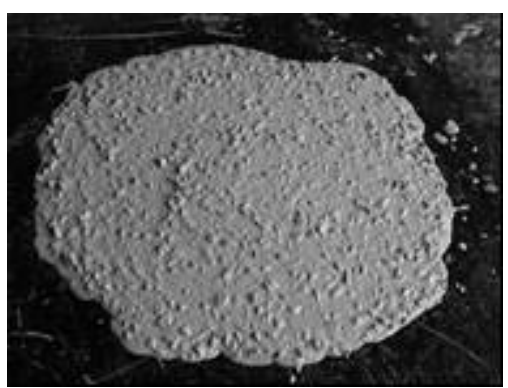

a) Espalhamento

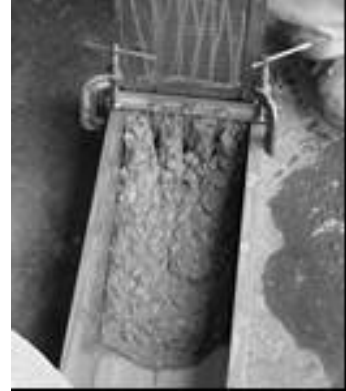

b) Caixa-L

Figura 5.29 Ensaios de espalhamento e de caixa-L da série complementar

A Figura 5.30 mostra o modo de ruptura dos modelos de arrancamento da série complementar.
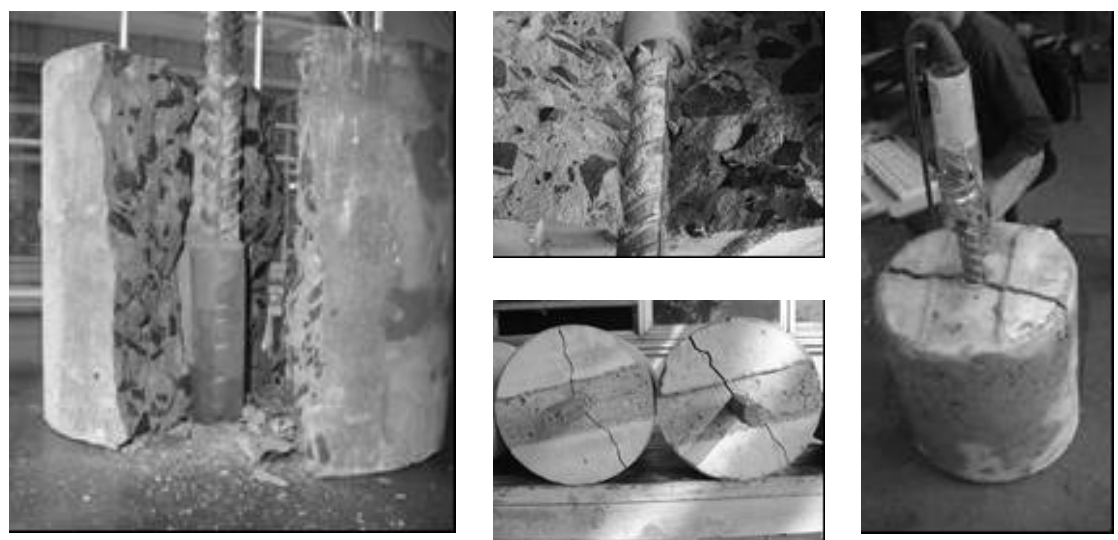

Figura 5.30 Modo de ruptura dos modelos de arrancamento da série complementar

Da mesma forma que nos modelos da série 2 , todos os modelos de arrancamento da série complementar apresentaram ruptura brusca por fendilhamento do concreto.

\subsection{Modelos de viga}

Da mesma forma que nos modelos de arrancamento, os modelos de viga foram divididos com base em sua resistência à compressão e o diâmetro da barra de aço utilizada.

Vale salientar que a quantidade de repetições para cada modelo de viga foi reduzido de quatro réplicas para uma em função das atividades no Laboratório de Estruturas. 


\subsubsection{Série 1}

Aqui se apresentam os resultados referentes aos modelos de arrancamento em concreto convencional (CC) e em concreto auto-adensável (CAA) com resistência à compressão de $30 \mathrm{MPa}$ aos 7 dias.

\subsubsection{Modelos em CC}

Os modelos de referência foram chamados de V-CC-C60-B10 e V-CC-C30-B16, onde $\mathrm{V}$ corresponde ao modelo de viga, CC corresponde ao concreto convencional, C30 corresponde a classe de resistência à compressão do concreto (30 MPa) e B10 e B16, correspondem ao diâmetro da barra de 10 e 16 mm, respectivamente.

A Tabela 5.3 mostra a composição do traço para o concreto convencional com resistência à compressão de $30 \mathrm{MPa}$.

Tabela 5.14 Composição do traço do CC da série 1

\begin{tabular}{lc}
\hline Material & Quant. (kg) \\
\hline Cimento & 365,3 \\
Água & 260,8 \\
Areia & 883,9 \\
Brita & 942,3 \\
\hline
\end{tabular}

\begin{tabular}{l}
\hline Ensaios \\
\hline Abatimento \\
$24,0 \mathrm{~cm}$ \\
\hline
\end{tabular}

Para esta etapa foram concretados três cp's para ensaio à compressão e três cp's para ensaio à tração, ambos com dimensões de $10 \times 20 \mathrm{~cm}$. Ainda, foram concretados mais três cp's de $10 \times 20 \mathrm{~cm}$ para ensaio de módulo de elasticidade longitudinal. A Figura 5.31 mostra o módulo de elasticidade longitudinal dos modelos de referência da série 1 .

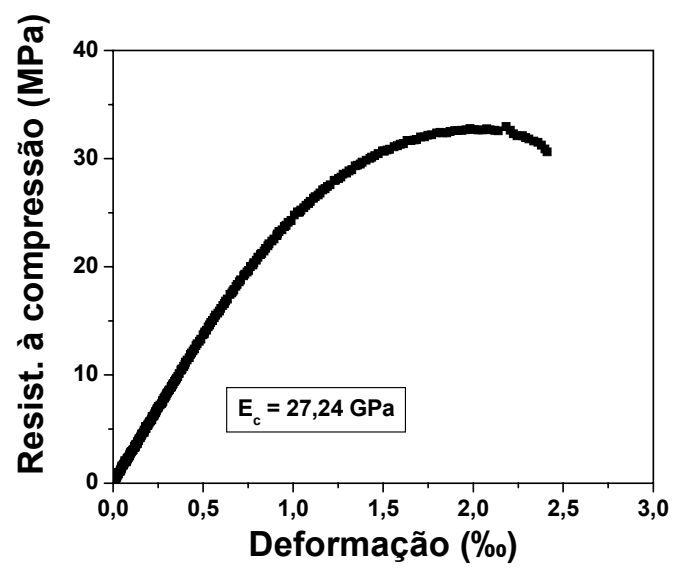

Figura 5.31 Módulo de elasticidade longitudinal para os modelos de referência da série 1 
A Tabela 5.4 ilustra as propriedades no estado endurecido para o CC de 30 MPa. Vale salientar que conforme adequação às atividades do Laboratório de Estruturas, os ensaios foram realizados aos 7 dias.

Tabela 5.15 Propriedades do CC aos 7 dias

\begin{tabular}{cccc}
\hline & Média (MPa) & D.P. (MPa) & C.V. \\
\hline $\mathbf{f}_{\mathrm{c}, 7}$ & 32,02 & 0,70 & $2,19 \%$ \\
$\mathbf{E}_{\mathrm{c}, 7}$ & 27237,00 & 631,00 & $2,32 \%$ \\
$\mathbf{f}_{\mathrm{ct}, \mathbf{s p}, 7}$ & 2,182 & 0,35 & $16,04 \%$ \\
\hline
\end{tabular}

Onde, $\mathrm{f}_{\mathrm{ct}, \mathrm{sp}, 7}$ é a resistência à tração indireta, $\mathrm{E}_{\mathrm{c}, 7}$ é o módulo de elasticidade longitudinal e $\mathrm{f}_{\mathrm{c}, 7}$ é a resistência à compressão do concreto, todos ensaiados aos 7 dias.

A Figura 5.32 ilustra os modelos de viga em CC.

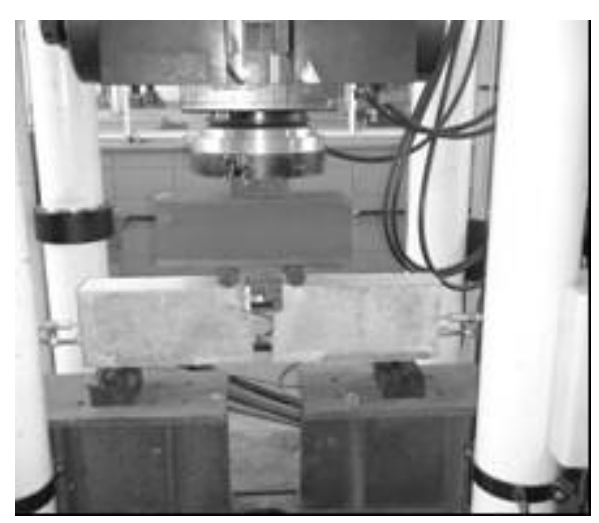

$\phi=10 \mathrm{~mm}$

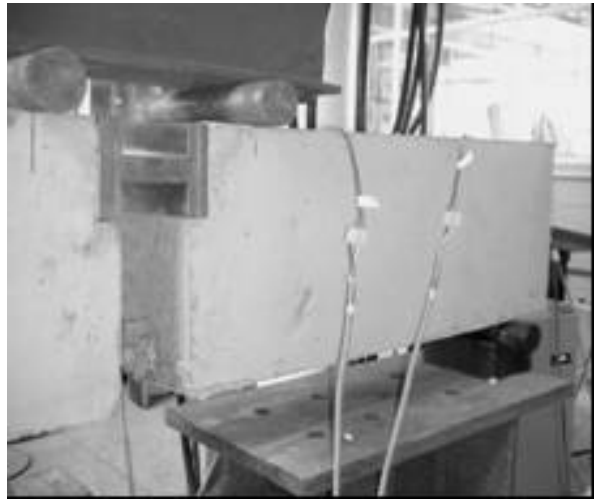

$\phi=16 \mathrm{~mm}$

Figura 5.32 Modelos de viga em CC ensaiados

A Figura 5.33 ilustra o comportamento dos modelos de viga.
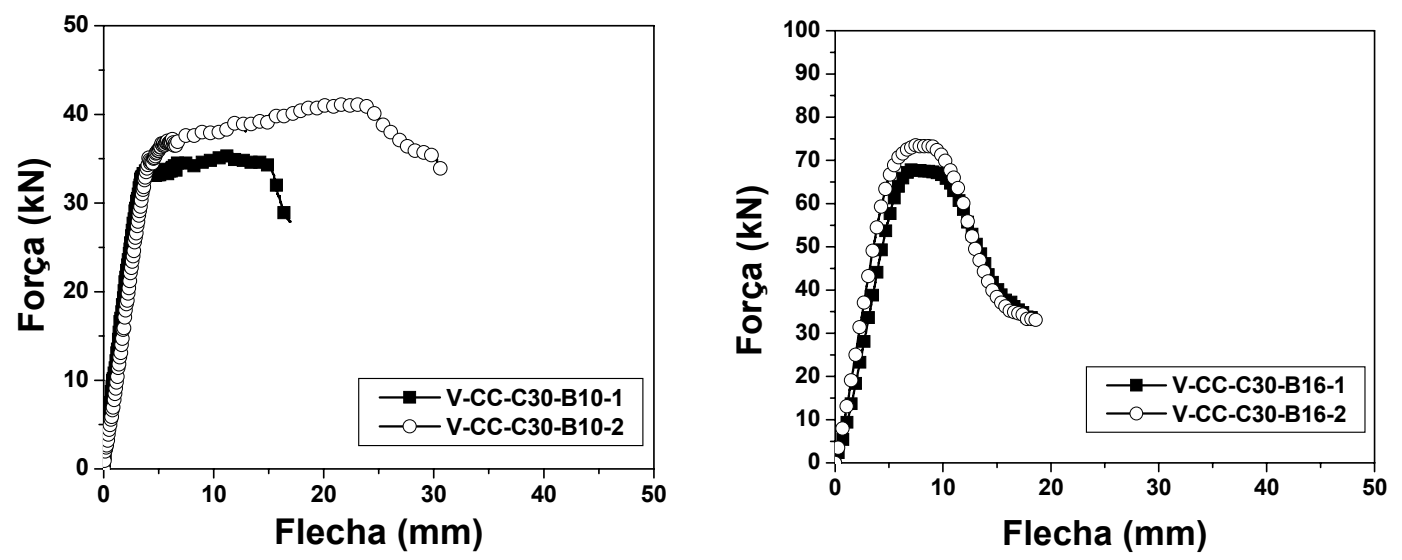

Figura 5.33 Comportamento dos modelos de viga em CC da série 1 
A Figura 5.34 mostra o comportamento do deslizamento da barra de aço e a correspondente resistência de aderência.
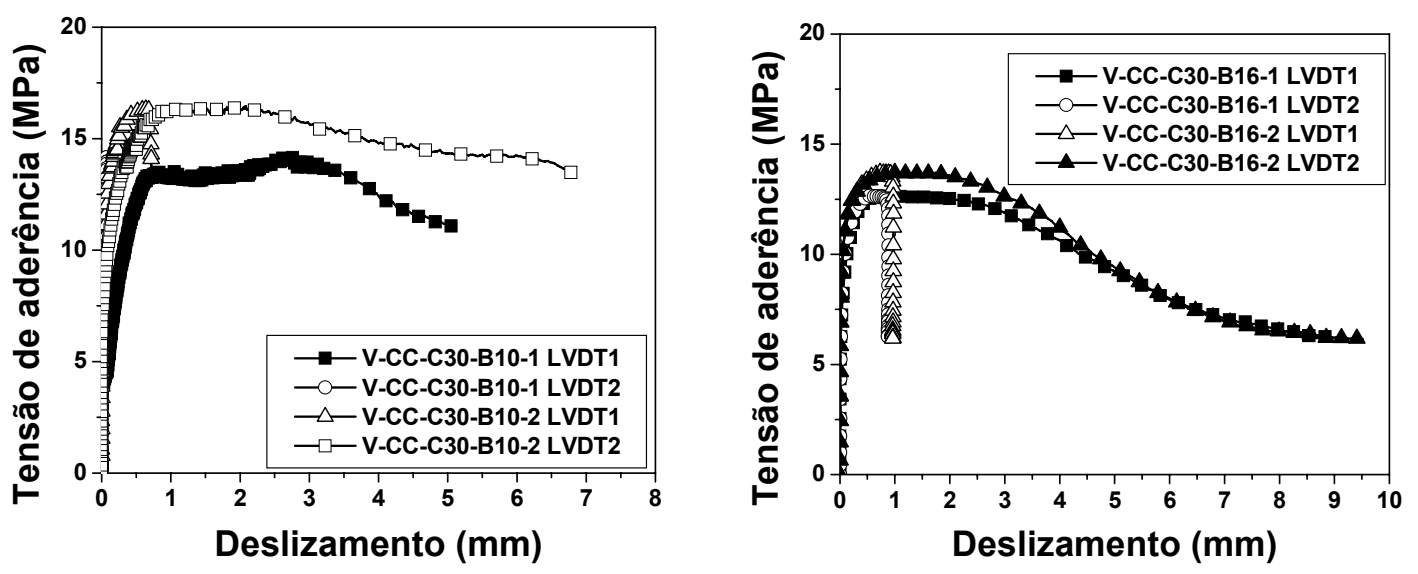

Figura 5.34 Resistência de aderência vs. Deslizamento dos LVDT's dos modelos de viga em CC da série 1

De acordo com a Figura 5.34, houve grande deslizamento da barra de aço corroborando os resultados obtidos nos ensaios de arrancamento. Entretanto, o comportamento das vigas com barra de $10 \mathrm{~mm}$ foi atípico, pois era de se esperar que houvesse grandes deslizamentos com pequenas deformações, fato que não ocorreu conforme a Figura 5.33, Figura 5.34 e Figura 5.35. Esse fato ocorreu em virtude de uma falha no correto posicionamento e manipulação da rótula presente no ensaio que em um dado instante houve uma restrição à sua rotação, favorecendo assim para um mecanismo resistente diferente da rótula. Sendo assim, os resultados para a viga com barra de $10 \mathrm{~mm}$ foram considerados até o instante da força máxima aplicada.

A Figura 5.35 mostra o comportamento dos extensômetros elétricos de resistência posicionados nos modelos de viga com barra de 10 e 16 mm.
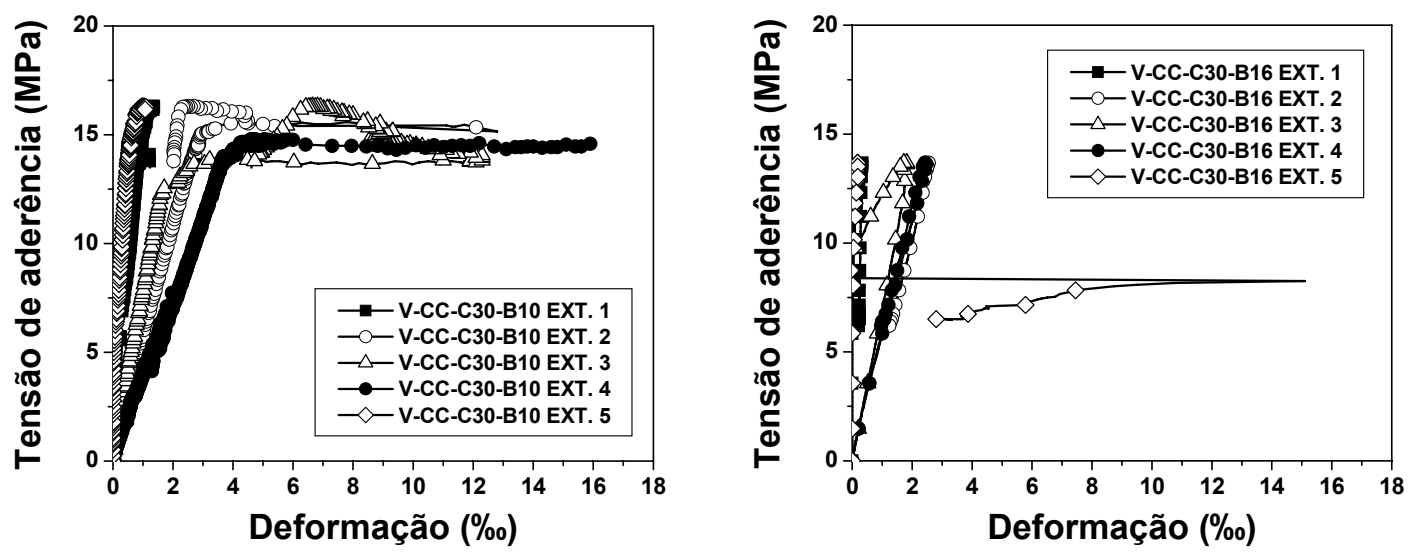

Figura 5.35 Comportamento dos modelos de viga com extensômetros em CC da série 1 
De acordo com a Figura 5.35, a variação das deformações na barra de aço se concentra nos extensômetros elétricos de resistência 2, 3 e 4. A Figura 5.36 mostra os modelos de viga com barra de $10 \mathrm{~mm}$ após o ensaio, onde a ruptura se caracterizou pelo fendilhamento do cobrimento do concreto na zona entre os extensômetros 2 e 4.
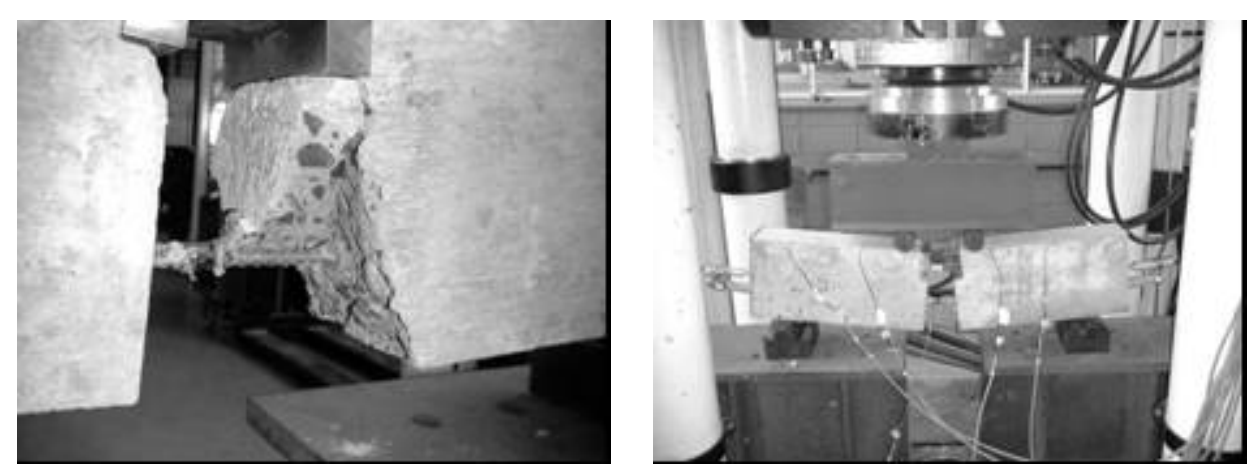

Figura 5.36 Modo de ruptura do modelo de viga com barra de $10 \mathrm{~mm}$ em CC da série 1

Isso representa que o deslocamento excessivo da viga, combinado com o escoamento da barra de aço, conduzissem ao esmagamento do concreto no trecho entre a barra e a rótula. A Figura 5.37 mostra os modelos de viga com barra de $16 \mathrm{~mm}$ após a ruptura.
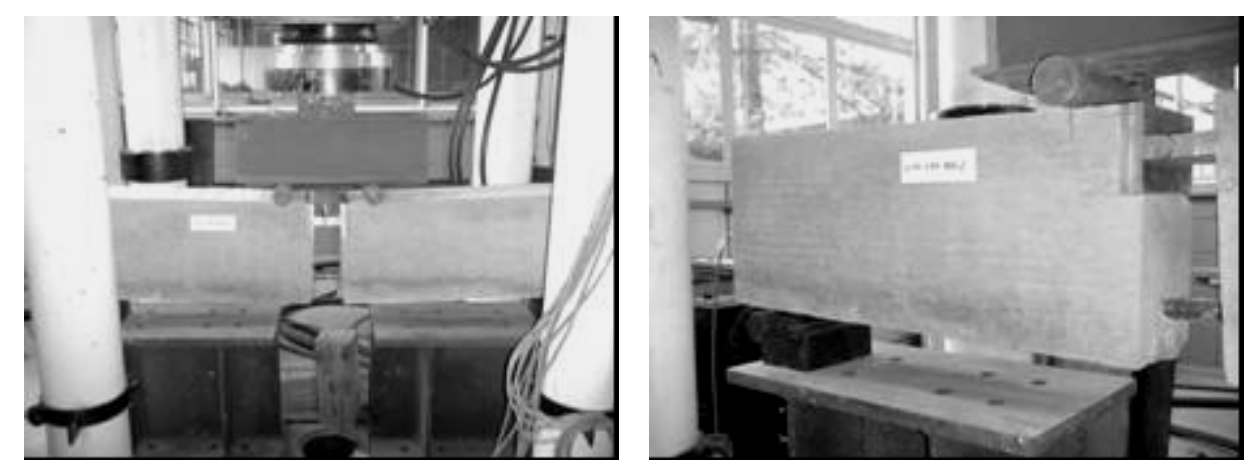

Figura 5.37 Modo de ruptura do modelo de viga com barra de $16 \mathrm{~mm}$ em CC da série 1

Os modelos com barra de $16 \mathrm{~mm}$ não apresentaram ruptura do cobrimento na zona entre os extensômetros 2 e 4 por causa dos valores de deslizamento obtidos para a barra de aço, mostrando que o mecanismo de ruptura da aderência açoconcreto se deu por deslizamento da barra de aço e não por escoamento da barra, que era esperado. 


\subsubsection{Modelos em CAA}

Os modelos em CAA foram chamados de V-CAA-C30-B10 e V-CAA-C30-B16, onde $\mathrm{V}$ corresponde ao modelo de viga, CAA corresponde ao concreto autoadensável, C30 corresponde a classe de resistência à compressão do concreto (30 MPa) e B10 e B16, correspondem ao diâmetro da barra de 10 e 16 mm, respectivamente.

A Tabela 5.16 mostra a composição do traço para o concreto auto-adensável com resistência à compressão de $30 \mathrm{MPa}$.

Tabela 5.16 Composição do traço do CAA da série 1

\begin{tabular}{lc}
\hline Material & Quant. (kg) \\
\hline Cimento & 338,8 \\
Água & 273,6 \\
Filler & 101,6 \\
Areia & 854,7 \\
Brita & 919,1 \\
Superplast. & $0,4 \%$ \\
V $_{\text {pasta }}$ & $35,0 \%$ \\
\hline
\end{tabular}

\begin{tabular}{lc}
\hline Ensaios & \\
\hline Espalhamento & \\
$\mathrm{T}_{50}(\mathrm{~s})=$ & 1,0 \\
$\mathrm{D}_{\text {esp. }}(\mathrm{cm})=$ & 67,5 \\
Caixa-L & \\
$\mathrm{T}_{60}(\mathrm{~s})=$ & 1,0 \\
$\mathrm{CB}=$ & 0,95 \\
Funil-V & \\
$\mathrm{T}_{\mathrm{v}}(\mathrm{s})=$ & 1,5 \\
\hline
\end{tabular}

Para esta etapa foram concretados três cp's para ensaio à compressão e três cp's para ensaio à tração, ambos com dimensões de $10 \times 20 \mathrm{~cm}$. Ainda, foram concretados mais três cp's de $10 \times 20 \mathrm{~cm}$ para ensaio de módulo de elasticidade longitudinal. A Figura 5.38 mostra o módulo de elasticidade longitudinal dos modelos em CAA da série 1.

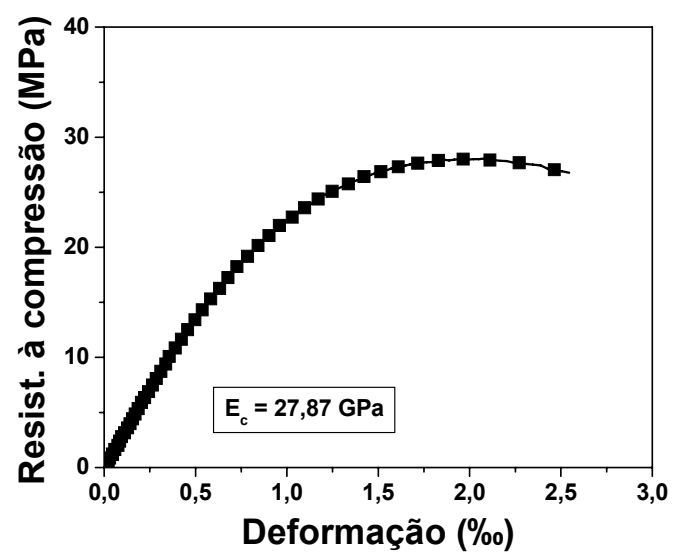

Figura 5.38 Módulo de elasticidade longitudinal para os modelos em CAA da série 1

A Tabela 5.17 ilustra as propriedades no estado endurecido para o CAA de 30 MPa. Vale salientar que conforme adequação às atividades do Laboratório de Estruturas, os ensaios foram realizados aos 7 dias. 
Tabela 5.17 Propriedades do CAA aos 7 dias

\begin{tabular}{cccc}
\hline & Média (MPa) & D.P. (MPa) & C.V. \\
\hline $\mathbf{f}_{\mathbf{c}, 7}$ & 30,10 & 1,297 & $4,31 \%$ \\
$\mathbf{E}_{\mathrm{c}, 7}$ & 27873,00 & 775,40 & $2,78 \%$ \\
$\mathbf{f}_{\mathrm{ct}, \mathbf{s p}, 7}$ & 2,45 & 0,61 & $24,88 \%$ \\
\hline
\end{tabular}

Onde, $\mathrm{f}_{\mathrm{ct}, \mathrm{sp}, 7}$ é a resistência à tração indireta, $\mathrm{E}_{\mathrm{c}, 7}$ é o módulo de elasticidade longitudinal e $\mathrm{f}_{\mathrm{c}, 7}$ é a resistência à compressão do concreto, todos ensaiados aos 7 dias.

A Figura 5.39 ilustra os modelos de viga em CAA.

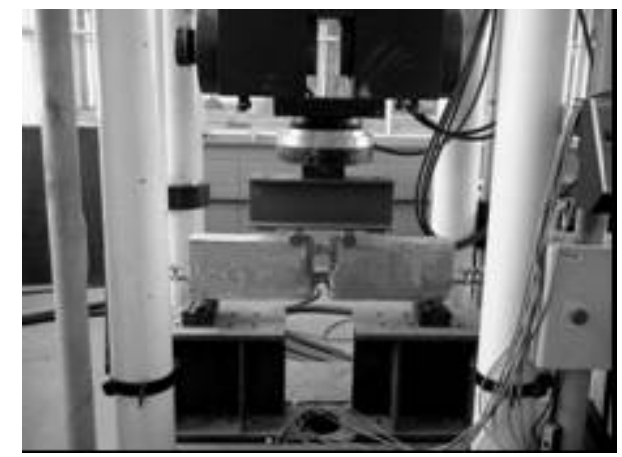

$\phi=10 \mathrm{~mm}$

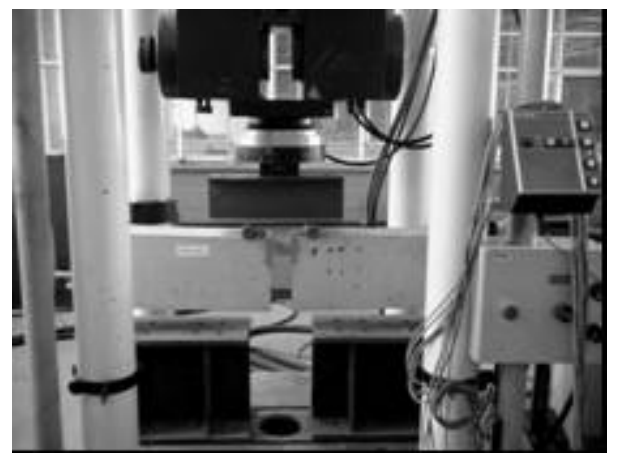

$\phi=16 \mathrm{~mm}$

Figura 5.39 Modelos de viga em CAA ensaiados

A Figura 5.40 ilustra o comportamento dos modelos de viga.
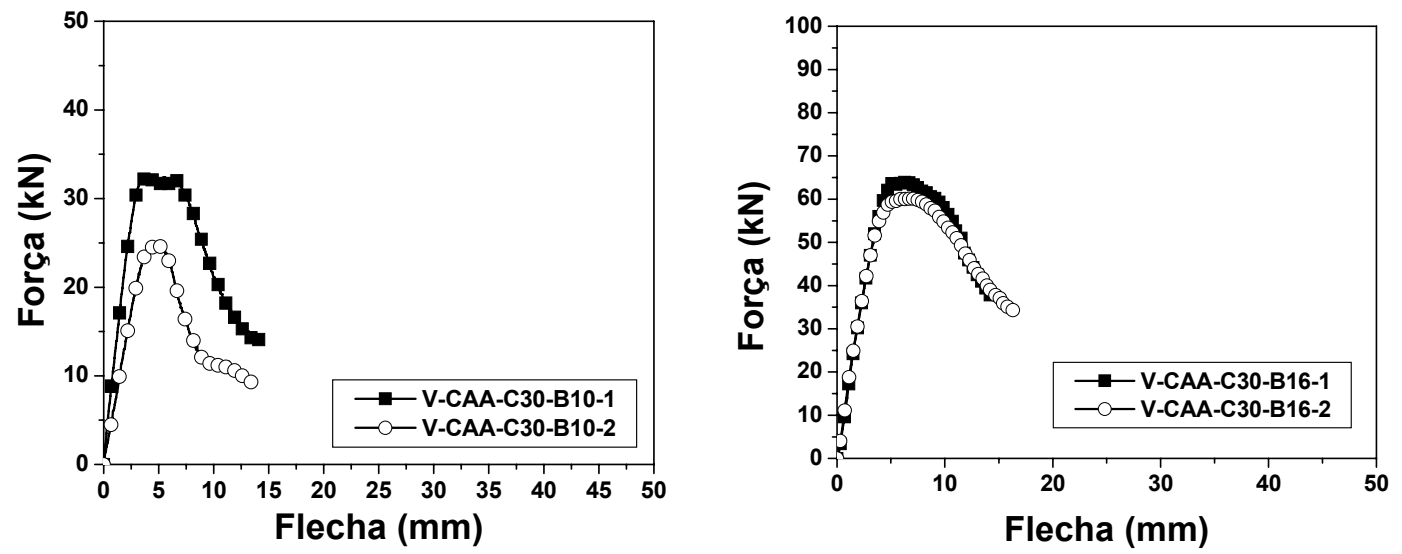

Figura 5.40 Comportamento dos modelos de viga em CAA da série 1

A Figura 5.41 mostra o comportamento do deslizamento da barra de aço e a correspondente resistência de aderência. 

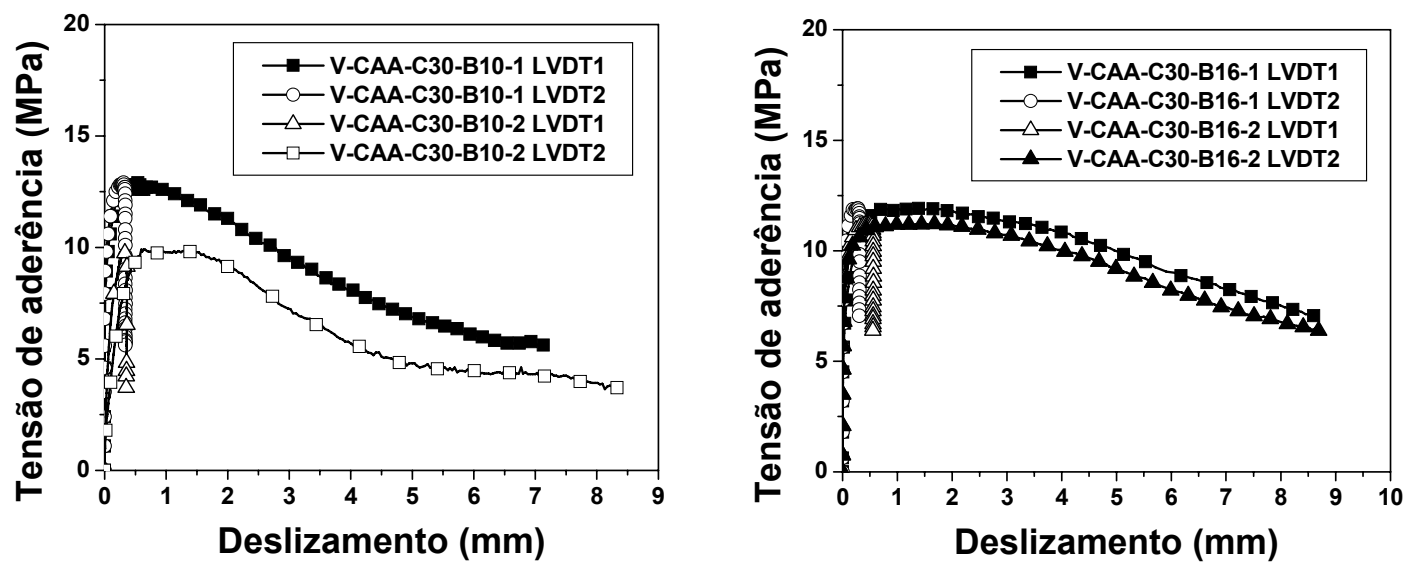

Figura 5.41 Resistência de aderência vs. deslizamento dos LVDT's dos modelos de viga em CAA da série 1

De acordo com a Figura 5.41, houve grande deslizamento da barra de aço corroborando os resultados obtidos nos ensaios de arrancamento.

A Figura 5.42 mostra o comportamento dos extensômetros elétricos de resistência posicionados nos modelos de viga com barra de 10 e $16 \mathrm{~mm}$.
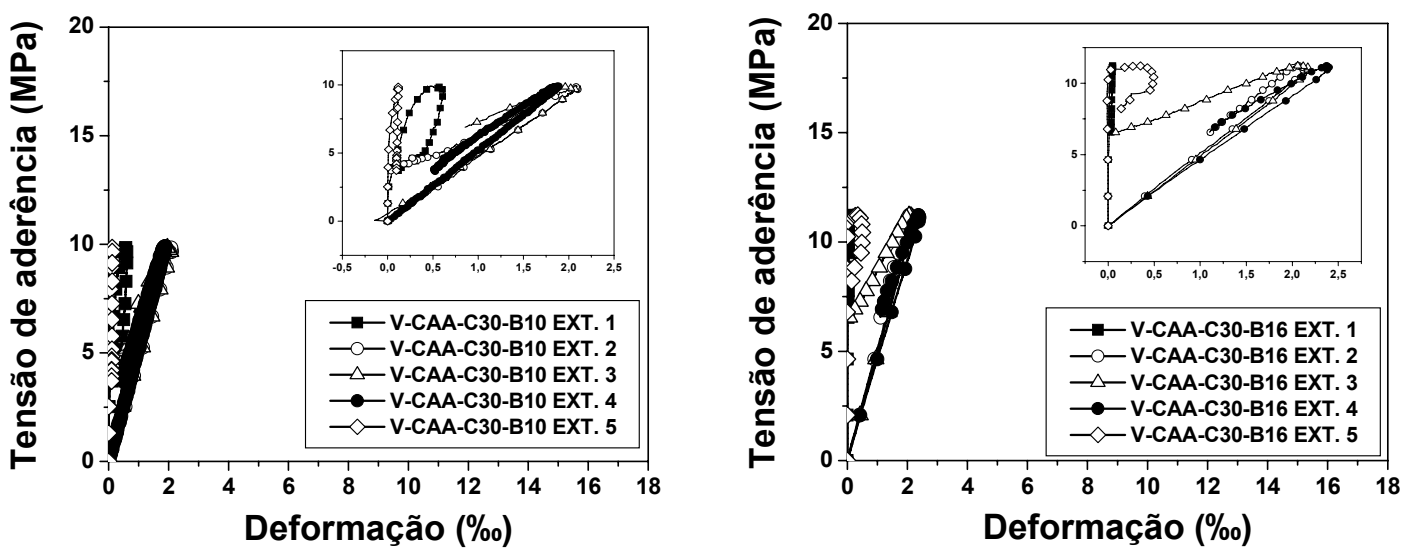

Figura 5.42 Comportamento dos modelos de viga com extensômetros em CAA da série 1

Da mesma forma que nos modelos de viga moldados com concreto convencional, a variação das deformações na barra de aço se concentra nos extensômetros elétricos de resistência 2, 3 e 4. Entretanto, o valor das deformações é pequeno e a ruptura foi caracterizado pelo deslizamento da barra de aço na viga.

A Figura 5.42 mostra os modelos de viga em CAA da série 1 após a ruptura. 

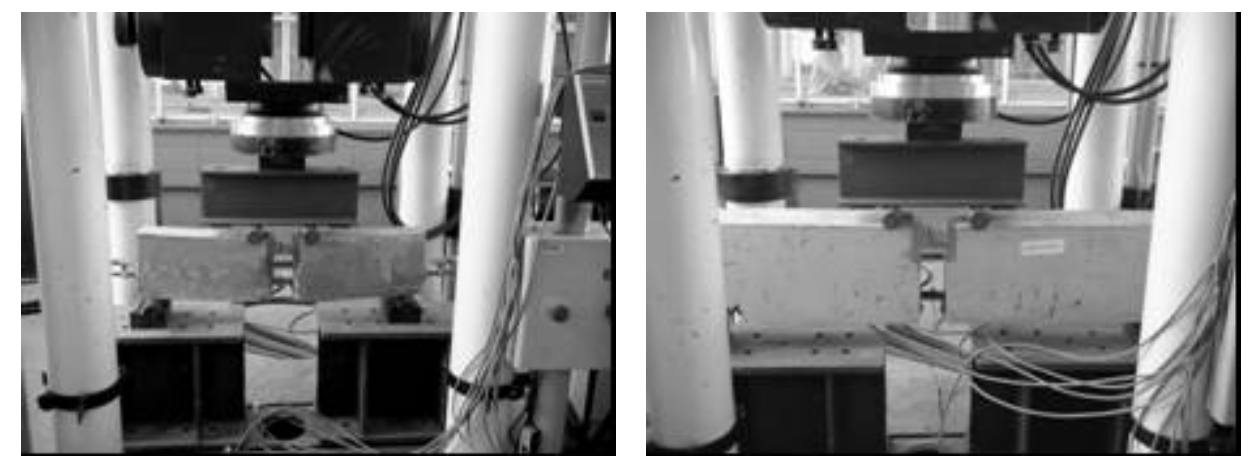

Figura 5.43 Modo de ruptura do modelo de viga em CAA da série 1

Ao contrário dos modelos em $\mathrm{CC}$ de referência, os modelos de viga em CAA apresentaram grande deslizamento da barra de aço, pequeno deslocamento vertical (flecha) e pequenas deformações na barra. Os modelos com barra de $10 \mathrm{~mm}$ não apresentaram ruptura do cobrimento na zona entre os extensômetros 2 e 4, mostrando que o mecanismo de ruptura da aderência aço-concreto se deu por deslizamento da barra de aço e não por escoamento da barra, para ambos os modelos de viga.

\subsubsection{Série 2}

Aqui se apresentam os resultados referentes aos modelos de viga em concreto convencional (CC) e em concreto auto-adensável (CAA) com resistência à compressão de $60 \mathrm{MPa}$.

\subsubsection{Modelos em CC}

Os modelos de referência foram chamados de V-CC-C60-B10 e V-CC-C60-B16, onde $\mathrm{V}$ corresponde ao modelo de viga, CC corresponde ao concreto convencional, C60 corresponde a classe de resistência à compressão do concreto (60 MPa) e B10 e B16, correspondem ao diâmetro da barra de 10 e 16 mm, respectivamente.

A Tabela 5.18 mostra a composição do traço para o concreto convencional com resistência à compressão de $60 \mathrm{MPa}$ aos 14 dias.

Tabela 5.18 Composição do traço do CC da série 2

\begin{tabular}{lc}
\hline Material & Quant. (kg) \\
\hline Cimento & 488,3 \\
Água & 227,0 \\
Areia & 766,6 \\
Brita & 942,4 \\
\hline
\end{tabular}

\begin{tabular}{l}
\hline Ensaios \\
\hline Abatimento \\
$9 \mathrm{~cm}$ \\
\hline
\end{tabular}


Para esta etapa foram concretados três cp's para ensaio à compressão e três cp's para ensaio à tração, ambos com dimensões de $10 \times 20 \mathrm{~cm}$. Ainda, foram concretados mais três cp's de $10 \times 20 \mathrm{~cm}$ para ensaio de módulo de elasticidade longitudinal. A Figura 5.44 mostra o módulo de elasticidade longitudinal dos modelos de referência da série 2 .

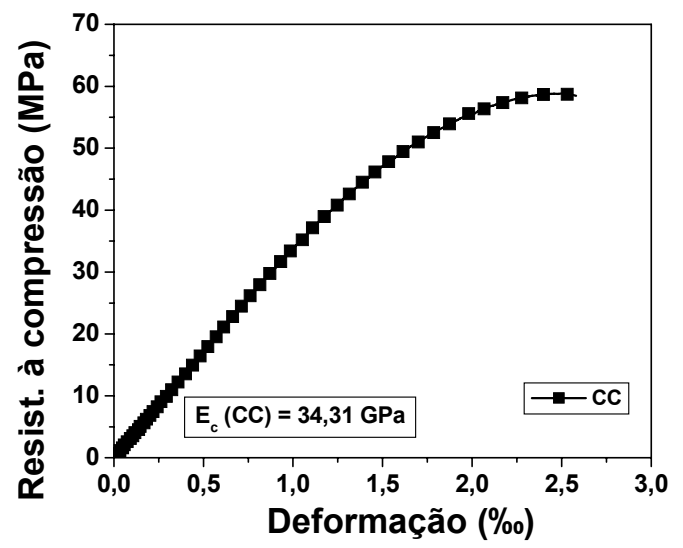

Figura 5.44 Módulo de elasticidade longitudinal para os modelos de referência

A Figura 5.45 ilustra os modelos de viga em CC.

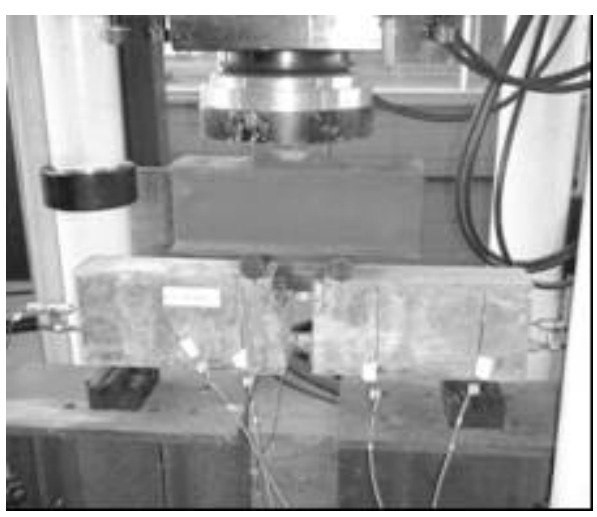

$\phi=10 \mathrm{~mm}$

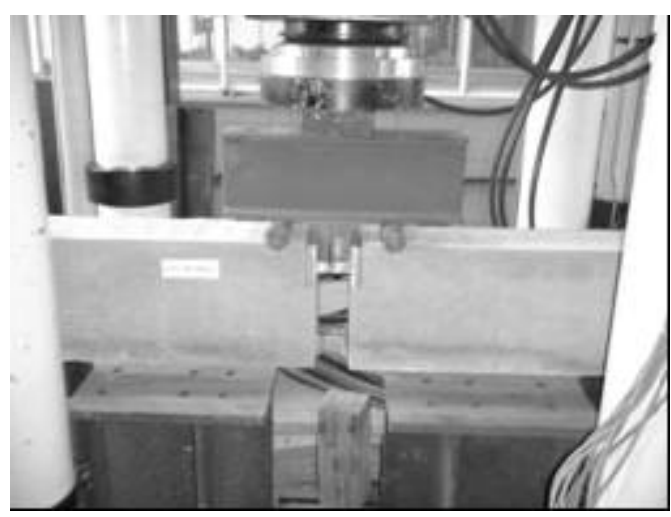

$\phi=16 \mathrm{~mm}$

Figura 5.45 Modelos de viga em CC ensaiados

A Tabela 5.19 ilustra as propriedades no estado endurecido para os modelos de viga em CC da série 2.

Tabela 5.19 Propriedades do CC aos 14 dias

\begin{tabular}{cccc}
\hline & Média (MPa) & D.P. (MPa) & C.V. \\
\hline $\mathbf{f}_{\mathrm{c}, \mathbf{1 4}}$ & 50,20 & 1,48 & $2,95 \%$ \\
$\mathbf{E}_{\mathbf{c}}$ & 34308,0 & 422,5 & $1,23 \%$ \\
$\mathbf{f}_{\mathrm{ct}, \mathbf{s p}}$ & 3,92 & 0,31 & $7,91 \%$ \\
\hline
\end{tabular}


Onde, $\mathrm{f}_{\mathrm{ct}, \mathrm{sp}}$ é a resistência à tração indireta, $\mathrm{f}_{\mathrm{c}, 14}$ é a resistência à compressão do concreto aos 14 dias e $E_{c}$ é o módulo de elasticidade longitudinal. Vale comentar que o módulo de elasticidade longitudinal foi determinado aos 21 dias.

A Figura 5.46 ilustra o comportamento dos modelos de viga.
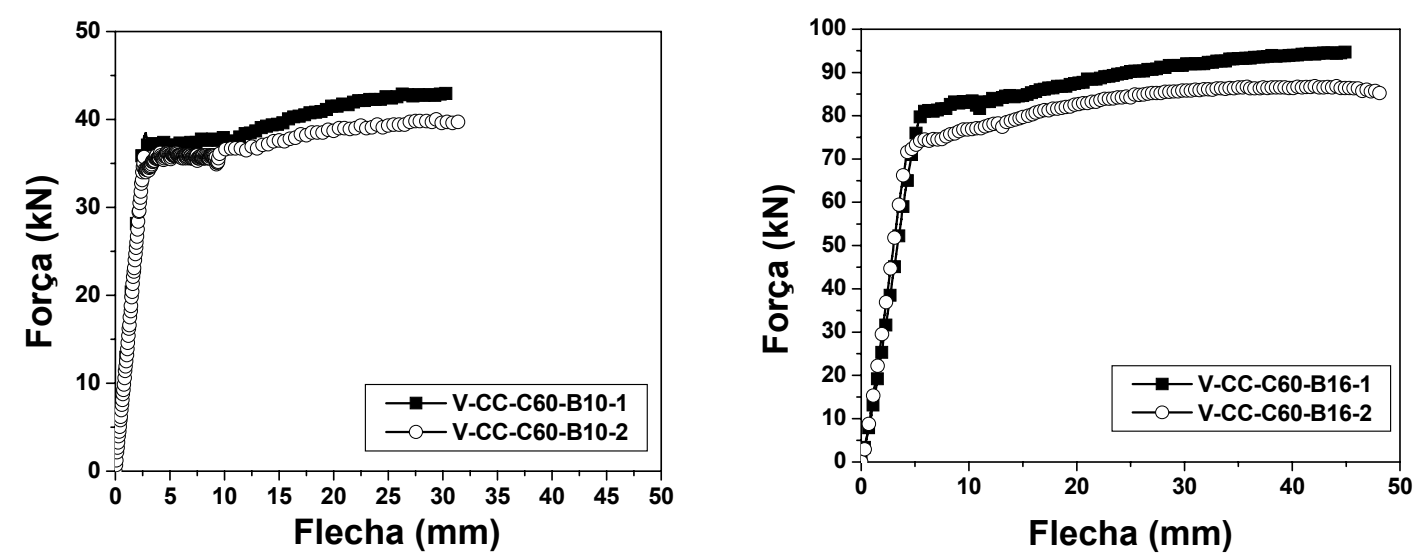

Figura 5.46 Comportamento dos modelos de viga em CC da série 2

Os modelos de viga apresentam ruptura por escoamento da barra de aço, confirmando o comportamento dos modelos de arrancamento onde o ocorria ruptura por fendilhamento do prisma de concreto. Os modelos de viga apresentaram deformação excessiva na barra de aço, e o deslocamento (flecha) excessivo da viga provocou o interrupção do ensaio por motivo de segurança.

A Figura 5.47 mostra o comportamento do deslizamento da barra de aço e a correspondente resistência de aderência.
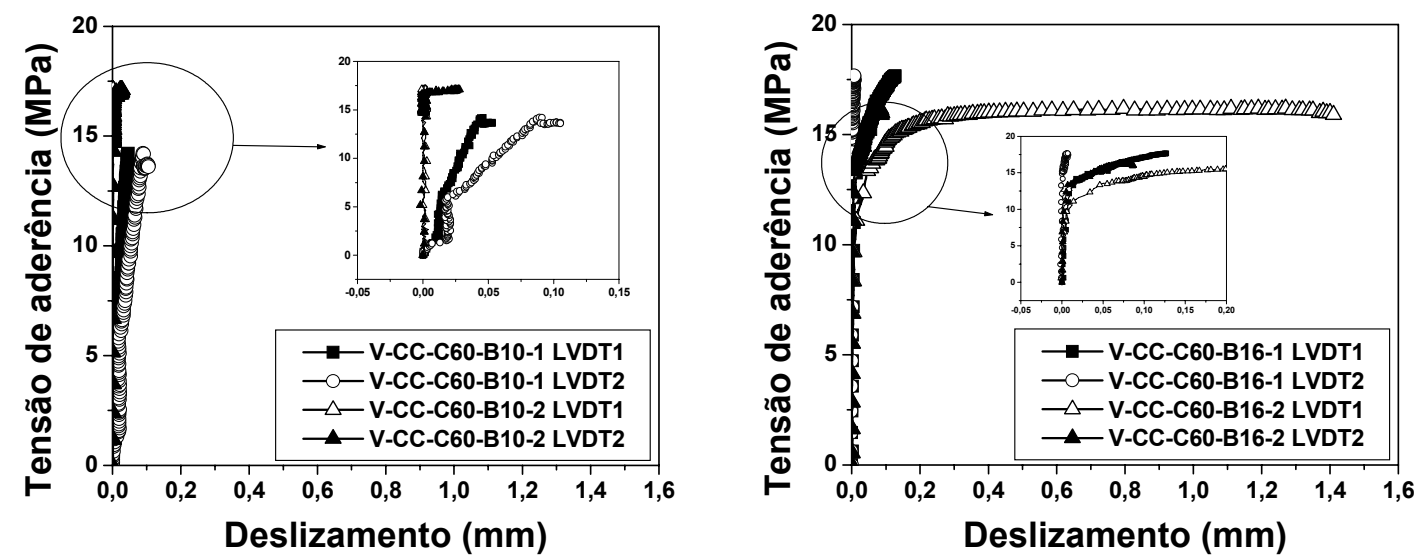

Figura 5.47 Resistência de aderência vs. Deslizamento dos LVDT's dos modelos de viga em CC da série 2

De acordo com a Figura 5.47, houve pouco deslizamento da barra de aço corroborando os resultados obtidos nos ensaios de arrancamento, que se 
caracterizaram pelo pouco deslizamento da barra conduzindo ao fendilhamento do prisma de concreto.

A Figura 5.48 mostra o comportamento dos extensômetros elétricos de resistência posicionados nos modelos de viga com barra de 10 e $16 \mathrm{~mm}$.
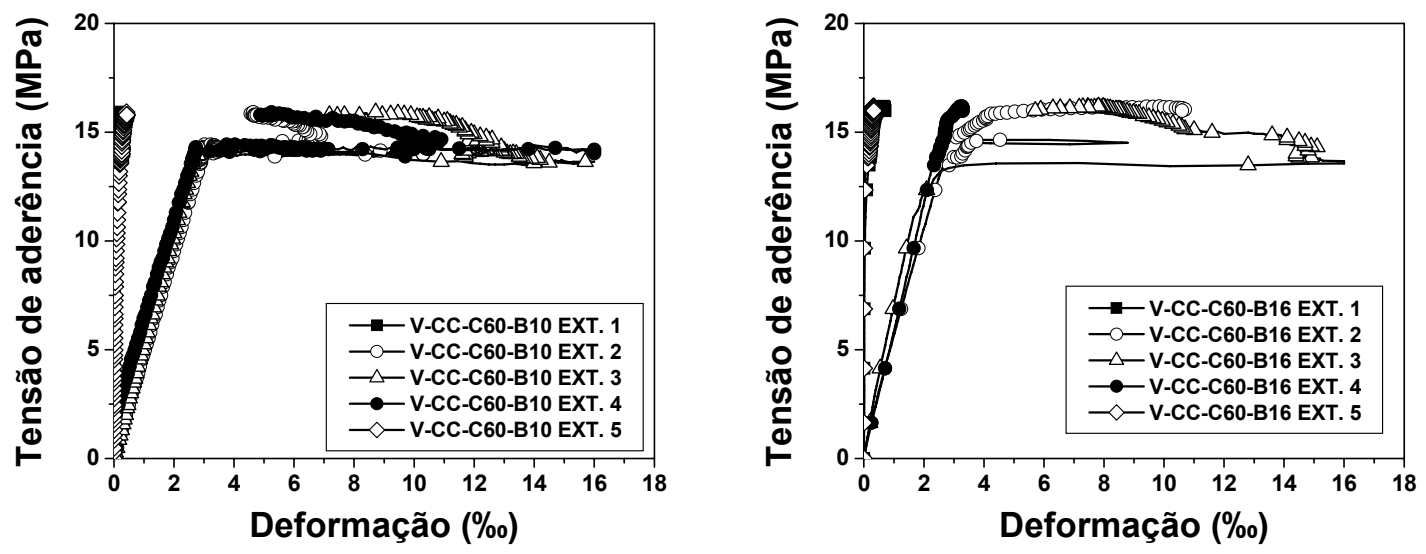

Figura 5.48 Comportamento dos modelos de viga com extensômetros em CC da série 2

De acordo com a Figura 5.48, a variação das deformações na barra de aço se concentra nos extensômetros elétricos de resistência 2, 3 e 4. A Figura 5.49 mostra os modelos de viga após a ruptura.
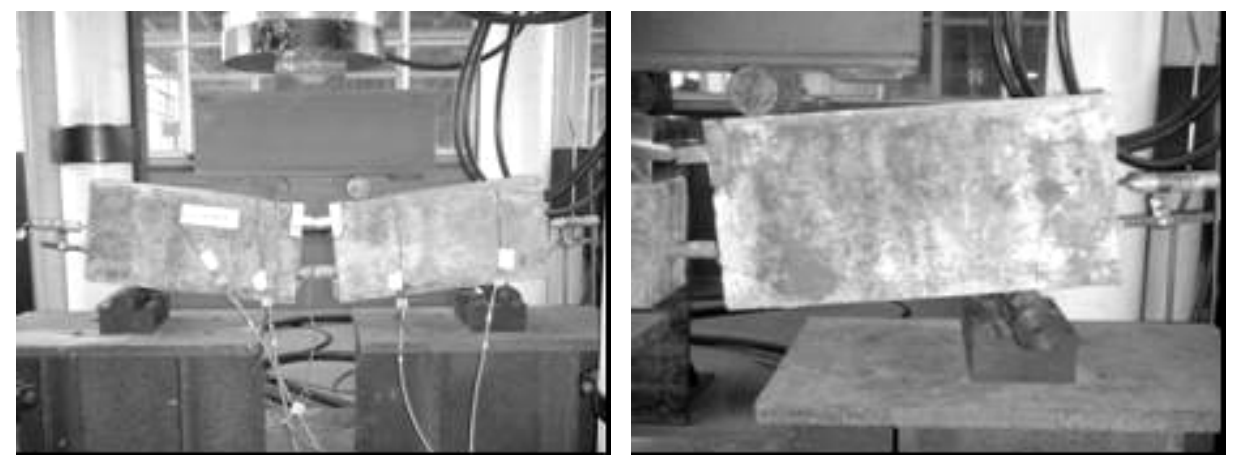

Figura 5.49 Modo de ruptura do modelo de viga com barra de $10 \mathrm{~mm}$ em CAA da série 2

Já os modelos com barra de $16 \mathrm{~mm}$ apresentaram ruptura do cobrimento na zona entre os extensômetros 2 e 4, conforme a Figura 5.50. 

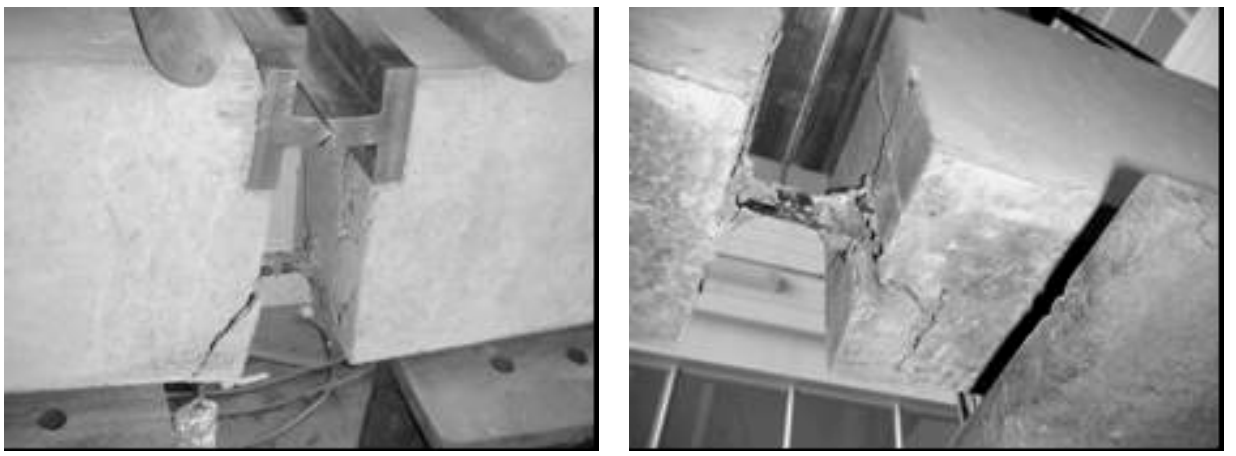

Figura 5.50 Modo de ruptura do modelo de viga com barra de $16 \mathrm{~mm}$ em CAA da série 2

Isso representa que o deslocamento excessivo da viga, combinado com o pequeno deslizamento e as grandes deformações da barra de aço, conduz ao esmagamento do concreto no trecho entre a barra e a rótula.

\subsubsection{Modelos em CAA}

A Tabela 5.20 mostra a composição do traço para o CAA utilizado na confecção dos modelos de arrancamento desta série.

Tabela 5.20 Composição do traço do CAA da série 2 e resultados do estado fresco

\begin{tabular}{lc}
\hline Material & Quant. (kg) \\
\hline Cimento & 365,1 \\
Água & 146,1 \\
Filler & 146,1 \\
Sílica ativa & 36,5 \\
Areia & 815,3 \\
Brita & 876,7 \\
Superplast. & $1,8 \%$ \\
V $_{\text {pasta }}$ & $38,0 \%$ \\
\hline
\end{tabular}

\begin{tabular}{lc}
\hline Ensaios & \\
\hline Espalhamento & \\
$\mathrm{T}_{50}(\mathrm{~s})=$ & 1,0 \\
$\mathrm{D}_{\text {esp. }}(\mathrm{cm})=$ & 61,0 \\
Caixa-L & \\
$\mathrm{T}_{60}(\mathrm{~s})=$ & 1,0 \\
$\mathrm{CB}=$ & 0,9 \\
Funil-V & \\
$\mathrm{T}_{\mathrm{v}}(\mathrm{s})=$ & 2,0 \\
\hline
\end{tabular}

Durante a concretagem foram moldados três cp's para ensaio à compressão e três cp's para ensaio à tração, ambos com dimensões de 10x20 cm. Além deles, foram concretados mais três cp's de $10 \times 20 \mathrm{~cm}$ para ensaio de módulo de elasticidade longitudinal.

Os modelos em CAA da série 2 foram chamados de V-CAA-C60-B10 e V-CAAC60-B16, onde $V$ corresponde ao modelo de viga, CAA corresponde ao concreto autoadensável, C60 corresponde a classe de resistência à compressão do concreto (60 MPa) e B10 e B16, correspondem ao diâmetro da barra, 10 e 16 mm, respectivamente.

A Figura 5.51 ilustra a variação da resistência à compressão do CAA até a data do ensaio e o módulo de elasticidade longitudinal dos modelos em CAA. 


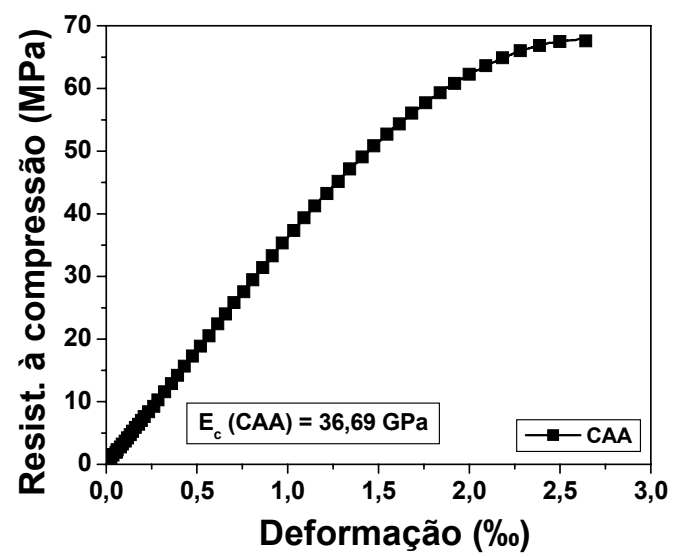

Figura 5.51 Variação da resistência à compressão e módulo de elasticidade longitudinal para os modelos em CAA

A Figura 5.52 ilustra os modelos de viga de barras com diâmetro da barra de aço de 10 e de $16 \mathrm{~mm}$.

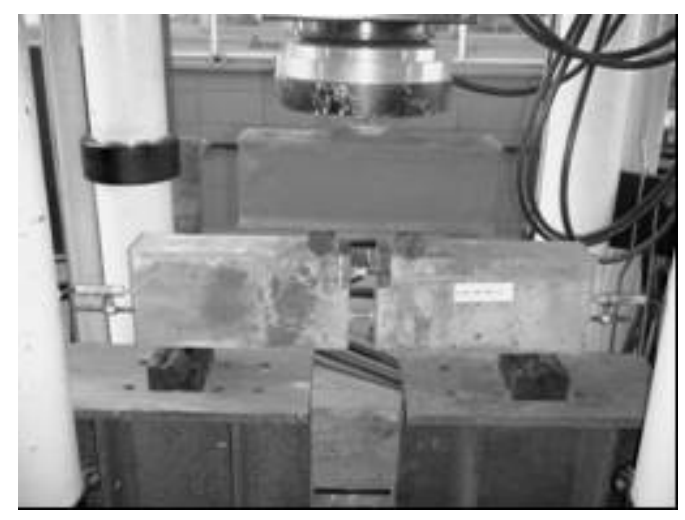

$\phi=10 \mathrm{~mm}$

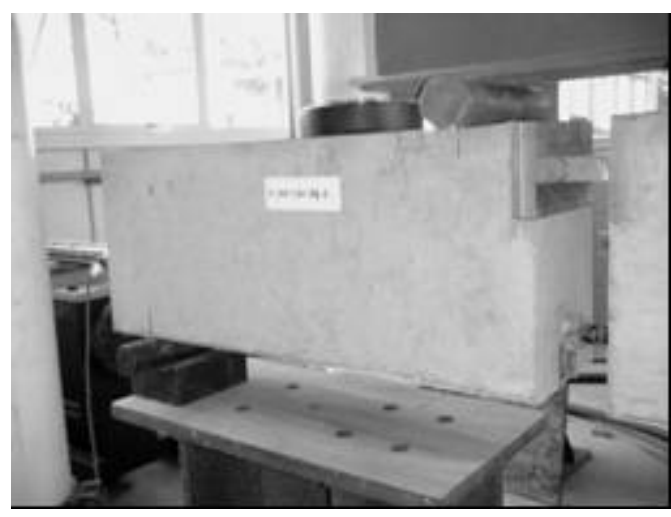

$\phi=16 \mathrm{~mm}$

Figura 5.52 Modelos de viga em CAA ensaiados

A Tabela 5.21 ilustra as propriedades no estado endurecido para o CAA de 60 MPa.

Tabela 5.21 Propriedades do CAA aos 15 dias

\begin{tabular}{cccc}
\hline & Média (MPa) & D.P. (MPa) & C.V. \\
\hline $\mathbf{f}_{\mathrm{c}, 14}$ & 53,3 & 2,75 & $5,16 \%$ \\
$\mathbf{E}_{\mathbf{c}}$ & 36686,0 & 522,6 & $1,42 \%$ \\
$\mathbf{f}_{\mathrm{ct}, \mathrm{sp}}$ & 4,99 & 0,42 & $8,42 \%$ \\
\hline
\end{tabular}

Onde, $\mathrm{f}_{\mathrm{ct}, \mathrm{sp}}$ é a resistência à tração indireta, $\mathrm{f}_{\mathrm{c}, 14}$ é a resistência à compressão do concreto aos 14 dias e $E_{c}$ é o módulo de elasticidade longitudinal. Vale comentar que o módulo de elasticidade longitudinal foi determinado aos 21 dias. 
A Figura 5.53 ilustra o comportamento dos modelos de viga em CAA da série 2.
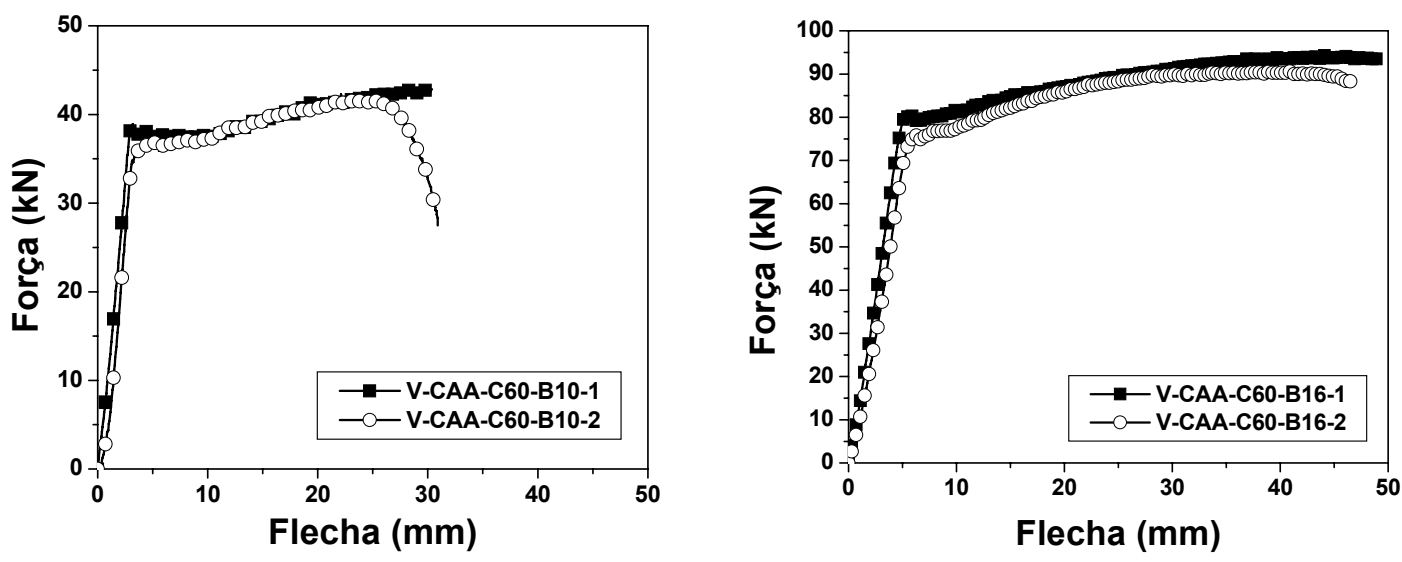

Figura 5.53 Comportamento dos modelos de viga em CAA da série 2

Os modelos de viga apresentam ruptura por escoamento da barra de aço, confirmando o comportamento dos modelos de arrancamento onde o ocorria ruptura por fendilhamento do prisma de concreto. Os modelos de viga apresentaram deformação excessiva na barra de aço, e o deslocamento (flecha) excessivo da viga provocou o interrupção do ensaio por motivo de segurança.

A Figura 5.54 mostra o comportamento do deslizamento da barra de aço e a correspondente resistência de aderência.
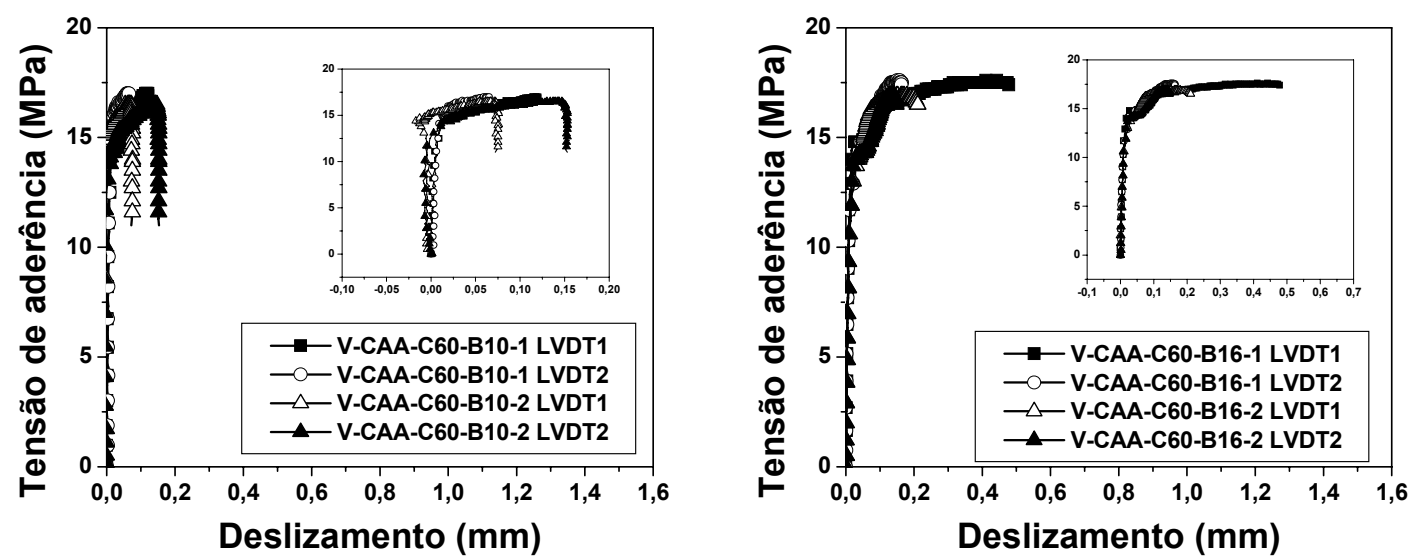

Figura 5.54 Resistência de aderência vs. deslizamento dos LVDT's dos modelos de viga em CAA da série 2

De acordo com a Figura 5.54, houve pouco deslizamento da barra de aço corroborando os resultados obtidos nos ensaios de arrancamento, que se 
caracterizaram pelo pouco deslizamento da barra conduzindo ao fendilhamento do prisma de concreto.

A Figura 5.55 mostra o comportamento dos extensômetros elétricos de resistência posicionados nos modelos de viga com barra de 10 e $16 \mathrm{~mm}$.
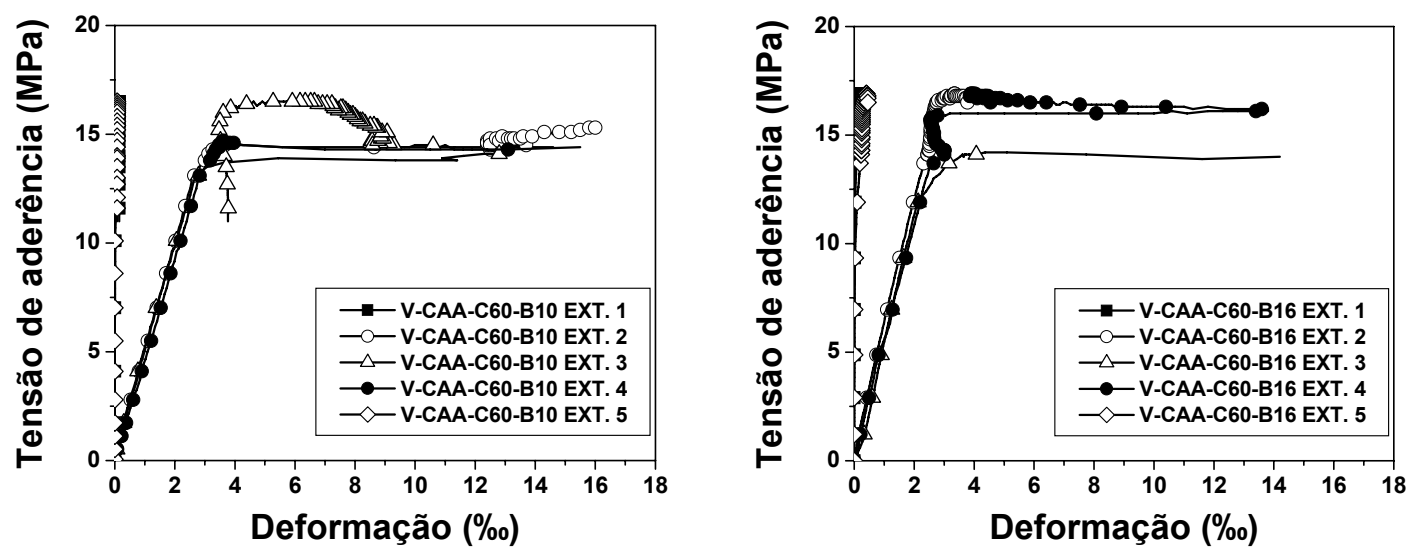

Figura 5.55 Comportamento dos modelos de viga com extensômetros em CAA da série 2

De acordo com a Figura 5.55, a variação das deformações na barra de aço se concentra nos extensômetros elétricos de resistência 2,3 e 4. A ruptura do modelo com extensômetros elétricos de resistência com barra de $10 \mathrm{~mm}$ se deu pelo escoamento da barra de aço na posição do extensômetro 3. A Figura 5.56 mostra o modelo após a ruptura.

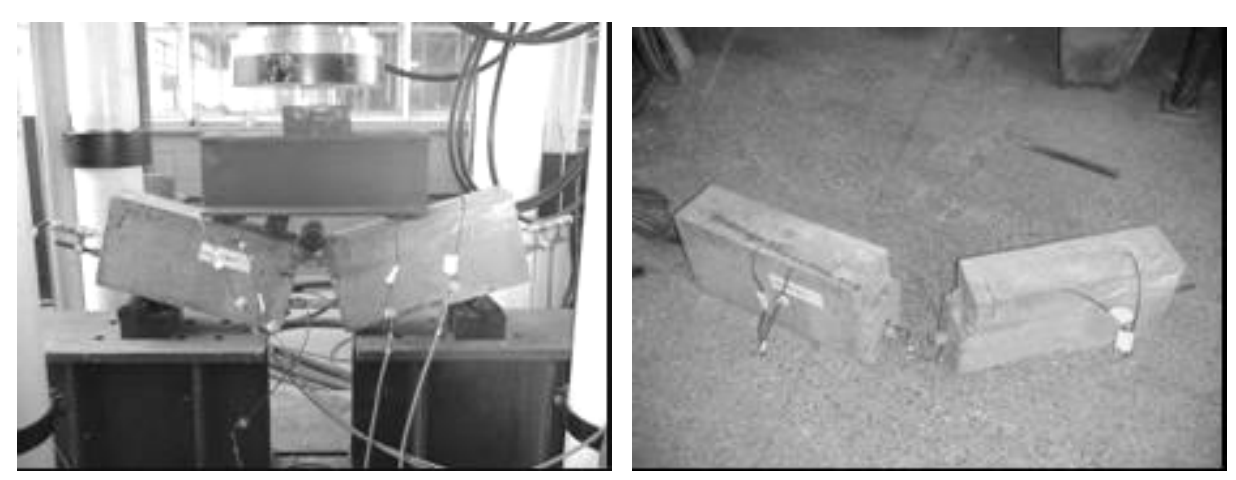

Figura 5.56 Modo de ruptura do modelo de viga com barra de $10 \mathrm{~mm}$ em CAA da série 2

Já os modelos com barra de $16 \mathrm{~mm}$, do mesmo modo que os modelos similares em concreto convencional, apresentaram ruptura do cobrimento na zona entre os extensômetros 2 e 4, conforme a Figura 5.57. 

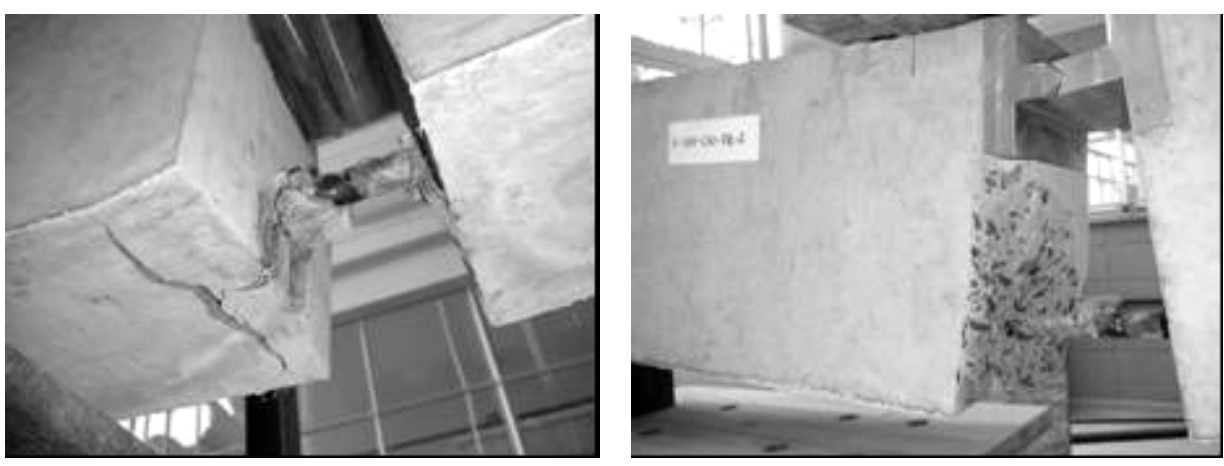

Figura 5.57 Modo de ruptura do modelo de viga com barra de $16 \mathrm{~mm}$ em CAA da série 2

Isso representa que o deslocamento excessivo da viga, combinado com o pequeno deslizamento da barra de aço, conduzissem ao esmagamento do concreto no trecho entre a barra e a rótula.

\subsection{Considerações finais}

Neste capítulo foi realizado o programa experimental previsto, incluindo modelos de arrancamento e de vigas confeccionados em concreto convencional e concreto auto-adensável, com diferentes diâmetros de barra.

Com relação aos ensaios dos modelos de arrancamento se pode concluir que:

- O modelo de arrancamento adotado foi adequado para se medir o deslizamento entre a barra de aço e o prisma de concreto;

- A resistência à compressão do concreto e o diâmetro da barra têm forte influência no resultado da resistência de aderência, sendo que, conforme a literatura técnica, quanto maior a resistência à compressão do concreto maior a resistência de aderência, sendo o mesmo válido para o diâmetro da barra, menor diâmetro significa em maior resistência de aderência;

- Os modelos de arrancamento foram de fácil operação durante a concretagem e o seu posicionamento na máquina de ensaios era simples, facilitando os procedimentos para ensaio e minimizando quaisquer erros operativos por sua simplicidade de execução;

- Os ensaios de arrancamento são eficazes na determinação da resistência de aderência, apresentado pequena variação em seus resultados; 
- Os modelos de arrancamento da série 1 foram caracterizados pela ruptura por deslizamento da barra de aço e, em alguns casos com barra de $16 \mathrm{~mm}$, houve ruptura por fendilhamento do concreto;

- Os modelos de arrancamento da série 2 foram caracterizados pela ruptura por fendilhamento do concreto, para todos os diâmetros de barra;

- Os modelos da série complementar tiveram comportamento similar aos da série 2, sendo caracterizados pela ruptura por fendilhamento do prisma de concreto;

- No que se refere ao comportamento dos concretos utilizados, o comportamento da resistência de aderência foi similar para ambos os diâmetros de barra utilizados.

Com relação aos ensaios dos modelos de viga se pode concluir que:

- O modelo de viga apresenta uma série de deslizamentos combinados com a deformação da barra à medida que há deformação na barra, o concreto com alta resistência à compressão limitará o seu deslizamento ocasionando a ruptura do modelo por escoamento da barra de aço, fato que foi observado nos modelos de viga da série 2. Em contrapartida, à medida que se aumenta o deslizamento da barra, ocorre um alívio nas tensões da mesma, ocasionando a ruptura da aderência por deslizamento da barra de aço;

- Os modelos da série 1 foram caracterizados pelo pequeno deslocamento (flecha) dos modelos e pequenas deformações, o que denotou que a ruptura do modelo se deu por deslizamento da barra;

- Durante os ensaios da série 1 de vigas, os modelos em CC com barra de $10 \mathrm{~mm}$ tiveram comportamento atípico em função de uma falha na utilização da rótula, sendo que seu comportamento ficou caracterizado pela ruptura por deformação excessiva da barra de aço. Entretanto, os resultados referentes ao pré-pico puderam ser utilizados descartandose o pós-pico do comportamento dos modelos;

- Já os modelos da série 2 foram caracterizados pelo excessivo deslocamento (flecha) dos modelos, que denotou o escoamento da barra de aço e, em um caso houve ruptura da barra. 
Assim, do mesmo modo que os modelos de arrancamento, os modelos de viga, tanto em CAA quanto em CC de cada série, apresentaram comportamento similar mostrando que o CAA apresenta propriedades mecânicas similares ao CC. 



\section{Variabilidade das propriedades do CAA no estado fresco e endurecido}

Este capítulo tem por objetivo avaliar o grau de confiança que se pode ter na previsão do comportamento do CAA, particularmente no que diz respeito à aderência quando são usados os ensaios de vigas padronizados pelo Rilem-Ceb-Fip (1973).

\subsection{Considerações iniciais}

Hoje em dia, é cada dia maior o interesse no estudo da variabilidade das propriedades dos materiais. Esses estudos necessitam uma quantidade considerável de repetições para que se tenha uma maior representatividade do fenômeno a ser estudado.

Para os estudos de variabilidade, são utilizados desde processos estatísticos mais simples (média, desvio padrão e coeficiente de variação) até os mais complexos como a análise de variância, o qual permite uma melhor avaliação dos parâmetros mais importantes e que tem influência no comportamento do modelo estudado.

A aplicação dos processos estatísticos para avaliação do comportamento dos materiais foi sempre tema de investigações experimentais, mas muitas vezes contraditórios. Isso ocorria por causa da má utilização do processo estatístico dos resultados obtidos, ou seja, às vezes ou não havia resultados suficientes (ou mais precisamente, havia a falta de uma quantidade significativa de réplicas de um mesmo modelo para avaliar a repetição do resultado) ou o procedimento estatístico utilizado não era adequado para aquela análise. 
As desvantagens desses processos são que, a média e o desvio padrão necessitam de uma quantidade grande de amostras para que não ocorram variações significativas. Para a análise da variância, a principal desvantagem é que este processo necessita de uma análise mais detalhada dos parâmetros que possuem maior influência no resultado.

Diversas pesquisas foram realizadas com o objetivo de se avaliar a variabilidade do comportamento dos ensaios, principalmente para concretos com fibras (Song et al., 2005a; Song et al., 2005b; Kocaoz et al., 2005; Bayramov et al., 2004; Chanvillard \& Aïtcint, 1996) e caracterização de parâmetros do concreto (Lin et al., 2004; Gesoglu et al., 2002; Freidin, 2005; Hueste et al., 2004).

\subsection{Objetivos}

O objetivo principal deste projeto era obter informações a respeito da variabilidade do concreto auto-adensável no estado fresco e endurecido. Os parâmetros a serem analisados foram abordados de um ponto de vista estatístico, envolvendo a utilização da média, desvio padrão, coeficiente de variação, distribuição normal e freqüência.

Para o estado fresco a ênfase foi dada à variabilidade da repetição da mesma composição do traço do CAA com diferentes tamanhos máximos de agregado graúdo. Já para o estado endurecido, o objetivo foi avaliar a variabilidade das propriedades mecânicas do CAA aos 28 dias, notadamente: resistência à compressão, módulo de elasticidade, resistência à tração e resistência de aderência, com a modificação do tamanho máximo do agregado graúdo. Os ensaios foram conduzidos no Laboratório de Tecnología de Estructuras do Departamento de Ingeniería de la Construcción (ETSECCPB-UPC/Barcelona) e, em função disso, novos estudos dos materiais foram necessários.

A justificativa para esta investigação se baseia na ausência de informações sobre a variabilidade do comportamento do CAA no estado fresco, notadamente suas propriedades nos ensaios de avaliação de fluidez e coesão; e no estado endurecido, da resistência à compressão, resistência à tração, módulo de elasticidade e resistência de aderência.

Os objetivos desta etapa são:

- Avaliar a variação da resistência de aderência em concretos autoadensáveis com resistência à compressão do concreto em torno de 50 
$\mathrm{MPa}$, variando o tamanho máximo do agregado graúdo (de 12 a 18 $\mathrm{mm})$;

- Avaliar a variabilidade da resistência de aderência em concretos autoadensáveis de mesma resistência à compressão, mas com maior coesão (espalhamento de aproximadamente $50 \mathrm{~cm}$ ) e outro com espalhamento adequado de acordo com os parâmetros de aceitabilidade estabelecidos.

Assim, de posse dessas informações, o objetivo global é observar se a falta de fluidez do CAA influi na resistência de aderência e no aspecto geral das vigas concretadas (acabamento). Além disso, a variabilidade da resposta do CAA foi analisada de um ponto de vista estatístico.

\subsection{Materiais utilizados}

Figura 6.1 mostra a distribuição granulométrica dos agregados.

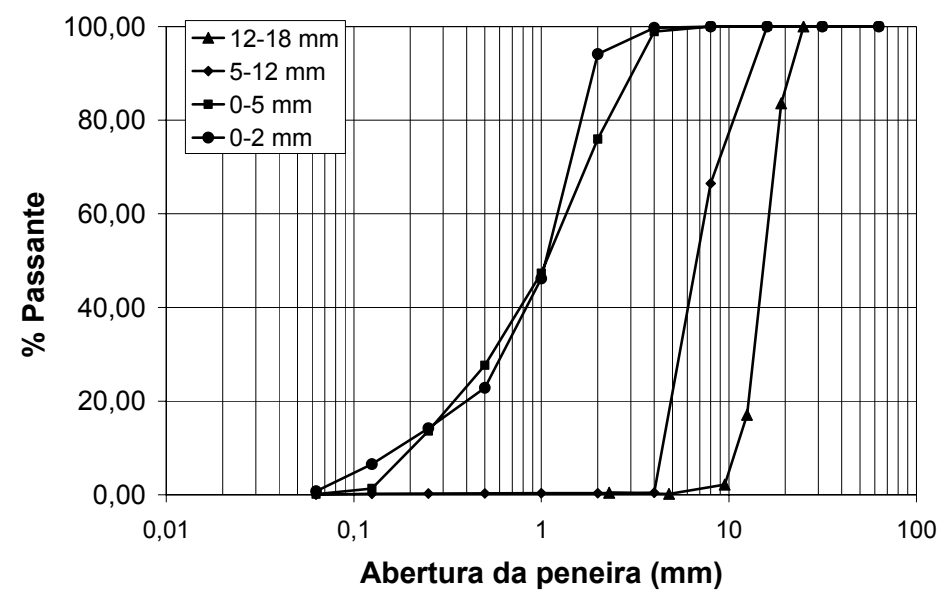

Figura 6.1 Distribuição granulométrica dos agregados

A Tabela 6.1 mostra as características dos agregados utilizados.

Tabela 6.1 Características dos agregados

\begin{tabular}{lcccc}
\hline Agregado & Areia1 & Areia2 & Brita1 & Brita2 \\
\hline Dimensão $(\mathbf{m m})$ & $0-2$ & $0-5$ & $5-12$ & $12-18$ \\
Densidade $\mathbf{( k g / \mathbf { m } ^ { 3 } )}$ & 2610,0 & 2650,0 & 2650,0 & 2650,0 \\
Absorção (\%) & 1,52 & 1,52 & 1,01 & 0,35 \\
\hline
\end{tabular}


O aditivo superplastificante utilizado foi o Glenium C303 SCC, baseado em cadeias de policarboxylato. A Tabela 6.2 mostra suas principais características.

Tabela 6.2 Características do aditivo superplastificante

\begin{tabular}{ll}
\hline Densidade (kg/l) & 1,08 \\
Conteúdo de partículas sólidas & $19 \%$ \\
Conteúdo de água & $81 \%$ \\
\hline
\end{tabular}

O cimento utilizado foi o CEM II 42.5 com o objetivo de se obter um CAA de resistência a compressão cerca de $50 \mathrm{MPa}$ aos 28 dias. O filler utilizado, assim como os agregados eram de origem calcária, com densidade aproximada de $2630 \mathrm{~kg} / \mathrm{m}^{3} \mathrm{e}$ com diâmetro de partícula inferior a 0,125 $\mu \mathrm{m}$ (Efnarc, 2002).

\subsection{Estudo da composição do traço}

Neste segmento, apresenta-se o desenvolvimento dos concretos autoadensáveis utilizados na investigação sobre sua variabilidade. Vale salientar que a teoria aplicada é a mesma adotada no Capítulo 3 e, portanto, somente serão ilustrados os resultados obtidos para a determinação do CAA.

\subsubsection{Etapa pasta}

A Tabela 6.3 mostra a seqüência de lançamento dos materiais, tempos e velocidades para a argamassadeira.

Tabela 6.3 Seqüência de mistura para a etapa pasta

\begin{tabular}{clcc}
\hline Seqüência & Materiais & Tempo (s) & Velocidade \\
\hline 1 & Cimento + filler calcário & 30 & Lenta \\
2 & $90 \%$ água & 60 & Lenta \\
3 & Raspar e misturar & 60 & Lenta \\
4 & Superplastificante + 10\% água & 30 & Lenta \\
5 & Mistura final & 150 & Rápido \\
\hline
\end{tabular}

Assim, o tempo total da mistura era de 6 minutos e 30 segundos. Depois desse procedimento, a pasta era ensaiada no cone de Marsh e no mini-slump.

$A$ relação água/cimento $(A / C)$ foi estabelecida em 0,45 (para se ter menor resistência à compressão) e a relação filler calcário/cimento (FC/C) foi de 0,3.

A Figura 6.2 mostra a curva Log $\left(T_{m}\right)$ vs. SP/C (\%), com o ponto de saturação de $1,4 \%\left(0,266 \%\right.$ conteúdo de partículas sólidas) com $137,7^{\circ}$ (limite de $\left.140^{\circ} \pm 10^{\circ}\right)$ e diâmetro de espalhamento no mini-slump de $18 \mathrm{~cm}$ (limite de $18 \pm 1 \mathrm{~cm}$ ). 


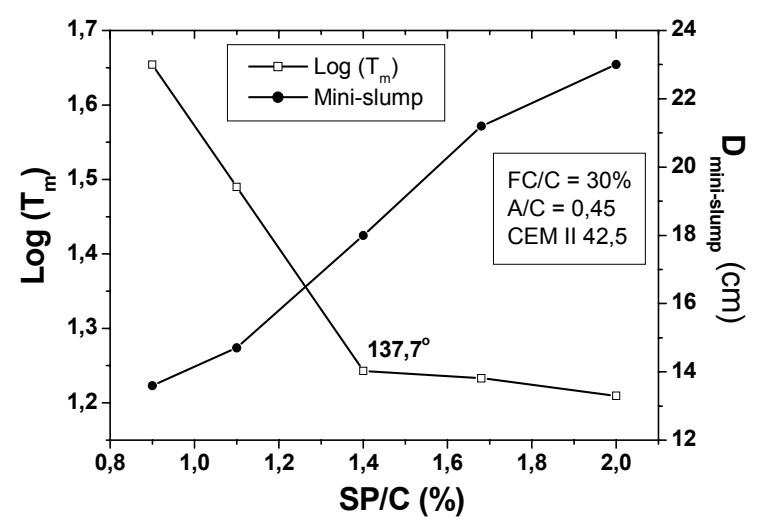

Figura 6.2 Curva Log $\left(T_{m}\right)$ vs. $\mathrm{SP} / \mathrm{C}(\%)$ para relacões $\mathrm{A} / \mathrm{C}=0,45$ e $\mathrm{FC} / \mathrm{C}=0,3$

\subsubsection{Etapa esqueleto granular}

Com a mistura otimizada para as areias 1 e 2, foi realizado o mesmo procedimento com a brita 1 e com a composição dos 4 agregados, ou seja, depois da otimização das duas areias com a brita 1 (Figura 6.3a), utilizou-se a mesma para otimizar a mistura com a brita 2 (Figura 6.3b).

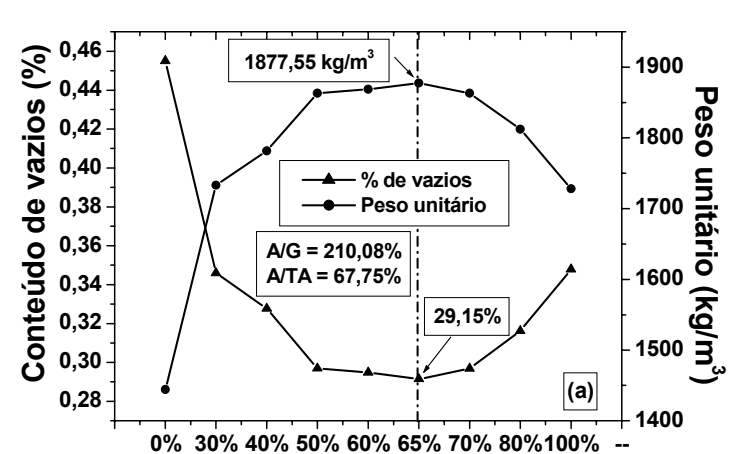

Areia 1 e 2 (\%)

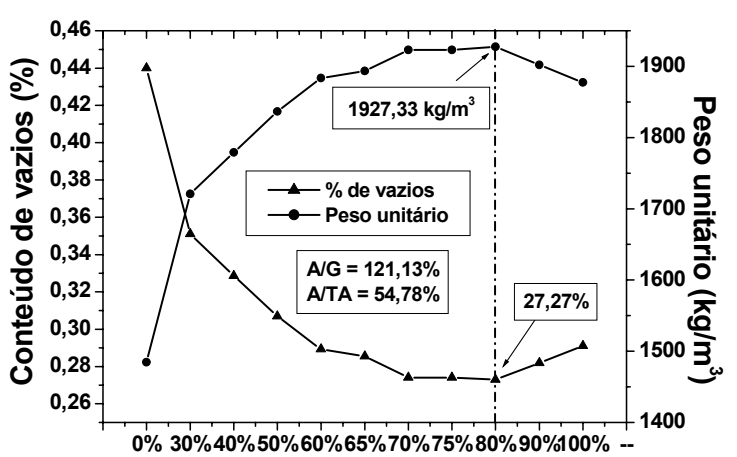

Areia 1 e 2 + Brita 1 (\%)

Figura 6.3 Índice de vazios para a composição dos agregados com a brita 1 e 2

Para a determinação de cada um dos pontos para o peso unitário, foram realizadas três repetições para se ter uma melhor aproximação dos resultados. 


\subsubsection{Etapa concreto}

Para a determinação se um concreto é ou não auto-adensável, é preciso estabelecer limites de aceitação, independente do tamanho do agregado. A Tabela 6.4 ilustra esses limites.

Tabela 6.4 Critérios para aceitação do CAA

\begin{tabular}{ll}
\hline Espalhamento (slump-flow) & \\
\hline$T_{50}(\mathrm{~s})$ & 2 a 4 \\
$D_{\mathrm{e}}(\mathrm{cm})$ & 65 a 75 \\
Caixa-L & \\
\hline$T_{60}(\mathrm{~s})$ & 1 a 4 \\
CB (coef. de bloqueio) & 0,80 a 0,95 \\
Anel-J & \\
\hline CB (coef. de bloqueio) & 0,80 a 1,00 \\
$D_{J}(\mathrm{~cm})$ & Até $5 \mathrm{~cm}$ de diferença do $D_{e}$ \\
$T_{50}(\mathrm{~s})$ & 2 a 4 \\
Funil-V & \\
\hline$T_{V}(\mathrm{~s})$ & 5 a 12 \\
\hline
\end{tabular}

Foram utilizadas três betoneiras de eixo vertical para a verificação das propriedades do CAA no estado fresco, sendo que, a primeira betoneira tinha 50 de capacidade máxima, a segunda de 30 litros e a terceira de 220 litros de capacidade. A diferença entre as betoneiras residia na velocidade de giro da cuba e do eixo da mesma. A betoneira de maior energia era a de 200 litros (aqui chamada de B1), a segunda era a betoneira de 50 litros (B2) e a terceira, de menor energia, chamada de B3.

O objetivo de se utilizar três betoneiras era avaliar o grau de influência da velocidade da betoneira (sua energia de mistura) nas propriedades do CAA no estado fresco. A Tabela 6.5 mostra as composições dos traços dos CAA estudados.

Tabela 6.5 Composição do traço para o CAA1 e CAA2 $(A / C=0,45)$

\begin{tabular}{lcccccccc}
\hline & \multicolumn{1}{c}{ CAA1 } & \multicolumn{7}{c}{ CAA2 } \\
\hline $\mathrm{V}_{\text {pasta }}(\%)$ & 37 & 38 & 39 & 32 & 34.5 & 35 & 36 & 37 \\
Cimento $\left(\mathrm{kg} / \mathrm{m}^{3}\right)$ & 352,9 & 362,5 & 372,0 & 305,2 & 329,0 & 333,8 & 343,3 & 352,8 \\
Água $\left(\mathrm{kg} / \mathrm{m}^{3}\right)$ & 177,3 & 181,3 & 185,37 & 154,6 & 164,8 & 166,9 & 170,9 & 175,0 \\
Superplast. $\left(\mathrm{kg} / \mathrm{m}^{3}\right)$ & 6,0 & 6,2 & 6,3 & 5,2 & 5,6 & 5,7 & 5,8 & 6,0 \\
Filler $\left(\mathrm{kg} / \mathrm{m}^{3}\right)$ & 105,9 & 108,74 & 111,6 & 91,5 & 98,7 & 100,1 & 103,0 & 105,9 \\
Areia 1 $\left(\mathrm{kg} / \mathrm{m}^{3}\right)$ & 722,3 & 710,9 & 699,4 & 630,3 & 607,1 & 602,5 & 593,2 & 584,0 \\
Areia 2 $\left(\mathrm{kg} / \mathrm{m}^{3}\right)$ & 404,2 & 397,8 & 391,4 & 352,7 & 339,7 & 337,1 & 331,9 & 326,8 \\
Brita 1 $\left(\mathrm{kg} / \mathrm{m}^{3}\right)$ & 534,4 & 525,9 & 517,4 & 467,9 & 450,7 & 447,3 & 440,4 & 433,5 \\
Brita 2 $\left(\mathrm{kg} / \mathrm{m}^{3}\right)$ & - & - & - & 343,6 & 330,0 & 328,5 & 323,4 & 318,4 \\
\hline
\end{tabular}


A Tabela 6.6 e a Tabela 6.7 mostram a otimização para o CAA1 e CAA2, respectivamente.

Tabela 6.6 Otimização do CAA1

\begin{tabular}{|c|c|c|c|c|c|c|}
\hline Betoneira & B1 & \multicolumn{2}{|c|}{ B2 } & \multicolumn{3}{|c|}{ B3 } \\
\hline $\operatorname{Temp}\left({ }^{\circ} \mathrm{C}\right)$ & 22 & 22 & 23 & 22 & 22 & 22 \\
\hline Umidade (\%) & 70 & 66 & 70 & 66 & 70 & 68 \\
\hline$V_{\text {pasta }}(\%)$ & 38 & 39 & 39 & 37 & 38 & 39 \\
\hline \multicolumn{7}{|c|}{ Espalhamento (slump-flow) } \\
\hline $\mathrm{T}_{50}(\mathrm{~s})$ & 1,0 & 2,0 & 1,5 & 2,5 & 1,5 & 1,0 \\
\hline $\mathrm{D}_{\mathrm{e}}(\mathrm{cm})$ & 74,0 & 70,0 & 69,5 & 53,5 & 58,0 & 61,0 \\
\hline \multicolumn{7}{|l|}{ Caixa-L } \\
\hline $\mathrm{T}_{60}(\mathrm{~s})$ & 1,0 & 4,0 & 2,0 & - & 3,0 & 2,0 \\
\hline CB & 1,0 & 0,84 & 0,84 & - & 0,57 & 0,75 \\
\hline \multicolumn{7}{|l|}{ Anel-J } \\
\hline $\mathrm{CB}$ & 1,0 & 0,90 & 0,87 & - & 0,50 & 0,67 \\
\hline$D_{J}(\mathrm{~cm})$ & 74,25 & 68,1 & 66,25 & - & 54,0 & 56,5 \\
\hline $\mathrm{T}_{50}(\mathrm{~s})$ & 1,0 & - & 2,0 & - & 2,5 & 2,5 \\
\hline \multicolumn{7}{|l|}{ Funil-V } \\
\hline $\mathrm{T}_{\mathrm{V}}(\mathrm{s})$ & 2,5 & 4,0 & 4,5 & - & 6,5 & 6,0 \\
\hline
\end{tabular}

Tabela 6.7 Otimização do CAA2

\begin{tabular}{|c|c|c|c|c|c|c|}
\hline \multirow{2}{*}{$\begin{array}{l}\text { Betoneira } \\
\text { Temp }\left({ }^{\circ} \mathrm{C}\right)\end{array}$} & \multicolumn{2}{|c|}{ B1 } & \multicolumn{4}{|c|}{ B2 } \\
\hline & 22 & 23 & 23 & 23 & 22 & 23 \\
\hline Umidade (\%) & 78 & 66 & 70 & 66 & 70 & 66 \\
\hline $\mathrm{V}_{\text {pasta }}(\%)$ & 34.5 & 35 & 32 & 34.5 & 36 & 37 \\
\hline \multicolumn{7}{|c|}{ Espalhamento (slump-flow) } \\
\hline $\mathrm{T}_{50}(\mathrm{~s})$ & 1,5 & 1,0 & 4,0 & 2,5 & 1,5 & 0,5 \\
\hline$D_{e}(\mathrm{~cm})$ & 57,0 & 74,0 & 51,0 & 58,0 & 64,5 & 80,0 \\
\hline \multicolumn{7}{|l|}{ Caixa-L } \\
\hline $\mathrm{T}_{60}(\mathrm{~s})$ & 3,0 & 1,0 & - & 3,5 & 2,0 & - \\
\hline $\mathrm{CB}$ & 0,7 & 0,95 & - & 0,69 & 0,69 & - \\
\hline \multicolumn{7}{|l|}{ Anel-J } \\
\hline CB & 0,77 & 1,0 & - & 0,74 & 0,76 & - \\
\hline$D_{J}(\mathrm{~cm})$ & 55,5 & 73,5 & - & 53,5 & 60,0 & - \\
\hline $\mathrm{T}_{50}(\mathrm{~s})$ & 2,0 & 1,0 & - & 3,0 & 3,0 & - \\
\hline \multicolumn{7}{|l|}{ Funil-V } \\
\hline $\mathrm{T}_{\mathrm{V}}(\mathrm{s})$ & 5,5 & 5,0 & - & 7,0 & 10,5 & - \\
\hline
\end{tabular}

Vale comentar que, o estudo da variabilidade no estado endurecido foi realizado com os traços desenvolvidos na betoneira 1 , de 220 litros de capacidade.

\subsection{Variabilidade do concreto auto-adensável no estado fresco}

A repetição de cada uma das concretagens teve como objetivo avaliar o grau de variação do concreto auto-adensável, mantendo as mesmas condições de volume, temperatura e umidade relativa. A Tabela 6.8 mostra a composição do traço para o CAA1 e CAA2. 
Tabela 6.8 Composição do traço para o CAA1 e CAA2

\begin{tabular}{lcc}
\hline & HAC1 & HAC2 \\
\hline $\mathrm{V}_{\text {pasta }}(\%)$ & $38 \%$ & $35 \%$ \\
$\mathrm{~V}_{\text {areia }}(\%)$ & $42,2 \%$ & $35 \%$ \\
$\mathrm{~V}_{\text {brita }}(\%)$ & $19,8 \%$ & $29,3 \%$ \\
Índice de vazios $(\%)$ & $29,2 \%$ & $27,4 \%$ \\
Cimento $\left(\mathrm{kg} / \mathrm{m}^{3}\right)$ & 362,5 & 333,8 \\
Água $\left(\mathrm{kg} / \mathrm{m}^{3}\right)$ & 181,3 & 166,9 \\
Superplastificante $\left(\mathrm{kg} / \mathrm{m}^{3}\right)$ & 6,2 & 5,7 \\
Filler $\left(\mathrm{kg} / \mathrm{m}^{3}\right)$ & 108,7 & 100,1 \\
Areia 1 $\left(\mathrm{kg} / \mathrm{m}^{3}\right)$ & 710,9 & 602,5 \\
Areia 2 $\left(\mathrm{kg} / \mathrm{m}^{3}\right)$ & 397,8 & 337,1 \\
Brita 1 $\left(\mathrm{kg} / \mathrm{m}^{3}\right)$ & 525,9 & 447,3 \\
Brita 2 $\left(\mathrm{kg} / \mathrm{m}^{3}\right)$ & - & 328,5 \\
\hline
\end{tabular}

Assim, a Tabela 6.9 mostra os resultados obtidos para o CAA1 e CAA2.

Tabela 6.9 Variabilidade do CAA1 e do CAA2 no estado fresco

\begin{tabular}{|c|c|c|c|c|c|c|c|c|}
\hline $\begin{array}{l}\text { CAA1 } \\
\text { Ensaio }\end{array}$ & 1 & 2 & 3 & 4 & 5 & $\mathbf{M}$ & D.P. & C.V. \\
\hline Temp. $\left({ }^{\circ} \mathrm{C}\right)=$ & 22 & 22 & 22,5 & 23 & 23 & 22,50 & 0,50 & $2,22 \%$ \\
\hline $\begin{array}{l}\text { Umidade }(\%)= \\
\text { Espalhamento }\end{array}$ & 66 & 83 & 75 & 75 & 72 & 74,20 & 6,14 & $8,27 \%$ \\
\hline $\mathrm{T}_{50}(\mathrm{~s})=$ & 1,0 & 1,5 & 1,0 & 1,0 & 1,0 & 1,10 & 0,22 & $20,33 \%$ \\
\hline $\begin{array}{l}D_{e}(\mathrm{~cm})= \\
\text { Caixa-L }\end{array}$ & 74,0 & 69,5 & 71,25 & 65,5 & 63,5 & 68,75 & 4,26 & $6,19 \%$ \\
\hline$T_{60}(s)=$ & 1,0 & 2,0 & 1,5 & 2,0 & 1,5 & 1,60 & 0,42 & $26,15 \%$ \\
\hline $\begin{array}{l}\mathrm{CB}= \\
\text { Funil-V }\end{array}$ & 1,0 & 0,92 & 0,84 & 0,88 & 0,79 & 0,89 & 0,08 & $9,02 \%$ \\
\hline $\begin{array}{l}T_{V}(s)= \\
\text { Anel-J }\end{array}$ & 2,5 & 4,0 & 4,0 & 4,0 & 4,0 & 3,70 & 0,67 & $18,13 \%$ \\
\hline$T_{50}(s)=$ & 1,0 & 2,0 & 1,0 & 1,5 & 1,0 & 1,30 & 0,45 & $34,40 \%$ \\
\hline$D_{J}(\mathrm{~cm})=$ & 74,25 & 65,5 & 66,5 & 62,5 & 65,5 & 66,85 & 4,40 & $6,58 \%$ \\
\hline $\mathrm{CB}=$ & 1,0 & 0,85 & 0,75 & 0,8 & 0,77 & 0,83 & 0,10 & $12,01 \%$ \\
\hline $\begin{array}{l}\text { Densidade } \\
\rho\left(\mathrm{kg} / \mathrm{m}^{3}\right) \\
\end{array}$ & 2400,41 & 2386,04 & 2386,04 & 2388,09 & 2388,09 & 2389,73 & 6,06 & $0,25 \%$ \\
\hline $\begin{array}{l}\text { CAA2 } \\
\text { Ensaio }\end{array}$ & 1 & 2 & 3 & 4 & 5 & $\mathbf{M}$ & D.P. & C.V. \\
\hline Temp. $\left({ }^{\circ} \mathrm{C}\right)=$ & 23 & 22 & 22 & 22,5 & 22,5 & 22,40 & 0,42 & $1,87 \%$ \\
\hline $\begin{array}{l}\text { Umidade }(\%)= \\
\text { Espalhamento }\end{array}$ & 66 & 73 & 89 & 67 & 73 & 73,60 & 9,21 & $12,51 \%$ \\
\hline$T_{50}(s)=$ & 1,0 & 1,0 & 1,3 & 1,3 & 1,5 & 1,22 & 0,22 & $17,77 \%$ \\
\hline $\begin{array}{l}D_{e}(\mathrm{~cm})= \\
\text { Caixa-L }\end{array}$ & 74,0 & 66,5 & 66 & 58,5 & 55,75 & 64,15 & 7,22 & $11,25 \%$ \\
\hline$T_{60}(s)=$ & 1,0 & 2,0 & 2,0 & 3,0 & 2,4 & 2,08 & 0,73 & $35,07 \%$ \\
\hline $\mathrm{CB}=$ & 0,95 & 0,8 & 0,8 & 0,44 & 0,59 & 0,72 & 0,20 & $28,01 \%$ \\
\hline $\begin{array}{l}\text { Funil-V } \\
T_{\vee}(s)= \\
\text { Anel-J }\end{array}$ & 5,0 & 4,8 & 6,9 & 7,1 & 12,4 & 7,24 & 3,07 & $42,42 \%$ \\
\hline$T_{50}(s)=$ & 1,0 & 1,2 & 2,5 & 1,6 & 1,5 & 1,56 & 0,58 & $36,99 \%$ \\
\hline$D_{J}(\mathrm{~cm})=$ & 73,5 & 66,5 & 52,5 & 53,5 & 56 & 60,40 & 9,20 & $15,22 \%$ \\
\hline $\begin{array}{l}\mathrm{CB}= \\
\text { Densidade }\end{array}$ & 1,0 & 0,7 & 0,58 & 0,67 & 0,65 & 0,72 & 0,16 & $22,59 \%$ \\
\hline$\rho\left(\mathrm{kg} / \mathrm{m}^{3}\right)$ & 2400,41 & 2404,52 & 2383,98 & 2404,52 & 2390,14 & 2396,71 & 9,23 & $0,39 \%$ \\
\hline
\end{tabular}


A Figura 6.4 mostra alguns dos ensaios feitos para o CAA1.
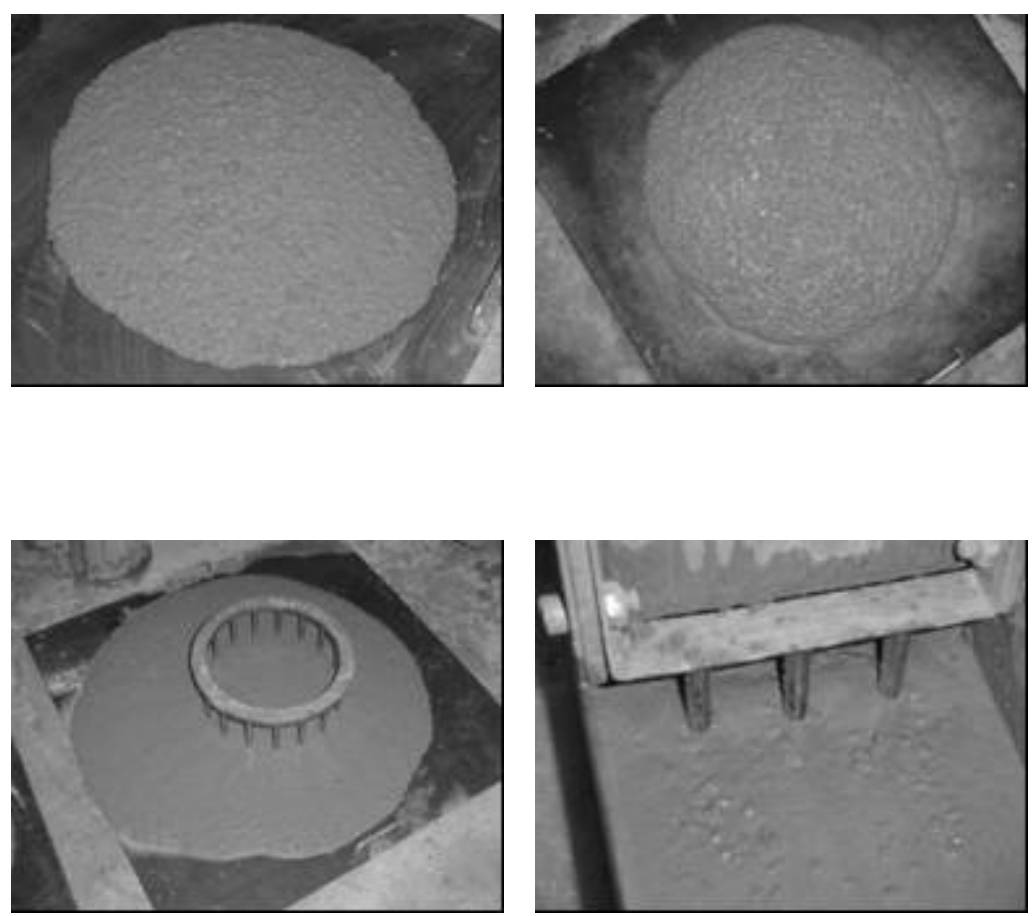

Figura 6.4 Ensaios realizados para o CAA1

A Figura 6.5 mostra alguns dos ensaios feitos para o CAA2.
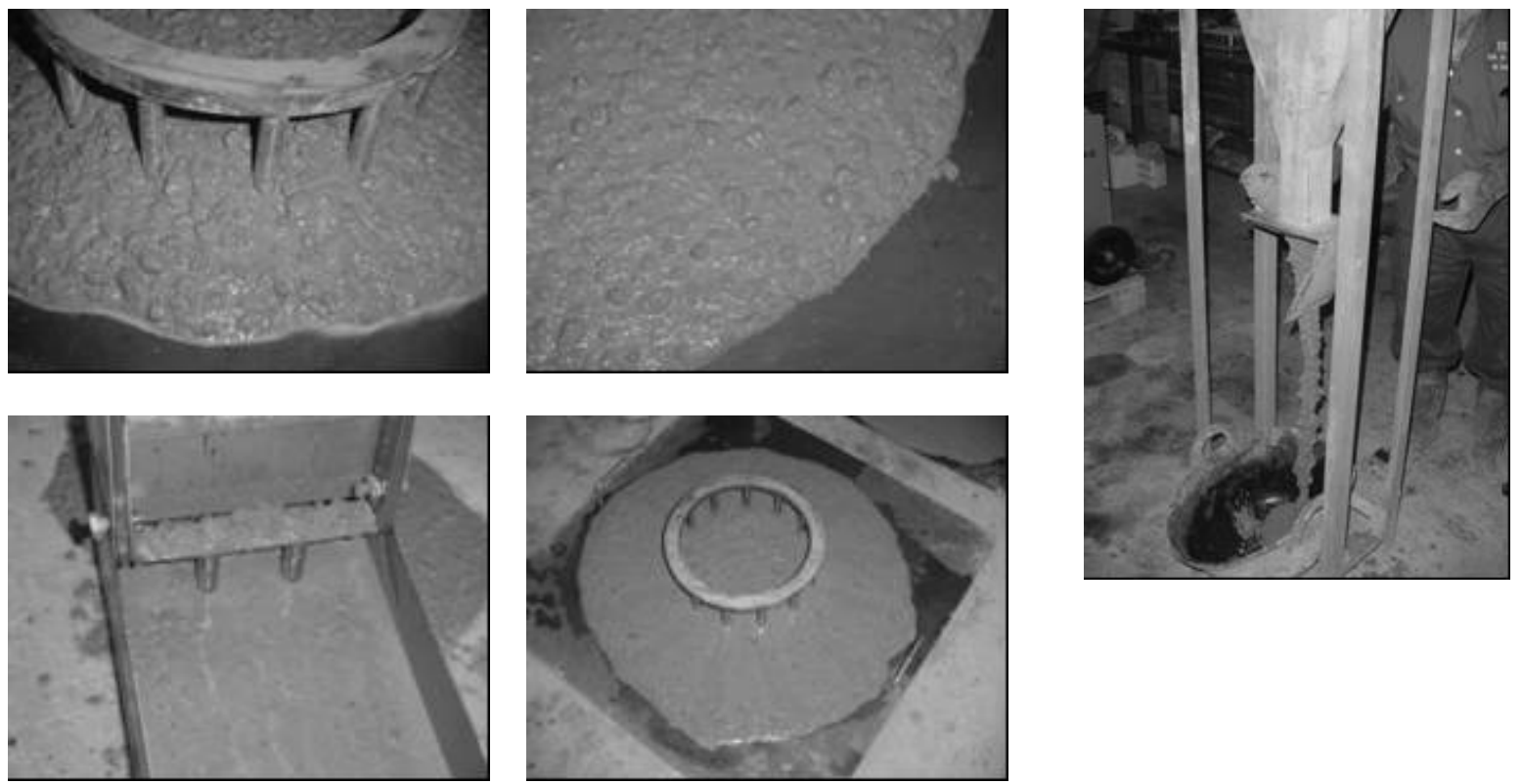

Figura 6.5 Ensaios realizados para o CAA2 


\subsection{Variabilidade do concreto auto-adensável no estado endurecido}

O estudo da variabilidade do CAA no estado endurecido teve como objetivo avaliar, em condições de laboratório, a variação de suas propriedades mecânicas, sendo elas a resistência à tração, resistência à compressão e o módulo de elasticidade.

Para os ensaios foi utilizada a ASTM C496 (1996) para os ensaios a compressão indireta (ensaio brasileiro). A ASTM E111-04 (2004) para a determinação do módulo de elasticidade e, para a resistência à compressão, a ENV 197 (1996).

A Tabela 6.10 mostra a composição de cada um dos CAA utilizados.

Tabela 6.10 Composição do traço para o estudo da variabilidade no estado endurecido

\begin{tabular}{lccc}
\hline & CAA1 & CAA2 & CAA3 \\
\hline $\mathrm{V}_{\text {pasta }}(\%)$ & $38 \%$ & $34,5 \%$ & $35 \%$ \\
$\mathrm{~V}_{\text {areia }}(\%)$ & $42,2 \%$ & $36 \%$ & $35 \%$ \\
$\mathrm{~V}_{\text {brita }}(\%)$ & $19,8 \%$ & $29,5 \%$ & $29,3 \%$ \\
Índice de vazios $(\%)$ & $29,2 \%$ & $27,4 \%$ & $27,4 \%$ \\
Cimento $\left(\mathrm{kg} / \mathrm{m}^{3}\right)$ & 362,5 & 329,0 & 333,8 \\
Água $\left(\mathrm{kg} / \mathrm{m}^{3}\right)$ & 181,3 & 164,8 & 166,9 \\
Superplastificante $\left(\mathrm{kg} / \mathrm{m}^{3}\right)$ & 6,2 & 5,6 & 5,7 \\
Filler $\left(\mathrm{kg} / \mathrm{m}^{3}\right)$ & 108,7 & 98,7 & 100,1 \\
Areia 1 $\left(\mathrm{kg} / \mathrm{m}^{3}\right)$ & 710,9 & 607,1 & 602,5 \\
Areia 2 $\left(\mathrm{kg} / \mathrm{m}^{3}\right)$ & 397,8 & 339,7 & 337,1 \\
Brita 1 $\left(\mathrm{kg} / \mathrm{m}^{3}\right)$ & 525,9 & 450,7 & 447,3 \\
Brita 2 $\left(\mathrm{kg} / \mathrm{m}^{3}\right)$ & - & 330,0 & 328,5 \\
\hline
\end{tabular}

Os resultados para o estado fresco podem ser vistos na Tabela 6.11.

Tabela 6.11 Resultados para o estado fresco para o CAA1, CAA2 e CAA3

\begin{tabular}{lccc}
\hline & CAA1 & CAA2 & CAA3 \\
\hline Temp. $\left({ }^{\circ} \mathrm{C}\right)=$ & 22 & 22 & 23 \\
Umidade (\%) $=$ & 66 & 78 & 66 \\
Espalhamento & & & \\
$\mathrm{T}_{50}(\mathrm{~s})=$ & 1,0 & 1,5 & 1,0 \\
$\mathrm{D}_{\mathrm{e}}(\mathrm{cm})=$ & 74,0 & 57,0 & 74,0 \\
Caixa-L & & & \\
$\mathrm{T}_{60}(\mathrm{~s})=$ & 1,0 & 3,0 & 1,0 \\
$\mathrm{CB}=$ & 1,0 & 0,7 & 0,95 \\
Funil-V & & & \\
$\mathrm{T}_{\mathrm{V}}(\mathrm{s})=$ & 2,5 & 5,5 & 5,0 \\
Anel-J & 1,0 & 2,0 & 1,0 \\
$\mathrm{~T}_{50}(\mathrm{~s})=$ & 14,25 & 55,5 & 73,5 \\
$\mathrm{D}_{\mathrm{J}}(\mathrm{cm})=$ & & 0,77 & 1,0 \\
CB $=$ & & & \\
Densidade & 1,0 & & \\
$\rho\left(\mathrm{kg} / \mathrm{m}^{3}\right)$ & 2400,41 & 2420,95 & 2425,21 \\
\hline
\end{tabular}


Para a análise no estado endurecido, todos os corpos-de-prova de cada traço tiveram seus pesos determinados para verificação da densidade do CP no estado endurecido.

Todos os corpos-de-prova foram levados a uma câmara úmida $(90 \%<$ UR<95\%) por 26 dias, quando depois eram capeados para ensaio.

Os ensaios foram realizados com uma máquina de ensaios lbertest, disponível no Laboratorio de Tecnología de Estructuras. A Tabela 6.12 mostra os resultados para o CAA1 no estado endurecido.

Vale salientar que os valores mostrados para o CAA1, CAA2 e CAA3 já passaram por um tratamento estatístico para eliminação de valores que, de acordo com um diagrama em papel probabilístico, que apontou valores que estavam fora da distribuição normal.

Tabela 6.12 Resultados para o CAA1 aos 28 dias

\begin{tabular}{cccccc}
\hline $\mathbf{C P}$ & $\mathbf{P e s o} \mathbf{( k g )}$ & $\mathbf{\rho}\left(\mathbf{k g} / \mathbf{m}^{3}\right)$ & $\left.\mathbf{E}_{\mathrm{cM}} \mathbf{( M P a}\right)$ & $\left.\mathbf{f}_{\mathrm{c}} \mathbf{( M P a}\right)$ & $\mathbf{f}_{\mathbf{t}}(\mathbf{M P a})$ \\
\hline 1 & 12,39 & 2337,17 & 36143,00 & 47,70 & \\
2 & 12,62 & 2380,56 & 38256,50 & 48,59 & \\
3 & 12,43 & 2344,72 & 36387,00 & 46,56 & \\
4 & 12,53 & 2363,58 & 37050,50 & 42,38 & \\
5 & 12,36 & 2331,51 & 36076,00 & 45,54 & \\
6 & 12,36 & 2331,51 & 35581,00 & 47,39 & \\
7 & 12,45 & 2348,49 & 36932,00 & 47,19 & \\
8 & 12,48 & 2354,15 & 37389,50 & 45,75 & \\
9 & 12,48 & 2354,15 & 36485,00 & 49,10 & \\
10 & 12,42 & 2342,83 & 37211,50 & 47,98 & \\
11 & 12,36 & 2331,51 & 35670,50 & 41,90 & \\
12 & 12,54 & 2365,47 & 36862,50 & & 4,40 \\
13 & 12,44 & 2346,60 & 36504,50 & & 2,64 \\
14 & 12,53 & 2363,58 & 36949,00 & & 3,95 \\
15 & 12,55 & 2367,35 & 36183,50 & & 4,06 \\
16 & 12,36 & 2331,51 & 35176,50 & & 2,81 \\
17 & 12,49 & 2356,03 & 37292,00 & & 3,38 \\
18 & 12,44 & 2346,60 & 35570,50 & & 3,67 \\
19 & 12,43 & 2344,72 & 36416,00 & & 4,45 \\
20 & 12,37 & 2333,40 & 36141,50 & & 3,96 \\
21 & 12,45 & 2348,49 & 36514,00 & & 4,00 \\
22 & 12,41 & 2340,94 & 35315,50 & & 3,65 \\
\hline $\mathbf{M}$ & 12,45 & 2348,40 & 36459,45 & 46,37 & 3,72 \\
D.P. & 0,07 & 13,60 & 752,90 & 2,36 & 0,58 \\
C.V. (\%) & $0,58 \%$ & $0,58 \%$ & $2,07 \%$ & $5,08 \%$ & $15,69 \%$ \\
\hline
\end{tabular}

Dois CP's foram utilizados para estimar a resistência à compressão do CAA e, a partir daí, tinha-se o valor da força aplicada para a determinação do módulo de elasticidade (1/3 da força de ruptura). Um fator que prejudicou e reduziu a quantidade de CP's foi o material utilizado para o capeamento, pois alguns tiveram ruptura prematura. 
A Figura 6.6 mostra a variação das propriedades no estado endurecido para o CAA1.
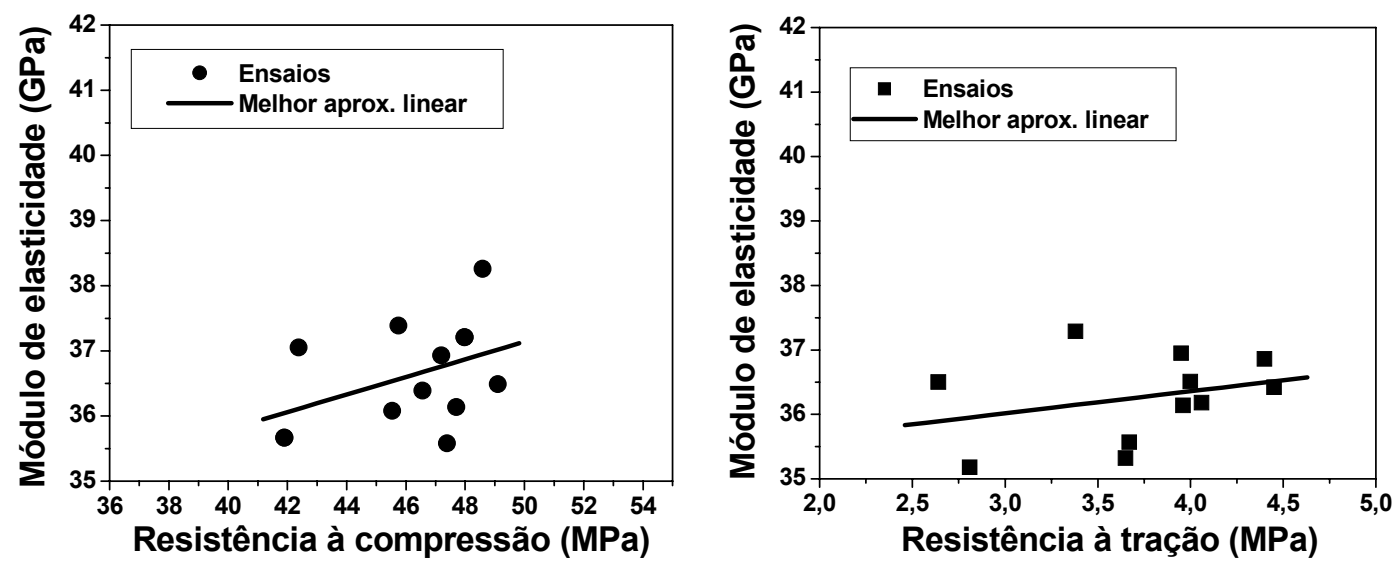

Figura 6.6 Resultados da variabilidade das propriedades no estado endurecido para o CAA1

A Tabela 6.13 mostra os resultados para o CAA2 no estado endurecido.

Tabela 6.13 Resultados para o CAA2 aos 28 dias

\begin{tabular}{cccccc}
\hline $\mathbf{C P}$ & $\mathbf{P e s o} \mathbf{( k g )}$ & $\mathbf{\rho}\left(\mathbf{k g} / \mathbf{m}^{\mathbf{3}}\right)$ & $\left.\mathbf{E}_{\mathbf{c M}} \mathbf{( M P a}\right)$ & $\mathbf{f}_{\mathbf{c}}(\mathbf{M P a})$ & $\mathbf{f}_{\mathbf{t}}(\mathbf{M P a})$ \\
\hline 1 & 12,59 & 2374,90 & 39090,50 & 50,50 & \\
2 & 12,61 & 2378,67 & 39667,50 & 48,23 & \\
3 & 12,62 & 2380,56 & 40587,00 & $42,74^{*}$ & \\
4 & 12,57 & 2371,12 & 38570,00 & 50,70 & \\
5 & 12,49 & 2356,03 & 38323,50 & 50,62 & \\
6 & 12,52 & 2361,69 & 38612,50 & 50,62 & \\
7 & 12,48 & 2354,15 & 38389,00 & 49,21 & \\
8 & 12,55 & 2367,35 & 39285,50 & 49,48 & \\
9 & 12,61 & 2378,67 & 38860,00 & 49,59 & \\
10 & 12,55 & 2367,35 & 37984,00 & $40,98^{*}$ & \\
11 & 12,51 & 2359,81 & 38031,50 & 49,85 & \\
12 & 12,54 & 2365,47 & 39148,50 & 49,60 & \\
13 & 12,55 & 2367,35 & 38762,50 & & 3,42 \\
14 & 12,63 & 2382,44 & $31483,00^{*}$ & & 3,40 \\
15 & 12,52 & 2361,69 & 39736,00 & & 3,27 \\
16 & 12,57 & 2371,12 & $31373,50 *$ & & 4,45 \\
17 & 12,59 & 2374,90 & 40089,50 & & 4,25 \\
18 & 12,61 & 2378,67 & 39332,50 & & 3,57 \\
19 & 12,54 & 2365,47 & 39511,50 & & 4,19 \\
20 & 12,57 & 2371,12 & 38915,00 & & 3,17 \\
21 & 12,50 & 2357,92 & 38245,50 & & 3,61 \\
22 & 12,62 & 2380,56 & 38982,00 & & 3,80 \\
23 & 12,44 & 2346,60 & 38605,50 & & 4,09 \\
24 & 12,59 & 2374,90 & 38894,50 & & 3,51 \\
\hline $\mathbf{M}$ & 12,56 & 2368,69 & 38982,90 & 49,84 & 3,73 \\
D.P. & 0,05 & 9,51 & 659,22 & 0,79 & 0,42 \\
C.V. (\%) & $0,38 \%$ & $0,38 \%$ & $1,69 \%$ & $1,59 \%$ & $11,32 \%$ \\
\hline
\end{tabular}

* Não levado em consideração para a análise estatística 
A Figura 6.7 mostra a variação das propriedades no estado endurecido para o CAA2.
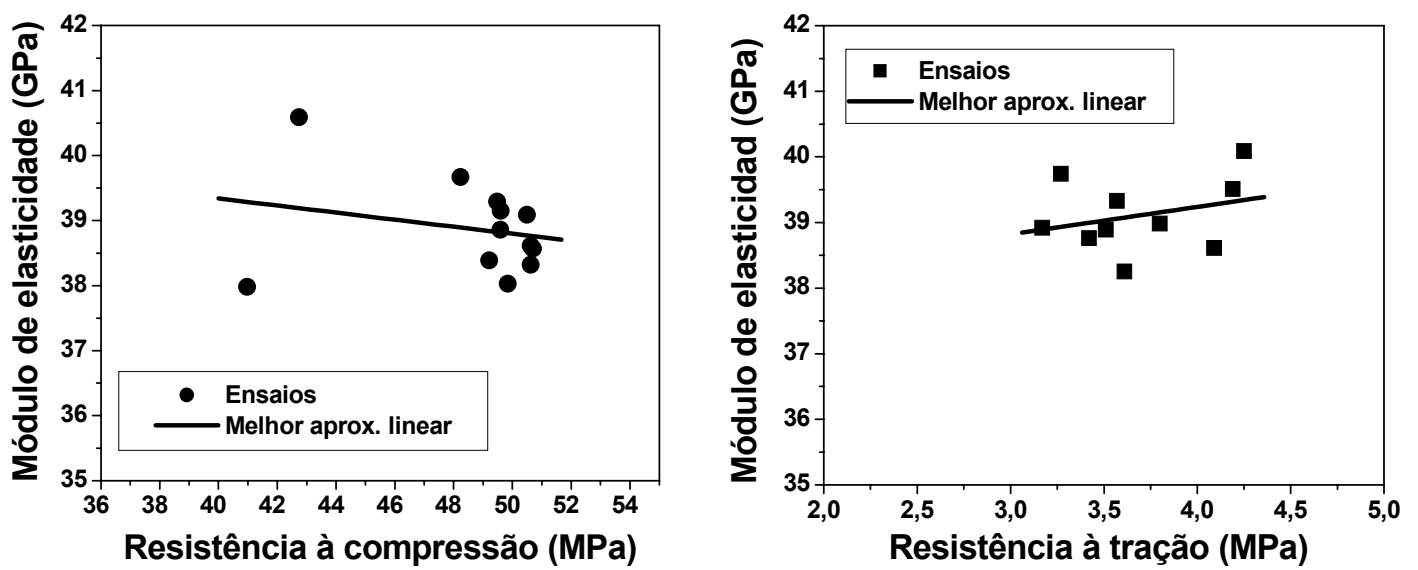

Figura 6.7 Resultados da variabilidade das propriedades no estado endurecido para o CAA2

A Tabela 6.14 mostra os resultados para o CAA3 no estado endurecido.

Tabela 6.14 Resultados para o CAA3 aos 28 dias

\begin{tabular}{cccccc}
\hline $\mathbf{C P}$ & Peso $\mathbf{( k g )}$ & $\mathbf{\rho}\left(\mathbf{k g} / \mathbf{m}^{\mathbf{3}}\right)$ & $\mathbf{E}_{\mathbf{c M}}(\mathbf{M P a})$ & $\mathbf{f}_{\mathbf{c}}(\mathbf{M P a})$ & $\mathbf{f}_{\mathbf{t}}(\mathbf{M P a})$ \\
\hline 1 & 12,59 & 2374,90 & 37856,50 & 44,47 & \\
2 & 12,62 & 2380,56 & 37745,00 & 43,34 & \\
3 & 12,7 & 2395,65 & 37953,00 & 38,08 & \\
4 & 12,68 & 2391,87 & 38776,50 & 43,53 & \\
5 & 12,63 & 2382,44 & 38238,50 & 42,82 & \\
6 & 12,43 & 2344,72 & 36497,50 & 43,46 & \\
7 & 12,66 & 2388,10 & 38449,00 & 45,99 & \\
8 & 12,58 & 2373,01 & 38039,50 & 39,72 & \\
9 & 12,72 & 2399,42 & 38821,00 & 41,19 & \\
10 & 12,60 & 2376,78 & 38095,00 & 43,47 & \\
11 & 12,42 & 2342,83 & 36728,00 & & 3,75 \\
12 & 12,64 & 2384,33 & 38539,00 & & 2,74 \\
13 & 12,59 & 2374,90 & 37612,50 & & 2,44 \\
14 & 12,78 & 2410,74 & 39217,50 & & 3,05 \\
15 & 12,55 & 2367,35 & 36765,00 & & 2,47 \\
16 & 12,46 & 2350,38 & 35354,50 & & 3,10 \\
17 & 12,57 & 2371,12 & 39695,00 & & 3,59 \\
18 & 12,65 & 2386,22 & 39551,50 & & 3,94 \\
19 & 12,6 & 2376,78 & 38669,00 & & 3,12 \\
20 & 12,62 & 2380,56 & 37154,00 & & 3,36 \\
\hline $\mathbf{M}$ & 12,60 & 2377,63 & 37987,88 & 42,61 & 3,16 \\
D.E. & 0,09 & 17,15 & 1085,72 & 2,33 & 0,51 \\
C.V. $(\%)$ & $0,72 \%$ & $0,72 \%$ & $2,86 \%$ & $5,46 \%$ & $16,25 \%$ \\
\hline
\end{tabular}

A Figura 6.8 mostra a variação das propriedades no estado endurecido para o CAA2. 

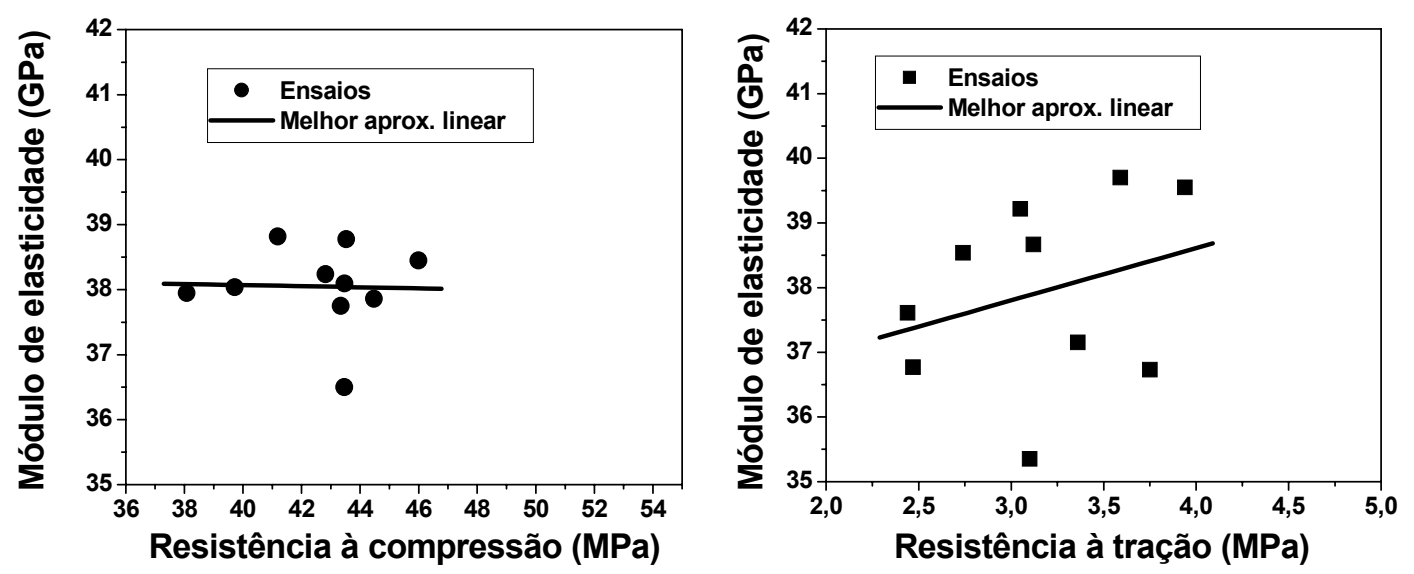

Figura 6.8 Resultados da variabilidade das propriedades no estado endurecido para o CAA3

A Figura 6.9 ilustra a variação do módulo de elasticidade em função da densidade de cada corpo-de-prova (CP).
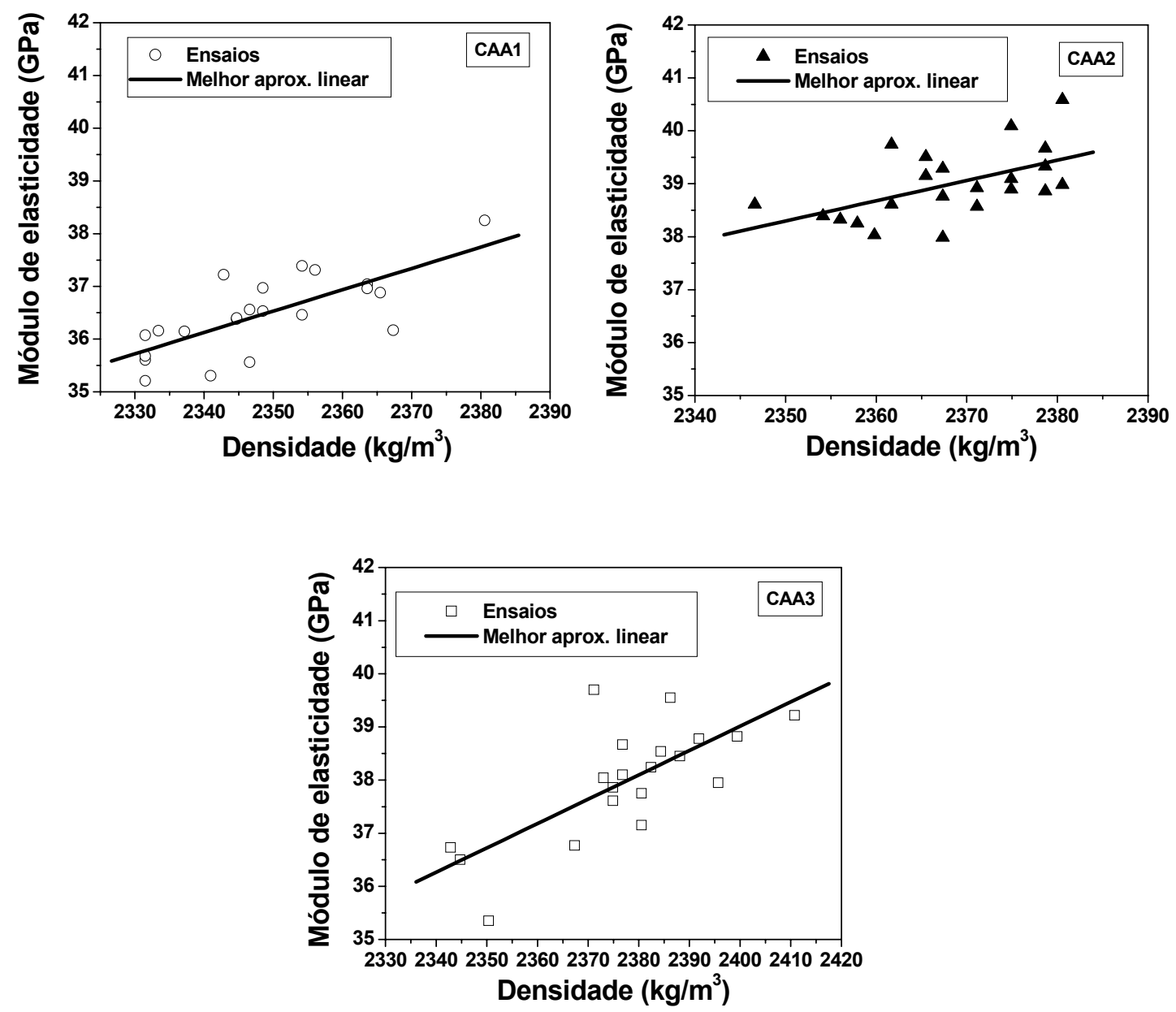

Figura 6.9 Resultados da variabilidade do módulo de elasticidade em função da densidade de cada corpo-de-prova para o CAA1, CAA2 3 CAA3 


\subsection{Variabilidade da aderência do concreto auto-adensável}

\subsubsection{Materiais e equipamentos utilizados}

Os materiais e equipamentos utilizados foram os mesmos da investigação experimental sobre a variabilidade do CAA no estado endurecido.

\subsubsection{Aço}

Para o estudo da resistência de aderência foram utilizadas barras de aço com diâmetro nominal de $12 \mathrm{~mm}$. A Figura 6.10 ilustra o diagrama tensão vs. deformação das barras de aço de $12 \mathrm{~mm}$.

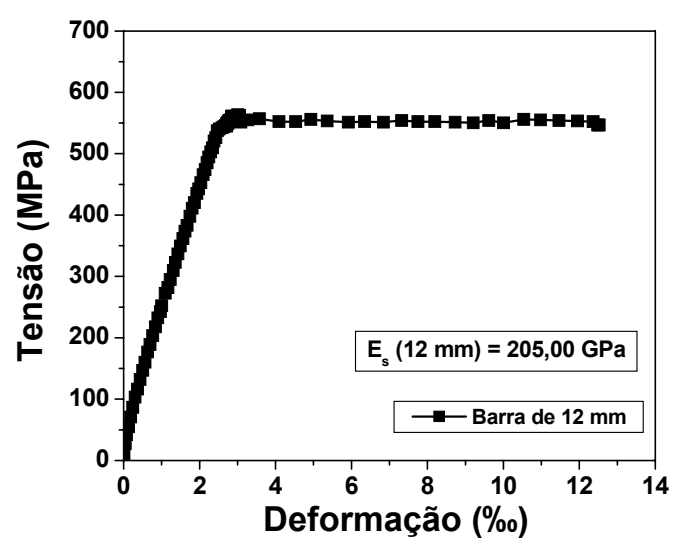

Figura 6.10 Diagrama tensão vs. deformação para as barras de aço de $12 \mathrm{~mm}$

\subsubsection{Concreto}

OS materiais componentes dos concretos auto-adensáveis deste programa de ensaios foram os mesmos do programa de ensaios de variabilidade no estado fresco e endurecido.

\subsubsection{Equipamentos utilizados}

Os equipamentos utilizados para este programa experimental foram:

- Betoneira de eixo vertical com capacidade de 220l;

- Equipamentos de caixa-L, funil-V e anel-J para verificação do CAA;

- Máquina capeadora de CP;

- Câmara úmida;

- Máquina de ensaios universal, Instron, para ensaio das vigas; 
- Transdutores de deslocamento de $10 \mathrm{~mm}$ de curso;

- Máquina de ensaios universal, Ibertest, para ensaio dos CP's;

\subsubsection{Programa de ensaios}

Os ensaios para avaliação da resistência de aderência foram desenvolvidos com modelos de viga, em fôrmas de aço, disponíveis no Laboratorio de Tecnología de Estructuras. Para cada série de ensaios foram moldadas 8 (oito) vigas, de acordo com a Figura 6.11 e Figura 6.12.
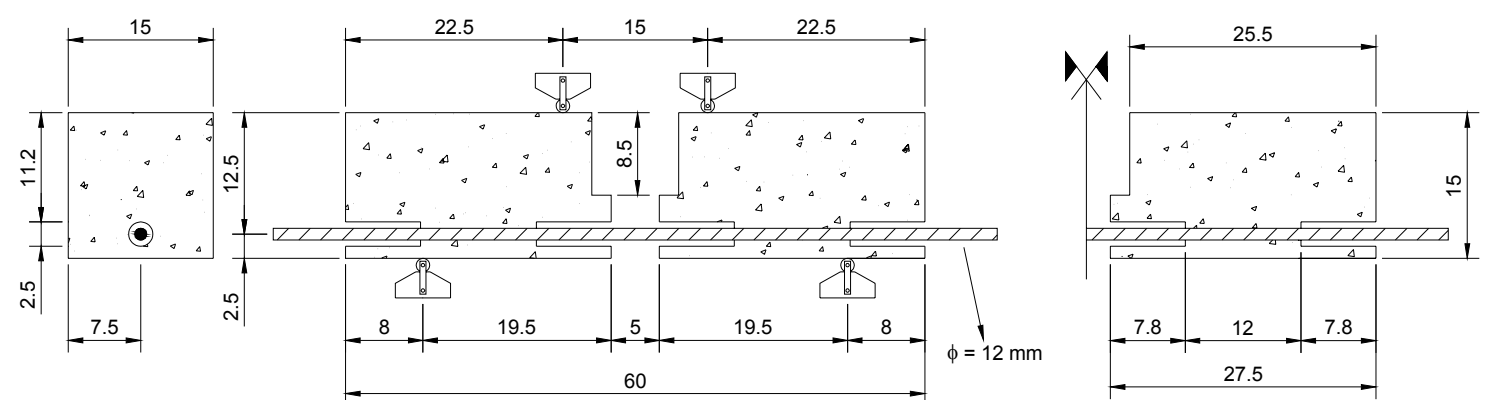

Figura 6.11 Dimensões das vigas para ensaio de resistência de aderência $(\mathrm{em} \mathrm{cm})$
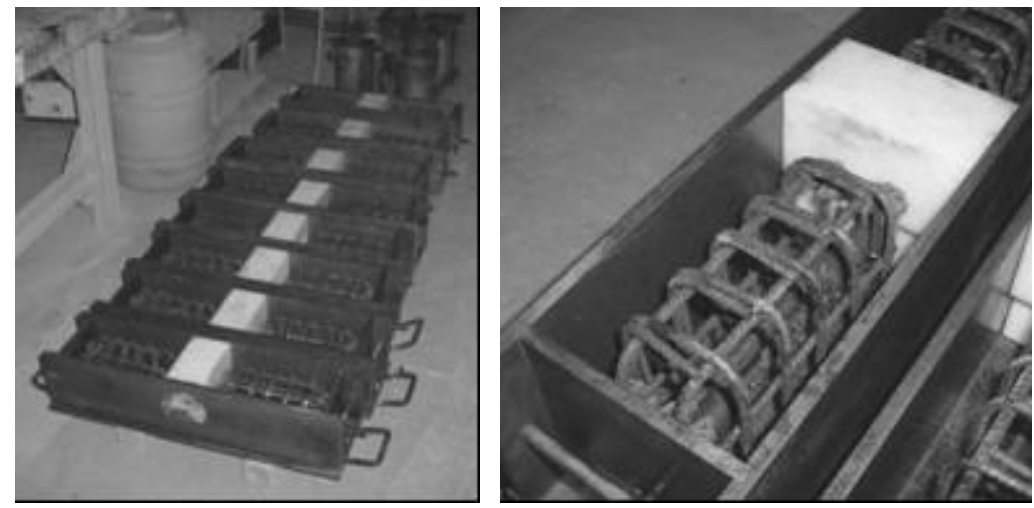

Figura 6.12 Fôrmas das vigas e armadura de confinamento

A armadura para as vigas foi a mesma estabelecida pelo Rilem-Ceb-Fip (1973) e a EHE (1999) com uma pequena modificação na altura da armadura para respeitar o cobrimento de $1 \mathrm{~cm}$.

A Tabela 6.15 mostra as séries de ensaios e como foram divididas. 
Tabela 6.15 Séries e composição do traço para os ensaios de viga

\begin{tabular}{|c|c|c|c|}
\hline & C1 & C2 & C3 \\
\hline $\mathrm{V}_{\text {pasta }}(\%)$ & $35 \%$ & $38 \%$ & $35 \%$ \\
\hline$V_{\text {areia }}(\%)$ & $35,7 \%$ & $42,2 \%$ & $35,7 \%$ \\
\hline $\mathrm{V}_{\text {brita }}(\%)$ & $29,3 \%$ & $19,8 \%$ & $29,3 \%$ \\
\hline Índice de vazios (\%) & $27,4 \%$ & $29,2 \%$ & $27,4 \%$ \\
\hline Cimento $\left(\mathrm{kg} / \mathrm{m}^{3}\right)$ & 333,8 & 362,5 & 333,8 \\
\hline Água $\left(\mathrm{kg} / \mathrm{m}^{3}\right)$ & 166,9 & 181,3 & 166,9 \\
\hline Superplastificante $\left(\mathrm{kg} / \mathrm{m}^{3}\right)$ & 5,7 & 6,2 & 5,9 \\
\hline Filler $\left(\mathrm{kg} / \mathrm{m}^{3}\right)$ & 100,1 & 108,7 & 100,1 \\
\hline Areia $1\left(\mathrm{~kg} / \mathrm{m}^{3}\right)$ & 602,5 & 710,9 & 602,5 \\
\hline Areia $2\left(\mathrm{~kg} / \mathrm{m}^{3}\right)$ & 337,1 & 397,8 & 337,1 \\
\hline Brita $1\left(\mathrm{~kg} / \mathrm{m}^{3}\right)^{\prime}$ & 447,3 & 525,9 & 447,3 \\
\hline Brita $2\left(\mathrm{~kg} / \mathrm{m}^{3}\right)$ & 328,5 & - & 328,5 \\
\hline \multicolumn{4}{|l|}{ Ensaios } \\
\hline $\operatorname{Temp} .\left({ }^{\circ} \mathrm{C}\right)=$ & 20 & 17 & 20 \\
\hline \multirow{2}{*}{\multicolumn{4}{|c|}{ Espalhamento }} \\
\hline & & & \\
\hline$T_{50}(s)=$ & 2,0 & 1,2 & 1,0 \\
\hline$D_{e}(\mathrm{~cm})=$ & 50,0 & 64,0 & 64,0 \\
\hline \multicolumn{4}{|l|}{ Caixa-L } \\
\hline $\mathrm{T}_{60}(\mathrm{~s})=$ & 2,3 & 1,6 & 1,9 \\
\hline $\mathrm{CB}=$ & 0,63 & 0,84 & 0,86 \\
\hline \multicolumn{4}{|l|}{ Funil-V } \\
\hline$T_{V}(s)=$ & 6,2 & 3,6 & 7,6 \\
\hline \multicolumn{4}{|l|}{ Anel-J } \\
\hline$T_{50}(s)=$ & 3,0 & 1,6 & 2,3 \\
\hline$D_{J}(\mathrm{~cm})=$ & 50,0 & 62,3 & 64,0 \\
\hline $\mathrm{CB}=$ & 0,60 & 0,80 & 0,80 \\
\hline \multicolumn{4}{|l|}{ Densidade } \\
\hline$\rho\left(\mathrm{kg} / \mathrm{m}^{3}\right)$ & 2390,1 & 2390,1 & 2390,1 \\
\hline
\end{tabular}

A Figura 6.13 mostra o ensaio de espalhamento de cada CAA e a concretagem dos modelos de viga.
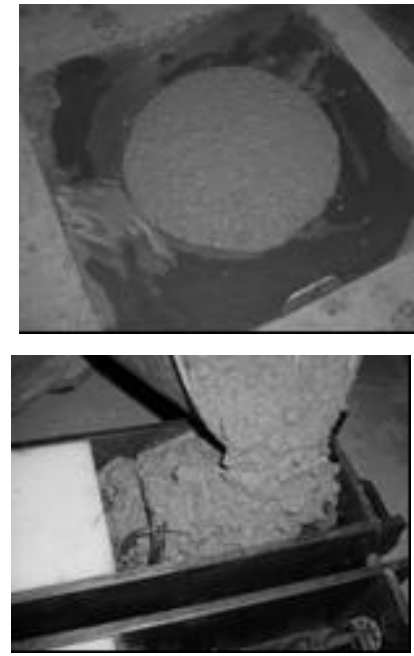

Série C1
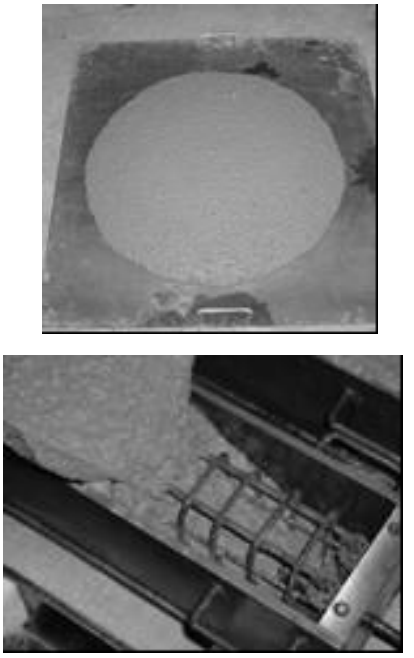

Série C2
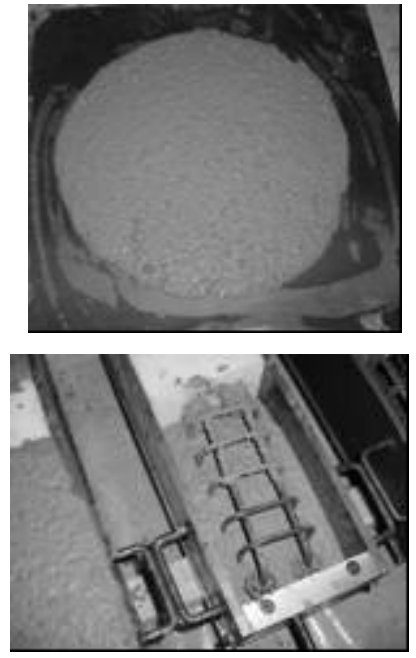

Série C3

Figura 6.13 Ensaio de espalhamento e concretagem das vigas em CAA 
A Figura 6.14 mostra a montagem do primeiro equipamento de ensaios na máquina Instron. Vale comentar que o primeiro aparato utilizado não foi adequado e foi modificado por outro, que era utilizado pela máquina Ibertest.

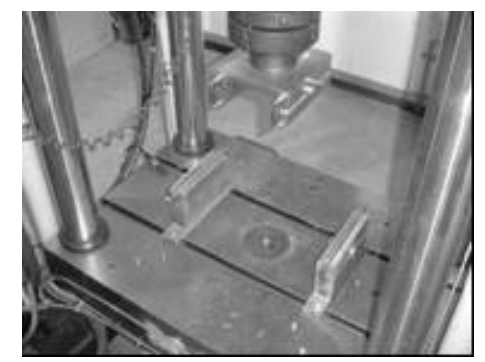

a) Aparato para ensaio

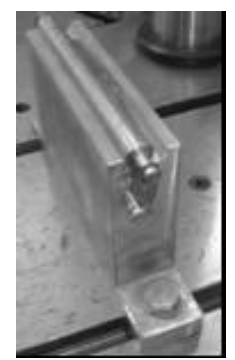

b) apoios inferiores

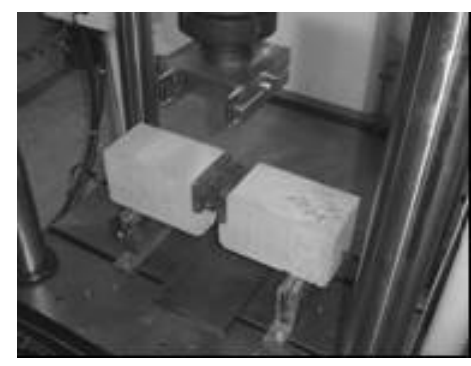

c) Aparato com viga

Figura 6.14 Aparato inicial de ensaio das vigas

Esse aparato de ensaio não foi adequado, pois os apoios inferiores não permitiam a rotação da rótula no apoio e, para grandes deslocamentos, havia o deslocamento da rótula que alcançava uma restrição ao deslocamento ao final do percurso existente no aparato. Essa falta de deslocamento no apoio provocava um aumento das suas reações e acarretava um confinamento na região, tornando-a mais frágil. Por isso, a viga inicialmente ensaiada com esse aparato apresentou um comportamento distinto das demais da mesma série. Por causa dessa dificuldade, o aparato foi trocado por outro, especificado pela EHE (1999).

O segundo aparato foi mais adequado, pois apresentava uma rótula que girava livremente no apoio, apesar de não poder deslocar-se (Figura 6.15).

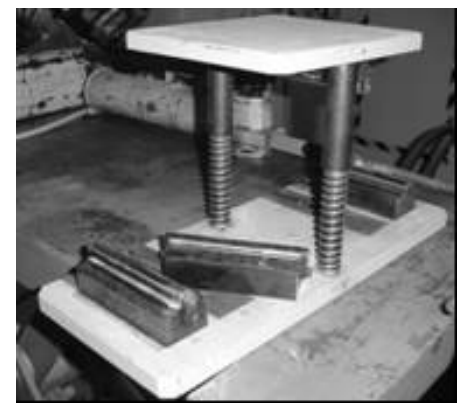

a) Aparato para ensaio

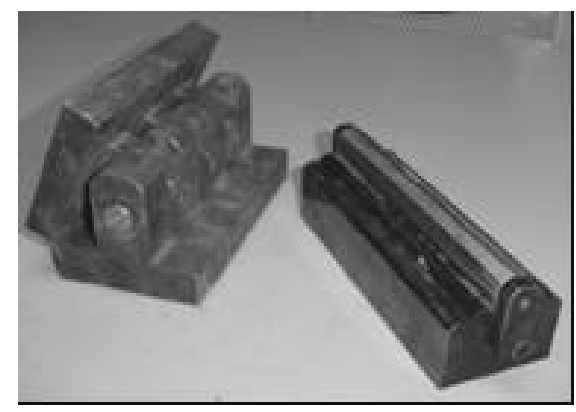

b) Rótula e forma do apoios

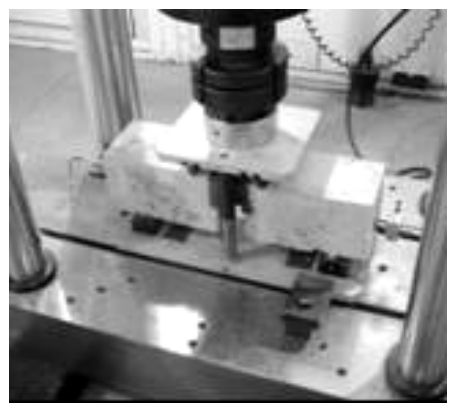

c) Aparato com viga

Figura 6.15 Aparato utilizado para os ensaios de viga

A aplicação do carregamento às vigas foi do tipo monotônico e com velocidade de deslocamento do pistão de 0,05 mm/s. 


\subsubsection{Resultados}

O ensaio foi conduzido com deslocamento constante e era interrompido caso a flecha máxima do aparato de ensaio fosse alcançada (cerca de $30 \mathrm{~mm}$ ) ou quando era atingido o deslocamento máximo disponível pelo LVDT.

\subsubsection{Série $\mathrm{C} 1$}

O concreto auto-adensável, $\mathrm{C} 1$, foi caracterizado como um concreto de pouca fluidez e o objetivo era avaliar a influência da fluidez na resistência de aderência.

A Tabela 6.16 mostra as propriedades mecânicas da série $\mathrm{C} 1$ aos 28 dias.

Tabela 6.16 Propriedades mecânicas da série $\mathrm{C} 1$ aos 28 dias

\begin{tabular}{cccc}
\hline & $\begin{array}{c}\mathbf{M} \\
(\mathbf{M P a})\end{array}$ & $\begin{array}{c}\text { D.P. } \\
(\mathbf{M P a})\end{array}$ & $\begin{array}{c}\text { C.V. } \\
(\%)\end{array}$ \\
\hline $\mathbf{f}_{\mathrm{c}, 28}$ & 51,77 & 0,18 & $0,36 \%$ \\
$\mathbf{E}_{\mathrm{c}, 28}$ & 37313,75 & 904,04 & $2,42 \%$ \\
$\mathbf{f}_{\mathrm{t}, 28}$ & 3,10 & 0,09 & $2,84 \%$ \\
\hline
\end{tabular}

Por causa da pouca fluidez do $\mathrm{C} 1$, a presença de nichos sem concreto foi freqüente em todas as vigas concretadas, o que retrata que o concreto de pouca fluidez apresenta um aspecto final de acabamento de péssima qualidade e, essa presença de nichos no concreto acarreta uma fragilidade da estrutura ao ataque de agentes nocivos à armadura exposta (Figura 6.16).
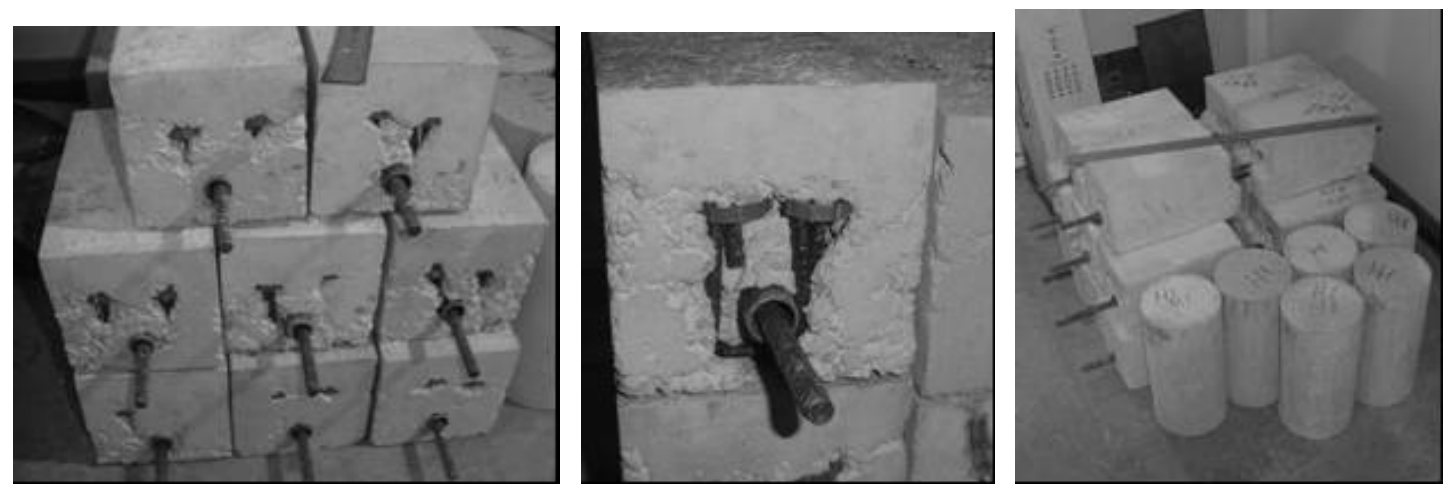

Figura 6.16 Aspecto final das vigas com a série $C 1$

A Figura 6.17 mostra o comportamento força vs. deslocamento das vigas ensaiadas. Durante os ensaios das vigas, o primeiro modelo (C1V1) foi ensaiado com um aparato de ensaios que modificou seu comportamento (conforme comentado anteriormente) e esse valor foi descartado da análise estatística. 

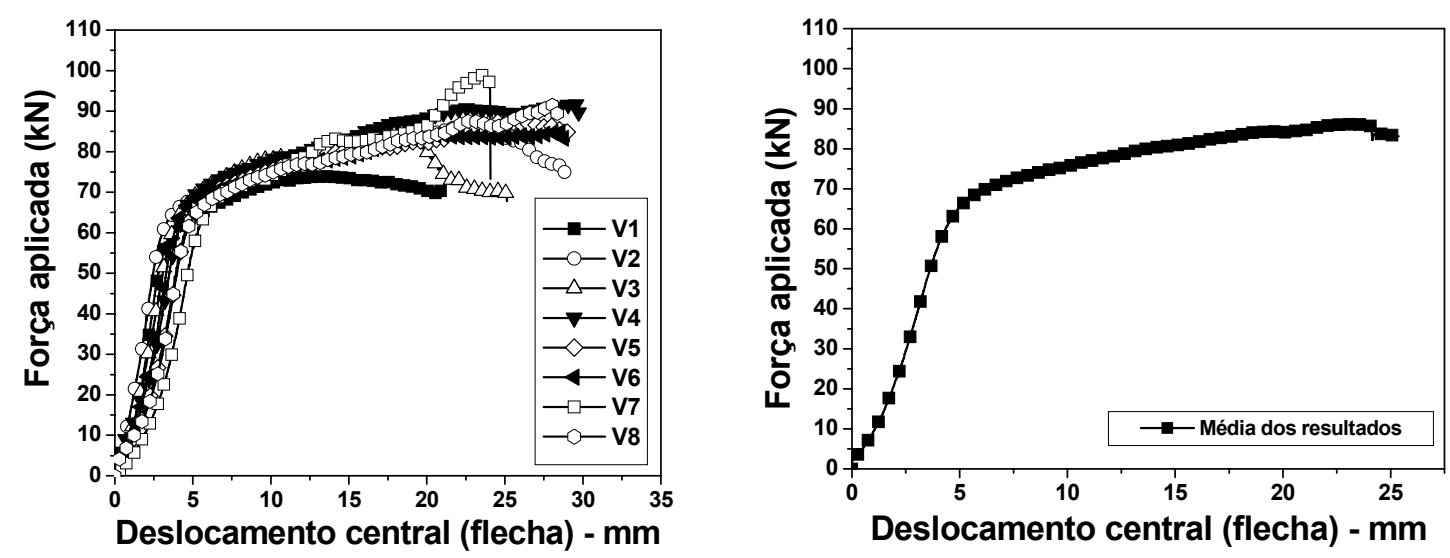

Figura 6.17 Comportamento força vs. deslocamento da série $\mathrm{C} 1$ e média dos resultados

O comportamento das vigas se apresentou de uma forma constante para todos os modelos; sendo somente distintos a partir da flecha de $20 \mathrm{~mm}$ (com exceção da viga $\mathrm{C} 1 \mathrm{~V} 1$, que foi desconsiderada). A Tabela 6.17 mostra os resultados de cada viga ensaiada.

Tabela 6.17 Resultados para as vigas da série $\mathrm{C} 1$

\begin{tabular}{ccccccccccc}
\hline & C1V2 & C1V3 & C1V4 & C1V5 & C1V6 & C1V7 & C1V8 & M & D.P. & C.V. \\
\hline $\mathbf{P}_{5 \mathrm{~mm}}(\mathbf{k N})$ & 68,42 & 68,47 & 68,40 & 65,15 & 67,81 & 56,46 & 63,62 & 65,48 & 4,41 & $6,73 \%$ \\
$\mathbf{P}_{\mathbf{1 0 m m}} \mathbf{( k N )}$ & 74,84 & 78,04 & 78,08 & 75,22 & 74,55 & 74,00 & 74,66 & 75,63 & 1,70 & $2,25 \%$ \\
$\mathbf{P}_{\mathbf{1 5 m m}} \mathbf{( k N )}$ & 79,73 & 82,24 & 83,07 & 80,03 & 78,60 & 82,74 & 79,18 & 80,80 & 1,83 & $2,27 \%$ \\
$\mathbf{P}_{\mathbf{2 0 m m}}(\mathbf{k N})$ & 83,82 & 79,50 & 88,44 & 82,95 & 84,00 & 86,14 & 83,50 & 84,05 & 2,76 & $3,29 \%$ \\
$\mathbf{P}_{\max }(\mathbf{k N})$ & 86,71 & 85,99 & 92,33 & 88,12 & 85,44 & 99,22 & 92,49 & 90,04 & 4,97 & $5,52 \%$ \\
$\boldsymbol{\delta}_{\max }(\mathbf{m m})$ & 22,67 & 18,38 & 29,68 & 25,86 & 28,74 & 23,72 & 28,33 & 25,34 & 4,04 & $15,93 \%$ \\
\hline
\end{tabular}

Onde, $\mathrm{P}_{5 \mathrm{~mm}}, \mathrm{P}_{10 \mathrm{~mm}}, \mathrm{P}_{15 \mathrm{~mm}}, \mathrm{P}_{20 \mathrm{~mm}}$ e $\mathrm{P}_{\text {max }}$, representam a força correspondente a flecha de $5 \mathrm{~mm}, 10 \mathrm{~mm}, 15 \mathrm{~mm}, 20 \mathrm{~mm}$ e máxima, respectivamente e, $\delta_{\max }$ representa a flecha quando da força de ruptura ou máxima do modelo. A Figura 6.18 mostra a variação da força aplicada no ensaio de viga.

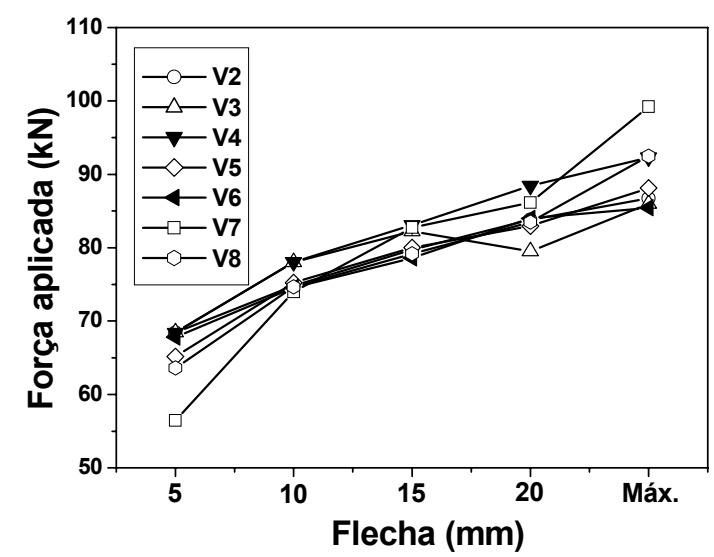

Figura 6.18 Variação da força aplicada na série C1 
Do mesmo modo que na série $C 1$, tanto no início quanto no final do ensaio $\left(P_{5 \mathrm{~mm}}\right.$ e $\left.P_{\max }\right)$ apresentam uma variação superior a encontrada durante o ensaio $\left(P_{10 \mathrm{~mm}}, P_{15 \mathrm{~mm}}\right.$ e $\mathrm{P}_{20 \mathrm{~mm}}$ ). A pequena variação mostra que os dados são representativos para a análise da resistência de aderência.

A Figura 6.19 mostra os resultados correspondentes à tensão de aderência e os respectivos deslizamentos de cada viga da série $\mathrm{C} 1$. A resistência de aderência foi calculada de acordo com a formulação de Isa \& Aguado (2003), ilustrado na Eq. 6.3.

$\tau=0,221055 \cdot P$

Eq. 6.1

Onde "P" é a força aplicada no ensaio.

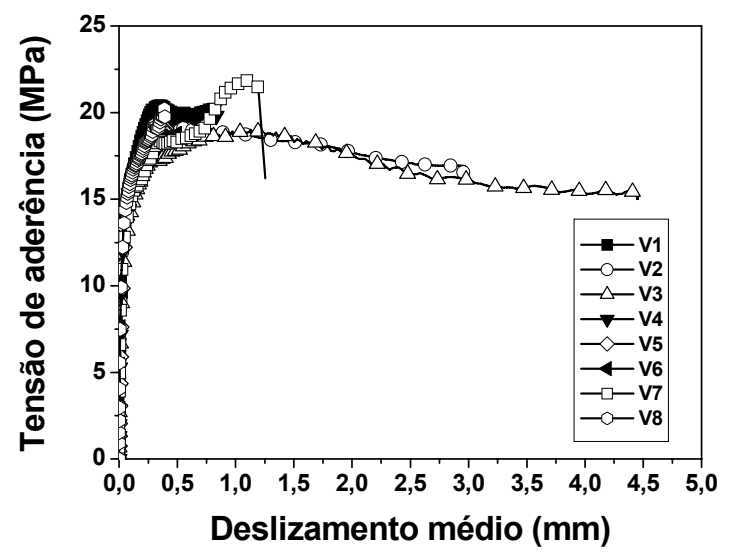

Figura 6.19 Comportamento da tensão de aderência de cada viga da série $\mathrm{C} 1$

\subsubsection{Série $\mathrm{C} 2$}

O concreto auto-adensável, $\mathrm{C} 2$, foi caracterizado como um concreto com tamanho máximo de agregado graúdo de $12 \mathrm{~mm}$ e o objetivo era avaliar sua influência na resistência de aderência.

A Tabela 6.18 mostra as propriedades mecânicas da série C2 aos 28 dias.

Tabela 6.18 Propriedades mecânicas da série C2 aos 28 dias

\begin{tabular}{cccc}
\hline & $\begin{array}{c}\mathbf{M} \\
(\mathbf{M P a})\end{array}$ & $\begin{array}{c}\text { D.P. } \\
(\mathbf{M P a})\end{array}$ & $\begin{array}{c}\mathbf{C . V} . \\
(\%)\end{array}$ \\
\hline $\mathbf{f}_{\mathrm{c}, 28}$ & 52,61 & 1,38 & $2,62 \%$ \\
$\mathbf{E}_{\mathrm{c}, 28}$ & 35906,00 & 333,05 & $0,93 \%$ \\
$\mathbf{f}_{\mathrm{t}, 28}$ & 3,23 & 0,01 & $0,43 \%$ \\
\hline
\end{tabular}


A Figura 6.20 mostra o acabamento das vigas concretadas da série C2. O acabamento se apresentou de modo excelente sem a presença de nichos sem concreto em qualquer parte da viga.
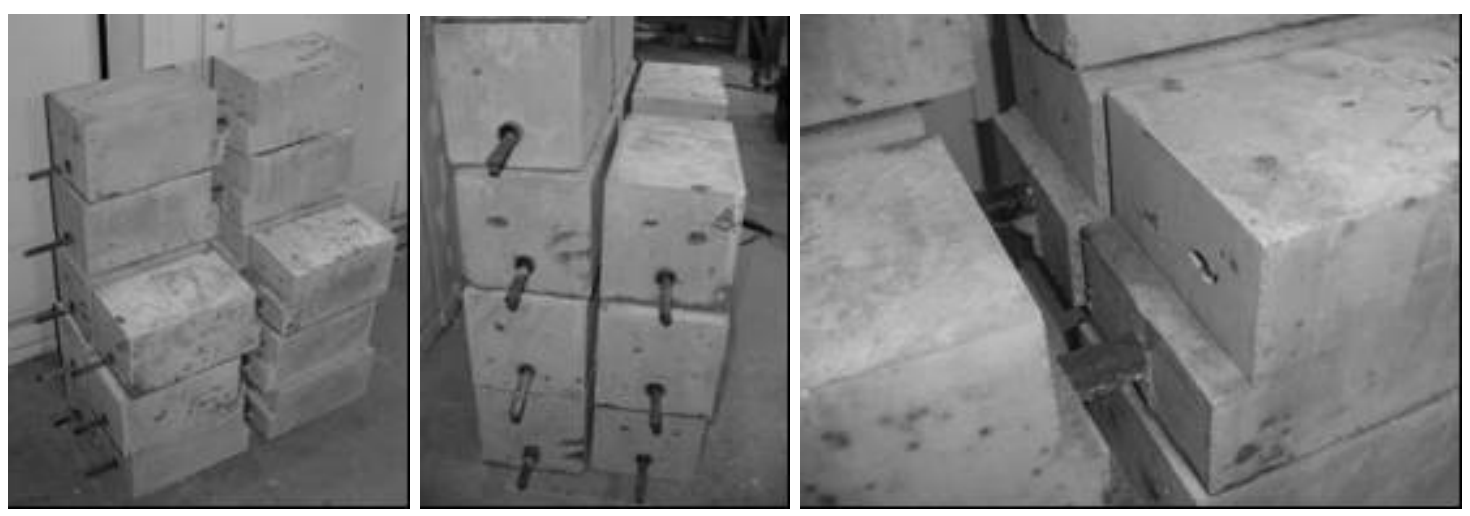

Figura 6.20 Aspecto final das vigas da série C2

A Figura 6.21 mostra o comportamento força vs. deslocamento das vigas ensaiadas.
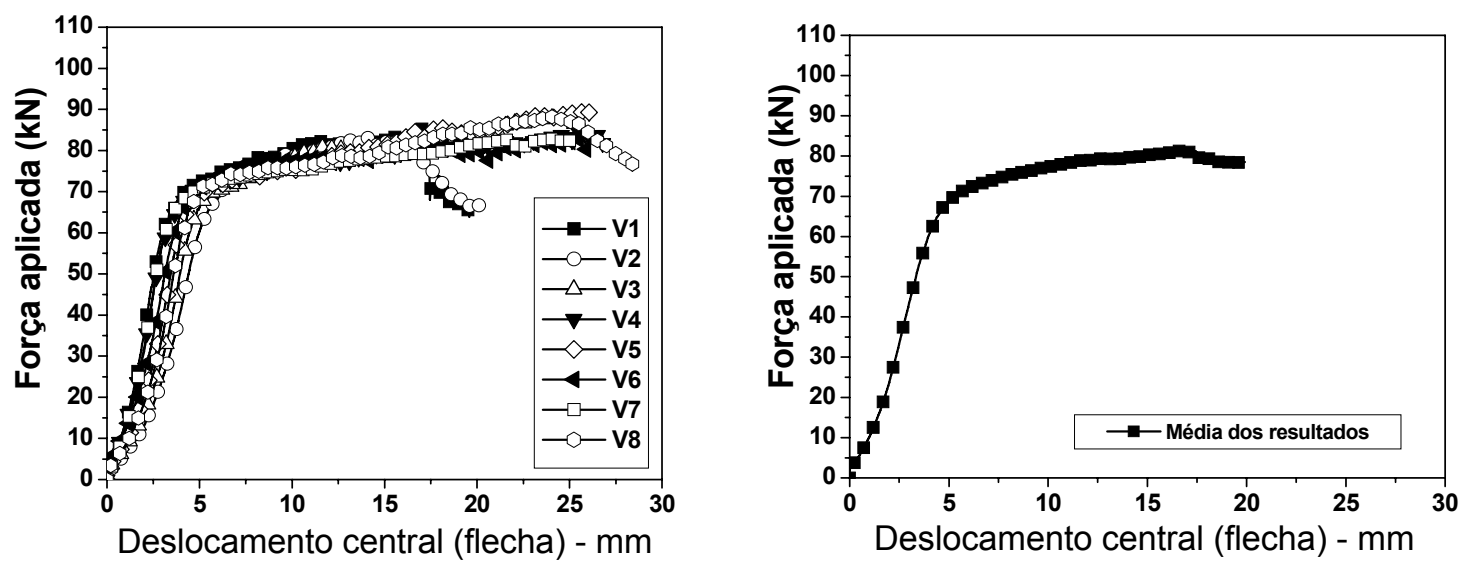

Figura 6.21 Comportamento força vs. deslocamento da série C2 e média dos resultados

A Tabela 6.19 mostra os resultados de cada viga ensaiada.

Tabela 6.19 Resultados das vigas ensaiadas da série C2

\begin{tabular}{|c|c|c|c|c|c|c|c|c|c|c|c|}
\hline & C2V1 & C2V2 & C2V3 & C2V4 & C2V5 & C2V6 & C2V7 & C2V8 & $M$ & D.P. & C.V. \\
\hline $\begin{array}{l}P_{5 \mathrm{~mm}} \\
(\mathbf{k N})\end{array}$ & 71,76 & 60,35 & 66,15 & 70,47 & 69,23 & 70,86 & 70,74 & 69,11 & 68,58 & 3,74 & $5,45 \%$ \\
\hline $\begin{array}{l}P_{10 \mathrm{~mm}} \\
(\mathrm{kN})\end{array}$ & 79,67 & 78,32 & 78,09 & 77,10 & 75,04 & 78,13 & 75,41 & 76,93 & 77,34 & 1,55 & $2,01 \%$ \\
\hline $\begin{array}{l}P_{15 \mathrm{~mm}} \\
(\mathrm{kN})\end{array}$ & 82,41 & 81,12 & 78,11 & 78,90 & 80,98 & 78,56 & 78,53 & 80,19 & 79,85 & 1,55 & $1,95 \%$ \\
\hline $\begin{array}{c}P_{20 \mathrm{~mm}} \\
(\mathbf{k N})\end{array}$ & - & - & 83,84 & 82,18 & 84,42 & 79,58 & 81,49 & 85,04 & 82,76 & 2,06 & $2,48 \%$ \\
\hline
\end{tabular}




\begin{tabular}{llllllllllll}
\hline $\mathbf{P}_{\max }$ & 85,26 & 83,35 & 88,90 & 84,43 & 89,88 & 83,63 & 84,13 & 88,62 & 86,03 & 2,66 & $3,09 \%$ \\
$(\mathbf{k N})$ & & & & & & & & & \\
$\boldsymbol{\delta}_{\max }$ & 17,02 & 13,82 & 25,15 & 26,48 & 25,93 & 25,34 & 24,64 & 23,38 & 22,72 & 4,68 & $20,58 \%$ \\
\hline $\mathbf{m m})$ & $\mathbf{m m}$ & & &
\end{tabular}

A Figura 6.22 mostra a variação da força aplicada no ensaio de viga.

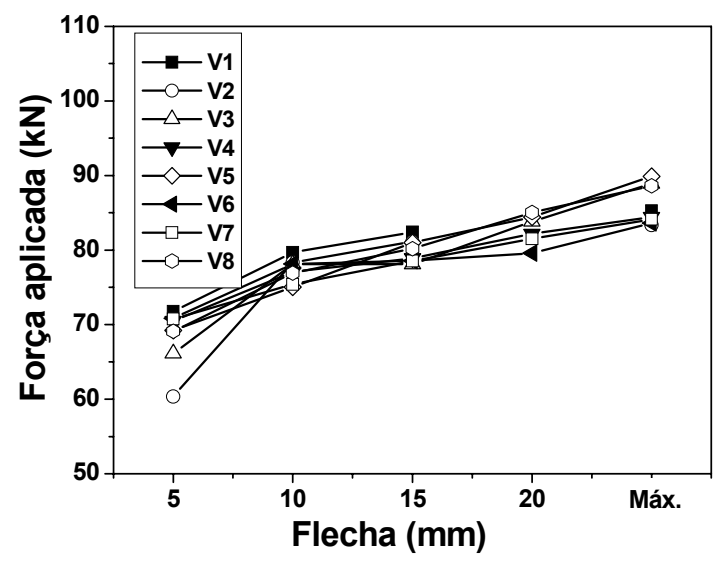

Figura 6.22 Variação da força aplicada na série C2

Do mesmo modo que na série $C 1$, tanto no início quanto no final do ensaio $\left(P_{5 \mathrm{~mm}}\right.$ e $\left.P_{\max }\right)$ apresentam uma variação superior a encontrada durante o ensaio $\left(P_{10 \mathrm{~mm}}, P_{15 \mathrm{~mm}}\right.$ e $\mathrm{P}_{20 \mathrm{~mm}}$ ). A pequena variação mostra que os dados são representativos para a análise da resistência de aderência.

A Figura 6.23 mostra os resultados correspondentes à tensão de aderência e os respectivos deslizamentos de cada viga da série $\mathrm{C} 2$.

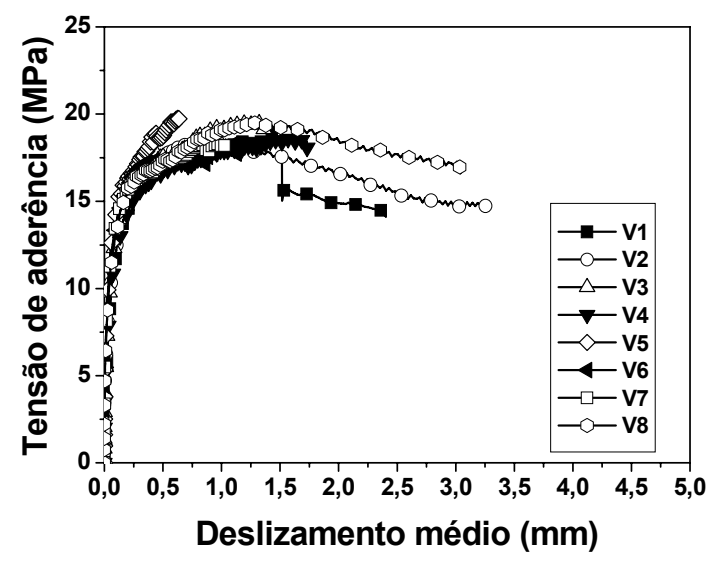

Figura 6.23 Comportamento da tensão de aderência de cada viga da série C2 


\subsubsection{Série C3}

O concreto auto-adensável, C3, foi caracterizado como um concreto com tamanho máximo de agregado graúdo de $18 \mathrm{~mm}$ e o objetivo era avaliar sua influência na resistência de aderência. A Tabela 6.20 mostra as propriedades mecânicas da série C3 aos 28 dias.

Tabela 6.20 Propriedades mecânicas da série C3 aos 28 dias

\begin{tabular}{cccc}
\hline & $\mathbf{M}$ & $\mathbf{D . P}$. & $\mathbf{C . V}$. \\
& $\mathbf{M P a})$ & $(\mathbf{M P a})$ & $(\mathbf{\%})$ \\
\hline $\mathbf{f}_{\mathrm{c}, 28}$ & 53,75 & 0,64 & $1,18 \%$ \\
$\mathbf{E}_{\mathrm{c}, 28}$ & 38408,00 & 521,14 & $1,36 \%$ \\
$\mathbf{f}_{\mathrm{t}, 28}$ & 2,28 & 0,10 & $4,60 \%$ \\
\hline
\end{tabular}

A Figura 6.24 mostra o acabamento das vigas concretadas da série C2. Da mesma forma que na série $\mathrm{C} 2$, o acabamento da série $\mathrm{C} 3$ se apresentou de modo excelente sem a presença de nichos sem concreto em qualquer parte da viga.
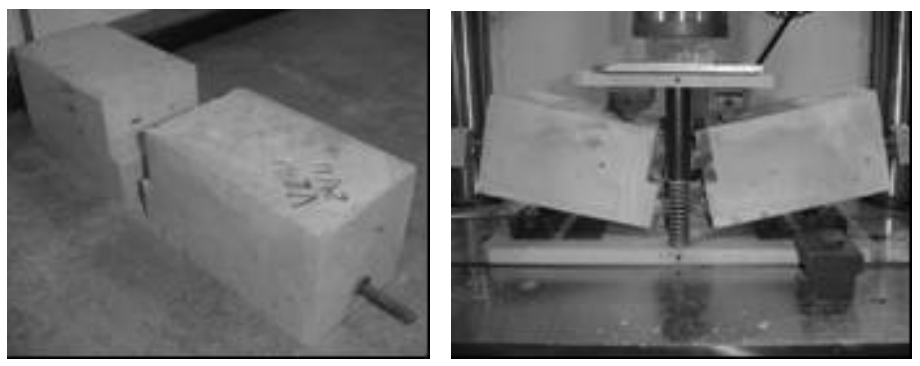

Figura 6.24 Aspecto final das vigas da série C3

A Figura 6.25 mostra o comportamento força vs. deslocamento das vigas ensaiadas
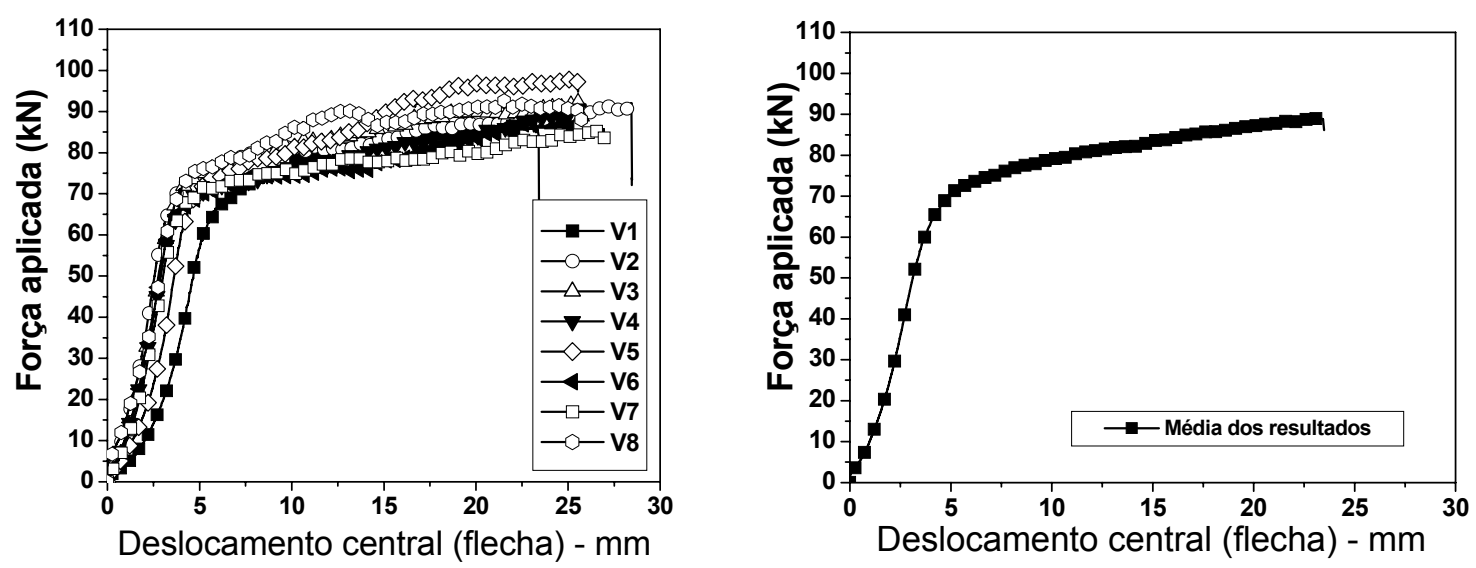

Figura 6.25 Comportamento força vs. deslocamento da série C2 e média dos resultados 
A Tabela 6.21 mostra os resultados de cada viga ensaiada.

Tabela 6.21 Resultados das vigas ensaiadas da série C3

\begin{tabular}{|c|c|c|c|c|c|c|c|c|c|c|c|}
\hline & C3V1 & C3V2 & C3V3 & C3V4 & C3V5 & C3V6 & C3V7 & C3V8 & $M$ & D.P. & C.V. \\
\hline $\begin{array}{l}P_{5 \mathrm{~mm}} \\
(\mathbf{k N})\end{array}$ & 56,81 & 74,98 & 74,72 & 69,89 & 70,74 & 70,07 & 70,20 & 75,40 & 70,35 & 5,97 & $8,49 \%$ \\
\hline $\begin{array}{c}P_{10 \mathrm{~mm}} \\
(\mathbf{k N})\end{array}$ & 77,65 & 80,42 & 81,15 & 75,53 & 81,11 & 75,22 & 75,24 & 84,74 & 78,88 & 3,51 & $4,45 \%$ \\
\hline $\begin{array}{c}P_{15 \mathrm{~mm}} \\
(\mathrm{kN})\end{array}$ & 82,74 & 83,60 & 86,82 & 80,69 & 88,61 & 77,22 & 78,13 & 86,32 & 83,02 & 4,14 & $4,99 \%$ \\
\hline $\begin{array}{c}P_{20 \mathrm{~mm}} \\
(\mathrm{kN})\end{array}$ & 85,12 & 87,25 & 89,28 & 84,18 & 96,59 & 83,19 & 79,74 & 91,50 & 87,11 & 5,29 & $6,08 \%$ \\
\hline $\begin{array}{l}P_{\max } \\
(\mathbf{k N})\end{array}$ & 88,32 & 92,03 & 92,85 & 90,74 & 98,42 & 88,17 & 86,00 & 92,61 & 91,14 & 3,82 & $4,19 \%$ \\
\hline $\begin{array}{c}\delta_{\max } \\
(\mathrm{mm})\end{array}$ & 24,92 & 28,44 & 25,63 & 25,55 & 25,43 & 22,92 & 26,82 & 21,52 & 25,15 & 2,15 & $8,53 \%$ \\
\hline
\end{tabular}

A Figura 6.26 mostra a variação da força aplicada no ensaio de viga.

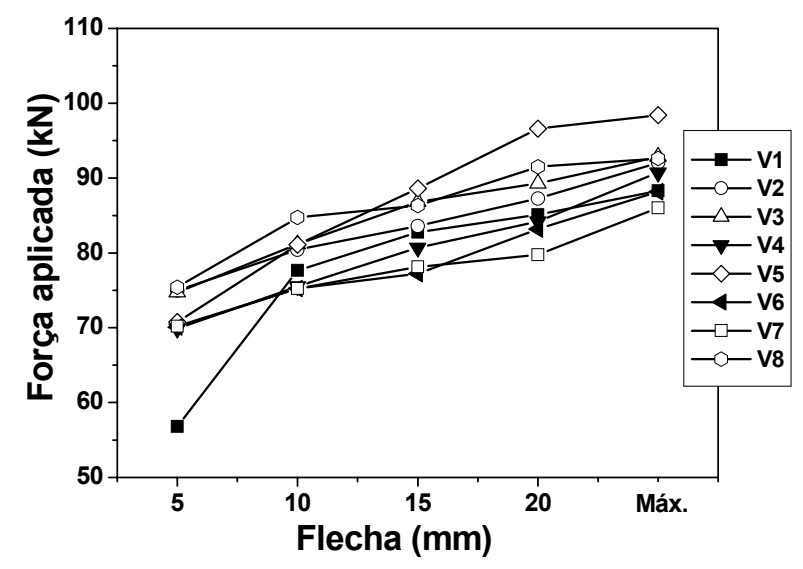

Figura 6.26 Variação da força aplicada na série C3

Do mesmo modo que na série $C 1$, tanto no início quanto no final do ensaio $\left(P_{5 \mathrm{~mm}}\right.$ e $\left.P_{\max }\right)$ apresentam uma variação superior a encontrada durante o ensaio $\left(P_{10 \mathrm{~mm}}, P_{15 \mathrm{~mm}}\right.$ e $\left.\mathrm{P}_{20 \mathrm{~mm}}\right)$. A pequena variação mostra que os dados são representativos para a análise da resistência de aderência.

A Figura 6.27 mostra os resultados correspondentes à tensão de aderência e os respectivos deslizamentos de cada viga da série C3. 


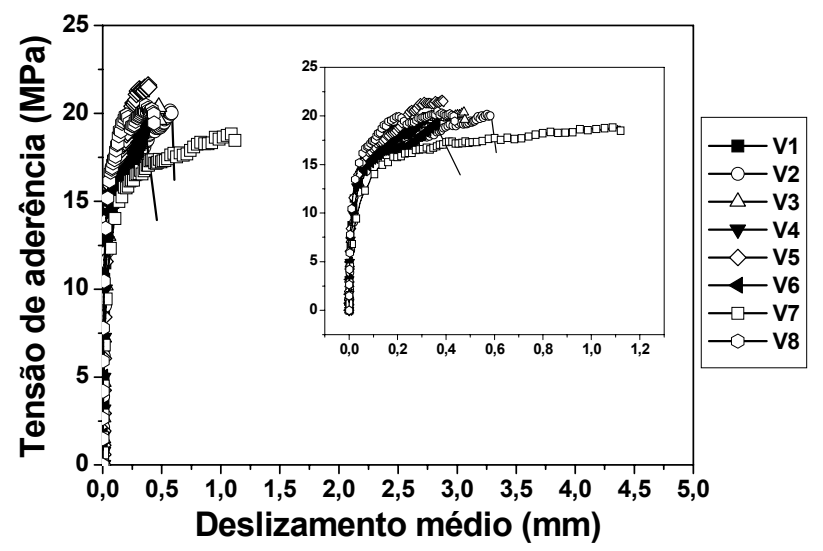

Figura 6.27 Comportamento da tensão de aderência de cada viga da série C3

A série C3 foi que teve maior variabilidade quando se analisa a força aplicada, mas quando se analisa o deslizamento da barra de aço, esta série obteve a menor variação.

\subsection{Considerações finais}

Este capítulo abordou o estudo da variabilidade do CAA no seu estado fresco e endurecido. O objetivo do estudo do CAA no estado fresco foi o de verificar a variabilidade dos resultados, enquanto o estudo no estado endurecido procurou verificar a variabilidade de suas propriedades mecânicas e da resistência de aderência.

De acordo com os resultados obtidos com relação à variabilidade do estado fresco, foi possível verificar a influência de parâmetros que modificam significativamente as propriedades do CAA no estado fresco, e se pode dizer que o fator que mostrou ter maior influência foi a limpeza da betoneira depois das concretagens, pois quando foram realizadas três concretagens em um dia, houve uma nítida perda de fluidez nos concretos auto-adensáveis. Isso ocorreu em função da absorção de água por parte do concreto presente na betoneira, oriundo de uma concretagem anterior. Assim, se conclui que é preciso no caso de se repetirem muitas concretagens no mesmo dia, que haja a previsão de limpezas periódicas na betoneira, de preferência após cada concretagem (mais recomendado) ou que haja uma compensação para a perda de fluidez, ou por adição de água ou por adição de superplastificante. 
Com relação à variabilidade do CAA no estado endurecido, se pode dizer que, nos ensaios de resistência à compressão, muitos fatores tiveram influência na sua variabilidade, como por exemplo, o capeamento e o ar incorporado aos corpos-deprova $(\mathrm{CP})$ e para os ensaios de resistência à tração, a grande variabilidade encontrada foi conseqüência da forma de ruptura do CP.

Para maiores informações sobre o comportamento no estado endurecido, o Capítulo 8 realiza uma ampla abordagem dos resultados.

De acordo com os resultados dos modelos de vigas, pode-se concluir que:

- O ensaio de viga apresentou variação inferior a $10 \%$ de seus resultados, o que conclui que o ensaio de viga é adequado para o estudo da aderência por sua pequena variabilidade;

- A interface aço-CAA foi extremamente rígida, uma vez que a resistência à compressão do concreto esteve cerca de $50 \mathrm{MPa}$. Isso causou a plastificação da barra de aço em seu ponto central com pouco deslizamento na zona aderente. Essa informação é sujeita a contestação, pois o ensaio de viga utilizado apresenta a peculiaridade que pode "mascarar" os resultados analisados. A Figura 6.28 mostra uma exemplificação dos passos do ensaio de viga e, utilizando uma analogia rudimentar do modelo de bielas e tirantes, pode-se observar que a trajetória da reação da força aplicada passa pela zona aderente.

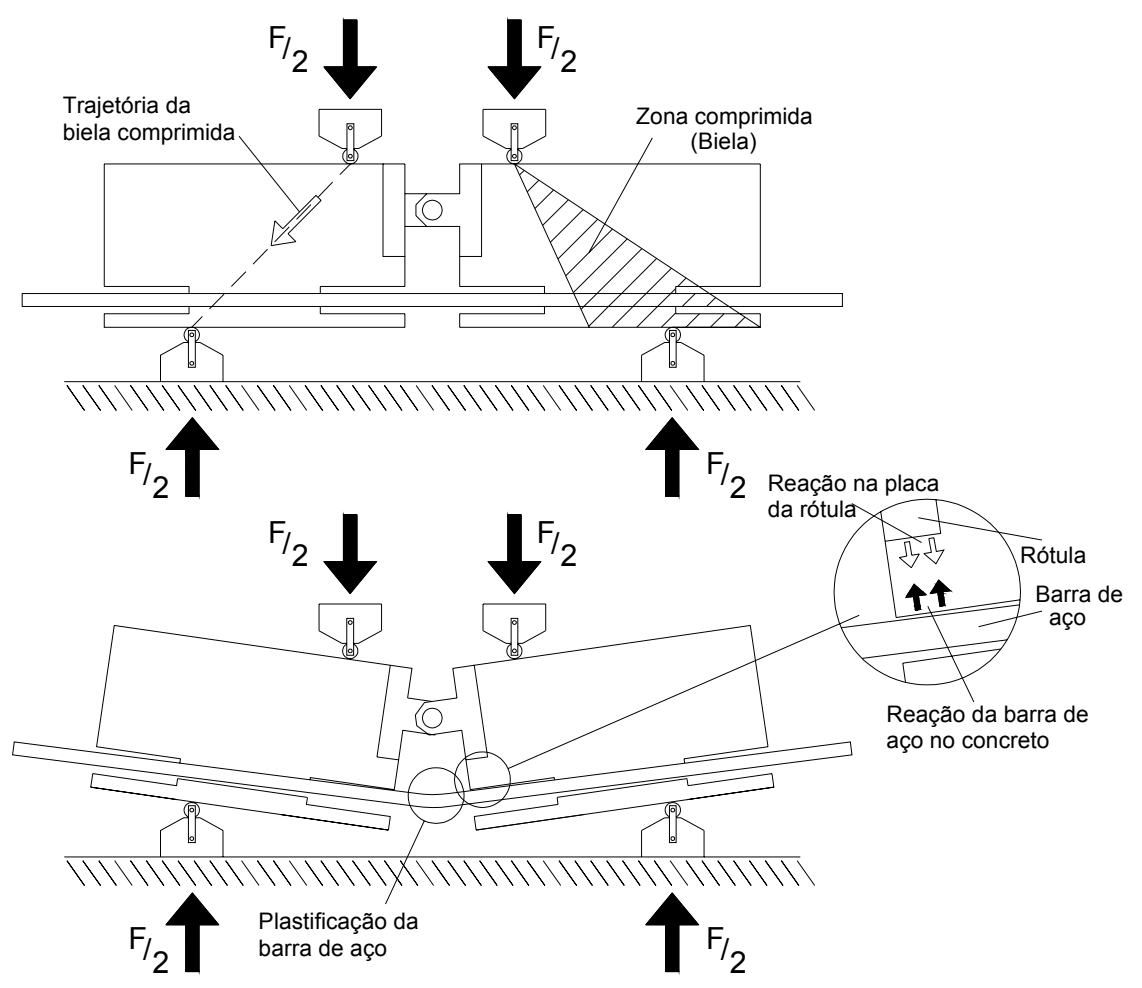

Figura 6.28 Peculiaridade do ensaio de viga 
A zona aderente se encontra dentro da região comprimida pela biela que vai até o apoio inferior do aparato de ensaio. Esse comportamento, inicialmente reduz o valor do deslizamento, pois a componente horizontal da reação da força "F" aplicada na viga possui valor pequeno quando comparado com a componente vertical. Essa componente vertical incrementa o valor da força de compressão na barra de aço e melhora o confinamento do trecho aderente. Quando a flecha atinge valores elevados, o valor da componente vertical inicia uma perda de influência, mas o ensaio já apresenta grande deslocamento central (flecha) e plastificação da barra de aço. Assim, quando ocorre a plastificação da barra de aço, o deslizamento medido pelo LVDT corresponde à soma do deslizamento da barra de aço em contato com o concreto mais a deformação da barra em sua zona plastificada.

Ainda, quando ocorre a plastificação da barra, se inicia um esmagamento do concreto que se situa entre a barra e a placa da rótula, que por sua vez provoca uma reação na própria rótula, aumentando a rigidez do sistema, mesmo depois de atingindo deslocamentos excessivos (Figura 6.28) e, isso ocorreu em todos os modelos ensaiados. A Figura 6.29 mostra um modelo de viga ensaiado de cada série com o esmagamento do concreto na zona situada entre a barra e a placa da rótula.

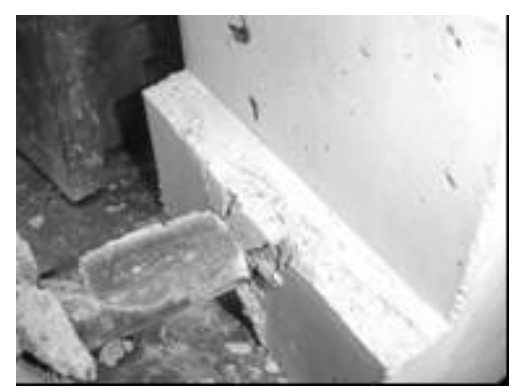

Série C1

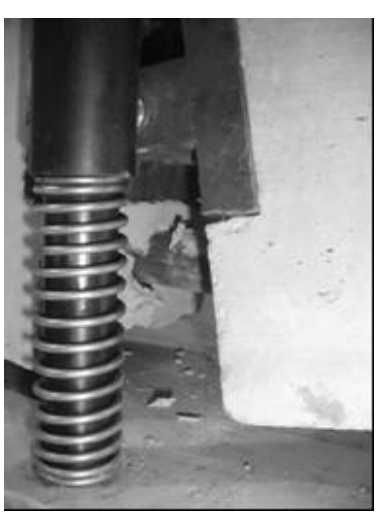

Série C2

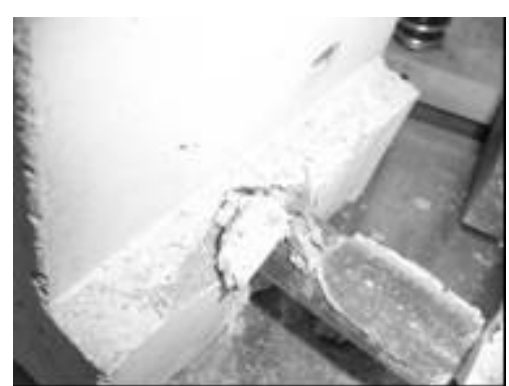

Série C3

Figura 6.29 Esmagamento do concreto na zona situada entre a placa da rótula e a barra de aço

O ensaio de viga utilizado nesta investigação experimental fixou o valor máximo do deslizamento em 3,0 mm. Entretanto, esse valor nem sempre pôde ser atingindo, em função do deslocamento (flecha) excessivo da viga ou da plastificação da barra em seu ponto central, que provocam o esmagamento do concreto situado entre a placa da rótula e a barra de aço (De Larrard et al., 1993). 


\section{Simulação numérica}

A simulação numérica consistiu do desenvolvimento de modelos numéricos consistentes para a representação da aderência aço-concreto, que se constitui num problema de difícil solução: um problema de contato. Isso posto, foi realizado um estudo preliminar a fim de se realizar uma parametrização do comportamento do ensaio de arrancamento, considerando o comportamento dos materiais (Almeida Filho et al., 2004, De Nardin, et al., 2005). Posteriormente, efetuou-se uma análise dos resultados numéricos fornecidos, em comparação com aqueles obtidos experimentalmente, tanto para os modelos de viga quanto para os de arrancamento. As simulações numéricas mostraram-se eficientes na representação do comportamento dos ensaios. Além disso, forneceram previsão de distribuição das tensões na interface aço-concreto, embora não se tenham dados experimentais para uma comparação mais adequada.

\subsection{Considerações iniciais}

$\mathrm{Na}$ análise numérica da aderência, pode-se facilmente confundir o esgotamento dos diferentes mecanismos de aderência com outros tipos de ruptura. Assim, para que a aderência seja representada, o contato deve conter, pelo menos (Lundgren et al., 2002): atrito, habilidade de causar tensões normais no deslizamento, adesão e possibilidade de ruptura do concreto entre as nervuras. 
Segundo Kotsovos \& Pavlovic (1995), a interação aço-concreto depende de dois aspectos, sendo eles a aderência e a rigidez na tração (tension stiffening).

A aderência perfeita foi a primeira simplificação assumida com o objetivo de se estabelecer uma lei que representasse o comportamento da ligação aço-concreto. Porém, como essas leis se baseiam em resultados experimentais geralmente escassos, limitados e com resultados não muito confiáveis (Kotsovos \& Pavlovic, 1995), sua aplicação é restrita.

Quanto à hipótese de aderência perfeita em si, embora seja uma simplificação, é compatível com o modelo de fissura no cobrimento (smeared-crack model), sendo com isso evitada a descrição detalhada de efeitos locais. A perda de aderência entre o aço e o concreto próximo de uma fissura não contradiz a hipótese de aderência perfeita, desde que a fissura do cobrimento propague o efeito de fissuração como uma extensão dos pontos de integração nos elementos de barra.

Kwak \& Kim (2001) simularam o comportamento da interação aço-concreto com um modelo analítico baseado na consideração do efeito do deslizamento sem tomar os nós duplos (um no aço e outro no concreto). De acordo com os referidos autores, raramente a barra de aço estaria sujeita à ação direta do carregamento; assim, o aço somente receberia a parte do carregamento do concreto adjacente à sua superfície.

De acordo com Bangash (1989), existem duas aproximações para se determinar o deslizamento entre o aço e o concreto. A primeira utiliza um elemento de ligação para a aderência proposta por Ngo \& Scordelis (1967), onde o elemento conecta um nó do elemento finito de concreto com outro nó do elemento finito do aço; desse modo, esse elemento não possui dimensão física, e os nós dos elementos de aço e concreto possuem as mesmas coordenadas. A segunda aproximação considera uma zona de aderência proposta por De Groot et al. (1981), onde o comportamento da superfície de contato entre o aço e o concreto, e o comportamento do concreto adjacente são descritos por uma lei constitutiva o qual considera propriedades especiais para a zona aderente. Segundo as observações do estudo dos referidos autores, o modelo proposto tem a possibilidade de considerar o efeito do deslizamento em elementos de viga. A solução não-linear baseada no equilíbrio de cada nó do aço e a compatibilidade entre o aço e o concreto é determinada em sua ligação. A eficiência e a confiabilidade do modelo proposto foram comprovadas através de correlações entre análises experimentais e analíticas.

Para se avaliar a ruptura da interface aço-concreto, pode-se utilizar o modelo combinado da hipótese friccional de Coulomb com um limite para a tensão máxima (Figura 7.1), que pode resultar em dois modos de ruptura distintos, sendo eles a ruptura por deslizamento e a ruptura por separação (Nielsen, 1998). A ruptura por 
deslizamento é admitida quando em uma seção a tensão de cisalhamento excede a resistência ao deslizamento, que pode ser determinada por dois parâmetros, sendo eles a coesão (c) e o coeficiente de atrito $(\mu)$. A ruptura por separação ocorre quando, em uma seção, a tensão de tração excede a resistência à separação $\left(f_{A}\right)$. Assim, esses dois modos de ruptura podem ser combinados em um e este pode ser chamado de Mohr-Coulomb Modificado.

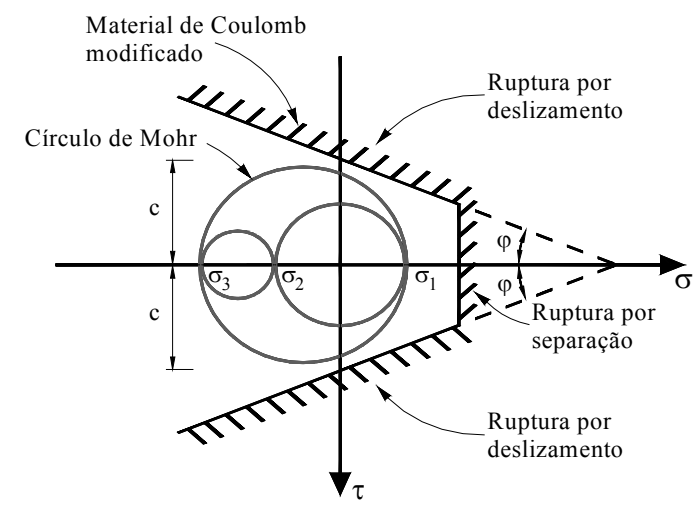

Figura 7.1 Material de Mohr-Coulomb modificado (Nielsen, 1998)

As condições para que ocorram as rupturas por deslizamento e por separação podem ser vistas na Eq.7.1 e Eq.7.2, respectivamente (Nielsen, 1998).

$$
\begin{aligned}
& |\tau|=c-\mu \cdot \sigma \\
& \sigma=f_{A}
\end{aligned}
$$

O coeficiente de atrito ( $\mu$ ) e a coesão (c) podem ser determinados pelas Eq.7.3 e Eq. 7.4, respectivamente (Nielsen, 1998; Chen \& Saleeb, 1982).

$$
\begin{aligned}
& f_{c}=2 \cdot c \cdot \sqrt{k}=2 \cdot c \cdot\left(\frac{\cos \varphi}{1-\operatorname{sen} \varphi}\right) \\
& k=\left(\mu+\sqrt{1+\mu^{2}}\right)^{2}=\left(\frac{\cos \varphi}{1-\operatorname{sen} \varphi}\right)^{2}
\end{aligned}
$$

De acordo com a literatura se o concreto for considerado um material MohrCoulomb modificado, o parâmetro "k" assume o valor igual a 4, o que leva, substituindo na Eq. 7.4, ao valor do coeficiente de atrito igual a 0,75 , que corresponde 
ao ângulo de atrito de $37^{\circ}$. O valor da coesão, utilizando o valor do parâmetro "k", é igual a $0,75 \mathrm{kN} / \mathrm{cm}^{2}$. Entretanto, foram utilizados outros valores para o coeficiente de atrito e seus respectivos valores para coesão com o objetivo de se avaliar a variação e a distribuição da tensão de aderência ao longo do comprimento de ancoragem (Nielsen, 1998).

\subsubsection{Materiais}

Para a simulação numérica da aderência aço-concreto muitas abordagens foram desenvolvidas, envolvendo sempre as leis constitutivas dos materiais, sejam experimentais ou numéricas. Estas leis sempre procuram representar o comportamento dos materiais separadamente. Neste caso em particular, pode-se dizer que a simulação numérica conta com a presença de três materiais, sendo eles: o concreto, o aço e a zona de contato.

Em vista disso, foi realizada uma ampla investigação bibliográfica para se avaliar os modelos de materiais constitutivos aplicados nas simulações numéricas desenvolvidas hoje em dia e, fica claro que o desenvolvimento de elementos finitos (unidimensionais, bidimensionais e tridimensionais) que representam essa interface está cada vez mais eficaz (Désir et al., 1999; Kwak \& Kim, 2001; Salari \& Spacone, 2001; Kwak \& Filippou, 1997; Yankelevsky, 1997; Neto \& Assan, 2003; Girard \& Bastien, 2002; Kotsovos \& Pavlovic, 1995; etc). Entretanto, ainda são necessárias maiores investigações, tanto experimentais quanto numéricas, para melhorar o entendimento deste assunto, uma vez que a quantidade de fatores que influenciam seu comportamento é elevada.

A seguir, são mostradas sucintamente as considerações com relação aos materiais utilizados na simulação numérica desta pesquisa, que, no caso, envolvem o modelo de arrancamento do Rilem-Ceb-Fip (1973).

\subsubsection{Concreto}

A simulação numérica do concreto pode ser realizada considerando modelos uniaxiais, biaxiais e triaxiais.

A resposta de uma estrutura submetida a um tipo de carregamento depende das relações tensão vs. deformação dos materiais constituintes e da magnitude da tensão. Desse modo, o concreto possui uma excelente característica de resistência à compressão, mas uma baixa resistência à tração, fazendo com que essa resistência à 
compressão seja o alvo primário para a utilização na construção civil. Com isso, diversos modelos matemáticos com o objetivo de simular o diagrama de tensão vs. deformação do concreto foram propostos, conforme o modelo de Scott et al. (1982). Esse modelo, de grande facilidade para uso computacional, apresenta para o comportamento monotônico o diagrama tensão vs. deformação do concreto submetido à compressão dividido em três regiões. Para o caso do concreto submetido à tração, esse modelo assume que o concreto apresenta comportamento linear elástico até o limite estabelecido para a resistência à tração do concreto $\left(f_{t}^{\prime}\right)$, com a inclinação igual a $E_{b 1}$ função do módulo de elasticidade longitudinal $\left(E_{c}\right)$, e a inclinação $E_{b 2}$, em função do módulo de elasticidade transversal $(G)$.

\subsubsection{Aço}

A armadura de aço pode ser considerada com comportamento linear, para reduzir o custo computacional com a consideração do escoamento, visto que o comportamento de elementos estruturais de concreto armado é fortemente influenciado pelo escoamento da armadura (Kwak \& Kim, 2001).

\subsubsection{Interface aço-concreto}

A interface aço-concreto consiste de uma superfície descontínua de um corpo, composto de dois materiais, entre duas superfícies paralelas de materiais adjacentes que pode ser considerada infinitesimal, se levarmos em consideração o volume total do elemento estrutural. O comportamento da superfície depende dos materiais constituintes, que neste caso é composto de barra de aço com nervuras, agregados e argamassa (Désir et al., 1999); no caso da presente pesquisa, será considerada a barra lisa, conforme o esquema na Figura 7.2(b), com características adequadas para representar a barra real.

Assim, diversas leis constitutivas para simular a interface aço-concreto têm sido desenvolvidas utilizando diagramas de comportamento bilinear ou trilinear associados a elementos uniaxiais, biaxiais e triaxiais (Désir et al., 1999; Kwak \& Kim, 2001; Salari

\& Spacone, 2001; Kwak \& Filippou, 1997; Yankelevsky, 1997; Bangash, 1989; Abrishami \& Mitchell, 1996; Feenstra \& De Borst, 1995).

Foram realizadas pesquisas utilizando elementos de ligação do tipo mola para representar o deslizamento entre a barra de aço e o concreto adjacente, conforme a Figura 7.2. O modelo associado a esse elemento utiliza um processo minimizador de 
energia capaz de mostrar a influência da aderência na abertura de fissuras da interface (Chen \& Baker, 2004).

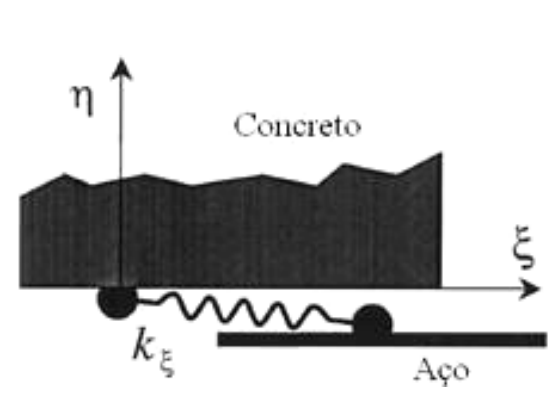

a)

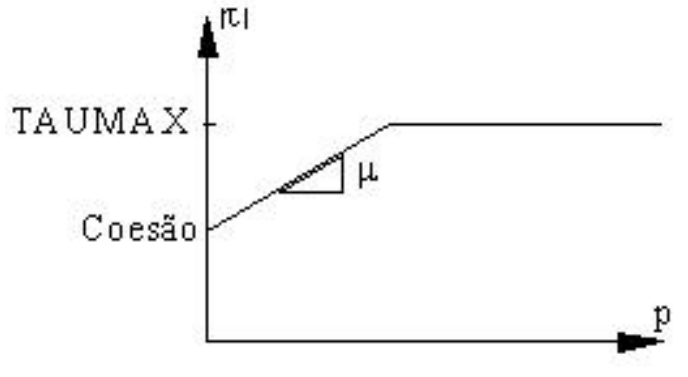

b)

Figura 7.2 a) Modelo de aderência na direção axial (Chen \& Baker, 2004) e b) Modelo de material de Mohr-Coulomb modificado adotado pelo software Ansys ${ }^{\circledR}$

Para a presente pesquisa, a interface aço-concreto utilizou o modelo de MohrCoulomb modificado do software Ansys ${ }^{\circledR}$, representado na Figura 7.2b. Pode-se ver que, ao contrário dos demais modelos constitutivos (Kwak \& Kim, 2001; Yankelevsky, 1997), este modelo adota um diagrama bilinear para representar o escorregamento ou separação dos materiais, onde o escorregamento da barra ocorre depois que a tensão de coesão dos materiais seja ultrapassada. Depois de atingida a tensão de coesão, o escorregamento progride de acordo com o coeficiente de atrito, conforme ilustrado na Figura 7.2b. Quando a tensão atinge o valor referente à tensão TAUMAX, de acordo com os manuais do software, ocorre o descolamento ou separação dos materiais. No entanto, de acordo com alguns trabalhos publicados, é possível obter uma resposta numérica mais representativa do comportamento experimental utilizando leis constitutivas da interface que considerem a adesão (Girard \& Bastien, 2002) e a perda progressiva de rigidez da interface antes de atingida a resistência da coesão entre os materiais (Kwak \& Kim, 2001; Yankelevsky, 1997).

\subsection{Elementos utilizados}

Os elementos utilizados foram os disponibilizados pela biblioteca de elementos do software Ansys ${ }^{\circledR}$. Todos os elementos a seguir mostrados foram utilizados em ambos os modelos numéricos de arrancamento e de viga.

O elemento finito SOLID65 é utilizado para a modelagem tridimensional de corpos sólidos como o concreto com ou sem armadura. Esse elemento permite fissuração na tração, esmagamento na compressão, deformação plástica e fluência. É 
definido por oito nós com três graus de liberdade cada um: translações nas direções $\mathrm{x}$, y e z.

O elemento finito SOLID45 é utilizado para a modelagem tridimensional de corpos sólidos. É definido por oito nós com três graus de liberdade cada um: translações nas direções $x, y$ e z. Esse elemento permite plasticidade, fluência, dilatação térmica, rigidez à tração, grandes deslocamentos e deformações.

O elemento finito TARGE170 é utilizado para representar o contato e o deslizamento entre a superfície "rígida" e a superfície deformável definida. Possui três graus de liberdade em cada nó, correspondendo às translações nas direções nodais $\mathrm{x}$, y e z. As características geométricas desse elemento são as mesmas da face do elemento sólido ao qual está ligado.

O elemento finito CONTA174 é utilizado para representar várias superfícies "rígidas" bidimensionais associadas com elementos de contato (CONTA174 ou CONTA173). Os elementos de contato revestem os elementos sólidos descrevendo o contorno do corpo deformável e estão potencialmente ligados à superfície "rígida". Tal superfície é discretizada por uma série de elementos TARGE170, formando um par com a superfície de contato associada através de uma mesma constante. Este elemento possui três graus de liberdade em cada nó, correspondendo às translações nas direções nodais $x, y$ e $z$. Vale salientar que as direções dos vetores normais às superfícies dos elementos TARGE170 e CONTA174 devem estar em sentido contrário.

\subsection{Simulação numérica}

A simulação numérica dos modelos de arrancamento em concreto autoadensável e convencional tem como base extenso estudo paramétrico realizado com o modelo de arrancamento de Fernandes (2000) (Almeida Filho et al., 2004, De Nardin, et al., 2005).

Esta etapa será dividida em duas partes, sendo a primeira referente aos modelos de arrancamento e a segunda aos modelos de viga.

\subsubsection{Modelos de arrancamento}

Nesta etapa foi realizada a simulação numérica dos ensaios monotônicos de arrancamento moldados em concreto auto-adensável e convencional com barras de 10 e de $16 \mathrm{~mm}$. 
A Tabela 7.1 mostra a divisão das séries de modelos de arrancamento.

Tabela 7.1 Divisão dos modelos de arrancamento

\begin{tabular}{cccc}
\hline Série & Modelo & Diâmetro da barra & Resistência à compressão do concreto \\
\hline 1 & A-CC-C30-B10 & $10 \mathrm{~mm}$ & $30 \mathrm{MPa}$ \\
& A-CC-C30-B16 & $16 \mathrm{~mm}$ & $30 \mathrm{MPa}$ \\
2 & A-CC-C60-B10 & $10 \mathrm{~mm}$ & $60 \mathrm{MPa}$ \\
& A-CC-C60-B16 & $16 \mathrm{~mm}$ & $60 \mathrm{MPa}$ \\
1 & A-CAA-C30-B10 & $10 \mathrm{~mm}$ & $30 \mathrm{MPa}$ \\
& A-CAA-C30-B16 & $16 \mathrm{~mm}$ & $30 \mathrm{MPa}$ \\
2 & A-CAA-C60-B10 & $10 \mathrm{~mm}$ & $60 \mathrm{MPa}$ \\
& A-CAA-C60-B16 & $16 \mathrm{~mm}$ & $60 \mathrm{MPa}$ \\
\hline
\end{tabular}

Onde, A corresponde ao modelo de arrancamento, CC e CAA correspondem ao concreto convencional e auto-adensável, respectivamente; C30 e C60 são as classes de resistência à compressão do concreto de 30 e de $60 \mathrm{MPa}$, respectivamente; e B10 e B16, correspondem ao diâmetro da barra de 10 e 16 mm, respectivamente.

A Figura 7.3 mostra a malha em elementos finitos utilizada. Por causa da simetria do prisma de concreto, utilizou-se $1 / 4$ do modelo.

Modelo de arrancamento com barra de $10 \mathrm{~mm}$
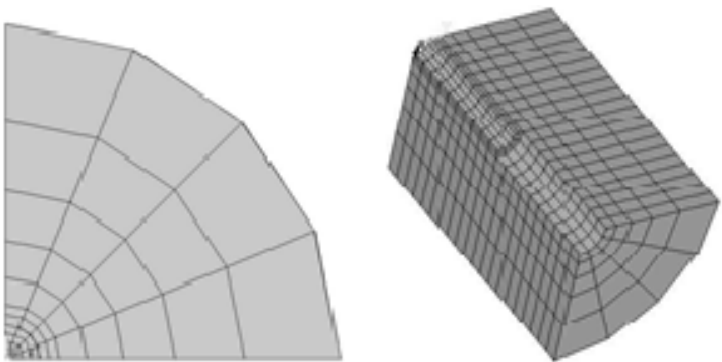

a) Seção transversal

b) Prisma de concreto

c) Modelo completo

d) elementos de contato

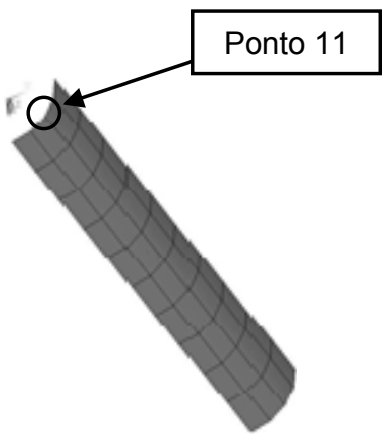

Modelo de arrancamento com barra de $16 \mathrm{~mm}$
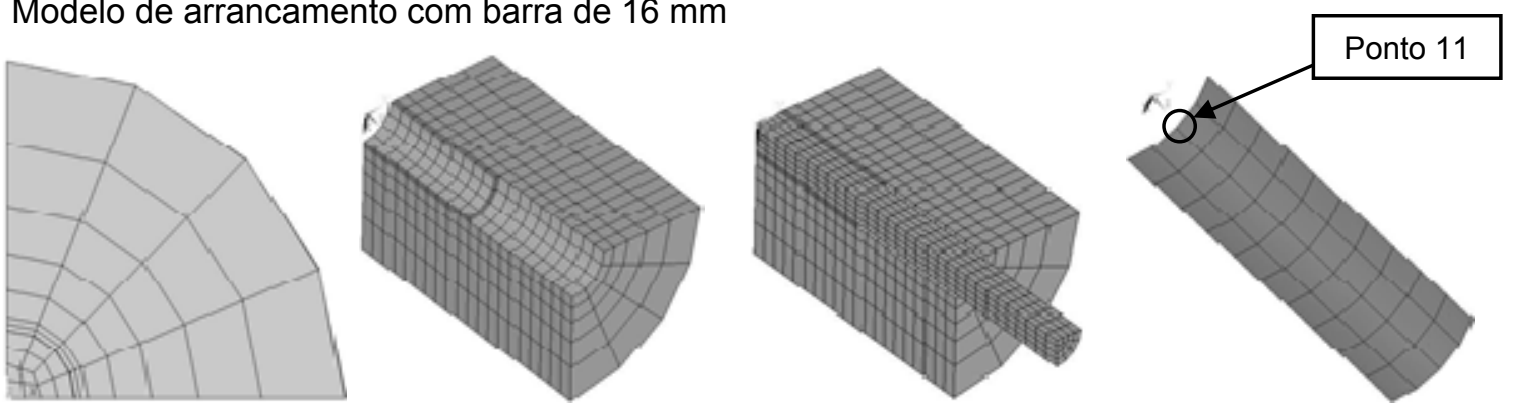

a) Seção transversal

b) Prisma de concreto

c) Modelo completo

d) elementos de contato

Figura 7.3 Malha em elementos finitos para os modelos de arrancamento 
Os elementos utilizados na simulação numérica foram o Solid65, Solid45, Conta174 e Targe170 (Ansys, 2002).

A Tabela 7.2 mostra a quantidade de elementos por modelo.

Tabela 7.2 Quantidade de elementos utilizados para cada modelo

\begin{tabular}{ccc}
\hline Elemento & $\mathbf{1 0 ~} \mathbf{~ m m}$ & $\mathbf{1 6} \mathbf{~ m m}$ \\
\hline Solid65 & 480 & 480 \\
Solid45 & 600 & 360 \\
Conta174 & 40 & 40 \\
Targe170 & 40 & 40 \\
\hline
\end{tabular}

Durante a discretização dos modelos numéricos, procurou-se manter um número semelhante de elementos de contato e, consequentemente de concreto. Somente os elementos de aço tiveram alteração por conta da discretização interna da barra de aço.

A Figura 7.4 mostra o layout do ensaio e o esquema do modelo numérico.

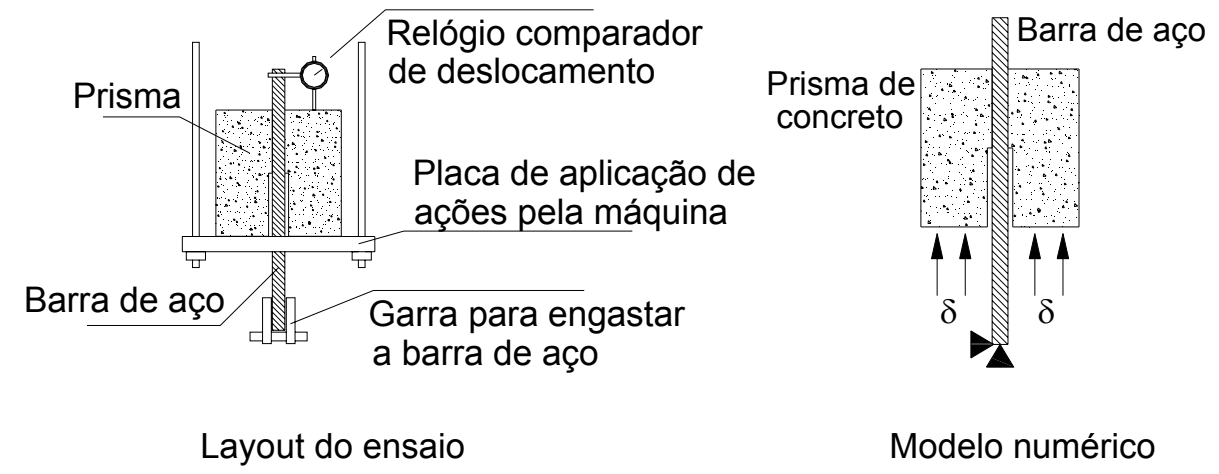

Figura 7.4 Layout do ensaio e modelo numérico

A aplicação do deslocamento no modelo foi correspondente ao deslocamento do pistão, para se validar os resultados de acordo com o ensaio de arrancamento.

A Figura 7.5 mostra o comportamento dos materiais utilizados nos ensaios de arrancamento tanto da série 1 quanto da série 2 . 

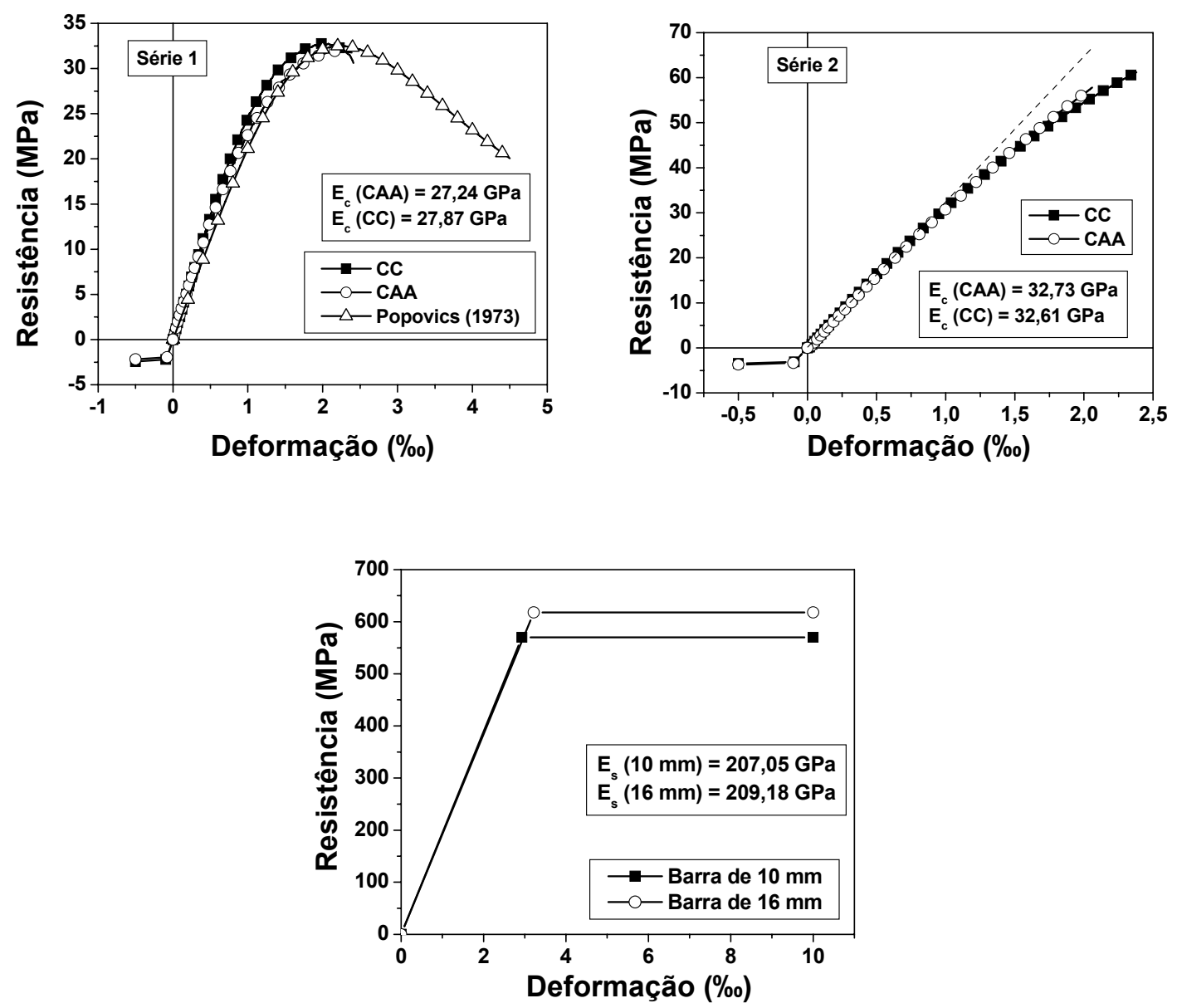

Figura 7.5 Comportamento do concreto (CAA e CC) das séries 1 e 2 e do aço (10 e 16 $\mathrm{mm}$ )

A Tabela 7.3 mostra os valores obtidos dos ensaios de arrancamento e adotados nas simulações numéricas e utilizados para comparação.

Tabela 7.3 Resultados dos ensaios dos modelos de arrancamento das séries 1 e 2

\begin{tabular}{ccccccc}
\hline Modelo & $\begin{array}{c}\mathbf{P}_{\mathbf{u}} \\
(\mathbf{k N})\end{array}$ & $\begin{array}{c}\tau_{\mathbf{u}} \\
(\mathbf{M P a})\end{array}$ & $\begin{array}{c}\mathbf{S}_{\mathrm{u}} \\
(\mathbf{m m})\end{array}$ & $\mathbf{F K N}$ & $\mathbf{F K T}$ & $\begin{array}{c}\mathbf{D} \\
(\mathbf{m m})\end{array}$ \\
\hline A-CAA-C30-B10 & 22,52 & 14,34 & 0,96 & 10 & 0,7 & $7,0 \mathrm{~mm}$ \\
A-CAA-C30-B16 & 52,01 & 12,93 & 1,059 & 5 & 1,0 & $7,0 \mathrm{~mm}$ \\
A-CAA-C60-B10 & 24,44 & 15,56 & 1,226 & 0,048 & 1,0 & $3,0 \mathrm{~mm}$ \\
A-CAA-C60-B16 & 74,46 & 18,52 & 1,652 & 0,0135 & 1,0 & $3,0 \mathrm{~mm}$ \\
\hline A-CC-C30-B10 & 18,09 & 11,52 & 0,979 & 10 & 0,7 & $7,0 \mathrm{~mm}$ \\
A-CC-C30-B16 & 42,36 & 10,53 & 1,64 & 5 & 1,0 & $7,0 \mathrm{~mm}$ \\
A-CC-C60-B10 & 24,70 & 15,73 & 1,292 & 0,048 & 1,0 & $3,0 \mathrm{~mm}$ \\
A-CC-C60-B16 & 85,70 & 21,31 & 2,054 & 0,0135 & 1,0 & $3,0 \mathrm{~mm}$ \\
\hline
\end{tabular}

Onde " $\mathrm{P}_{\mathrm{u}}$ " é a força de ruptura do ensaio, " $\tau_{\mathrm{u}}$ " é a resistência última de aderência, "Su" é o deslizamento correspondente à força de ruptura do ensaio e "D" é o deslocamento aplicado pelo pistão no ensaio. 
O carregamento aplicado no modelo numérico foi similar ao modelo experimental (Figura 7.4). Na simulação numérica foram aplicadas as taxas de deslocamento de acordo com o resultado do modelo experimental.

A Figura 7.6 mostra os resultados para a simulação numérica do modelo de arrancamento utilizando o modelo Bonded, para o modelo experimental com barra de 10 e $16 \mathrm{~mm}$ da série 1.
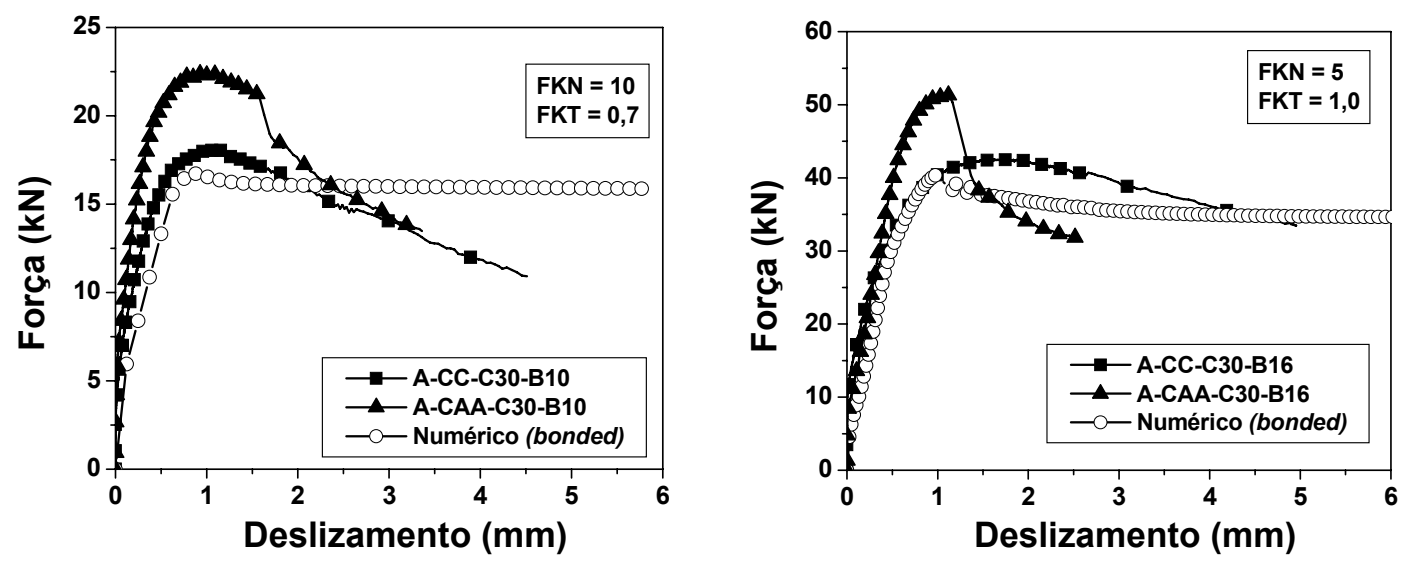

Figura 7.6 Comparação entre o resultado numérico e o experimental para os modelos de arrancamento em CAA e em CC para o com barra de 10 e $16 \mathrm{~mm}$ da série 1

A Figura 7.7 mostra os resultados para a simulação numérica do modelo de arrancamento utilizando o modelo Bonded, para o modelo experimental com barra de 10 e $16 \mathrm{~mm}$ da série 2.
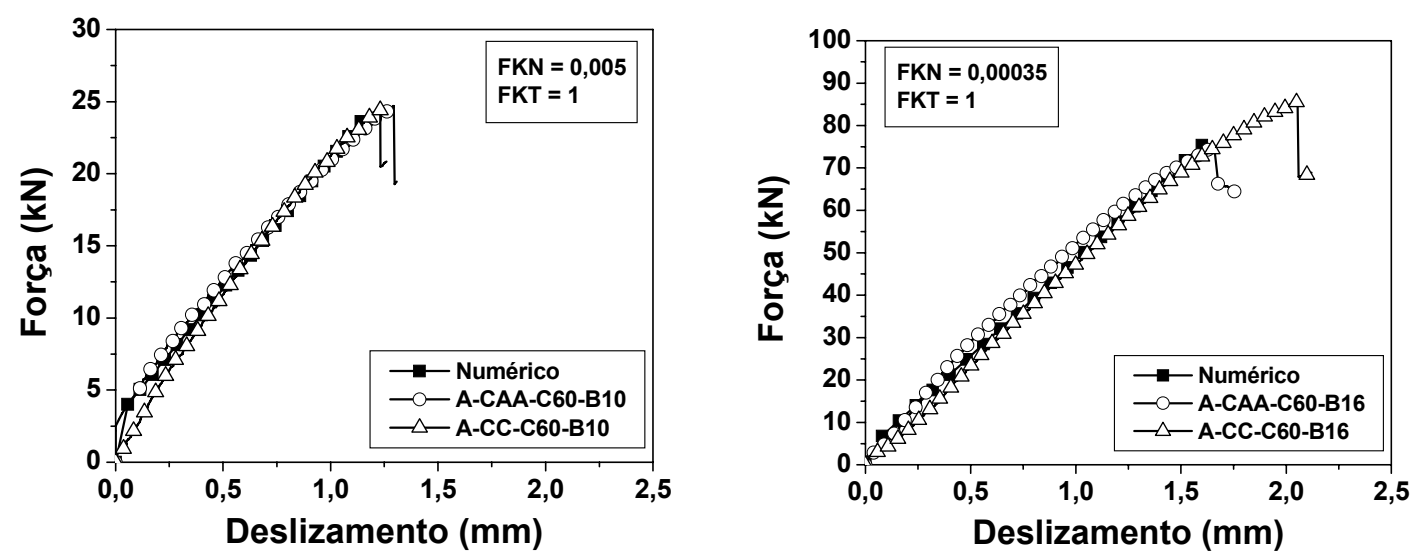

Figura 7.7 Comparação entre o resultado numérico e o experimental para os modelos de arrancamento em CAA e em CC para o com barra de 10 e $16 \mathrm{~mm}$ da série 2 
De acordo com a Figura 7.6, a simulação numérica do modelo de arrancamento em CC apresentou um comportamento mais flexível que o modelo experimental. Isso ocorreu devido ao fato do programa em elementos finitos não considerar a parcela referente à adesão, sendo esta somada a partir do resultado do modelo experimental (do mesmo modo que fora realizado na simulação preliminar). Nesta etapa se verificou que os limites estabelecidos para FKN fornecem uma aproximação satisfatória, no caso de se analisar o modelo de arrancamento em CC e em CAA, e a favor da segurança. Para a aproximação numérica com o modelo Bonded, o valor utilizado para o FKN foi elevado por causa do valor do módulo de elasticidade do concreto. $\mathrm{O}$ comportamento do modelo experimental foi satisfatório apresentando uma boa correspondência com o modelo experimental.

Já os modelos de arrancamento da série 2 apresentaram um valor para o FKN foi igual a 0,005 e 0,00035 por causa do valor do módulo de elasticidade dos materiais. O comportamento do modelo experimental foi satisfatório apresentando uma boa correspondência com o modelo experimental, mas não foi possível representar o deslizamento máximo do ensaio.

A Tabela 7.4 mostra os valores para cada resultado numérico em comparação com o resultado experimental.

Tabela 7.4 Comparação entre os resultados numérico e experimental para modelo de arrancamento com barra de 10 e $16 \mathrm{~mm}$

\begin{tabular}{|c|c|c|}
\hline \multicolumn{3}{|c|}{ A-CAA-C30-B10 } \\
\hline & Exp. & $\begin{array}{c}\text { Bonded } \\
\text { (Num. / } \lambda \text { ) }\end{array}$ \\
\hline$P_{u}(k N)$ & 22,52 & $16,72 / 1,35$ \\
\hline $\mathbf{s}_{\mathrm{u}(\mathrm{mm})}$ & 0,96 & $0,882 / 1,09$ \\
\hline \multicolumn{3}{|c|}{ A-CAA-C30-B16 } \\
\hline & Exp. & $\begin{array}{c}\text { Bonded } \\
(\text { Num. I } \lambda \text { ) }\end{array}$ \\
\hline$P_{u}(k N)$ & 52,01 & $40,33 / 1,29$ \\
\hline $\mathbf{S}_{\mathrm{u}(\mathrm{mm})}$ & 1,06 & $0,98 / 1,08$ \\
\hline \multicolumn{3}{|c|}{ A-CAA-C60-B10 } \\
\hline & Exp. & $\begin{array}{c}\text { Bonded } \\
\text { (Num. } / \lambda \text { ) }\end{array}$ \\
\hline$P_{u}(k N)$ & 24,70 & $23,61 / 1,046$ \\
\hline$s_{u(m m)}$ & 1,29 & $1,14 / 1,131$ \\
\hline \multicolumn{3}{|c|}{ A-CAA-C60-B16 } \\
\hline & Exp. & $\begin{array}{c}\text { Bonded } \\
\text { (Num. } / \lambda)\end{array}$ \\
\hline$P_{u}(k N)$ & 74,46 & 75,39 / 0,988 \\
\hline $\mathbf{S}_{\mathrm{u}(\mathrm{mm})}$ & 1,65 & $1,60 / 1,031$ \\
\hline
\end{tabular}

\begin{tabular}{|c|c|c|}
\hline \multicolumn{3}{|c|}{ A-CC-C30-B10 } \\
\hline & Exp. & $\begin{array}{c}\text { Bonded } \\
\text { (Num. / } \lambda \text { ) }\end{array}$ \\
\hline$P_{u}(k N)$ & 18,09 & $16,72 / 1,08$ \\
\hline$S_{\mathrm{u}(\mathrm{mm})}$ & 0,979 & $0,882 / 1,11$ \\
\hline \multicolumn{3}{|c|}{ A-CC-C30-B16 } \\
\hline & Exp. & $\begin{array}{c}\text { Bonded } \\
(\text { Num. I } \lambda \text { ) }\end{array}$ \\
\hline$P_{u}(k N)$ & 42,36 & $40,33 / 1,05$ \\
\hline$S_{u(m m)}$ & 1,64 & $0,98 / 1,67$ \\
\hline \multicolumn{3}{|c|}{ A-CC-C60-B10 } \\
\hline & Exp. & $\begin{array}{c}\text { Bonded } \\
\text { (Num. I } \lambda \text { ) }\end{array}$ \\
\hline$P_{u}(k N)$ & 24,44 & $23,61 / 1,035$ \\
\hline$s_{u(m m)}$ & 1,23 & $1,14 / 1,079$ \\
\hline \multicolumn{3}{|c|}{ A-CC-C60-B16 } \\
\hline & Exp. & $\begin{array}{c}\text { Bonded } \\
\text { (Num. } / \lambda \text { ) }\end{array}$ \\
\hline$P_{u}(k N)$ & 85,7 & $75,39 / 1,137$ \\
\hline $\mathbf{S}_{\mathrm{u}(\mathrm{mm})}$ & 2,05 & $1,60 / 1,281$ \\
\hline
\end{tabular}


Onde, " $\lambda$ " corresponde à relação entre o resultado experimental e o numérico (fator bias), " $\mathrm{P}_{\mathrm{u}}$ " corresponde ao valor da força de ruptura da média dos resultados e " $\mathrm{S}_{\mathrm{u}}$ " corresponde ao deslizamento máximo da média dos resultados.

De acordo com os modelos experimentais da série 1 , foi visto que 0 comportamento do modelo experimental em CAA e em CC foi muito diferente, mostrando uma clara superioridade na força de arrancamento por parte dos modelos em CAA. Essa diferença teve repercussão no resultado do modelo numérico, uma vez que este considerava a não-linearidade física dos materiais e não levava em consideração a adesão existente. Essa não consideração conduziu a uma má aproximação do resultado, com uma diferença da ordem de $35 \%$ em relação ao modelo de arrancamento em CAA. Já o modelo numérico se portou de uma maneira mais adequada para os modelos de arrancamento em CC, conduzindo a uma boa aproximação com uma diferença de cerca de $8 \%$ em relação ao modelo experimental.

Assim, o modelo é adequado para se estimar a força de arrancamento do ensaio e o deslizamento correspondente quando da utilização de concreto convencional e, no caso do CAA, este modelo numérico subestima a força de arrancamento fornecendo resultados muito aquém do esperado (conservador). Com relação ao CAA, são necessárias maiores investigações de modo a se obter um modelo de comportamento do contato que possa levar em consideração a adesão existente.

De acordo com os modelos experimentais da série 2, foi visto que o comportamento do modelo em CAA e em CC foi semelhante, mostrando apenas uma menor rigidez para os modelos com barra de $16 \mathrm{~mm}$ em CAA.

De acordo com os resultados obtidos, houve uma boa aproximação entre os resultados numérico e experimental com uma diferença de cerca de $5 \%$ para o caso de barras de $10 \mathrm{~mm}$ e de $14 \%$ para o caso de barras com $16 \mathrm{~mm}$. Assim, o modelo é adequado para se estimar a força de arrancamento do ensaio e o deslizamento correspondente.

\subsubsection{Modelos de viga}

Nesta etapa foi realizada a simulação numérica dos ensaios monotônicos de arrancamento moldados em concreto auto-adensável e convencional com barras de 10 e de $16 \mathrm{~mm}$.

A Tabela 7.5 mostra como serão divididas as séries de modelos de viga. 
Tabela 7.5 Divisão dos modelos de viga

\begin{tabular}{cccc}
\hline Série & Modelo & Diâmetro da barra & Resistência à compressão do concreto \\
\hline \multirow{2}{*}{1} & V-CC-C30-B10 & $10 \mathrm{~mm}$ & $30 \mathrm{MPa}$ \\
& V-CC-C30-B16 & $16 \mathrm{~mm}$ & $30 \mathrm{MPa}$ \\
2 & V-CC-C60-B10 & $10 \mathrm{~mm}$ & $60 \mathrm{MPa}$ \\
& V-CC-C60-B16 & $16 \mathrm{~mm}$ & $60 \mathrm{MPa}$ \\
& V-CAA-C30-B10 & $10 \mathrm{~mm}$ & $30 \mathrm{MPa}$ \\
& V-CAA-C30-B16 & $16 \mathrm{~mm}$ & $30 \mathrm{MPa}$ \\
2 & V-CAA-C60-B10 & $10 \mathrm{~mm}$ & $60 \mathrm{MPa}$ \\
2 & V-CAA-C60-B16 & $16 \mathrm{~mm}$ & $60 \mathrm{MPa}$ \\
\hline
\end{tabular}

Onde, $\mathrm{V}$ corresponde ao modelo de arrancamento, CC e CAA correspondem ao concreto convencional e auto-adensável, respectivamente; C30 e C60 são as classes de resistência à compressão do concreto de 30 e $60 \mathrm{MPa}$, respectivamente; e B10 e B16, correspondem ao diâmetro da barra de 10 e 16 mm, respectivamente.

A Figura 7.8 mostra a malha em elementos finitos utilizada. Por causa da simetria da viga de concreto, utilizou-se $1 / 4$ do modelo.

Modelo de viga com barra de $10 \mathrm{~mm}$

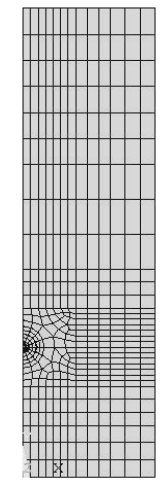

a) Seção transversal

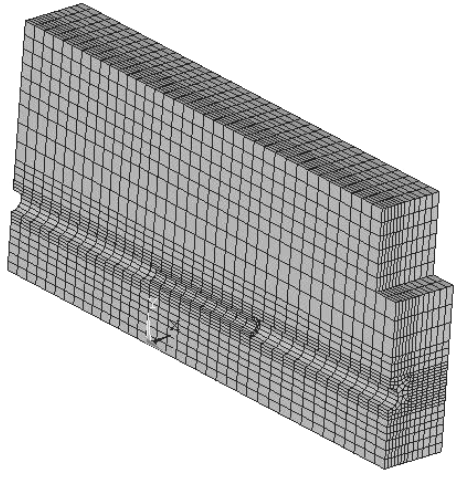

b) Elementos de concreto

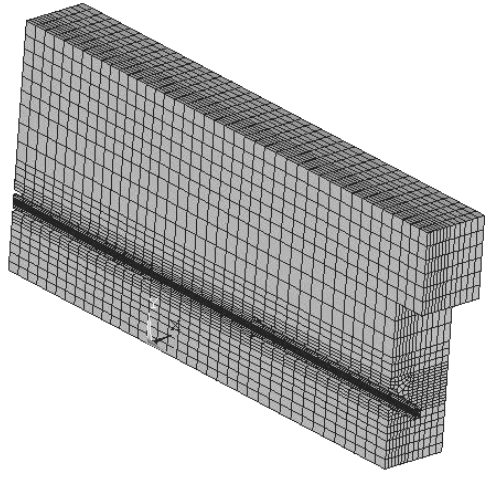

c) Modelo completo

Modelo de viga com barra de $16 \mathrm{~mm}$

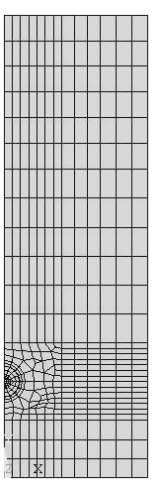

a) Seção transversal

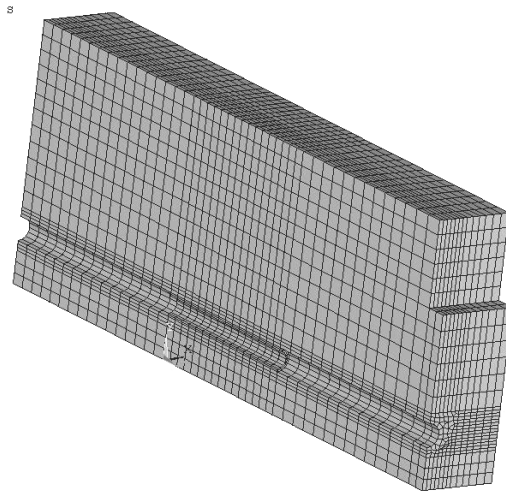

b) Elementos de concreto

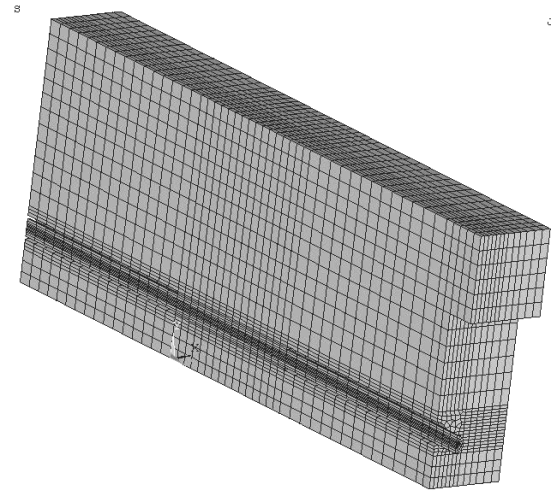

c) Modelo completo

Figura 7.8 Malha em elementos finitos para os modelos de viga 
Os elementos utilizados foram os mesmos adotados na simulação numérica dos modelos de arrancamento, que foram o Solid65, Solid45, Conta174 e Targe170 (Ansys, 2002). A quantidade de elementos por modelo de viga é visto na Tabela 7.6.

Tabela 7.6 Quantidade de elementos utilizados para cada modelo de viga

\begin{tabular}{ccc}
\hline Elemento & Viga10 & Viga16 \\
\hline Solid65 & 14330 & 16315 \\
Solid45 & 2030 & 2390 \\
Conta174 & 80 & 128 \\
Targe170 & 80 & 128 \\
\hline
\end{tabular}

A Figura 7.9 mostra o layout do ensaio e as restrições do modelo numérico.

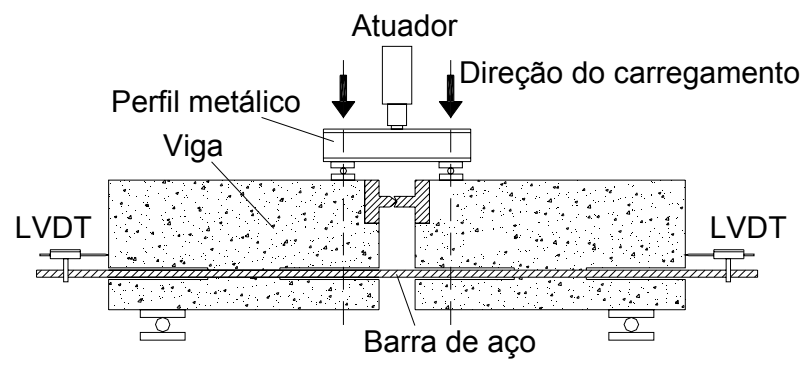

Layout do ensaio

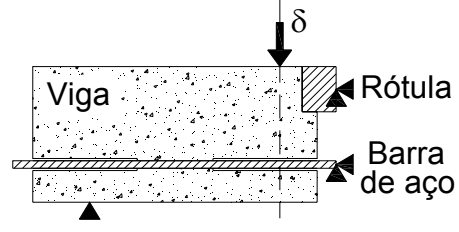

Modelo numérico

Figura 7.9 Layout do ensaio e modelo numérico

A aplicação do deslocamento no modelo foi correspondente ao deslocamento do pistão, para se validar os resultados de acordo com o ensaio de viga.

A Figura 7.10 mostra o comportamento dos concretos utilizados nos ensaios de viga.
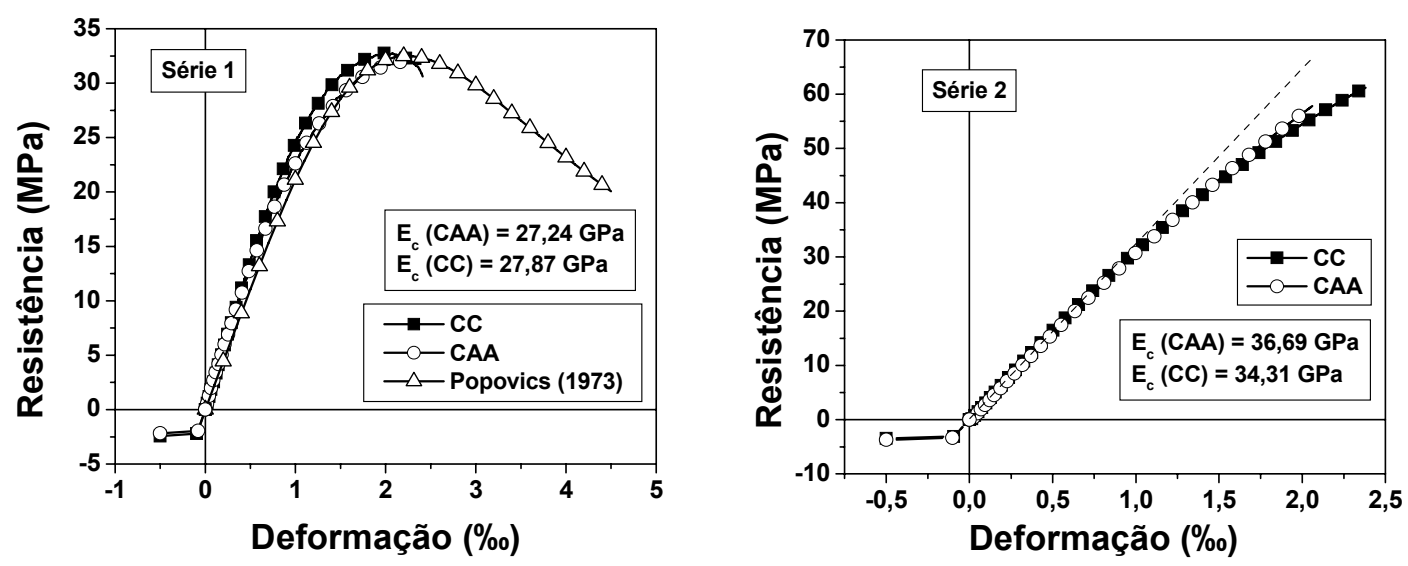

Figura 7.10 Comportamento do concreto (CAA e CC) das séries 1 e 2 
A Tabela 7.7 mostra os valores obtidos dos ensaios de viga e adotados nas simulações numéricas e utilizados para comparação.

Tabela 7.7 Resultados dos ensaios dos modelos de viga das séries 1 e 2

\begin{tabular}{cccccccc}
\hline Modelo & $\begin{array}{c}\mathbf{P}_{\mathrm{u}} \\
\mathbf{( k N )}\end{array}$ & $\begin{array}{c}\delta \\
(\mathbf{m m})\end{array}$ & $\begin{array}{c}\tau_{\mathrm{u}} \\
(\mathbf{M P a})\end{array}$ & $\begin{array}{c}\mathbf{S}_{\mathrm{u}} \\
(\mathbf{m m})\end{array}$ & FKN & FKT & $\begin{array}{c}\mathbf{D} \\
(\mathbf{m m})\end{array}$ \\
\hline V-CAA-C30-B10 & 32,66 & 3,97 & 13,00 & 0,398 & 3 & $1 / 0,15$ & 12,0 \\
V-CAA-C30-B16 & 61,99 & 6,59 & 11,57 & 0,938 & 40 & 1 & 18,0 \\
V-CAA-C60-B10 & 42,35 & 27,08 & 16,86 & 0,096 & 0,0001 & 1 & 31,0 \\
V-CAA-C60-B16 & 92,48 & 40,96 & 17,25 & 0,215 & 0,0001 & 1 & 50,0 \\
\hline V-CC-C30-B10 & 33,49 & 3,82 & 13,33 & 0,295 & 3 & $1 / 0,15$ & 12,0 \\
V-CC-C30-B16 & 70,77 & 7,32 & 13,20 & 0,758 & 40 & 1 & 18,0 \\
V-CC-C60-B10 & 41,58 & 29,87 & 16,55 & 0,068 & 0,0001 & 1 & 31,0 \\
V-CC-C60-B16 & 90,84 & 42,95 & 16,95 & 0,660 & 0,0001 & 1 & 50,0 \\
\hline
\end{tabular}

Onde " $\delta$ " corresponde à flecha do ensaio no instante da força de ruptura.

A Figura 7.11 mostra os resultados para a simulação numérica do modelo de viga utilizando o modelo Bonded com barra de 10 e de $16 \mathrm{~mm}$ da série 1.
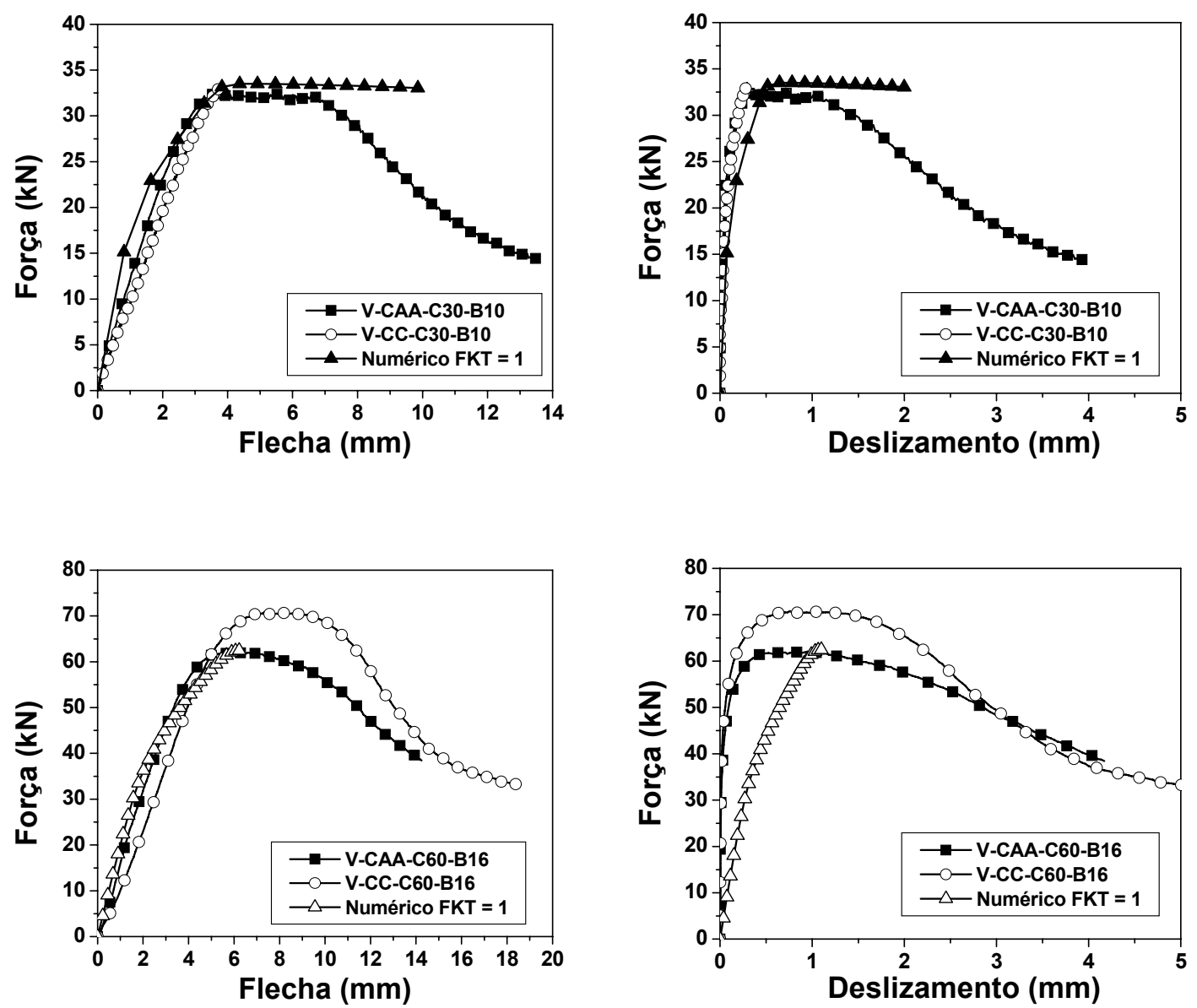

Figura 7.11 Comparação entre o resultado numérico e o experimental para os modelos de viga em CAA e em CC para o com barra de 10 e $16 \mathrm{~mm}$ da série 1 
De acordo com os modelos experimentais da série $1 \mathrm{com}$ barra de $10 \mathrm{~mm}$, foi visto que o comportamento do modelo em CAA e em CC foi semelhante, entretanto o modelo de viga em CC apresentou, conforme explicado anteriormente, um problema na aferição dos resultados logo após o ápice da força aplicada, gerado por um problema no dispositivo de rótula utilizado. Por isso, foi considerado apenas o pré-pico do ensaio e este se mostrou semelhante ao comportamento de pré-pico do modelo de viga em CAA. Os modelos com barra de $16 \mathrm{~mm}$ foram bem representados, da mesma forma que no caso dos modelos com barra de $10 \mathrm{~mm}$ apenas para o comportamento força vs. flecha, não apresentando uma aproximação adequada para o deslizamento.

A Figura 7.11 mostra os resultados para a simulação numérica do modelo de viga utilizando o modelo Bonded com barra de 10 e de $16 \mathrm{~mm}$ da série 2 .
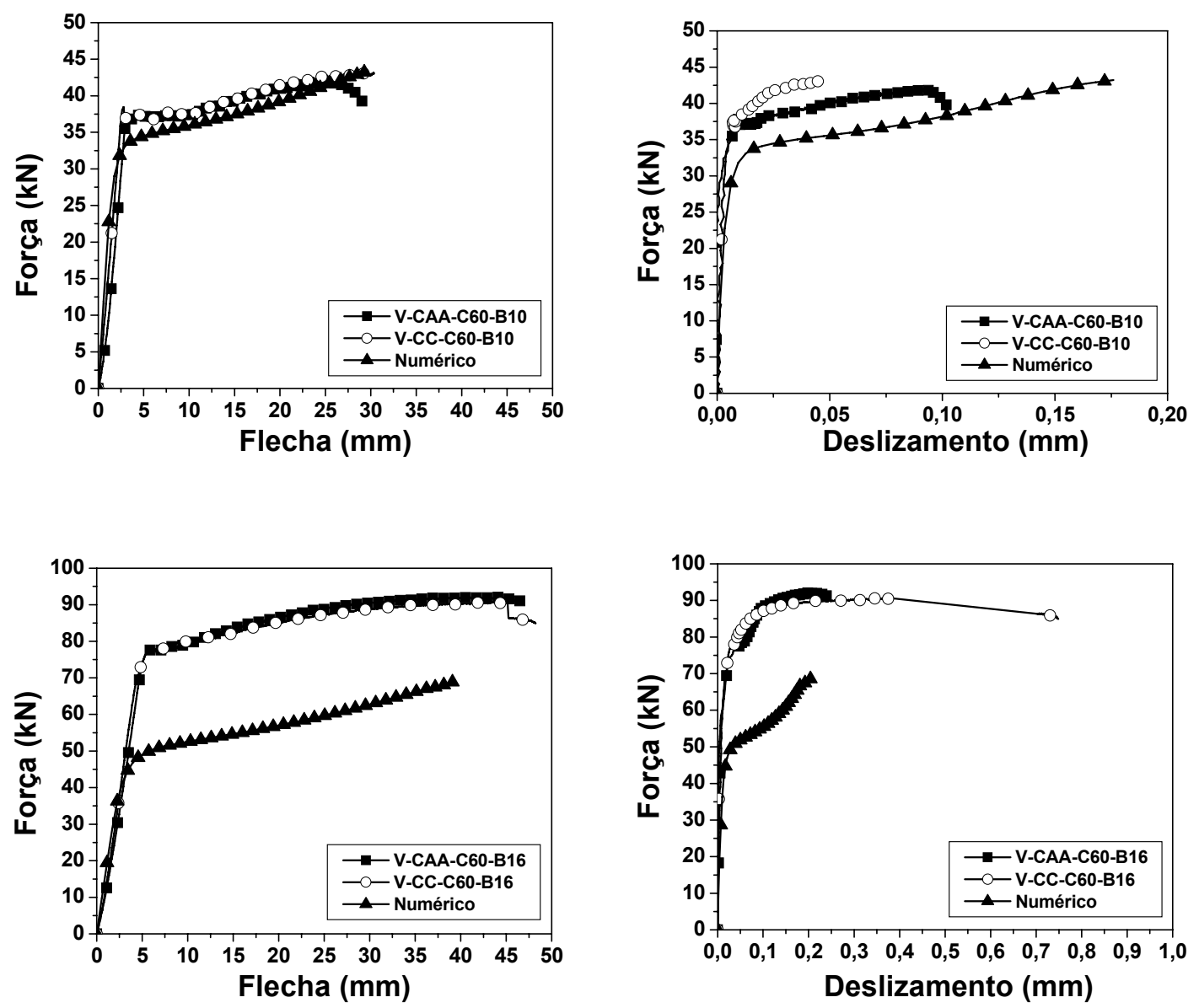

Figura 7.12 Comparação entre o resultado numérico e o experimental para os modelos de viga em CAA e em CC para o com barra de 10 e $16 \mathrm{~mm}$ da série 2

De acordo com a Figura 7.12, houve uma boa representação do comportamento do ensaio e do deslizamento existente; entretanto, o modelo numérico se mostrou menos rígido que o experimental. De acordo com os resultados, foi visto que o 
comportamento do modelo numérico em relação aos modelos experimentais em CAA e em CC foi semelhante, porém, não foi possível representar, adequadamente o deslizamento da barra. Assim, o modelo numérico consegue representar o comportamento do ensaio (força vs. flecha), mas não é suficientemente adequado para representar à média dos deslizamentos da barra. Vale salientar que, caso não fosse utilizada a média dos valores dos deslizamentos no modelo, o resultado poderia apresentar uma melhor aproximação. Ainda, o modelo com barra de $16 \mathrm{~mm}$ apresentou uma pior aproximação que o modelo com barra de $10 \mathrm{~mm}$.

A Tabela 7.8 mostra os valores para cada resultado numérico em comparação com o resultado experimental.

Tabela 7.8 Comparação entre os resultados numérico e experimental para modelo de viga com barra de 10 e $16 \mathrm{~mm}$

\begin{tabular}{|c|c|c|}
\hline \multicolumn{3}{|c|}{ V-CAA-C30-B10 } \\
\hline \multirow{4}{*}{$\begin{array}{l}\mathbf{P}_{\mathrm{u}}(\mathrm{kN}) \\
\mathbf{S}_{\mathrm{u}}(\mathrm{mm}) \\
\delta_{\mathrm{u}}(\mathrm{mm}) \\
\end{array}$} & Exp. & $\begin{array}{c}\text { Bonded } \\
\text { (Num. } / \lambda \text { ) }\end{array}$ \\
\hline & 32,66 & $32,51 / 0,97$ \\
\hline & 0,398 & 0,644 / 0,62 \\
\hline & 3,97 & 4,37 / 0,91 \\
\hline \multicolumn{3}{|c|}{ V-CAA-C30-B16 } \\
\hline \multirow{4}{*}{$\begin{array}{l}\mathbf{P}_{\mathrm{u}}(\mathbf{k N}) \\
\mathbf{S}_{\mathrm{u}(\mathrm{mm})} \\
\delta_{\mathrm{u}}(\mathrm{mm})\end{array}$} & Exp. & $\begin{array}{c}\text { Bonded } \\
\text { (Num. } / \lambda)\end{array}$ \\
\hline & 61,99 & $62,45 / 0,99$ \\
\hline & 0,938 & 1,09 / 0,85 \\
\hline & 6,59 & $6,23 / 1,06$ \\
\hline \multicolumn{3}{|c|}{ V-CAA-C60-B10 } \\
\hline \multirow{4}{*}{$\begin{array}{l}P_{\mathrm{u}}(\mathbf{k N}) \\
\mathbf{S}_{\mathrm{u}(\mathrm{mm})} \\
\delta_{\mathrm{u}}(\mathrm{mm})\end{array}$} & Exp. & $\begin{array}{c}\text { Bonded } \\
\text { (Num. / } \lambda \text { ) }\end{array}$ \\
\hline & 42,35 & $43,20 / 0,98$ \\
\hline & 0,096 & $0,176 / 0,55$ \\
\hline & 27,08 & $29,28 / 0,92$ \\
\hline \multicolumn{3}{|c|}{ V-CAA-C60-B16 } \\
\hline & Exp. & $\begin{array}{c}\text { Bonded } \\
\text { (Num. } / \lambda)\end{array}$ \\
\hline$P_{u}(k N)$ & 92,06 & $68,86 / 1,337$ \\
\hline $\mathbf{S}_{\mathrm{u}(\mathrm{mm})}$ & 0,204 & $0,206 / 0,992$ \\
\hline$\delta_{\mathrm{u}}(\mathrm{mm})$ & 40,69 & $39,09 / 1,041$ \\
\hline
\end{tabular}

\begin{tabular}{|c|c|c|}
\hline \multicolumn{3}{|c|}{ V-CC-C30-B10 } \\
\hline & Exp. & $\begin{array}{c}\text { Bonded } \\
\text { (Num. / } \lambda \text { ) }\end{array}$ \\
\hline$P_{u}(k N)$ & 33,49 & $33,51 / 1,00$ \\
\hline $\mathbf{s}_{\mathrm{u}(\mathrm{mm})}$ & 0,295 & $0,644 / 0,46$ \\
\hline$\delta_{u}(\mathrm{~mm})$ & 3,82 & $4,37 / 0,87$ \\
\hline \multicolumn{3}{|c|}{ V-CC-C30-B16 } \\
\hline & Exp. & $\begin{array}{c}\text { Bonded } \\
\text { (Num. / } \lambda \text { ) }\end{array}$ \\
\hline$P_{u}(k N)$ & 70,77 & $62,45 / 1,13$ \\
\hline $\mathbf{S}_{\mathrm{u}(\mathrm{mm})}$ & 0,758 & $1,09 / 0,69$ \\
\hline$\delta_{\mathrm{u}}(\mathrm{mm})$ & 7,32 & $6,23 / 1,18$ \\
\hline \multicolumn{3}{|c|}{ V-CC-C60-B10 } \\
\hline & Exp. & $\begin{array}{c}\text { Bonded } \\
\text { (Num. / } \lambda \text { ) }\end{array}$ \\
\hline$P_{u}(k N)$ & 41,58 & $43,20 / 0,96$ \\
\hline $\mathbf{S}_{\mathrm{u}(\mathrm{mm})}$ & 0,068 & $0,176 / 0,39$ \\
\hline$\delta_{\mathrm{u}}(\mathrm{mm})$ & 29,87 & $29,28 / 1,019$ \\
\hline \multicolumn{3}{|c|}{ V-CC-C60-B16 } \\
\hline & Exp. & $\begin{array}{c}\text { Bonded } \\
\text { (Num. I } \lambda \text { ) }\end{array}$ \\
\hline$P_{u}(k N)$ & 90,72 & $68,86 / 1,318$ \\
\hline $\mathbf{s}_{\mathrm{u}(\mathrm{mm})}$ & 0,372 & $0,206 / 1,811$ \\
\hline$\delta_{u}(\mathrm{~mm})$ & 44,19 & $39,09 / 1,130$ \\
\hline
\end{tabular}

De acordo com a Tabela 7.8, nos resultados da série 1 pode-se ver que houve uma aproximação satisfatória com relação à viga em CAA, mesmo com uma aproximação de $15 \%$ para o deslizamento existente. Já para o modelo em CC, o modelo experimental se mostrou mais rígido que o numérico, resultando em uma má aproximação para o deslizamento existente, sendo a diferença da ordem de $31 \%$. 
De acordo com os resultados da Tabela 7.8, nos resultados da série 2 foi visto que o comportamento do modelo numérico em relação aos modelos experimentais em CAA e em CC foi semelhante, porém, não foi possível representar, adequadamente a força de ruptura do ensaio para o caso da barra de $16 \mathrm{~mm}$. Desse modo, a simulação numérica realizada para esse ensaio em particular, foi a que apresentou maior diferença em relação ao resultado do comportamento experimental. Essa diferença se deu em função do valor do módulo de elasticidade do concreto que, conforme visto anteriormente nos outros modelos numéricos, possui influência elevada.

\subsection{Considerações finais}

Neste capítulo foi feita a simulação numérica do comportamento dos ensaios de arrancamento e de viga, moldados tanto em concreto auto-adensável quanto em concreto convencional, com diferentes classes de resistência à compressão do concreto e diâmetros de barra diferentes.

De acordo com os resultados das simulações numéricas realizadas, pode-se verificar que é possível a representação do comportamento tanto do ensaio de arrancamento quanto do ensaio de viga.

A representação dos modelos numéricos teve como parâmetros fundamentais para a sua calibração o fator FKN e o fator FKT, que são responsáveis pela influência da superfície normal e tangencial do contato, respectivamente. Foi observado que esses dois parâmetros, principalmente o FKN, era fortemente influenciado pelo valor do módulo de elasticidade do concreto. À medida que se aumenta o valor do módulo de elasticidade do concreto, deve ocorrer uma redução do valor do FKN. Isso pode ser bem observado nos resultados das séries 1 e 2 , tanto de arrancamento quanto de viga, onde o valor determinado para a série 1 utilizou FKN variando de 1 a 10 , enquanto a série 2 utilizou valores entre 0,005 até 0,0001 .

Os resultados das simulações apresentaram uma previsão satisfatória da força de ruptura do ensaio, com a ressalva de que a aproximação dos deslizamentos apresentou diferenças significativas em alguns modelos, principalmente nos modelos da série 2, por conta do valor do módulo de elasticidade do concreto.

Os modelos com barra de $16 \mathrm{~mm}$, tanto de arrancamento quanto de viga, apresentaram comportamentos satisfatórios; entretanto, a aproximação destes modelos foi pior que os modelos com barra de $10 \mathrm{~mm}$. Isso pode ser explicado pelo tamanho da superfície de contato existente, que provavelmente necessitaria uma maior discretização para uma melhor aproximação dos resultados. 
Foi verificado que, à medida que se aumenta o valor do módulo de elasticidade, o comportamento do modelo numérico tendia para o linear. Este fato também ocorria quando da simulação dos modelos numéricos com barra de $16 \mathrm{~mm}$. Isso significa que são necessárias mais investigações com relação ao nível de discretização da malha do contato e com relação aos parâmetros que influenciam o comportamento da interface para uma melhor representação da tensão de aderência quando da utilização de barras de diâmetro de $16 \mathrm{~mm}$.

De um modo geral, os modelos numéricos desenvolvidos representaram satisfatoriamente o ensaio e, no capítulo posterior, será dada maior ênfase à análise das tensões referentes à superfície de contato e ao comportamento das barras instrumentadas com extensômetros elétricos de resistência. 


\section{Análise e discussão dos resultados}

Neste capítulo se apresentam a análise e a discussão dos resultados obtidos. Ainda, faz-se a comparação dos resultados obtidos tanto experimentalmente quanto numericamente. Paralelamente, apresenta-se uma análise comparativa dos resultados experimentais com aqueles provenientes de alguns Códigos, bem como dos fornecidos por formulações teóricas, para previsão da resistência de aderência e das propriedades do concreto no estado endurecido.

\subsection{Considerações iniciais}

$\mathrm{Na}$ literatura técnica existem muitos modelos analíticos (Eligehausen et al., 1983) e numéricos (Almeida Filho et al., 2004) que tentam representar a resistência de aderência na interface aço-concreto. Nesses modelos, a maioria foi baseada em investigações experimentais onde era observada a influência de diversos parâmetros, tais como: resistência à compressão do concreto, cobrimento, diâmetro da barra, comprimento de aderência e etc. Esses ensaios resultaram em equações que calculam a resistência média de aderência por meio de regressões lineares ou nãolineares.

As pesquisas numéricas em geral foram desenvolvidas com o objetivo de se avaliar a propagação da perda de aderência, utilizando o Método dos Elementos Finitos (MEF) com modelos simplificados ou complexos (Almeida Filho et al., 2004). Nesses modelos, geralmente, são aplicadas hipóteses simplificadoras, como a de não 
considerar a presença das nervuras da barra de aço, pois essa consideração melhora consideravelmente a convergência da solução e livra a simulação do problema da penetração do elemento de barra da nervura no concreto (Almeida Filho et al., 2004). Assim, a consideração de uma superfície lisa, sem nervuras, conduz a resultados satisfatórios com bom grau de aproximação.

\subsubsection{Critérios para análise da resistência de aderência}

O procedimento adotado para o cálculo da resistência de aderência em ensaios de arrancamento (Eq. 8.1) e de viga (Eq. 8.2) foi o mesmo estabelecido pelo RilemCeb-Fip (1973).

Para o modelo de arrancamento,

$$
\tau=\frac{\mathrm{P}}{\pi \cdot l_{d} \cdot \phi}
$$

E para o modelo de viga,

$$
\tau=\frac{\sigma_{\mathrm{s}}}{40} ; \sigma_{s}=\mathrm{k} \cdot \frac{\mathrm{P}}{\mathrm{A}_{\mathrm{s}}}
$$

Onde, "u" é a resistência de aderência, "k" corresponde a 1,25 quando o diâmetro da barra de aço é inferior a $16 \mathrm{~mm}$ e corresponde a 1,5 quando o diâmetro da barra de aço é igual ou superior a $16 \mathrm{~mm}$, "P" é a força aplicada, " $A_{s}$ " é a área da barra de aço, " $\sigma_{s}$ " é a tensão na barra de aço, " $\phi$ " é o diâmetro da barra de aço e "/d" corresponde ao comprimento aderente.

Para o cálculo da resistência de aderência, foi adotado o procedimento de acordo com Soretz (1972), Rilem-Ceb-Fip (1983), Barbosa (2001) e Moreno Jr. \& Rossi (2002), onde a resistência média de aderência (Eq. 8.3) é dada pela média das resistências de aderência obtidas para os deslizamentos de 0,01 $\mathrm{mm}\left(\tau_{0,01}\right), 0,1 \mathrm{~mm}$ $\left(\tau_{0,1}\right)$ e $1,0 \mathrm{~mm}\left(\tau_{1,0}\right)$. Se o deslizamento máximo é menor que $1,0 \mathrm{~mm}$ no cálculo de $\tau_{\mathrm{m}}$, $\tau_{u}$ deverá ser empregado no lugar de $\tau_{1,0}$.

$$
\tau_{\mathrm{m}}=\frac{\tau_{0,01}+\tau_{0,1}+\tau_{1,0}}{3}
$$

Onde $\tau_{m}$ é a resistência média de aderência. 
De acordo com Leonhardt \& Mönnig (1977) e o Rilem-Ceb-Fip (1983), o valor referente ao deslizamento de $0,1 \mathrm{~mm}$ corresponde ao valor de cálculo para utilização no dimensionamento de estruturas em concreto armado.

De acordo com o Rilem-Ceb-Fip (1983), o valor para as resistências média e última de aderência deve obedecer a seguinte regra:

$$
\begin{aligned}
& \tau_{\mathrm{m}} \geq 8,0-0,12 \cdot \phi \\
& \tau_{\mathrm{u}} \geq 13,0-0,19 \cdot \phi
\end{aligned}
$$

Onde $\phi$ corresponde ao diâmetro da barra de aço, em milímetros.

Com relação às formulações utilizadas para prever o comportamento e o valor da resistência de aderência, a Tabela 8.1 ilustra as formulações utilizadas nas comparações com os resultados experimentais.

Tabela 8.1 Formulações empregadas na determinação aproximada da resistência de aderência

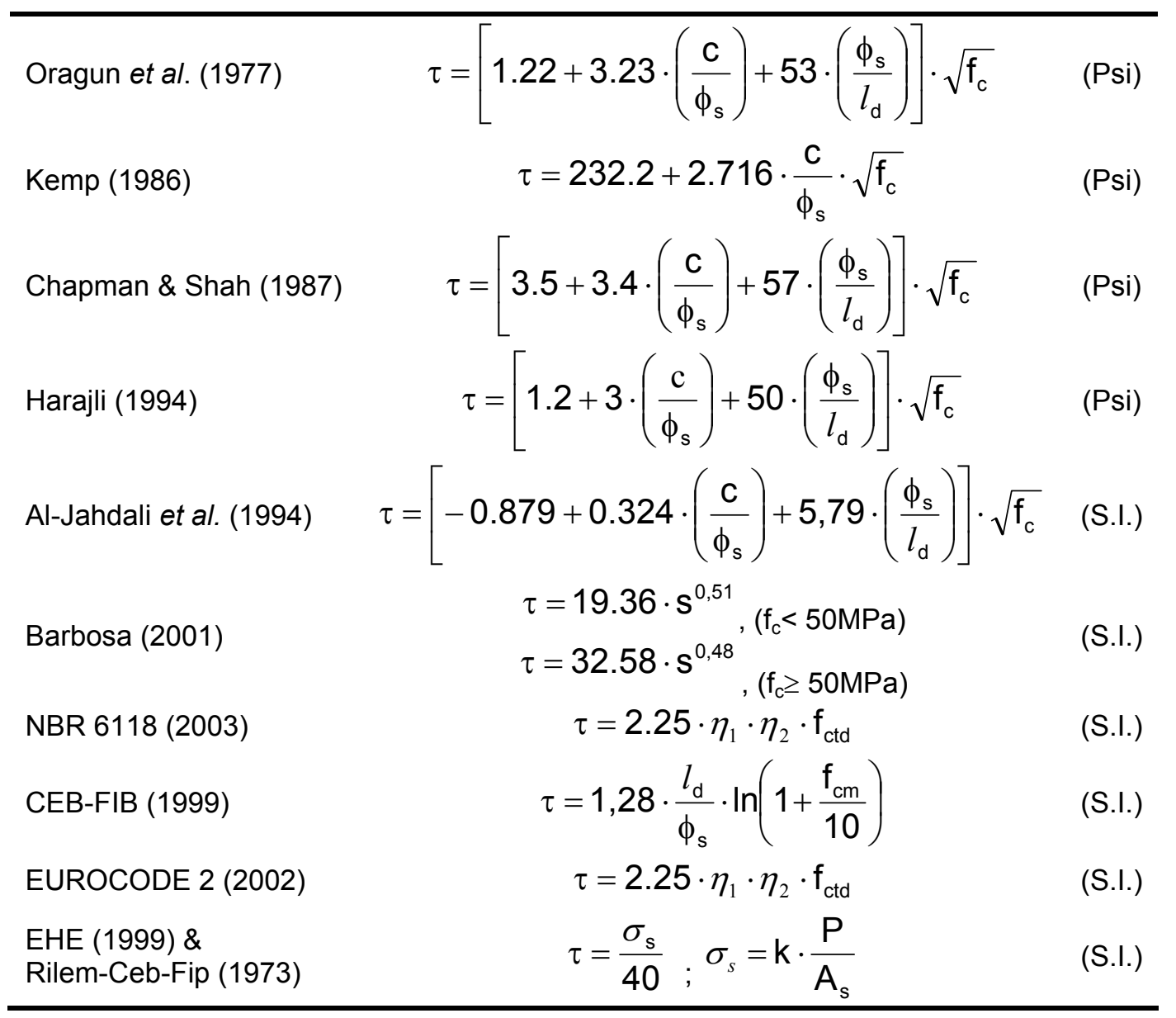


Onde " $\tau$ " é a resistência de aderência, "c" é o cobrimento, "P" é a força aplicada no ensaio de viga, "s" é o deslizamento da barra, "ld" é o comprimento de ancoragem, " $\phi_{s}$ " é o diâmetro da barra, " $f_{c}$ " é a resistência à compressão do concreto e " $f_{c t d}$ " é a resistência à tração de cálculo do concreto.

Nessas equações, existem algumas que representam o comportamento da resistência de aderência vs. deslizamento, como a de Barbosa (2001), Ceb-Fip 195/197 (1990) e Huang et al. (1996); e há outras que representam essa resistência em função de parâmetros fornecidos, tais como: cobrimento, diâmetro da barra e comprimento de aderência.

A Tabela 8.2 mostra os parâmetros estabelecidos para as formulações do CebFip 195/197 (1990) e Huang et al. (1996), adotados para a comparação dos resultados.

Tabela 8.2 Parâmetros estabelecidos para as formulações do Ceb-Fip 195/197 (1990) e Huang et al. (1996), considerando boas condições de aderência

\begin{tabular}{|c|c|c|c|c|}
\hline & \multicolumn{2}{|c|}{ Ceb-Fip 195/197 (1990) } & \multicolumn{2}{|c|}{ Huang et al. (1996) } \\
\hline & $\begin{array}{l}\text { Concreto } \\
\text { confinado }\end{array}$ & $\begin{array}{l}\text { Concreto não } \\
\text { confinado }\end{array}$ & $\begin{array}{l}\text { Concreto de alta } \\
\text { resistência à } \\
\text { compressão }\end{array}$ & $\begin{array}{c}\text { Concreto de } \\
\text { resistência normal à } \\
\text { compressão }\end{array}$ \\
\hline $\mathbf{s}_{1}$ & $1,0 \mathrm{~mm}$ & $0,6 \mathrm{~mm}$ & $0,5 \mathrm{~mm}$ & $1,0 \mathrm{~mm}$ \\
\hline $\mathbf{s}_{2}$ & $3,0 \mathrm{~mm}$ & $0,6 \mathrm{~mm}$ & $1,5 \mathrm{~mm}$ & $3,0 \mathrm{~mm}$ \\
\hline $\mathbf{S}_{3}$ & $\begin{array}{l}\text { Espaçamento } \\
\text { entre nervuras }\end{array}$ & $1,0 \mathrm{~mm}$ & $\begin{array}{c}\text { Espaçamento entre } \\
\text { nervuras }\end{array}$ & $\begin{array}{c}\text { Espaçamento entre } \\
\text { nervuras }\end{array}$ \\
\hline$\alpha$ & 0,4 & 0,4 & 0,3 & 0,4 \\
\hline$\tau_{\text {máx }}$ & $2,5 \cdot f_{c}^{1 / 2}$ & $2,0 \cdot f_{c}{ }^{1 / 2}$ & $0.40 \cdot f_{\mathrm{cm}}$ & $0.40 \cdot f_{\mathrm{cm}}$ \\
\hline$\tau_{\mathbf{u}}$ & $0,40 \cdot \tau_{\text {máx }}$ & $0,15 \cdot \tau_{\text {máx }}$ & $0,40 \cdot \tau_{\text {máx }}$ & $0,40 \cdot \tau_{\text {máx }}$ \\
\hline
\end{tabular}

A Figura 8.1 mostra o modelo de comportamento da aderência com relação ao deslizamento da barra, de acordo com as formulações de Ceb-Fip 195/197 (1990) e Huang et al. (1996).

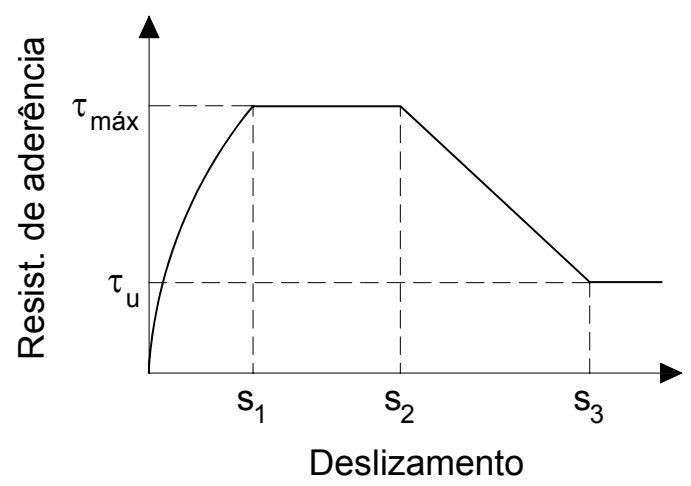

Figura 8.1 Modelo de comportamento da aderência 
A formulação para a determinação da resistência de aderência, Ceb-Fip 195/197 (1990) e Huang et al. (1996), é calculada da seguinte forma:

$$
\begin{aligned}
& \tau=\tau_{\text {máx }} \cdot\left(\frac{\mathrm{s}}{\mathrm{s}_{1}}\right)^{\alpha} \quad \text { Para } 0 \leq \mathrm{s} \leq \mathrm{s}_{1} \\
& \tau=\tau_{\text {máx }} \quad \text { Para } \mathrm{s}_{1}<\mathrm{s} \leq \mathrm{s}_{2} \\
& \tau=\tau_{\text {máx }}-\left(\tau_{\text {máx }}-\tau_{\mathrm{u}}\right) \cdot\left(\frac{\mathrm{s}-\mathrm{s}_{2}}{\mathrm{~s}_{3}-\mathrm{s}_{2}}\right) \quad \text { Para } \mathrm{s}_{2}<\mathrm{s} \leq \mathrm{s}_{3} \\
& \tau=\tau_{\mathrm{u}} \quad \text { Para } \mathrm{s}_{3}<\mathrm{s}
\end{aligned}
$$

Onde, " $\tau_{\text {máx }}$ é a resistência máxima de aderência.

\subsubsection{Critérios para previsão da resistência à tração e do módulo de elasticidade do concreto}

Com relação ao comportamento do CAA no estado endurecido, a Tabela 8.3

\begin{tabular}{|c|c|c|}
\hline & Módulo de elasticidade & Resistência à tração \\
\hline EHE (1999) & $E_{c}=10000 \cdot \sqrt[3]{f_{c}}$ & $f_{t}=0.21 \cdot f_{c}^{2 / 3}$ \\
\hline NBR 6118 (2003) & $E_{c}=5600 \cdot \sqrt{f_{c}}$ & $f_{t}=0.3 \cdot f_{c}^{2 / 3}$ \\
\hline CEB (1993) & $E_{c}=21.5 \cdot \sqrt[3]{f_{c} / 10}$ & $f_{t}=1.56 \cdot \sqrt[3]{\left(\frac{f_{c}-8}{10}\right)^{2}}$ \\
\hline ACI 318 (1999) & $E_{c}=43 \cdot \rho_{c}^{1.5} \cdot \sqrt{f_{c}} \cdot 10^{-6}$ & $\mathrm{f}_{\mathrm{t}}=0.56 \cdot \sqrt{\mathrm{f}_{\mathrm{c}}}$ \\
\hline Hueste et al. (2004) & $E_{c}=5230 \cdot \sqrt{f_{c}}$ & $f_{t}=0.55 \cdot \sqrt{f_{c}}$ \\
\hline Código Noruego (1992) & $E_{c}=9.5 \cdot\left(f_{c}\right)^{0.3} \cdot\left(\frac{\rho_{c}}{2400}\right)^{1.5}$ & --- \\
\hline Gardner \& Zao (1991) & $E_{c}=9 \cdot \sqrt[3]{f_{c}}\left(f_{c}>27 M P a\right)$ & --- \\
\hline Olokun (1991) & -- & $\mathrm{f}_{\mathrm{t}}=1.39 \cdot \mathrm{f}_{\mathrm{c}}^{0.69}$ \\
\hline Ahmad \& Shah (1985) & --- & $\mathrm{f}_{\mathrm{t}}=4.34 \cdot \mathrm{f}_{\mathrm{c}}^{0.55}$ \\
\hline Burg \& Ost (1992) & --- & $\mathrm{f}_{\mathrm{t}}=7.3 \cdot \sqrt{\mathrm{f}_{\mathrm{c}}}$ \\
\hline
\end{tabular}
mostra as formulações utilizadas.

Tabela 8.3 Formulações para previsão do módulo de elasticidade e da resistência à tração 
Onde, " $\rho_{c}$ " é a densidade do concreto, " $\mathrm{f}_{\mathrm{c}}$ " é a resistência à compressão do concreto, "f $\mathrm{f}_{\mathrm{t}}$ é a resistência à tração do concreto e $E_{\mathrm{c}}$ é o módulo de elasticidade longitudinal do concreto.

\subsubsection{Critérios para análise dos resultados}

Para se ter um nível de qualidade elevado, é preciso estabelecer parâmetros para se determinar a variação da propriedade o qual se quer avaliar, sendo que esta avaliação pode ser realizada por meio do desvio padrão (D.P.) e do coeficiente de variação (C.V.). O desvio padrão é o mais utilizado (Melchers, 1987), mas a utilização do coeficiente de variação apresenta um melhor entendimento e facilidade de visualização existente, pois ela não depende da magnitude da propriedade medida. $A$ Tabela 8.4 mostra os critérios estabelecidos para esta investigação e, vale reforçar que foi utilizado o coeficiente de variação como critério de avaliação da variabilidade existente.

Tabela 8.4 Limites estabelecidos para o critério de qualidade

\begin{tabular}{ccc}
\hline Controle de qualidade & $\begin{array}{c}\text { Limites aceitos para o } \\
\text { desvio padrão } \\
\left(\mathbf{f}_{\mathrm{c}}>\mathbf{2 7} \mathbf{M P a}\right) \\
(\text { Melchers, 1987) }\end{array}$ & $\begin{array}{c}\text { Limites aceitos para o } \\
\text { coeficiente de variação }\end{array}$ \\
\hline A (excelente) & 2,7 & $10 \%$ \\
B (médio) & 4,0 & $15 \%$ \\
C (pobre) & 5,4 & $20 \%$ \\
\hline
\end{tabular}

A justificativa para a adoção do coeficiente de variação para esta pesquisa está na ausência de informações a respeito dos limites do desvio padrão para o módulo de elasticidade e a resistência à tração, pois o controle de qualidade utilizado para determinar a qualidade do concreto se baseia somente na variação da resistência à compressão.

\subsubsection{Parâmetros estatísticos analisados}

Os parâmetros estatísticos utilizados para se avaliar a variabilidade das propriedades do CAA e do CC incluem a média (M), o desvio padrão (D.P.), o coeficiente de variação (C.V.), o Bias Factor $(\lambda)$, a análise do intervalo de confiança 
(I.C.) e, no caso da pesquisa desenvolvida, esta incorporou uma análise da freqüência e da distribuição normal probabilística para cada propriedade.

A seguir, se apresenta uma descrição sucinta dos parâmetros estatísticos utilizados.

\subsubsection{Média}

A média é definida como a relação entre a soma dos valores observados e a quantidade de amostras.

$$
M=\frac{\sum_{1}^{n} x_{i}}{n}
$$

Eq. 8.6

\subsubsection{Desvio Padrão}

O desvio padrão (DP) consiste da relação entre o valor da amostra e a média da população divididos pelo tamanho da população menos um.

$$
\mathrm{DP}=\sqrt{\frac{\sum_{1}^{\mathrm{n}}\left(\mathrm{x}_{\mathrm{i}}-\mathrm{M}\right)^{2}}{(\mathrm{n}-1)}}
$$

\subsubsection{Coeficiente de Variação}

O coeficiente de variação (C.V.) é definido como a relação entre o desvio padrão e a média.

$$
\mathrm{CV}=\frac{\mathrm{DP}}{\mathrm{M}}
$$

\subsubsection{Bias Factor $(\lambda)$}

O fator bias é definido como a relação entre o valor médio do experimento e o valor previsto (V.P.) por uma formulação. 


\subsubsection{Distribuição normal probabilística}

A distribuição normal e a freqüência variam em função da média e do desvio padrão. De acordo com Melchers (1987), a distribuição normal é mais utilizada nos casos em que o controle de qualidade da resistência à compressão é excelente (tipo A).

$$
f_{x}(x)=\frac{1}{D P \cdot \sqrt{2 \cdot \pi}} \cdot \exp \left[-\frac{1}{2} \cdot\left(\frac{x-M}{D P}\right)^{2}\right]
$$

Eq. 8.10

\subsubsection{Intervalo de confiança}

O intervalo de confiança (I.C.) fornece uma estimativa de um intervalo de valores no qual há uma probabilidade (a ser definida) em que a média se encontre. Para este trabalho, foi estabelecido um valor para o intervalo de confiança de 95\%. A Eq. 1.6 mostra os limites inferior e superior para o intervalo de confiança.

$$
I C=\left(M-t \cdot \frac{D P}{\sqrt{n}} ; M+t \cdot \frac{D P}{\sqrt{n}}\right)
$$

Onde, "t" corresponde ao valor da curva de t-student e " $n$ " é a quantidade de modelos.

\subsection{Comparação das propriedades mecânicas dos concretos desenvolvidos e as formulações}

O objetivo deste segmento é comprovar se os Códigos Normativos e as recomendações de previsão do comportamento do módulo de elasticidade e da resistência à tração representam as propriedades mecânicas do concreto convencional e do concreto auto-adensável desenvolvidos nesta pesquisa.

Nesta etapa, os concretos desenvolvidos foram divididos da seguinte maneira: para o concreto convencional, duas classes: CC30 e CC60, correspondendo à 
resistência à compressão de 30 e $60 \mathrm{MPa}$, respectivamente, e para o concreto autoadensável, três classes: CAA30, CAA60 e complementar, correspondendo à resistência à compressão de 30, 60 e $50 \mathrm{MPa}$, totalizando cinco séries.

A Tabela 8.5 mostra um resumo das propriedades mecânicas do CC e do CAA.

Tabela 8.5 Resumo das propriedades mecânicas do CC e do CAA

\begin{tabular}{cccc}
\hline & $\mathbf{f}_{\mathrm{c}}$ (MPa) & $\mathbf{E}_{\mathbf{c}} \mathbf{( G P a )}$ & $\mathbf{f}_{\mathbf{t}} \mathbf{( M P a )}$ \\
\hline CAA30 & 30,1 & 27,87 & 2,45 \\
CAA60 & 57,0 & 32,73 & 3,71 \\
CC30 & 32,0 & 27,24 & 2,18 \\
CC60 & 61,0 & 32,61 & 3,45 \\
Complementar & 53,0 & 34,62 & 3,07 \\
\hline
\end{tabular}

Vale salientar que as propriedades mecânicas dos concretos desenvolvidos foi realizada nas datas de 7 (série 1 e complementar) e de 14 dias (série 2).

A Figura 8.2 mostra a comparação dos Códigos Normativos e das recomendações para o módulo de elasticidade com relação à média dos resultados experimentais das cinco séries.
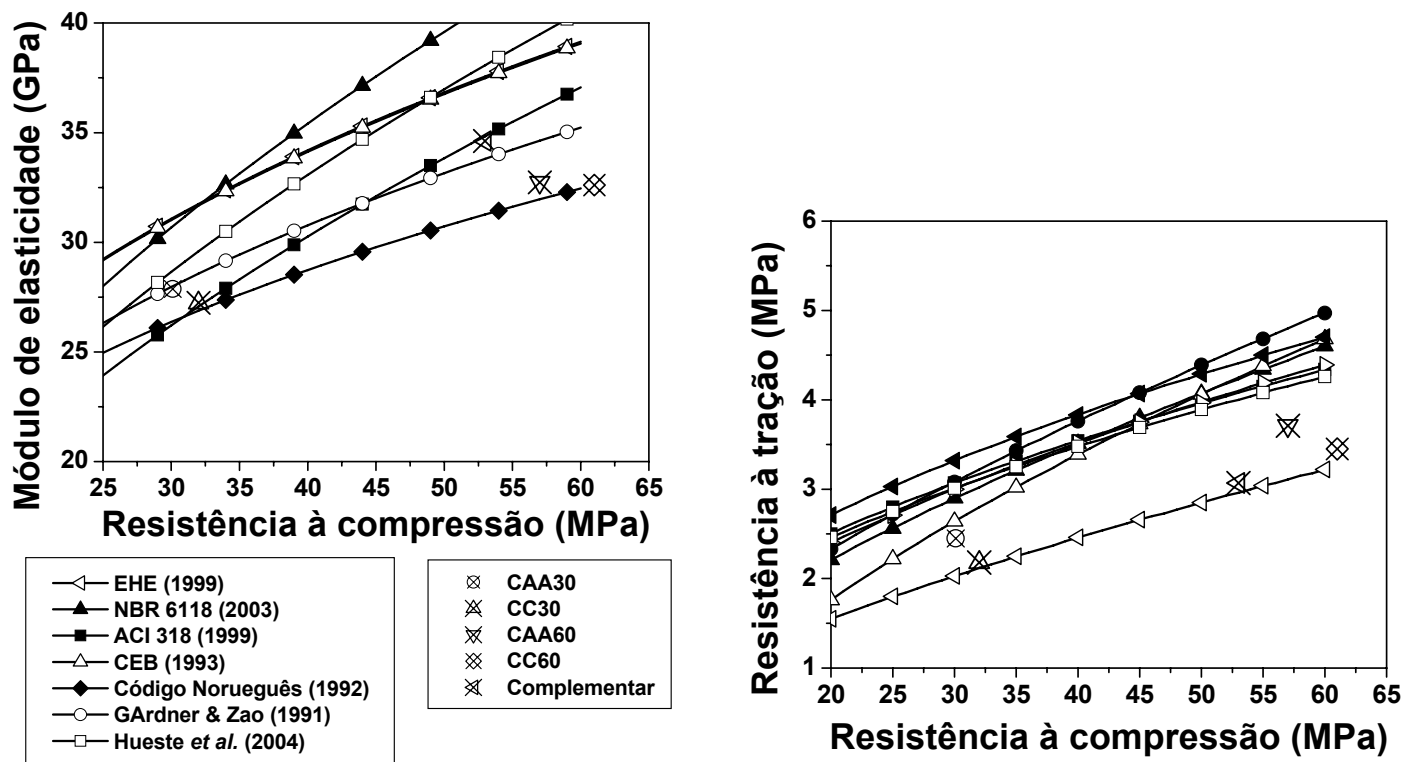

Figura 8.2 Comparação do módulo de elasticidade dos resultados experimentais com as formulações

De acordo com as comparações realizadas na Figura 8.2, grande parte dos Códigos Normativos superestimaram a relação entre o módulo de elasticidade e a resistência à tração do concreto, tanto para o concreto convencional quanto para o concreto auto-adensável. 
A Figura 8.3 e Figura 8.4 mostram as diferenças (fator bias) entre a previsão das formulações e os resultados experimentais para o módulo de elasticidade e a resistência à tração, respectivamente.

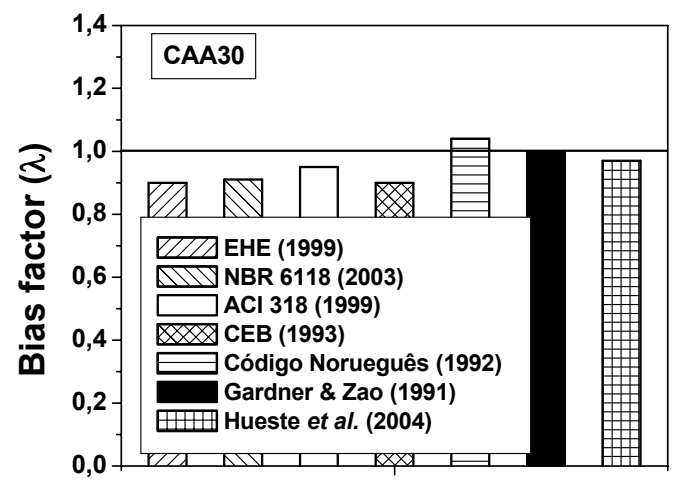

Formulacões

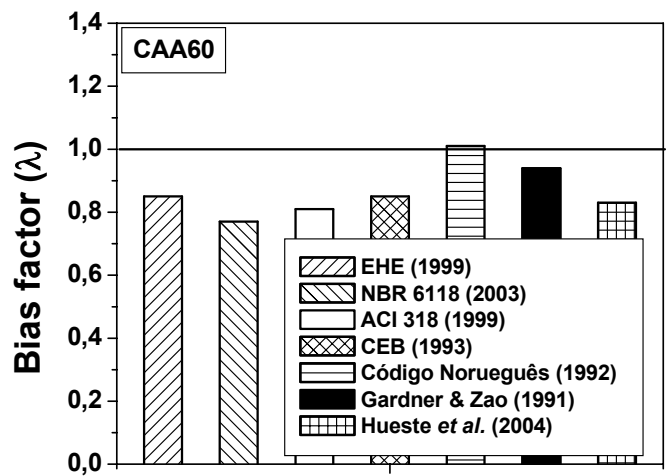

Formulações

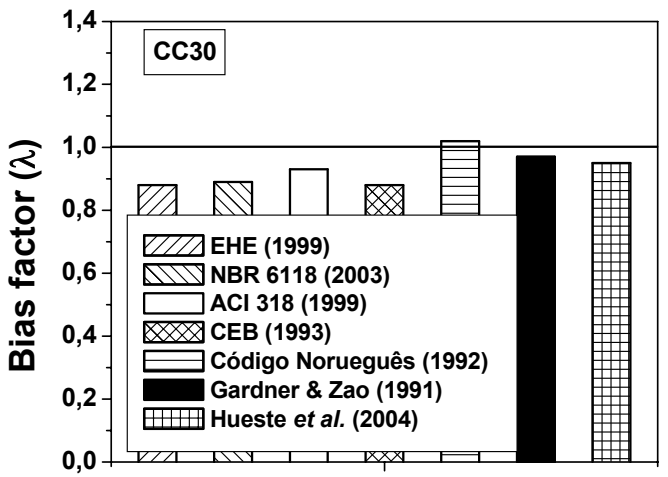

Formulacões

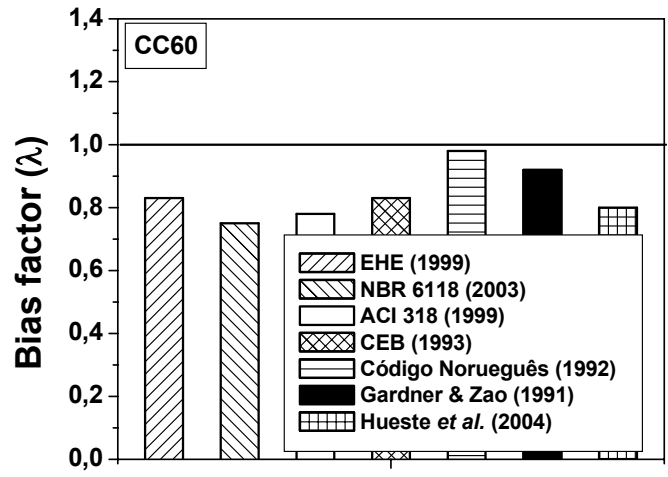

Formulações

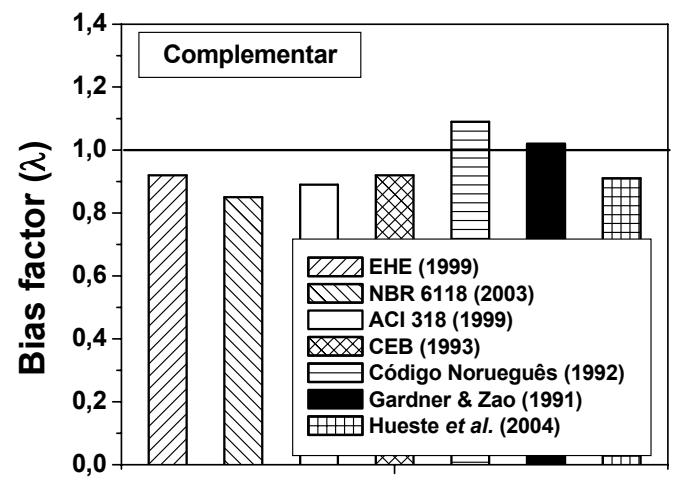

Formulações

Figura 8.3 Comparação do módulo de elasticidade entre os resultados experimentais e os valores previstos pelas formulações (Bias Factor) 

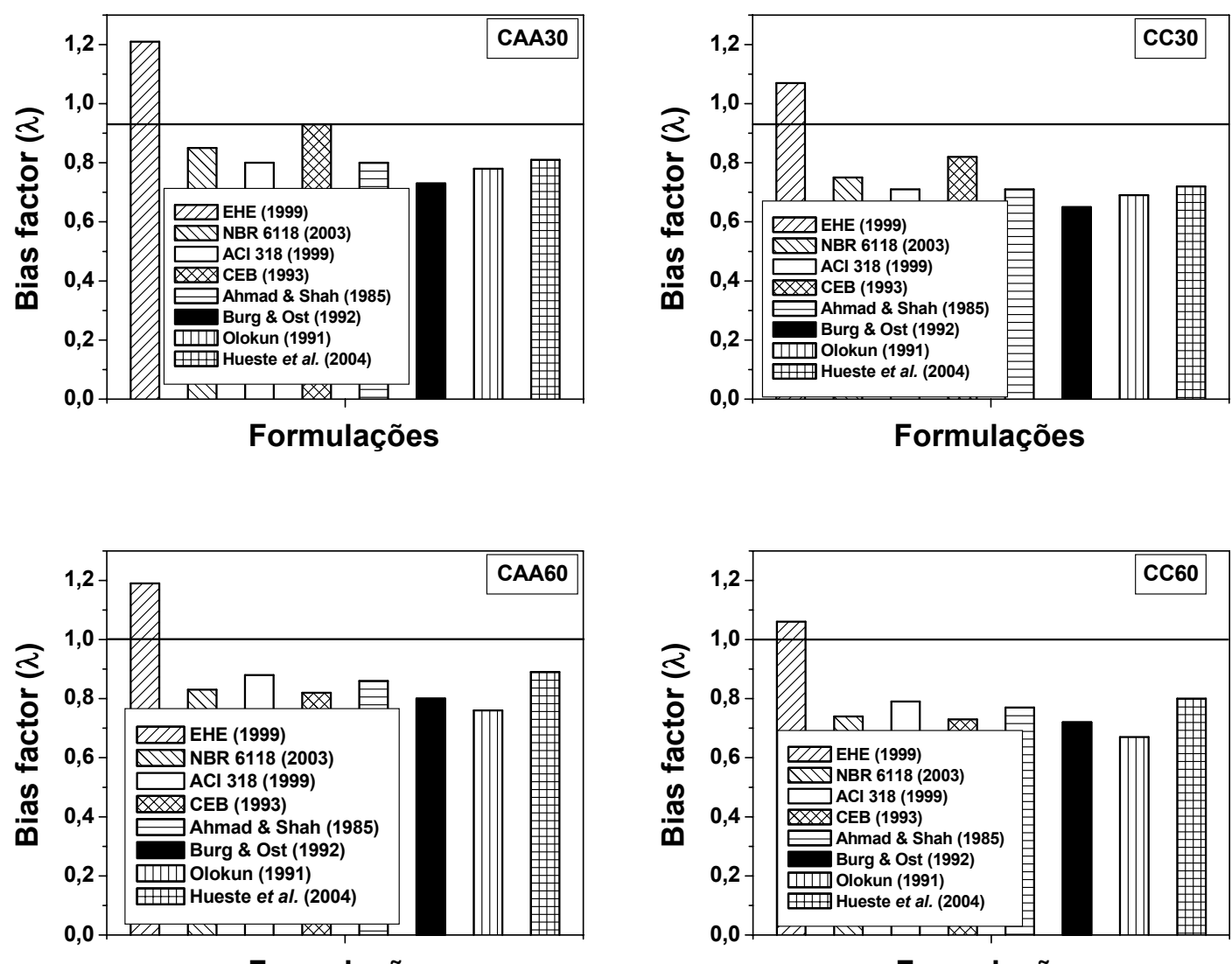

Formulações

Formulações

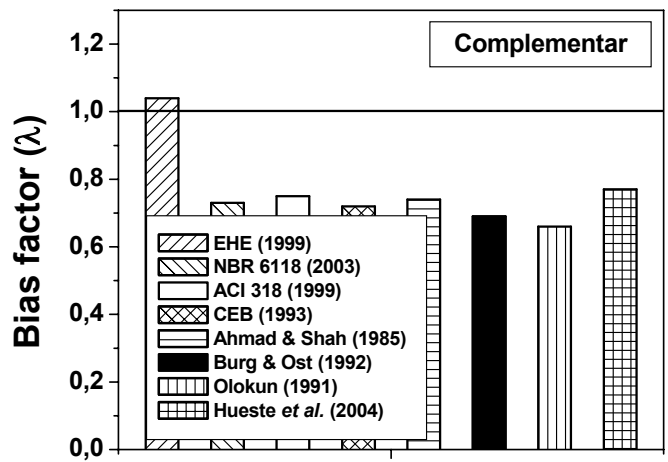

Formulações

Figura 8.4 Comparação da resistência à tração entre os resultados experimentais e os valores previstos pelas formulações (Bias Factor)

No caso da análise entre o módulo de elasticidade e a resistência à compressão, somente o Código Norueguês (NS 3473, 1992) apresentou resultados a favor da segurança com valores muito próximos aos resultados experimentais, seguido da formulação de Gardner \& Zao (1991).

No caso da relação entre a resistência à compressão e a resistência à tração, os resultados experimentais mostram que a maioria das formulações utilizadas superestima o valor da resistência à tração, com exceção da EHE (1999) que esteve a 
favor da segurança, e com resultados muito próximos à resposta dos valores experimentais.

De acordo com os resultados obtidos, as formulações utilizadas apresentaram resultados contra a segurança, o que pode conduzir a uma preocupação no dimensionamento de estruturas em concreto armado. Porém, são necessárias investigações com um maior número de repetições de modo a se obter uma média mais confiável, e assim propor recomendações para uma determinação mais adequada do módulo de elasticidade e da resistência à tração.

\subsection{Ensaios de arrancamento}

Aqui se apresentam a análise dos resultados referentes aos modelos de arrancamento estudados nesta pesquisa.

\subsubsection{Série 1}

Todos os modelos de arrancamento apresentaram ruptura por deslizamento da barra de aço em relação ao concreto. A Figura 8.5 ilustra o comportamento dos modelos de arrancamento para as séries em CAA e em CC e a comparação entre os seus módulos de elasticidade longitudinal $\left(E_{c}\right)$.
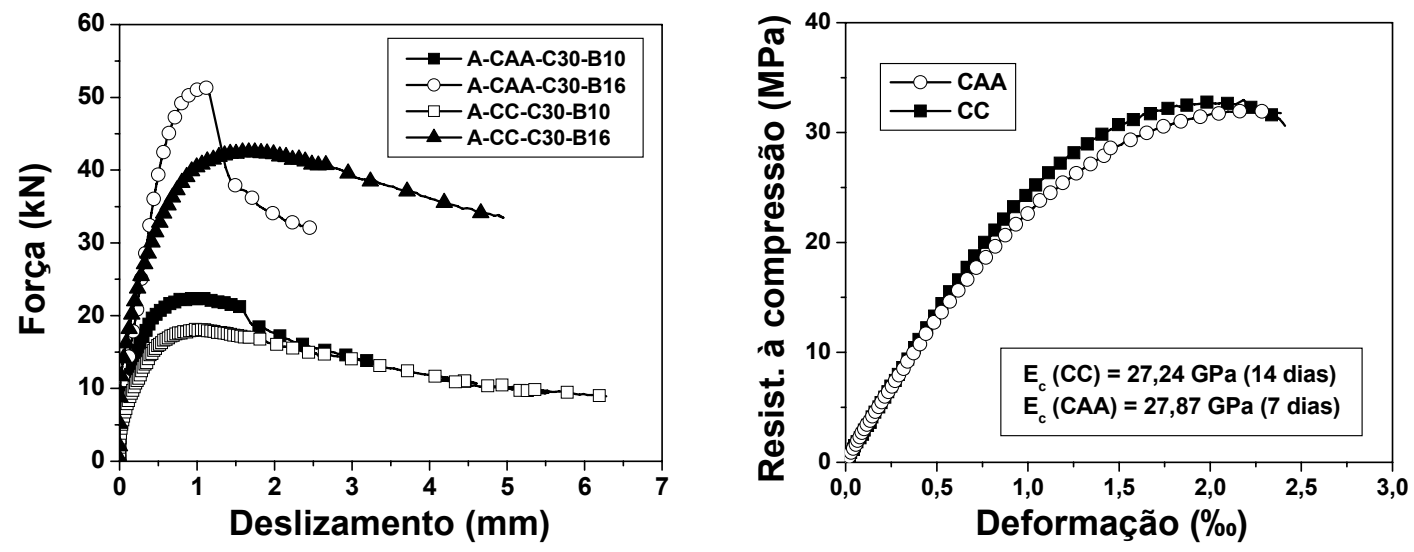

Figura 8.5 Média dos modelos de arrancamento e módulo de elasticidade

De acordo com a Figura 8.5 pode-se verificar que os modelos em CAA foram mais rígidos que os modelos em CC, principalmente para os modelos com barra de 16 $\mathrm{mm}$ e que o valor do módulo de elasticidade foi semelhante. 
A Tabela 8.6 ilustra a variação dos resultados nos ensaios de arrancamento.

Tabela 8.6 Variação da força de ruptura nos ensaios de arrancamento da série 1

\begin{tabular}{ccccccccc}
\hline & \multicolumn{2}{c}{ A-CAA-C30-B10 } & \multicolumn{2}{c}{ A-CAA-C30-B16 } & \multicolumn{2}{c}{ A-CC-C30-B10 } & \multicolumn{2}{c}{ A-CC-C30-B16 } \\
Modelo & $\mathbf{P}_{\mathbf{u}}(\mathbf{k N})$ & $\mathbf{S}_{\mathrm{u}}(\mathbf{m m})$ & $\mathbf{P}_{\mathrm{u}}(\mathbf{k N})$ & $\mathbf{S}_{\mathbf{u}}(\mathbf{m m})$ & $\mathbf{P}_{\mathbf{u}}(\mathbf{k N})$ & $\mathbf{S}_{\mathbf{u}}(\mathbf{m m})$ & $\mathbf{P}_{\mathbf{u}}(\mathbf{k N})$ & $\mathbf{S}_{\mathrm{u}}(\mathbf{m m})$ \\
\hline $\mathbf{1}$ & 23,58 & 0,949 & 51,05 & 0,930 & 16,48 & 1,19 & 40,36 & 1,85 \\
$\mathbf{2}$ & 22,13 & 0,989 & 56,31 & 1,198 & 19,61 & 1,09 & 41,81 & 1,59 \\
$\mathbf{3}$ & 22,28 & 0,940 & 51,20 & 1,097 & 19,38 & 0,79 & 43,19 & 1,32 \\
$\mathbf{4}$ & 21,22 & 1,063 & 49,51 & 1,005 & 17,93 & 1,19 & 43,19 & 1,83 \\
$\mathbf{5}$ & 23,41 & 0,857 & 51,97 & 1,066 & 18,39 & 0,98 & 43,26 & 1,60 \\
Média & 22,52 & 0,960 & 52,01 & 1,059 & 18,36 & 1,05 & 42,36 & 1,64 \\
D.P. & 0,976 & 0,075 & 2,565 & 0,101 & 1,257 & 0,168 & 1,271 & 0,217 \\
C.V. & $4,34 \%$ & $7,83 \%$ & $4,93 \%$ & $9,49 \%$ & $6,85 \%$ & $15,96 \%$ & $3,00 \%$ & $13,28 \%$ \\
\hline
\end{tabular}

A Tabela 8.7 mostra a variação da resistência de aderência, calculada de acordo com a Eq. 8.1 e Eq. 8.3.

Tabela 8.7 Resultados obtidos nos ensaios de arrancamento da série 1

\begin{tabular}{rccccc}
\hline \multicolumn{1}{c}{ Amostra } & $\tau_{0,01}$ (MPa) & $\tau_{0,1}$ (MPa) & $\tau_{1,0}$ (MPa) & $\tau_{\mathrm{u}}(\mathbf{M P a})$ & $\tau_{\mathrm{m}}$ (MPa) \\
\hline A-CAA-C30-B10-1 & 4,91 & 7,48 & 14,86 & 15,01 & 9,08 \\
A-CAA-C30-B10-2 & 3,11 & 6,46 & 13,99 & 14,09 & 7,85 \\
A-CAA-C30-B10-3 & 2,23 & 4,23 & 14,18 & 14,18 & 6,88 \\
A-CAA-C30-B10-4 & 4,42 & 6,56 & 13,33 & 13,51 & 8,10 \\
A-CAA-C60-B10-5 & 3,29 & 6,94 & 14,70 & 14,90 & 8,31 \\
Média (MPa) & 3,59 & 6,33 & 14,21 & 14,34 & 8,05 \\
D.P. (MPa) & 1,069 & 1,244 & 0,609 & 0,622 & 0,797 \\
C.V. (\%) & $29,78 \%$ & $19,64 \%$ & $4,28 \%$ & $4,34 \%$ & $9,91 \%$ \\
\hline A-CAA-C30-B16-1 & 2,73 & 4,50 & 12,64 & 12,69 & 6,62 \\
A-CAA-C30-B16-2 & 1,67 & 2,87 & 13,74 & 14,00 & 6,09 \\
A-CAA-C30-B16-3 & 1,57 & 2,54 & 12,62 & 12,73 & 5,58 \\
A-CAA-C30-B16-4 & 2,65 & 4,25 & 12,31 & 12,31 & 6,41 \\
A-CAA-C30-B16-5 & 1,60 & 2,70 & 12,92 & 12,92 & 5,74 \\
Média (MPa) & 2,05 & 3,37 & 12,85 & 12,93 & 6,09 \\
D.P. (MPa) & 0,592 & 0,927 & 0,543 & 0,638 & 0,438 \\
C.V. (\%) & $28,92 \%$ & $27,52 \%$ & $4,23 \%$ & $4,93 \%$ & $7,19 \%$ \\
\hline A-CC-C30-B10-1 & 3,11 & 4,95 & 10,15 & 10,49 & 6,07 \\
A-CC-C30-B10-2 & 1,85 & 3,69 & 12,19 & 12,48 & 5,91 \\
A-CC-C30-B10-3 & 5,34 & 7,72 & 12,05 & 12,34 & 8,37 \\
A-CC-C30-B10-4 & 2,82 & 3,93 & 10,93 & 11,42 & 5,89 \\
A-CC-C30-B10-5 & 3,84 & 5,93 & 11,46 & 11,71 & 7,08 \\
Média (MPa) & 3,39 & 4,93 & 11,20 & 11,56 & 6,48 \\
D.P. (MPa) & 1,305 & 1,408 & 0,378 & 0,206 & 0,836 \\
C.V. (\%) & $38,47 \%$ & $28,56 \%$ & $3,37 \%$ & $1,78 \%$ & $12,89 \%$ \\
\hline A-CC-C30-B16-1 & 2,41 & 3,11 & 8,96 & 10,04 & 4,83 \\
A-CC-C30-B16-2 & 2,47 & 3,59 & 9,53 & 10,40 & 5,19 \\
A-CC-C30-B16-3 & 4,12 & 5,79 & 10,40 & 10,74 & 6,77 \\
A-CC-C30-B16-4 & 2,39 & 3,93 & 10,32 & 10,74 & 5,55 \\
A-CC-C30-B16-5 & 2,62 & 3,72 & 9,90 & 10,76 & 5,41 \\
Média (MPa) & 2,80 & 3,82 & 10,11 & 10,75 & 5,48 \\
D.P. (MPa) & 0,741 & 0,148 & 0,295 & 0,013 & 0,094 \\
C.V. $(\%)$ & $26,48 \%$ & $3,86 \%$ & $2,92 \%$ & $0,12 \%$ & $1,71 \%$ \\
\hline & & & & &
\end{tabular}


A Figura 8.6 mostra o comportamento da resistência de aderência para a série 1, onde vale salientar que os valores para o comportamento médio foram medidos a partir do comportamento dos cinco modelos de arrancamento.

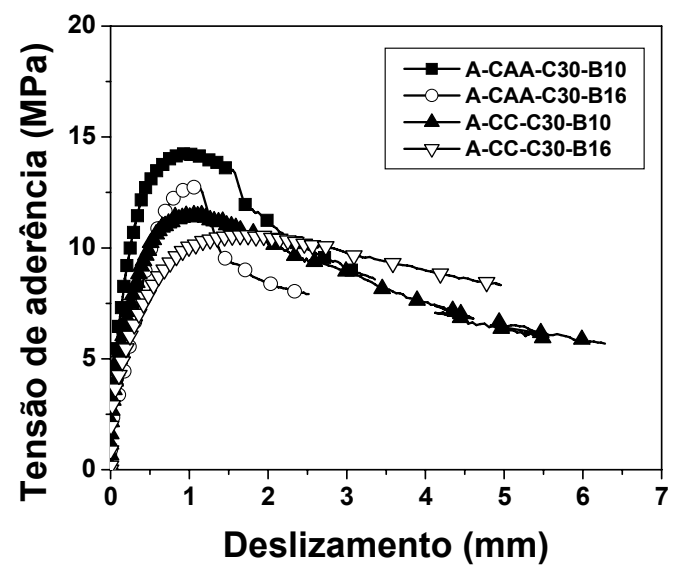

Figura 8.6 Comportamento da tensão de aderência para a série 1

A regressão exponencial não é adequada para representar o comportamento da resistência de aderência (pré-pico e pós-pico) quando não se utiliza concreto de alta resistência à compressão, sendo utilizada somente na representação do pré-pico. Para a representação do comportamento da resistência de aderência com a inclusão do pós-pico, adotou-se uma regressão polinomial. A Tabela 8.8 mostra as regressões exponenciais desenvolvidas para simular o comportamento do pré-pico da resistência de aderência dos modelos de arrancamento da série 1.

Tabela 8.8 Regressões exponenciais de pré-pico dos modelos de arrancamento

\begin{tabular}{cc}
\hline Modelo & \multicolumn{1}{c}{ Regressão exponencial } \\
\hline A-CAA-C30-B10 & $\tau(\mathrm{s})=14,289-12,636 \cdot \mathrm{e}^{(-\mathrm{s} / 0,2198)}$ \\
A-CAA-C30-B16 & $\tau(\mathrm{s})=12,764-12,295 \cdot \mathrm{e}^{(-\mathrm{s} / 0,368)}$ \\
A-CC-C30-B10 & $\tau(\mathrm{s})=11,522-10,138 \cdot \mathrm{e}^{(-\mathrm{s} / 0,2552)}$ \\
A-CC-C30-B16 & $\tau(\mathrm{s})=10,583-9,165 \cdot \mathrm{e}^{(-\mathrm{s} / 0,3597)}$ \\
\hline
\end{tabular}

A Tabela 8.9 mostra as regressões polinomiais desenvolvidas para simular o comportamento de pós-pico da resistência de aderência dos modelos de arrancamento da série 1 . 
Tabela 8.9 Regressões polinomiais até pós-pico dos modelos de arrancamento da série 1

\begin{tabular}{|c|c|}
\hline Modelo & Regressão exponencial \\
\hline $\begin{array}{l}\text { A-CAA- } \\
\text { C30-B10 }\end{array}$ & $\begin{array}{l}\tau(s)=1,63166+58,6942 \cdot s-136,32821 \cdot s^{2}+192,23047 \cdot s^{3}-164,54525 \cdot s^{4}+ \\
83,71709 \cdot s^{5}-24,70222 \cdot s^{6}+3,90538 \cdot s^{7}-0,25607 \cdot s^{8}\end{array}$ \\
\hline $\begin{array}{l}\text { A-CAA- } \\
\text { C30-B16 }\end{array}$ & $\begin{array}{l}\tau(s)=0,90274+28,11286 \cdot s-62,2817 \cdot s^{2}+164,88042 \cdot s^{3}-238,55563 \cdot s^{4}+ \\
174,80126 \cdot s^{5}-67,15922 \cdot s^{6}+12,8931 \cdot s^{7}-0,9667 \cdot s^{8}\end{array}$ \\
\hline $\begin{array}{c}\text { A-CC-C30- } \\
\text { B10 }\end{array}$ & $\begin{array}{l}\tau(s)=1,54321+34,13722 \cdot s-48,63661 \cdot s^{2}+37,71357 \cdot s^{3}-17,6379 \cdot s^{4}+ \\
5,01639 \cdot s^{5}-0,84388 \cdot s^{6}+0,07694 \cdot s^{7}-0,00292 \cdot s^{8}\end{array}$ \\
\hline $\begin{array}{c}\text { A-CC-C30- } \\
\text { B16 }\end{array}$ & $\begin{array}{l}\tau(s)=1,3067+29,62846 \cdot s-52,85265 \cdot s^{2}+58,18252 \cdot s^{3}-38,30515 \cdot s^{4}+ \\
14,89466 \cdot s^{5}-3,34392 \cdot s^{6}+0,39996 \cdot s^{7}-0,0197 \cdot s^{8}\end{array}$ \\
\hline
\end{tabular}

A Figura 8.7 mostra a regressão exponencial dos modelos de arrancamento da série 1.
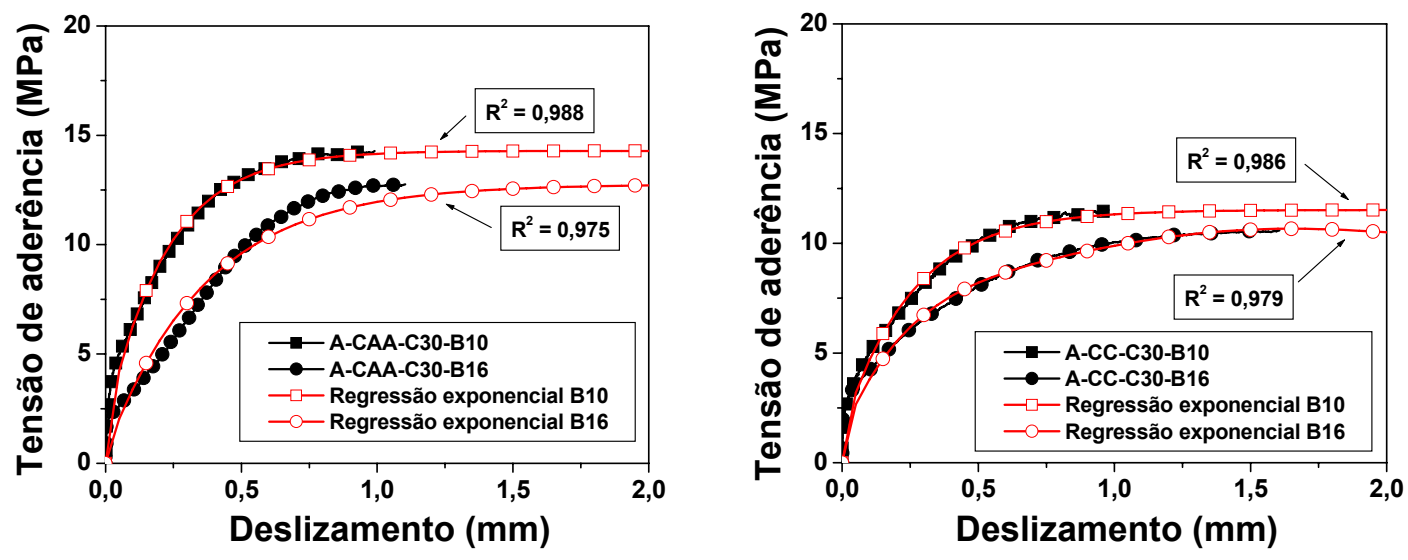

Figura 8.7 Regressão exponencial para representar a tensão de aderência dos modelos de arrancamento da série 1

A Tabela 8.10 mostra a diferença entre as resistências máximas de aderência, para o mesmo valor de deslizamento, para os modelos experimentais e as regressões desenvolvidas;

Tabela 8.10 Comparação entre os resultados experimentais e as regressões exponenciais e polinomiais dos modelos de arrancamento da série 1

\begin{tabular}{lccccc}
\hline & Experimental & $\begin{array}{c}\text { Regressão } \\
\text { exponencial }\end{array}$ & \multicolumn{3}{c}{$\begin{array}{c}\text { Regressão } \\
\text { polinomial }\end{array}$} \\
Modelo & $\tau_{\mathrm{u}}(\mathbf{M P a})$ & $\tau_{\mathrm{u}}(\mathbf{M P a})$ & $\lambda$ & $\tau_{\mathrm{u}}(\mathbf{M P a})$ & $\lambda$ \\
\hline A-CAA-C30-B10 & 14,34 & 14,287 & 1,00 & 14,347 & 0,99 \\
A-CAA-C30-B16 & 12,93 & 12,710 & 1,02 & 12,715 & 1,02 \\
A-CC-C30-B10 & 11,56 & 11,518 & 1,00 & 11,366 & 1,02 \\
A-CC-C30-B16 & 10,75 & 10,548 & 1,02 & 10,663 & 1,01 \\
\hline
\end{tabular}


A Figura 8.8 mostra a regressão polinomial para os modelos de arrancamento da série 1.
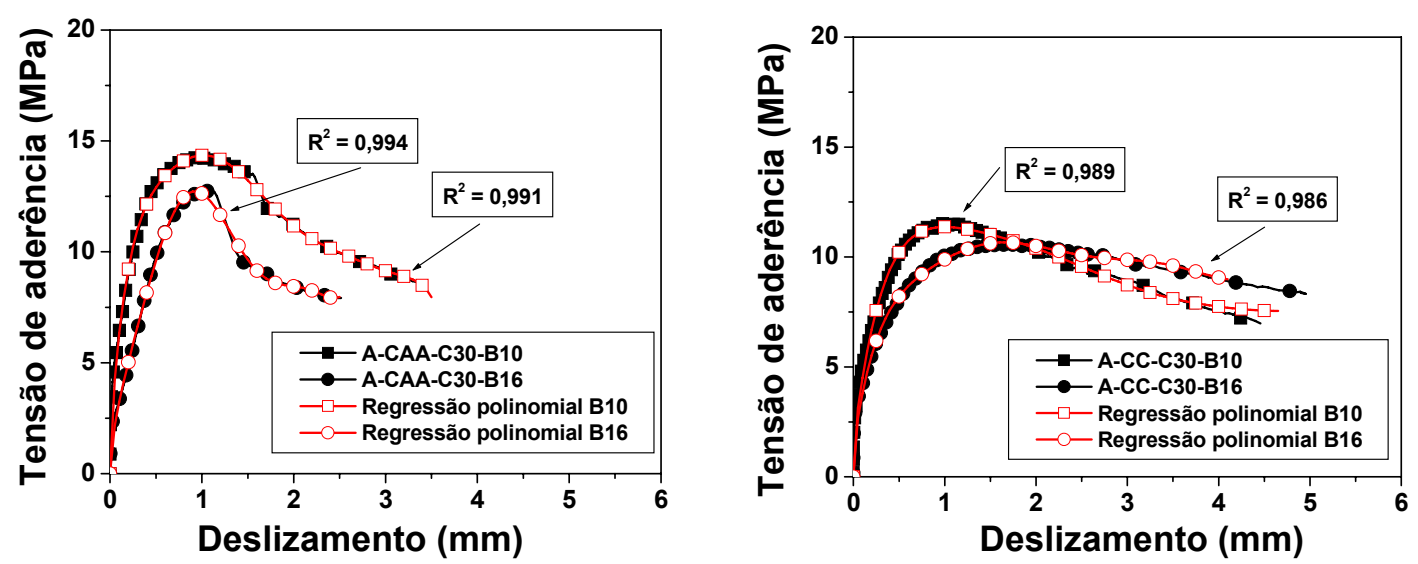

Figura 8.8 Regressão polinomial para representar a tensão de aderência dos modelos de arrancamento da série 1

De acordo com as análises dos modelos de arrancamento da série 1, pode-se concluir que:

- $\quad$ Os modelos de arrancamento em CAA apresentaram resistência de aderência superior aos modelos em CC, para ambos os diâmetros de barra utilizados (Tabela 8.7);

- Com relação aos modelos em concreto convencional, ambos os modelos apresentaram pequena variabilidade da força de ruptura $(6,85 \%$ para barras de $10 \mathrm{~mm}$ e 3,00\% para barras de $16 \mathrm{~mm}$ ). Somente o valor do deslizamento apresentou grande variação, chegando a quase $16 \%$;

- Os modelos apresentaram ruptura por deslizamento e, somente em alguns casos houve a ruptura por fendilhamento quando da utilização de barras de $16 \mathrm{~mm}$;

- Com relação à resistência de aderência, os modelos com barras de menor diâmetro apresentaram maior resistência de aderência que as barras de maior diâmetro (Tabela 8.7);

- Com relação às regressões exponenciais e polinomiais, houve boa correspondência com o comportamento da resistência de aderência. Ainda foi realizada uma regressão polinomial para representar o trecho de pós-pico da resistência de aderência;

- De acordo com a Tabela 8.10, as aproximações fornecidas pelas regressões conduzem a um erro de aproximação máximo de $1 \%$ contra a segurança;

- As regressões, tanto exponencial quanto polinomial, fornecem uma boa estimativa do comportamento da resistência de aderência com relação ao 
deslizamento ocorrido, entretanto a regressão polinomial, apesar de descrever o comportamento de pós-pico do ensaio, apresenta uma margem de erro elevada se for levado em consideração o truncamento dos radicais multiplicadores do deslizamento, o que pode conduzir a uma má aproximação do resultado;

- Com relação à variabilidade dos resultados, não houve variação significativa, sendo que esta permaneceu abaixo de $10 \%$. Somente no caso de se analisar o valor da resistência de aderência para o deslizamento de $0,01 \mathrm{~mm}$ foi que ocorreu variação, por causa do valor da adesão do concreto à barra de aço, que pode conduzir a uma grande variação dos resultados;

- $\quad$ O valor da resistência de aderência dos modelos de arrancamento com barra de $10 \mathrm{~mm}$ foi superior aos modelos com barra de $16 \mathrm{~mm}$, o que corrobora as considerações iniciais realizadas, que, à medida que se aumenta o diâmetro da barra, se reduz a resistência de aderência (Barbosa, 2001).

\subsubsection{Série 2}

Todos os modelos de arrancamento apresentaram ruptura por fendilhamento do concreto. A Figura 8.9 ilustra o comportamento dos modelos de arrancamento para as séries em CAA e em CC e a comparação entre os seus módulos de elasticidade longitudinal $\left(E_{c}\right)$.
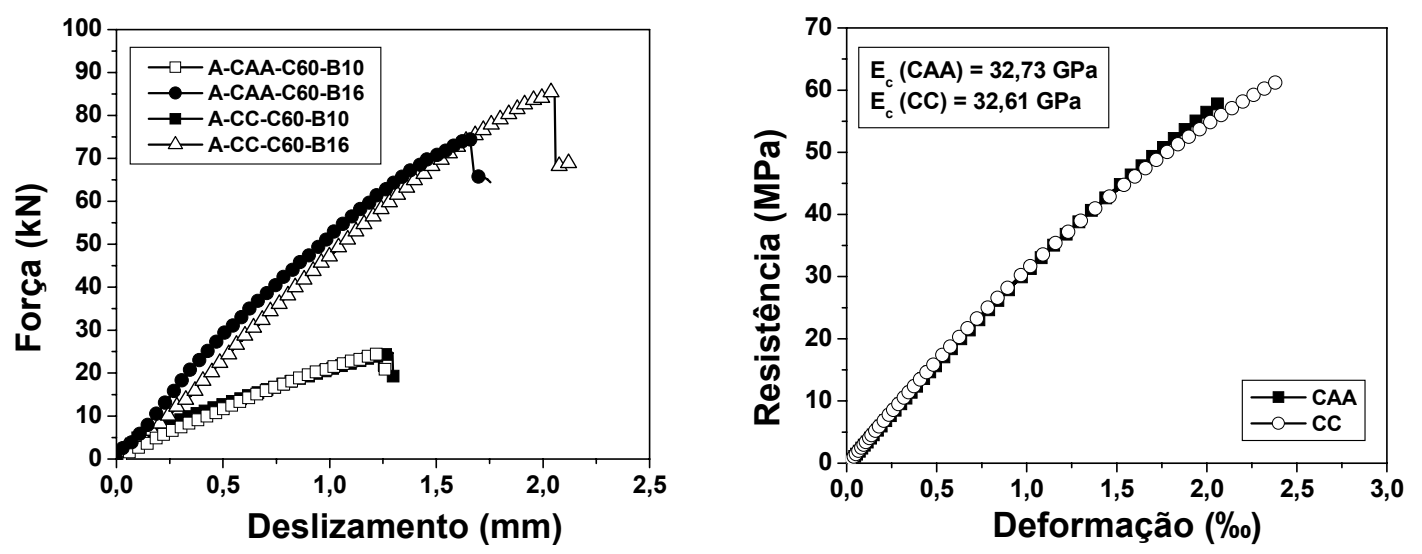

Figura 8.9 Média dos modelos de arrancamento

Os modelos de arrancamento apresentaram uma boa correlação em seus resultados, principalmente para os modelos com barra de $10 \mathrm{~mm}$. Para os modelos 
com barra de $16 \mathrm{~mm}$, os modelos em CC apresentaram força de ruptura superior ao dos modelos em CAA (12,3\%) e que o valor do módulo de elasticidade foi semelhante.

A Tabela 8.11 ilustra a variação dos resultados nos ensaios de arrancamento.

Tabela 8.11 Variação da força de ruptura nos ensaios de arrancamento da série 2

\begin{tabular}{ccccccccc}
\hline & \multicolumn{2}{c}{ A-CAA-C60-B10 } & \multicolumn{2}{c}{ A-CAA-C60-B16 } & \multicolumn{2}{c}{ A-CC-C60-B10 } & \multicolumn{2}{c}{ A-CC-C60-B16 } \\
Modelo & $\mathbf{P}_{\mathbf{u}}(\mathbf{k N})$ & $\mathbf{S}_{\mathbf{u}}(\mathbf{m m})$ & $\mathbf{P}_{\mathbf{u}}(\mathbf{k N})$ & $\mathbf{S}_{\mathrm{u}}(\mathbf{m m})$ & $\mathbf{P}_{\mathbf{u}}(\mathbf{k N})$ & $\mathbf{s}_{\mathbf{u}}(\mathbf{m m})$ & $\mathbf{P}_{\mathbf{u}}(\mathbf{k N})$ & $\mathbf{s}_{\mathbf{u}}(\mathbf{m m})$ \\
\hline 1 & 23,73 & 1,65 & 81,30 & 1,97 & 25,26 & 1,51 & 88,05 & 2,19 \\
2 & 29,61 & 1,86 & 76,00 & 1,86 & 23,73 & 1,65 & 83,09 & 2,44 \\
3 & 23,73 & 1,21 & 72,80 & 1,65 & 31,74 & 1,85 & 84,70 & 2,24 \\
4 & 34,03 & 1,90 & 77,50 & 1,92 & 29,00 & 1,55 & 95,99 & 2,11 \\
5 & 31,13 & 1,61 & 79,10 & 1,78 & 24,19 & 1,62 & 89,27 & 2,02 \\
Média & 28,45 & 1,65 & 77,34 & 1,84 & 26,78 & 1,64 & 88,22 & 2,20 \\
D.P. & 4,59 & 0,27 & 3,21 & 0,13 & 3,46 & 0,14 & 5,00 & 0,16 \\
C.V. & $16,13 \%$ & $16,68 \%$ & $4,15 \%$ & $6,85 \%$ & $12,92 \%$ & $8,27 \%$ & $5,67 \%$ & $7,27 \%$ \\
\hline
\end{tabular}

Para os modelos com barra de $10 \mathrm{~mm}$, houve uma grande variabilidade tanto da força de ruptura quanto do valor do deslizamento no instante da ruptura, para os modelos com CAA.

Um fator que deve ser levado em consideração é que foram realizadas poucas amostras para cada diâmetro de barra. Para uma avaliação estatística mais apurada seriam necessárias séries de arrancamento com uma quantidade significativa de réplicas.

A Figura 8.10 mostra o comportamento da tensão de aderência dos modelos de arrancamento da série 2 , onde, vale salientar que os valores para o comportamento médio foram medidos a partir do comportamento dos cinco modelos de arrancamento.

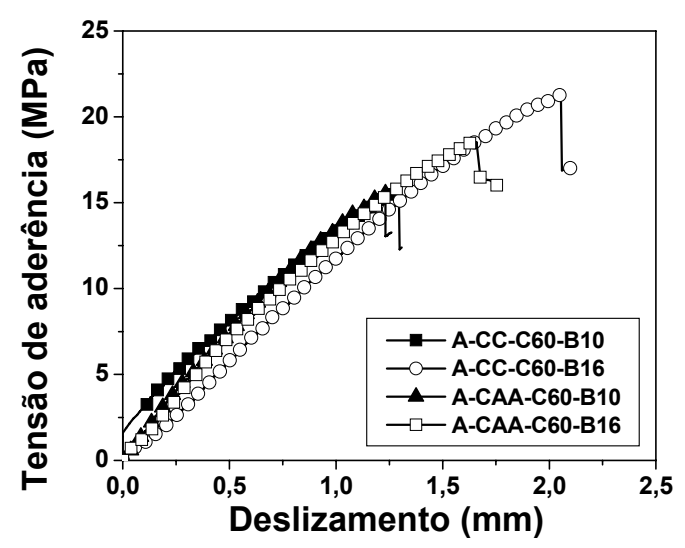

Figura 8.10 Comportamento da tensão de aderência para a série 2

A Tabela 8.12 mostra as regressões exponenciais desenvolvidas para simular o comportamento da resistência de aderência dos modelos de arrancamento da série 2. 
Tabela 8.12 Regressões exponenciais para os modelos de arrancamento da série 2

\begin{tabular}{cc}
\hline Modelo & Regressão exponencial \\
\hline A-CAA-C60-B10 & $\tau(s)=15,56-16,91 \cdot e^{(-s / 0,585)}$ \\
A-CAA-C60-B16 & $\tau(s)=18,52-20,35 \cdot e^{(-s / 0,745)}$ \\
A-CC-C60-B10 & $\tau(s)=15,73-15,79 \cdot e^{(-s / 0,602)}$ \\
A-CC-C60-B16 & $\tau(s)=21,31-24,23 \cdot e^{(-s / 0,956)}$ \\
\hline
\end{tabular}

A Tabela 8.13 mostra a variação da resistência de aderência, calculada de acordo com a Eq. 8.1 e Eq. 8.3.

Tabela 8.13 Resultados obtidos nos ensaios de arrancamento da série 2

\begin{tabular}{rccccc}
\hline \multicolumn{1}{c}{ Amostra } & $\tau_{0,01}$ (MPa) & $\tau_{0,1}$ (MPa) & $\tau_{1,0}$ (MPa) & $\tau_{\mathrm{u}}$ (MPa) & $\tau_{\mathrm{m}}$ (MPa) \\
\hline A-CAA-C60-B10-1 & 0,24 & 1,60 & 13,60 & 15,11 & 5,15 \\
A-CAA-C60-B10-2 & 0,05 & 1,11 & 14,28 & 18,85 & 5,15 \\
A-CAA-C60-B10-3 & 0,05 & 1,02 & 13,70 & 15,11 & 4,92 \\
A-CAA-C60-B10-4 & 0,15 & 2,43 & 13,84 & 21,66 & 5,44 \\
A-CAA-C60-B10-5 & 0,19 & 1,99 & 14,57 & 19,82 & 5,59 \\
Média (MPa) & 0,14 & 1,63 & 14,00 & 18,11 & 5,25 \\
D.P. (MPa) & 0,09 & 0,59 & 0,41 & 2,92 & 0,26 \\
C.V. (\%) & $64,03 \%$ & $36,44 \%$ & $2,95 \%$ & $16,13 \%$ & $5,02 \%$ \\
\hline A-CAA-C60-B16-1 & 0,28 & 0,44 & 12,04 & 20,22 & 4,25 \\
A-CAA-C60-B16-2 & 0,27 & 1,23 & 12,76 & 18,90 & 4,75 \\
A-CAA-C60-B16-3 & 0,53 & 0,74 & 12,16 & 18,10 & 4,48 \\
A-CAA-C60-B16-4 & 0,91 & 2,01 & 13,18 & 19,27 & 5,37 \\
A-CAA-C60-B16-5 & 0,95 & 2,49 & 14,10 & 19,67 & 5,85 \\
Média (MPa) & 0,59 & 1,38 & 12,85 & 19,23 & 4,94 \\
D.P. (MPa) & 0,33 & 0,86 & 0,84 & 0,80 & 0,66 \\
C.V. (\%) & $56,00 \%$ & $62,12 \%$ & $6,53 \%$ & $4,15 \%$ & $13,30 \%$ \\
\hline A-CC-C60-B10-1 & 2,09 & 3,89 & 12,78 & 16,08 & 6,25 \\
A-CC-C60-B10-2 & 1,89 & 3,45 & 11,22 & 15,11 & 5,52 \\
A-CC-C60-B10-3 & 1,75 & 3,45 & 14,96 & 20,21 & 6,72 \\
A-CC-C60-B10-4 & 1,80 & 3,50 & 14,52 & 18,46 & 6,61 \\
A-CC-C60-B10-5 & 0,97 & 3,74 & 12,05 & 15,40 & 5,59 \\
Média (MPa) & 1,70 & 3,60 & 13,11 & 17,05 & 6,14 \\
D.P. (MPa) & 0,43 & 0,20 & 1,60 & 2,20 & 0,56 \\
C.V. (\%) & $25,15 \%$ & $5,50 \%$ & $12,21 \%$ & $12,92 \%$ & $9,13 \%$ \\
\hline A-CC-C60-B16-1 & 0,44 & 1,14 & 12,33 & 21,90 & 4,64 \\
A-CC-C60-B16-2 & 0,34 & 0,42 & 9,81 & 20,66 & 3,52 \\
A-CC-C60-B16-3 & 0,42 & 0,42 & 9,16 & 21,06 & 3,33 \\
A-CC-C60-B16-4 & 0,72 & 2,64 & 14,61 & 23,87 & 5,99 \\
A-CC-C60-B16-5 & 0,59 & 2,24 & 13,57 & 22,20 & 5,47 \\
Média (MPa) & 0,50 & 1,37 & 11,90 & 21,94 & 4,59 \\
D.P. (MPa) & 0,15 & 1,03 & 2,35 & 1,24 & 1,17 \\
C.V. (\%) & $30,42 \%$ & $75,12 \%$ & $19,79 \%$ & $5,67 \%$ & $25,43 \%$ \\
\hline & & & & &
\end{tabular}

A Figura 8.11 mostra a regressão exponencial para cada modelo de arrancamento da série 2 , onde se pode ver uma boa correspondência com 0 comportamento experimental. 

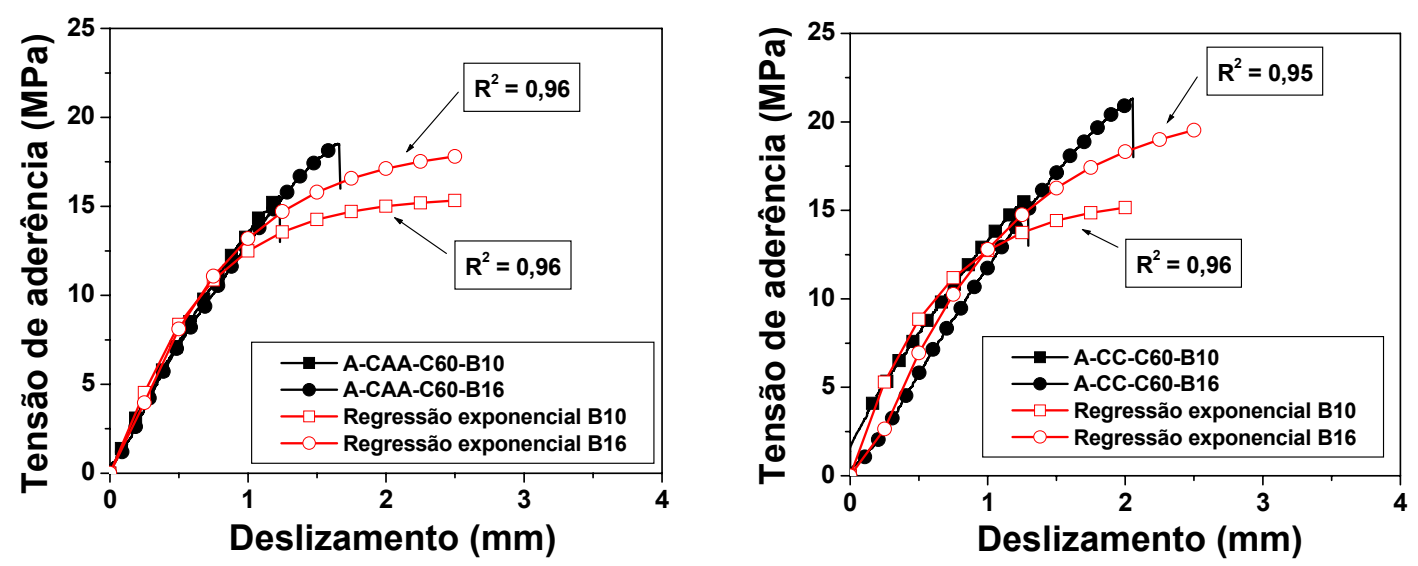

Figura 8.11 Regressão exponencial para representar a tensão de aderência dos modelos de arrancamento da série 2

De acordo com as análises dos resultados da série 2, pode-se concluir que:

- Os modelos de arrancamento apresentaram uma boa correlação em seus resultados, principalmente para os modelos com barra de $10 \mathrm{~mm}$, mas para os modelos com barra de $16 \mathrm{~mm}$, os modelos em CC apresentaram força de ruptura superior ao dos modelos em CAA (12,3\%). Essa diferença pode ser explicada pela menor resistência à compressão do CAA e em virtude do superplastificante utilizado não promover maior coesão ao concreto, que pode ter interferido no comportamento da interface aço-CAA;

- O comportamento da resistência de aderência para os quatro casos de arrancamento foi similar, sendo representados por um comportamento quase linear até a ruptura por fendilhamento do prisma de concreto (Figura 8.10). Ainda, o mesmo comportamento pode ser observado no ensaio (Figura 8.9);

- Com relação à resistência de aderência, os modelos com barras de menor diâmetro apresentaram maior resistência de aderência que as barras de maior diâmetro (Tabela 8.13);

- Com relação à regressão exponencial desenvolvida, houve boa correspondência com o comportamento da resistência de aderência, o que pode levar a consideração de novas formulações para descrever a resistência de aderência. $A$ Tabela 8.14 mostra a diferença entre as resistências máximas de aderência, para o mesmo valor de deslizamento, para os modelos experimentais e as formulações desenvolvidas; 
Tabela 8.14 Comparação entre os resultados experimentais e as regressões exponenciais dos modelos de arrancamento da série 2

\begin{tabular}{lccc}
\hline Modelo & $\begin{array}{c}\text { Experimental } \\
\tau_{\mathrm{u}}(\mathbf{M P a})\end{array}$ & $\begin{array}{c}\text { Regressão } \\
\tau_{\mathrm{u}}(\mathbf{M P a})\end{array}$ & $\boldsymbol{\lambda}$ \\
\hline A-CAA-C60-B10 & 15,56 & 13,70 & 1,14 \\
A-CAA-C60-B16 & 18,52 & 17,23 & 1,07 \\
A-CC-C60-B10 & 15,73 & 13,67 & 1,15 \\
A-CC-C60-B16 & 21,31 & 17,00 & 1,25 \\
\hline
\end{tabular}

- De acordo com a Tabela 8.14, a aproximação fornecida pela regressão linear conduz a um erro de aproximação máximo de $20 \%$, a favor da segurança;

- Com relação à variabilidade dos resultados, a variação dos modelos pode ser atribuída à pequena dimensão dos modelos e do comprimento aderente, pois a mínima variação em seu comprimento de ancoragem (50 e $80 \mathrm{~mm}$, para os modelos com barra de 10 e $16 \mathrm{~mm}$, respectivamente) pode conduzir a uma grande variação dos resultados;

- $\quad$ Durante o ensaio de arrancamento houve uma grande variação do resultado da resistência de aderência, chegando a valores acima de 60\% (A-CAA-C60-B10), para o caso de se analisar a resistência de aderência quando do deslizamento igual a $0,01 \mathrm{~mm}$;

- O valor da resistência de aderência dos modelos de arrancamento com barra de $10 \mathrm{~mm}$ foi inferior aos modelos com barra de $16 \mathrm{~mm}$, o que mostra que a contribuição da resistência à compressão do concreto é significativa e, além disso, há a contribuição da rigidez da barra em conjunto com suas nervuras que promovem o aumento da resistência de aderência;

- $\quad$ o valor da resistência média de aderência apresentou pequena variação com exceção dos modelos com barra de $16 \mathrm{~mm}$, o que pode levar a uma conclusão inicial que o concreto de alta resistência trabalhando em conjunto com barra de diâmetro acima de $10 \mathrm{~mm}$, apresenta alta variabilidade em função da alta resistência de aderência existente entre as nervuras, o que pode contribuir para uma maior variação do resultado.

\subsubsection{Série complementar}

Todos os modelos de arrancamento apresentaram ruptura por fendilhamento do concreto. A Figura 8.12 ilustra o comportamento dos modelos de arrancamento para a série complementar. 

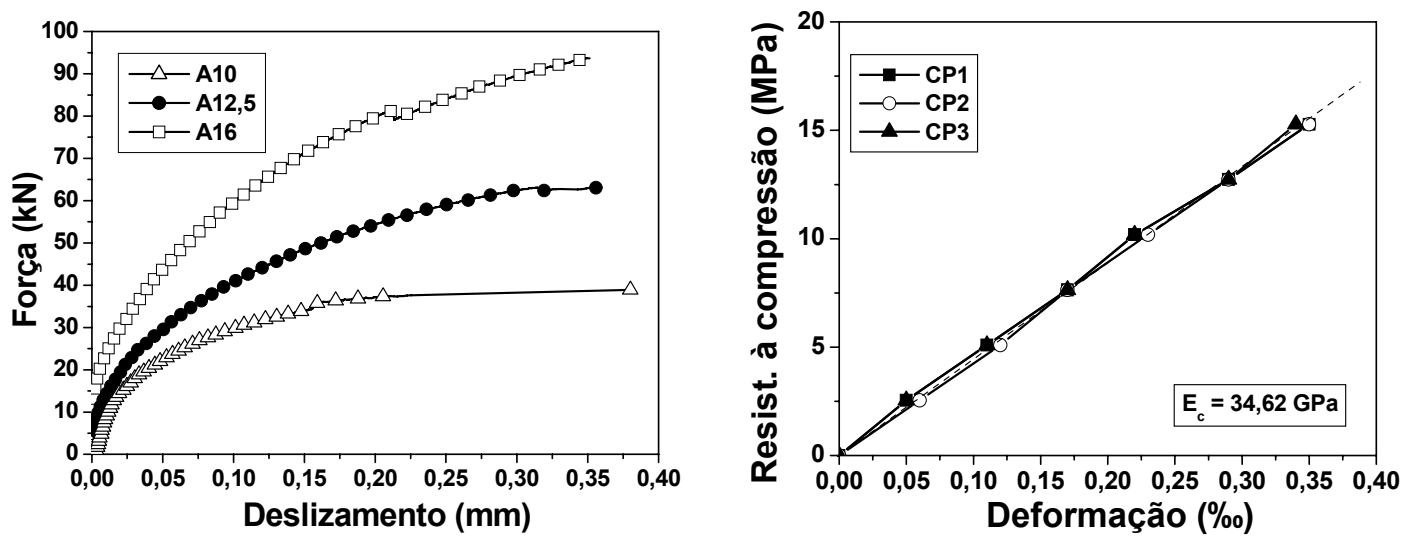

Figura 8.12 Média dos modelos de arrancamento

A Tabela 8.15 mostra a variabilidade da resposta dos ensaios de arrancamento.

Tabela 8.15 Variação dos resultados obtidos nos ensaios de arrancamento

\begin{tabular}{ccccccc}
\hline Diâmetro & \multicolumn{2}{c}{$\mathbf{1 0} \mathbf{~ \mathbf { m }}$} & \multicolumn{2}{c}{$\mathbf{1 2 , 5} \mathbf{~ m m}$} & \multicolumn{2}{c}{$\mathbf{1 6} \mathbf{~ \mathbf { m }}$} \\
Amostra & $\mathbf{F}_{\mathrm{u}}(\mathbf{k N})$ & $\mathbf{S}_{\mathrm{u}}(\mathbf{m m})$ & $\mathbf{F}_{\mathrm{u}}(\mathbf{k N})$ & $\mathbf{S}_{\mathrm{u}}(\mathbf{m m})$ & $\mathbf{F}_{\mathrm{u}}(\mathbf{k N})$ & $\mathbf{S}_{\mathrm{u}}(\mathbf{m m})$ \\
\hline $\mathbf{1}$ & 37,62 & 0,163 & 62,42 & 0,332 & 94,23 & 0,306 \\
$\mathbf{2}$ & 31,67 & 0,211 & 66,61 & 0,303 & 104,23 & 0,318 \\
$\mathbf{3}$ & 39,07 & 0,383 & 63,41 & 0,294 & 87,44 & 0,192 \\
$\mathbf{4}$ & 36,7 & 0,215 & 68,44 & 0,399 & 86,22 & 0,251 \\
$\mathbf{5}$ & 36,24 & 0,074 & 63,87 & 0,413 & 90,19 & 0,514 \\
Média & 36,26 & 0,209 & 64,95 & 0,348 & 92,46 & 0,316 \\
D.P. & 2,784 & 0,113 & 2,494 & 0,055 & 7,262 & 0,121 \\
C.V. (\%) & $7,68 \%$ & $53,79 \%$ & $3,84 \%$ & $15,75 \%$ & $7,85 \%$ & $38,38 \%$ \\
\hline
\end{tabular}

A Figura 8.13 mostra o comportamento da resistência de aderência para a série complementar, onde, vale salientar que os valores para o comportamento médio foram medidos a partir do comportamento dos cinco modelos de arrancamento.

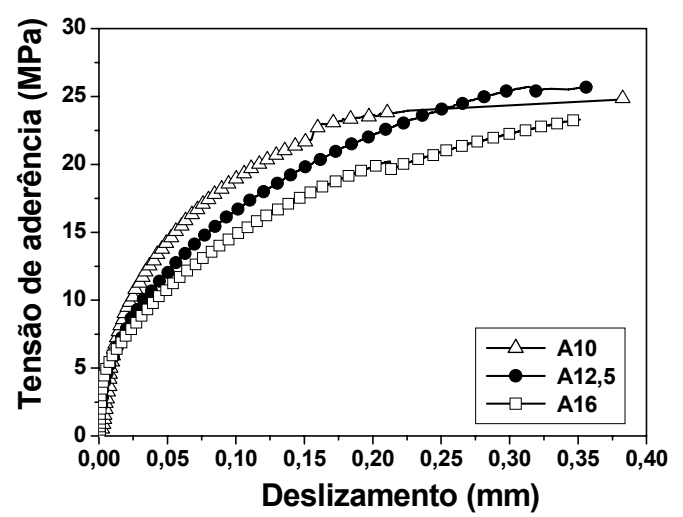

Figura 8.13 Comportamento da tensão de aderência para a série complementar 
A Tabela 8.12 mostra as regressões exponenciais desenvolvidas para simular o comportamento da resistência de aderência dos modelos de arrancamento da série 2.

Tabela 8.16 Regressões exponenciais para os modelos de arrancamento da série complementar

\begin{tabular}{cc}
\hline Modelo & Regressão exponencial \\
\hline A10 & $\tau(s)=24,87-23,13 \cdot \mathrm{e}^{(-\mathrm{s} / 0,066)}$ \\
$\mathrm{A} 12,5$ & $\tau(\mathrm{s})=25,74-22,48 \cdot \mathrm{e}^{(-\mathrm{s} / 0,105)}$ \\
$\mathrm{A} 16$ & $\tau(\mathrm{s})=23,30-20,75 \cdot \mathrm{e}^{(-\mathrm{s} / 0,107)}$ \\
\hline
\end{tabular}

A Figura 8.11 mostra a regressão exponencial para cada modelo de arrancamento da série complementar, onde se pode ver uma boa correspondência com o comportamento experimental.

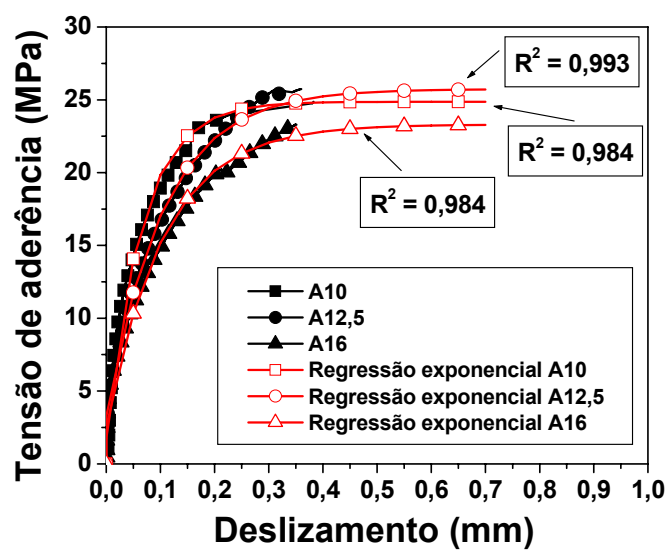

Figura 8.14 Regressão exponencial para representar a tensão de aderência dos modelos de arrancamento da série complementar

A Tabela 8.17 mostra a variação da resistência de aderência, calculada de acordo com a Eq. 8.1 e Eq. 8.3. 
Tabela 8.17 Resultados obtidos nos ensaios de arrancamento da série complementar

\begin{tabular}{cccccc}
\hline Amostra & $\tau_{0,01}$ (MPa) & $\tau_{0,1}(\mathbf{M P a})$ & $\tau_{1,0}(\mathbf{M P a})$ & $\tau_{\mathrm{u}}(\mathbf{M P a})$ & $\tau_{\mathrm{m}}(\mathbf{M P a})$ \\
\hline A10-1 & 7,04 & 20,16 & 23,95 & 23,95 & 17,05 \\
A10-2 & 0,15 & 15,45 & 20,16 & 20,16 & 11,92 \\
A10-3 & 6,22 & 17,29 & 24,87 & 24,87 & 16,13 \\
A10-4 & 9,47 & 18,68 & 23,36 & 23,36 & 17,17 \\
A10-5 & 21,62 & 23,07 & 23,07 & 23,07 & 22,59 \\
Média (MPa) & 8,90 & 18,93 & 23,08 & 23,08 & 16,97 \\
D.P. (MPa) & 7,89 & 2,90 & 1,77 & 1,77 & 3,80 \\
C.V. (\%) & $88,71 \%$ & $15,30 \%$ & $7,68 \%$ & $7,68 \%$ & $22,41 \%$ \\
\hline A12,5-1 & 0,75 & 13,27 & 25,43 & 25,43 & 13,15 \\
A12,5-2 & 6,59 & 17,07 & 27,14 & 27,14 & 16,93 \\
A12,5-3 & 7,74 & 18,19 & 25,83 & 25,83 & 17,25 \\
A12,5-4 & 7,34 & 17,38 & 27,89 & 27,89 & 17,53 \\
A12,5-5 & 8,95 & 16,82 & 26,02 & 26,02 & 17,26 \\
Média (MPa) & 6,27 & 16,55 & 26,46 & 26,46 & 16,43 \\
D.P. (MPa) & 3,21 & 1,90 & 1,02 & 1,02 & 1,84 \\
C.V. (\%) & $51,11 \%$ & $11,48 \%$ & $3,85 \%$ & $3,85 \%$ & $11,23 \%$ \\
\hline A16-1 & 5,31 & 15,22 & 23,43 & 23,43 & 14,65 \\
A16-2 & 6,34 & 16,51 & 25,92 & 25,92 & 16,26 \\
A16-3 & 7,65 & 17,61 & 21,75 & 21,75 & 15,67 \\
A16-4 & 5,83 & 14,76 & 21,44 & 21,44 & 14,01 \\
A16-5 & 4,33 & 11,29 & 22,43 & 22,43 & 12,68 \\
Média (MPa) & 5,89 & 15,08 & 22,99 & 22,99 & 14,65 \\
D.P. (MPa) & 1,23 & 2,39 & 1,81 & 1,81 & 1,40 \\
C.V. (\%) & $20,91 \%$ & $15,88 \%$ & $7,85 \%$ & $7,85 \%$ & $9,59 \%$ \\
\hline
\end{tabular}

De acordo com as análises dos resultados da série complementar, pode-se concluir parcialmente que:

- O comportamento da resistência de aderência para os três casos de arrancamento foi similar, sendo representados por um comportamento curvilíneo até a ruptura por fendilhamento do prisma de concreto (Figura 8.13). Ainda, o mesmo comportamento pode ser observado no ensaio (Figura 8.12);

- Com relação à regressão exponencial desenvolvida, do mesmo modo que nos casos anteriores, houve boa correspondência com o comportamento da resistência de aderência. A Tabela 8.18 mostra a diferença entre as resistências máximas de aderência, para o mesmo valor de deslizamento, para os modelos experimentais e as formulações desenvolvidas;

Tabela 8.18 Comparação entre os resultados experimentais e as regressões exponenciais dos modelos de arrancamento da série complementar

\begin{tabular}{cccc}
\hline Modelo & $\begin{array}{c}\text { Experimental } \\
\tau_{\mathrm{u}}(\mathrm{MPa})\end{array}$ & $\begin{array}{c}\text { Regressão } \\
\tau_{\mathrm{u}}(\mathrm{MPa})\end{array}$ & $\boldsymbol{\lambda}$ \\
\hline A10 & 24,87 & 24,80 & 1,00 \\
A12,5 & 25,74 & 25,01 & 0,97 \\
A16 & 23,31 & 22,51 & 0,97 \\
\hline
\end{tabular}


- De acordo com a Tabela 8.18, a aproximação fornecida pela regressão exponencial conduz a um erro de aproximação máximo de $3 \%$, contra a segurança;

- Com relação à variação dos resultados na Tabela 8.18, os modelos com barra de menor dimensão apresentaram maior variação em seu trecho inicial, o que conduz a conclusão parcial que pequenos diâmetros de barra possuem alta variação da resistência de aderência inicial $\left(\tau_{0,01}\right)$ e essa variação diminui à medida que se aumenta o diâmetro da barra. Ainda, o valor da resistência de aderência máxima $\left(\tau_{u}\right)$ possui pouca variação, independente do diâmetro da barra;

- Do mesmo modo que nos casos anteriores de arrancamento, variabilidade dos resultados pode ser também atribuída à pequena dimensão dos modelos e do comprimento aderente, pois a mínima variação em seu comprimento de ancoragem (50, 62,5 e $80 \mathrm{~mm}$, para os modelos com barra de 10, 12,5 e $16 \mathrm{~mm}$, respectivamente);

- Durante o ensaio de arrancamento houve uma grande variação do comportamento da resistência de aderência, chegando em alguns casos a valores acima de $88 \%$, principalmente para barras com diâmetro de $10 \mathrm{~mm}$, corroborando o mesmo ocorrido nas séries de arrancamento realizadas anteriormente;

- $\quad$ O valor da resistência de aderência dos modelos de arrancamento com barra de $10 \mathrm{~mm}$ foi superior aos modelos com barra de $16 \mathrm{~mm}(6,3 \%)$, o que corrobora as considerações iniciais realizadas, que, à medida que se aumenta o diâmetro da barra, se reduz a resistência de aderência (Barbosa, 2001).

Assim, a coesão do concreto apresenta alta influência no comportamento da resistência média de aderência $\left(\tau_{m}\right)$. A Tabela 8.17 mostra que para os três diâmetros de barra escolhidos, a maior influência foi registrada justamente em barras de menor dimensão e, essa variação influencia justamente o comportamento inicial do modelo de arrancamento.

\subsection{Ensaios de viga}

Aqui se apresentam a análise dos resultados referentes aos modelos de viga. 


\subsubsection{Série 1}

Os modelos de viga da série 1 apresentaram interrupção no ensaio por causa do deslizamento excessivo obtido e em alguns casos por ruptura por escoamento da barra de aço. A Figura 8.15 ilustra o comportamento dos modelos de viga para a série 1 em CAA e em CC e o valor do módulo de elasticidade longitudinal.
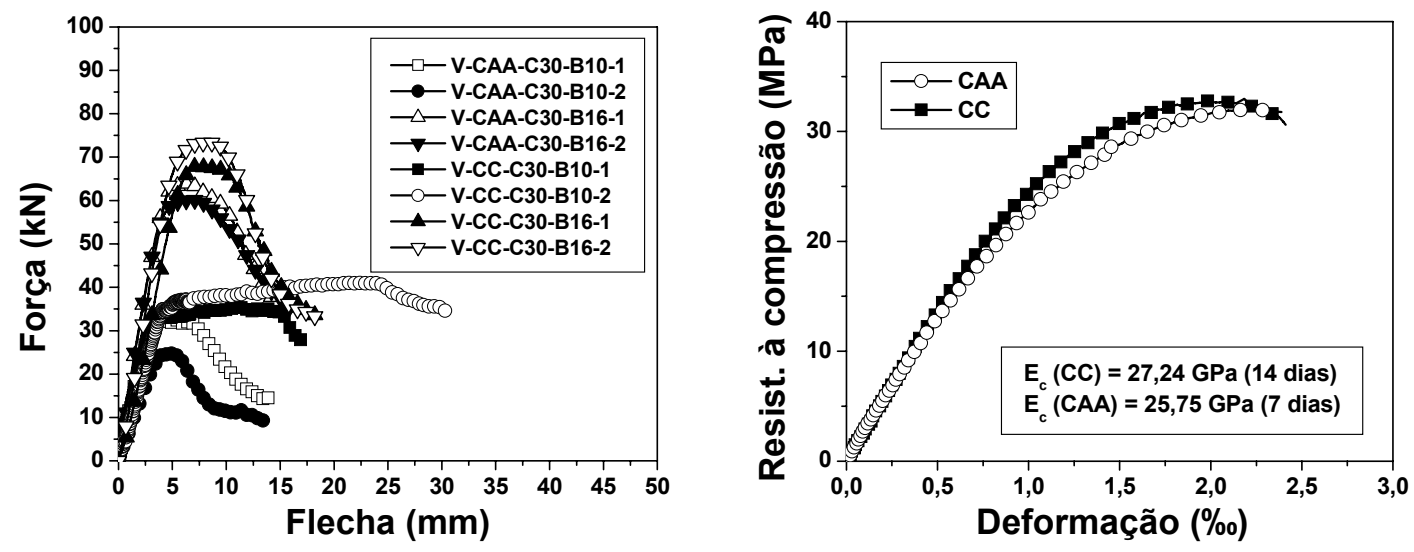

Figura 8.15 Média dos modelos de viga e módulo de elasticidade

Para os modelos de viga, somente uma réplica fora realizada de modo a se comprovar os resultados do modelo instrumentado com extensômetros elétricos de resistência.

A Tabela 8.19 ilustra a variação dos resultados nos ensaios de viga.

Tabela 8.19 Variação da força de ruptura nos ensaios de viga da série 1

\begin{tabular}{|c|c|c|c|c|c|c|c|c|}
\hline \multirow[b]{2}{*}{ Modelo } & \multicolumn{4}{|c|}{ V-CAA-C30-B10 } & \multicolumn{4}{|c|}{ V-CAA-C30-B16 } \\
\hline & $P_{u}(k N)$ & $\begin{array}{c}\text { Flecha } \\
(\mathrm{mm})\end{array}$ & $\begin{array}{c}\mathbf{s}_{1 \mathrm{u}} \\
(\mathrm{mm})\end{array}$ & $\begin{array}{c}\mathbf{S}_{2 u} \\
(\mathbf{m m})\end{array}$ & $\begin{array}{c}P_{u} \\
(k N)\end{array}$ & $\begin{array}{l}\text { Flecha } \\
(\mathrm{mm})\end{array}$ & $\mathbf{s}_{1 \mathrm{u}}(\mathrm{mm})$ & $\mathrm{s}_{2 u}(\mathrm{~mm})$ \\
\hline 1 & 32,66 & 3,98 & 0,272 & 0,429 & 64,02 & 6,34 & 0,277 & 1,445 \\
\hline 2 & 24,87 & 3,98 & 0,294 & 0,596 & 60,13 & 6,60 & 0,474 & 1,393 \\
\hline Média & 28,77 & 3,98 & 0,283 & 0,513 & 62,07 & 6,47 & 0,38 & 1,42 \\
\hline D.P. & 5,503 & 0,000 & 0,016 & 0,118 & 2,752 & 0,178 & 0,139 & 0,036 \\
\hline \multirow[t]{2}{*}{ C.V. } & $19,13 \%$ & $0,00 \%$ & $5,52 \%$ & $23,01 \%$ & $4,43 \%$ & $2,75 \%$ & $37,12 \%$ & $2,57 \%$ \\
\hline & \multicolumn{4}{|c|}{ V-CC-C30-B10 } & \multicolumn{4}{|c|}{ V-CC-C30-B16 } \\
\hline Modelo & $P_{u}(k N)$ & $\begin{array}{c}\text { Flecha } \\
(\mathrm{mm})\end{array}$ & $\begin{array}{c}s_{1 u} \\
(\mathrm{~mm})\end{array}$ & $\begin{array}{c}\mathbf{S}_{2 u} \\
(\mathrm{~mm})\end{array}$ & $\begin{array}{c}P_{u} \\
(k N)\end{array}$ & $\begin{array}{l}\text { Flecha } \\
(\mathrm{mm})\end{array}$ & $\mathrm{s}_{1 \mathrm{u}}(\mathrm{mm})$ & $\mathbf{s}_{2 u}(\mathrm{~mm})$ \\
\hline 1 & 33,95 & 3,70 & 0,049 & 0,717 & 67,99 & 7,32 & 0,802 & 0,596 \\
\hline 2 & 33,57 & 3,82 & 0,115 & 0,268 & 73,56 & 7,31 & 0,703 & 0,929 \\
\hline Média & 33,76 & 3,76 & 0,08 & 0,49 & 70,77 & 7,32 & 0,75 & 0,76 \\
\hline D.P. & 0,269 & 0,084 & 0,047 & 0,318 & 3,939 & 0,008 & 0,070 & 0,235 \\
\hline C.V. & $0,80 \%$ & $2,22 \%$ & $56,93 \%$ & $64,49 \%$ & $5,57 \%$ & $0,11 \%$ & $9,30 \%$ & $30,88 \%$ \\
\hline
\end{tabular}


Os modelos de viga com barra de $16 \mathrm{~mm}$ apresentaram boa correlação, entretanto, os modelos com barra de $10 \mathrm{~mm}$ em CC apresentaram um comportamento diferente do esperado, pois não houve perda de rigidez da mesma forma encontrada nos modelos em CAA.

Vale salientar que, durante o ensaio do modelo V-CAA-C30-B10-2, houve um deslocamento do apoio da máquina que ocasionou uma perda de rigidez do modelo, sendo claramente visto na Figura 8.15 e na Tabela 8.19. Com isso, não foi levado em consideração seus resultados sendo utilizado somente os resultados do modelo $\mathrm{V}$ CAA-C30-B10-1.

A Figura 8.16 mostra o comportamento da resistência de aderência para os modelos de viga em CC e em CAA com barra de 10 e de 16 mm da série 1.
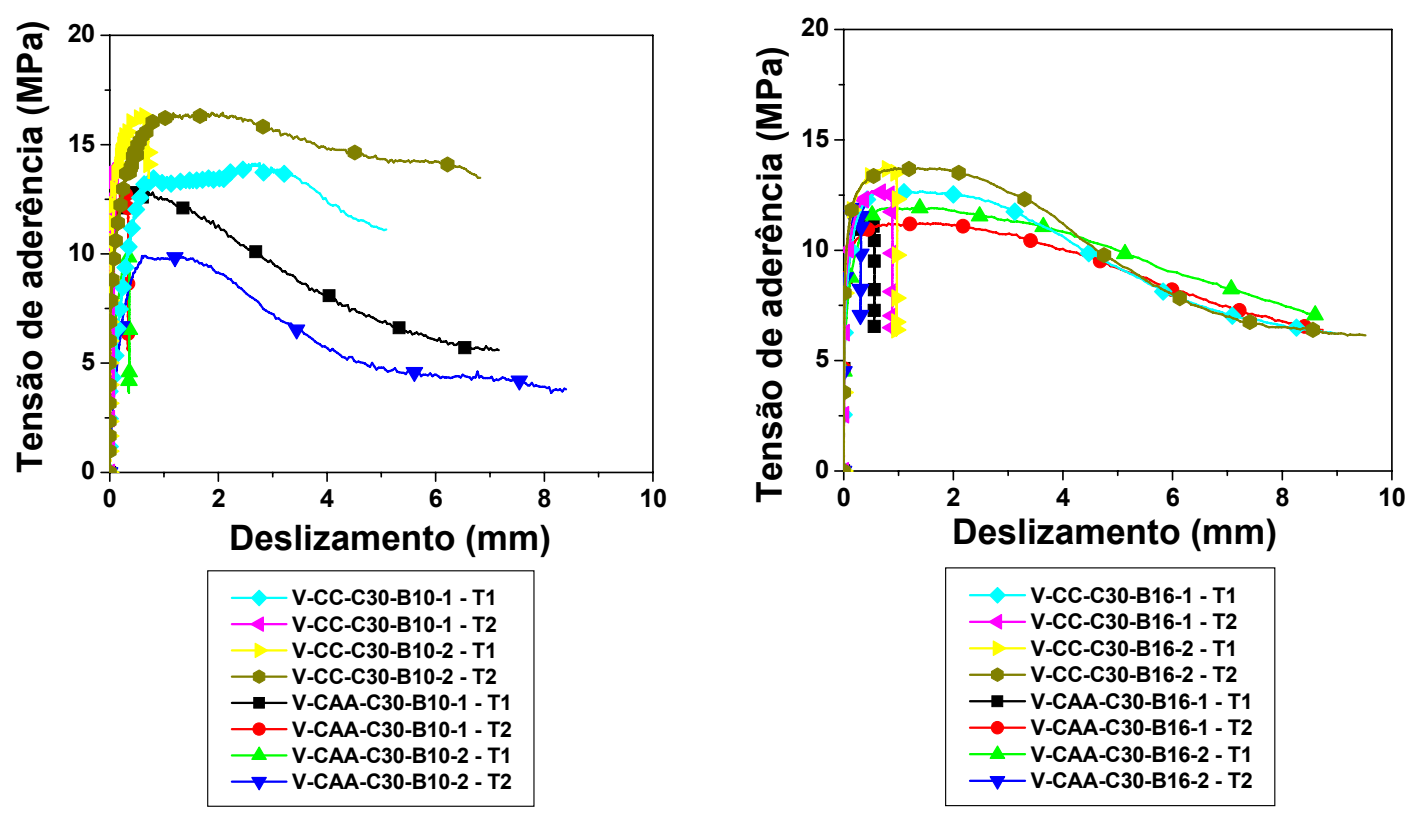

Figura 8.16 Comportamento da tensão de aderência com barra de 10 e de 16 mm

Com relação ao deslizamento das barras, houve grande variação, pois não há meios de se prever que ponto será mais frágil nos pontos com aderência, uma vez que o modelo é simétrico para ambos os lados da viga. Para uma avaliação estatística mais apurada seriam necessárias séries de viga com uma quantidade significativa de réplicas.

A Figura 8.17 ilustra a variação da resistência de aderência com relação à deformação de cada extensômetro para os modelos com barra de $10 \mathrm{~mm}$. Pode-se ver que não houve uma boa correspondência entre os resultados dos modelos em CC e em CAA, o que pode conseqüência da perda de fluidez no CAA. 

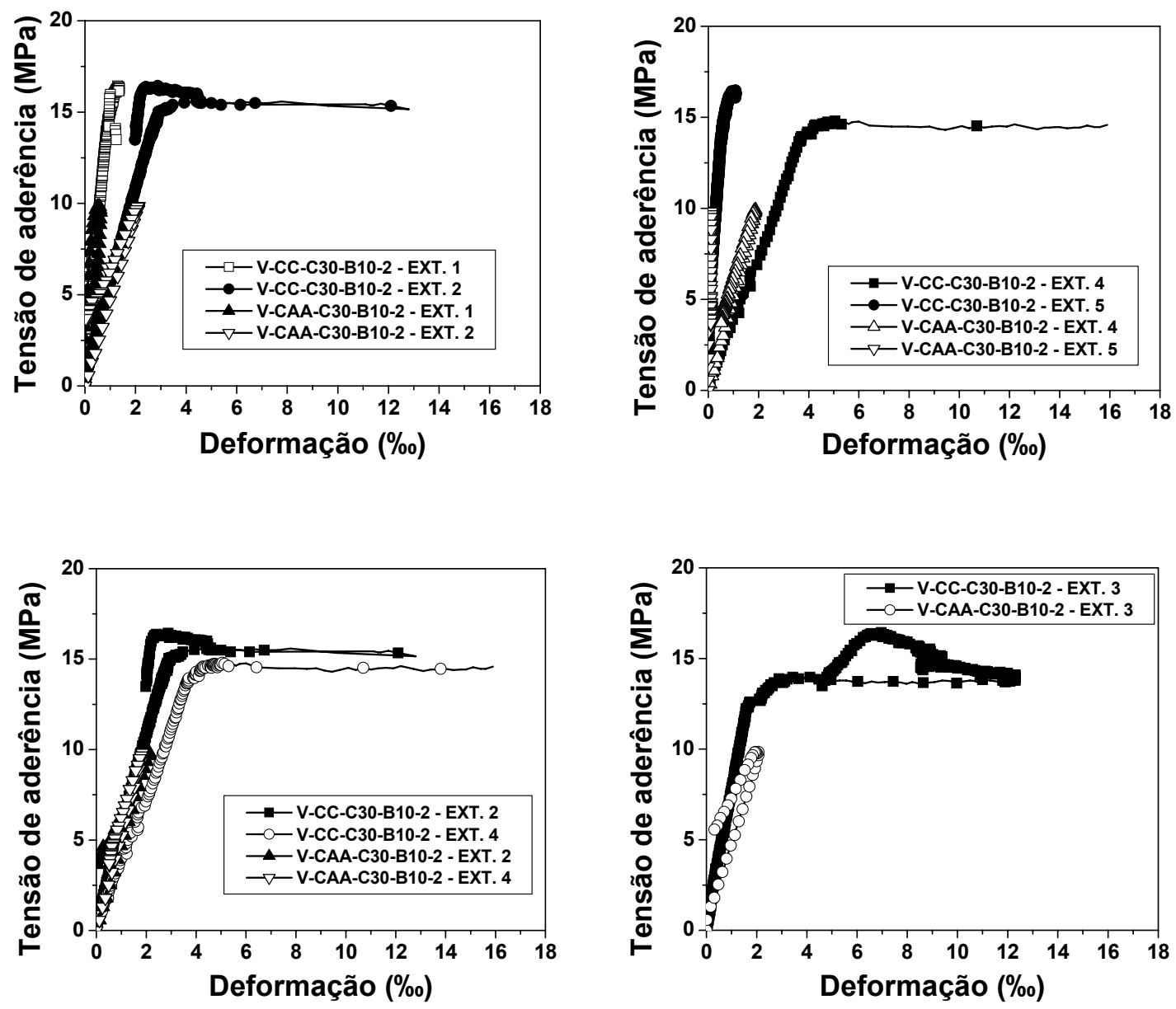

Figura 8.17 Variação das deformações para modelo de viga com barra de $10 \mathrm{~mm}$

A Figura 8.18 ilustra a variação da resistência de aderência com relação à deformação de cada extensômetro para os modelos com barra de $16 \mathrm{~mm}$. Pode-se ver que houve uma boa equivalência entre os resultados dos modelos em CC e em CAA. 

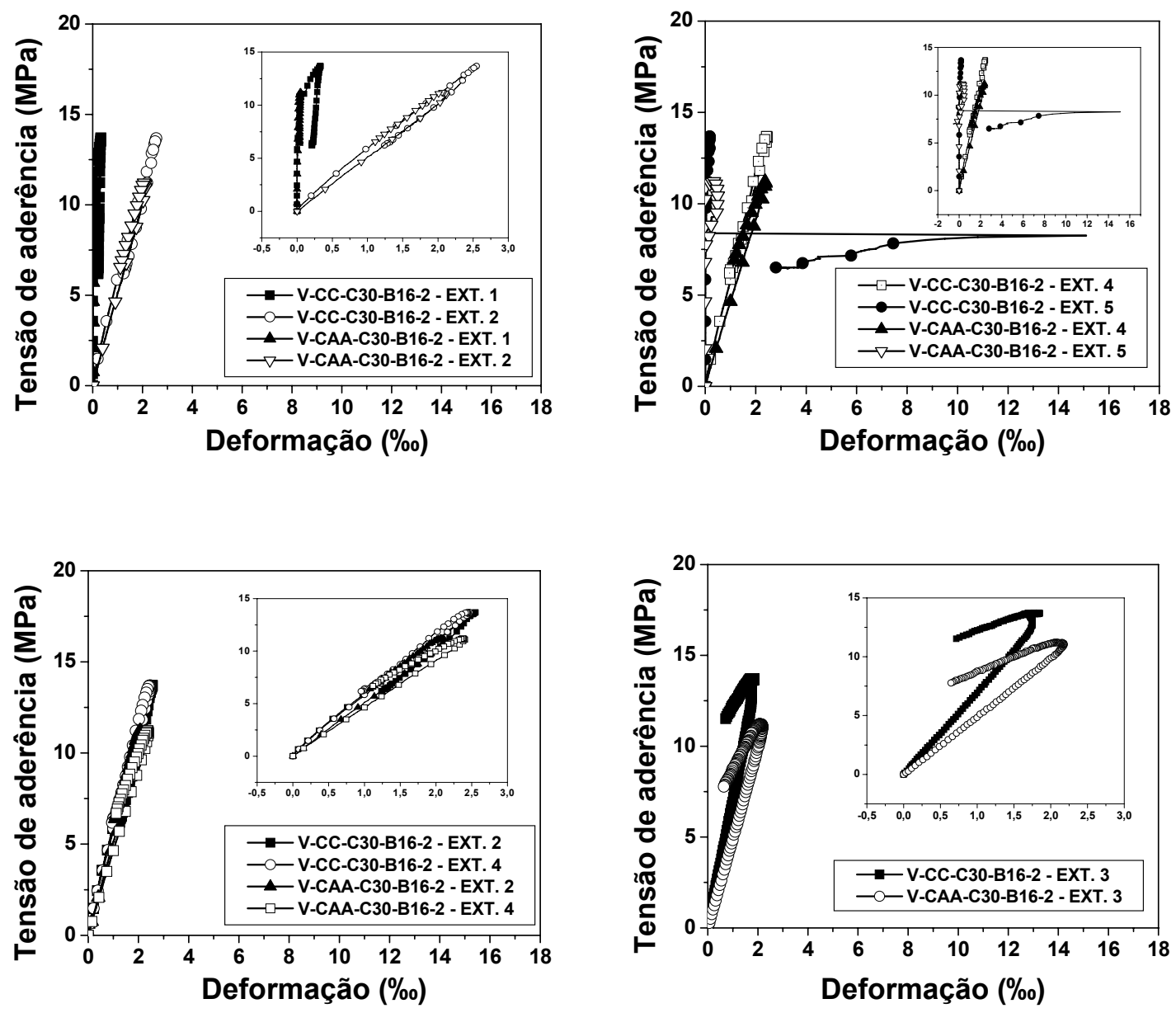

Figura 8.18 Variação das deformações para modelo de viga com barra de $16 \mathrm{~mm}$

De acordo com a Figura 8.17 e Figura 8.18, o comportamento dos modelos de viga em CC e em CAA foi semelhante quando da utilização de barras de $16 \mathrm{~mm}$ de diâmetro e apresentou diferenças quando da utilização das barras de $10 \mathrm{~mm}$. Esse fato pode ser explicado pela perda de fluidez durante a concretagem dos modelos em CAA ocasionada pelo superplastificante utilizado.

A análise dos resultados mostrou que o comportamento dos modelos de viga se baseia em uma sucessão de deslizamentos e deformações, ou seja, conforme aumenta o deslizamento da barra, se reduz a deformação da barra e vice-versa. A Figura 8.19 mostra o comportamento deslizamento vs. deformação para os modelos de viga com barra de 10 e $16 \mathrm{~mm}$, respectivamente. 

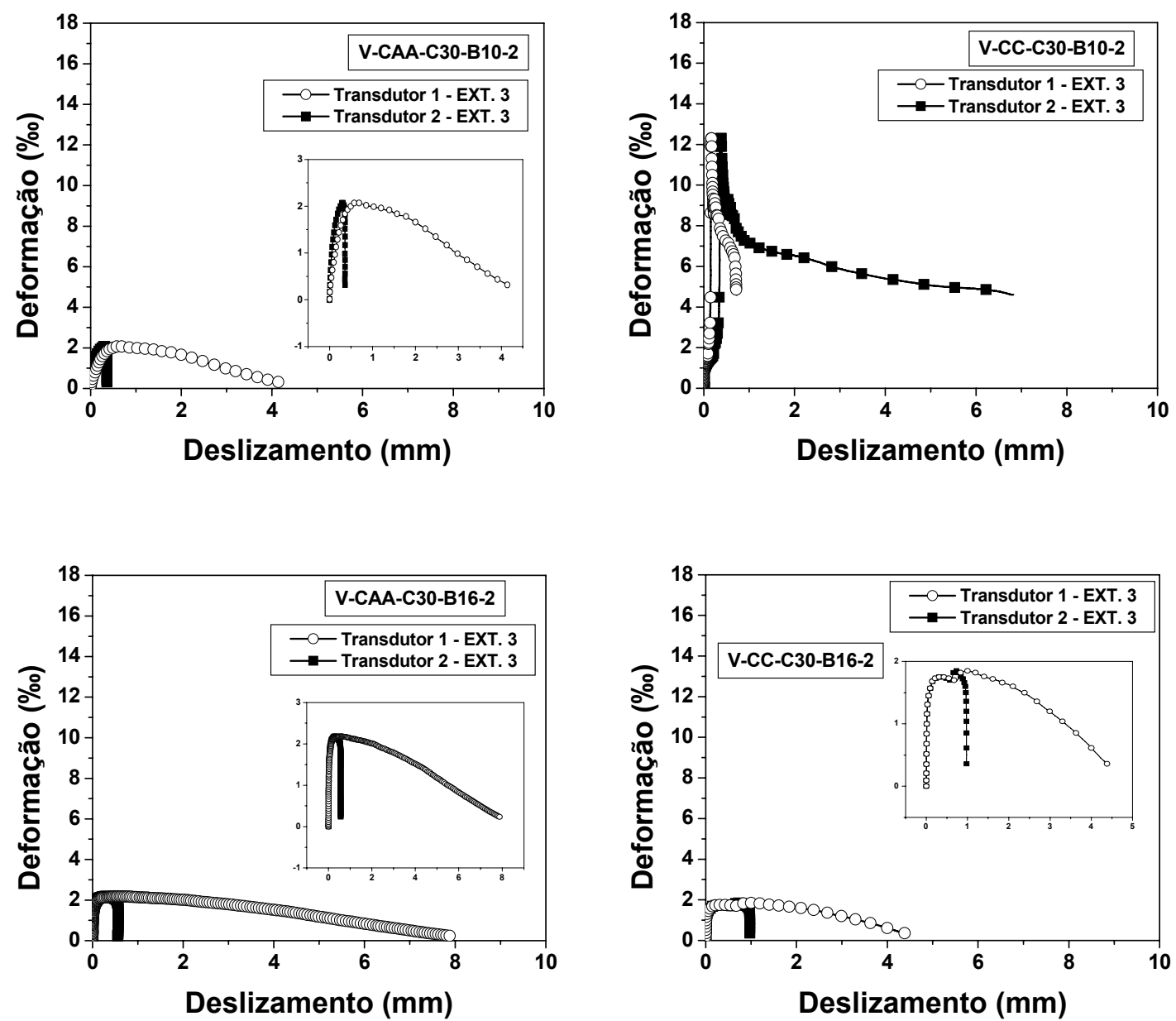

Figura 8.19 Deslizamento vs. deformação no extensômetro 3 para modelo de viga com barra de 10 e de $16 \mathrm{~mm}$ da série 1

De acordo com a Figura 8.19, os extensômetros elétricos de resistência demonstraram a existência de pequenas deformações, fato característico deste ensaio com concreto com resistência normal à compressão; entretanto, a viga em CC com barra de $10 \mathrm{~mm}$ apresentou grandes deformações, comprovando o mal funcionamento da rótula durante o ensaio.

Do mesmo modo que os modelos de arrancamento de resistência à compressão de $30 \mathrm{MPa}$, a regressão exponencial não é adequada para representar o comportamento da resistência de aderência (pré-pico e pós-pico), sendo utilizada somente na representação do pré-pico. Para a representação do comportamento da resistência de aderência, adotou-se uma regressão polinomial.

A Tabela 8.20 mostra as regressões exponenciais desenvolvidas para simular o comportamento do pré-pico da resistência de aderência dos modelos de viga com barra de 10 e de $16 \mathrm{~mm}$ da série 1. 
Tabela 8.20 Regressões exponenciais de pré-pico dos modelos de viga da série 1

\begin{tabular}{cc}
\hline Modelo & Regressão exponencial \\
\hline V-CAA-C30-B10 & $\tau(s)=13,000-11,551 \cdot e^{(-s / 0,0621)}$ \\
V-CAA-C30-B16 & $\tau(s)=11,516-9,712 \cdot e^{(-s / 0,0379)}$ \\
V-CC-C30-B10 & $\tau(s)=13,334-11,322 \cdot e^{(-s / 0,0914)}$ \\
V-CC-C30-B16 & $\tau(s)=12,876-11,366 \cdot e^{(-s / 0,0323)}$ \\
\hline
\end{tabular}

A Tabela 8.21 mostra as regressões polinomiais desenvolvidas para simular o comportamento de pós-pico da resistência de aderência dos modelos de viga com barra de 10 e de $16 \mathrm{~mm}$ da série 1.

Tabela 8.21 Regressões polinomiais até pós-pico dos modelos de viga da série 1

\begin{tabular}{cc}
\hline Modelo & Regressão exponencial \\
\hline $\begin{array}{c}\text { V-CAA- } \\
\text { C30-B10 }\end{array}$ & $\tau(s)=2,80863+91,39384 \cdot s-291,34707 \cdot s^{2}+445,51518 \cdot s^{3}-371,4744 \cdot s^{4}+$ \\
& $177,55051 \cdot s^{5}-48,58808 \cdot s^{6}+7,079 \cdot s^{7}-0,42567 \cdot s^{8}$ \\
V-CAA- & $\tau(s)=3,288+74,8464 \cdot s-231,22867 \cdot s^{2}+337,9502 \cdot s^{3}-267,7694 \cdot s^{4}+$ \\
C30-B16 & $121,522 \cdot s^{5}-31,57105 \cdot s^{6}+4,36477 \cdot s^{7}-0,24888 \cdot s^{8}$ \\
V-CC-C30- & $\tau(s)=3,60+71,2139 \cdot s-182,78778 \cdot s^{2}+222,15088 \cdot s^{3}-145,95257 \cdot s^{4}+$ \\
B16 & $54,712 \cdot s^{5}-11,7161 \cdot s^{6}+1,3343 \cdot s^{7}-0,06269 \cdot s^{8}$ \\
\hline
\end{tabular}

A Figura 8.20 mostra a regressão exponencial para os modelos de viga com barra de 10 e de $16 \mathrm{~mm}$ da série 1.
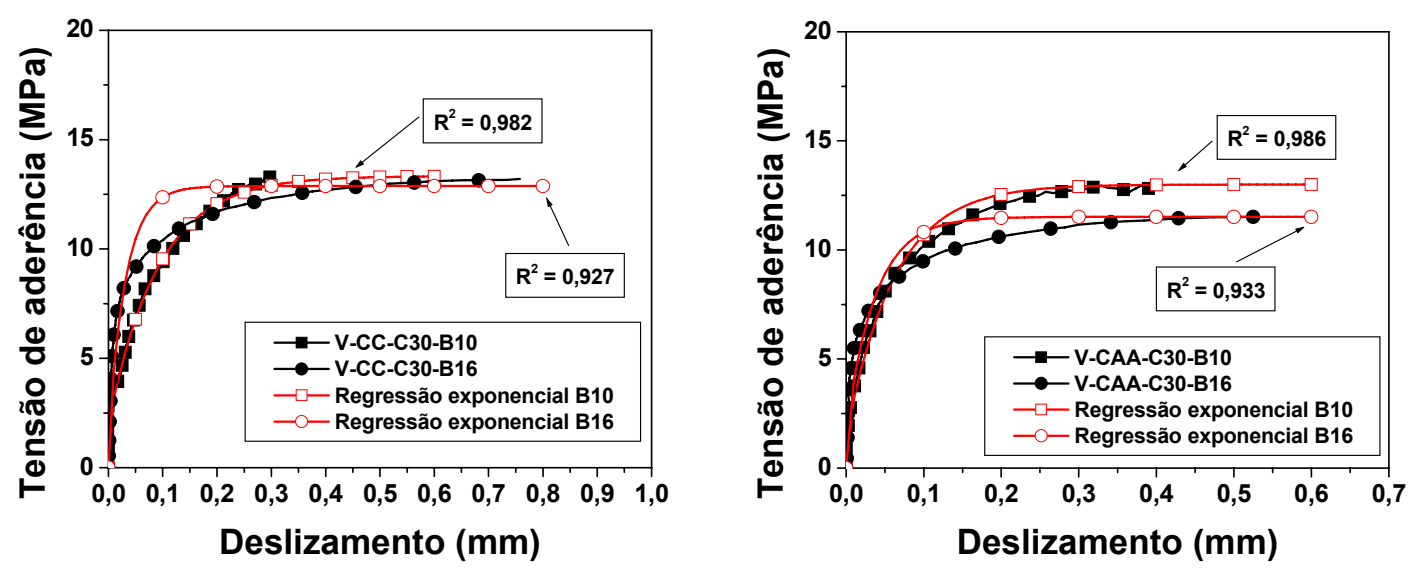

Figura 8.20 Regressão exponencial para representar a tensão de aderência dos modelos de viga da série 1 
A Figura 8.21 mostra a regressão polinomial dos modelos de viga da série 1 . Vale salientar que a curva referente ao modelo em CC com barra de $10 \mathrm{~mm}$ não é mostrado devido ao seu modo de ruptura.
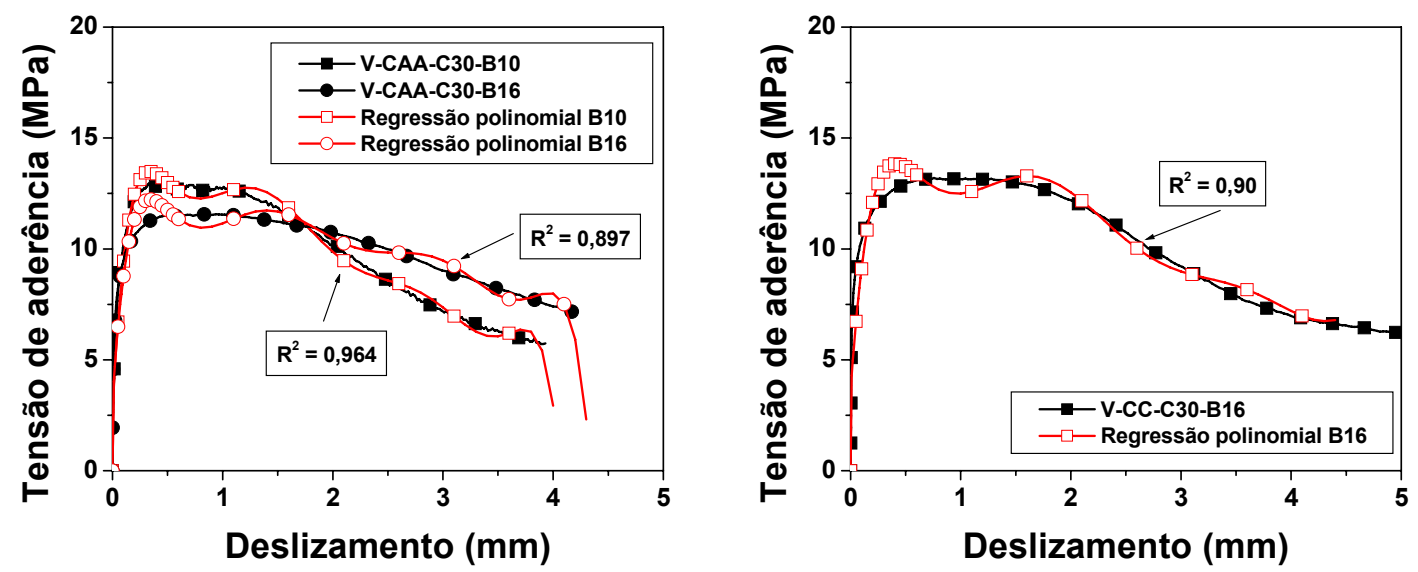

Figura 8.21 Regressão polinomial para representar a tensão de aderência dos modelos de viga da série 1

A Tabela 8.22 mostra a variação da resistência de aderência, calculada de acordo com a Eq. 8.2.

Tabela 8.22 Resultados obtidos nos ensaios de viga da série 1

\begin{tabular}{rccccc}
\hline \multicolumn{1}{c}{ Amostra } & $\tau_{0,01}(\mathbf{M P a})$ & $\tau_{0,1}(\mathbf{M P a})$ & $\tau_{1,0}(\mathrm{MPa})$ & $\tau_{\mathrm{u}}(\mathbf{M P a})$ & $\tau_{\mathrm{m}}$ (MPa) \\
\hline V-CAA-C30-B10-1 & 7,93 & 10,84 & 12,51 & 13,00 & 10,43 \\
V-CAA-C30-B10-2 & 1,79 & 4,10 & 9,78 & 9,90 & 5,22 \\
Média (MPa) & 4,86 & 7,47 & 11,15 & 11,45 & 7,83 \\
D.P. (MPa) & 4,339 & 4,768 & 1,933 & 2,191 & 3,680 \\
C.V. (\%) & $89,27 \%$ & $63,82 \%$ & $17,34 \%$ & $19,13 \%$ & $47,02 \%$ \\
\hline V-CAA-C30-B16-1 & 4,80 & 8,37 & 11,89 & 11,94 & 8,35 \\
V-CAA-C30-B16-2 & 5,55 & 9,44 & 11,12 & 11,22 & 8,70 \\
Média (MPa) & 5,17 & 8,90 & 11,50 & 11,58 & 8,53 \\
D.P. (MPa) & 0,533 & 0,755 & 0,544 & 0,513 & 0,248 \\
C.V. (\%) & $10,31 \%$ & $8,48 \%$ & $4,73 \%$ & $4,43 \%$ & $2,91 \%$ \\
\hline V-CC-C30-B10-1 & 4,10 & 5,22 & 13,52 & 13,52 & 7,61 \\
V-CC-C30-B10-2 & 7,08 & 10,30 & 13,37 & 13,37 & 10,25 \\
Média (MPa) & 5,59 & 7,76 & 13,44 & 13,44 & 8,93 \\
D.P. (MPa) & 2,105 & 3,587 & 0,107 & 0,107 & 1,862 \\
C.V. (\%) & $37,66 \%$ & $46,22 \%$ & $0,80 \%$ & $0,80 \%$ & $20,85 \%$ \\
\hline V-CC-C30-B16-1 & 5,48 & 9,48 & 12,60 & 12,68 & 9,19 \\
V-CC-C30-B16-2 & 6,02 & 11,22 & 13,68 & 13,72 & 10,31 \\
Média (MPa) & 5,75 & 10,35 & 13,14 & 13,20 & 9,75 \\
D.P. (MPa) & 0,383 & 1,228 & 0,765 & 0,735 & 0,792 \\
C.V. (\%) & $6,65 \%$ & $11,87 \%$ & $5,82 \%$ & $5,57 \%$ & $8,12 \%$ \\
\hline & & & & &
\end{tabular}

De acordo com as análises dos resultados dos modelos de viga da série 1, podese concluir que: 
- Os modelos de viga apresentaram uma boa correlação em seus resultados, mostrando que ambos os diâmetros de barra apresentaram comportamento semelhante com força de ruptura equivalente;

- O comportamento da resistência de aderência para os quatro casos de viga foi similar, sendo representados por um comportamento quase linear até a ruptura por deslizamento e todos, com exceção da viga em CC com barra de $10 \mathrm{~mm}$, apresentaram um pós-pico característico da perda de aderência;

- O modelo de viga em CC com barra de $10 \mathrm{~mm}$ apresentou um comportamento peculiar, pois este apresentou deformações excessivas ao contrário do modelo similar em CAA. Isso ocorreu por uma má utilização da rótula onde foi percebido após esta série de ensaios V-CC-C30-B10 que a rótula apresentou um travamento em seu giro, formando uma rótula plástica no local do extensômetro 3 (EXT. 3). Por isso, os dados referentes ao pós-pico do modelo em CC com barra de $10 \mathrm{~mm}$ foram descartados;

- Houve uma boa correspondência entre o resultado das deformações na barra de aço para os modelos com barra de $16 \mathrm{~mm}$. Isso mostra que o comportamento da resistência de aderência é similar tanto para o CAA quanto para o CC;

- Com relação às regressões exponenciais e polinomiais, houve boa correspondência com o comportamento da resistência de aderência. Ainda foi realizada uma regressão polinomial para representar o trecho de pós-pico da resistência de aderência. A Tabela 8.23 mostra a diferença entre as resistências máximas de aderência, para o mesmo valor de deslizamento, para os modelos experimentais e as regressões desenvolvidas;

Tabela 8.23 Comparação entre os resultados experimentais e as regressões exponenciais e polinomiais dos modelos de viga da série 1

\begin{tabular}{lccccc}
\hline & Experimental & $\begin{array}{l}\text { Regressão } \\
\text { exponencial }\end{array}$ & \multicolumn{3}{c}{$\begin{array}{c}\text { Regressão } \\
\text { polinomial }\end{array}$} \\
Modelo & $\tau_{\mathrm{u}}(\mathbf{M P a})$ & $\tau_{\mathrm{u}}(\mathbf{M P a})$ & $\lambda$ & $\tau_{\mathrm{u}}(\mathbf{M P a})$ & $\lambda$ \\
\hline V-CAA-C30-B10 & 13,000 & 12,981 & 1,002 & 13,391 & 0,971 \\
V-CAA-C30-B16 & 11,566 & 12,876 & 0,938 & 11,048 & 1,046 \\
V-CC-C30-B10 & 13,334 & 12,883 & 1,035 & - & - \\
V-CC-C30-B16 & 13,203 & 12,876 & 1,025 & 12,780 & 1,033 \\
\hline
\end{tabular}

- De acordo com a Tabela 8.23, a aproximação fornecida pela regressão exponencial conduz a um erro de aproximação máximo de $8,0 \%$, contra a segurança e a regressão polinomial a um erro contra a segurança de $1,2 \%$;

- A resistência última de aderência $\left(\tau_{u}\right)$ nos modelos em CC foi superior aos modelos em CAA (2,5\% para barra de $10 \mathrm{~mm}$ e 12,4\% para barra de $16 \mathrm{~mm}$ ), 
mostrando que há uma tendência ao CAA apresentar um comportamento igual ou um pouco inferior para a resistência de aderência, entretanto, como houve perda de fluidez nos modelos de viga desta série em CAA, é necessária a realização de mais uma série a fim de se verificar a veracidade dessa afirmação, o que infelizmente não pode ser realizado nesta pesquisa;

- A resistência média de aderência $\left(\tau_{m}\right)$ foi influenciada pelo diâmetro da barra, pois as vigas com $10 \mathrm{~mm}$ tiveram maior resistência quando confeccionadas em CAA, e quando da utilização de barras de $16 \mathrm{~mm}$, as vigas em CC apresentam melhor comportamento (Tabela 8.22);

- Com relação à variabilidade da resistência de aderência, houve grande variação no comportamento dos modelos com barra de $10 \mathrm{~mm}$ por causa do deslizamento existente. Já os modelos com barra de $16 \mathrm{~mm}$ apresentaram pequena variação;

- $\quad$ o valor da resistência última de aderência $\left(\tau_{u}\right)$ dos modelos de viga com barra de $10 \mathrm{~mm}$ e $16 \mathrm{~mm}$ foi praticamente o mesmo, mostrando que barras de 10 e 16 $\mathrm{mm}$ apresentam comportamento semelhante para a resistência de aderência, quando se utiliza concreto com resistência à compressão em torno de $30 \mathrm{MPa}$.

\subsubsection{Série 2}

Os modelos de viga da série 2 apresentaram interrupção no ensaio por causa dos elevados deslocamentos verticais (flecha) obtidos e por ruptura por escoamento da barra de aço do concreto. A Figura 8.22 ilustra o comportamento dos modelos de viga para a série 2 em CAA e em CC e o valor do módulo de elasticidade longitudinal.
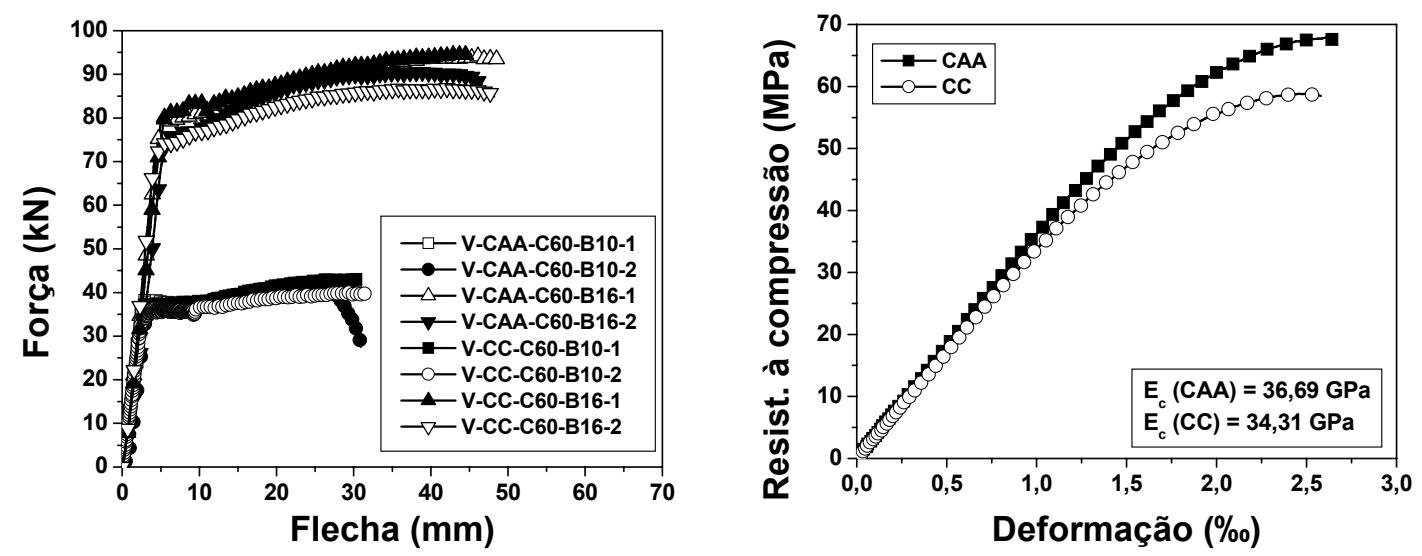

Figura 8.22 Média dos modelos de viga e módulo de elasticidade 
Da mesma forma que nos modelos de viga da série 1, somente uma réplica fora realizada de modo a se comprovar os resultados do modelo instrumentado com extensômetros elétricos de resistência, apresentaram uma boa correlação em seus resultados para ambos os diâmetros de barra.

A Tabela 8.24 ilustra a variação dos resultados nos ensaios de viga.

Tabela 8.24 Variação da força de ruptura nos ensaios de viga da série 2

\begin{tabular}{|c|c|c|c|c|c|c|c|c|}
\hline \multirow[b]{2}{*}{ Modelo } & \multicolumn{4}{|c|}{ V-CAA-C60-B10 } & \multicolumn{4}{|c|}{ V-CAA-C60-B16 } \\
\hline & $\begin{array}{c}\mathbf{P}_{\mathbf{u}} \\
(\mathbf{k N})\end{array}$ & $\begin{array}{c}\text { Flecha } \\
(\mathrm{mm})\end{array}$ & $\begin{array}{c}\mathbf{s}_{1 \mathrm{u}} \\
(\mathbf{m m})\end{array}$ & $\begin{array}{c}\mathbf{S}_{2 \mathrm{u}} \\
(\mathrm{mm})\end{array}$ & $P_{u}(k N)$ & $\begin{array}{l}\text { Flecha } \\
(\mathrm{mm})\end{array}$ & $s_{1 u}(m m)$ & $\mathbf{s}_{2 u}(\mathbf{m m})$ \\
\hline 1 & 42,88 & 29,98 & 0,120 & 0,062 & 94,31 & 44,11 & 0,411 & 0,151 \\
\hline 2 & 41,81 & 24,17 & 0,066 & 0,136 & 90,65 & 37,81 & 0,166 & 0,135 \\
\hline Média & 42,35 & 27,08 & 0,093 & 0,099 & 92,48 & 40,96 & 0,289 & 0,140 \\
\hline D.P. & 0,76 & 4,11 & 0,038 & 0,052 & 2,59 & 4,45 & 0,17 & 0,01 \\
\hline \multirow[t]{2}{*}{ C.V. } & $1,78 \%$ & $15,17 \%$ & $41,05 \%$ & $52,85 \%$ & $2,80 \%$ & $10,87 \%$ & $60,05 \%$ & $7,91 \%$ \\
\hline & \multicolumn{4}{|c|}{ V-CC-C60-B10 } & \multicolumn{4}{|c|}{ V-CC-C60-B16 } \\
\hline Modelo & $\begin{array}{c}P_{u} \\
(k N)\end{array}$ & $\begin{array}{c}\text { Flecha } \\
\text { (mm) }\end{array}$ & $\begin{array}{c}s_{1 u} \\
(\mathrm{~mm})\end{array}$ & $\begin{array}{c}\mathbf{S}_{2 \mathrm{u}} \\
(\mathbf{m m})\end{array}$ & $P_{u}(k N)$ & $\begin{array}{l}\text { Flecha } \\
(\mathrm{mm})\end{array}$ & $\mathrm{s}_{1 \mathrm{u}}(\mathrm{mm})$ & $\mathbf{s}_{2 u}(\mathrm{~mm})$ \\
\hline 1 & 43,19 & 30,31 & 0,051 & 0,107 & 86,83 & 42,27 & 1,196 & 0,079 \\
\hline 2 & 39,98 & 29,44 & 0,002 & 0,115 & 94,84 & 43,63 & 0,124 & 0,004 \\
\hline Média & 41,58 & 29,87 & 0,025 & 0,111 & 90,84 & 42,95 & 0,660 & 0,04 \\
\hline D.P. & 2,27 & 0,62 & 0,037 & 0,006 & 5,66 & 0,97 & 0,758 & 0,05 \\
\hline C.V. & $5,45 \%$ & $2,06 \%$ & $152,97 \%$ & $5,10 \%$ & $6,24 \%$ & $2,25 \%$ & $114,85 \%$ & $127,79 \%$ \\
\hline
\end{tabular}

Com relação aos resultados obtidos, houve pequena variação com relação à força de ruptura e a flecha nesse instante (com exceção das vigas em CAA que apresentaram maior variação). Essa pequena variabilidade dos resultados se deu em função o mecanismo de ruptura ser baseado na flexão pura do modelo combinado com o deslizamento-deformação da barra de aço.

Com relação ao deslizamento das barras, houve grande variação, pois não há meios de se prever que ponto será mais frágil nos pontos com aderência, uma vez que o modelo é simétrico para ambos os lados da viga. Para uma avaliação estatística mais apurada seriam necessárias séries de viga com uma quantidade significativa de réplicas.

A Figura 8.23 mostra o comportamento da resistência de aderência para os modelos de viga em CC e em CAA com barra de 10 e de $16 \mathrm{~mm}$ da série 2 . 

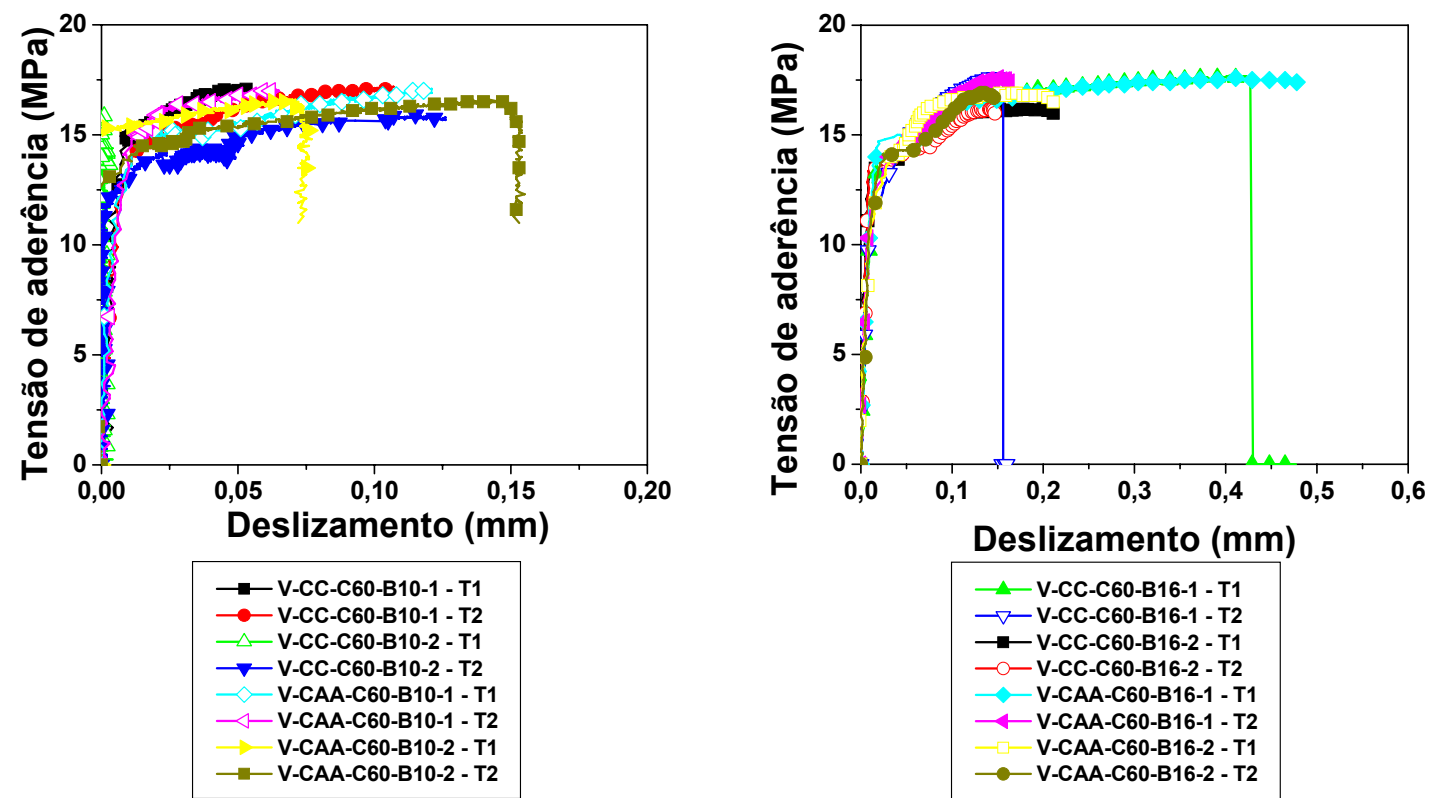

Figura 8.23 Comportamento da tensão de aderência com barra de 10 e de 16 mm

Com relação às deformações na barra de aço, a Figura 8.24 e Figura 8.25 mostra a variação do resultado.
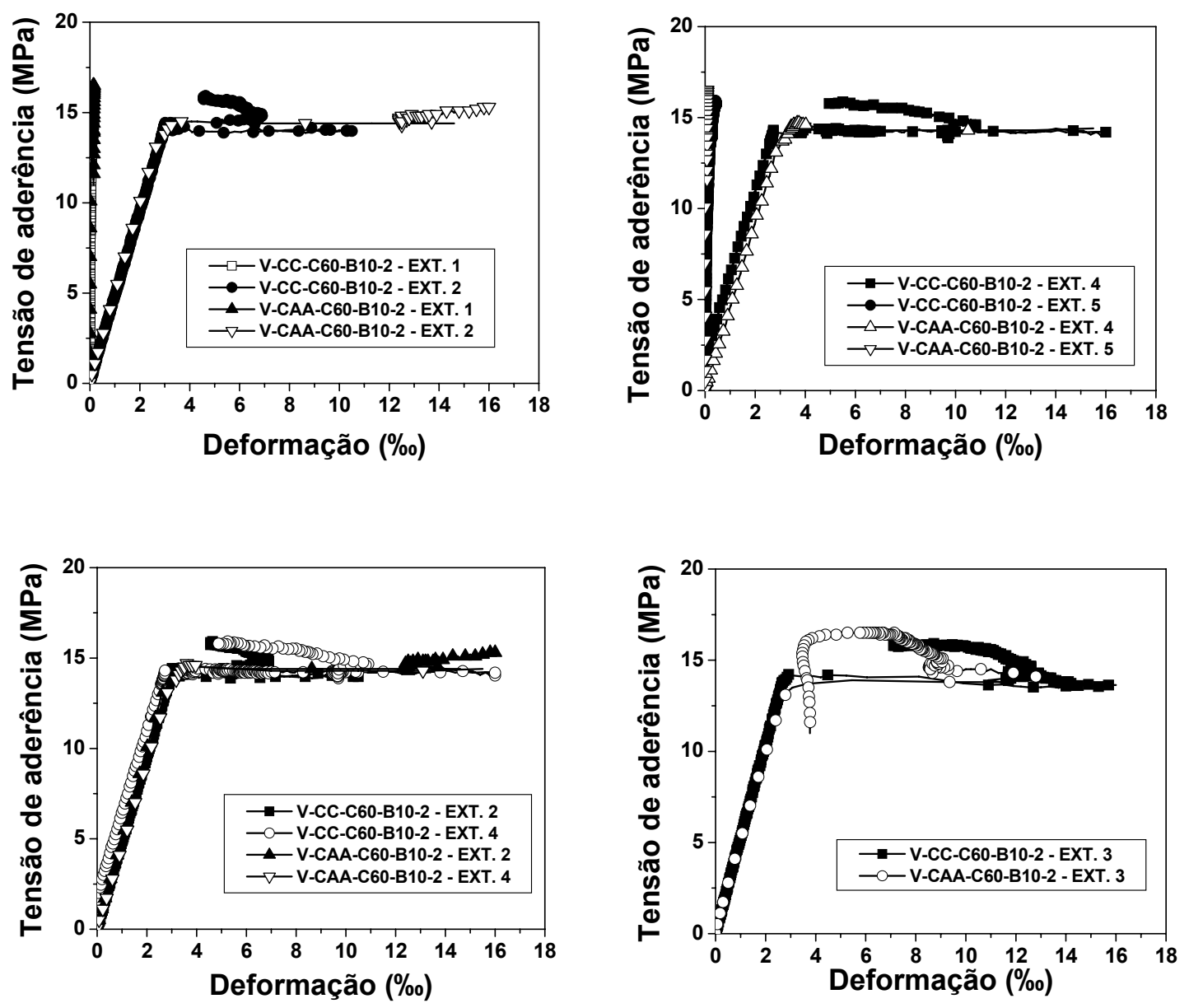

Figura 8.24 Variação das deformações para modelo de viga com barra de $10 \mathrm{~mm}$ 

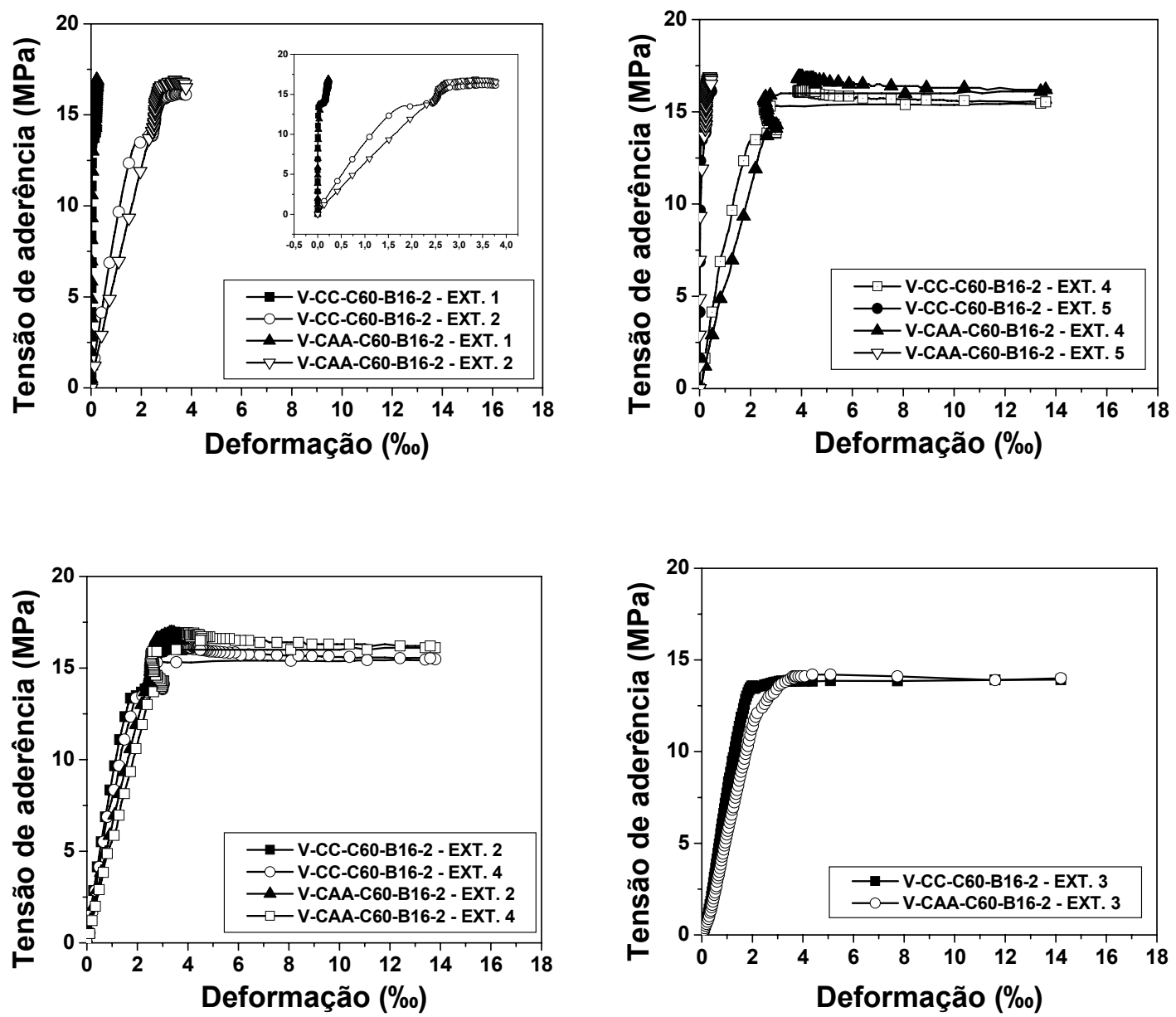

Figura 8.25 Variação das deformações para modelo de viga com barra de $16 \mathrm{~mm}$

De acordo com a Figura 8.24 e Figura 8.25, o comportamento dos modelos de viga em $\mathrm{CC}$ e em CAA foi semelhante mostrando que o concreto auto-adensável possui um comportamento para a resistência de aderência similar ao concreto convencional quando da utilização de barras de 10 e $16 \mathrm{~mm}$.

É possível fazer uma comparação entre os deslizamentos e as deformações respectivas, pois o modelo apresenta ruptura por deslocamento vertical excessivo e conseqüentemente, grandes deformações por causa da alta resistência à compressão do concreto. Já os modelos com menor resistência à compressão apresentam a peculiaridade do deslizamento ser preponderante como modo de ruptura do modelo de viga, o que faz com que não haja um meio de prever onde ocorrerá a ruptura por deslizamento do modelo.

A análise dos resultados mostrou que o comportamento dos modelos de viga se baseia em uma sucessão de deslizamentos e deformações, ou seja, conforme aumenta o deslizamento da barra, se reduz a deformação da barra e vice-versa. 
Assim, a Figura 8.26 mostra o comportamento deslizamento vs. deformação para os modelos de viga com barra de 10 e de $16 \mathrm{~mm}$.
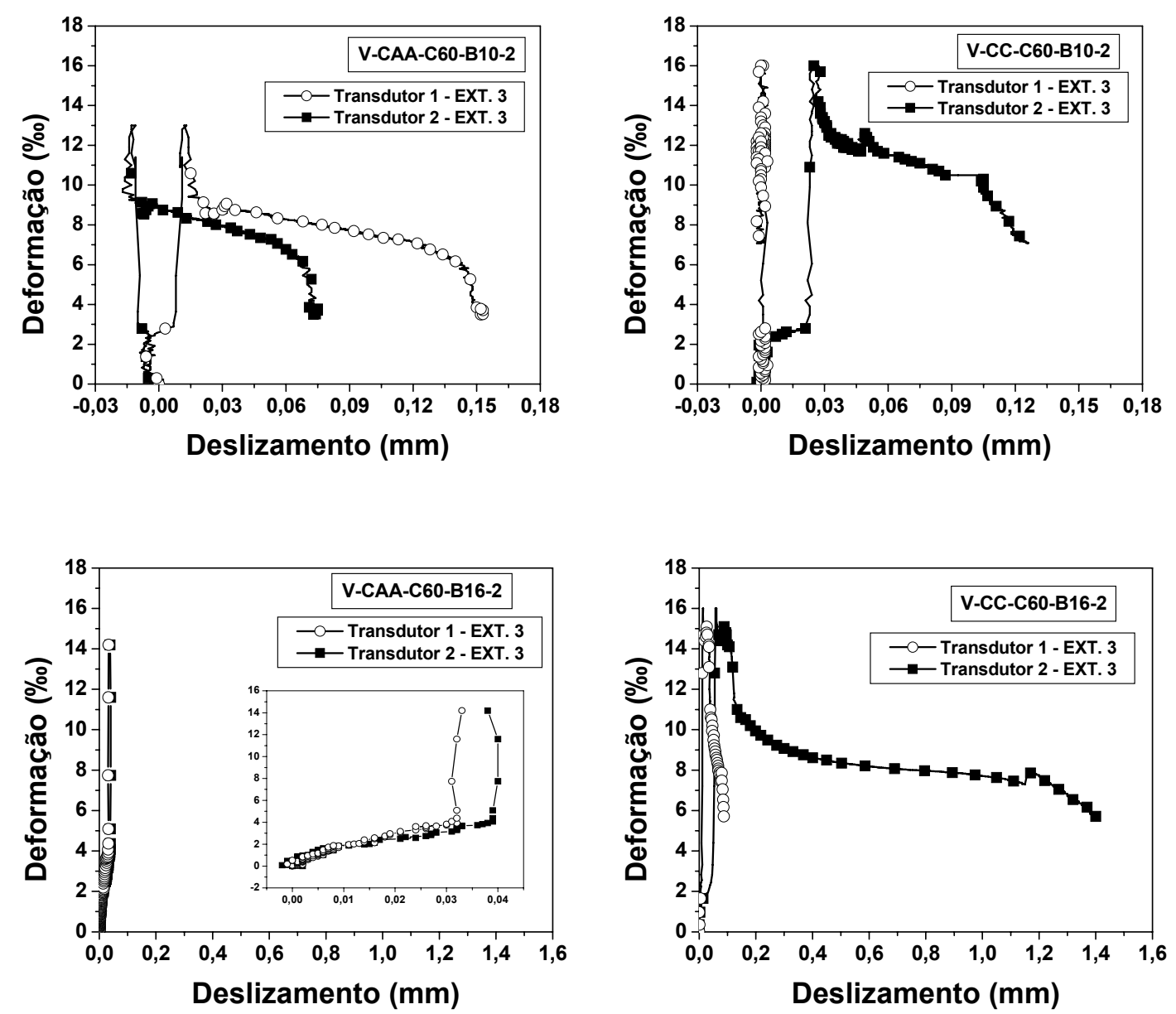

Figura 8.26 Deslizamento vs. deformação para modelo de viga com barra de 10 e $16 \mathrm{~mm}$

De acordo com a Figura 8.26, o extensômetro elétrico de resistência 3 (EXT. 3) foi similar para ambos os modelos de viga em CAA e em CC com barra de 10 e 16 $\mathrm{mm}$, apesar de que o resultado de do modelo com barra de $16 \mathrm{~mm}$ em CC apresentar um comportamento diferenciado. Ainda, o modelo com barra de $16 \mathrm{~mm}$ em CAA foi mais rígido que o modelo em $\mathrm{CC}$, pois o deslizamento da barra é muito pequeno, fazendo com que a resistência do modelo se baseie na deformação da barra de aço (quanto maior o deslizamento, menor a resistência). O modelo em CC apresentou grande deslizamento mostrando que a ligação aço-concreto é mais resistente quando da utilização do CAA. Entretanto é necessária uma maior amostragem de resultados para se ter uma comprovação com base estatística desse resultado.

A Tabela 8.25 mostra as regressões exponenciais desenvolvidas para simular o comportamento da resistência de aderência dos modelos de viga da série 2 . 
Tabela 8.25 Regressões exponenciais para os modelos de viga da série 2

\begin{tabular}{cc}
\hline Modelo & Regressão exponencial \\
\hline V-CAA-C60-B10 & $\tau(\mathrm{s})=16,621-10,52 \cdot \mathrm{e}^{(-\mathrm{s} /, 0082)}$ \\
V-CAA-C60-B16 & $\tau(\mathrm{s})=17,495-13,734 \cdot \mathrm{e}^{(-\mathrm{s} / 0,033)}$ \\
V-CC-C60-B10 & $\tau(\mathrm{s})=17,192-14,572 \cdot \mathrm{e}^{(-\mathrm{s} / 0,0086)}$ \\
V-CC-C60-B16 & $\tau(\mathrm{s})=16,923-13,062 \cdot \mathrm{e}^{(-\mathrm{s} / 0,0205)}$ \\
\hline
\end{tabular}

A Figura 8.27 mostra a regressão exponencial para os modelos de viga da série 2. Vale salientar que o deslizamento mostrado corresponde à média dos transdutores de cada ensaio de viga.
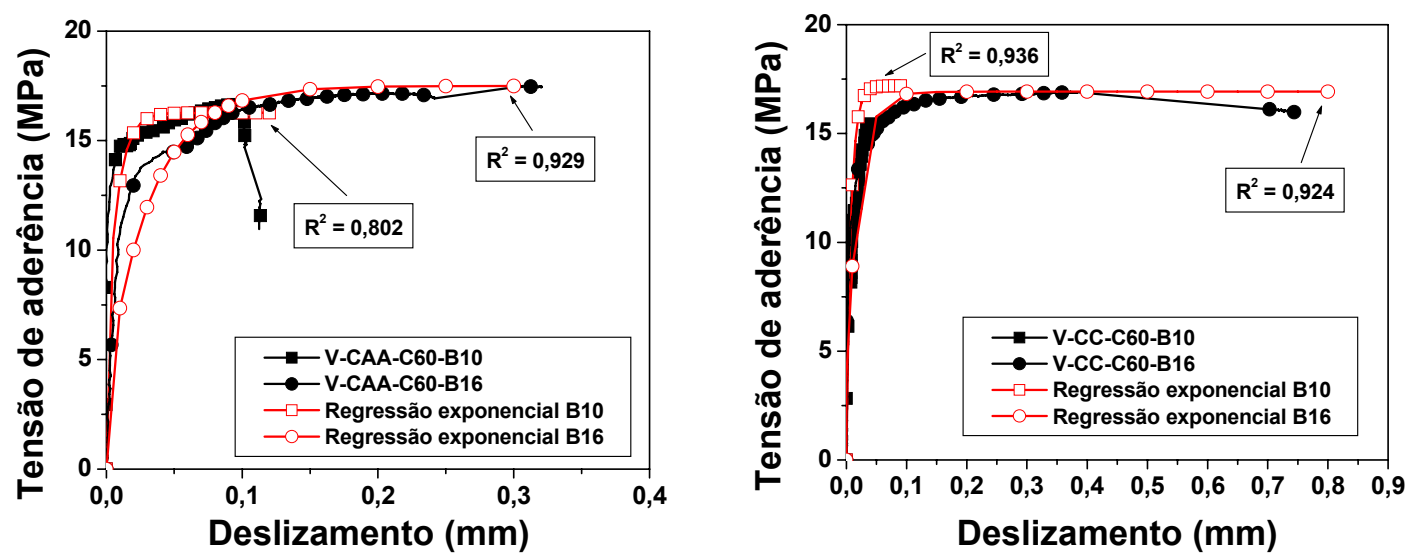

Figura 8.27 Regressão exponencial para representar a tensão de aderência dos modelos de viga da série 2

A Tabela 8.26 mostra a variação da resistência de aderência, calculada de acordo com a Eq. 8.2. 
Tabela 8.26 Resultados obtidos nos ensaios de viga da série 2

\begin{tabular}{rccccc}
\hline \multicolumn{1}{c}{ Amostra } & $\tau_{0,01}$ (MPa) & $\tau_{0,1}$ (MPa) & $\tau_{1,0}(\mathbf{M P a})$ & $\tau_{\mathrm{u}}(\mathrm{MPa})$ & $\tau_{\mathrm{m}}(\mathrm{MPa})$ \\
\hline V-CAA-C60-B10-1 & 13,37 & 16,83 & 17,07 & 17,07 & 15,75 \\
V-CAA-C60-B10-2 & 13,52 & 16,16 & 16,65 & 16,65 & 15,44 \\
Média (MPa) & 13,44 & 16,49 & 16,86 & 16,86 & 15,60 \\
D.P. (MPa) & 0,107 & 0,473 & 0,301 & 0,301 & 0,222 \\
C.V. (\%) & $0,80 \%$ & $2,87 \%$ & $1,78 \%$ & $1,78 \%$ & $1,42 \%$ \\
\hline V-CAA-C60-B16-1 & 10,61 & 15,94 & 16,91 & 16,91 & 14,49 \\
V-CAA-C60-B16-2 & 10,62 & 16,26 & 17,60 & 17,59 & 14,824 \\
Média (MPa) & 10,61 & 16,10 & 17,25 & 17,25 & 14,66 \\
D.P. (MPa) & 0,010 & 0,221 & 0,483 & 0,483 & 0,238 \\
C.V. (\%) & $0,10 \%$ & $1,38 \%$ & $2,80 \%$ & $2,80 \%$ & $1,63 \%$ \\
\hline V-CC-C60-B10-1 & 13,67 & 16,98 & 17,19 & 17,19 & 15,95 \\
V-CC-C60-B10-2 & 12,91 & 15,61 & 15,92 & 15,92 & 14,81 \\
Média (MPa) & 13,29 & 16,30 & 16,55 & 16,55 & 15,38 \\
D.P. (MPa) & 0,537 & 0,967 & 0,902 & 0,902 & 0,802 \\
C.V. (\%) & $4,04 \%$ & $5,93 \%$ & $5,45 \%$ & $5,45 \%$ & $5,21 \%$ \\
\hline V-CC-C60-B16-1 & 10,78 & 17,11 & 17,69 & 17,69 & 15,73 \\
V-CC-C60-B16-2 & 10,25 & 14,58 & 16,17 & 16,20 & 13,67 \\
Média (MPa) & 10,51 & 15,84 & 16,93 & 16,95 & 14,70 \\
D.P. (MPa) & 0,372 & 1,792 & 1,077 & 1,057 & 1,460 \\
C.V. (\%) & $3,54 \%$ & $11,31 \%$ & $6,36 \%$ & $6,24 \%$ & $9,93 \%$ \\
\hline
\end{tabular}

De acordo com as análises dos resultados dos modelos de viga da série 2, podese concluir que:

- Os modelos de viga apresentaram uma boa correlação em seus resultados, mostrando que ambos os diâmetros de barra apresentaram comportamento semelhante com força de ruptura equivalente;

- $\quad$ O comportamento da resistência de aderência para os quatro casos de viga foi similar, sendo representados por um comportamento quase linear até a ruptura por deformação excessiva da barra de aço acompanhada de grande deslocamento vertical da viga;

- Com relação às deformações obtidas nas barras de aço, houve uma boa correspondência entre o resultado das deformações na barra de aço para ambos os diâmetros de barra, conforme a Figura 8.24 e Figura 8.25. Isso mostra que o comportamento da resistência de aderência é similar tanto para o CAA quanto para o CC;

- $\quad$ Com relação à regressão exponencial desenvolvida, houve boa correspondência com o comportamento da resistência de aderência. A Tabela 8.27 mostra a diferença entre as resistências máximas de aderência, para o mesmo valor de deslizamento, para os modelos experimentais e as formulações desenvolvidas; 
Tabela 8.27 Comparação entre os resultados experimentais e as regressões exponenciais dos modelos de viga da série 2

\begin{tabular}{lccc}
\hline Modelo & $\begin{array}{c}\text { Experimental } \\
\tau_{\mathrm{u}}(\mathrm{MPa})\end{array}$ & $\begin{array}{c}\text { Regressão } \\
\tau_{\mathrm{u}}(\mathrm{MPa})\end{array}$ & $\boldsymbol{\lambda}$ \\
\hline V-CAA-C60-B10 & 16,86 & 16,27 & 1,036 \\
V-CAA-C60-B16 & 17,25 & 17,47 & 0,987 \\
V-CC-C60-B10 & 16,55 & 17,04 & 0,971 \\
V-CC-C60-B16 & 16,95 & 16,92 & 1,001 \\
\hline
\end{tabular}

- De acordo com a Tabela 8.27, a aproximação fornecida pela regressão exponencial conduz a um erro de aproximação até de 3\%, contra a segurança;

- Com relação à variabilidade dos resultados, houve pequena variação no comportamento dos modelos, porém é necessária a elaboração de mais séries de vigas com mais réplicas para se ter uma melhor representatividade desta pequena variação;

- $\quad$ O valor da resistência de aderência dos modelos de arrancamento com barra de $10 \mathrm{~mm}$ foi inferior aos modelos com barra de $16 \mathrm{~mm}$ (do mesmo modo que os modelos da série 2 de arrancamento), o que mostra que a contribuição da resistência à compressão do concreto é significativa e, além disso, há a contribuição da rigidez da barra em conjunto com suas nervuras que promovem o aumento da resistência de aderência;

- $\quad$ O valor da resistência de aderência média apresentou pequena variação com exceção dos modelos com barra de $16 \mathrm{~mm}$, o que pode levar a uma conclusão inicial que o concreto de alta resistência trabalhando em conjunto com barra de diâmetro acima de $10 \mathrm{~mm}$, apresenta alta variabilidade em função da alta resistência de aderência existente entre as nervuras, o que pode contribuir para uma maior variação do resultado.

\subsection{Comparação entre os modelos de viga e de arrancamento e as formulações para previsão da resistência de aderência}

Neste segmento se apresenta a comparação entre os resultados experimentais para os modelos de arrancamento e de viga e sua correspondente comparação com os modelos de previsão da resistência de aderência pelas formulações da Tabela 8.1.

Inicialmente foi realizada uma comparação entre os modelos de arrancamento e de viga e em seguida, uma comparação de todos os modelos em relação às formulações empregadas. 


\subsubsection{Modelos de arrancamento}

A Tabela 8.28 mostra a variação da resistência de aderência, calculada de acordo com a Eq. 8.2 para os modelos de arrancamento das séries 1 e 2 .

Tabela 8.28 Resultados obtidos nos ensaios de arrancamento das séries 1 e 2

\begin{tabular}{cccccc}
\hline Amostra & $\tau_{0,01}(\mathbf{M P a})$ & $\tau_{0,1}(\mathbf{M P a})$ & $\tau_{1,0}(\mathbf{M P a})$ & $\tau_{\mathrm{u}}(\mathbf{M P a})$ & $\tau_{\mathrm{m}}(\mathbf{M P a})$ \\
\hline A-CAA-C30-B10 & 3,59 & 6,33 & 14,21 & 14,34 & 8,05 \\
A-CAA-C30-B16 & 2,05 & 3,37 & 12,85 & 12,93 & 6,09 \\
A-CAA-C60-B10 & 0,12 & 1,63 & 14,00 & 18,11 & 5,25 \\
A-CAA-C60-B16 & 0,59 & 1,38 & 12,85 & 19,23 & 4,94 \\
A-CC-C30-B10 & 3,39 & 4,93 & 11,20 & 11,56 & 6,48 \\
A-CC-C30-B16 & 2,80 & 3,82 & 10,11 & 10,75 & 5,48 \\
A-CC-C60-B10 & 1,70 & 3,60 & 13,11 & 17,05 & 6,14 \\
A-CC-C60-B16 & 0,50 & 1,37 & 11,9 & 21,94 & 4,59 \\
A10 & 8,90 & 18,93 & 23,08 & 23,08 & 16,97 \\
A12,5 & 6,27 & 16,55 & 26,46 & 26,46 & 16,43 \\
A16 & 5,89 & 15,08 & 22,99 & 22,99 & 14,65 \\
\hline
\end{tabular}

A Figura 8.28 ilustra a variação do resultado da resistência média de aderência dos ensaios de arrancamento e sua correspondente resistência à compressão.
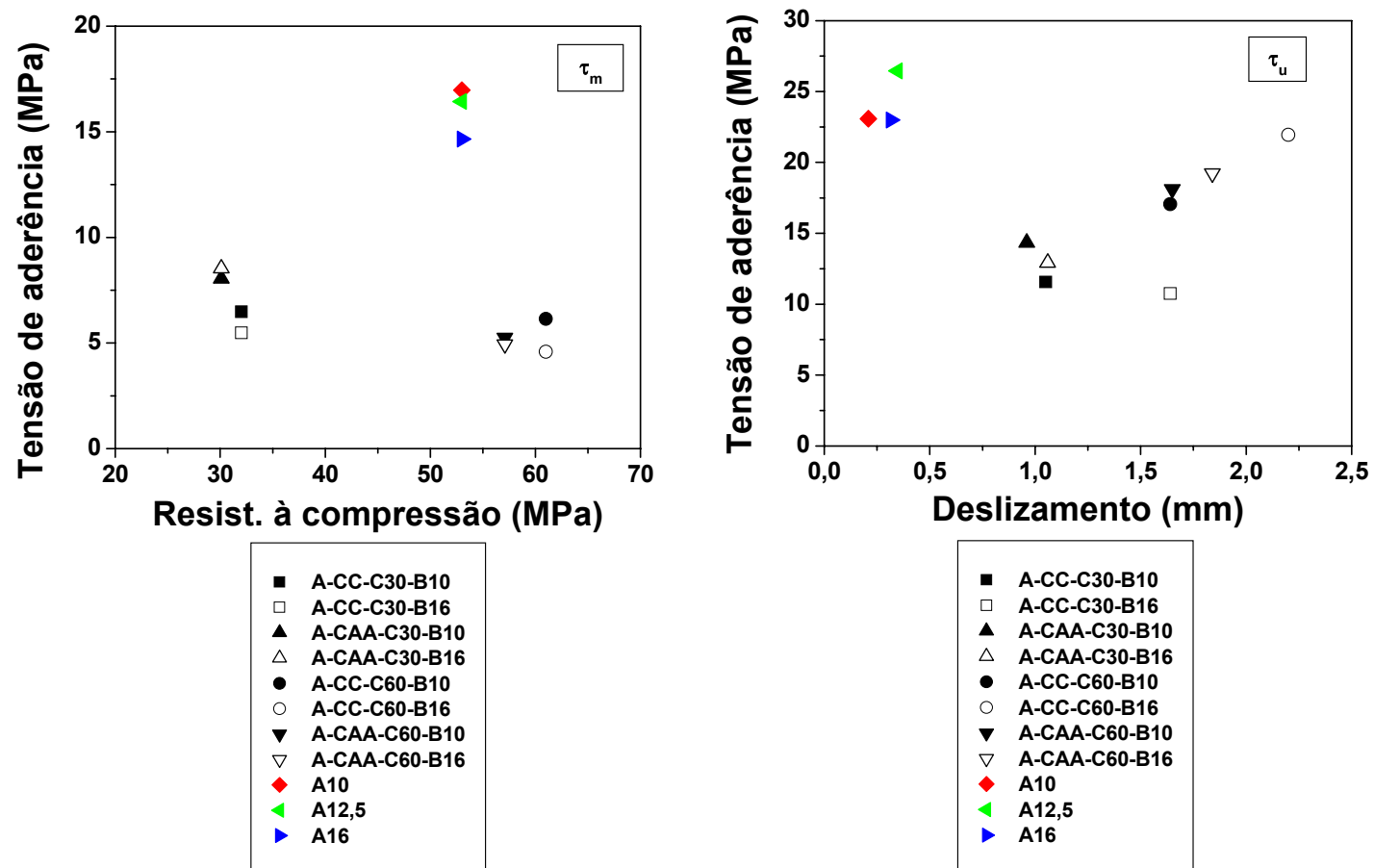

- A-CC-C30-B10

A-CC-C30-B16

$\triangle$ A-CAA-C30-B10

$\triangle$ A-CAA-C30-B16

- A-CC-C60-B10

A-CC-C60-B16

$\checkmark$ A-CAA-C60-B10

$\nabla$ A-CAA-C60-B16

- A10

A12,5

A16

Figura 8.28 Variação do comportamento da tensão média e última de aderência para os ensaios de arrancamento das séries 1, 2 e complementar

De acordo com a Figura 8.28, pode-se ver uma boa aproximação entre os resultados referentes aos modelos em CAA e em CC. Ainda, com exceção dos 
modelos da série complementar, os modelos de arrancamento para a resistência à compressão do concreto de 30 e de $60 \mathrm{MPa}$, apresentaram resultados aproximados para a resistência de aderência, com valores superiores para o concreto de classe C30. Ainda, os modelos com resistência à compressão os modelos com barra de 10 $\mathrm{mm}$ apresentaram maior resistência de aderência em relação aos modelos com barra de $16 \mathrm{~mm}$. A série complementar apresentou as maiores resistências médias de aderência registradas, por causa da alta adesão existente entre o concreto e a superfície da barra de aço.

Ainda de acordo com a Figura 8.28, pode-se ver que os modelos das séries $1 \mathrm{e}$ 2 apresentam uma significativa dispersão, variando de 10,75 a 21,94 MPa. Já os modelos da série complementar apresentaram uma dispersão menor, variando de 22,99 a 26,46 MPa.

\subsubsection{Modelos de viga}

A Tabela 8.29 mostra a variação da resistência de aderência, calculada de acordo com a Eq. 8.3 para os modelos de viga das séries 1 e 2 .

Tabela 8.29 Resultados obtidos nos ensaios de viga das séries 1 e 2

\begin{tabular}{cccccc}
\hline Amostra & $\tau_{0,01}(\mathbf{M P a})$ & $\tau_{0,1}(\mathrm{MPa})$ & $\tau_{1,0}(\mathrm{MPa})$ & $\tau_{\mathrm{u}}(\mathrm{MPa})$ & $\tau_{\mathrm{m}}(\mathrm{MPa})$ \\
\hline V-CAA-C30-B10 & 4,86 & 7,47 & 11,15 & 11,45 & 7,83 \\
V-CAA-C30-B16 & 5,17 & 8,90 & 11,50 & 11,58 & 8,53 \\
V-CAA-C60-B10 & 13,44 & 16,49 & 16,86 & 16,86 & 15,60 \\
V-CAA-C60-B16 & 10,61 & 16,10 & 17,25 & 17,25 & 14,66 \\
V-CC-C30-B10 & 5,59 & 7,76 & 7,43 & 13,44 & 6,93 \\
V-CC-C30-B16 & 5,75 & 10,35 & 13,14 & 13,20 & 9,75 \\
V-CC-C60-B10 & 13,29 & 16,30 & 16,55 & 16,55 & 15,38 \\
V-CC-C60-B16 & 10,51 & 15,84 & 16,93 & 16,95 & 14,70 \\
\hline
\end{tabular}

A Figura 8.29 ilustra a variação do resultado da resistência média de aderência dos ensaios de viga e sua correspondente resistência à compressão. 

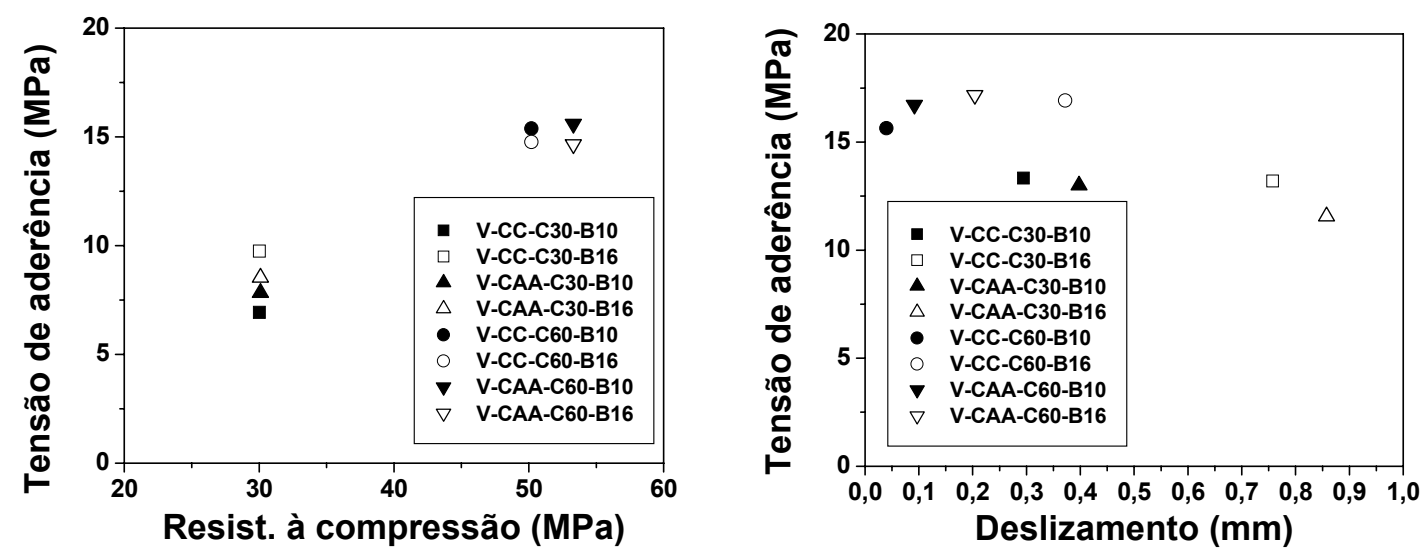

Figura 8.29 Variação do comportamento da resistência média e última de aderência para os ensaios de viga das séries 1 e 2

De acordo com a Figura 8.29, pode-se ver uma boa aproximação entre os resultados referentes aos modelos em CAA e em CC. Ainda, com exceção dos modelos com resistência à compressão do concreto de $30 \mathrm{MPa}$, os modelos com barra de $10 \mathrm{~mm}$ apresentaram maior resistência de aderência. $\mathrm{O}$ fato dos modelos em CC e em CAA com resistência à compressão do concreto de $30 \mathrm{MPa}$ ter apresentado resistência média de aderência maior para barras de $16 \mathrm{~mm}$ pode ser explicado pela variação dos deslizamentos que provocam oscilações no resultado final.

Com relação ao deslizamento na Figura 8.29, pode-se ver que os modelos com barra de $16 \mathrm{~mm}$ apresentaram deslizamentos superiores com relação aos modelos com barra de $10 \mathrm{~mm}$. A proximidade entre os resultados para os modelos da série 2 mostra que há pequena variação no resultado da resistência última de aderência (16,55 a 17,25 MPa). O mesmo ocorrendo com os modelos da série 1 (11,45 a 13,44 $\mathrm{MPa}$ ), porém a dispersão entre os modelos com barra de 10 e $16 \mathrm{~mm}$ tornou-se mais evidente por causa do deslizamento existente.

\subsubsection{Comparação dos resultados da resistência de aderência entre os modelos de arrancamento e de viga}

De acordo com as comparações realizadas nos itens anteriores, resta fazer a comparação do comportamento da resistência de aderência entre os ensaios de viga e de arrancamento.

A Figura 8.30 ilustra a comparação entre os modelos de viga e de arrancamento da série 1. 

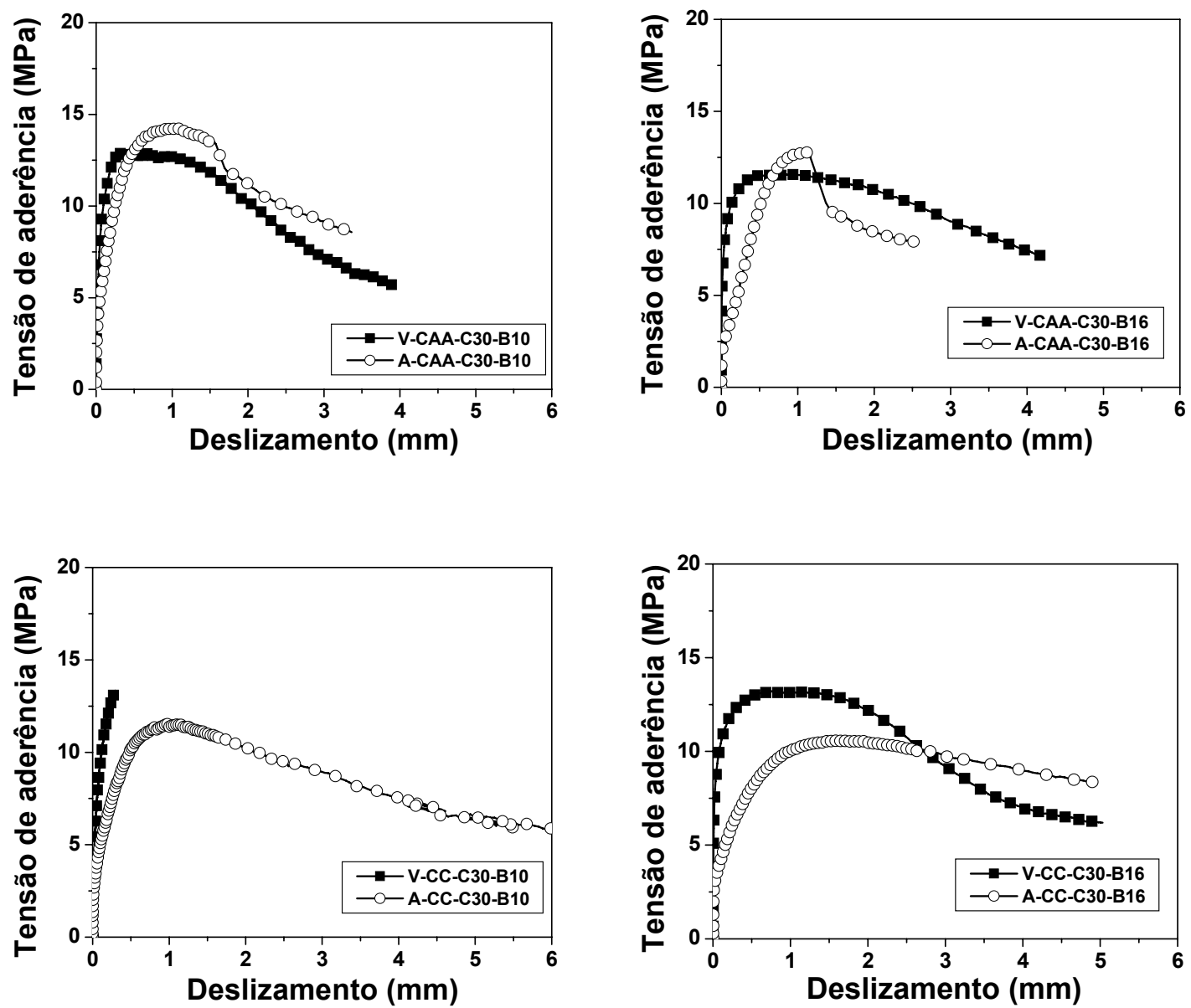

Figura 8.30 Comparação da tensão de aderência dos modelos de viga e de arrancamento da série 1

De acordo com a Figura 8.30, pode-se ver que a resposta da resistência de aderência para os modelos de arrancamento e de viga é semelhante no caso de se utilizar o CAA e, que inclusive apresenta resultados superiores quando da utilização dos modelos de arrancamento. Já os modelos em CC apresentaram uma maior variação mostrando que os modelos de viga apresentam maior resistência de aderência, mesmo no caso V-CC-C30-B10, onde houve perda de dados, o valor da resistência de aderência foi superior ao modelo de arrancamento.

A Figura 8.31 ilustra a comparação entre os modelos de viga e de arrancamento da série 2. 

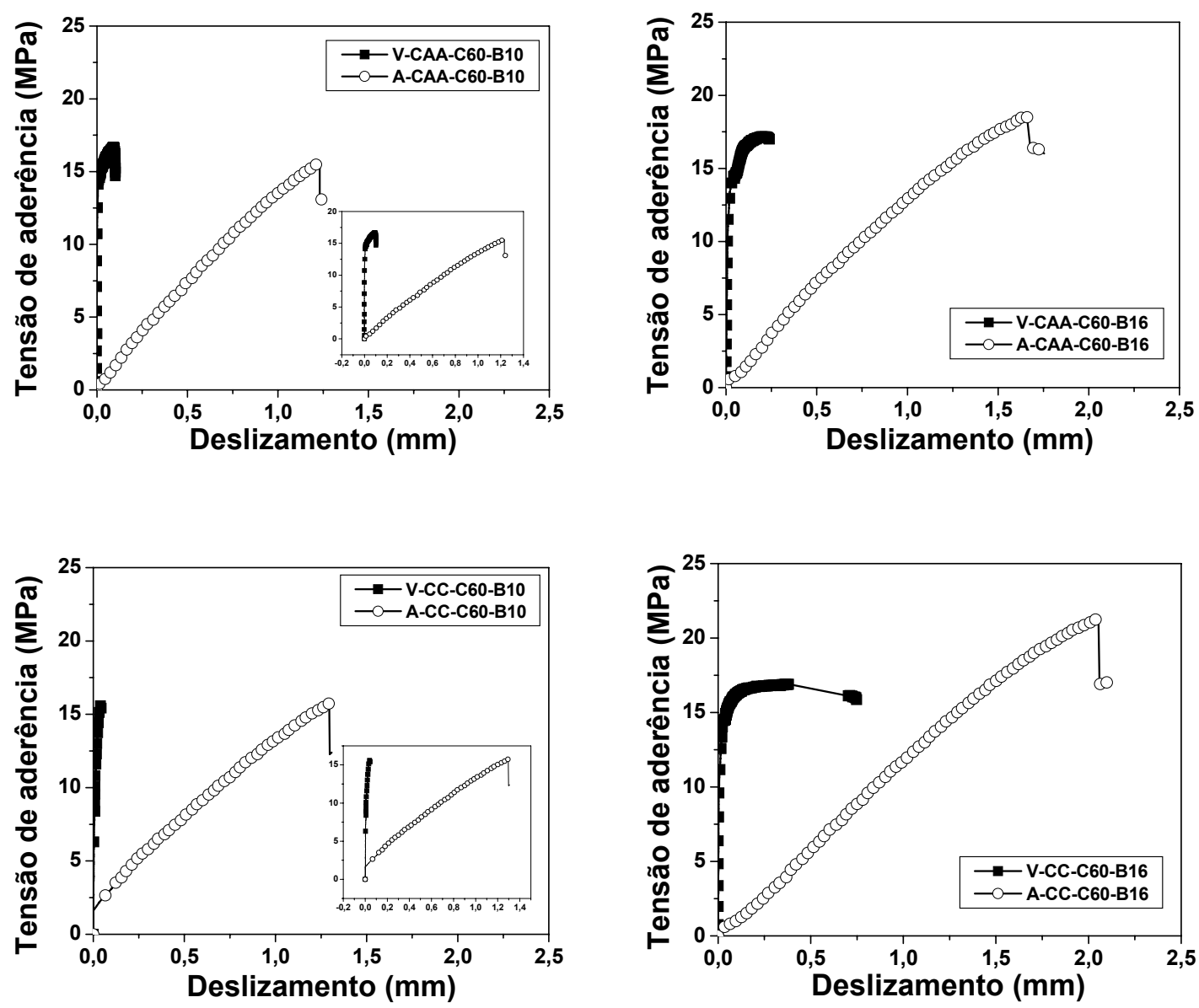

Figura 8.31 Comparação da tensão de aderência dos modelos de viga e de arrancamento da série 2

De acordo com a Figura 8.31, pode-se ver que a resposta da resistência de aderência dos modelos de arrancamento foi superior à resposta dos modelos de viga. Além disso, os modelos de arrancamento apresentaram maior deslizamento, enquanto os modelos de viga apresentaram deslizamentos muito pequenos, onde o ensaio se caracterizou por deformação excessiva das barras de aço.

Assim, constatou-se que os modelos da série 1 apresentaram um comportamento similar, enquanto que os modelos da série 2 apresentaram um comportamento distinto, onde os modelos de viga apresentaram pequenos deslizamentos com grandes deformações enquanto o modelo de arrancamento, embora não tenha sido realizado uma instrumentação com a finalidade de se verificar as deformações na barra de aço, os modelos de arrancamento dessa série apresentaram ruptura por fendilhamento do prisma de concreto.

Portanto, os modelos de arrancamento forneceram resultados semelhantes aos resultados dos ensaios de viga para a série 1 , comprovando que a utilização de modelos de arrancamento apresenta resultados satisfatórios para a estimativa da 
resistência de aderência em elementos de concreto armado. Já para a série 2, constatou-se que o modelo possui valores semelhantes para a resistência de aderência, mas apresenta maior deslizamento. Isso ocorre pelo fato da deformação existente na barra está sujeita à tração pura enquanto a deformação e o deslizamento da barra no modelo de viga estão sujeitos à flexão e, portanto, apresenta menores deslizamentos, e, além desses fatores, a região aderente se encontra confinada.

\subsubsection{Comparação com a previsão da resistência de aderência}

De acordo com as formulações utilizadas para se prever o valor da resistência de aderência, estas se concentraram em prever o valor da resistência última de aderência $\left(\tau_{u}\right)$ se valendo regressões não-lineares a fim de obter um comportamento da resistência de aderência até a sua ruptura.

Durante a revisão da literatura técnica e a realização dos ensaios de viga e de arrancamento, percebeu-se que o valor encontrado nos ensaios não faz alusão ao valor de projeto (no caso de se ter ensaios de verificação da resistência de aderência), pois surgiu uma dúvida se este se refere ao valor médio $\left(\tau_{m}\right)$, último de aderência $\left(\tau_{u}\right)$ ou se este equivale ao valor da resistência de aderência para qual ocorre um deslizamento da barra de aço em relação ao concreto igual a 0,1 $\mathrm{mm}\left(\tau_{0,1}\right)$ (Leonhardt \& Mönnig, 1977). Desse modo, foram elaboradas comparações entre os valores de previsão das formulações e os valores da resistência de aderência referente à $\tau_{m}, \tau_{u} \mathrm{e}$ $\tau_{0,1}$

De acordo com a Figura 8.32, Figura 8.33 e Figura 8.34, foi possível verificar que algumas formulações superestimam a resistência de aderência, permanecendo contra a segurança. Entretanto, sabe-se que as formulações propostas na Tabela 8.1, com exceção das equações fornecidas por normativas, fornecem uma previsão da resistência última de aderência, mas realizou-se a comparação dessas formulações com relação à $\tau_{m}$ e $\tau_{0,1}$, a fim de obter uma comparação do comportamento de sua resistência de aderência.

A Figura 8.32 mostra a variação da resistência média de aderência dos resultados em relação à previsão das formulações da Tabela 8.1 . 

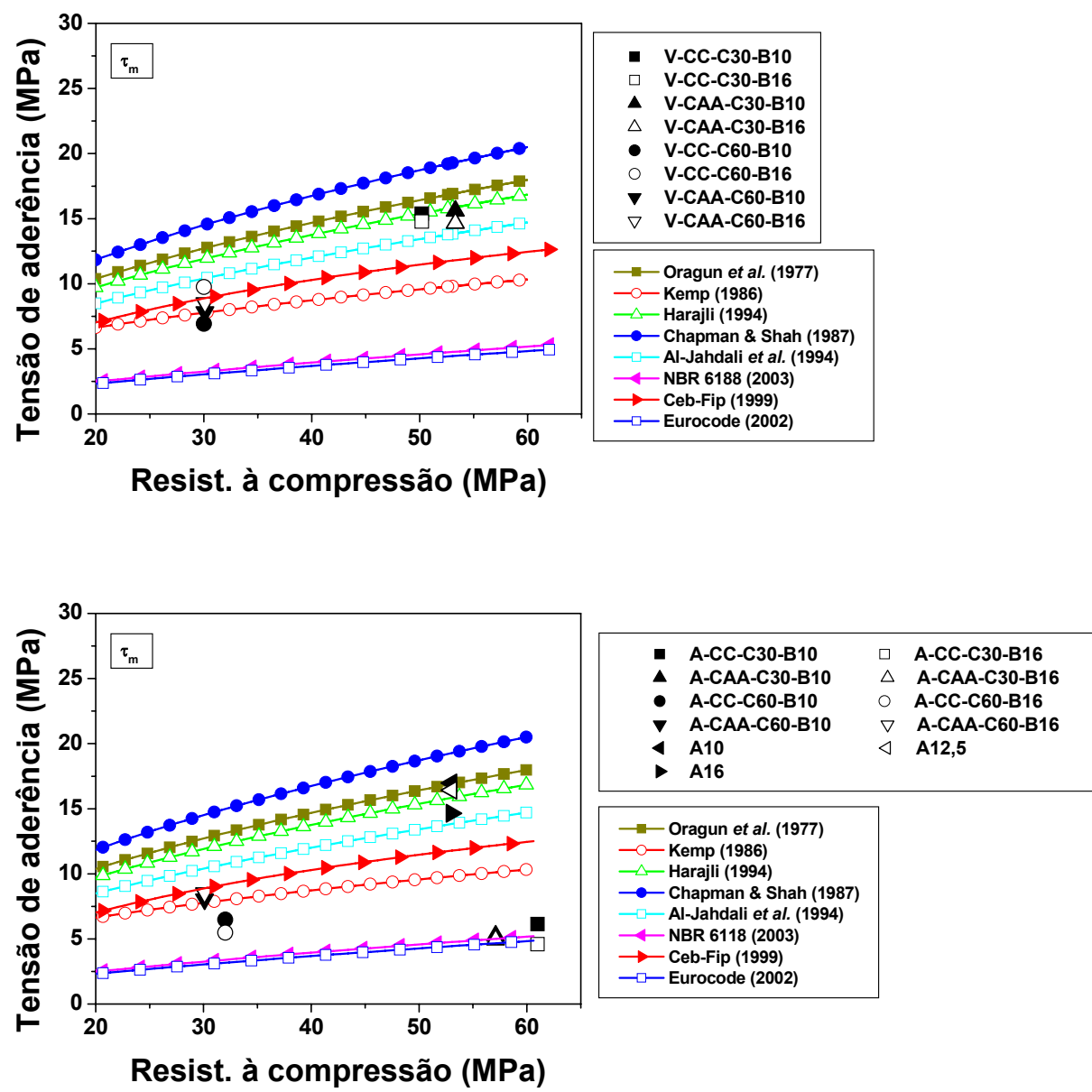

- - Oragun et al. (1977)

$\longrightarrow-$ Kemp (1986)

$\rightarrow-$ Chapman \& Shah (1987)

Al-Jahdali et al. (1994)

-NBR 6118 (2003)

$\rightarrow-$ Ceb-Fip (1999)

$\longrightarrow$ - Eurocode (2002)

Figura 8.32 Variação do comportamento da resistência média de aderência com relação à resistência à compressão do concreto para os ensaios de viga e de arrancamento das séries estudadas e as formulações de previsão da resistência de aderência

Nas análises de $\tau_{\mathrm{m}}$, foi visto que na série 1 todas as formulações à exceção da equação de Kemp (1986) foram contra a segurança. Para a série 2, a formulação de Kemp (1986) subestima claramente a resistência de aderência e a equação de Chapman \& Shah (1987) foi contra a segurança. Já a formulação de Harajli (1994) e a de Oragun et al. (1994) apresentam uma boa aproximação.

A Figura 8.33 mostra a variação da resistência última de aderência dos resultados em relação à previsão das formulações da Tabela 8.1. 

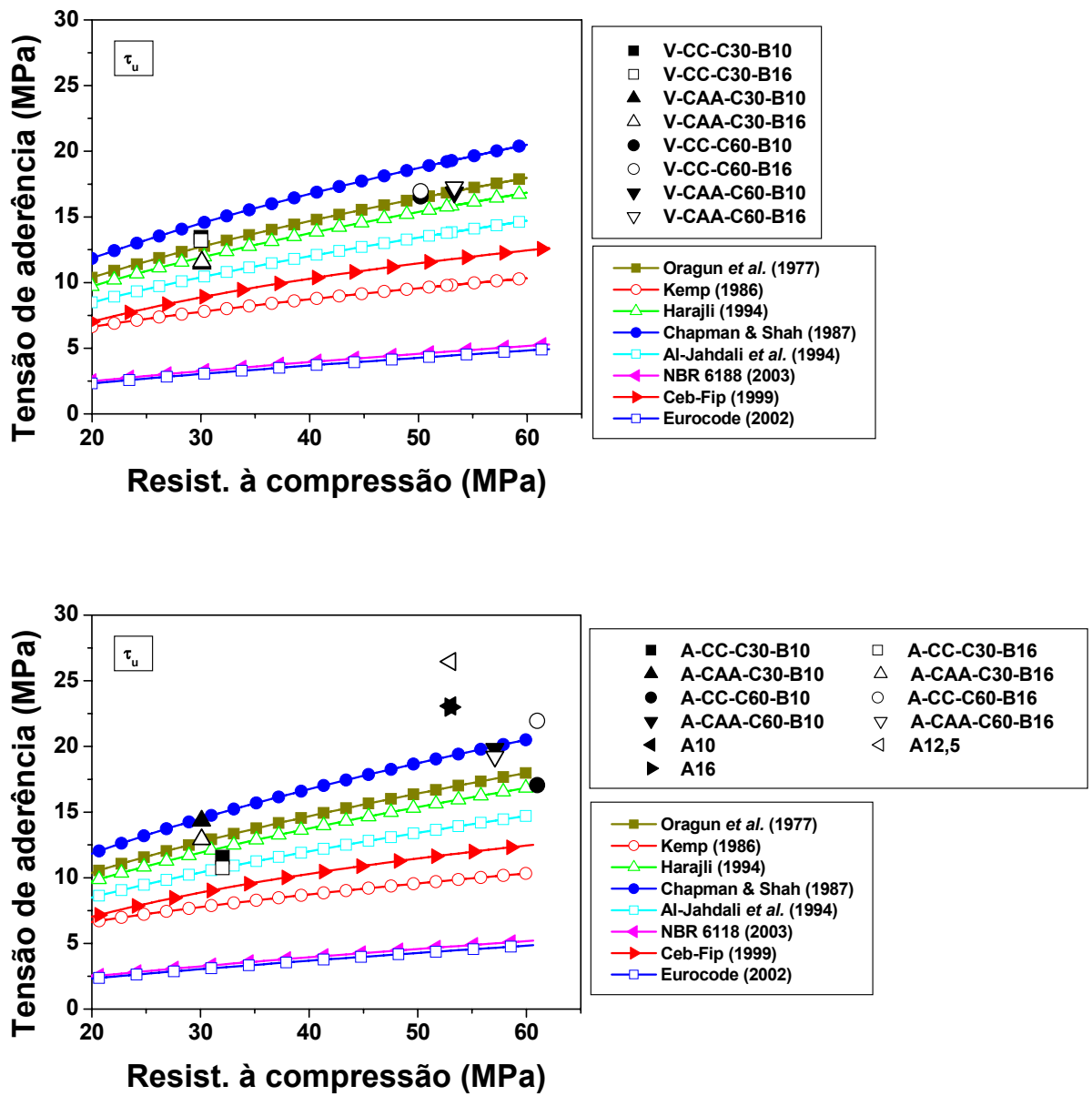

Figura 8.33 Variação do comportamento da resistência última de aderência com relação à resistência à compressão do concreto para os ensaios de viga e de arrancamento das séries estudadas e as formulações de previsão da resistência de aderência

Nas análises de $\tau_{u}$, houve uma melhor aproximação dos resultados por parte das formulações, com exceção de Chapman \& Shah (1987). De acordo com os resultados foi visto que independentemente da resistência à compressão do concreto, todas as formulações à exceção da equação de Chapman \& Shah (1987) foram a favor da segurança. Nesta análise, a formulação de Kemp (1986) foi claramente conservadora e as formulações de Oragun et al. (1994) e Harajli (1994) apresentaram uma boa aproximação da resposta experimental. O modelo de Chapman \& Shah (1987) apresentou uma aproximação satisfatória no caso dos modelos de arrancamento das séries 1 e 2, e foi, assim como todas as outras formulações, a favor da segurança quando se analisou a série complementar.

A Figura 8.34 mostra a variação da resistência de aderência $\left(\tau_{0,1}\right)$ dos resultados em relação à previsão das formulações da Tabela 8.1 . 

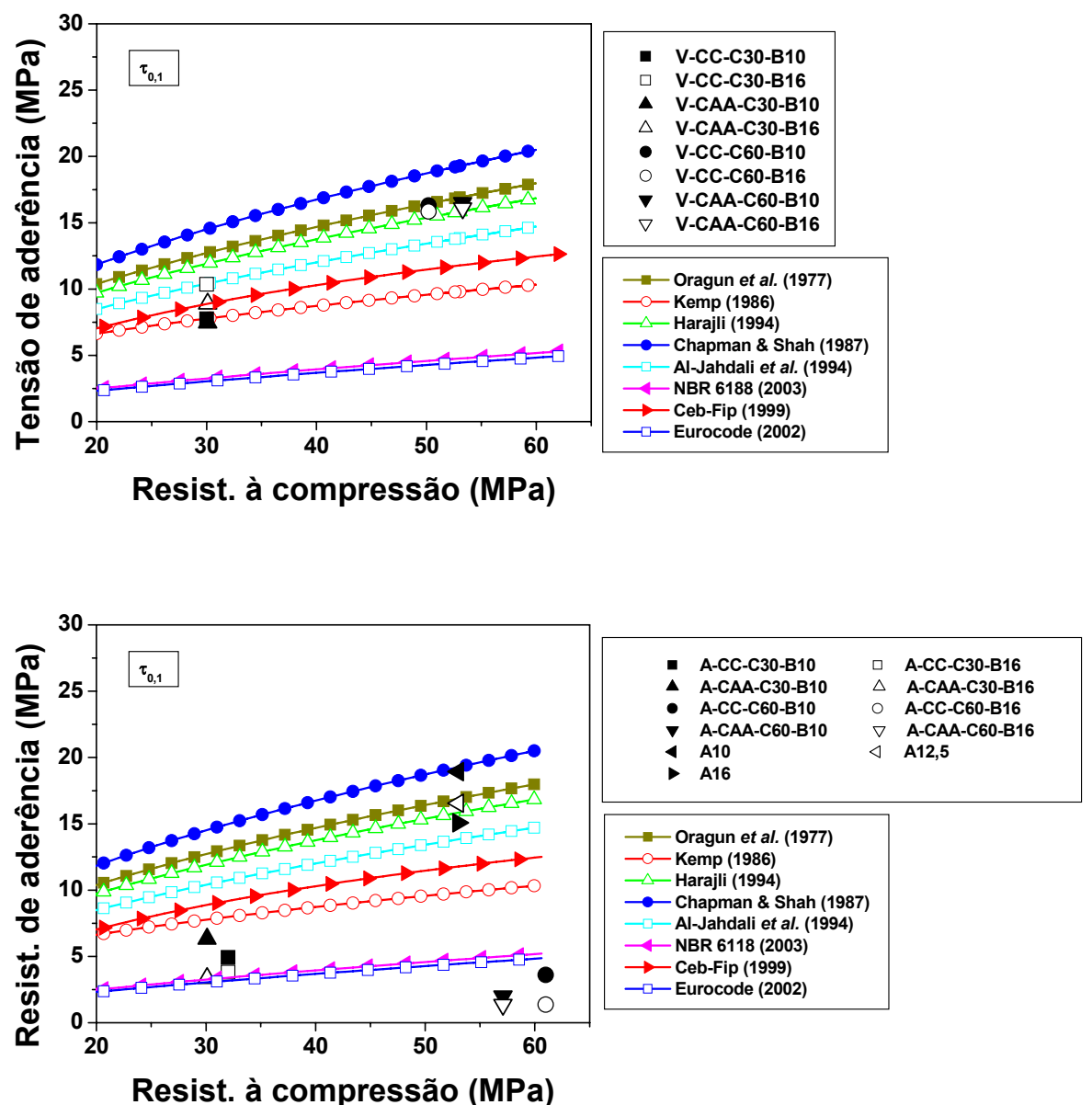

Figura 8.34 Variação do comportamento da resistência de aderência $\left(\tau_{0,1}\right)$ com relação à resistência à compressão do concreto para os ensaios de viga e de arrancamento das séries estudadas e as formulações de previsão da resistência de aderência

Nas análises de $\tau_{0,1}$, houve um comportamento misto com relação ao $\tau_{\mathrm{m}} \mathrm{e} \tau_{\mathrm{u}}$, e novamente ficou evidenciado que a formulação de Chapman \& Shah (1987) ficou contra a segurança, e que para a série 1, à exceção da equação de Kemp (1986), as demais formulações foram contra a segurança. Já para a série 2 , todas as formulações, inclusive as normativas, permaneceram contra a segurança. Para a série complementar, as formulações de Oragun et al. (1994) e Harajli (1994) apresentaram uma boa aproximação da resposta experimental e a formulação de Kemp (1986) foi claramente conservadora.

A Tabela 8.30 ilustra a variação do resultado em relação aos limites estabelecidos pela formulação do Rilem-Ceb-Fip (1983). 
Tabela 8.30 Limites dos valores estabelecidos pelo Rilem-Ceb-Fip (1983) e o resultado experimental

\begin{tabular}{ccccccc}
\hline Amostra & $\begin{array}{c}\tau_{\mathbf{m}} \text { (MPa) } \\
\text { Exp. }\end{array}$ & $\begin{array}{c}\tau_{\mathbf{m}} \text { (MPa) } \\
\text { Rilem-Ceb-Fip } \\
(\mathbf{1 9 8 3 )}\end{array}$ & $\boldsymbol{\lambda}$ & $\begin{array}{c}\tau_{\mathbf{u}} \text { (MPa) } \\
\text { Exp. }\end{array}$ & $\begin{array}{c}\tau_{\mathbf{u}} \text { (MPa) } \\
\text { Rilem-Ceb-Fip } \\
(\mathbf{1 9 8 3 )}\end{array}$ & $\lambda$ \\
\hline V-CAA-C30-B10 & 7,83 & 6,8 & 1,151 & 11,45 & 11,1 & 1,032 \\
V-CAA-C30-B16 & 8,53 & 6,08 & 1,403 & 11,58 & 9,96 & 1,163 \\
V-CAA-C60-B10 & 15,60 & 6,8 & 2,294 & 16,86 & 11,1 & 1,519 \\
V-CAA-C60-B16 & 14,66 & 6,08 & 2,411 & 17,25 & 9,96 & 1,732 \\
V-CC-C30-B10 & 6,93 & 6,8 & 1,019 & 13,44 & 11,1 & 1,211 \\
V-CC-C30-B16 & 9,75 & 6,08 & 1,604 & 13,20 & 9,96 & 1,325 \\
V-CC-C60-B10 & 15,38 & 6,8 & 2,262 & 16,55 & 11,1 & 1,491 \\
V-CC-C60-B16 & 14,70 & 6,08 & 2,418 & 16,95 & 9,96 & 1,702 \\
A-CAA-C30-B10 & 8,05 & 6,8 & 1,184 & 14,34 & 11,1 & 1,292 \\
A-CAA-C30-B16 & 6,09 & 6,08 & 1,002 & 12,93 & 9,96 & 1,298 \\
A-CAA-C60-B10 & 5,25 & 6,8 & 0,772 & 18,11 & 11,1 & 1,632 \\
A-CAA-C60-B16 & 4,94 & 6,08 & 0,813 & 19,23 & 9,96 & 1,931 \\
A-CC-C30-B10 & 6,48 & 6,8 & 0,953 & 11,56 & 11,1 & 1,041 \\
A-CC-C30-B16 & 5,48 & 6,08 & 0,901 & 10,75 & 9,96 & 1,079 \\
A-CC-C60-B10 & 6,14 & 6,8 & 0,903 & 17,05 & 11,1 & 1,536 \\
A-CC-C60-B16 & 4,59 & 6,08 & 0,755 & 21,94 & 9,96 & 2,203 \\
A10 & 16,97 & 6,8 & 2,496 & 23,08 & 11,1 & 2,079 \\
A12,5 & 16,43 & 6,5 & 2,528 & 26,46 & 10,625 & 2,490 \\
A16 & 14,65 & 6,08 & 2,410 & 22,99 & 9,96 & 2,308 \\
\hline
\end{tabular}

A Tabela 8.31, Tabela 8.32 e Tabela 8.33, mostram as diferenças dos resultados experimentais e os calculados (bias factor), levando em consideração a resistência à compressão de cada série.

Tabela 8.31 Diferenças na previsão (bias factor) da resistência última de aderência experimental com relação às formulações de Oragun et al. (1977), Kemp (1986) e Chapman \& Shah (1987)

\begin{tabular}{ccccc}
\hline Série & $\begin{array}{c}\text { Ensaio } \\
\tau_{\mathbf{u}} \mathbf{( M P a )}\end{array}$ & $\begin{array}{c}\lambda \\
\text { Oragun et al. (1977) }\end{array}$ & $\begin{array}{c}\lambda \\
\text { Kemp (1986) }\end{array}$ & $\begin{array}{c}\lambda \\
\text { Chapman \& Shah (1987) }\end{array}$ \\
\hline V-CAA-C30-B10 & 7,83 & 0,613 & 1,003 & 0,537 \\
V-CAA-C30-B16 & 8,53 & 0,667 & 1,093 & 0,585 \\
V-CAA-C60-B10 & 15,60 & 0,863 & 1,503 & 0,757 \\
V-CAA-C60-B16 & 14,66 & 0,811 & 1,413 & 0,711 \\
V-CC-C30-B10 & 6,93 & 0,542 & 0,888 & 0,475 \\
V-CC-C30-B16 & 9,75 & 0,763 & 1,249 & 0,669 \\
V-CC-C60-B10 & 15,38 & 0,851 & 1,482 & 0,746 \\
V-CC-C60-B16 & 14,70 & 0,813 & 1,417 & 0,713 \\
A-CAA-C30-B10 & 14,34 & 1,128 & 1,845 & 0,989 \\
A-CAA-C30-B16 & 12,93 & 1,017 & 1,663 & 0,892 \\
A-CAA-C60-B10 & 18,11 & 1,007 & 1,753 & 0,883 \\
A-CAA-C60-B16 & 19,23 & 1,069 & 1,861 & 0,938 \\
A-CC-C30-B10 & 11,56 & 0,909 & 1,487 & 0,797 \\
A-CC-C30-B16 & 10,75 & 0,845 & 1,383 & 0,741 \\
A-CC-C60-B10 & 17,05 & 0,948 & 1,650 & 0,831 \\
A-CC-C60-B16 & 21,94 & 1,220 & 2,124 & 1,070 \\
A10 & 23,08 & 1,366 & 2,354 & 1,197 \\
A12,5 & 26,46 & 1,565 & 2,698 & 1,373 \\
A16 & 22,99 & 1,360 & 2,344 & 1,193 \\
\hline
\end{tabular}


Tabela 8.32 Diferenças na previsão (bias factor) da resistência última de aderência experimental com relação às formulações de Harajli (1994) e Al-Jahdali et al. (1994)

\begin{tabular}{cccc}
\hline Série & $\begin{array}{c}\text { Ensaio } \\
\tau_{\mathbf{u}} \text { (MPa) }\end{array}$ & $\begin{array}{c}\lambda \\
\text { Harajli (1994) }\end{array}$ & $\begin{array}{c}\lambda \\
\text { Al-Jahdali et al. (1994) }\end{array}$ \\
\hline V-CAA-C30-B10 & 7,83 & 0,654 & 0,749 \\
V-CAA-C30-B16 & 8,53 & 0,712 & 0,816 \\
V-CAA-C60-B10 & 15,60 & 0,921 & 1,055 \\
V-CAA-C60-B16 & 14,66 & 0,866 & 0,991 \\
V-CC-C30-B10 & 6,93 & 0,579 & 0,663 \\
V-CC-C30-B16 & 9,75 & 0,814 & 0,932 \\
V-CC-C60-B10 & 15,38 & 0,908 & 1,040 \\
V-CC-C60-B16 & 14,70 & 0,868 & 0,994 \\
A-CAA-C30-B10 & 14,34 & 1,204 & 1,379 \\
A-CAA-C30-B16 & 12,93 & 1,085 & 1,243 \\
A-CAA-C60-B10 & 18,11 & 1,075 & 1,231 \\
A-CAA-C60-B16 & 19,23 & 1,142 & 1,307 \\
A-CC-C30-B10 & 11,56 & 0,970 & 1,111 \\
A-CC-C30-B16 & 10,75 & 0,902 & 1,034 \\
A-CC-C60-B10 & 17,05 & 1,012 & 1,159 \\
A-CC-C60-B16 & 21,94 & 1,302 & 1,492 \\
A10 & 23,08 & 1,458 & 1,669 \\
A12,5 & 26,46 & 1,671 & 1,914 \\
A16 & 22,99 & 1,452 & 1,663 \\
\hline
\end{tabular}

Tabela 8.33 Diferenças na previsão (bias factor) da resistência última de aderência experimental com relação às formulações da NBR 6118 (2003), Ceb-Fip (1999) e

Eurocode (2002)

\begin{tabular}{ccccc}
\hline Série & $\begin{array}{c}\text { Ensaio } \\
\tau_{\mathbf{u}} \text { (MPa) }\end{array}$ & $\begin{array}{c}\lambda \\
\text { NBR 6118 (2003) }\end{array}$ & $\begin{array}{c}\lambda \\
\text { Ceb-Fip (1999) }\end{array}$ & $\begin{array}{c}\lambda \\
\text { Eurocode (2002) }\end{array}$ \\
\hline V-CAA-C30-B10 & 7,83 & 2,403 & 0,883 & 2,575 \\
V-CAA-C30-B16 & 8,53 & 2,618 & 0,961 & 2,805 \\
V-CAA-C60-B10 & 15,60 & 3,016 & 1,253 & 3,231 \\
V-CAA-C60-B16 & 14,66 & 3,016 & 1,253 & 3,231 \\
V-CC-C30-B10 & 6,93 & 2,127 & 0,781 & 2,279 \\
V-CC-C30-B16 & 9,75 & 2,992 & 1,099 & 3,206 \\
V-CC-C60-B10 & 15,38 & 2,973 & 1,235 & 3,186 \\
V-CC-C60-B16 & 14,70 & 2,842 & 1,180 & 3,045 \\
A-CAA-C30-B10 & 14,34 & 4,401 & 1,616 & 4,715 \\
A-CAA-C30-B16 & 12,93 & 3,968 & 1,457 & 4,251 \\
A-CAA-C60-B10 & 18,11 & 3,501 & 1,454 & 3,751 \\
A-CAA-C60-B16 & 19,23 & 3,718 & 1,544 & 3,983 \\
A-CC-C30-B10 & 11,56 & 3,548 & 1,303 & 3,801 \\
A-CC-C30-B16 & 10,75 & 3,299 & 1,212 & 3,535 \\
A-CC-C60-B10 & 17,05 & 3,296 & 1,369 & 3,532 \\
A-CC-C60-B16 & 21,94 & 4,242 & 1,762 & 4,545 \\
A10 & 23,08 & 4,847 & 1,959 & 5,193 \\
A12,5 & 26,46 & 5,556 & 2,246 & 5,953 \\
A16 & 22,99 & 4,828 & 1,952 & 5,173 \\
\hline
\end{tabular}

Com relação ao comportamento das normativas adotadas, a formulação tanto da NBR 6118 (2003) quanto do Eurocode (2002) fornecem valores conservadores para a resistência de aderência de cálculo. Já o Ceb-Fip (1999) fornece valores mais 
próximos do comportamento experimental, entretanto se mostraram contra a segurança quando da análise de $\tau_{0,1}$, para os modelos com barra de $10 \mathrm{~mm}$ da série 1 .

De acordo com a Tabela 8.30 , houve uma boa aproximação com a ressalva de uma grande margem de segurança para alguns casos, entretanto, em alguns modelos de arrancamento houve uma superestimativa da resistência de aderência, conduzindo a resultados contra a segurança.

A Figura 8.35 mostra o comportamento da tensão de aderência vs. deslizamento das formulações do Ceb-Fip 195/197 (1990), Huang et al. (1996) e Barbosa (2001), comparado com os resultados experimentais de cada série de viga.
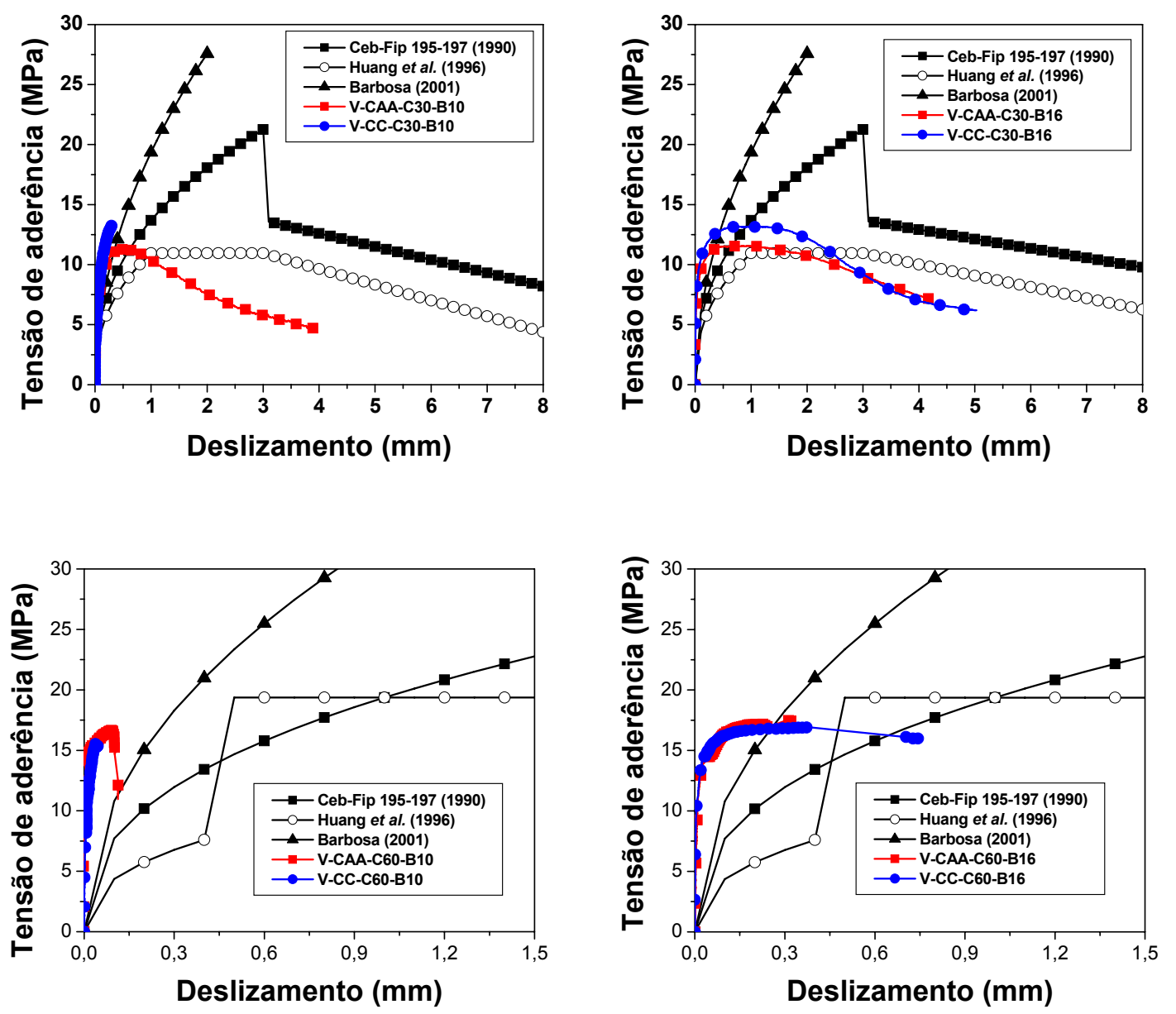

Figura 8.35 Comparação das formulações de Ceb-Fip 195/197 (1990), Huang et al. (1996) e Barbosa (2001) com os resultados dos ensaios de viga

Vale salientar que o modelo de análise do Ceb-Fip 195-197 (1990) foi considerado como concreto confinado com boas condições de aderência.

De acordo com a Figura 8.35, o comportamento dos modelos com resistência à compressão do concreto de $30 \mathrm{MPa}$ é satisfatória de acordo com a formulação do Ceb-Fip 195-197 (1990), permanecendo a favor da segurança. Já os modelos de 
Huang et al. (1996) e Barbosa (2001) superestimaram o valor da resistência de aderência. Com relação aos dos modelos com resistência à compressão do concreto de $30 \mathrm{MPa}$, não houve aproximação satisfatória por parte de nenhum dos modelos utilizados, mostrando que as formulações utilizadas superestimam o comportamento da resistência de aderência. Foi observado que as formulações estimam um valor muito alto para o deslizamento da barra de aço, dificultando a sua aproximação.

Com relação às formulações normativas, pode-se ver que os Códigos da NBR 6118 (2003) e do Eurocode (2002) foram claramente conservativos, pois adotaram como consideração de perda de aderência a ruptura da adesão entre os materiais. Já o modelo proposto pelo Ceb-Fip (1999) apresentou resultados menos conservativos, porém superestimou a resistência de aderência em alguns casos de vigas.

A Figura 8.36 mostra o comportamento da tensão de aderência vs. deslizamento das formulações do Ceb-Fip 195/197 (1990), Huang et al. (1996) e Barbosa (2001), comparado com os resultados experimentais de cada série de arrancamento.
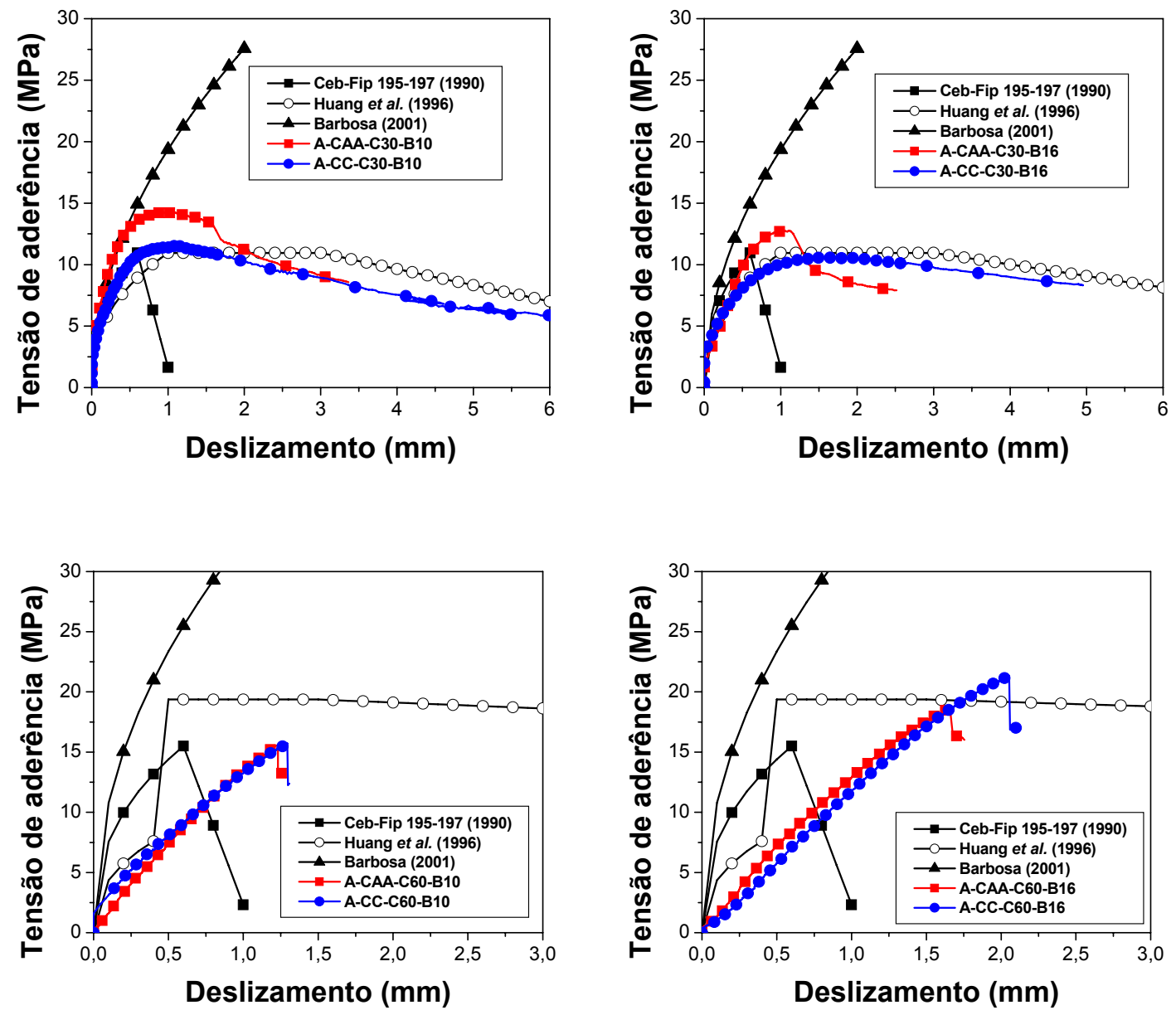

Figura 8.36 Comparação das formulações de Ceb-Fip 195/197 (1990), Huang et al. (1996) e Barbosa (2001) com os resultados dos ensaios de arrancamento 
Assim, de acordo com a Tabela 8.31, Tabela 8.32 e Tabela 8.33, as formulações não apresentaram uma aproximação satisfatória da resistência última de aderência tanto para os modelos de viga quanto para os modelos de arrancamento. A formulação de Kemp (1986) foi a única que conseguiu fornecer valores de previsão da resistência de aderência a favor da segurança para todos os casos, com exceção do modelo V-CC-C30-B10.

De posse dessas afirmações, fica claro que a adoção de um coeficiente de segurança, ou seja, um redutor de resistência deve ser aplicado aos valores obtidos pelas formulações de previsão da resistência de aderência, para que a resistência de aderência de cálculo dessas formulações possa ser adotada no caso em que seja crítica a verificação do deslizamento entre a barra de aço e o concreto.

\subsection{Variabilidade do concreto auto-adensável}

Com relação à variabilidade das propriedades do concreto auto-adensável, pode-se dizer que:

\subsubsection{Estado fresco}

Com relação à variabilidade do CAA no estado fresco, embora tenha sido realizado um estudo muito simples, pode-se dizer que o principal fator que influiu nos resultados foi o nível de limpeza da cuba da betoneira depois de cada concretagem. Nesse caso, foram realizadas três concretagens em um dia e evidenciou-se uma perda de fluidez para o CAA. Essa perda de fluidez é conseqüência da absorção de água da nova concretagem por parte da argamassa da concretagem anterior que está na cuba da betoneira. Assim, no caso de serem realizadas muitas concretagens em um mesmo dia e na mesma betoneira, recomendam-se: ou providenciar uma limpeza a cada concretagem ou, fazer uma compensação de água ou de superplastificante para garantir as mesmas propriedades no estado fresco para o CAA.

\subsubsection{Estado endurecido}

A Figura 8.37 mostra a variação do módulo de elasticidade com relação à densidade e o módulo de elasticidade de cada corpo-de-prova (CP) ensaiado. De acordo com os resultados, nos concretos mais fluidos houve variação um pouco 
superior ao concreto menos fluido (CAA2). Essa variabilidade foi um pouco menor quando se descartaram CP's depois da análise estatística em papel probabilístico. Uma explicação, como comentado anteriormente, para essa variabilidade pode ser conseqüência do capeamento (possibilidade mais preponderante), presença de vazios na face do CP (possibilidade provável) ou má utilização do equipamento (possibilidade menos provável).
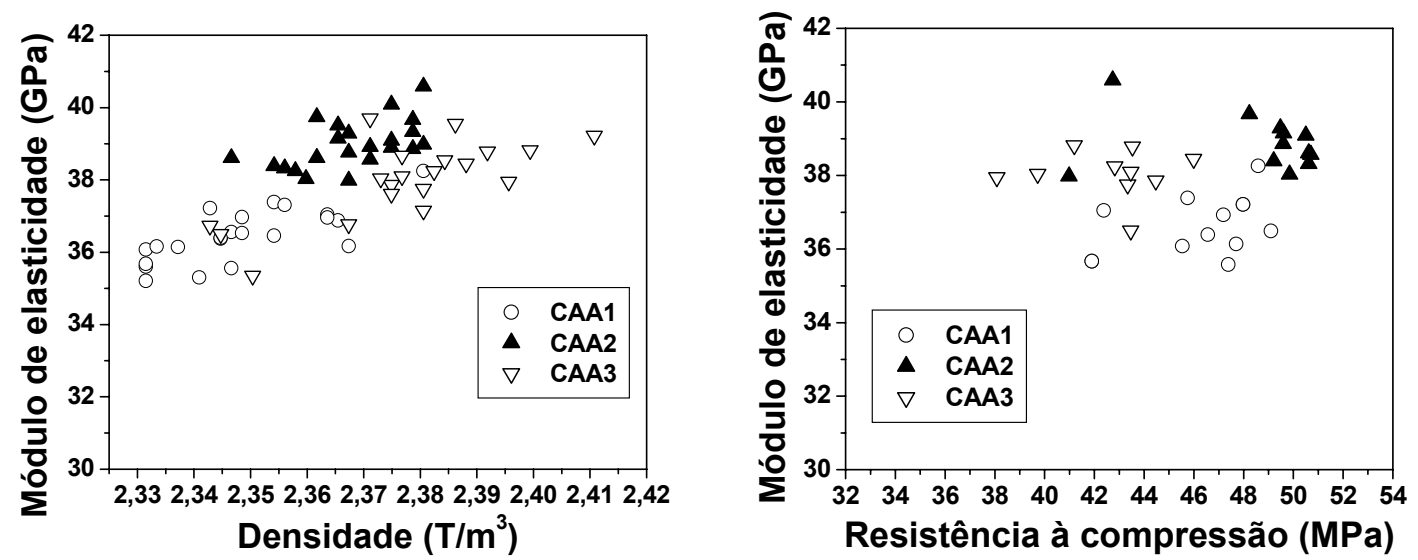

Figura 8.37 Variação do módulo de elasticidade com relação à densidade e resistência à compressão de cada CP

Na Figura 8.37 se nota que, à medida que se aumenta a densidade do $\mathrm{CP}$, se aumenta o valor do módulo de elasticidade e, constatou-se que quando se aumenta o valor da resistência à compressão, se aumenta o valor do módulo de elasticidade, com uma pequena variabilidade.

A Figura 8.38 mostra a variação do módulo de elasticidade com relação à resistência à tração de cada $\mathrm{CP}$.

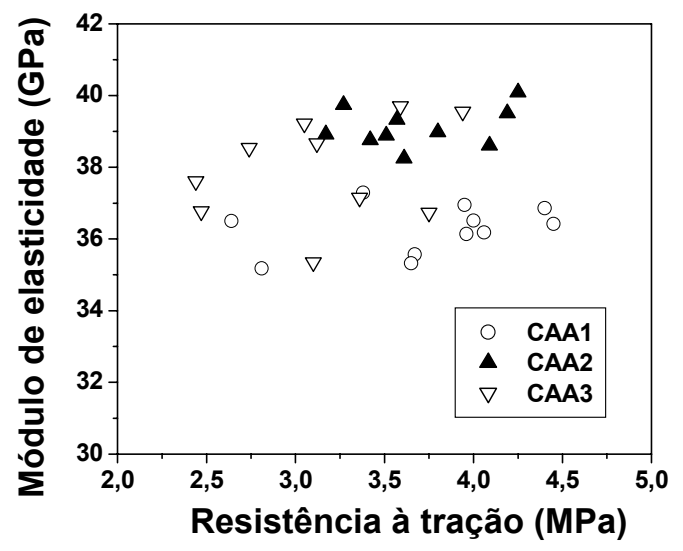

Figura 8.38 Variação do módulo de elasticidade com relação à resistência à tração de cada CP 
Constatou-se que, por maior que seja a resistência à tração, isso não significa aumento do módulo de elasticidade, o que reforça a conclusão anterior sobre a influência do modo de ruptura do CP na resistência à tração, juntamente com sua dispersão de resultados para cada série.

O ensaio de compressão indireta ou "brasileiro" apresenta uma alta variabilidade por causa de seu modo de ruptura, o qual depende do apoio do CP no aparato.

Com relação à variabilidade da Figura 8.38 , essa variação para os concretos menos fluidos, em relação aos concretos mais fluidos, pode ser conseqüência da velocidade de preenchimento das fôrmas dos CP's, pois, quanto maior a velocidade de lançamento do CAA, maior a possibilidade que o ar presente na fôrma não tenha tempo suficiente para escapar, provocando assim a formação de bolhas de ar incorporado no concreto (Figura 8.39), mas ainda são necessários mais ensaios para verificar o grau de influência para se ter uma avaliação mais confiável.

Um fator que alterou o comportamento de alguns resultados foram os danos presentes na superfície de alguns CP's. A Figura 8.39 mostra os danos causados em dois CP's das séries CAA2 e CAA3 e que, em alguns casos, os CP's não puderam sequer ser ensaiados.

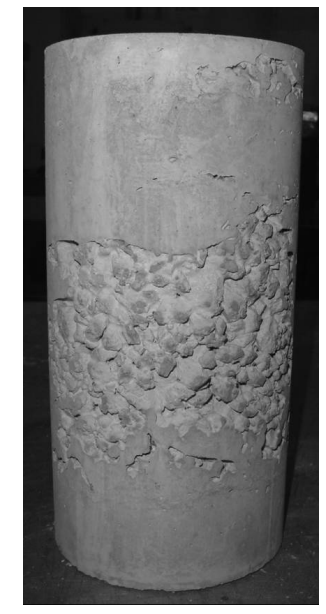

CAA2

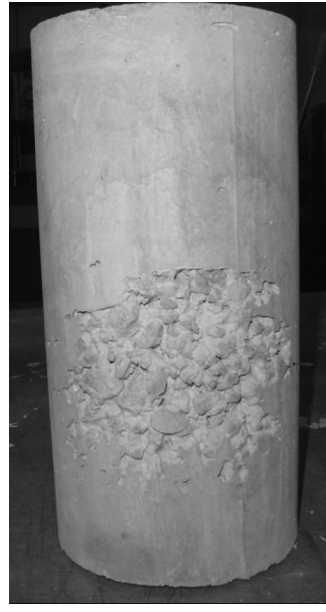

CAA3

Figura 8.39 Exemplo de CP's com danos superficiais

Quanto à comparação dos Códigos Normativos e as formulações com os resultados experimentais do CAA para o estado endurecido, se pode concluir que:

- Com relação ao módulo de elasticidade, todas as formulações apresentaram resultados muito próximos aos valores experimentais e a favor da segurança (sendo em alguns casos bastante conservativas, como o Código Norueguês (1992) e Gardner \& Zao (1991)), com exceção da NBR 6118 (2003) que apresentou um valor um pouco um pouco 
inferior com relação ao experimental, mas foi o mais próximo dos valores experimentais encontrados.

- Com relação à resistência à tração, a Tabela 8.3 mostra que as formulações apresentaram resultados muito próximos dos resultados experimentais, entretanto, contra a segurança. Somente a EHE (1999) apresentou valores a favor da segurança, porém, claramente conservativos.

Com relação ao estudo estatístico dessa investigação experimental, a análise dos resultados no estado endurecido foi realizada com a utilização da média, desvio padrão e coeficiente de variação de cada série.

A Figura 8.40 mostra a representação dos dados obtidos na investigação experimental em papel probabilístico normal. Com isso, se comprovou que os resultados seguiam uma distribuição normal probabilística.
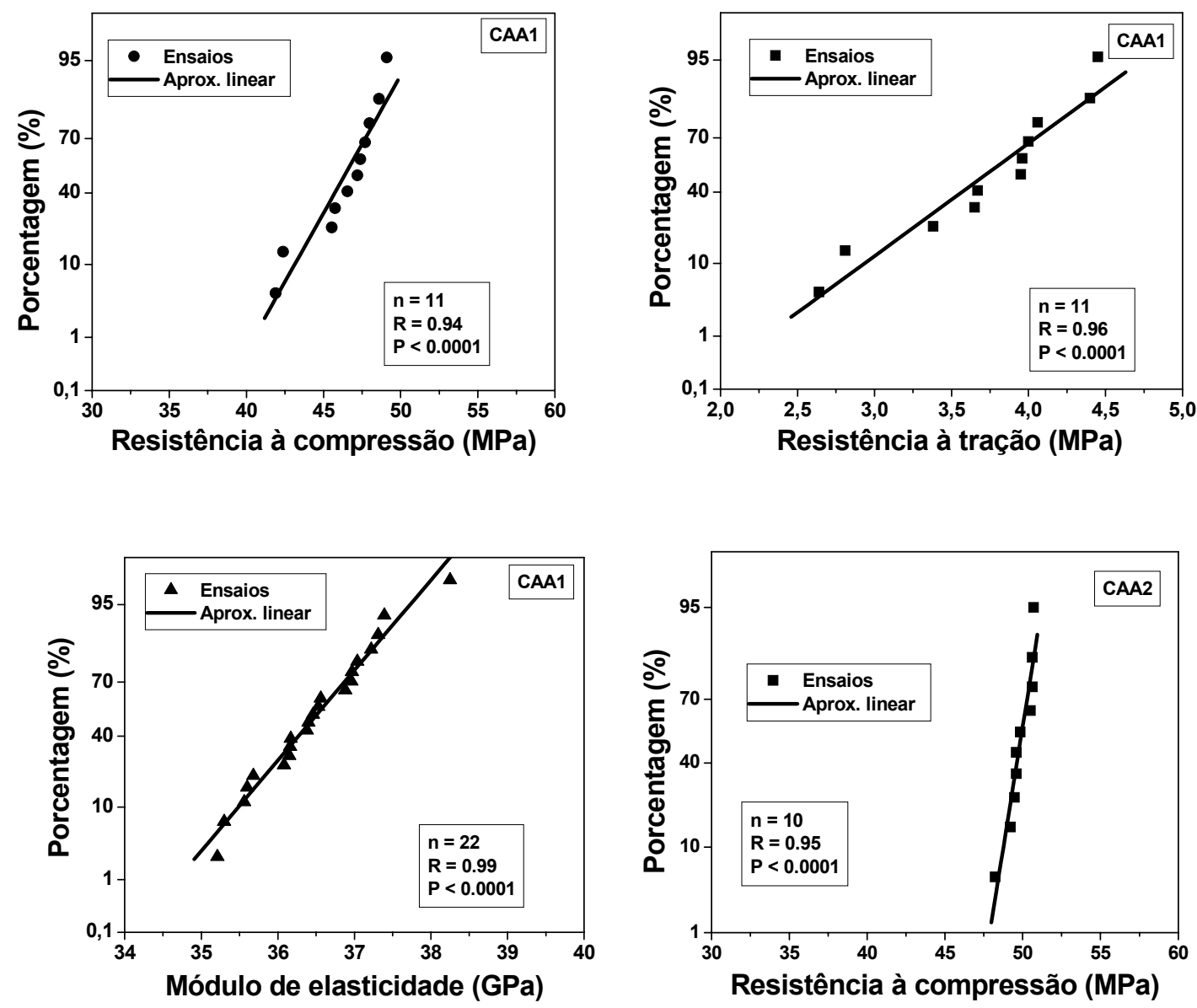

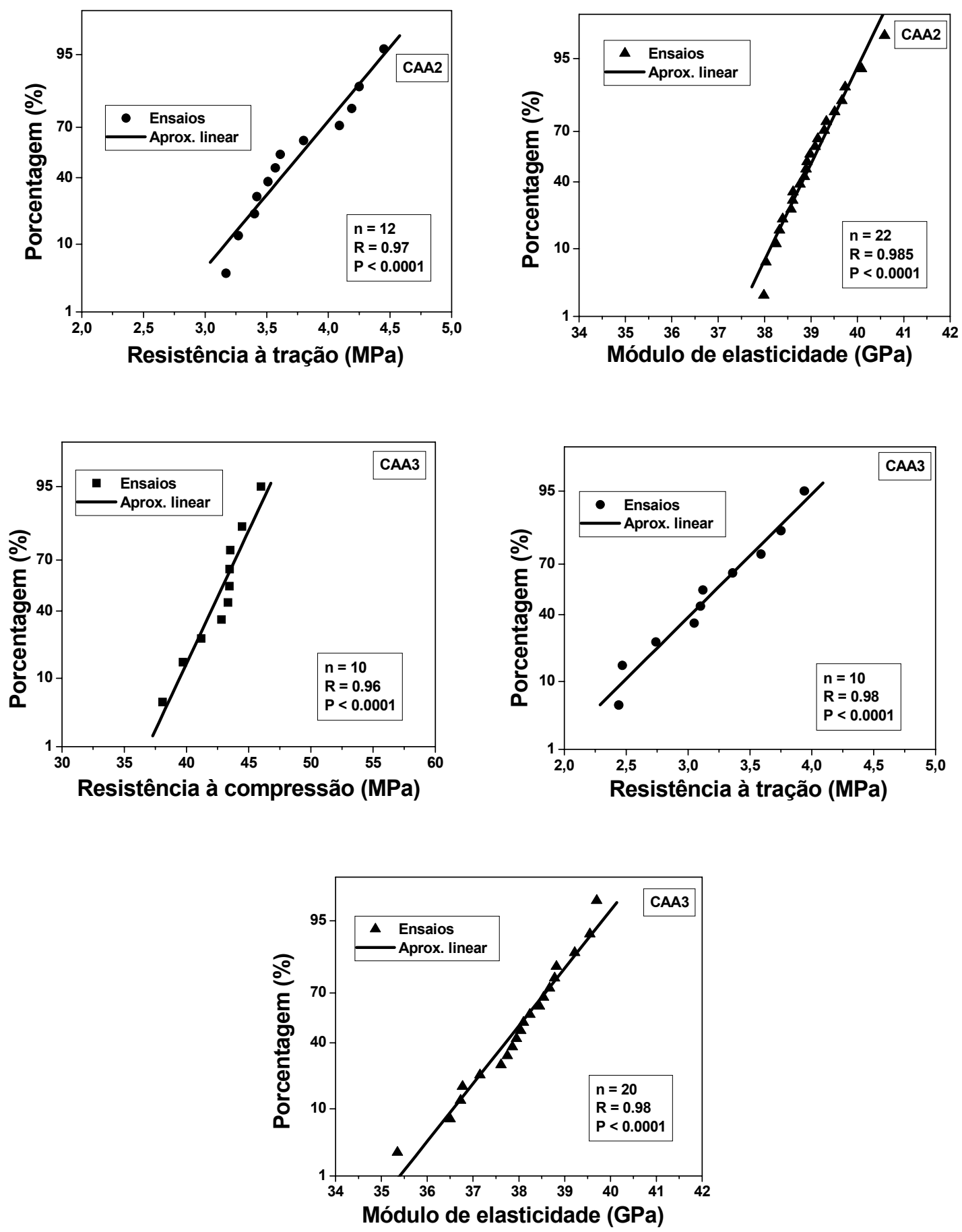

Figura 8.40 Representação em papel probabilístico

A Tabela 8.34, Tabela 8.35 e Tabela 8.36, mostram os intervalos de confiança para o módulo de elasticidade, resistência à compressão e à tração das três séries. 
Tabela 8.34 Intervalo de confiança (IC) para o módulo de elasticidade

\begin{tabular}{lcccccc}
\hline & $\begin{array}{c}\text { M } \\
(\mathbf{G P a})\end{array}$ & $\begin{array}{c}\text { D.P. } \\
(\mathbf{G P a})\end{array}$ & $\begin{array}{c}\text { Graus de } \\
\text { Liberdade }\end{array}$ & $\begin{array}{c}\text { Valor de t (t- } \\
\text { student) }\end{array}$ & $\begin{array}{c}\text { Limite } \\
\text { inferior }\end{array}$ & $\begin{array}{c}\text { Limite } \\
\text { superior }\end{array}$ \\
\hline CAA1 & 34,46 & 0,75 & 21 & 2,080 & 34,90 & 38,02 \\
CAA2 & 39,98 & 0,66 & 21 & 2,080 & 37,61 & 40,35 \\
CAA3 & 37,96 & 1,07 & 19 & 2,086 & 35,73 & 40,19 \\
\hline
\end{tabular}

Tabela 8.35 Intervalo de confiança (IC) para resistência à compressão

\begin{tabular}{lcccccc}
\hline & $\begin{array}{c}\text { M } \\
\text { (MPa) }\end{array}$ & $\begin{array}{c}\text { D.P. } \\
\text { (MPa) }\end{array}$ & $\begin{array}{c}\text { Graus de } \\
\text { Liberdade }\end{array}$ & $\begin{array}{c}\text { Valor de t (t- } \\
\text { student) }\end{array}$ & $\begin{array}{c}\text { Limite } \\
\text { inferior }\end{array}$ & $\begin{array}{c}\text { Limite } \\
\text { superior }\end{array}$ \\
\hline CAA1 & 46.37 & 2.36 & 10 & 2.228 & 41.11 & 51.63 \\
CAA2 & 49.84 & 0.79 & 9 & 2.262 & 48.05 & 51.63 \\
CAA3 & 42.62 & 2.33 & 10 & 2.228 & 37.36 & 47.88 \\
\hline
\end{tabular}

Tabela 8.36 Intervalo de confiança (IC) para resistência à tração

\begin{tabular}{ccccccc}
\hline & $\begin{array}{c}\text { M } \\
\text { (MPa) }\end{array}$ & $\begin{array}{c}\text { D.P. } \\
(\mathbf{M P a})\end{array}$ & $\begin{array}{c}\text { Graus de } \\
\text { Liberdade }\end{array}$ & $\begin{array}{c}\text { Valor de } \mathbf{t}(\mathbf{t}- \\
\text { student) }\end{array}$ & $\begin{array}{c}\text { Limite } \\
\text { inferior }\end{array}$ & $\begin{array}{c}\text { Limite } \\
\text { superior }\end{array}$ \\
\hline CAA1 & 3.72 & 0.58 & 10.00 & 2.228 & 2.42 & 5.03 \\
CAA2 & 3.73 & 0.42 & 11.00 & 2.201 & 2.80 & 4.66 \\
CAA3 & 3.16 & 0.51 & 9.00 & 2.262 & 2.00 & 4.32 \\
\hline
\end{tabular}

A Figura 8.41, Figura 8.42 e Figura 8.43 mostram a distribuição normal e a freqüência dos resultados para o módulo de elasticidade para as três séries.

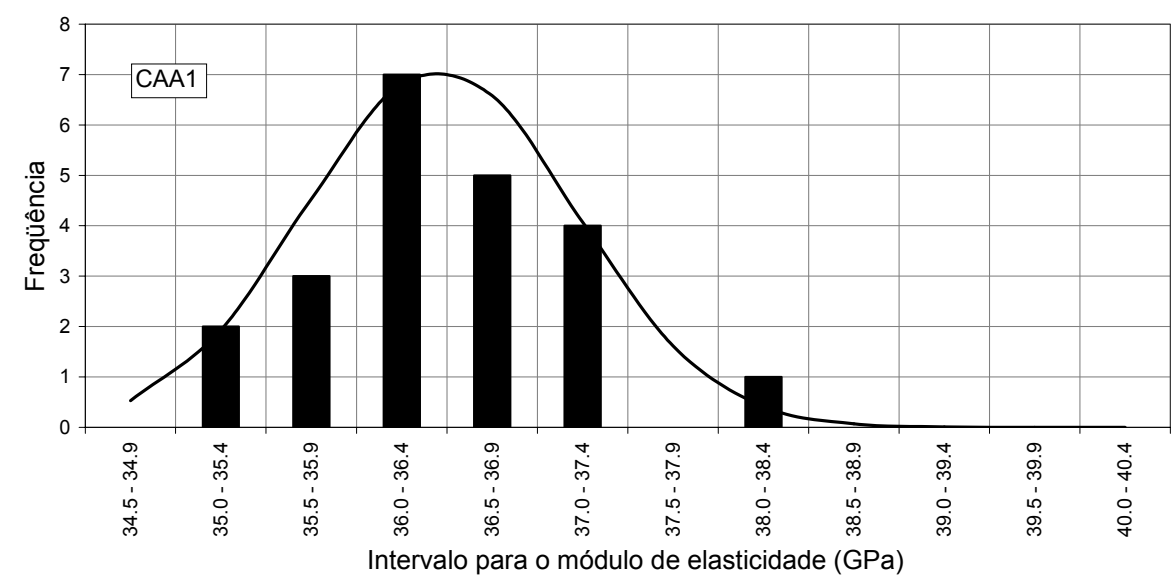

Figura 8.41 Distribuição normal e freqüência para o módulo de elasticidade da série CAA1 


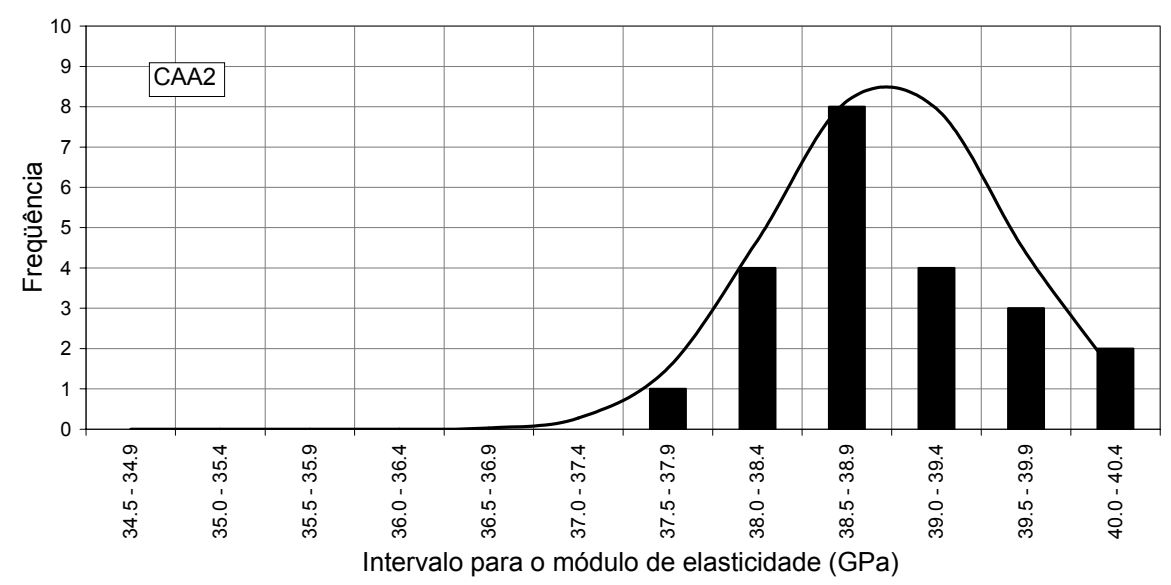

Figura 8.42 Distribuição normal e freqüência para o módulo de elasticidade da série CAA2

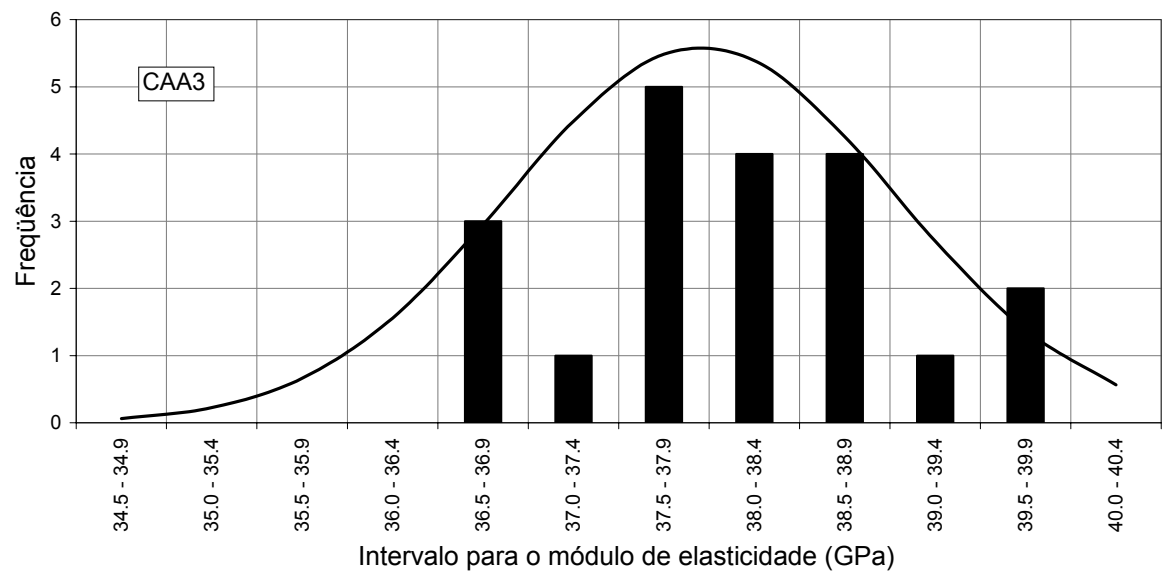

Figura 8.43 Distribuição normal e freqüência para o módulo de elasticidade da série CAA3

A Figura 8.44, Figura 8.45 e Figura 8.46 mostram a distribuição normal e a freqüência dos resultados para resistência à compressão para as três séries.

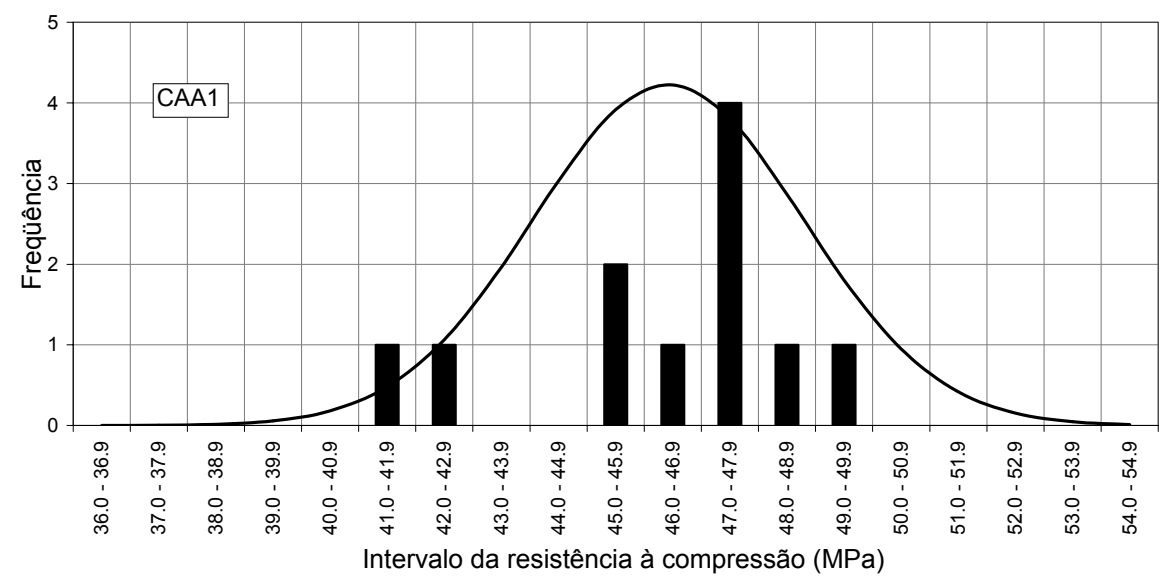

Figura 8.44 Distribuição normal e freqüência para resistência à compressão da série CAA1 


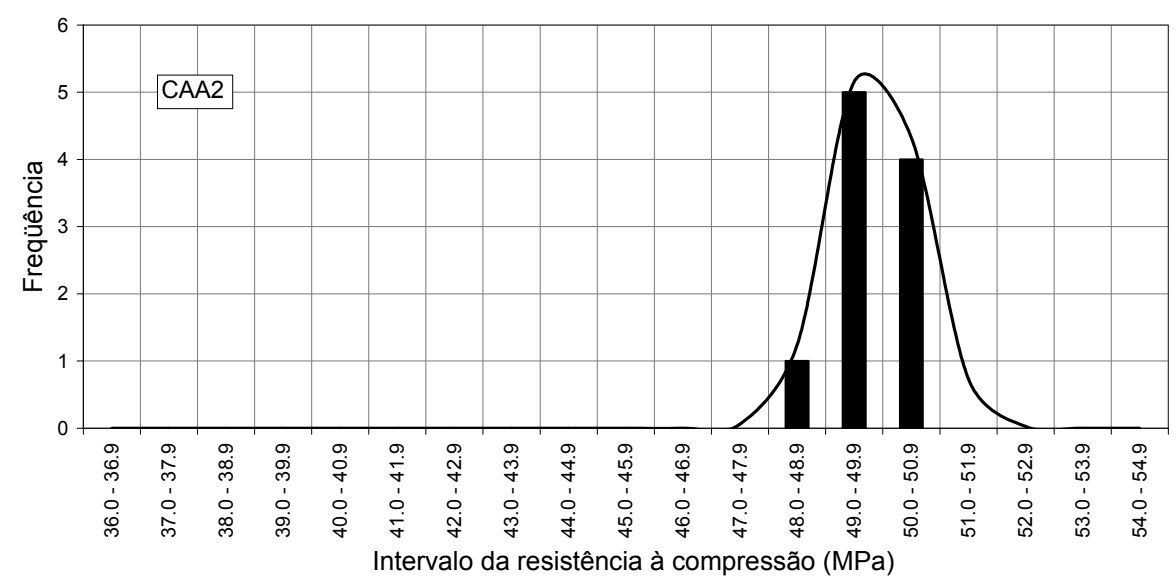

Figura 8.45 Distribuição normal e freqüência para resistência à compressão da série CAA2

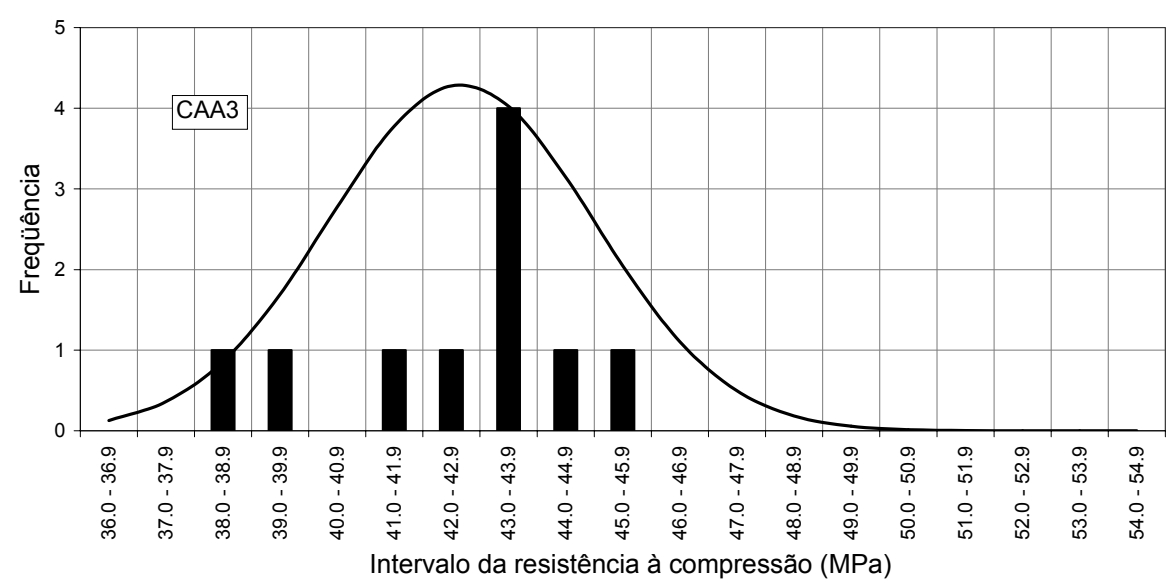

Figura 8.46 Distribuição normal e freqüência para resistência à compressão da série CAA3

A Figura 8.47, Figura 8.48 e Figura 8.49 mostram a distribuição normal e a freqüência dos resultados para resistência à compressão para as três séries.

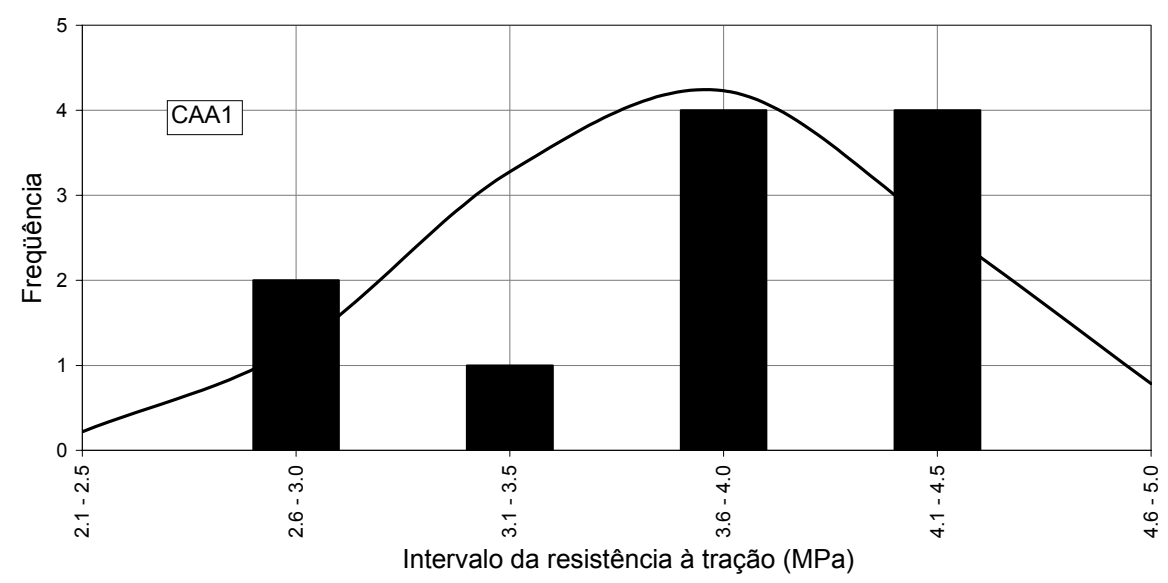

Figura 8.47 Distribuição normal e freqüência para resistência à tração da série CAA1 


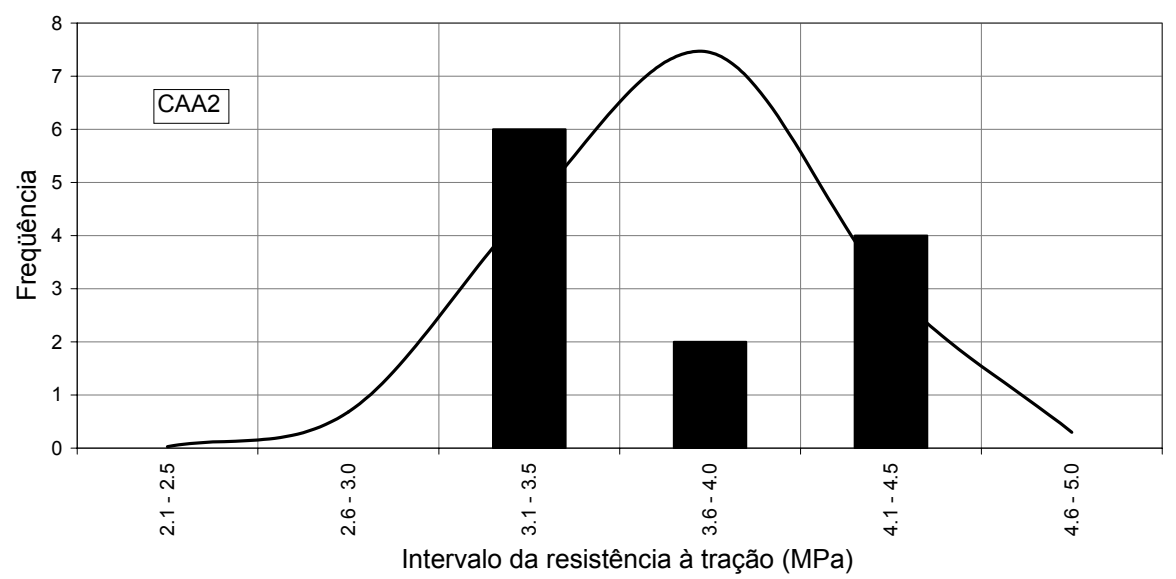

Figura 8.48 Distribuição normal e freqüência para resistência à tração da série CAA2

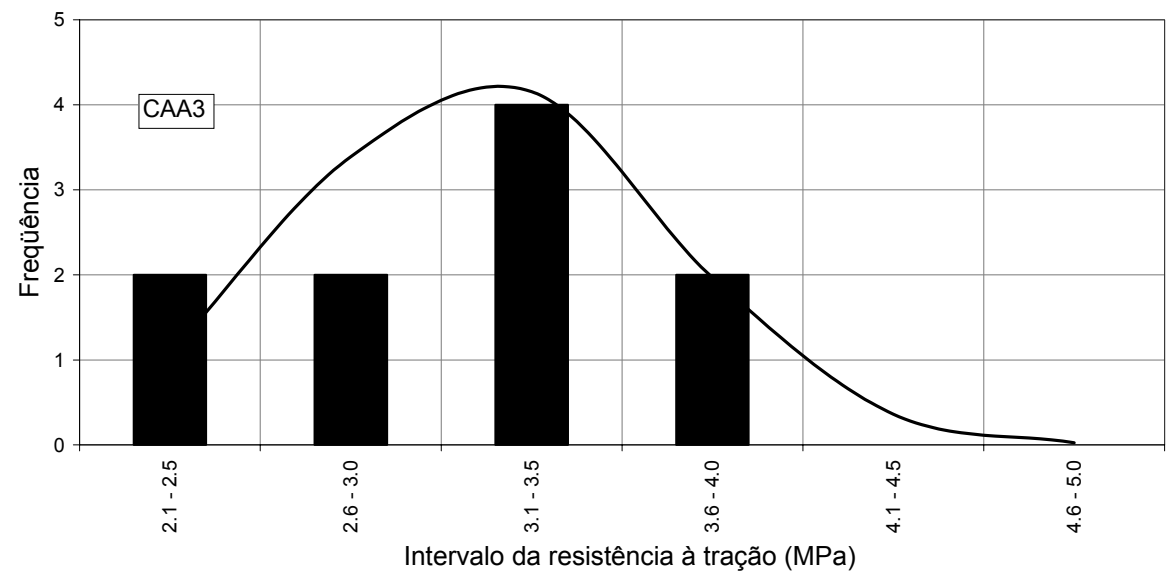

Figura 8.49 Distribuição normal e freqüência para resistência à tração da série CAA3

Com relação à comparação com as formulações mencionadas, vários modelos matemáticos (baseados em análises teóricas e experimentais) foram utilizados, com o objetivo de estimar o nível de previsão, formulações feitas por Códigos Normativos e recomendações para o módulo de elasticidade e a resistência à tração. Todas as formulações variaram em função da resistência à compressão e algumas em função da densidade do concreto.

A Figura 8.50 mostra a comparação dos Códigos Normativos e das recomendações para o módulo de elasticidade e para a resistência à tração com relação aos resultados experimentais das três séries. 

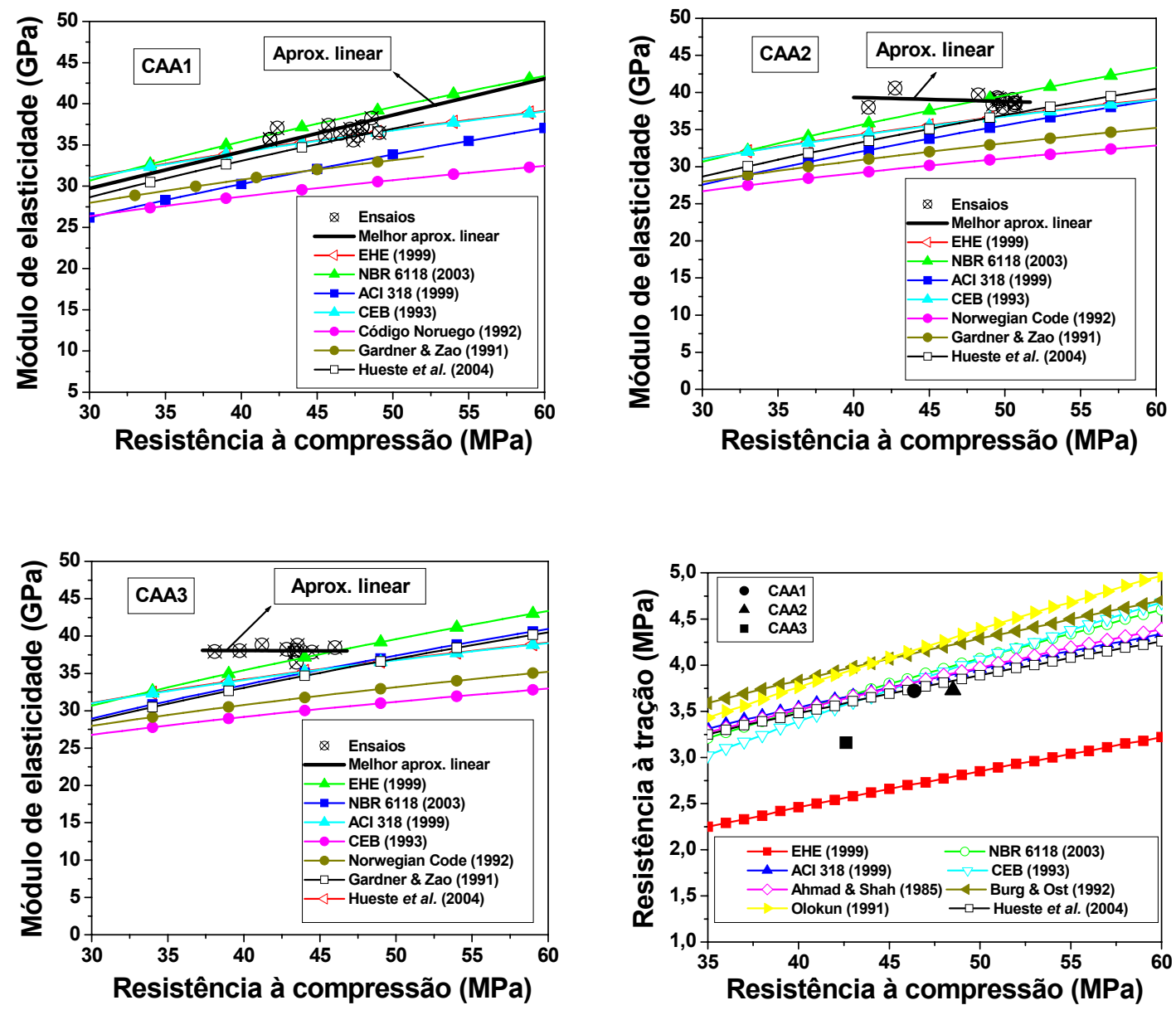

Figura 8.50 Comparação dos resultados experimentais com as formulações

A Figura 8.50 mostra que a relação entre a resistência à compressão e o módulo de elasticidade, para as formulações são em maioria muito próximas aos valores experimentais, o que é o mesmo esperado para o caso do concreto convencional (Hueste et al., 2004).

No caso de se analisar a relação entre a resistência à compressão e a resistência à tração, os resultados experimentais mostram que a maioria das formulações utilizadas superestima o valor da resistência à tração, com exceção da EHE (1999) que esteve a favor da segurança, mas mostrando resultados conservadores para a resistência à tração.

A Tabela 8.37 e a Tabela 8.38 mostram os valores obtidos para o fator bias para o módulo de elasticidade e a resistência à tração. 
Tabela 8.37 Bias Factor para os resultados de módulo de elasticidade

\begin{tabular}{lccccccc}
\hline & $\begin{array}{c}\text { EHE } \\
(\mathbf{1 9 9 9})\end{array}$ & $\begin{array}{c}\text { NBR } \\
\mathbf{6 1 1 8} \\
\mathbf{( 2 0 0 3 )}\end{array}$ & $\begin{array}{c}\text { ACI 318 } \\
\mathbf{( 1 9 9 9 )}\end{array}$ & $\begin{array}{c}\text { CEB } \\
\mathbf{( 1 9 9 3 )}\end{array}$ & $\begin{array}{c}\text { Código } \\
\text { Norueguês } \\
(\mathbf{1 9 9 2 )}\end{array}$ & $\begin{array}{c}\text { Gardner \& } \\
\text { Zao (1991) }\end{array}$ & $\begin{array}{c}\text { Hueste et } \\
\text { al. (2004) }\end{array}$ \\
\hline CAA1 & 1,01 & 0,96 & 1,00 & 1,02 & 1,20 & 1,13 & 1,02 \\
CAA2 & 1,05 & 0,98 & 1,03 & 1,05 & 1,24 & 1,17 & 1,05 \\
CAA3 & 1,09 & 1,04 & 1,09 & 1,09 & 1,28 & 1,21 & 1,11 \\
Média & 1,05 & 0,99 & 1,04 & 1,05 & 1,24 & 1,17 & 1,06 \\
\hline
\end{tabular}

Tabela 8.38 Bias Factor para os resultados de resistência à tração

\begin{tabular}{lcccccccc}
\hline & $\begin{array}{c}\text { EHE } \\
\mathbf{( 1 9 9 9 )}\end{array}$ & $\begin{array}{c}\text { NBR } \\
\mathbf{6 1 1 8} \\
\mathbf{( 2 0 0 3 )}\end{array}$ & $\begin{array}{c}\text { ACI 318 } \\
\mathbf{( 1 9 9 9 )}\end{array}$ & $\begin{array}{c}\text { CEB } \\
\mathbf{( 1 9 9 3 )}\end{array}$ & $\begin{array}{c}\text { Ahmad } \\
\mathbf{8} \text { Shah } \\
\mathbf{( 1 9 8 5 )}\end{array}$ & $\begin{array}{c}\text { Burg \& } \\
\text { Ost } \\
(\mathbf{1 9 9 2})\end{array}$ & $\begin{array}{c}\text { Olokun } \\
(\mathbf{1 9 9 1 )}\end{array}$ & $\begin{array}{c}\text { Hueste et } \\
\text { al. (2004) }\end{array}$ \\
\hline CAA1 & 1,37 & 0,96 & 0,98 & 0,97 & 0,96 & 0,89 & 0,88 & 0,99 \\
CAA2 & 1,33 & 0,93 & 0,96 & 0,94 & 0,94 & 0,87 & 0,85 & 0,97 \\
CAA3 & 1,23 & 0,86 & 0,86 & 0,88 & 0,85 & 0,79 & 0,79 & 0,88 \\
Média & 1,31 & 0,92 & 0,93 & 0,93 & 0,92 & 0,85 & 0,84 & 0,95 \\
\hline
\end{tabular}

\subsubsection{Variabilidade da aderência}

Nos ensaios de viga, o objetivo foi avaliar a variabilidade do comportamento da resistência de aderência e do ensaio.

A variabilidade do ensaio foi inferior a $10 \%$, garantindo que o ensaio era adequado para analisar a resistência de aderência. A Figura 8.51 mostra a média dos resultados experimentais dos ensaios de viga e mostra o comportamento da resistência de aderência vs. deslizamento para as três séries.
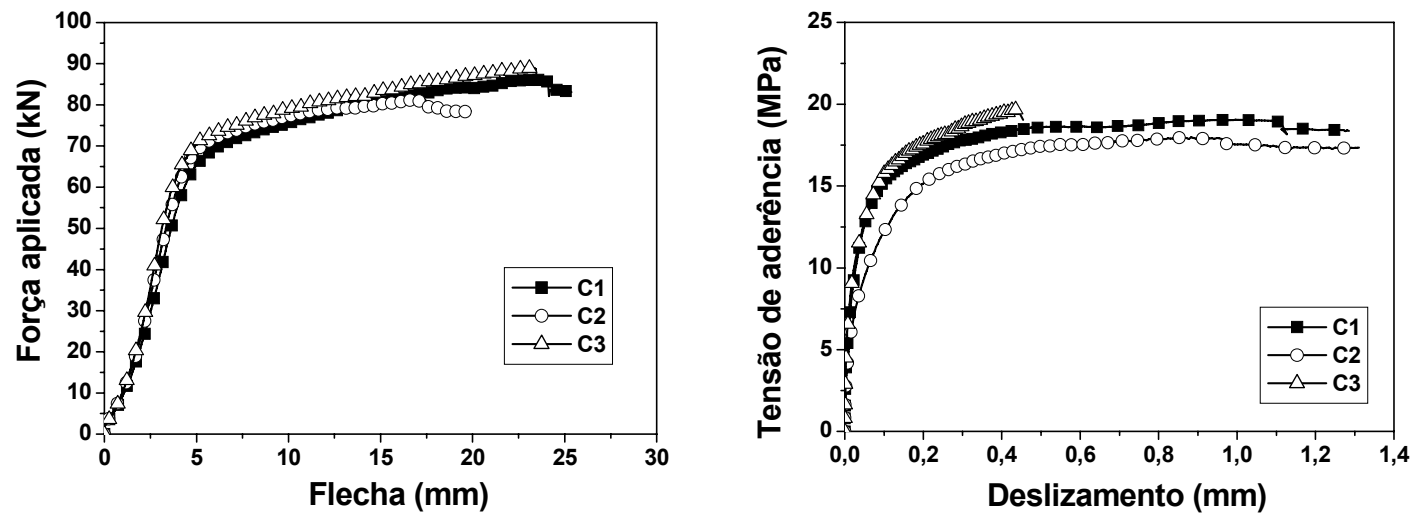

Figura 8.51 Comparação das três séries no diagrama força aplicada vs. flecha e tensão de aderência vs. deslizamento 
As séries de viga C1 e C3 foram as que apresentaram maior rigidez quando comparadas com a série C2 (com diâmetro máximo de brita de $12 \mathrm{~mm}$ ). Isso foi conseqüência do valor do módulo de elasticidade, que foi menor na série C2 (o valor da resistência à compressão foi muito próximo nas três séries). A Tabela 8.39 mostra as diferenças entre as propriedades mecânicas das três séries.

Tabela 8.39 Comparação das propriedades mecânicas das três séries de CAA

\begin{tabular}{|c|c|c|c|}
\hline CAA & $E_{c}(G P a)$ & CAA & $\mathrm{f}_{\mathrm{t}}(\mathrm{MPa})$ \\
\hline C1 & 37,31 & C1 & 3,10 \\
\hline C2 & 35,91 & C2 & 3,23 \\
\hline C3 & 38,41 & C3 & 2,28 \\
\hline $\mathrm{C}_{1 / \mathrm{C} 2}$ & 1,039 & C1/C3 & 1,360 \\
\hline $\mathrm{C} 2 / \mathrm{C} 2$ & 1,000 & $\mathrm{C} 2 / \mathrm{C}_{3}$ & 1,417 \\
\hline $\mathrm{C} 3 / \mathrm{C} 2$ & 1,070 & $\mathrm{C} 3 / \mathrm{C}_{3}$ & 1,000 \\
\hline
\end{tabular}

\begin{tabular}{cr}
\hline $\mathbf{C A A}$ & $\mathbf{f}_{\mathbf{c}}$ (MPa) \\
\hline $\mathbf{C} 1$ & 51,77 \\
$\mathbf{C 2}$ & 52,61 \\
$\mathbf{C} 3$ & 53,75 \\
$\mathbf{C} 1 / \mathbf{C} 1$ & 1,000 \\
$\mathbf{C} 2 / \mathbf{C} 1$ & 1,016 \\
$\mathbf{C} 3 / \mathbf{C} 1$ & 1,038 \\
\hline
\end{tabular}

Com relação ao cálculo da resistência de aderência, o modelo de viga utilizado não apresentava as mesmas dimensões estabelecidas pelo Rilem-Ceb-Fip (1973), sendo assim necessária a determinação da expressão que calcula a resistência de aderência do ensaio.

A Tabela 8.40 mostra os valores da resistência de aderência para os deslizamentos de 0,01, 0,1 e $1 \mathrm{~mm}$. Vale salientar que a série C3 não alcançou $1 \mathrm{~mm}$ de deslizamento, sendo utilizado o seu valor de ruptura.

Tabela 8.40 Resistência de aderência média para as vigas ensaiadas

\begin{tabular}{cccccc}
\hline & $\tau_{0,01}$ (MPa) & $\tau_{0,1}$ (MPa) & $\tau_{1,0}$ (MPa) & $\tau_{u}$ (MPa) & $\tau_{\mathrm{m}}$ (MPa) \\
\hline $\mathbf{C} 1$ & 6,34 & 15,28 & 19,04 & 19,06 & 13,56 \\
C2 & 5,07 & 12,34 & 17,55 & 18,98 & 11,65 \\
C3 & 7,49 & 15,73 & 20,34 & 20,34 & 14,52 \\
Média (MPa) & 6,30 & 14,45 & 18,98 & 19,46 & 13,24 \\
D.P. (MPa) & 1,213 & 1,841 & 1,397 & 0,765 & 1,460 \\
C.V. (\%) & $19,25 \%$ & $12,74 \%$ & $7,36 \%$ & $3,93 \%$ & $11,02 \%$ \\
\hline
\end{tabular}

De acordo com a variação da tensão de aderência na Figura 8.51, pode-se ver que a série C2 apresentou menor resistência de aderência quando comparada com as demais séries e, a série C3 foi a que apresentou maior resistência de aderência e menor deslizamento.

A Figura 8.52 mostra a variação da força aplicada e a correspondente flecha de cada ensaio de viga. 

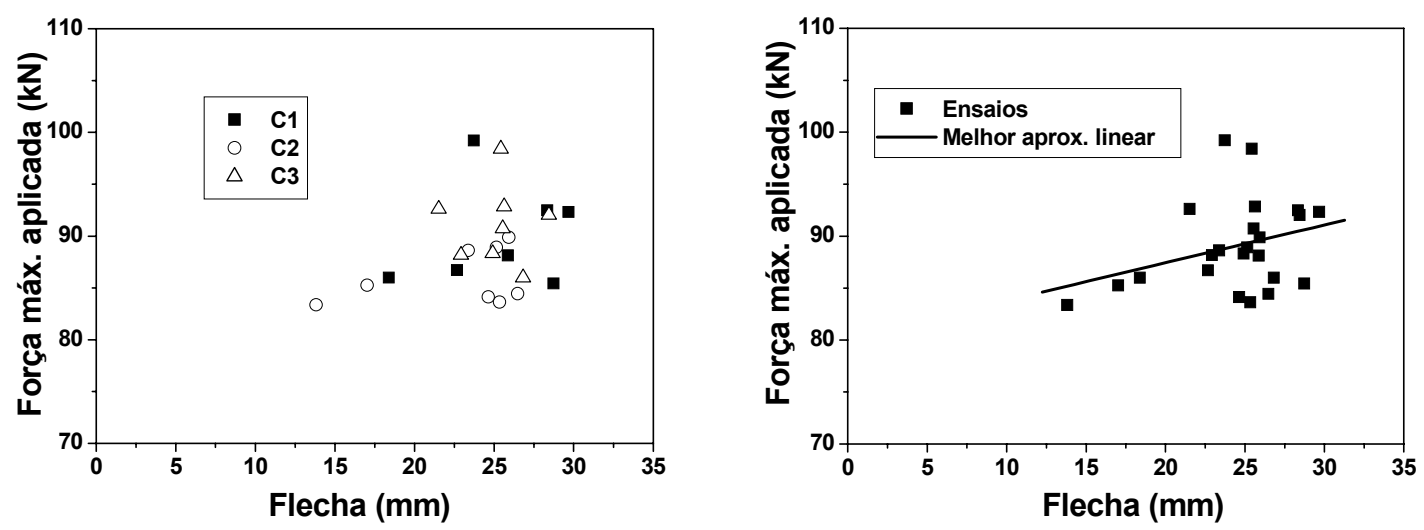

Figura 8.52 Resultados para a força máxima aplicada e a correspondente flecha de cada ensaio

A Figura 8.53 mostra a variação da resistência última de aderência para as três séries de vigas.
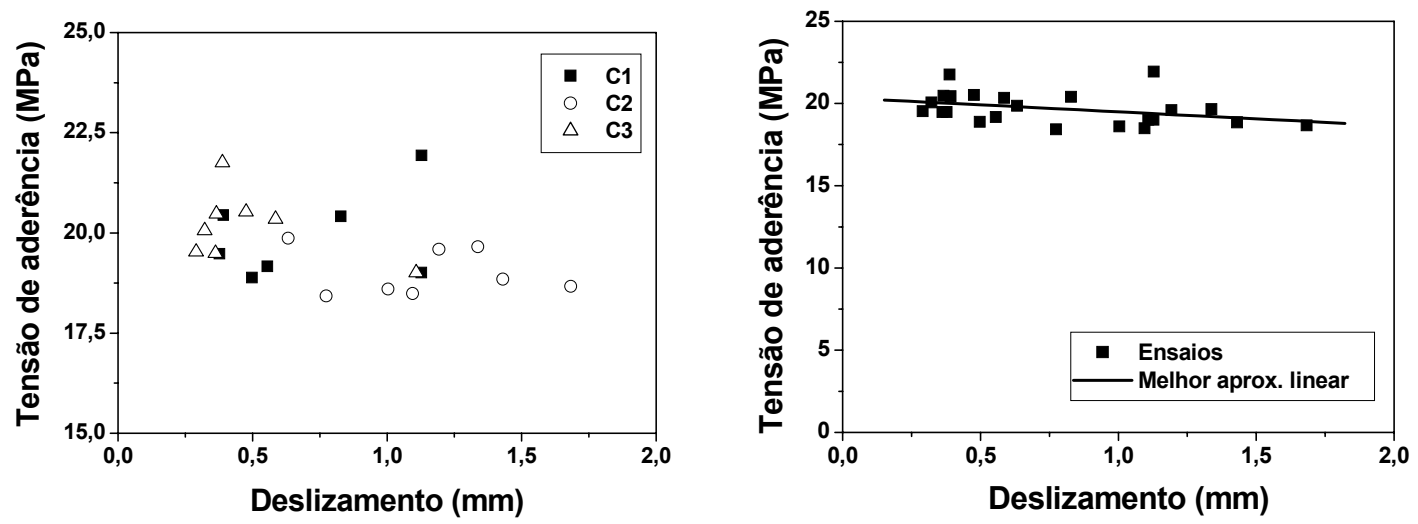
Figura 8.53 Resultados para a resistência última de aderência e o correspondente
deslizamento

De acordo com a Figura 8.53, à medida que se aumenta o deslizamento da barra, ocorre a redução do valor da resistência de aderência. Isso pode ser explicado pelo fato de, quando se mediam os resultados da força máxima aplicada ao ensaio, há possibilidade da interferência do conjunto referente à reação da barra de aço na placa da rótula e plastificação no ponto central da barra de aço. Outro fator que promoveu para essa variação foi o valor do módulo de elasticidade das séries, onde a série C2 foi a que apresentou maior deslizamento.

Para se avaliar estatisticamente os resultados dos ensaios de viga, uma distribuição normal e uma análise de freqüência não seria adequada devido à pequena quantidade de amostras (oito para cada série). Mesmo assim, com um coeficiente de 
variação inferior a 10\%, optou por realizar uma análise em papel probabilístico normal se os resultados são representativos e podem ser representados em uma distribuição normal. A Figura 8.54 mostra os resultados referentes à força máxima aplicada nos ensaios de viga ordenados em papel probabilístico normal.
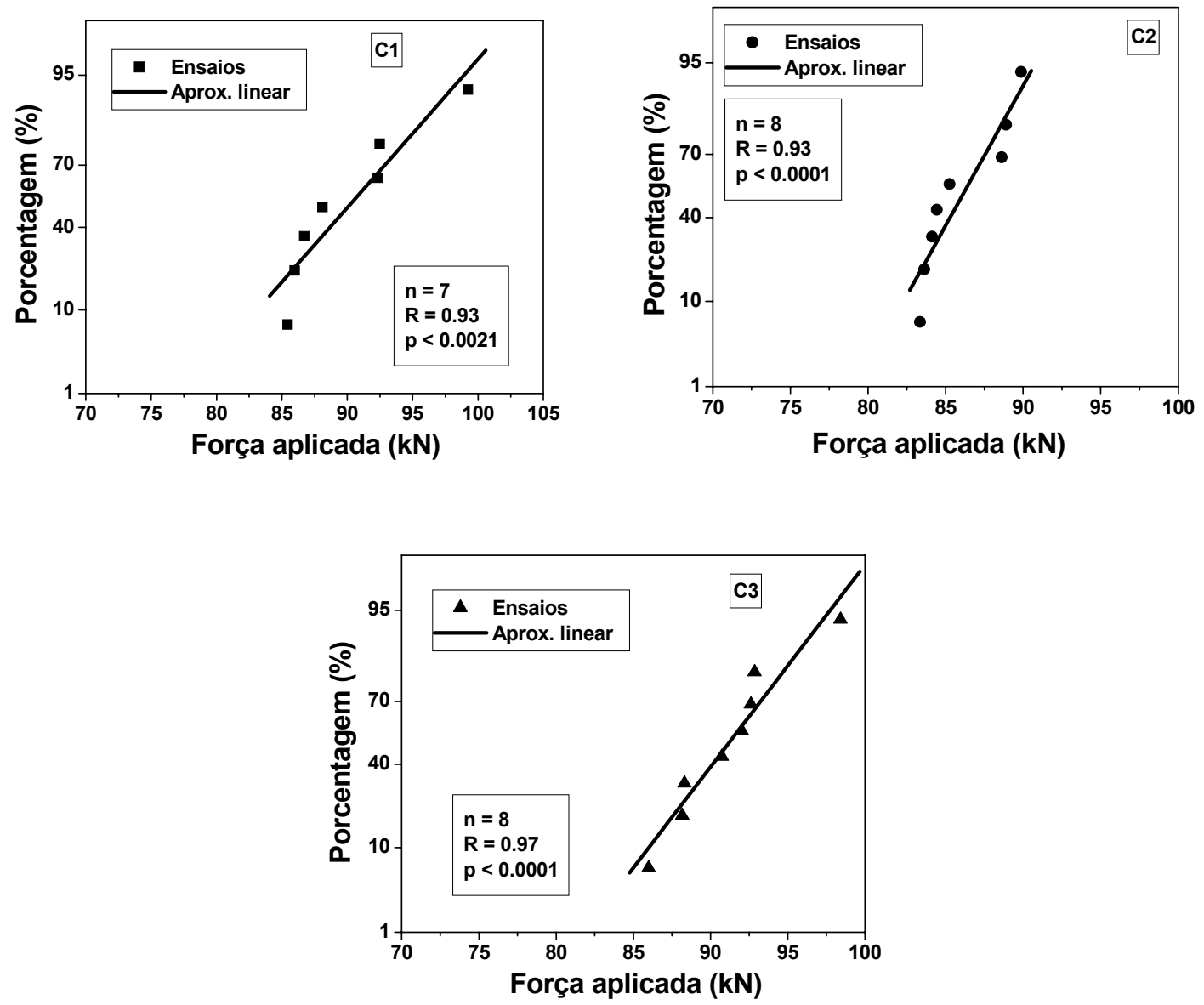

Figura 8.54 Representação em papel probabilístico normal da força máxima aplicada no ensaio de viga

Da mesma forma realizada para os resultados de variabilidade no estado endurecido, se comprovou com essa análise que os dados são representativos para se avaliar a variabilidade do ensaio de viga e é possível realizar uma distribuição normal.

A Tabela 8.41 mostra os intervalos de confiança (IC=95\%) para a força máxima aplicada para as três séries.

Tabela 8.41 Intervalos de confiança (IC) para a força máxima aplicada

\begin{tabular}{ccccccc}
\hline & $\begin{array}{c}\mathbf{M} \\
(\mathbf{k N})\end{array}$ & $\begin{array}{c}\text { D.P. } \\
(\mathbf{k N})\end{array}$ & $\begin{array}{c}\text { G. } \\
\text { Liberd. }\end{array}$ & $\begin{array}{c}\text { Valor de t (t- } \\
\text { student) }\end{array}$ & $\begin{array}{c}\text { Limite } \\
\text { inferior }\end{array}$ & $\begin{array}{c}\text { Limite } \\
\text { superior }\end{array}$ \\
\hline C1 & 90,04 & 4,97 & 6 & 2,447 & 77,89 & 102,20 \\
C2 & 86,03 & 2,66 & 7 & 2,365 & 79,74 & 92,31 \\
C3 & 91,14 & 3,82 & 7 & 2,365 & 82,10 & 100,18 \\
\hline
\end{tabular}


A Figura 8.55 mostra a freqüência e a distribuição normal das séries.
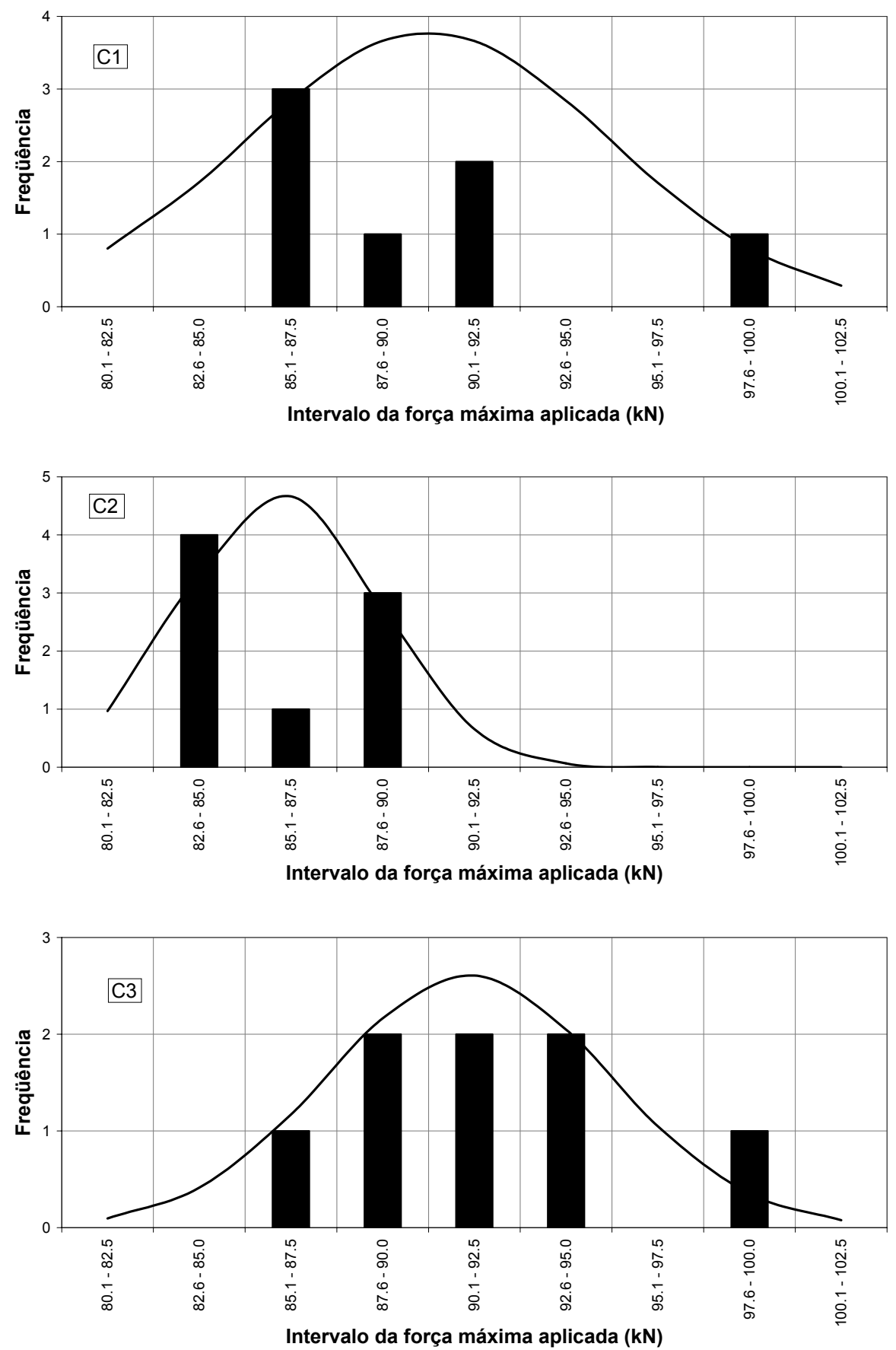

Figura 8.55 Freqüência e distribuição normal para as três séries de vigas

A Figura 8.56 mostra a variação da resistência última de aderência vs. resistência à compressão do concreto para as três séries comparadas com as formulações da Tabela 8.1. 


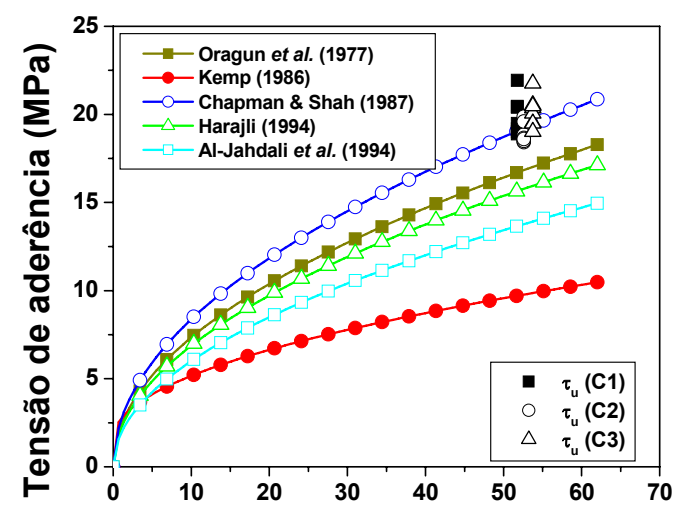

Resistencia à compressão (MPa)

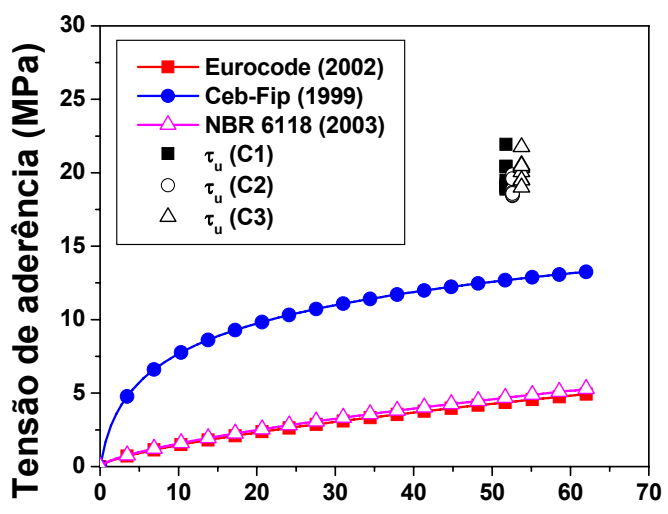

Resistência à compressão (MPa)

Figura 8.56 Resistência de aderência vs. resistência à compressão das três séries

A EHE (1999) determina a resistência de aderência por meio do ensaio de viga estabelecido pelo Rilem-Ceb-Fip (1973) (Eq. 8.2). Entretanto, a formulação utilizada para medir a resistência última de aderência foi a mesma adotada por Isa \& Aguado (2003) e viu-se que os valores referentes à EHE (1999) foram contra a segurança (Figura 8.57).

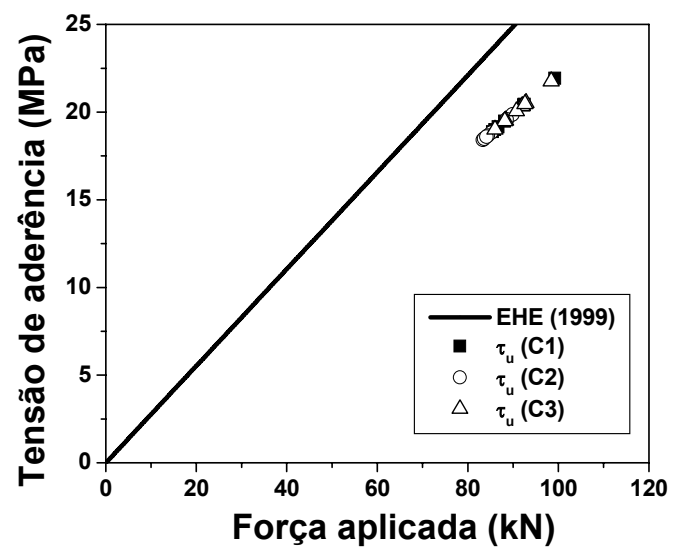

Figura 8.57 Resistência de aderência vs. força aplicada das três séries

A Tabela 8.42, Tabela 8.43 e Tabela 8.44 , mostram as diferenças dos resultados experimentais e os calculados (bias factor), levando em consideração a resistência à compressão de cada série. 
Tabela 8.42 Diferenças na previsão (bias factor) da resistência última de aderência experimental para as formulações de Oragun et al. (1977), Kemp (1986), Chapman \& Shah (1987)

\begin{tabular}{ccccc}
\hline Série & $\begin{array}{c}\text { Ensaio } \\
\end{array}$ & $\lambda$ & $\lambda$ & $\lambda$ \\
& $\tau_{\mathrm{u}}$ (MPa) & Oragun et al. (1977) & Kemp (1986) & Chapman \& Shah (1987) \\
\hline C1 & 19,06 & 1,14 & 1,96 & 1,00 \\
C2 & 18,98 & 1,13 & 1,94 & 0,99 \\
C3 & 20,34 & 1,19 & 2,06 & 1,05 \\
\hline
\end{tabular}

Tabela 8.43 Diferenças na previsão (bias factor) da resistência de aderência experimental para as formulações de Harajli (1994), Al-Jahdali et al. (1994), Ceb-Fip (1999)

\begin{tabular}{ccccc}
\hline \multirow{2}{*}{ Série } & $\begin{array}{c}\text { Ensaio } \\
\tau_{\mathrm{u}} \text { (MPa) }\end{array}$ & $\begin{array}{c}\lambda \\
\text { Harajli (1994) }\end{array}$ & $\begin{array}{c}\lambda \\
\text { Al-Jahdali et al. (1994) }\end{array}$ & $\begin{array}{c}\lambda \\
\text { Ceb-Fip (1999) }\end{array}$ \\
\hline C1 & 19,06 & 1,22 & 1,39 & 1,50 \\
C2 & 18,98 & 1,20 & 1,38 & 1,49 \\
C3 & 20,34 & 1,28 & 1,46 & 1,59 \\
\hline
\end{tabular}

Tabela 8.44 Diferenças na previsão (bias factor) da resistência de aderência experimental para as formulações do Eurocode (2002) e da NBR 6118 (2003)

\begin{tabular}{cccc}
\hline \multirow{2}{*}{ Série } & $\begin{array}{c}\text { Ensaio } \\
\tau_{u} \text { (MPa) }\end{array}$ & $\begin{array}{c}\lambda \\
\text { Eurocode (2002) }\end{array}$ & $\begin{array}{c}\lambda \\
\text { NBR 6118 (2003) }\end{array}$ \\
\hline C1 & 19,06 & 4,35 & 4,07 \\
C2 & 18,98 & 4,29 & 4,01 \\
C3 & 20,34 & 4,53 & 4,23 \\
\hline
\end{tabular}

Assim, de acordo com os dados acima, as formulações apresentaram uma aproximação satisfatória da resistência de aderência, onde se pode destacar Oragun et al. (1977) e Chapman \& Shah (1987), sendo a favor da segurança. Todas as formulações foram a favor da segurança, onde a pior aproximação, claramente subestimando a resistência de aderência, foi dada pelo Eurocode (2002) e pela NBR 6118 (2003), pois estas consideram que a resistência última de aderência ocorre para o deslizamento de $0,01 \mathrm{~mm}$, ou seja, o limite de perda de adesão entre os materiais.

A Figura 8.58 mostra o comportamento da tensão de aderência vs. deslizamento para as formulações de Ceb-Fip 195/197 (1990), Huang et al. (1996) e Barbosa (2001), comparado com os resultados experimentais de cada série. 

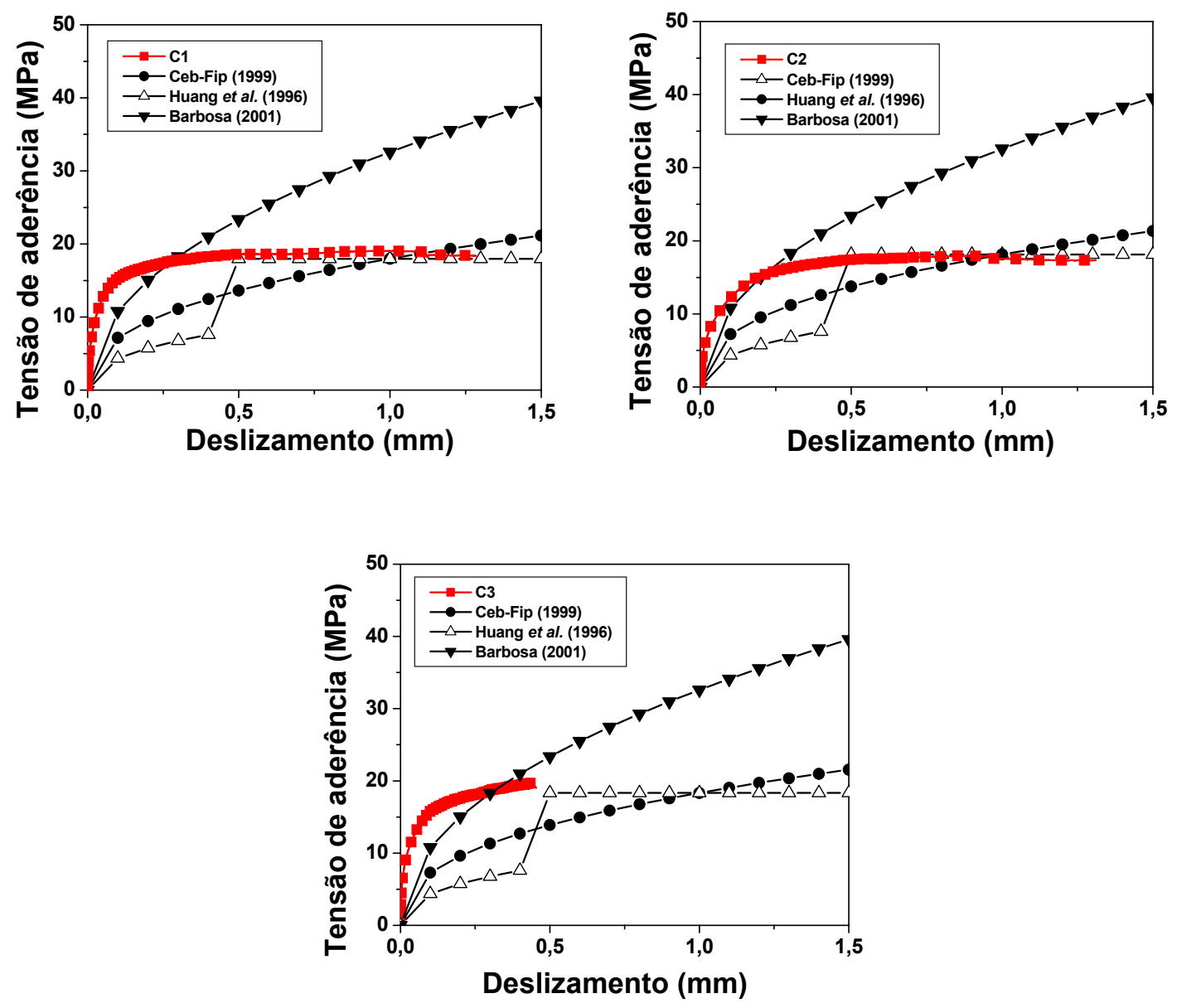

Figura 8.58 Comparação das formulações de Ceb-Fip 195/197 (1990), Huang et al. (1996) e Barbosa (2001) com os resultados experimentais

De acordo com os resultados da Figura 8.58, vê-se que a formulação de Huang et al. (1996) apresentou um resultado mais próximo da resistência última de aderência, conseguindo representar o patamar onde a resistência de aderência se mantém constante devido ao escoamento da barra de aço. Já o Código do Ceb-Fip (1999) e a formulação de Barbosa (2001) não conseguiram representar o comportamento da resistência de aderência do ensaio de viga, fornecendo valores que superestimaram a resistência de aderência.

\subsection{Simulação numérica}

Este segmento procurou analisar o comportamento das tensões na superfície de contato utilizando os resultados provenientes dos elementos de contato e dos elementos de concreto. Os modelos de arrancamento e de viga apresentaram uma distribuição das tensões em sua superfície aparentemente satisfatória, pois não havia 
resultados experimentais para corroborar essa afirmação. As tensões na barra de aço dos modelos de viga tiveram um comportamento satisfatório sendo que, na extremidade descarregada houve diferenças significativas por causa da pequena transferência de tensões para a barra de aço (pequenas deformações).

\subsubsection{Série 1}

Neste segmento se apresenta a análise dos resultados para os modelos numéricos de arrancamento e de viga da série 1, realizados no Capítulo 7.

\subsubsection{Modelos de arrancamento}

Os modelos numéricos de arrancamento desta série foram comparados com os resultados experimentais referente ao CAA e ao CC. No resultado experimental foi visto que ambos apresentaram propriedades mecânicas (resistência à compressão e módulo de elasticidade) semelhantes, o que facilitou a representação numérica do ensaio. Assim, os resultados numéricos de arrancamento da série 1 foram reduzidos a um modelo de cada (modelo com barra de $10 \mathrm{~mm}$ e com $16 \mathrm{~mm}$ ).

Vale salientar que nos casos de verificação da superfície de contato, isto é, avaliação da distribuição e intensidade da resistência ao deslizamento do modelo numérico não tiveram modelo para comparação, ficando assim esses resultados como uma estimativa de como seria o comportamento da resistência ao deslizamento nessa superfície.

A Figura 8.59 ilustra a variação da resistência na superfície de contato durante o passo de carga da maior força de arrancamento do modelo.

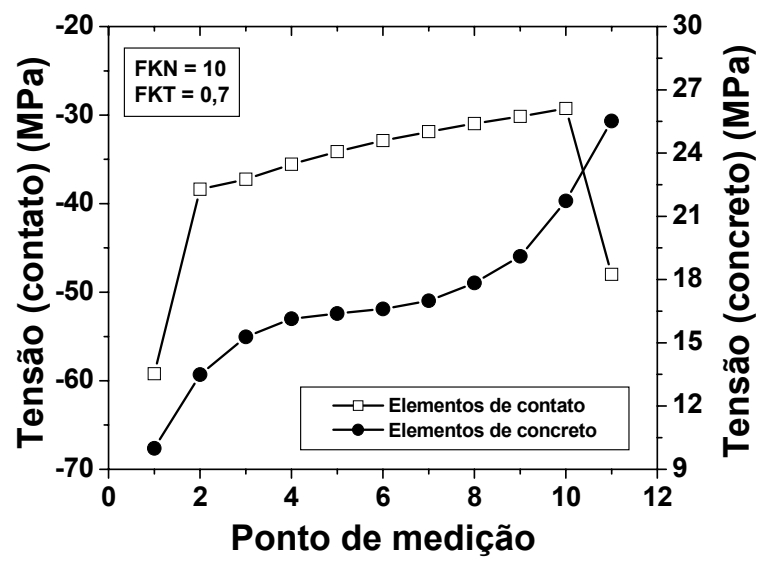

Figura 8.59 Tensão na superfície de contato para os modelos de arrancamento com barra de $10 \mathrm{~mm}$ no passo de carga de força máxima aplicada 
Embora o modelo numérico possa representar satisfatoriamente o comportamento do ensaio de arrancamento, não existiam dados para se fazer uma representação da variação da resistência de aderência na superfície de contato (utilizando elementos de contato). Assim, se avaliou a variação das tensões no prisma de concreto na superfície mais próxima à superfície de contato e as dos elementos na superfície de contato (Figura 8.60).

A Figura 8.60 mostra o valor da variação da tensão nos elementos de contato e de concreto na superfície de contato aço-concreto.
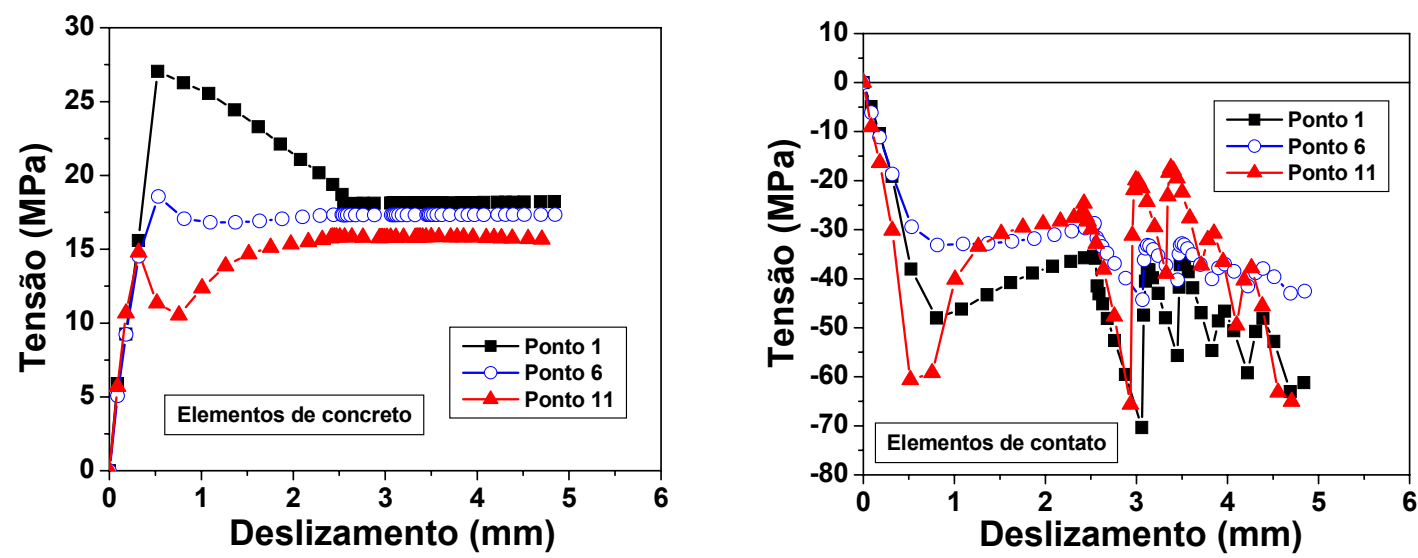

Figura 8.60 Variação das tensões nos elementos de concreto e elementos de contato

De acordo com a Figura 8.60, pode-se ver que a representação da resistência de aderência é complexa e que a superfície de com elementos de contato se mostrou muito rígida, embora esta tenha representado adequadamente o comportamento do ensaio de arrancamento. O comportamento das tensões no concreto se mostrou mais adequado, uma vez que as tensões existentes na interface conduziram a resultados mais próximos da realidade, pois os pontos iniciais do contato apresentaram tensões de tração enquanto os pontos finais apresentaram tensões de compressão.

Vale salientar que, na Figura 8.60, a resistência de aderência proveniente dos elementos de concreto e do contato têm sinais opostos, sendo que as tensões no concreto são de compressão (+) e as do contato, de tração (-).

A Figura 8.61 ilustra as tensões principais na direção $Z$ (sentido do deslizamento da barra em relação ao concreto) dos modelos numéricos de arrancamento com barra de $10 \mathrm{~mm}$ quando do passo de carga correspondente à força de arrancamento do modelo. 

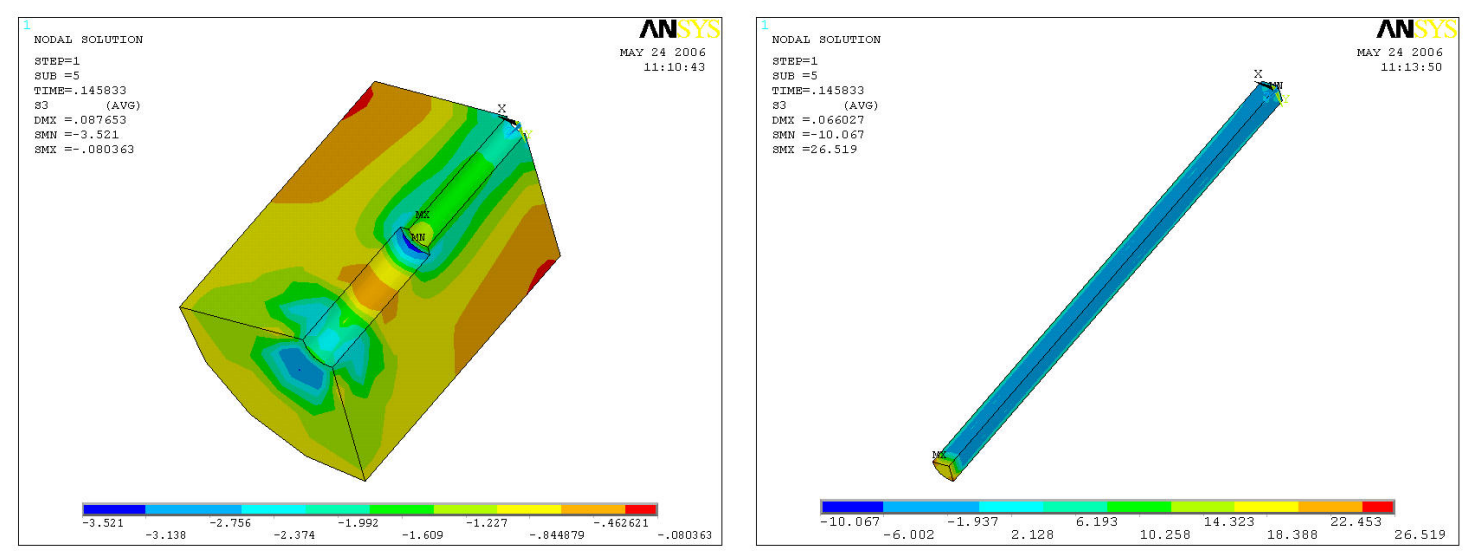

Figura 8.61 Tensões principais na direção $Z$ quando se atinge o passo de carga correspondente a força máxima de arrancamento

Vale comentar que a resposta do programa em elementos finitos fornecia a compressão com sinal negativo (-) e a tração com sinal positivo (+) e, na unidade de $\mathrm{kN} / \mathrm{cm}^{2}$.

De acordo com a Figura 8.61, pode-se ver que o prisma de concreto permaneceu dentro dos limites característicos de resistência, nesse caso, à compressão, fornecendo uma boa aproximação do comportamento experimental do modelo, muito embora não se tenham dados experimentais para sua comprovação. Do mesmo modo, as tensões na barra se aço se portaram dentro do esperado, pois era previsto que não ocorresse escoamento da barra, por causa da resistência à compressão do concreto.

Com relação aos modelos de arrancamento com barra de 16 mm, a Figura 8.62 mostra a variação da resistência na superfície de contato para o passo de carga de maior rigidez do modelo numérico.

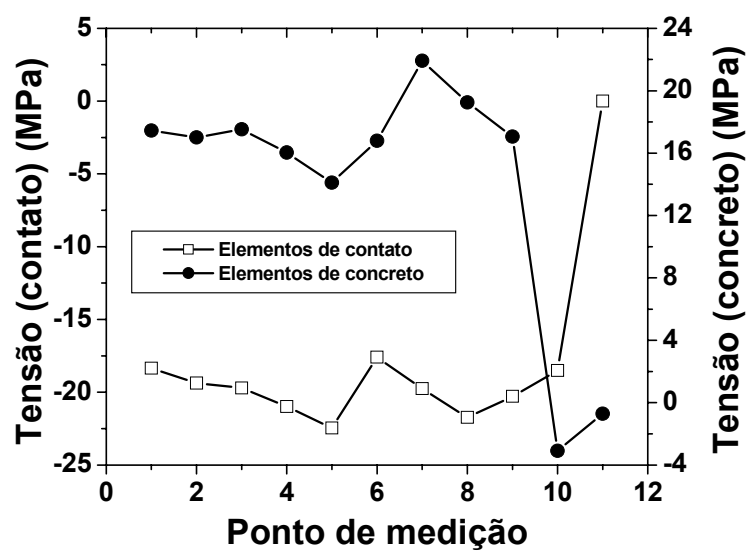

Figura 8.62 Resistência de aderência na superfície de contato para os modelos de arrancamento com barra de $16 \mathrm{~mm}$ no passo de carga de força máxima aplicada 
A Figura 8.63 mostra a variação das tensões na superfície de contato e no concreto adjacente à barra de aço.
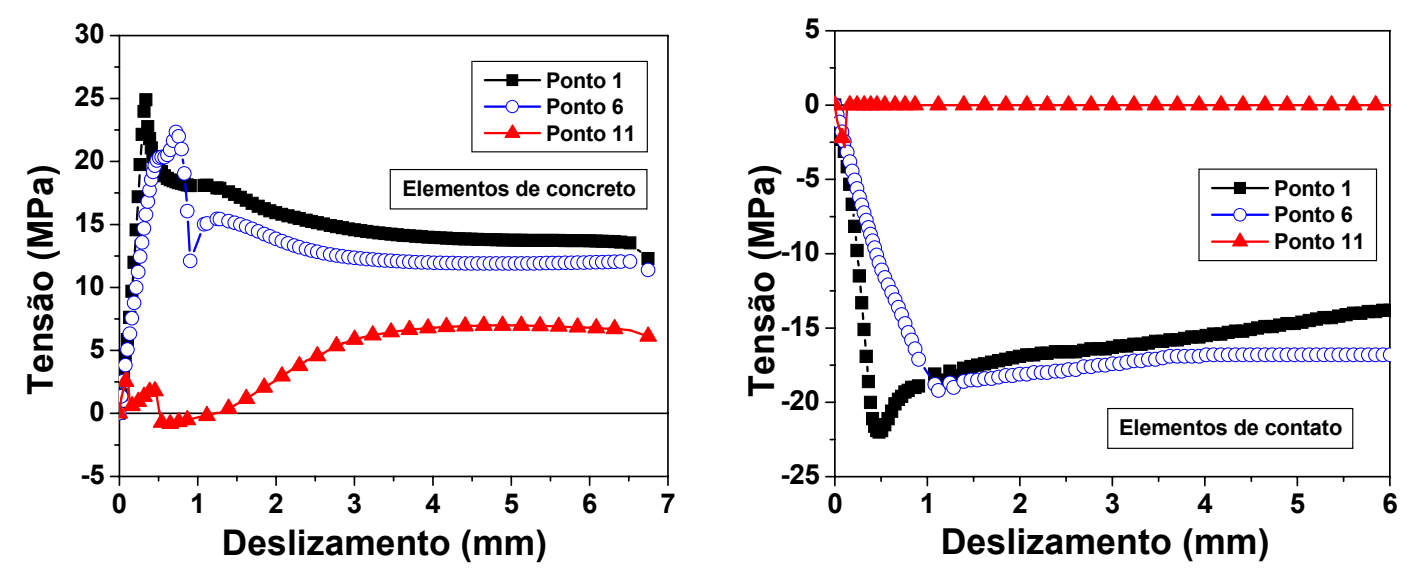

Figura 8.63 Variação das tensões nos elementos de concreto e elementos de contato

A Figura 8.64 ilustra as tensões principais na direção Z (sentido do deslizamento da barra em relação ao concreto) dos modelos numéricos de arrancamento com barra de $16 \mathrm{~mm}$ quando do passo de carga correspondente a força de arrancamento do modelo.
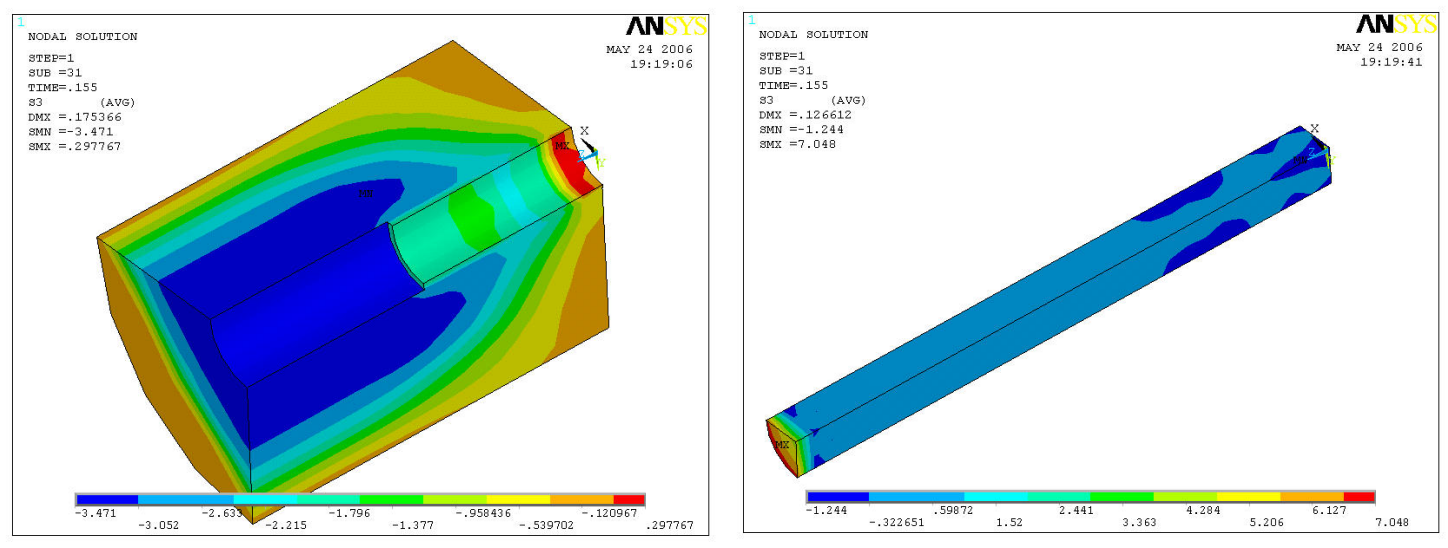

Figura 8.64 Tensões principais na direção $Z$ quando se atinge o passo de carga correspondente a força máxima de arrancamento

Do mesmo modo que os modelos de arrancamento com barra de $10 \mathrm{~mm}$, o prisma de concreto do modelo com barra de $16 \mathrm{~mm}$ permaneceu dentro dos limites característicos de resistência, nesse caso, à compressão, fornecendo uma boa aproximação do comportamento experimental do modelo, muito embora não se tenham dados experimentais para sua comprovação. Do mesmo modo, as tensões na barra se aço se portaram dentro do esperado, pois era previsto que não ocorresse escoamento da barra, por causa da resistência à compressão do concreto. 


\subsubsection{Modelos de viga}

O modelo numérico desenvolvido teve como parâmetros semelhantes o módulo de elasticidade e o carregamento aplicado e por isso, foi desenvolvido apenas um modelo numérico para cada diâmetro de barra.

Vale salientar que nos casos de verificação da superfície de contato, isto é, avaliação da distribuição e intensidade da resistência ao deslizamento do modelo numérico, tiveram como resultado para comparação o valor das deformações medidas no início e fim do comprimento de ancoragem e no meio da barra, ficando assim esses resultados como uma estimativa de como seria o comportamento da resistência ao deslizamento nessa superfície.

A Figura 8.65 mostra os pontos de medição para cada modelo de viga, que serão adotados como pontos de verificação das tensões na barra de aço e de resistência de aderência.

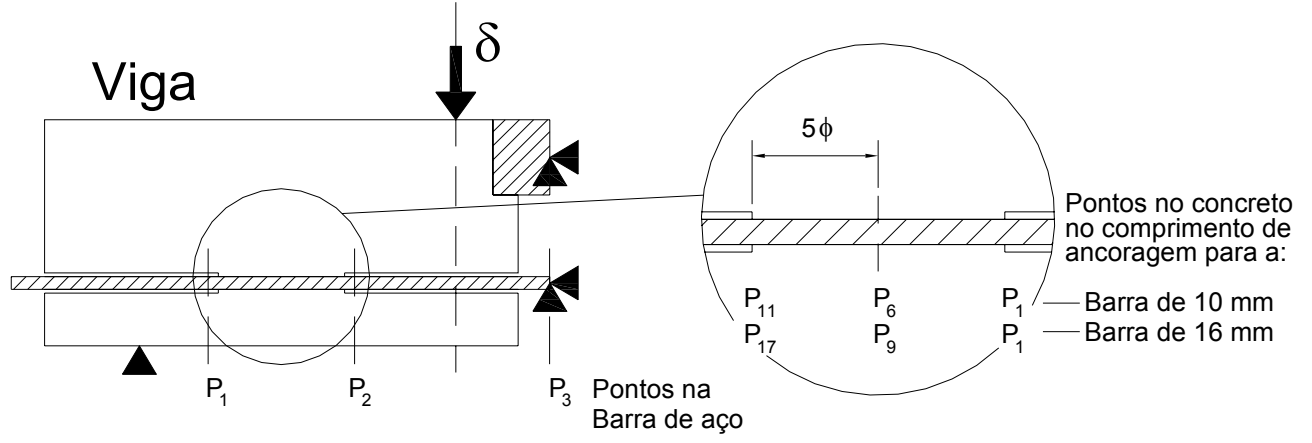

Figura 8.65 Pontos de medição para os modelos de viga

A Figura 8.66 ilustra a variação da resistência na superfície de contato durante o passo de carga da maior força de ruptura do modelo com barra de $10 \mathrm{~mm}$.

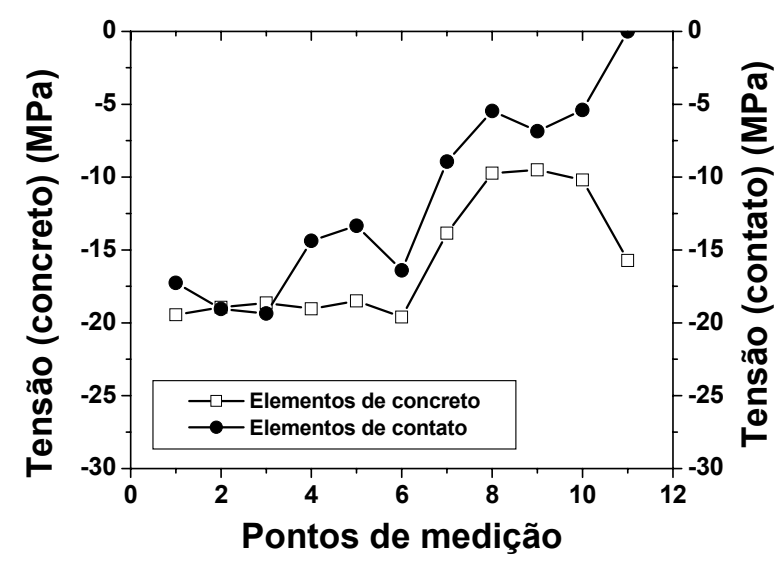

Figura 8.66 Tensão na superfície de contato para os modelos de viga com barra de 10 $\mathrm{mm}$ no passo de carga de força máxima aplicada 
Pode-se ver na Figura 8.71, que as tensões existentes em ambos os elementos (concreto e contato) são de tração, ao contrário do modelo de arrancamento que possuía elementos de concreto comprimidos. A distribuição das tensões foi satisfatória, denotando a maior resistência ao deslizamento nos pontos iniciais com uma redução da resistência a partir do ponto 6 (centro do trecho aderente).

A Figura 8.67 mostra a variação das tensões na superfície de contato e no concreto adjacente à barra de aço, no passo de carga de maior força de ruptura.
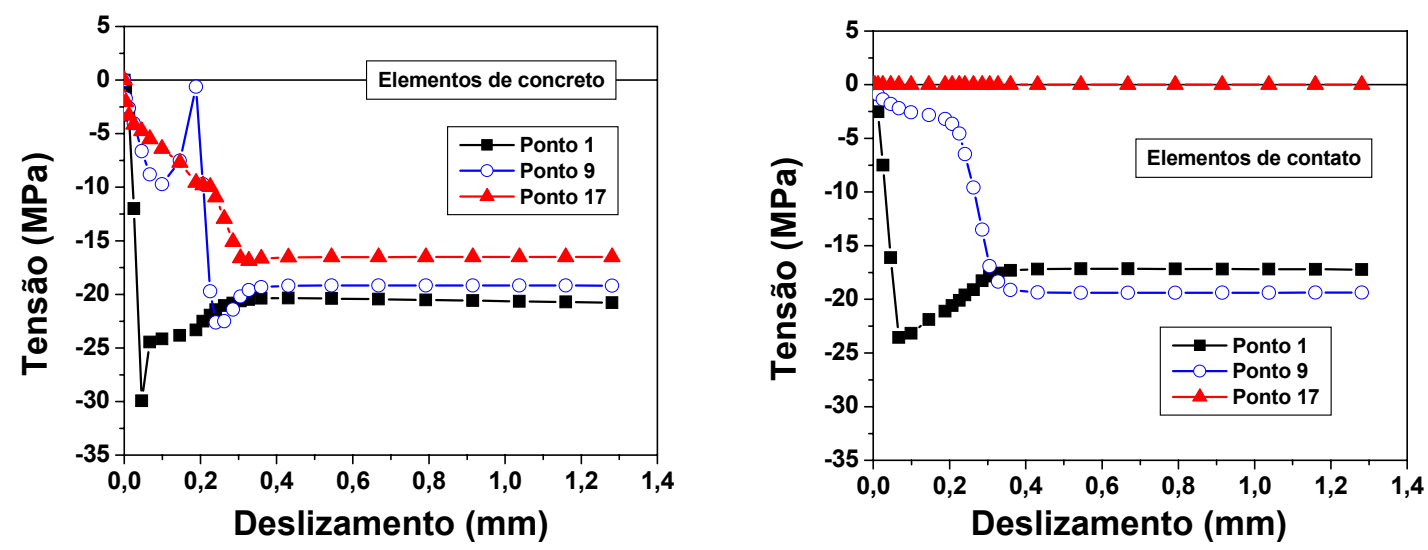

Figura 8.67 Variação das tensões nos elementos de concreto e elementos de contato

De acordo com a Figura 8.67, pode-se ver que o comportamento das tensões nos elementos de concreto e de contato foi semelhante, pois ambos permaneceram submetidos à tração. Ainda, os pontos 1 e 6 apresentaram comportamento similar enquanto o ponto 11 apresentou uma diferença significativa em seu comportamento, mostrando que os elementos de concreto possuem uma transferência gradual para as tensões, pois as tensões do ponto 6 são maiores que as do ponto 11. Já os elementos de contato apresentaram um comportamento diferente, pois as tensões no ponto 11 foram iguais à zero, e, portanto, inferiores as tensões do ponto 6 .

A Figura 8.68 ilustra as tensões principais dos modelos numéricos de viga com barra de $10 \mathrm{~mm}$ quando do passo de carga correspondente à força de ruptura do modelo. 


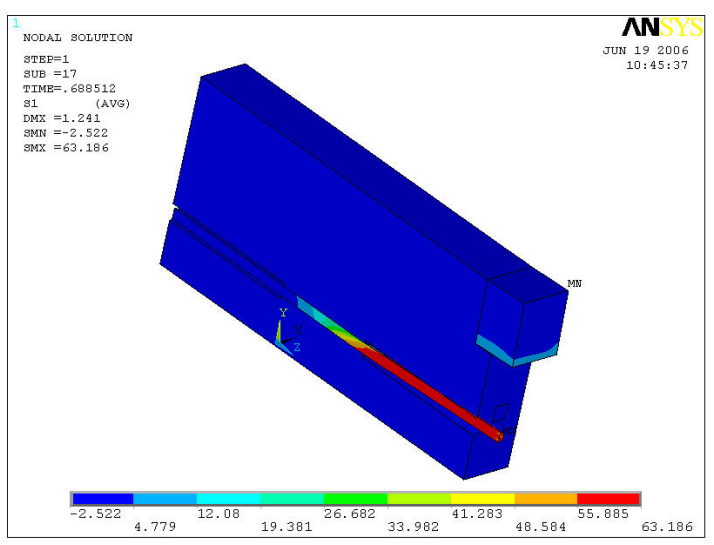

Direção Z - Completo

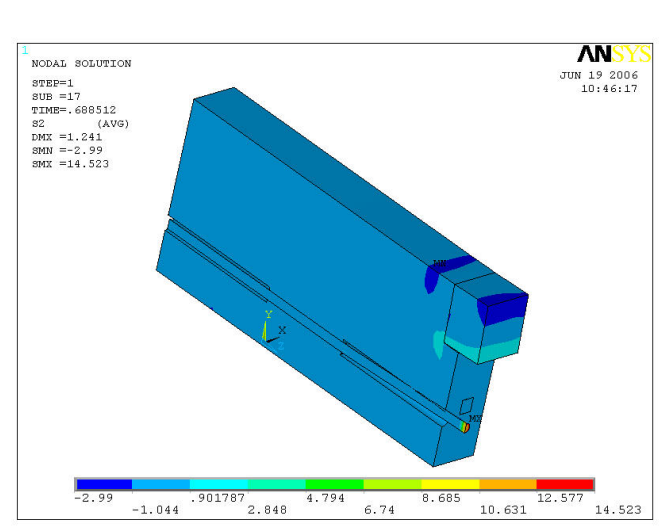

Direção X - Completo

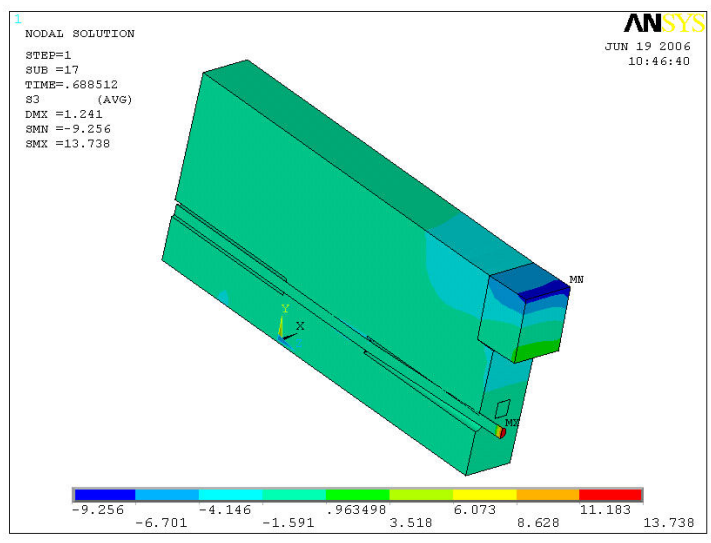

Direção Y - Completo

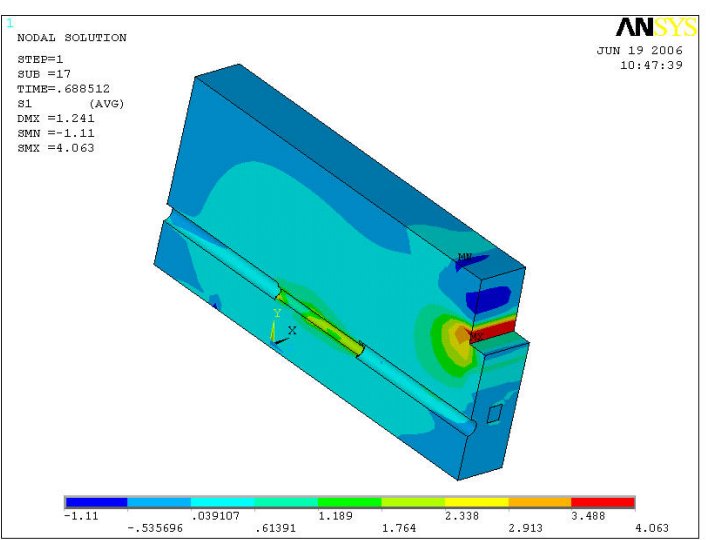

Direção Z - Concreto

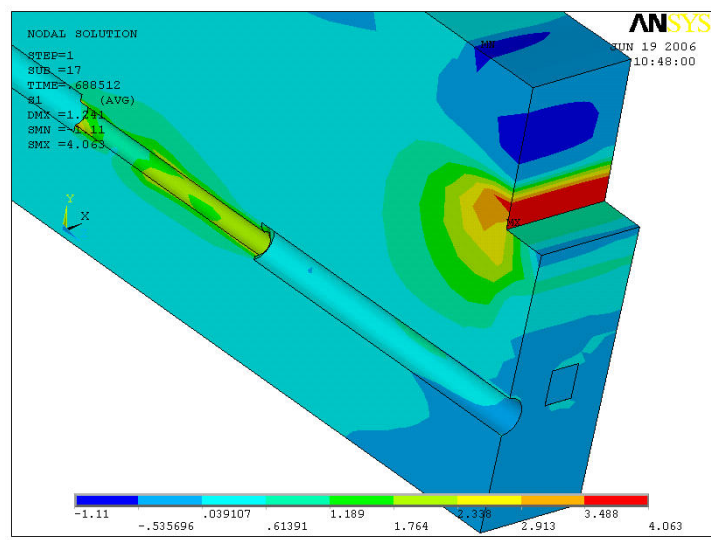

Direção Z - Concreto (detalhe)

Figura 8.68 Tensões principais quando se atinge o passo de carga correspondente a força máxima de viga

A Figura 8.69 ilustra a comparação entre as tensões provenientes dos resultados das deformações dos extensômetros elétricos de resistência do modelo experimental e as tensões do modelo numérico. 

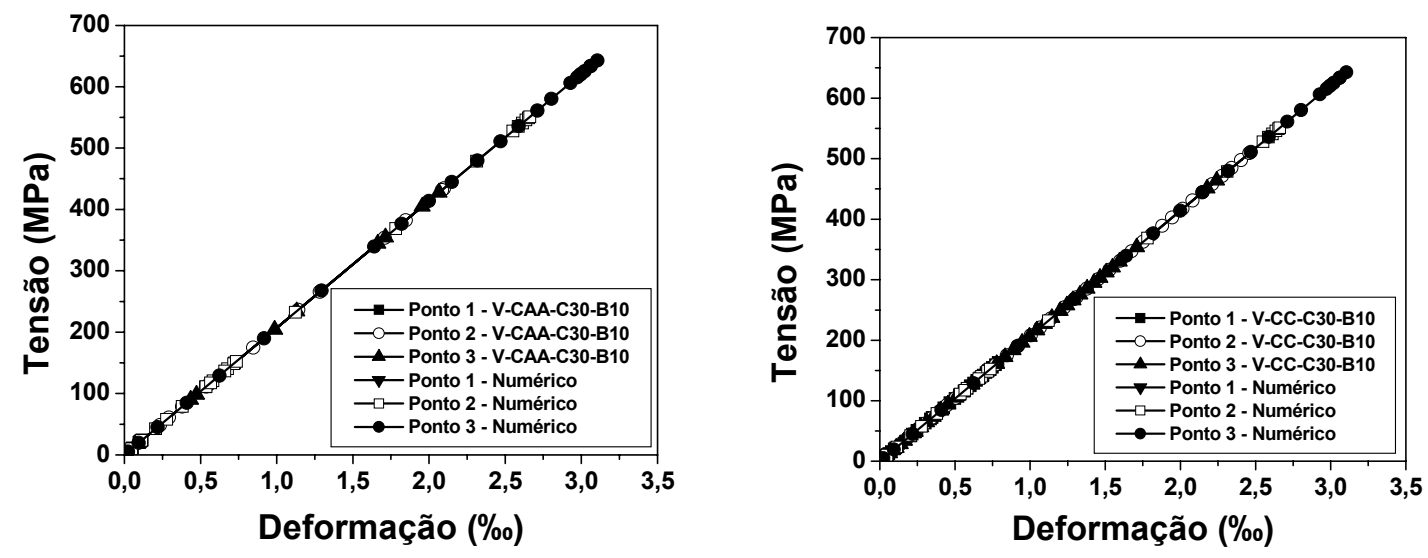

Figura 8.69 Tensões principais quando se atinge o passo de carga correspondente a força máxima de viga

A Figura 8.70 mostra a diferença entre os resultados obtidos para tensão na barra de aço.

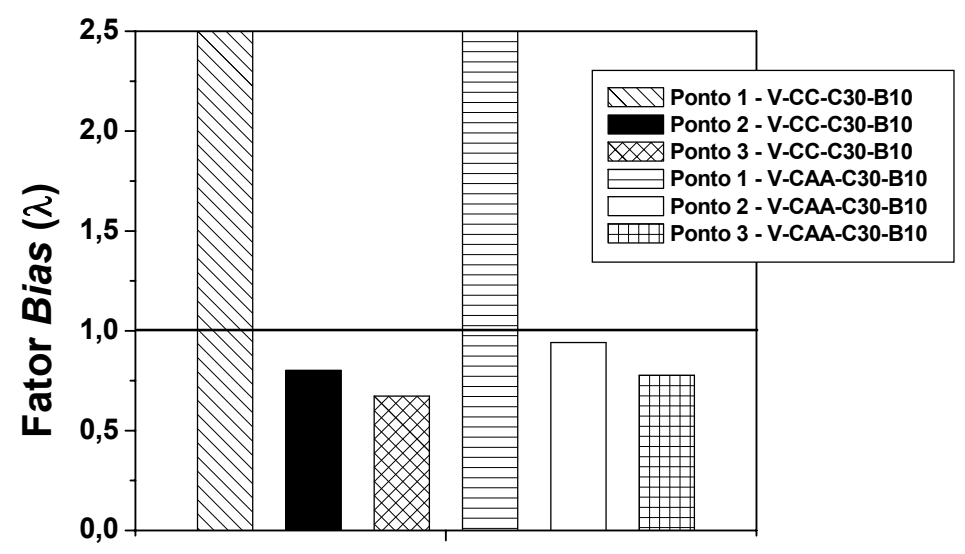

Figura 8.70 Diferença entre as tensões na barra de aço do modelo experimental e numérico

De acordo com a Figura 8.70, pode-se ver que o modelo numérico foi menos rígido que o modelo experimental, apresentando um comportamento satisfatório na representação das tensões nos pontos 2 e 3 . Já a deformação no ponto 1 apresentou muita diferença uma vez que no modelo numérico houve pouca transferência de esforços para esta região da barra ( $\sigma_{y}$ máximo do ensaio no ponto 1 foi de $24,5 \mathrm{MPa}$, para o modelo em CAA e 98,66 MPa para o modelo em CC) e por isso, se encontram fora de escala, conforme a Figura 8.70.

Com relação aos modelos com barra de $16 \mathrm{~mm}$, a Figura 8.71 ilustra a variação da resistência na superfície de contato durante o passo de carga da maior força de ruptura. 


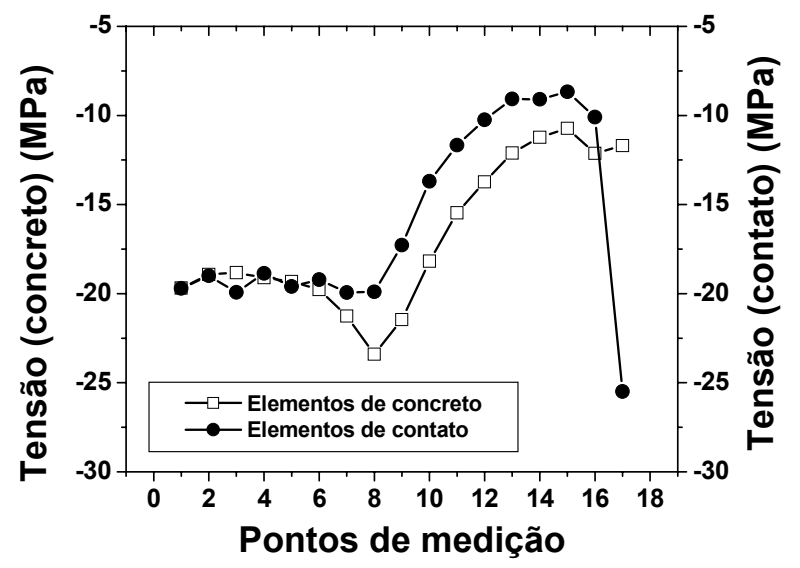

Figura 8.71 Tensão na superfície de contato para os modelos de viga com barra de 16 $\mathrm{mm}$ no passo de carga de força máxima aplicada

Pode-se ver na Figura 8.71, que as tensões existentes em ambos os elementos (concreto e contato) são de tração, ao contrário do modelo de arrancamento que possuía elementos de contato comprimidos. A distribuição das tensões foi satisfatória, denotando a maior resistência ao deslizamento nos pontos iniciais com uma redução da resistência a partir do ponto 8 (centro do trecho aderente).

A Figura 8.72 mostra a variação das tensões na superfície de contato e no concreto adjacente à barra de aço.
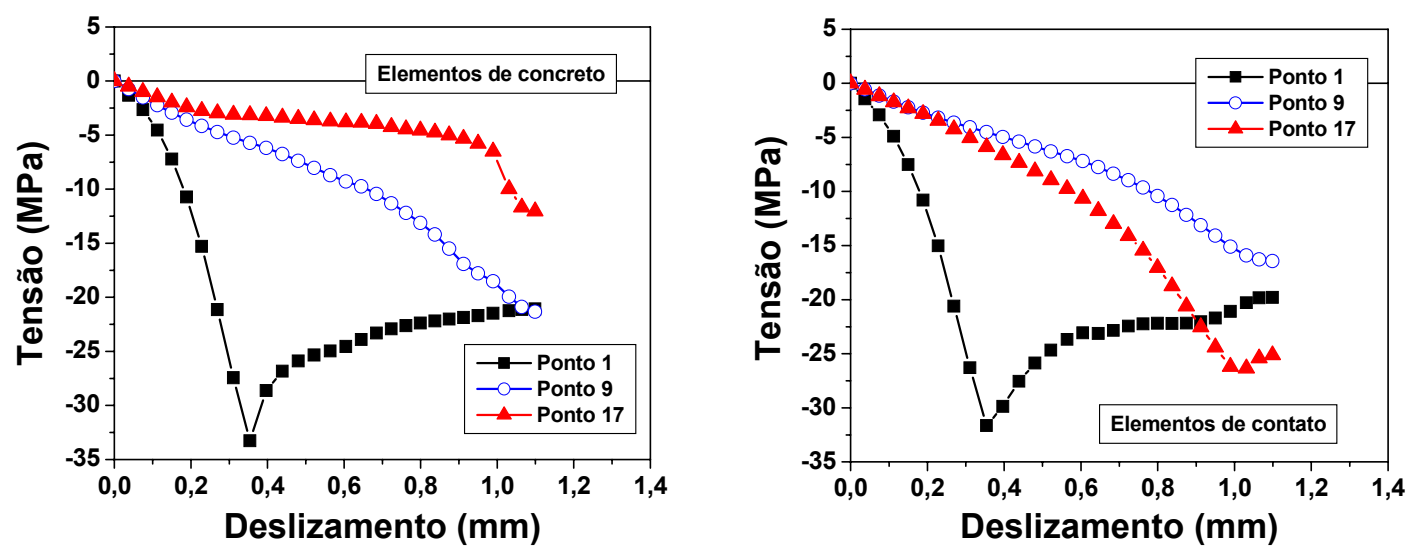

Figura 8.72 Variação das tensões nos elementos de concreto e elementos de contato

A Figura 8.73 ilustra as tensões principais dos modelos numéricos de viga com barra de $16 \mathrm{~mm}$ quando do passo de carga correspondente à força de ruptura do modelo. 


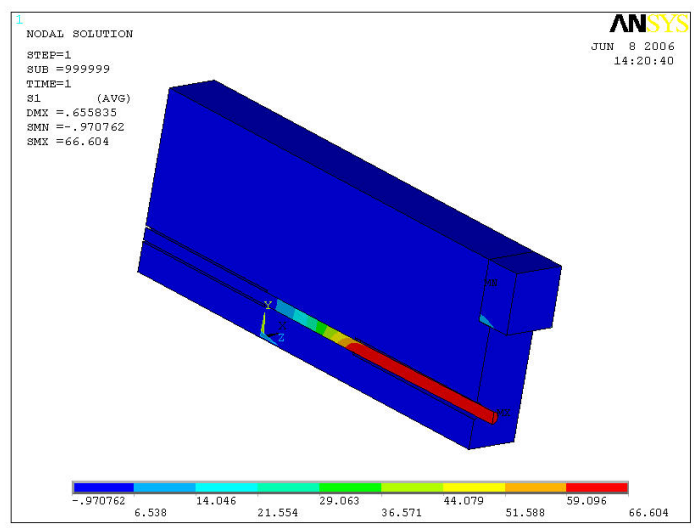

Direção Z - Completo

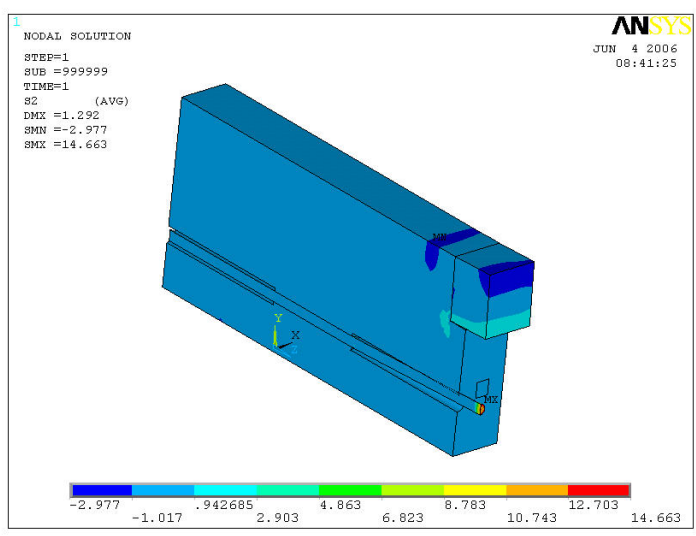

Direção X - Completo

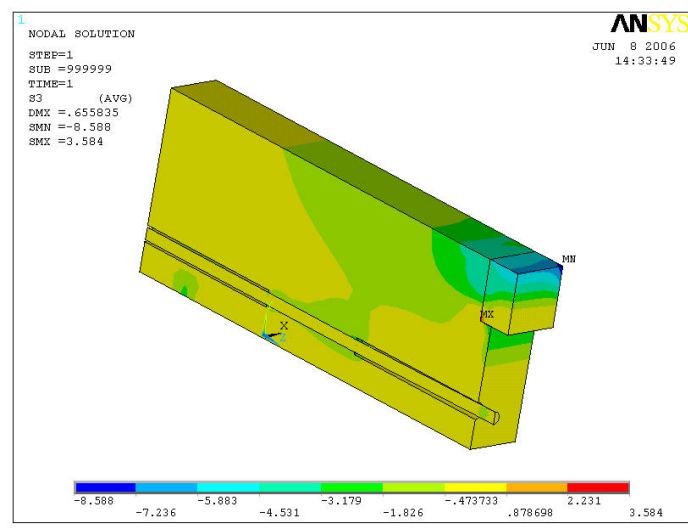

Direção Y - Completo

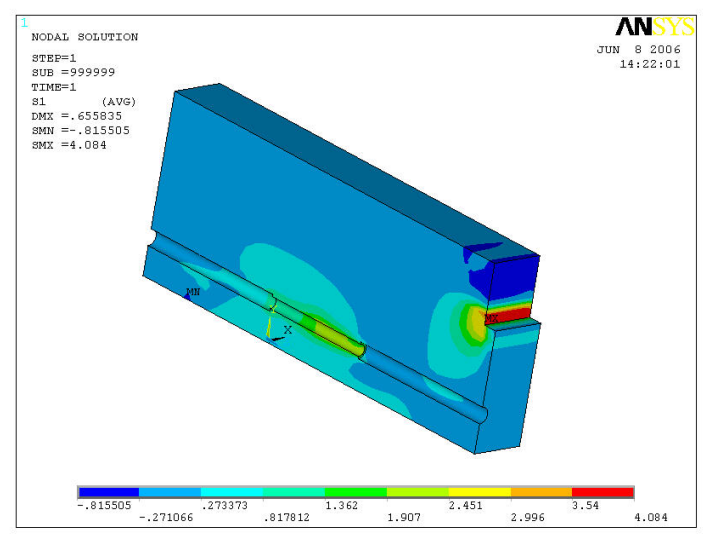

Direção Z - Concreto

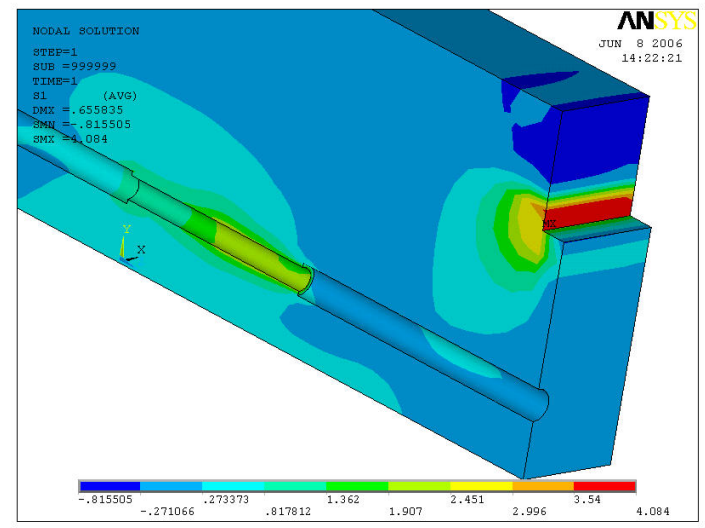

Direção Z - Concreto (detalhe)

Figura 8.73 Tensões principais quando se atinge o passo de carga correspondente a força máxima de viga

De acordo com a Figura 8.72, pode-se ver que o comportamento das tensões nos elementos de concreto e de contato foi semelhante, pois ambos permaneceram submetidos à tração. Ainda, o ponto 1 apresentou comportamento similar enquanto os pontos 9 e 17 apresentaram uma diferença significativa em seu comportamento, mostrando que os elementos de concreto possuem uma transferência gradual para as 
tensões, pois as tensões do ponto 8 são maiores que as do ponto 17. Já os elementos de contato apresentaram um comportamento diferente, pois as tensões no ponto 17 foram maiores que as do ponto 8.

A Figura 8.74 ilustra a comparação entre as tensões provenientes dos resultados das deformações dos extensômetros elétricos de resistência do modelo experimental e as tensões do modelo numérico.
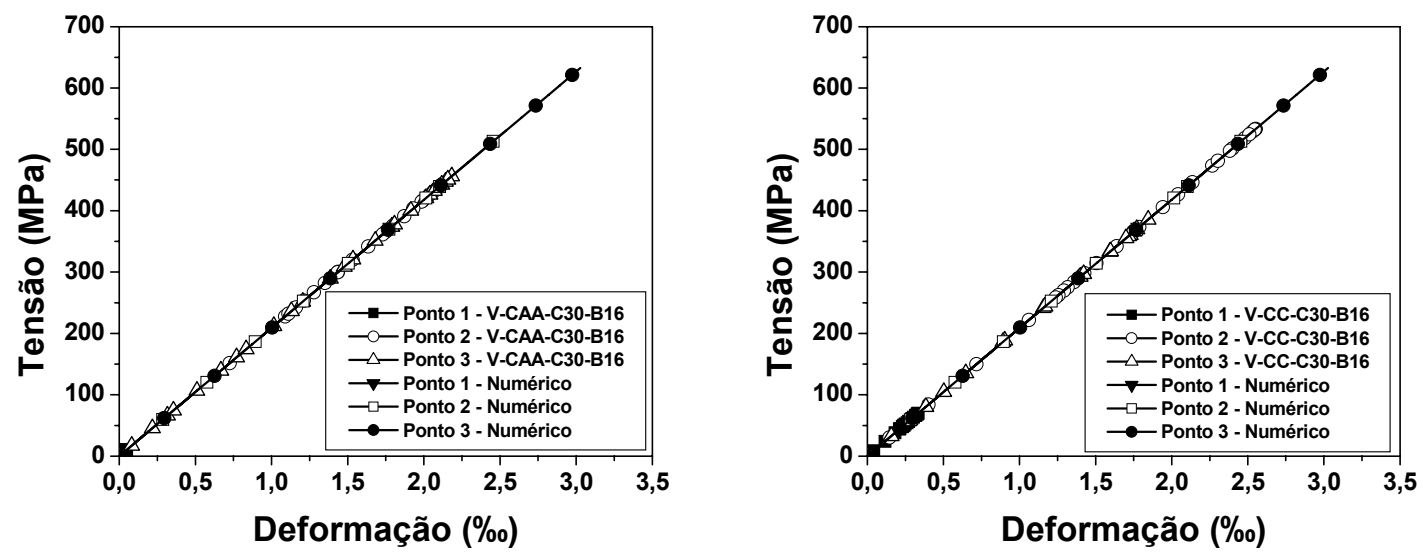

Figura 8.74 Tensões principais quando se atinge o passo de carga correspondente a força máxima de viga

A Figura 8.75 mostra a diferença entre os resultados obtidos para tensão na barra de aço.

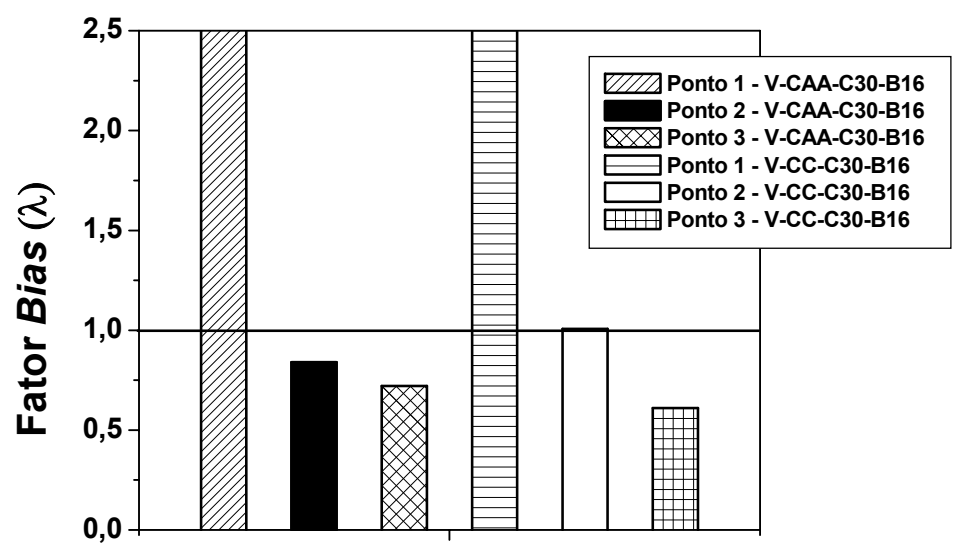

Figura 8.75 Diferença entre as tensões na barra de aço do modelo experimental e numérico

De acordo com a Figura 8.75 , pode-se ver que o modelo numérico foi mais deformável que o modelo experimental, entretanto o comportamento foi satisfatório na representação das tensões no ponto 2 , pois foi possível se estimar as tensões na barra de aço com uma diferença máxima de $17 \%$ para o modelo em CAA, e em 0,7\% para o modelo em $\mathrm{CC}$, entretanto o ponto 3 se mostrou muito deformável e a 
aproximação do modelo em CAA ficou em $28 \%$ e a aproximação para o modelo em CC ficou em $39 \%$. A deformação no ponto 1 apresentou muita diferença uma vez que no modelo numérico houve pouca transferência de esforços para esta região da barra ( $\sigma_{y}$ máximo do ensaio no ponto 1 foi de $30 \mathrm{MPa}$ ) e por isso, se encontram fora de escala na Figura 8.75.

\subsubsection{Série 2}

Neste segmento se apresenta a análise dos resultados para os modelos numéricos de arrancamento e de viga da série 2, realizados no Capítulo 7.

\subsubsection{Modelos de arrancamento}

O comportamento dos ensaios dos modelos de arrancamento em CC e em CAA foi similar e por isso, foi desenvolvido um modelo numérico para cada diâmetro de barra.

Do mesmo modo que nos modelos de arrancamento da série 1, vale salientar que nos casos de verificação da superfície de contato, isto é, avaliação da distribuição e intensidade da resistência ao deslizamento do modelo numérico não tiveram modelo para comparação, ficando assim esses resultados como uma estimativa de como seria o comportamento da resistência ao deslizamento nessa superfície.

A variação da resistência de aderência na superfície de contato na Figura 8.76 foi tomada no último passo de carga, para verificar a tensão quando do deslizamento máximo, tanto para o concreto convencional quanto para o auto-adensável.

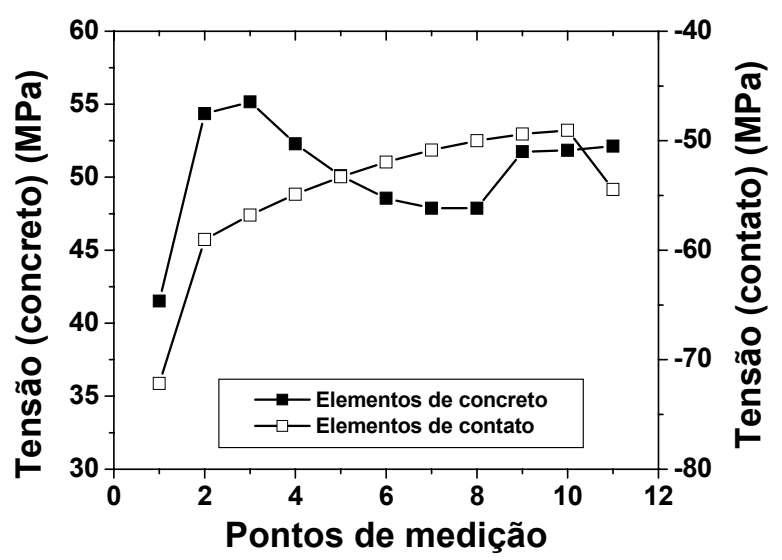

Figura 8.76 Tensão na superfície de contato para os modelos de arrancamento com barra de $10 \mathrm{~mm}$ no último passo de carga 
Embora o modelo numérico possa representar satisfatoriamente 0 comportamento do ensaio de arrancamento, não foi possível representar a variação da resistência de aderência na superfície de contato (utilizando elementos de contato). Assim, se avaliou a variação das tensões no prisma de concreto na superfície mais próxima à superfície de contato e as dos elementos na superfície de contato (Figura 8.77). Essas tensões foram tomadas a partir do ponto 11 mostrado no Capítulo 7. O valor encontrado tanto para as tensões no concreto quanto no contato foram similares para ambos os modelos, porém mesmo que o modelo Rough represente o comportamento do ensaio, ele não conseguiu representar o valor da resistência de aderência.
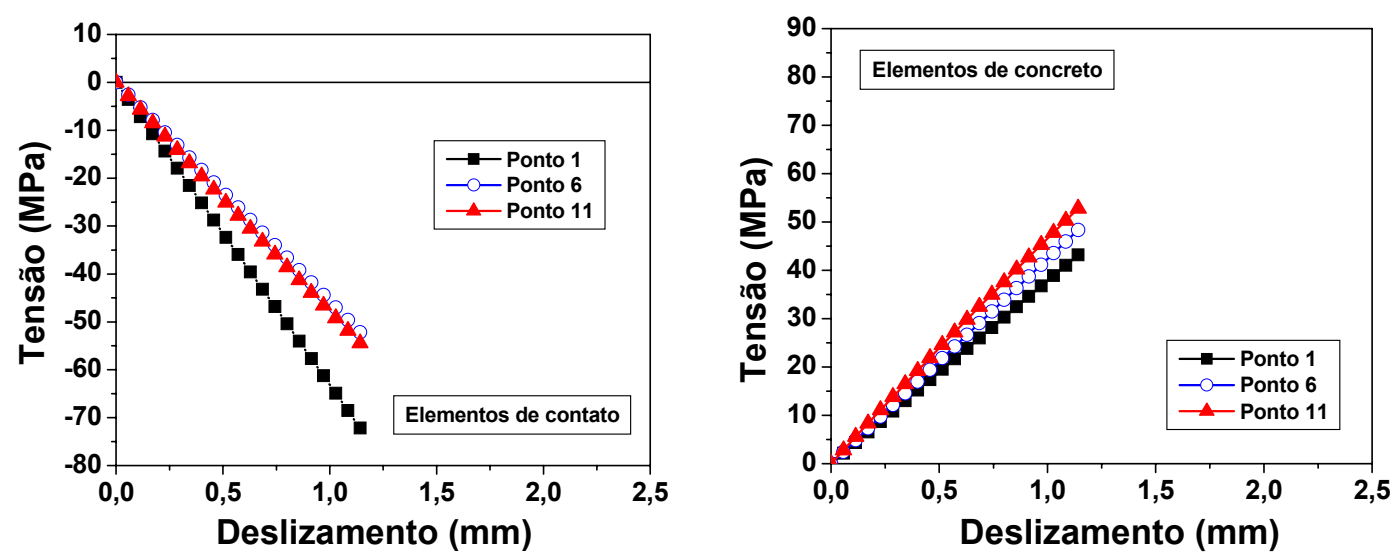

Figura 8.77 Variação das tensões nos elementos de contato e de concreto para o modelo de arrancamento com barra de $10 \mathrm{~mm}$

A Figura 8.78 ilustra as tensões principais na direção $Z$ (sentido do deslizamento da barra em relação ao concreto) dos modelos numéricos de arrancamento com barra de $10 \mathrm{~mm}$ quando do passo de carga correspondente à força de arrancamento do modelo.
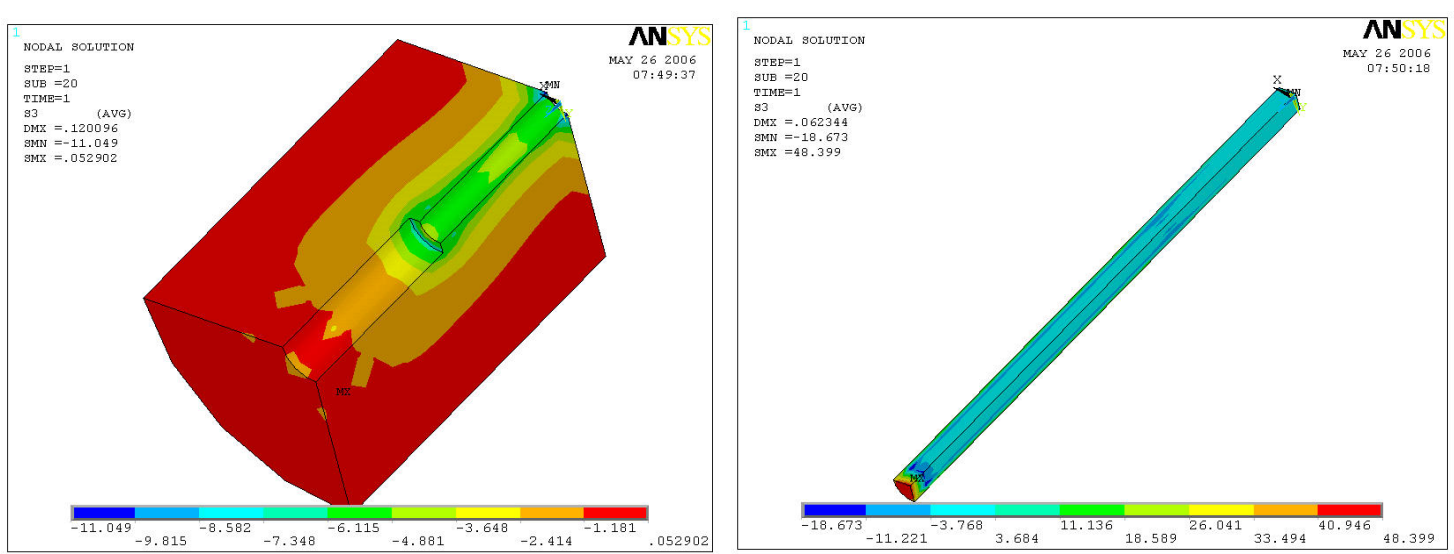

Figura 8.78 Tensões principais na direção $Z$ quando se atinge o passo de carga correspondente a força máxima de arrancamento 
Com relação aos modelos de arrancamento com barra de $16 \mathrm{~mm}$, a Figura 8.79 a variação da resistência na interface aço-concreto tomada para o último passo de carga do modelo numérico, que coincidiu com o passo de carga que atingiu a maior força de arrancamento.

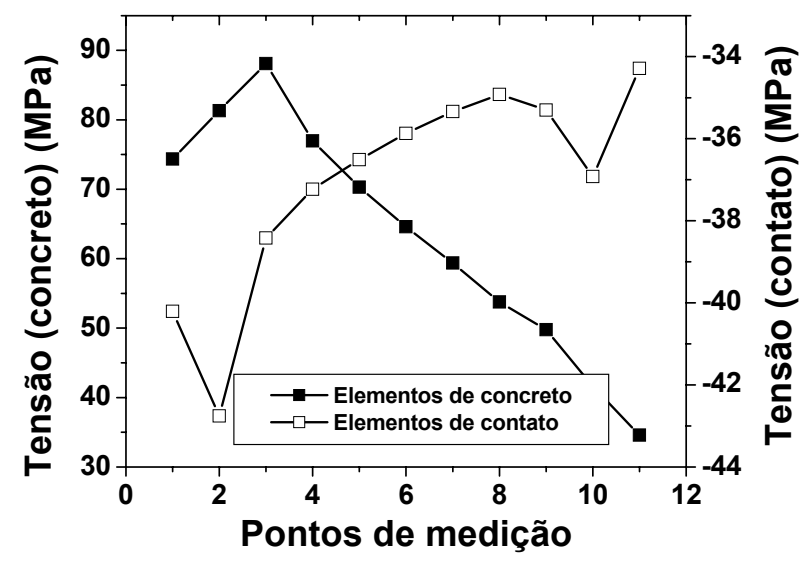

Figura 8.79 Tensão na superfície de contato para os modelos de arrancamento com barra de $16 \mathrm{~mm}$ no último passo de carga

A Figura 8.80 mostra a variação das tensões na superfície de contato e no concreto adjacente à barra de aço.
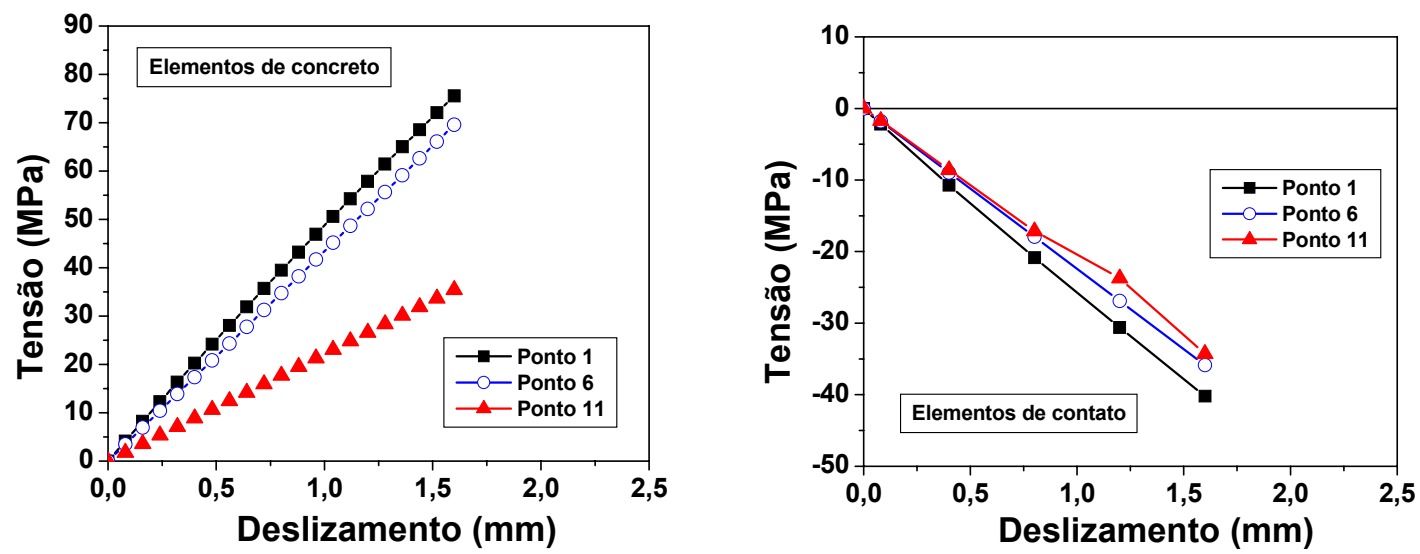

Figura 8.80 Variação das tensões no concreto e no contato com barra de $16 \mathrm{~mm}$

A Figura 8.81 ilustra as tensões principais na direção $Z$ (sentido do deslizamento da barra em relação ao concreto) dos modelos numéricos de arrancamento com barra de $16 \mathrm{~mm}$ quando do passo de carga correspondente à força de arrancamento do modelo. 

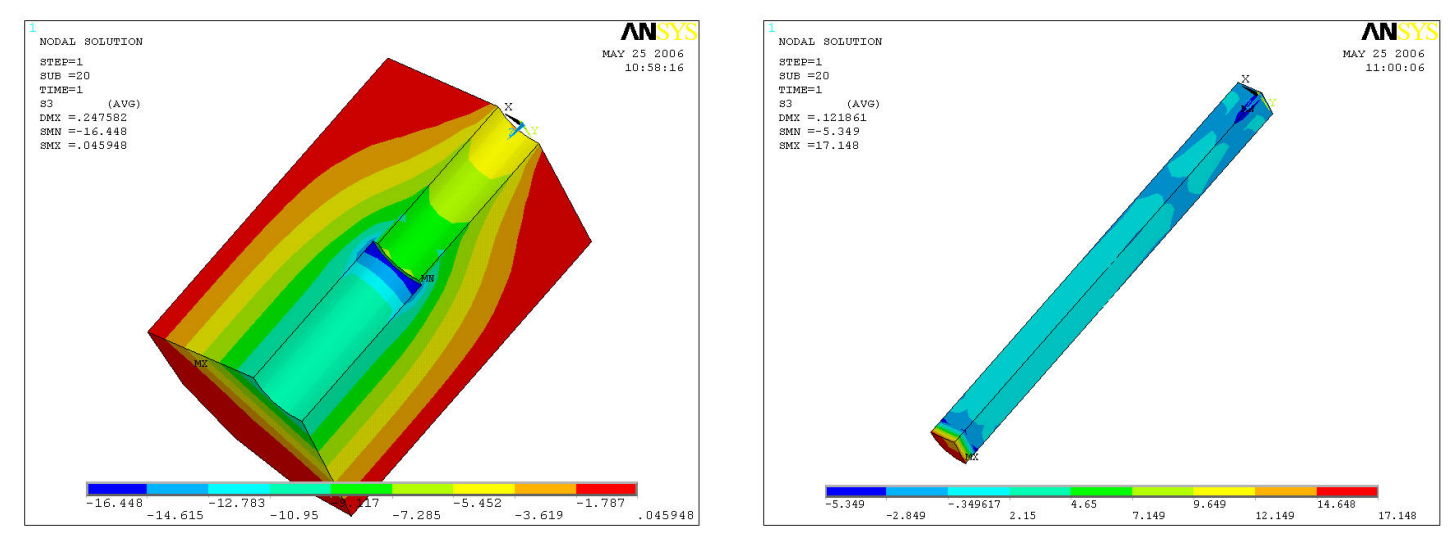

Figura 8.81 Tensões principais na direção $Z$ quando se atinge o passo de carga correspondente a força máxima de arrancamento

A Figura 8.78 e a Figura 8.81 mostram que as tensões de tração (em vermelho) permanecem no contorno do modelo, demonstrando o aumento das tensões que provocam o fendilhamento do concreto, fato que ocorreu nos ensaios de arrancamento desta série. Ainda, pode-se ver que as tensões na barra de aço permanecem muito abaixo do seu limite de escoamento, entretanto não se tem dados experimentais para corroborar essa afirmação.

Assim, o prisma de concreto do modelo com barra de $16 \mathrm{~mm}$ permaneceu dentro dos limites característicos de resistência até o limite de ruptura do ensaio que se deu por fendilhamento fornecendo uma boa aproximação do comportamento experimental do modelo, muito embora não se tenham dados experimentais para sua comprovação.

\subsubsection{Modelos de viga}

A Figura 8.82 ilustra a variação da resistência na superfície de contato durante o passo de carga da maior força de ruptura do modelo com barra de $10 \mathrm{~mm}$.

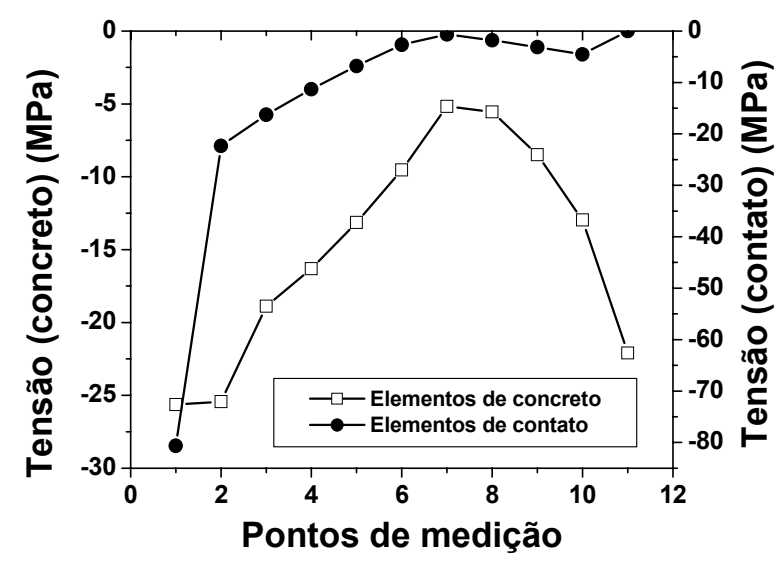

Figura 8.82 Tensão na superfície de contato para os modelos de viga com barra de 10 $\mathrm{mm}$ no passo de carga de força máxima aplicada 
Pode-se ver na Figura 8.82, que as tensões existentes em ambos os elementos (concreto e contato) são de tração, ao contrário do modelo de arrancamento que possuía elementos de concreto comprimidos. A distribuição das tensões foi satisfatória, denotando a maior resistência ao deslizamento nos pontos iniciais com uma redução da resistência até o ponto 7 , com um posterior acréscimo de resistência, para ambos elementos. Entretanto, os elementos de contato apresentaram tensões elevadas (cerca de $80 \mathrm{MPa}$ no ponto 1) enquanto os elementos de concreto, no ponto 1 , registraram cerca de $25 \mathrm{MPa}$.

A Figura 8.83 mostra a variação das tensões na superfície de contato e no concreto adjacente à barra de aço, no passo de carga de maior força de ruptura.
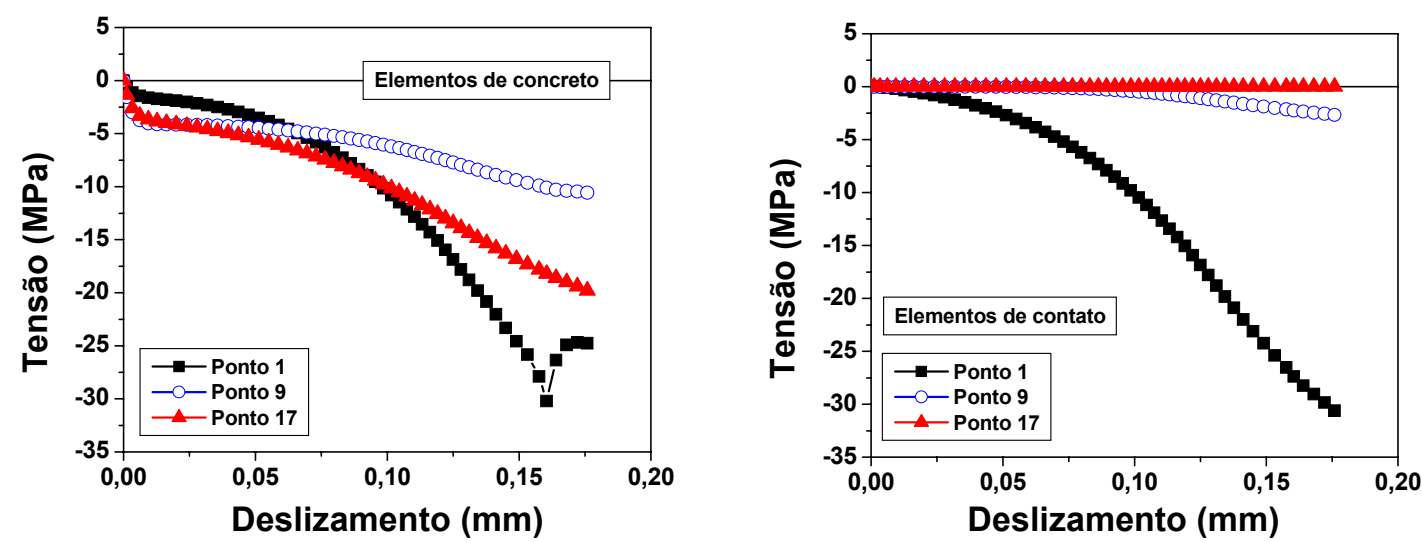

Figura 8.83 Variação das tensões nos elementos de concreto e elementos de contato

De acordo com a Figura 8.83, pode-se ver que o comportamento das tensões nos elementos de concreto e de contato foi semelhante, pois ambos permaneceram submetidos à tração. Ainda, no caso dos elementos de concreto, os pontos 1 e 11 apresentaram comportamento similar enquanto o ponto 6 apresentou uma diferença significativa em seu comportamento. Já os elementos de contato apresentaram um comportamento similar aos modelos com barra de $10 \mathrm{~mm}$ da série 1 , pois as tensões no ponto 11 foram iguais à zero, e, portanto, inferiores as tensões do ponto 6 , mostrando uma redução gradual da resistência de aderência ao longo do comprimento de ancoragem.

A Figura 8.84 ilustra as tensões principais dos modelos numéricos de viga com barra de $10 \mathrm{~mm}$ quando do passo de carga correspondente à força de ruptura do modelo. 


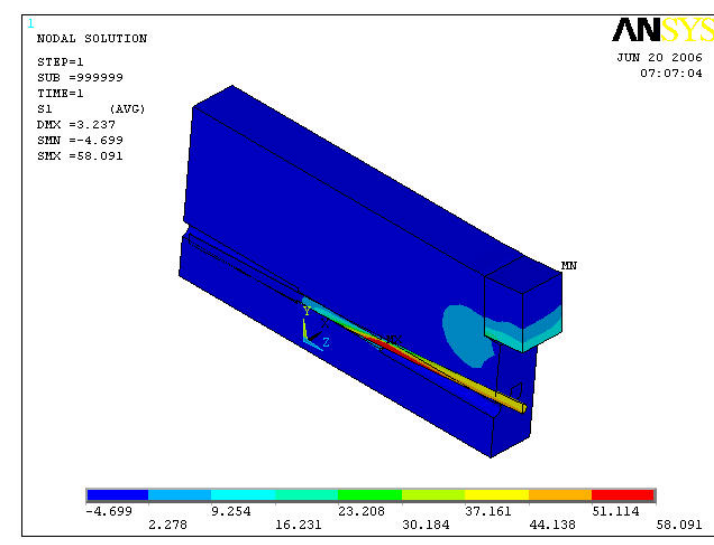

Direção Z - Completo

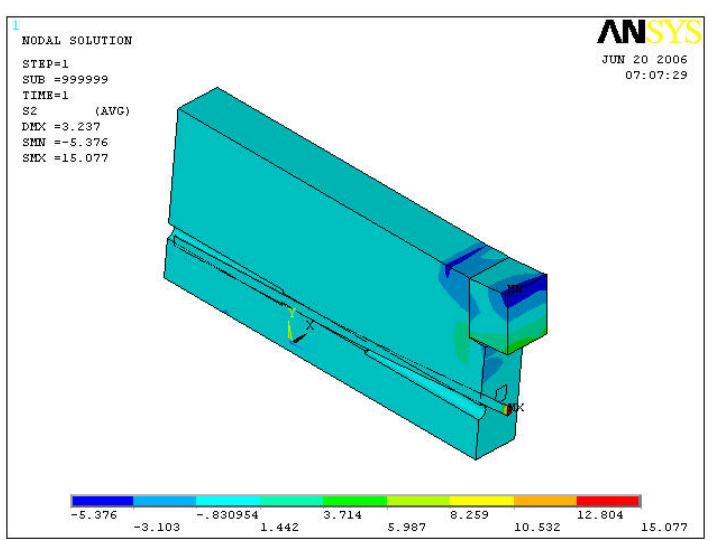

Direção X - Completo

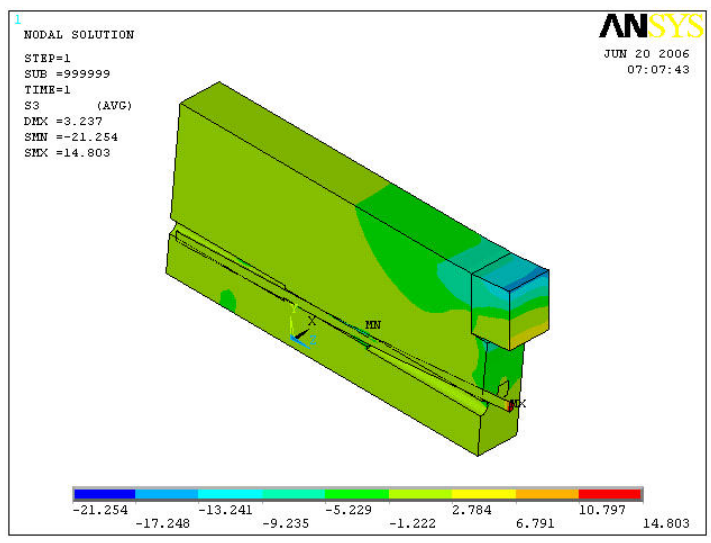

Direção $\mathrm{Y}$ - Completo

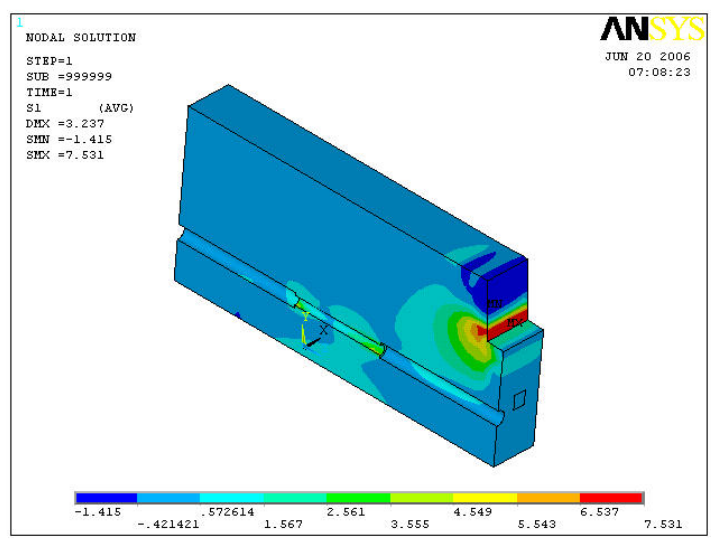

Direção Z - Concreto

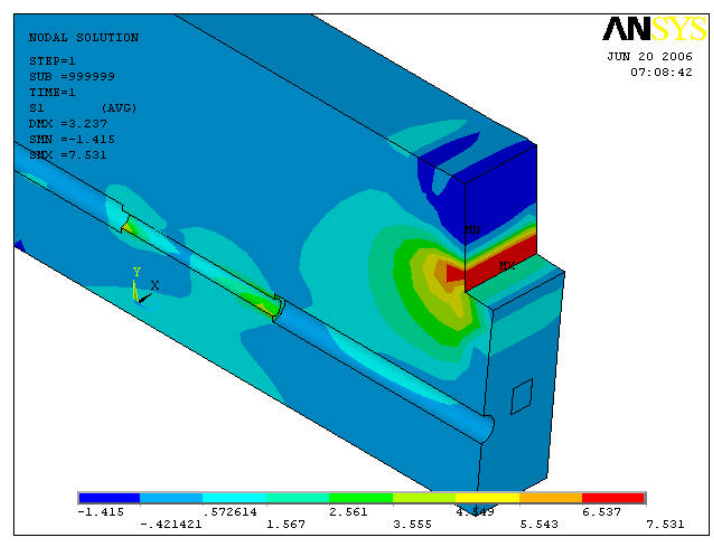

Direção Z - Concreto (detalhe)

Figura 8.84 Tensões principais quando se atinge o passo de carga correspondente a força máxima de viga

A Figura 8.85 ilustra a comparação entre as tensões provenientes dos resultados das deformações dos extensômetros elétricos de resistência do modelo experimental e as tensões do modelo numérico. 

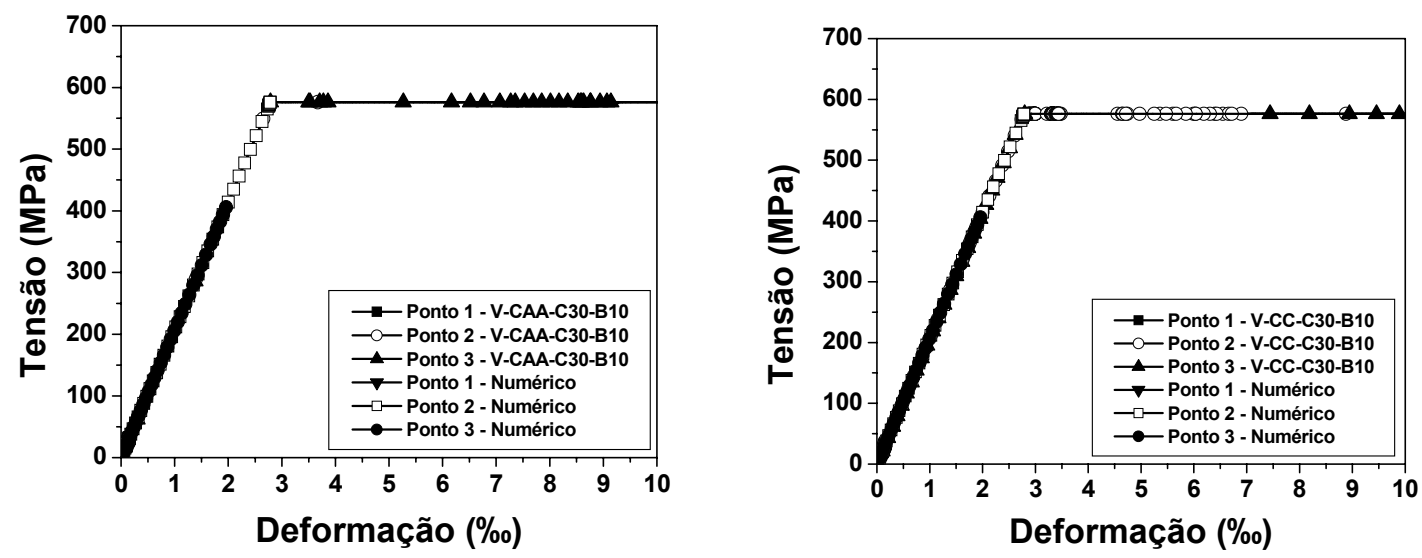

Figura 8.85 Tensões principais quando se atinge o passo de carga correspondente a força máxima de viga

A Figura 8.86 mostra a diferença entre os resultados obtidos para tensão na barra de aço.

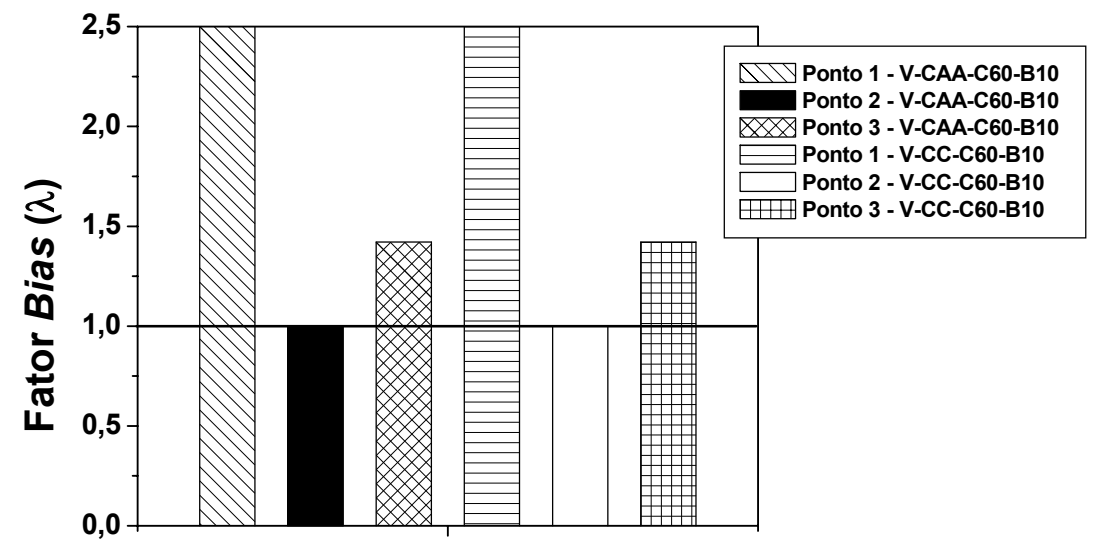

Figura 8.86 Diferença entre as tensões na barra de aço do modelo experimental e numérico

De acordo com a Figura 8.86, pode-se ver que o modelo numérico foi menos rígido que o modelo experimental, apresentando um comportamento satisfatório na representação das tensões nos pontos 2 e 3 . Já a deformação no ponto 1 apresentou muita diferença uma vez que no modelo numérico houve pouca transferência de esforços para esta região da barra ( $\sigma_{y}$ máximo do ensaio no ponto 1 foi de $32,2 \mathrm{MPa}$, para o modelo em CAA e 35,01 MPa para o modelo em CC) e por isso, se encontram fora de escala, conforme a Figura 8.86.

Com relação aos modelos com barra de $16 \mathrm{~mm}$, a Figura 8.87 ilustra a variação da resistência na superfície de contato durante o passo de carga da maior força de ruptura. 


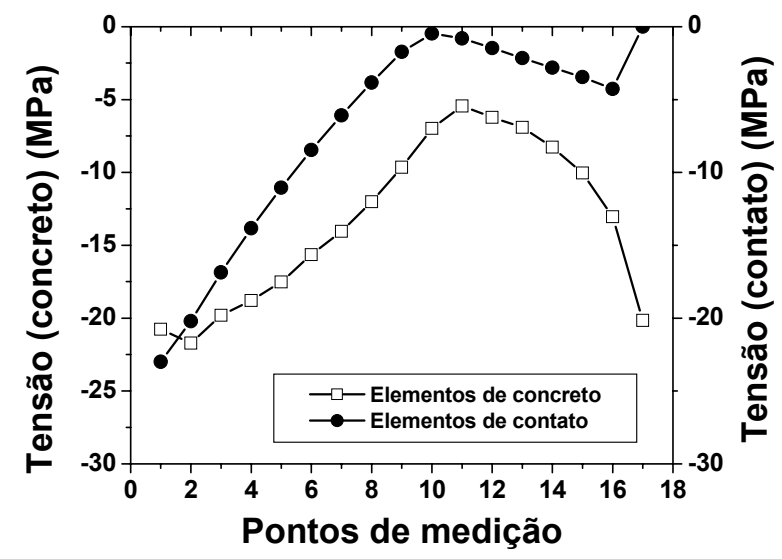

Figura 8.87 Tensão na superfície de contato para os modelos de viga com barra de 16 $\mathrm{mm}$ no passo de carga de força máxima aplicada

Pode-se ver na Figura 8.87, que as tensões existentes em ambos os elementos (concreto e contato) são de tração, ao contrário do modelo de arrancamento que possuía elementos de concreto comprimidos. A distribuição das tensões foi satisfatória, denotando a maior resistência ao deslizamento nos pontos iniciais com uma redução da resistência até o ponto 11, e, a partir desse ponto, ocorreu um aumento na resistência ao deslizamento.

A Figura 8.88 mostra a variação das tensões na superfície de contato e no concreto adjacente à barra de aço.
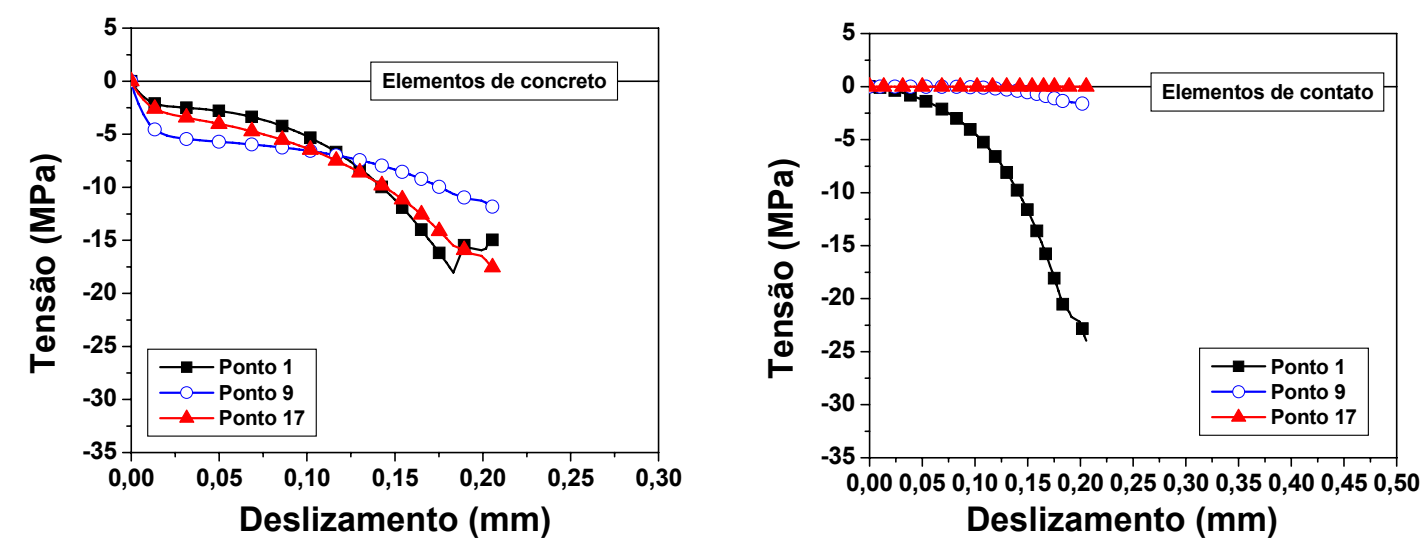

Figura 8.88 Variação das tensões nos elementos de concreto e elementos de contato

A Figura 8.89 ilustra as tensões principais dos modelos numéricos de viga com barra de $16 \mathrm{~mm}$ quando do passo de carga correspondente à força de ruptura do modelo. 


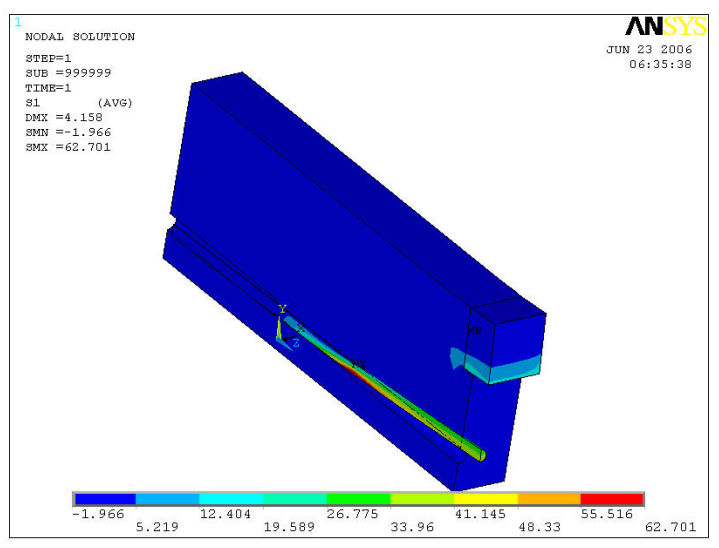

Direção Z - Completo

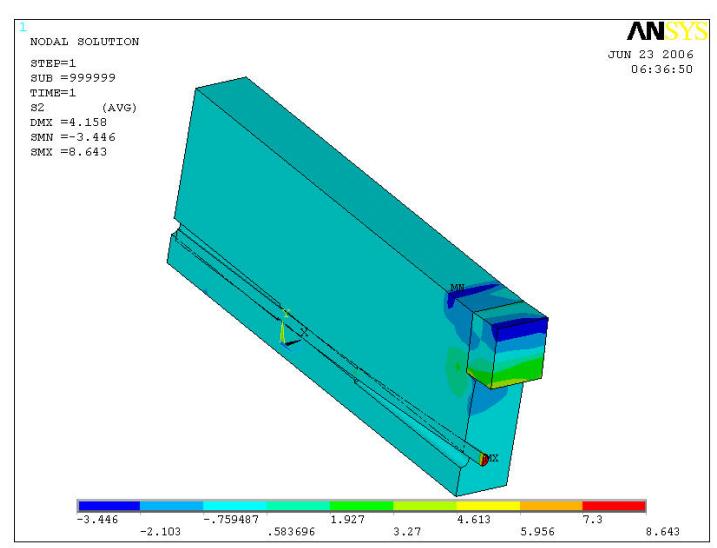

Direção X - Completo

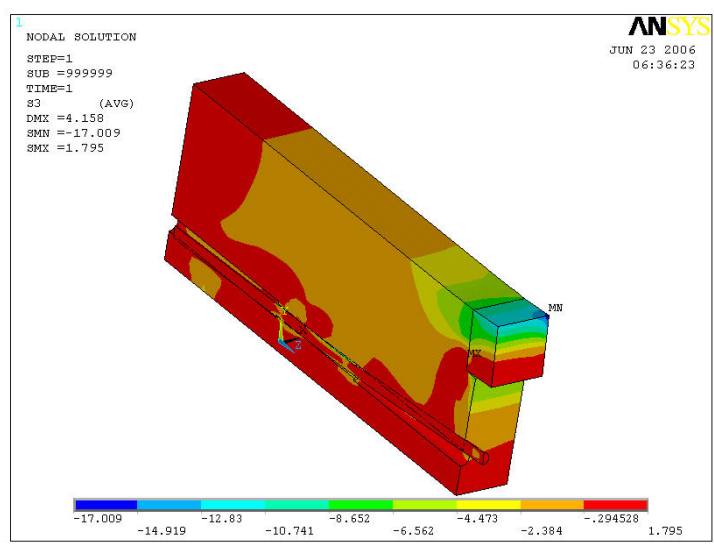

Direção Y - Completo

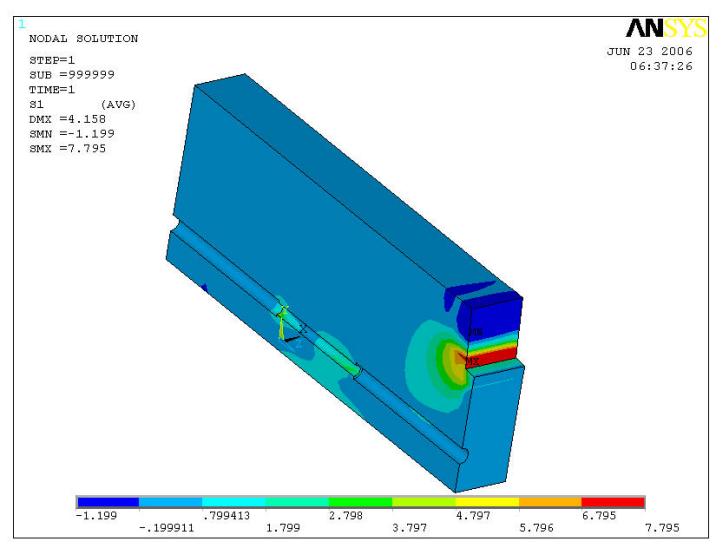

Direção Z - Concreto

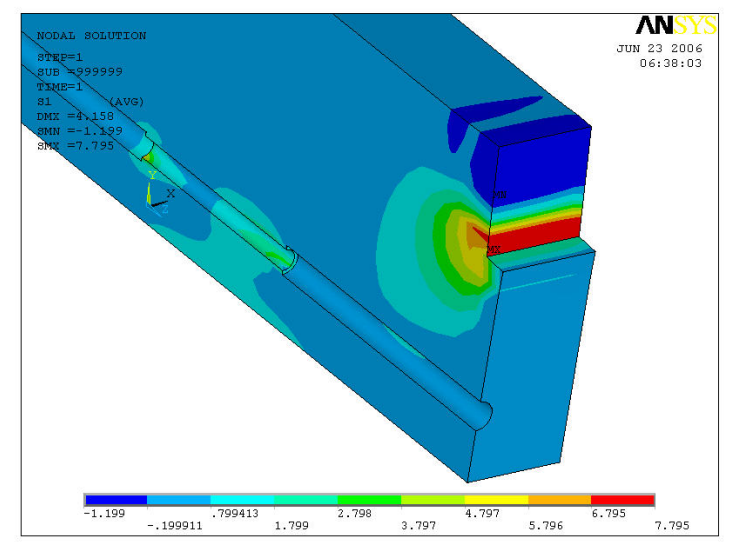

Direção Z - Concreto (detalhe)

Figura 8.89 Tensões principais quando se atinge o passo de carga correspondente a força máxima de viga

De acordo com a Figura 8.88, pode-se ver que o comportamento das tensões nos elementos de concreto e de contato foi semelhante ao caso com barra de $10 \mathrm{~mm}$ desta mesma série. Ainda, os elementos de concreto apresentaram um comportamento semelhante para os pontos 1,9 e 17 , mostrando que as tensões resistentes nos elementos adjacentes a superfície de contato resistem ao 
deslizamento de uma forma quase uniforme, entretanto, as tensões no ponto 17 foram superiores às tensões do ponto 9 , mostrando que há uma oscilação entre os elementos de concreto que resistem ao deslizamento. Já os elementos de contato apresentaram um comportamento diferente, pois a Figura 8.88 mostra que o ponto 1 é o maior responsável pela resistência ao deslizamento da superfície de contato.

A Figura 8.90 ilustra a comparação entre as tensões provenientes dos resultados das deformações dos extensômetros elétricos de resistência do modelo experimental e as tensões do modelo numérico.
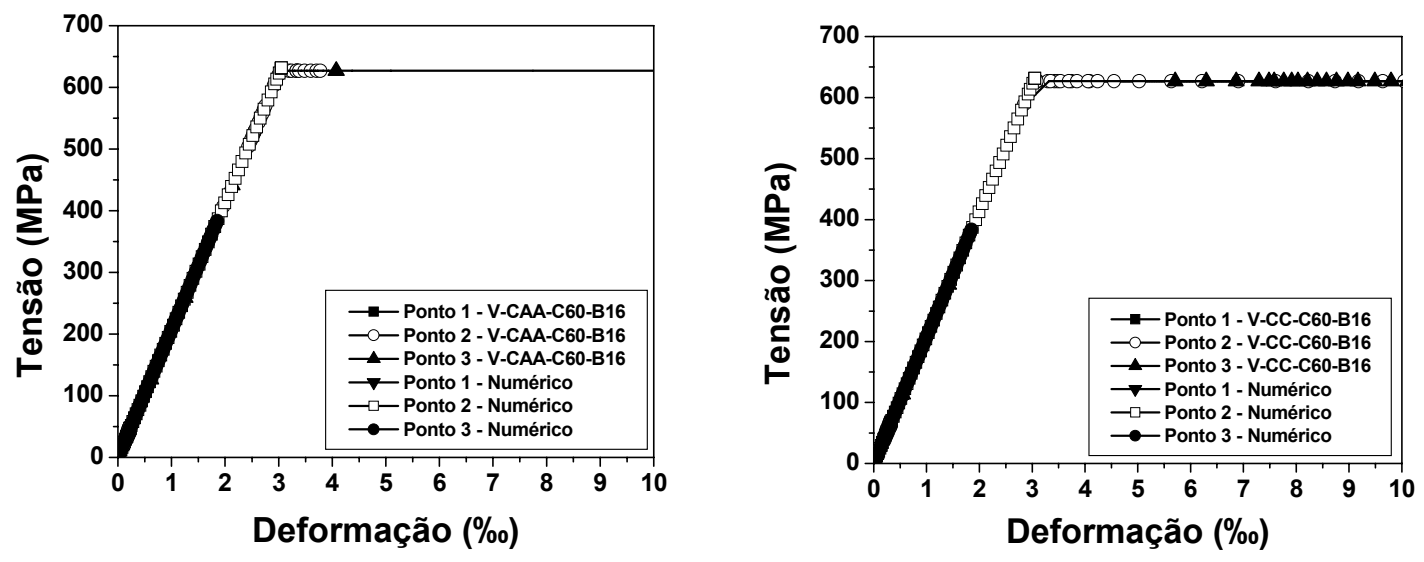

Figura 8.90 Tensões principais quando se atinge o passo de carga correspondente a força máxima de viga

A Figura 8.91 mostra a diferença entre os resultados obtidos para tensão na barra de aço.

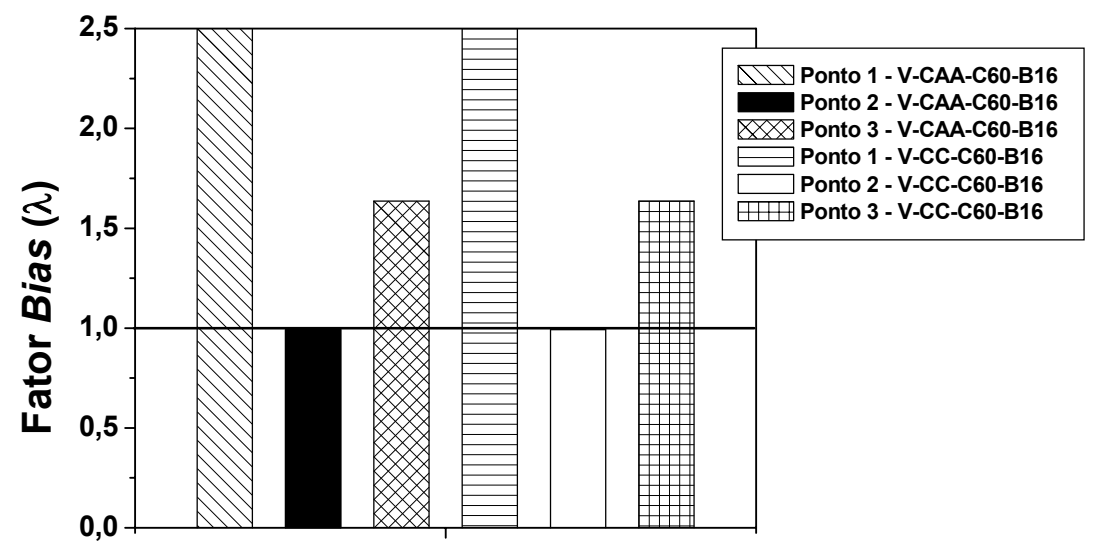

Figura 8.91 Diferença entre as tensões na barra de aço do modelo experimental e numérico

De acordo com a Figura 8.91, pode-se ver que o modelo numérico foi mais deformável que o modelo experimental. Entretanto, o modelo foi satisfatório na 
representação das tensões no ponto 2, pois foi possível se estimar as tensões na barra de aço com uma diferença máxima de $0,7 \%$ para o modelo em CAA e em CC. $O$ ponto 3 se mostrou muito deformável, e a diferença do modelo em relação aos resultados experimentais em CAA e em CC ficou em $63 \%$. A deformação no ponto 1 apresentou muita diferença, uma vez que no modelo numérico houve pouca transferência de esforços para esta região da barra ( $\sigma_{y}$ máximo do ensaio no ponto 1 foi de 48,22 MPa, para o modelo em CAA e 68,66 MPa para o modelo em CC) e por isso, se encontram fora de escala na Figura 8.91. 


\section{Considerações finais}

Este capítulo apresenta as conclusões do trabalho, bem como algumas sugestões para pesquisas futuras que possam complementar este estudo, visando tanto o aprimoramento dos concretos auto-adensáveis quanto o maior conhecimento do fenômeno da aderência aço-concreto.

De acordo com o que foi proposto inicialmente, o objetivo principal desta pesquisa foi estudar o comportamento da aderência aço-concreto mediante ensaios de arrancamento de barras e de vigas submetidas à flexão, onde o concreto a ser estudado era do tipo auto-adensável. Dentre os objetivos secundários colocados, destacou-se a comparação do concreto auto-adensável com o concreto convencional utilizado no mercado, verificando a variabilidade dos resultados obtidos. Outro objetivo secundário que se colocou estava vinculado à análise comparativa dos procedimentos dos dois ensaios em si, de suas vantagens e desvantagens na determinação do comportamento da aderência. Além disso, este trabalho propôs um modelo numérico consistente para a representação dos ensaios estudados, de forma a permitir uma análise paramétrica mais abrangente do fenômeno estudado. E finalizando esses objetivos, verificou-se a consistência das formulações empregadas na literatura corrente e pelos principais códigos internacionais, mediante sua comparação com os resultados obtidos experimentalmente.

A seguir, serão esboçadas as conclusões parciais do trabalho, obtidas em função da análise dos resultados dos diversos procedimentos adotados. 


\subsection{Comentários sobre os resultados obtidos}

\subsubsection{Investigação experimental do concreto auto-adensável}

De acordo com os resultados obtidos, pode-se constatar que:

- A utilização de relações $A / C$ maiores que 0,4 conduz a dosagens com menor consumo de cimento e de superplastificante, resultando um material de construção interessante e de fácil utilização, por dispensar o adensamento e com economia de material;

- Embora a metodologia para determinação da composição do traço do CAA necessite de um rígido controle tecnológico dos materiais envolvidos em sua elaboração, o que requer maiores investimentos na parte de capacitação profissional e de equipamentos, isso pode ser compensado pela alta qualidade final e durabilidade das construções em CAA, além do ganho de produtividade durante a construção.

\subsubsection{Investigação experimental da aderência}

Com relação aos ensaios dos modelos de arrancamento, pode-se constatar que:

- Os modelos de arrancamento tanto em CAA quanto em CC apresentaram comportamento semelhante;

- Os modelos de arrancamento foram de fácil operação durante a concretagem e o seu posicionamento na máquina de ensaios era simples, facilitando os procedimentos para ensaio e minimizando quaisquer erros operacionais por sua simplicidade de execução;

- Os ensaios de arrancamento são eficazes na determinação da resistência de aderência apresentado pequena variação em seus resultados;

- Os modelos de arrancamento da série 1 foram caracterizados pela ruptura por deslizamento da barra de aço e, em alguns casos com barra de $16 \mathrm{~mm}$, por fendilhamento do concreto;

- Os modelos de arrancamento da série 2 foram caracterizados pela ruptura por fendilhamento do concreto, para todos os diâmetros de barra; 
- Os modelos da série complementar tiveram comportamento similar aos da série 2 , sendo caracterizados pela ruptura por fendilhamento do prisma de concreto;

- No que se refere ao comportamento dos concretos utilizados, o comportamento da resistência de aderência foi similar para ambos os diâmetros de barra utilizados.

Com relação aos ensaios dos modelos de viga se pode concluir que:

- Da mesma forma que nos modelos de arrancamento, o comportamento dos modelos em CAA foi similar ao dos modelos em CC;

- O modelo de viga apresenta uma série de deslizamentos combinados com a deformação da barra. À medida que há deformação na barra, o concreto de alta resistência à compressão limitará o deslizamento da barra, ocasionando a ruptura do modelo por escoamento da barra de aço, fato que foi observado nos modelos de viga da série 2. Em contrapartida, à medida em que se aumenta o deslizamento da barra, ocorre um alívio nas tensões da mesma, ocasionando a ruptura da aderência por deslizamento da barra de aço;

- Os modelos da série 1 foram caracterizados pelo pequeno deslocamento (flecha) dos modelos e pequenas deformações, o que denotou que a ruptura do modelo se deu por deslizamento da barra. Já os modelos da série 2 foram caracterizados pelo excessivo deslocamento (flecha) dos modelos, que denotou o escoamento da barra de aço e, em um caso houve ruptura da barra;

- Durante os ensaios da série 1 de vigas, os modelos em CC com barra de 10 $\mathrm{mm}$ tiveram comportamento atípico em função de uma falha na utilização da rótula, sendo que seu comportamento ficou caracterizado pela ruptura por deformação excessiva da barra de aço. Entretanto, os resultados referentes ao pré-pico puderam ser utilizados, descartando-se o pós-pico do comportamento dos modelos.

A variabilidade dos modelos de arrancamento se mostrou pequena e abaixo de $10 \%$, mostrando que este ensaio de fácil execução é eficiente e fornece bons resultados, tornando-se uma boa opção para o estudo da resistência de aderência.

Assim, do mesmo modo que os modelos de arrancamento, os modelos de viga, tanto em CAA quanto em CC de cada série, apresentaram comportamento similar, mostrando que o CAA apresenta propriedades mecânicas similares ao CC, com a vantagem de possuir alta trabalhabilidade no estado fresco, melhorando a 
produtividade e qualidade (conseqüentemente a durabilidade) das estruturas em concreto.

\subsubsection{Simulação numérica dos ensaios de aderência}

De acordo com os resultados das simulações numéricas realizadas, pode-se verificar que é possível a representação do comportamento tanto do ensaio de arrancamento quanto do ensaio de viga.

A representação dos modelos numéricos teve como parâmetros fundamentais para a sua calibração o fator FKN e o fator FKT, que são responsáveis pela influência da superfície normal e tangencial do contato, respectivamente. Foi observado que esses dois parâmetros, principalmente o FKN, era fortemente influenciado pelo valor do módulo de elasticidade do concreto, pois à medida que se aumenta o valor do módulo de elasticidade do concreto, deve ocorrer uma redução do valor do FKN. Isso pode ser bem observado nos resultados das séries 1 e 2, tanto de arrancamento quanto de viga, onde o valor determinado para a série 1 utilizou FKN variando de 1 a 10 , enquanto a série 2 utilizou valores entre 0,005 até 0,0001 .

Os resultados das simulações apresentaram uma previsão satisfatória da força de ruptura do ensaio, com a ressalva de que a aproximação dos deslizamentos apresentou diferenças significativas em alguns modelos, principalmente nos modelos da série 2, por causa do valor do módulo de elasticidade do concreto.

Os modelos com barra de $16 \mathrm{~mm}$, tanto de arrancamento quanto de viga, apresentaram comportamentos satisfatórios, entretanto, a aproximação destes modelos foi menor que os modelos com barra de $10 \mathrm{~mm}$. Isso pode ser explicado pelo tamanho da superfície de contato existente, que provavelmente, necessitaria uma maior discretização para uma melhor aproximação dos resultados.

Foi verificado que, à medida que se aumenta o valor do módulo de elasticidade, o comportamento do modelo numérico tendia para o linear. Fato que também ocorria quando da simulação dos modelos numéricos com barra de $16 \mathrm{~mm}$. Isso significa que, são necessárias mais investigações com relação ao nível de discretização da malha do contato e com relação aos parâmetros que influenciam o comportamento da interface, para uma melhor representação da tensão de aderência quando da utilização de barras de diâmetro de $16 \mathrm{~mm}$.

Com relação à representação da resistência de aderência e das tensões nas barras de aço instrumentadas, embora não existissem dados para corroborar os resultados numéricos, a representação da superfície de contato pode dar uma idéia do 
comportamento e da variação da tensão de aderência; já as tensões nas barras de aço apresentaram uma aproximação satisfatória mostrando que os pontos de maior concentração de tensões foram bem representados e, somente o ponto 1 , que representa o ponto após o comprimento de ancoragem, que possuía pouca transferência de tensões, se mostrou muito flexível em relação ao modelo experimental.

\subsubsection{Comparação dos resultados com formulações de previsão do comportamento do CAA e da resistência de aderência}

De acordo com os resultados obtidos, pode-se constatar que:

- Grande parte dos Códigos Normativos superestimou o valor referente ao módulo de elasticidade e da resistência à tração do concreto, tanto para o concreto convencional quanto para o concreto auto-adensável;

- No caso da análise entre o módulo de elasticidade e a resistência à compressão, somente o Código Norueguês (NS 3473, 1992) apresentou resultados a favor da segurança com valores muito próximos aos resultados experimentais, seguido da formulação de Gardner \& Zao (1991);

- No caso de se analisar a relação entre a resistência à compressão e a resistência à tração, os resultados experimentais mostram que a maioria das formulações utilizadas superestima o valor da resistência à tração, com exceção da EHE (1999) que esteve a favor da segurança, e com resultados muito próximos à resposta experimental.

Assim, de acordo com os resultados obtidos, as formulações utilizadas apresentaram resultados contra a segurança, o que pode conduzir a uma preocupação no dimensionamento de estruturas em concreto armado. Porém, são necessárias mais investigações com um maior número de repetições de modo a se obter uma média mais confiável e assim, propor recomendações para uma determinação mais adequada para o módulo de elasticidade e para a resistência à tração.

\subsubsection{Variabilidade do concreto auto-adensável}

O objetivo desta investigação experimental foi analisar, estatisticamente, a variabilidade das propriedades mecânicas do concreto auto-adensável, notadamente: 
resistência à compressão e à tração do concreto, módulo de elasticidade em corposde-prova de $15 \times 30 \mathrm{~cm}$ e resistência de aderência em vigas adaptadas para o ensaio padronizado do Rilem-Ceb-Fip (1973). Todos os ensaios foram realizados aos 28 dias no Laboratorio de Tecnología de Estructuras do Departamento de Ingeniería de la Construcción em Barcelona (Espanha).

Com relação ao comportamento do CAA no estado fresco, pode-se concluir que a variabilidade do CAA foi muito influenciada pelo nível de limpeza da cuba da betoneira. À medida que se concretava e a limpeza da cuba não era realizada, ocorria um decréscimo na fluidez do concreto, pois o concreto que permanecia na cuba promovia uma absorção de água e/ou superplastificante. Assim, no caso de se concretar diversas vezes no mesmo dia, recomenda-se promover a limpeza da cuba a cada concretagem ou fazer uma compensação com água ou superplastificante para manter as mesmas propriedades no estado fresco.

Com relação ao estudo da variabilidade no estado endurecido, este foi dividido em duas partes, sendo a primeira referente às propriedades mecânicas no estado endurecido (resistência à compressão, resistência à tração e módulo de elasticidade) aos 28 dias, ensaiados conforme a metodologia comentada; e a segunda parte, que consistiu do estudo da variabilidade da resistência de aderência dos mesmos CAA's estudados na primeira parte aos 28 dias.

De acordo com os resultados observados na primeira parte dessa pesquisa, foi verificado que:

- Nos ensaios de resistência à compressão, muitos fatores tiveram influência em sua variabilidade, principalmente o capeamento e o ar incorporado nos corpos-de-prova;

- Para os ensaios à tração, a variabilidade foi conseqüência da forma de ruptura do $\mathrm{CP}$;

- Com um intervalo de confiança de 95\%, os concretos auto-adensáveis das três séries mostraram comportamento semelhante ao concreto convencional (que utiliza o mesmo IC de 95\%) e que a variabilidade foi inferior que $10 \%$ e, somente no caso da resistência à tração que houve resultados acima de $10 \%$, mostrando ser necessário um estudo sobre o ensaio de resistência à compressão indireta (ou "brasileiro").

Com relação à previsão das formulações e Códigos Normativos comparadas com os valores experimentais para a resistência à tração e módulo de elasticidade, se pode concluir que: 
- Com relação ao módulo de elasticidade, todas as formulações apresentaram resultados muito próximos aos valores experimentais e a favor da segurança (sendo em alguns casos bastante conservativas, como o Código Norueguês (1992) e Gardner \& Zao (1991)), com exceção da NBR 6118 (2003) que apresentou um valor um pouco inferior com relação ao experimental, mas foi o mais próximo dos valores experimentais encontrados;

- Com relação à resistência à tração, as formulações apresentaram resultados muito próximos dos resultados experimentais, entretanto, contra a segurança. Somente a EHE (1999) apresentou valores a favor da segurança, porém, claramente conservadores.

Com relação aos ensaios de resistência de aderência, se pode concluir que:

- A resistência de aderência não foi prejudicada pela falta de fluidez do CAA. De acordo com o que foi observado nos ensaios de viga, o aspecto das vigas concretadas com o CAA de pouca fluidez foi caracterizado pela presença de nichos sem concreto e alto índice de porosidade na superfície da viga, o que caracteriza uma fragilidade para a penetração de agentes nocivos à barra de aço (como íons de cloro, por exemplo);

- A resistência de aderência aumenta de acordo com o aumento do módulo de elasticidade. Dessa maneira, os concretos de alto desempenho (alta resistência à compressão, presença de fibras, baixa porosidade e etc.) são ideais para garantir uma boa resistência de aderência e, conseqüentemente, garantir a segurança do elemento estrutural;

- Em contrapartida, os concretos de alto desempenho (nesse caso de alta resistência à compressão) têm como característica a ruptura frágil, independente do tipo de concreto utilizado. Nestes casos, ocorrerá o fendilhamento do material adjacente à barra, em função da resistência à tração do concreto utilizado. E a menos que haja uma armadura de confinamento prevista, de modo a aumentar a capacidade resistente do concreto, o escoamento da barra ou seu deslizamento não irão ocorrer;

- O tamanho do agregado graúdo (dependendo de sua origem) tem forte influência no valor da resistência de aderência, pois este aumenta o valor do módulo de elasticidade;

- O comportamento dos ensaios de viga para as três séries de CAA foi similar, mesmo com a pequena fluidez da série $\mathrm{C} 1$; 
- Com relação ao ensaio, a limitação estabelecida pelo Rilem-Ceb-Fip (1973) para um deslizamento máximo de $3,0 \mathrm{~mm}$ e o intervalo de resistência à compressão entre 22,5 e 27,5 MPa, mostram que este ensaio possui uma limitação crítica, pois quando se utilizam concretos de alta resistência à compressão, os deslizamentos são reduzidos por causa da forte influência do confinamento promovido pela resistência à compressão do concreto combinado com a armadura existente. Assim, como foi visto em todos os ensaios, ocorria plastificação da barra de aço em seu ponto central e a concentração de esforços na zona entre a barra de aço e a placa da rótula;

- O estudo da variabilidade do ensaio de viga mostrou que o ensaio em si possui pouca variação. Os parâmetros utilizados para essa verificação foram $P_{5 \mathrm{~mm}}, P_{10 \mathrm{~mm}}, \mathrm{P}_{15 \mathrm{~mm}}, \mathrm{P}_{20 \mathrm{~mm}}$ e $P_{\text {máx }}$, que mostraram que para os deslizamentos iniciais e finais, onde ocorria maior variação, este valor foi inferior a $10 \%$. Essa variação se deu em parte por causa da variação da adesão e pela formação de fissuras ao redor da barra de aço quando ocorria o seu deslizamento.

Com relação às formulações utilizadas para prever o comportamento e o valor da resistência de aderência, se pode concluir que:

- Na maioria dos casos, o parâmetro que determina o valor da resistência de aderência é a resistência à compressão do concreto. Somente algumas formulações levam em consideração o cobrimento, diâmetro da barra de aço, o comprimento de ancoragem e o deslizamento;

- $\mathrm{Na}$ análise do fator bias, este forneceu uma boa idéia do grau de segurança de um elemento estrutural calculado pelas formulações estabelecidas e mostrou que os modelos de Kemp (1986), NBR 6118 (2003) e do Eurocode (2002) foram os mais conservadores. Vale comentar que dentre os modelos utilizados para se verificar o comportamento da resistência de aderência, somente os modelos do Ceb-Fip 195/197 (1990) e de Huang et al. (1996), levou em consideração a presença da armadura de confinamento;

Desse modo, essas formulações mostraram que, mesmo com a utilização de materiais diferentes para elaboração do concreto (areia, brita, cimento, superplastificante e etc.) a resistência de aderência pode ser representada, reforçando a afirmação que o comportamento do CAA no estado endurecido é semelhante ao do concreto convencional. 
Assim, como conclusões finais desta investigação experimental, pode-se afirmar que os concretos auto-adensáveis possuem alta qualidade e são bastante confiáveis e, em alguns casos, apresentam propriedades mecânicas até melhores que as do concreto convencional.

\subsection{Conclusões}

De acordo com o conjunto dos resultados obtidos, observou-se que o ensaio de arrancamento apresentou pequena variação, demonstrando ser uma boa ferramenta para avaliação da resistência de aderência e do comportamento da interface açoconcreto. O ensaio de viga, apesar de fornecer uma melhor representação da situação real, mostrou-se um ensaio de difícil execução, devendo ser reservado para casos específicos. Assim, nos casos usuais parece ser mais interessante a utilização do ensaio de arrancamento para a caracterização da aderência, desde que se tomem certos cuidados para que os parâmetros do modelo utilizado (comprimento de ancoragem, cobrimento, diâmetro da barra e etc) representem efetivamente o caso real.

De acordo com os resultados dos ensaios de arrancamento e de viga, em CC e em CAA, a forma de ruptura foi semelhante em ambos os casos, mostrando que o comportamento do CAA no estado endurecido é semelhante ao do CC.

A forma de ruptura dos modelos em concreto de alta resistência, tanto CAA como CC, foi por fendilhamento do prisma, que é determinada principalmente pela resistência do concreto à tração e não pela resistência da interface em si, não havendo diferença significativa no comportamento dos modelos. Para que a efetiva ruptura da interface possa ocorrer (com o deslizamento da barra), seria necessária a utilização de outros procedimentos de ensaio que impediriam a ruptura por fendilhamento.

Já para os concretos de baixa resistência à compressão, viu-se que a ruptura dos modelos se deu pelo deslizamento da barra, ou seja, com a ruptura da interface aço-concreto, conforme esperado. Nesse caso, ambos os concretos apresentaram comportamento similar. Entretanto, no caso dos modelos de arrancamento houve uma resposta melhor por parte dos modelos em CAA, o que pode ser atribuído à melhor qualidade do material da zona de transição.

Em relação à análise numérica efetuada, pode-se dizer que o modelo numérico desenvolvido mostrou-se adequado para a representação do comportamento obtido nos testes com modelos físicos. O modelo forneceu uma boa estimativa para a força 
de ruptura, e mediante a variação dos parâmetros adotados na presente investigação, pode se constituir numa ferramenta interessante para a extensão dos resultados.

E finalmente, como principal conclusão deste trabalho, pode-se afirmar que o comportamento da aderência entre as barras de aço e o concreto auto-adensável é equivalente ao do concreto convencional, podendo para a sua avaliação serem utilizados os mesmos procedimentos aplicados ao concreto convencional.

\subsection{Propostas de futuras pesquisas}

Como proposta para trabalhos futuros, se propõe:

- Estabelecer um ensaio de viga que não apresente o comprimento de ancoragem no caminho da biela comprimida;

- Avaliar e comparar a variabilidade no estado endurecido para concretos convencionais e auto-adensáveis com diferentes classes de resistência à compressão;

- Promover um estudo com o objetivo de se estabelecer limites aceitáveis para o coeficiente de variação, segundo ensaios normalizados, para os critérios de qualidade $A, B$ e C;

- Com relação ao estado fresco, promover um programa experimental de ensaios de fluidez e coesão, envolvendo um planejamento estatístico tendo em conta a repetição e reprodução dos ensaios e analisar a durabilidade e aspecto final do acabamento de cada concreto;

- Com relação aos modelos numéricos, embora se tenha desenvolvido um modelo com boa aproximação da resposta do ensaio, seria interessante promover um estudo numérico abordando os principais parâmetros que influenciam a resistência de aderência para o caso de vigas engastadas, vigas contínuas, barras atirantadas e etc;

- Além desse estudo numérico, é de grande importância a análise da tensão de aderência na interface aço-concreto, isto é, verificar a distribuição das tensões no contato a partir de modelos experimentais montados especialmente para esta aferição. 


\section{Bibliografia}

ABRISHAMINI, H. H.; MITCHELL, D. (1996). Analysis of bond stress distributions in pullout specimens. Journal of Structural Engineering, ASCE, Vol. 122, No. 3, March, p. 255-261.

AïTCIN, P.-C. (2000). Concreto de alto desempenho. 1ª. Edição, Editora: PINI Ltda. ISBN: 857266-123-9, p. 695, (Tradução de Geraldo G. Serra, 2000).

ALCÂNTARA, M. A. M.; LORRAIN, M. S.; BARBOSA, M. P. (2004). Avaliação da posição da armadura no desenvolvimento das tensões de aderência na interface entre o concreto auto-adensável e a armadura. Volume V - Pré-fabricados em concreto. In: $46^{\circ}$ Congresso Brasileiro do Concreto - IBRACON, Florianópolis, Brasil, 14-18 de agosto de 2004, Anais..., Editores: Ivo J. Padaratz \& Túlio N. Bittencourt, ISBN: 85-98576-02-6, Florianópolis, Trabalho CBC0165, p. V.76-V.90.

AL-JAHDALI, F. A.; WAFA, F. F.; SHIHATA, S. A. (1994). Development length for straight deformed bars in high-strength concrete (SP-149). Special Publication (ACl), Vol. 149, Octubre.

ALMEIDA FILHO, F. M.; DE NARDIN, S.; EL DEBS, A. L. H. C. (2004). Interface aço-concreto: análise dos parâmetros do contato e sua influência na simulação via MEF. In: XXV CILAMCE: Iberian Latin American Congress on Computational Methods, Proceedings..., Recife-PE, Brasil.

AMBROISE, J.; ROLS, S.; PÉRA, J. (1999). Production and testing of self-levelling concrete. In: HIGH-PERFORMANCE CONCRETE AND PERFORMANCE AND QUALITY OF CONCRETE STRUCTURES: Proceedings of the second CANMET/ ACI INTERNATIONAL CONFERENTE (SP-186), Gramado - RS, Brazil, 1 a 4 de junho de 1999, Proceedings... Editores: V. M. Malhotra; P. Helene; L. R. Prudêncio Jr.; D. C. C. Dal Molin, publicado pelo ACI (E.U.A.), Gramado, p. 555-566.

ANSYS (2002). Engineering Analysis System. Manuais on-line. 
ARIMA, H.; SADAKANE, M.; AYANO , T.; SAKATA, K. (2002). Experimental study on stable production of self-compacting high performance concrete. In: CONCRETE STRUCTURES IN THE 21st CENTURY: Proceedings of the first FIB congress, Osaka, Japan, março de 2002, Proceedings..., Publicado por Japan prestressed concrete engineering association \& Japan concrete institute, Osaka, [CD-ROM].

ASHBY, J. B. (1998). Slag cement and slag aggregate in high performance concrete. In: INTERNATIONAL SYMPOSIUM ON HIGH-PERFORMANCE AND REACTIVE POWDER CONCRETES - VOLUME 2, Sherbrooke - Canada, 16 a 20 de agosto de 1998, Proceedings..., Editores: Pierre-Claude Aïtcin \& Yves Delagrave, Université de Sherbrooke, Sherbrooke, p. 63-74.

ASSOCIAÇÃO BRASILEIRA DE NORMAS TÉCNICAS (1982). NBR 7214 - Areia normal para ensaio de cimento. Rio de Janeiro, 1982, $7 f$.

ASSOCIAÇÃO BRASILEIRA DE NORMAS TÉCNICAS (1982). NBR 7251 -Agregado em estado solto: determinação da massa unitária - Método de ensaio. Rio de Janeiro, 1982, $3 f$.

ASSOCIAÇÃO BRASILEIRA DE NORMAS TÉCNICAS (1983). NBR 7682 - Calda de cimento para injeção: Determinação do índice de fluidez - Método de ensaio. Rio de Janeiro, 1983.

ASSOCIAÇÃO BRASILEIRA DE NORMAS TÉCNICAS (1983). NBR 7211 - Agregado para concreto. Rio de Janeiro, 1983, 9 f.

ASSOCIAÇÃO BRASILEIRA DE NORMAS TÉCNICAS (1984). NBR 8522 - Determinação do módulo de deformação estática e diagrama de tensão $x$ deformação - Método de ensaio. Rio de Janeiro, 1984.

ASSOCIAÇÃO BRASILEIRA DE NORMAS TÉCNICAS (1987). NBR 7216 - Amostragem de agregados. Rio de Janeiro, 1987, $4 \mathrm{f}$.

ASSOCIAÇÃO BRASILEIRA DE NORMAS TÉCNICAS (1987). NBR 7217 - Agregados: determinação da composição granulométrica - Método de ensaio. Rio de Janeiro, 1987, $4 f$.

ASSOCIAÇÃO BRASILEIRA DE NORMAS TÉCNICAS (1987). NBR 9776 - Agregados: determinação da massa específica de agregados miúdos por meio do frasco Chapman Método de ensaio. Rio de Janeiro, 1987, 3f.

ASSOCIAÇÃO BRASILEIRA DE NORMAS TÉCNICAS (1987). NBR 9833 - Massa específica e teor de ar pelo método gravimétrico. Rio de Janeiro, 1987, 4f.

ASSOCIAÇÃO BRASILEIRA DE NORMAS TÉCNICAS (1987). NBR 9937 - Agregados: Determinação da absorção e da massa específica de agregado graúdo. Rio de Janeiro, $6 f$. 
ASSOCIAÇÃO BRASILEIRA DE NORMAS TÉCNICAS (1992). NBR 12142 - Concreto: Determinação da resistência à tração na flexão de corpos-de-prova prismáticos - Método de ensaio. Rio de Janeiro, 1992.

ASSOCIAÇÃO BRASILEIRA DE NORMAS TÉCNICAS (1992). NBR 6152 - Materiais metálicos: Determinação das propriedades mecânicas à tração - Método de ensaio. Rio de Janeiro, 1992.

ASSOCIAÇÃO BRASILEIRA DE NORMAS TÉCNICAS (1994). NBR 5738 - Moldagem e cura de corpos-de-prova cilíndricos ou prismáticos de concreto - Método de ensaio. Rio de Janeiro, 1994.

ASSOCIAÇÃO BRASILEIRA DE NORMAS TÉCNICAS (1994). NBR 5739 - Concreto: Ensaio de compressão em corpos-de-prova cilíndricos. Rio de Janeiro, 1994.

ASSOCIAÇÃO BRASILEIRA DE NORMAS TÉCNICAS (1994). NBR 7222 - Argamassa e concreto - Determinação da resistência à tração por compressão diametral de corposde-prova cilíndricos. Rio de Janeiro, 1994.

ASSOCIAÇÃO BRASILEIRA DE NORMAS TÉCNICAS (1996). NBR 7480 - Barras e fios de aço destinados a armaduras para concreto armado. Rio de Janeiro, 1996.

AUDENAERT, K.; BOEL, V.; DE SHUTTER, G. (2002). Carbonation of self-compacting concrete. In: 6th INTERNATIONAL SYMPOSIUM ON UTILIZATION OF HIGH STRENGTH / HIGH-PERFORMANCE CONCRETE, Leipzig, Alemanha, junho de 2002, Proceedings..., Editores: Gert König; Frank Dehn; Thosten Faust, König, Heunisch und partner, consulting engineers, publicado por Leipzig University: Institute for structural concrete and building materials, ISBN: 3-934178-18-9, Leipzig: Leipzig University, p.853862.

AZAZAMINI, A; PAVEL, R.; HATFIELD, E.; GHOSH, S. K. (1999). Behavior of lap-spliced reinforcing bars embedded in high-strength concrete. ACI Structural Journal, Vol. 96, No. 5, Sept.-Oct., p. 826-835.

AZAZAMINI, A.; STARK, M.; ROLLER, J. J.; GHOSH, S. K. (1993). Bond performance of reinforcing bars embedded in high-strength concrete. ACI Structural Journal, Vol. 90, No. 5, Sept.-Oct., p. 554-561.

BABU, K. G.; PRAKASH, P. V. S. (1995). Efficiency of silica fume in concrete. Cement and Concrete Research, Vol. 25, No. 6, p 1273-1283, 1995.

BANGASH, M. Y. H. (1989). Concrete and concrete structures: numerical modeling and applications. Barking: Elsevier science publishers Itd., 687 p.,ISBN: 1-85166-294-4.

BARBOSA, M. P.; COSTA, O. J.; SILVA, L. M.; SALLES, F. M. (2004). Concreto autoadensável: avaliação da aderência aço-concreto através dos ensaios de determinação do coeficiente de conformação superficial das barras de aço. Volume II - Construções em concreto. In: $46^{\circ}$ Congresso Brasileiro do Concreto - IBRACON, Florianópolis, Brasil, 
14-18 de agosto de 2004, Anais..., Editores: Ivo J. Padaratz \& Túlio N. Bittencourt, ISBN: 85-98576-02-6, Florianópolis, Trabalho CBC0167, p. II.484-II.497.

BARBOSA, M. P.; SILVA, L. M.; MENOSSI, R. T.; SALLES, F. M.; RÓS, P. S. (2004). A influência da adição de finos basálticos nas características reológicas e mecânicas dos concretos auto-adensáveis. In: $46^{\circ}$ Congresso Brasileiro do Concreto - IBRACON, Florianópolis, Brasil, 14-18 de agosto de 2004, Anais..., Editores: Ivo J. Padaratz \& Túlio N. Bittencourt, ISBN: 85-98576-02-6, Florianópolis, Trabalho CBC0162, p. II.7-II.22.

BARBOSA, M. T. G. (2004). Análise comparativa e crítica de diversos modelos numéricos aplicáveis ao estudo da aderência aço-concreto. In: XXXI JORNADAS SUDAMERICANAS DE INGENIERÍA ESTRUCTURAL, Mendoza, Argentina, 17 a 21 de maio de 2004, Universidad Nacional de Cuyo, Anais..., Mendoza, 14p., [CD-ROM].

BARTOS, P. J. M. (2000). Measurement of key properties of fresh self-compacting concrete. In: Measurement, testing and standardization: future needs in the field of construction materials, Proceedings..., Paris, 5-6 june, 2000, 6 p.

BAYRAMOV, F.; TASDEMIR, C.; TASDEMIR, M. A. (2004). Optimisation of steel fibre reinforced concretes by jeans of statistical response surface method. Cement and Concrete Composites, Vol. 26, p. 665-675, 2004

BERNABEU (2000). Final report of task 7: Form-system and surface quality. SCC, GTM Construction, $83 \mathrm{p}$.

BHANJA, S.; SENGUPTA, B. (2003). Investigations on the compressive strength of silica fume concrete using statistical methods. Cement and Concrete Research, Vol. 25, p 13911394, 2002.

BHANJA, S.; SENGUPTA, B. (2003). Optimum silica fume content and its mode of action on concrete. ACI Materials Journal, Vol. 100, No. 5, sept.-oct., p. 407-412.

BLONTROCK, H.; TAERWE, L. (2002). Exploratory spalling tests on self-compacting concrete. In: 6th INTERNATIONAL SYMPOSIUM ON UTILIZATION OF HIGH STRENGTH / HIGHPERFORMANCE CONCRETE, Leipzig, Alemanha, junho de 2002, Proceedings..., Editores: Gert König; Frank Dehn; Thosten Faust, König, Heunisch und partner, consulting engineers, publicado por Leipzig University: Institute for structural concrete and building materials, ISBN: 3-934178-18-9, Leipzig: Leipzig University, p.659-666.

BONAVETTI, V.; DONZA, H.; RAHHAL; V.; IRASSAR, E. F. (1999). High-strength concrete with limestone filler cements. In: HIGH-PERFORMANCE CONCRETE AND PERFORMANCE AND QUALITY OF CONCRETE STRUCTURES: Proceedings of the second CANMET/ ACI INTERNATIONAL CONFERENTE (SP-186), Gramado - RS, Brazil, 1 a 4 de junho de 1999, Proceedings... Editores: V. M. Malhotra; P. Helene; L. R. Prudêncio Jr.; D. C. C. Dal Molin, publicado pelo ACI (E.U.A.), Gramado, p. 567-580. 
BOUZOUBAÂ, N.; LACHEMI, M. (2001). Self-compacting concrete incorporating high volumes of class F fly ash: preliminary results. Cement and Concrete Research, Vol. 31, p. 413420.

BOUZOUBAÂ, N.; ZHANG, M. H.; MALHOTRA, V. M. (1998). Superplasticized Portland cement: production and compressive strength of mortars and concrete (poster). In: INTERNATIONAL SYMPOSIUM ON HIGH-PERFORMANCE AND REACTIVE POWDER CONCRETES - VOLUME 4, Sherbrooke - Canada, 16 a 20 de agosto de 1998, Proceedings..., Editores: Pierre-Claude Aïtcin \& Yves Delagrave, Université de Sherbrooke, Sherbrooke, p. 435-454.

BRAMESHUBER, W.; UEBACHS, S. (2002). Self-compacting concrete - application in Germany. In: 6th INTERNATIONAL SYMPOSIUM ON UTILIZATION OF HIGH STRENGTH / HIGH-PERFORMANCE CONCRETE, Leipzig, Alemanha, junho de 2002, Proceedings..., Editores: Gert König; Frank Dehn; Thosten Faust, König, Heunisch und partner, consulting engineers, publicado por Leipzig University: Institute for structural concrete and building materials, ISBN: 3-934178-18-9, Leipzig: Leipzig University, p.1503-1514.

BUI, V. K.; AKKAYA, Y.; SHAH, S. P. (2002). Rheological model for self-consolidanting concrete. ACI Materials Journal, Vol. 99, No. 6, November-december, p. 549-559.

BUI, V. K.; MONTGOMERY, D.; HINCZAK, I.; TURNER, K. (2002). Rapid testing method for segregation resistance of self-compacting concrete. Cement and Concrete Research, Vol. 32, p. 1489-1496.

CABRERA, J. G.; GAAFAR, B. A. (1998). Effect of curing temperature on the strength and performance properties of concrete. In: FOURTH CANMET/ACI/JCI INTERNATIONAL CONFERENTE: Recent advances in concrete technology (SP-179), Tokushima, Japão, 7 a 11 de junho de 1998, Proceedings... Editores: V. M. Malhotra, publicado pelo ACl (E.U.A.), Tokushima, p. 855-874.

CABRERA, J. G.; ATIS, C. D. (1999). Design and properties of high-volume fly ash higperformance concrete. In: HIGH-PERFORMANCE CONCRETE AND PERFORMANCE AND QUALITY OF CONCRETE STRUCTURES: Proceedings of the second CANMET/ ACI INTERNATIONAL CONFERENTE (SP-186), Gramado - RS, Brazil, 1 a 4 de junho de 1999, Proceedings... Editores: V. M. Malhotra; P. Helene; L. R. Prudêncio Jr.; D. C. C. Dal Molin, publicado pelo ACI (E.U.A.), Gramado, p. 21-38.

CALISKAN, S. (2003). Aggregate/mortar interface: influence of the sílica fume at the micro- and macro-level. Cement \& Concrete Composites, Vol. 25, p. 557-564.

CANHA, R. M. F.; EL DEBS, M. K. (2003). Modelagem da ligação entre pilar pré-moldado e cálice de fundação através de elementos finitos: análise dos parâmetros relativos à nãolinearidade de contato. IN: XXIV - Iberian Latin-American Congress on Computational Methods, Anais..., 16p, [CD-ROM]. 
CASTRO, C. M. (2002). Concreto de alto desempenho: estudo da aderência com a armadura sob ações repetidas. Dissertação de Mestrado, Escola de Engenharia de São Carlos, Universidade de São Paulo, 155 p.

CHAN, Y.-W.; CHEN, Y.-S.; LIU, Y.-S. (2003). Effect of consolidation on bond of reinforcement in concrete of different workabilities. ACI Structural Journal, Vol. 100, No. 4, July-august, p. 294-301.

CHAN, Y.-W.; CHEN, Y.-S.; LIU, Y.-S. (2003). Development of bond strength of reinforcement steel in self-consolidating concrete. ACI Structural Journal, Vol. 100, No. 4, July-august, p. $490-498$.

CHANVILLARD, G.; AÏTCINT, P.-C. (1996). Pull-out behaviour of corrugated steel fibers. Advacend Cement Based Materials, Vol. 4, p. 28-41, 1996.

CHEN, G.; BAKER, G. (2003). Influence of bond-slip on crack spacing in numerical modeling of reinforced concrete. Journal of Structural Engineering, ASCE, Vol. 129, No. 11, November 1, p. 1514-1521.

CHU, H.; MACHIDA, A. (1998). Experimental evaluation and theoretical simulation of self compacting concrete by the modified distinct element method (MDEM). In: FOURTH CANMET/ACI/JCI INTERNATIONAL CONFERENTE: Recent advances in concrete technology (SP-179), Tokushima, Japão, 7 a 11 de junho de 1998, Proceedings... Editores: V. M. Malhotra, publicado pelo ACI (E.U.A.), Tokushima, p. 691-714.

COLLEPARDI, S.; COPPOLA, L.; TROLI, R.; COLLEPARDI, M. (1999). Mechanisms of actions of different superplasticizers for high-performance concrete. In: HIGH-PERFORMANCE CONCRETE AND PERFORMANCE AND QUALITY OF CONCRETE STRUCTURES: Proceedings of the second CANMET/ ACI INTERNATIONAL CONFERENTE (SP-186), Gramado - RS, Brazil, 1 a 4 de junho de 1999, Proceedings... Editores: V. M. Malhotra; P. Helene; L. R. Prudêncio Jr.; D. C. C. Dal Molin, publicado pelo ACI (E.U.A.), Gramado, p. $503-524$.

DE ALMEIDA, I. R. (2002). On the influence of the modulus of elasticity of coarse aggregate on the modulus of elasticity of high performance concrete. In: 6th INTERNATIONAL SYMPOSIUM ON UTILIZATION OF HIGH STRENGTH / HIGH-PERFORMANCE CONCRETE, Leipzig, Alemanha, junho de 2002, Proceedings..., Editores: Gert König; Frank Dehn; Thosten Faust, König, Heunisch und partner, consulting engineers, publicado por Leipzig University: Institute for structural concrete and building materials, ISBN: 3-934178-18-9, Leipzig: Leipzig University, p.887-896.

DE GROOT, A.K.; KUSTERS, G. M. A.; MONNIER, T. (1981). Numerical Modeling of Bond-Slip Behavior. Heron, Concrete Mechanics, Vol. 26 (1B) 
DE LARRARD, F.; BOSE, F.; CATHERINE, C.; DEFLORENNE, F. (1997). The AFREM method for mix-design of high performance concrete. Materials and Structures, Vol. 30, p. 439446.

DE LARRAD, F.; SCHALLER, I.; FUCHS, J. (1993). Effect of bar diameter on the bond strength of passive reinforcement in high-performance concrete. ACl Materials Journal, Vol. 90, No. 4, July-Aug., p. 333-339.

DE LARRARD, F.; SEDRAN, T.; HU, C.; SZITKAR, J. C.; JOLY, M.; DERKX, F. (1996). Evolution of the workability of superplasticised concretes: assessment with the BTRHEOM rheometer. In: PRODUCTIONS METHODS AND WORKABILITY OF CONCRETE (International RILEM Conference), Paisley, Scotland, 3 a 5 de junho de 1996, Proceedings... Editores: P. J. M. Bartos; D. L. Marrs; D. J. Cleland, published by E\&FN SPON (London), ISSN: 0-419-22070-4, Paisley: University of Paisley, p. 377-388.

DE NARDIN, S.; ALMEIDA FILHO, F. M.; OLIVEIRA FILHO, J.; HAACH, V. G.; EL DEBS, A. L. $H$. C. (2005). non-linear analysis of the bond strength behavior on the steel-concrete interface by numerical models and pull-out tests. In: ASCE Congress: Strutures 2005, 171, No. 107, 2005.

DEHN, F.; HOLSHEMACHER, K.; WEIßE, D. (2000). Self-compacting concrete (SCC) time development of the material properties and the bond behavior. LACER, No. 5, $10 \mathrm{p}$.

DÉSIR, J.; ROMDHANE, M. R. B.; ULM, F.-J.; FAIRBAIN, E. M. R. (1999). Steel-concrete interface: revisiting constitutive and numerical models. Computer and Structures, Vol. 71 , p. 489-503.

DINIZ, F. E. G.;BRAGA FILHO, A. C.; BARBOSA, N. P. (2004). Materiais locais e resíduos industriais em pastas de cimento para concretos auto-adensáveis. In: $46^{\circ}$ Congresso Brasileiro do Concreto - IBRACON, Florianópolis, Brasil, 14-18 de agosto de 2004, Anais..., Editores: Ivo J. Padaratz \& Túlio N. Bittencourt, ISBN: 85-98576-02-6, Florianópolis, Trabalho CBC0374, p. II.1230-II.1244.

DOMONE, P. L.; CHAI, H.-W. (1996). Design and testing of self-compacting concrete. Part V Flowing and superfluid mixes. In: PRODUCTIONS METHODS AND WORKABILITY OF CONCRETE (International RILEM Conference), Paisley, Scotland, 3 a 5 de junho de 1996, Proceedings... Editores: P. J. M. Bartos; D. L. Marrs; D. J. Cleland, published by E\&FN SPON (London), ISSN: 0-419-22070-4, Paisley: University of Paisley, p. 223-236.

DUMÊT, T. B. (2003). Aderência de cordoalhas em concretos de alta resistência com e sem fibras de aço. Tese de doutorado, Escola de Engenharia de São Carlos, Universidade de São Paulo, 330 p.

DUVAL, R.; KADRI, E. H. (1998). Influence of silica fume on the workability and the compressive strength of high performance concretes. Cement and Concrete Research, Vol. 28, No. 4, p 533-548. 
EFNARC (2002). Specification and guidelines for self-compacting concrete. 32 p., february, ISBN: 0-9539733-4-4.

EHE (1999). Instrucción de Hormigón Estructural. Real Decreto 2661/1998 del 11 de diciembre, Madrid, 1999.

ELIGEHAUSEN, R.; POPOV, E. P.; BERTERO, V. V. (1983). Local bond stress-slip relationships of deformed bars under generalized excitations. Report no UCB/EERC83/23, University of California, Berkeley. 162 p.

EMBORG, M. (2000). Final report of task 8.1: mixing and transport. SCC, Betongindustri AB, 64 p.

ESFAHANI, M. R. (2000). Effect of silica fume, superplasticizer and concrete strength on steelconcrete bond. In: PCI/FHWA/FIB - INTERNATIONAL SYMPOSIUM ON HIGH PERFORMANCE CONCRETE: The economical solution for durable bridges and transportation structures, Orlando - Flórida, E.U.A., 25 a 27 de setembro de 2000, Proceedings...Editores: L.S. (Paul) Johal, publicado pelo PCI (E.U.A), ISBN: 0-93704065-7, Orlando, p. 154-161.

EZELDIN, A. S; BALAGURU, P. N. (1989). Bond behavior of normal and high-strength fiber reinforced concrete. ACI Materials Journal, Vol. 86, No. 5, Sept.-Oct., p. 515-524.

FARD, M. A.; MARZOUK, H. (1998). Effects of rebar diameter and rib geometries on bond strength of high strength concrete. In: INTERNATIONAL SYMPOSIUM ON HIGHPERFORMANCE AND REACTIVE POWDER CONCRETES - VOLUME 4, Sherbrooke Canada, 16 a 20 de agosto de 1998, Proceedings..., Editores: Pierre-Claude Aïtcin \& Yves Delagrave, Université de Sherbrooke, Sherbrooke, p. 365-382.

FEENSTRA, P. H.; DE BORST, R. (1995). Constitutive model for reinforced concrete. Journal of Structural Engineering, ASCE, Vol. 121, No. 5, May, p. 587-595.

FERGUNSON, P. M. (1979). Reinforced concrete fundamentals. Fourth Edition, John Wiley \& Sons, ISBN: 0-471-01459-1, 724p.

FERGUSON, P. M.; THOMPSON, N. (1965). Development length for large high strength reinforcing bars. ACl Journal, Vol. 59, Jan., p. 71-91.

FERNANDES, R. M. (2000). A influência das ações repetidas na aderência aço-concreto. Dissertação de Mestrado, Escola de Engenharia de São Carlos, Universidade de São Paulo, $155 \mathrm{p}$.

FERRARIS, C.; BROWER, L.; OZYILDIRIM, C.; DACZKO, J. (2000). Workability of selfcompacting concrete. In: PCI/FHWA/FIB - INTERNATIONAL SYMPOSIUM ON HIGH PERFORMANCE CONCRETE: The economical solution for durable bridges and transportation structures, Orlando - Flórida, E.U.A., 25 a 27 de setembro de 2000, Proceedings...Editores: L.S. (Paul) Johal, publicado pelo PCI (E.U.A), ISBN: 0-93704065-7, Orlando, p. 398-407. 
FREIDIN, C. (2005). Influence of variability of oil shale fly ash on compressive strength of cementless building compounds. Construction and Buildings Materials, Vol. 19, p. 127133, 2005.

FUJII, K.; ADACHI, S.; TAKEUCHI, M.; KAKIZAKI, M.; EDAHIRO, H.; INOUE, T.; YAMAMOTO, Y. (1998). Properties of high-strength and high-fluidity lightweight concrete. In: FOURTH CANMET/ACI/JCI INTERNATIONAL CONFERENTE: Recent advances in concrete technology (SP-179), Tokushima, Japão, 7 a 11 de junho de 1998, Proceedings... Editores: V. M. Malhotra, publicado pelo ACI (E.U.A.), Tokushima, p. 65-83.

FUJII, K.; KAKIZAKI, M.; EDAHIRO, H.; UNISUGA, Y.; YAMAMOTO, Y. (1998). Mixture proportions of high-strength and high-fluidity lightweight concrete. In: FOURTH CANMET/ACI/JCI INTERNATIONAL CONFERENTE: Recent advances in concrete technology (SP-179), Tokushima, Japão, 7 a 11 de junho de 1998, Proceedings... Editores: V. M. Malhotra, publicado pelo ACI (E.U.A.), Tokushima, p. 407-420.

FUJII, K.; KEMI, T.; SHIMIZU, G.; SAKUTA, M.; UNISUGA, Y. (1998). Effects of placement interval of high-fluidity concretes. In: FOURTH CANMET/ACI/JCI INTERNATIONAL CONFERENTE: Recent advances in concrete technology (SP-179), Tokushima, Japão, 7 a 11 de junho de 1998, Proceedings... Editores: V. M. Malhotra, publicado pelo ACl (E.U.A.), Tokushima, p. 981-994.

GALLIAS, J. L.; AGGOUN, S.; CABRILLAC, R.; KARA-ALI, R. (1996). Influence of fine mineral additions on workability and mechanical properties of cement pastes and mortars. In: PRODUCTIONS METHODS AND WORKABILITY OF CONCRETE (International RILEM Conference), Paisley, Scotland, 3 a 5 de junho de 1996, Proceedings... Editores: P. J. M. Bartos; D. L. Marrs; D. J. Cleland, published by E\&FN SPON (London), ISSN: 0-41922070-4, Paisley: University of Paisley, p. 523-536.

GEIKER, M. R.; BRANDL, M.; THRANE, M.; NIELSEN, L. F. (2002). On the effect of coarse aggregate fraction and shape on the rheological properties of self-compacting concrete. Cement, Concrete and Aggregates, Vol. 24, No. 1, ISSN: 0149-6123, June, p. 3-6.

GESOGLU, M.; GÜNEYISI, E.; ÖZTURAN, T. (2002). Effects of end conditions on compressive strength and static elastic modulus of very high strength concrete. Cement and Concrete Research, Vol. 32, p. 1545-1550, 2002.

GETTU, R.; AGULLÓ, L. (2004a). Estado del arte del hormigón autocompactable y su caracterización (parte I). Cemento Hormigón, No. 861, Abril, p. 50-67.

GETTU, R.; AGULLÓ, L. (2004b). Estado del arte del hormigón autocompactable y su caracterización (parte II). Cemento Hormigón, No. 862, mayo, p. 32-55.

GHEZAL, A.; KHAYAT, H. (2002). Optimizing self-compacting concrete with limestone filler by using statistical factorial design methods. ACI Materials Journal, Vol. 99, No. 3, may-june, p. 264-272. 
GIRARD, C.; BASTIEN, J. (2002). Finite element bond-slip model for concrete columns under cyclic loads. Journal of Structural Engineering, ASCE, Vol. 128, No. 12, december, p. $1502-1510$.

GOLTERMANN, P.; JOHANSEN, V.; PALBOL, L. (1997). Packing of aggregates: an alternative tool to determine the optimal mix. ACI Materials Journal, No. 94, p. 435-443.

GOMES, P. C. C. (2002). Optimization and characterization of high-strength self-compacting concrete. Tese de Doutorado, Universitat Politècnica de Catalunya, Escola Tècnica Superior D'Enginyers de Camins, Canals i Ports de Barcelona, 140 p., Barcelona, Spain.

GOMES, P. C. C.; GETTU, R.; AGULLÓ, L. (2003). Uma nova metodologia para obtenção do concreto auto-adensável de alta resistência com aditivos minerais. IN: $\mathrm{V}$ Simpósio EPUSP sobre Estruturas de Concreto, Anais..., PEC/PCC - EPUSP, 7 a 10 de junho de 2003, São Paulo, SP, Brasil, ISBN: 85-86686-18-2, 14 p., [CD-ROM].

GOTO, Y. (1971). Cracks formed in concrete around deformed tension bars. ACl Journal, Vol. 68, No. 4, April, p. 244-251.

GOTO, K.; HAYAKAWA, M.; UKIGAI, T.; TOBORI, N. (1996). Flowing concrete with packed powder superplasticiser. In: PRODUCTIONS METHODS AND WORKABILITY OF CONCRETE (International RILEM Conference), Paisley, Scotland, 3 a 5 de junho de 1996, Proceedings... Editores: P. J. M. Bartos; D. L. Marrs; D. J. Cleland, published by E\&FN SPON (London), ISSN: 0-419-22070-4, Paisley: University of Paisley, p. 285-292.

GROTH, P.; NEMEGEER, D. (1999). The use of fibres in self-compacting concrete. In: $1^{\text {st }}$ International RILEM Symposium on Self-Compacting Concrete, Proceedings, Estocolmo, Suécia, RILEM Publications S.A.R.L., pp. 497-508.

GRÜNEWALD, S.; WALRAVEN, J. C. (2002). High strength self-compacting fibre reinforced concrete: behavior in the fresh and the hardened state. In: 6th INTERNATIONAL SYMPOSIUM ON UTILIZATION OF HIGH STRENGTH / HIGH-PERFORMANCE CONCRETE, Leipzig, Alemanha, junho de 2002, Proceedings..., Editores: Gert König; Frank Dehn; Thosten Faust, König, Heunisch und partner, consulting engineers, publicado por Leipzig University: Institute for structural concrete and building materials, ISBN: 3-934178-18-9, Leipzig: Leipzig University, p.977-990.

GUO, J.; COX, J. (2000). Implemantation of a plasticity bond model for reinforced concrete. Computers and Structures, Vol. 77, pp. 65-82.

HAMAD, B. S. (1995). Bond strength improvement of reinforcing bars with specially designed rib geometries. ACl Structural Journal, Vol. 92, No. 1, Jan.-Feb., p. 3-12.

HAMAD, B. S.; ITANI, M. S. (1998). Bond strength of reinforcement in high-strength concrete: the role of silica fume, casting position and superplasticizer dosage. ACl Materials Journal, Vol. 95, No. 5, Sept.-Oct., p. 499-511. 
HAMAD, B. S.; HARAJLI, M. H.; JUMAA, G. (2001). Effect of fiber reinforcement on bond strength of tension lap splices in high-strength concrete. ACI Structural Journal, Vol. 98, No. 5, Sept.-Oct., p. 638-647.

HAMZA, A. M.; NAAMAN, A. E. (1996). Bond characteristics of deformed reinforcing steel bars embedded in SIFCON. ACI Materials Journal, Vol. 93, No. 6, Nov.-Dec., p. 578-588.

HANNA, E.; LUKE, K.; PERRATON, D.; AÏTCIN, P. -C. (1989). Rheological behavior of Portland cement in the presence of a superplasticizer., In: SUPERPLASTICIZERS AND OTHER CHEMICAL ADMIXTURES IN CONCRETE (SP-119) - Third International Conference, Ottawa, Canada, 1989, Proceedings... Ottawa, Vol. 1, p 171-188.

HAYASHI, S.; KOKUSHO, S. (1985). Bond behavior in the neighborhood of the crack. In: FINITE ELEMENT ANALYSIS OF REINFORCED CONCRETE STRUCTURES, 1985, Tokyo, Japan. $P$ roceedings...,Editores: Christian Meyer \& Hajime Okamura, published by ASCE, ISBN 0-87262-549-4, Japan: University of Tokyo, p. 364-373.

HELENE, P.; TERZIAN, P. (1992). Manual de dosagem e controle do concreto. Editora PINI, Brasília, DF, SENAI, 1992, ISBN: 85-7266-007-0, 1a Edição, 349 p., São Paulo/SP.

HIBINO, M.; MARUYAMA, K. (2002). Effect of surface moisture of sand on fluidity of fresh mortar. . In: CONCRETE STRUCTURES IN THE 21st CENTURY: Proceedings of the first FIB congress, Osaka, Japan, março de 2002, Proceedings..., Publicado por Japan prestressed concrete engineering association \& Japan concrete institute, Osaka, [CDROM].

HIRAISHI, S.; YOKOYAMA, K.; KASAI, Y. (1998). Shrinkage and crack propagation of flowing concrete in early ages. In: FOURTH CANMET/ACI/JCI INTERNATIONAL CONFERENTE: Recent advances in concrete technology (SP-179), Tokushima, Japão, 7 a 11 de junho de 1998, Proceedings... Editores: V. M. Malhotra, publicado pelo ACI (E.U.A.), Tokushima, p. 671-690.

HO, D. W. S.; SHEINN, C. C.; NG, C. T. TAM (2001). The use of quarry dust for SCC applications. Cement and Concrete Research, Vol. 32, p. 505-511.

HOLSHEMACHER, K.; DEHN, F.; WEIBE, D. (2002). Bond in high-strength concrete - influence of rebar position. In: 6th INTERNATIONAL SYMPOSIUM ON UTILIZATION OF HIGH STRENGTH / HIGH-PERFORMANCE CONCRETE, Leipzig, Alemanha, junho de 2002, Proceedings..., Editores: Gert König; Frank Dehn; Thosten Faust, König, Heunisch und partner, consulting engineers, publicado por Leipzig University: Institute for structural concrete and building materials, ISBN: 3-934178-18-9, Leipzig: Leipzig University, p.289298.

HOLSHEMACHER, K; KLUG, Y. (2002). A database for the evaluation of hardened properties of SCC. LACER, No. 7, 12p. 
HUESTE, M. B. D.; ChOMPREDA, P.; TREJO, D.; Cline, D. B. H.; KEATING, P. B. (2004). Mechanical properties of high-strength concrete for prestressed members. ACI Structural Journal, Vol. 101, No. 4, July-August, pp. 457-465, 2004.

HWANG, S. J.; LEU, Y. R.; HWANG, H. L. (1996). Tensile bond strengths of deformed bars in high-strength concrete. ACl Structural Journal, Vol. 93, No. 1, Jan.-Feb., p. 11-20.

ISA, M. M.; AGUADO, A. (2003). Comportamento da aderência entre o concreto autoadensável de alta resistência e a armadura. IN: V Simpósio EPUSP sobre Estruturas de Concreto, Anais..., PEC/PCC - EPUSP, 7 a 10 de junho de 2003, São Paulo, SP, Brasil, ISBN: 85-86686-18-2, 8 p., [CD-ROM].

JIMEREZ, R.; WHITE, R. N.; GERGELY, P. (1979). Bond and dowel capacities of reinforced concrete. ACl Journal, Vol. 76, No. 1, Jan., p. 73-91.

KAKUTA, S.; KOKADO, T. (1996). A new workability test on consolidation-free flowing (CFF) concrete. In: PRODUCTIONS METHODS AND WORKABILITY OF CONCRETE (International RILEM Conference), Paisley, Scotland, 3 a 5 de junho de 1996, Proceedings... Editores: P. J. M. Bartos; D. L. Marrs; D. J. Cleland, published by E\&FN SPON (London), ISSN: 0-419-22070-4, Paisley: University of Paisley, p. 389-398.

KANKAM, C. K. (1997). Relationship of bond stress, steel stress, and slip in reinforced concrete. Journal of Structural Engineering. ASCE, Vol. 123, No. 1, January, p. 79-85.

KAWAGUCHI, N.; KOHNO, K.; KUROSE, Y.; BAKOSHI, T. (1998). Investigations on durability of high-volume fly ash concrete. In: FOURTH CANMET/ACI/JCI INTERNATIONAL CONFERENTE: Recent advances in concrete technology (SP-179), Tokushima, Japão, 7 a 11 de junho de 1998, Proceedings... Editores: V. M. Malhotra, publicado pelo ACI (E.U.A.), Tokushima, p. 714-730.

KEMP, E. L.; WILHELM, W. J. (1979). Investigation of the parameters influencing bond cracking. ACl Journal, Vol. 76, No. 1, Jan., p.47-71.

KENT, D. C.; PARK, R. (1971). Flexural members with confined concrete. Journal of the Structural Division, ASCE, Vol. 97, No. ST7, July, p. 1969-1990.

KHAYAT, K. H. (1998). Viscosity-enhancing admixtures for cement-based materials - an overview. Cement and Concrete Research, Vol. 20, p. 171-188.

KHAYAT, K. H. (1998). Use of viscosity-modifiying admixtures to reduce top-bar effect of anchored bars cast with fluid concrete. ACI Materials Journal, Vol. 95, No. 2, march-april, p. 158-167.

KHAYAT, K. H. (1999). Workability, testing, and performance of self-compacting concrete. ACI Materials Journal, Vol. 96, No. 3, May-june, p. 346-353. 
KHAYAT, K. H.; ASSAAD, J.; DACZKO, J. (2004). Comparison of field-oriented test methods to assess dynamic stability of self-consolidating concrete. ACl Materials Journal, Vol. 101, No. 2, March-april, p. 168-176.

KHEDR, S. A.; ABOU-ZEID, M. N. (1994). Characteristics of silica-fume concrete. Journal of Materials in Civil Engineering, ASCE, Vol. 6, No. 3, pp 357-375, 1994.

KIM, J. K.; HAN, S. H.; PARK, Y. D.; NOH, J. H.; PARK, C. L.; KWON, Y. H.; LEE, S. G. (1996). Experimental research on the material properties of super flowing concrete. In: PRODUCTIONS METHODS AND WORKABILITY OF CONCRETE (International RILEM Conference), Paisley, Scotland, 3 a 5 de junho de 1996, Proceedings... Editores: P. J. M. Bartos; D. L. Marrs; D. J. Cleland, published by E\&FN SPON (London), ISSN: 0-41922070-4, Paisley: University of Paisley, p. 271-284.

KACAOZ, S.; SAMARANAYAKE, V. A.; NANNI, A. (2005). Tensile characterization of glass FRP bars. Composites: Part B, Vol. 36, p. 127-134, 2005.

KONIG G.; HOLSHEMACHER, K.; DEHN, F.; WEISSE, D. (2001). Self-compacting concretetime development of material properties and bond behavior. In: INTERNATIONAL SYMPOSIUM ON SELFCOMPACTING CONCRETE, 2, Tokio, Proceedings... v. 1, 2001, p. 507-516.

KOTSOVOS, M. D.; PAVLOVIC, M. N. (1995). Structural concrete: finite-element analysis for limit-state design. Trowbridge: Thomas Telford, Redwood Books, 1st Edition, 559 p., ISBN: 0-7277-2027-9.

KRSTULOVIC-OPARA, N.; WATSON, K. A., LAFAVE, J. M. (1994). Effect of increased tensile strength and toughness on reinforcing-bar bond behavior. Cement and Concrete Composites, No. 16, p. 129-141.

KWAK, H.-G.; FILIPPOU, F. C. (1997). Nonlinear FE analysis of R/C structures under monotonic loads. Computer and Structures, Vol. 65, No. 1, p. 1-16.

KWANK, H.-G.; KIM, S.-P. (2001). Bond-slip behavior under monotonic uniaxial loads. Engineering structures, Vol. 23, p. 298-309.

LACHEMI, M.; HOSSAIN, K. M. A.; LAMBROS, V.; BOUZOUBAÂ. (2003). Development of costeffective self-consolidating concrete incorporating fly ash, slag cement, or viscositymodifying admixtures. ACI Materials Journal, Vol. 100, No. 5, September-october, p. 419425.

LANOS, C.; LAQUERBE, M.; CASANDJIAN, C. (1996). Rheological behavior of mortars and concretes: experimental approach. In: PRODUCTIONS METHODS AND WORKABILITY OF CONCRETE (International RILEM Conference), Paisley, Scotland, 3 a 5 de junho de 1996, Proceedings... Editores: P. J. M. Bartos; D. L. Marrs; D. J. Cleland, published by E\&FN SPON (London), ISSN: 0-419-22070-4, Paisley: University of Paisley, p. 343-354. 
LEE, H.-K.; IM, J.-Y.; LEE, K.-M.; KIM, B.-G. (2002). Shrinkage properties of high strength concrete containing fly ash. In: CONCRETE STRUCTURES IN THE 21st CENTURY: Proceedings of the first FIB congress, Osaka, Japan, março de 2002, Proceedings..., Publicado por Japan prestressed concrete engineering association \& Japan concrete institute, Osaka, [CD-ROM].

LIN, C.-H.; LEE, W.-C. (2003). Shear behavior of high-workability concrete beams. ACl Materials Journal, Vol. 100, No. 5, sept.-oct., p. 599-608.

LIN, Y.-H.; TYAN, Y.-Y.; CHANG, T.-P.; CHANG, C.-Y. (2004) An assessment of optimal mixture for concrete made with recycled concrete aggregates. Cement and Concrete Research, Vol. 34, p. 1373-1380, 2004.

LORRIAN, M.; MAUREL, O. (1998). Pull-out behavior of high yield strength steel deformed bars embedded in high strength concrete. In: FOURTH CANMET/ACI/JCI INTERNATIONAL CONFERENTE: Recent advances in concrete technology (SP-179), Tokushima, Japão, 7 a 11 de junho de 1998, Proceedings... Editores: V. M. Malhotra, publicado pelo ACl (E.U.A.), Tokushima, p. 995-1010.

LOSBERG, A.; OLSSON, P. (1979). Bond Failure of Deformed Reinforcing Bars Based on the Longitudinal Splitting Effect of the Bars. ACl Journal, Vol. 76, No. 1, Jan., p. 5-17.

LUNDGREN, K.; GUSTAVSON, R.; MAGNUSSON, J. (2002). Finite element modelling as a tool to understand the bond mechanisms. Proceedings..., Bond in concrete - from research to standards, 8 p., Budapest.

LUTZ, L. A.; GERGELEY, P. (1967). Mechanics of bond and slip of deformed bars in concrete. ACl Journal, Vol. 64, No. 11, Nov., p. 711-721.

MALHOTRA, V. M. (1989). Superplasticizers: a global review with emphasis on durability and innovative concretes. In: Superplasticizers and Other Chemical Admixtures in Concrete (SP-119) - Third International Conference, Proceedings..., Ottawa, Canada, 1989, Vol. 1, p 1-17.

MAZLOOM, M.; RAMEZANIANPOUR, A. A.; BROOKS, J. J. (2004). Effect of the silica fume on the mechanical properties of high-strength concrete. Cement \& Concrete Composites, Vol. 26, p. 347-357.

McLEISH, A. (1996). Flowable concrete for structural repairs. Part IX - Special cements and concretes. In: PRODUCTIONS METHODS AND WORKABILITY OF CONCRETE (International RILEM Conference), Paisley, Scotland, 3 a 5 de junho de 1996, Proceedings... Editores: P. J. M. Bartos; D. L. Marrs; D. J. Cleland, published by E\&FN SPON (London), ISSN: 0-419-22070-4, Paisley: University of Paisley, p. 515-522.

MELCHERS, R. E. (1987). Structural Reliability: analysis and prediction, Ellis Horwood Limited, ISBN: 0-85312-930-4, 1987. 
MELHLHORN, G.; KEUSER, M. (1985). Isoparametric contact elements for analysis of reinforced concrete structures. In: FINITE ELEMENT ANALYSIS OF REINFRCED CONCRETE STRUCTURES, 1985, Tokyo, Japan. Proceedings...Editores: Christian Meyer \& Hajime Okamura, published by ASCE, ISBN 0-87262-549-4, Japan: University of Tokyo, p. 329-347.

MIRZA, S. M.; HOUDE, J. (1979). Study of bond stress-slip relationships in reinforced concrete. ACl Journal, Vol. 76, No. 1, Jan., p. 19-45.

MISHIMA, T. (2002). A performance design method of RC structures using high strength selfcompacting concrete and high strength steel bars. . In: CONCRETE STRUCTURES IN THE 21st CENTURY: Proceedings of the first FIB congress, Osaka, Japan, março de 2002, Proceedings..., Publicado por Japan prestressed concrete engineering association \& Japan concrete institute, Osaka, [CD-ROM].

MORENO JÚNIOR, A. L.; ROSSI, N. (2002). Resistência de aderência da armadura passiva no concreto de alto desempenho. In: JORNADAS SUL-AMERICANAS DE ENGENHARIA ESTRUTURAL, Brasília-DF, 27 a 31 de Maio de 2002, Anais... Brasília: UnB [1 CDROM].

MORITA, S.; FUJII, S. (1985). Bond-slip models in finite element analysis. In: FINITE ELEMENT ANALYSIS OF REINFRCED CONCRETE STRUCTURES, 1985, Tokyo, Japan. Proceedings..., Editores: Christian Meyer \& Hajime Okamura, published by ASCE, ISBN 0-87262-549-4, Japan: University of Tokyo, p. 348-363.

MORITA, S.; KAKU, T. (1979). Splitting bond failures of large deformed reinforcing bars. ACI Journal, Vol. 76, No. 1, Jan., p. 93-109.

MORTSELL, E.; MAAGE, M.; SMEPLASS, S. (1996). A particle-matrix model for prediction of workability of concrete. In: PRODUCTIONS METHODS AND WORKABILITY OF CONCRETE (International RILEM Conference), Paisley, Scotland, 3 a 5 de junho de 1996, Proceedings... Editores: P. J. M. Bartos; D. L. Marrs; D. J. Cleland, published by E\&FN SPON (London), ISSN: 0-419-22070-4, Paisley: University of Paisley, p. 429-438.

NETO, J. M.; ASSAN, A. E. (2003). Deslizamento entre o aço e o concreto: modelagem computacional de estruturas submetidas à tração uniaxial. In: V Simpósio EPUSP sobre Estruturas de Concreto, Anais..., PEC/PCC - EPUSP, 7 a 10 de junho de 2003, São Paulo, SP, Brasil, ISBN: 85-86686-18-2, 19 p., [CD-ROM].

NGO, D.; SCOEDELIS, A. C. (1967). Finite element analysis of reinforced concrete beams. Journal of American Concrete Institute, Vol. 64, No. 3, p. 152-164.

NIELSEN, M. P. (1984). Limit analysis and concrete plasticity. Prentice-Hall series in Civil Engineering and Engineering Mechanics, Editores: N. N. Newmark \& W. J. Hall, PrenticeHall, Inc., Englewood Cliffs, New Jersey 07632, 432 p., ISBN 0-13-536623-2. 
NIELSEN, M. P. (1998). Limit analysis and concrete plasticity. 2a. ed., CRC Press, 908 p., ISBN 0-8493-9126-1.

NISHIBAYASHI, S.; YOSHINO, A.; INOUE, S.; KURODA, T. (1996). Effect of properties of mix constituents on rheological constants of self-compacting concrete. In: PRODUCTIONS METHODS AND WORKABILITY OF CONCRETE (International RILEM Conference), Paisley, Scotland, 3 a 5 de junho de 1996, Proceedings... Editores: P. J. M. Bartos; D. L. Marrs; D. J. Cleland, published by E\&FN SPON (London), ISSN: 0-419-22070-4, Paisley: University of Paisley, p. 255-262.

NISHIO, A.; TAMURA, H.; OHASHI, M. (1998). Self-compacting concrete with high-volume crushed rock fines. In: FOURTH CANMET/ACI/JCI INTERNATIONAL CONFERENTE: Recent advances in concrete technology (SP-179), Tokushima, Japão, 7 a 11 de junho de 1998, Proceedings... Editores: V. M. Malhotra, publicado pelo ACI (E.U.A.), Tokushima, p. 617-630.

NOGUCHI, T; OH, S. G.; TOMOSAWA, F. (1999). Rheological approach to passing ability between reinforcing bars of self-compacting concrete. In: Proceedings of First International RILEM Symposium of Self-Compacting Concrete, Proceedings..., RILEM Publications, S.A.R.L., Estocolmo, Japan, 1999, 12 p., p. 83-94.

NUNES, S.; COUTINHO, J. S.; FIGUEIRAS, J. (2003). Tecnologia do betão auto-compactável. In: V Simpósio EPUSP sobre Estruturas de Concreto, Anais..., PEC/PCC - EPUSP, 7 a 10 de junho de 2003, São Paulo, SP, Brasil, ISBN: 85-86686-18-2, 15 p., [CD-ROM].

OGASAWARA, T.; NAITO, H.; MIURA, T.; ABE, Y,; OHMURA, R. (1998). Study on subsidence and shrinkage of super-workable concrete. In: FOURTH CANMET/ACI/JCI INTERNATIONAL CONFERENTE: Recent advances in concrete technology (SP-179), Tokushima, Japão, 7 a 11 de junho de 1998, Proceedings... Editores: V. M. Malhotra, publicado pelo $\mathrm{ACl}$ (E.U.A.), Tokushima, p. 631-650.

OKAMURA; H. (1997). Self-compacting high-performance concrete. Concrete International, Vol. 19 , No. 7 , July, p. 50-54

OKAMURA, H.; OUCHI, M. (2003). Self-compacting concrete. Journal of Advanced Concrete Technology, Vol. 1, No. 1, April, 2003, p. 5-15.

ORAGUN, C. O.; JIRSA, J. O.; BREEN, J. E. (1977). A reevaluation of test data on development length and splices. ACI Journal, Vol. 74, No. 3, Mar., p. 114-122.

PAPADAKIS, V. G. (1999). Experimental investigations and theoretical modeling of silica fume activity in concrete. Cement and Concrete Research, Vol. 29, p. 79-86.

PERSSON, B. (2001). A comparison between mechanical properties of self-compacting concrete and the corresponding properties of normal concrete. Cement and Concrete Research, Vol. 31, p. 193-198. 
PERSSON, B.; TERRASI, G. P. (2002). High performance self-compacting concrete, HPSCC. In: 6th INTERNATIONAL SYMPOSIUM ON UTILIZATION OF HIGH STRENGTH / HIGHPERFORMANCE CONCRETE, Leipzig, Alemanha, junho de 2002, Proceedings..., Editores: Gert König; Frank Dehn; Thosten Faust, König, Heunisch und partner, consulting engineers, publicado por Leipzig University: Institute for structural concrete and building materials, ISBN: 3-934178-18-9, Leipzig: Leipzig University, p. 1273-1290.

PETERSSON, Ö. (1999) Final report of task 2: Workability. SCC, Swedish Cement and Concrete Research Institute, $56 \mathrm{p}$.

PETERSSON, Ö. (2000). Final report of task 1: preliminary mix design. SCC, Swedish Cement and Concrete Research Institute, $41 \mathrm{p}$.

PETERSSON, Ö; BILLBERG, P.; VAN, B. K. (1996). A model for self-compacting concrete. In: PRODUCTIONS METHODS AND WORKABILITY OF CONCRETE (International RILEM Conference), Paisley, Scotland, 3 a 5 de junho de 1996, Proceedings... Editores: P. J. M. Bartos; D. L. Marrs; D. J. Cleland, published by E\&FN SPON, ISSN: 0-419-22070-4, Paisley: University of Paisley, p. 483-492.

POPOVICS, S. (1973). A numerical approach to the complete stress-strain curve of concrete. Cement and Concrete Research, Vol. 3, p. 583-599.

RAO, G. A.; PRASAD, B.K.R. (2002). Influence of the roughness of aggregate surface on the interface bond strength. Cement and Concrete Research, Vol. 32, p. 253-257.

RILEM-FIP-CEB (1973). Bond test for reinforcing steel: 1-Beam test (7-II-28 D). 2-Pullout test (7-II-128): Tentative recommendations. RILEM Journal Materials and Structures, Vol. 6, No. 32, Março-abril, p. 96-105.

RILEM-FIP-CEB (1983). Bond test for reinforcing steel: Beam test, recommendation RC 5. Concrete Reinforcement Technology, Paris, França.

RILEM-FIP-CEB (1983). Bond test for reinforcing steel: pull-out test, recommendation RC 6. Concrete Reinforcement Technology, Paris, França.

RIVIERA, R.; DÁVILA, R.; DURÁN, A. (1998). High-strength high-performance concrete using fly ash and superplasticizer admixture. In: HIGH-PERFORMANCE CONCRETE AND PERFORMANCE AND QUALITY OF CONCRETE STRUCTURES: Proceedings of the second CANMET/ ACI INTERNATIONAL CONFERENTE (SP-186), Gramado - RS, Brazil, 1 a 4 de junho de 1999, Proceedings... Editores: V. M. Malhotra; P. Helene; L. R. Prudêncio Jr.; D. C. C. Dal Molin, publicado pelo ACI (E.U.A.), Gramado, p. 341-356.

ROLS, S.; AMBROISE, J.; PÉRA, J. (1999). Effects of different viscosity agents on the properties of self-leveling concrete. Cement and Concrete Research, V. 29, pp. 261-266.

RONCERO, J. (2000). Effect of superplasticizers on the behavior of concrete in the fresh and hardened states: implications for high performance concretes. Tese de Doutorado, 
Universitat Politècnica de Catalunya, Escola Tècnica Superior D’Enginyers de Camins, Canals i Ports de Barcelona, 189 p., Barcelona, Spain.

ROTS, J. G. (1989). Bond of reinforcement. In: ELFGREN, L. Fracture mechanics of concrete structures: from theory to applications. Report of the Technical Committee 90-FMA Fracture Mechanics to Concrete - Applications, RILEM, Suffolk: St. Edmund Press Ltd, ISBN: 0-412-30680-8, Cap. 12, p. 245-262.

SAAK, A. W.; JENNINGS, H. M.; SHAH, S. P. (2001). New methodology for designing selfcompacting concrete. ACl Materials Journal, Vol. 98, No. 6, Nov.-Dec., p. 429-439.

SAKATA, N.; MARUYAMA, K.; MINAMI, M. (1996). Basic properties and effects of welan gum on self-consolidating concrete. In: PRODUCTIONS METHODS AND WORKABILITY OF CONCRETE (International RILEM Conference), Paisley, Scotland, 3 a 5 de junho de 1996, Proceedings... Editores: P. J. M. Bartos; D. L. Marrs; D. J. Cleland, published by E\&FN SPON (London), ISSN: 0-419-22070-4, Paisley: University of Paisley, p. 236-254.

SALARI, M. R.; SPACONE, E. (2001). Finite element formulations of one dimensional elements with bond-slip. Engineering Structures, Vol. 23, p. 815-826.

SARI, M.; PRAT, E.; LABASTIRE, J.-F. (1999). High strength self-compacting concrete: original solutions associating organic and inorganic admixtures. Cement and Concrete Research, Vol. 29, p. 813-818.

SCOTT, B. D.; PARK, R.; PRIESTLEY, M. J. N. (1982). Stress-strain behavior of concrete confined by overlapping hoops at low and high strain rates. Journal of $A C l$, Vol. 79, p. 1327.

SEDRAN, T. (2000). Final report of task 3: Rheology. SCC, LCPC, 20 p.

SEDRAN, T.; DE LARRARD, F.; HOURST, F.; CONTAMINES, C. (1996). Mix design of selfcompacting concrete (SCC). In: PRODUCTIONS METHODS AND WORKABILITY OF CONCRETE (International RILEM Conference), Paisley, Scotland, 3 a 5 de junho de 1996, Proceedings... Editores: P. J. M. Bartos; D. L. Marrs; D. J. Cleland, published by E\&FN SPON, ISSN: 0-419-22070-4, Paisley: University of Paisley, p. 439-450.

SENGUL, O.; TASDEMIR, C.; YÜCCER, Z.; ERBAYDAR, M.; TASDEMIR, M. A. (2002). Mechanical behavior of high strength concretes with high volume fly ash. In: 6th INTERNATIONAL SYMPOSIUM ON UTILIZATION OF HIGH STRENGTH / HIGHPERFORMANCE CONCRETE, Leipzig, Alemanha, junho de 2002, Proceedings..., Editores: Gert König; Frank Dehn; Thosten Faust, König, Heunisch und partner, consulting engineers, publicado por Leipzig University: Institute for structural concrete and building materials, ISBN: 3-934178-18-9, Leipzig: Leipzig University, p.1407-1420.

SHINDOH, T.; MATSUOKA, Y. (2003). Development of combination-type self-compacting concrete and evaluation test methods. Journal of Advanced Concrete Technology, Vol. 1, No. 1, pp. 26-36. 
SHINDOH, T.; YOKOTA, K.; YOKOI, K. (1996). Effect of mix constituents on rheological properties of super workable concrete. In: PRODUCTIONS METHODS AND WORKABILITY OF CONCRETE (International RILEM Conference), Paisley, Scotland, 3 a 5 de junho de 1996, Proceedings... Editores: P. J. M. Bartos; D. L. Marrs; D. J. Cleland, published by E\&FN SPON (London), ISSN: 0-419-22070-4, Paisley: University of Paisley, p. 263-270.

SILVEIRA, J. P.; ROCHA, J. C.; CHERIAF, M. (2004). Desenvolvimento de blocos de concreto com uso das cinzas de termelétricas. In: I CONFERÊNCIA LATINO-AMERICANA DE CONSTRUÇÃO SUSTENTÁVEL (ClaCS'04); X ENCONTRO NACIONAL DE TECNOLOGIA DO AMBIENTE CONSTRUÍDO (ENTAC'04), Anais..., São Paulo - SP, Brasil, 18-21 de julho de 2004, ISBN: 85-89478-08-4, 11f.

SIMONE, A.; WELLS, G. N.; SLUYS, L. J. (2001). A novel technique for modeling interfaces in reinforced brittle materials. IN: Fracture Mechanics of Concrete Structures, Proceedings..., Fourth International Conference on Fracture Mechanics of Concrete and Concrete Structures, 28 de maio a 1 de junho, 2001, Cachan, França, Ed.: R. de Borst, J. Mazars, G. Pijaudier-Cabot, J. G. M. Van Mier, Publicado por Swets \& Zeitlinger - Lisse, p. 841-846.

SOBOLEV, K. G.; SOBOLEVA, S. V. (1998). High-performance concrete mixture proportioning. In: FOURTH CANMET/ACI/JCI INTERNATIONAL CONFERENTE: Recent advances in concrete technology (SP-179), Tokushima, Japão, 7 a 11 de junho de 1998, Proceedings... Editores: V. M. Malhotra, publicado pelo ACl (E.U.A.), Tokushima, p. 421438.

SONEBI, M. (2004). Medium strength self-compacting concrete containing fly ash: modelling using factorial experiments plans. Cement and Concrete Research, Vol. 34, p. 11991208.

SONEBI, M.; BARTOS, P. J. M.; ZHU, W.; GIBBS, J.; TAMIMI, A. (2000). Final report of task 4: Properties of hardened concrete. SCC, Advance Concrete Masonry Centre (University of Paisley), $73 \mathrm{p}$.

SONEBI, M.; TAMIMI, A. K.; BARTOS, P. J. M. (2003). Performance and cracking behavior of reinforced beams cast with self-compacting concrete. ACl Materials Journal, Vol. 100, No. 6, November-december, p. 492-500.

SONG, P. S.; WU, J. C.; HWANG, S.; SHEU, B. C. (2005). Assessment of statistical variations in impact resistance of high-strength concrete and high-strength fiber-reinforced concrete. Cement and Concrete Research, Vol. 35, p. 393-399, 2005.

SONG, P. S.; WU, J. C.; HWANG, S.; SHEU, B. C. (2005). Statistical analysis of impact strength and strength reliability of steel-polypropylene hybrid fiber-reinforced concrete. Construction and Building Materials, Vol. 19, p. 1-9, 2005. 
SORETZ, S.; HÖLZENBEIN, H. (1979). Influence of rib dimensions of reinforced bars on bond and bendability. ACl Journal, Vol. 76, No. 1, Jan., p. 111-125.

SORETZ, S. (1972). Comparison of beam tests and pull-out tests. Matériaux et Constructions, Vol. 5, No. 28, July-Aug., p. 261-264.

SOROUSHIAN, P.; CHOI, K. B. (1989). Local bond of deformed bars with different diameters in confined concrete. ACl Materials Journal, Vol. 86, No. 2, Mar.-April, p. 217-222.

SOROUSHIAN, P.; CHOI, K. B.; PARK, G. H.; ASLANI, F. (1991). Bond of deformed bars to concrete: effects of confinement and strength of concrete. ACl Materials Journal, V. 88, No. 3, May- June, p. 227-232.

SU, N.; HSU, K.-C.; CHAI, H.-W. (2001). A simple mix design method for self-compacting concrete. Cement and Concrete Research, Vol. 31, p. 1799-1807.

SUGIYAMA, T.; OHTA, A; TANAKA, Y. (1998). Shrinkage reduction type of advanced superplasticizer. In: FOURTH CANMET/ACI/JCI INTERNATIONAL CONFERENTE: Recent advances in concrete technology (SP-179), Tokushima, Japão, 7 a 11 de junho de 1998, Proceedings... Editores: V. M. Malhotra, publicado pelo ACl (E.U.A.), Tokushima, p. 189-200.

SWAMY, R. N. (1989). Superplasticizers and concrete durability. In: Superplasticizers and Other Chemical Admixtures in Concrete (SP-119) - Third International Conference, Proceedings..., Ottawa, Canada, 1989, Vol. 1, p. 361-382.

TAKADA, K.; PELOVA, G. I.; WALRAVEN, J. C. (1998). Influence of mixing efficiency on the mixture proportion of general purpose self-compacting concrete. In: INTERNATIONAL SYMPOSIUM ON HIGH-PERFORMANCE AND REACTIVE POWDER CONCRETES VOLUME 2, Sherbrooke - Canada, 16 a 20 de agosto de 1998, Proceedings..., Editores: Pierre-Claude Aïtcin \& Yves Delagrave, Université de Sherbrooke, Sherbrooke, p. 19-40.

TAKENAKA, H.; KAKIZAKI, M.; ABE, Y.; OKADA, M. (1998). Effects of specimen preparation on the properties of fresh and hardened high fluidity concretes. In: FOURTH CANMET/ACI/JCI INTERNATIONAL CONFERENTE: Recent advances in concrete technology (SP-179), Tokushima, Japão, 7 a 11 de junho de 1998, Proceedings... Editores: V. M. Malhotra, publicado pelo ACI (E.U.A.), Tokushima, p. 605-616.

THIELEN, G.; KORDTS, S.; SPANKA, G. (2002). Rheological and setting behavior of mortar and concrete. In: CONCRETE STRUCTURES IN THE 21st CENTURY: Proceedings of the first FIB congress, Osaka, Japan, março de 2002, Proceedings..., Publicado por Japan prestressed concrete engineering association \& Japan concrete institute, Osaka, [CD-ROM].

TORRESAN, I.; KHURANA, R. (1998). New superplasticizers based on modified melanine polymer. In: FOURTH CANMET/ACI/JCI INTERNATIONAL CONFERENTE: Recent advances in concrete technology (SP-179), Tokushima, Japão, 7 a 11 de junho de 1998, 
Proceedings... Editores: V. M. Malhotra, publicado pelo ACI (E.U.A.), Tokushima, p. 235254.

TOUTANJI, H. A.; EL-KORCHI, T. (1995). The influence of silica fume on the compressive strength of cement paste and mortar. Cement and Concrete Research, Vol. 25, No. 7, p. 1591-1602.

TUTIKIAN, B. F.; KUHN, R. O.; BRESCOVIT, S. J.; DAL MOLIN, D. C. C.; CREMONINI, R. A. (2004). Comparação da curva de dosagem, resistência à tração, consumo de materiais e custos dos concretos auto-adensáveis com metacaulim e fíler calcário. Volume II Construções em concreto. In: $46^{\circ}$ Congresso Brasileiro do Concreto - IBRACON, Florianópolis, Brasil, 14-18 de agosto de 2004, Anais..., Editores: Ivo J. Padaratz \& Túlio N. Bittencourt, ISBN: 85-98576-02-6, Florianópolis, Trabalho CBC0390, p. II.431-II.442.

TVIKSTA, L.-G. (2000a). Final report of task 8.4: quality control. SCC, NCC AB, 28 p.

TVIKSTA, L.-G. (2000b). Final report of task 9: End product. SCC, NCC, 48 p.

URRETA, J. I.; ETXEBERRIA, A.; RAMIREZ, J. L.; GORBEÑA, J. (1998). Effect of limestone filler content on the compressive strength of high performance concrete. In: INTERNATIONAL SYMPOSIUM ON HIGH-PERFORMANCE AND REACTIVE POWDER CONCRETES - VOLUME 2, Sherbrooke - Canada, 16 a 20 de agosto de 1998, Proceedings..., Editores: Pierre-Claude Aïtcin \& Yves Delagrave, Université de Sherbrooke, Sherbrooke, p. 75-96.

VAN, B. K.; MONTGOMERY, D. G.; HINCZAK, I.; TURNER, K. (1998). Rapid tests methods for segregation resistance and filling ability of self-compacting concrete. In: FOURTH CANMET/ACI/JCI INTERNATIONAL CONFERENTE: Recent advances in concrete technology (SP-179), Tokushima, Japão, 7 a 11 de junho de 1998, Proceedings... Editores: V. M. Malhotra, publicado pelo ACI (E.U.A.), Tokushima, p. 85-103.

WALLEVIK, O.; SIMMERMAN, T. (1996). Effect of some plasticizers on the rheological behavior of fresh concrete paste. In: PRODUCTIONS METHODS AND WORKABILITY OF CONCRETE (International RILEM Conference), Paisley, Scotland, 3 a 5 de junho de 1996, Proceedings... Editores: P. J. M. Bartos; D. L. Marrs; D. J. Cleland, published by E\&FN SPON (London), ISSN: 0-419-22070-4, Paisley: University of Paisley, p. 307-318.

WILD, S.; SABIR, B. B.; KHATIB, J. M. (1995). Factors influencing strength development of concrete containing silica fume. Cement and Concrete Research, Vol. 25, No. 7, p. 15671580.

XIE, Y.; LIU, B.; YIN, J.; ZHOU, S. (2002). Optimum mix parameters of high-strength selfcompacting concrete with ultrapulverized fly ash. Cement and Concrete Research, Vol. 32, p. $477-480$.

YAMADA, K.; HANEHARA, S. (2002). Incompatibility between cement and superplasticizer and the prevention method. In: CONCRETE STRUCTURES IN THE 21st CENTURY: 
Proceedings of the first FIB congress, Osaka, Japan, março de 2002, Proceedings..., Publicado por Japan prestressed concrete engineering association \& Japan concrete institute, Osaka, [CD-ROM].

YANG, C. C.; HUANG, R. (1996). Double inclusion model for approximate elastic moduli of concrete material. Cement and Concrete Research, Vol. 26, No. 1, p. 83-91.

YANKELEVSKY, D. Z. (1997). A two-phase one dimensional model for steel-concrete interaction. Computer and Structures, Vol. 65, No. 6, p. 781-794.

YASUMOTO, A.; EDAMATSU, Y.; MIZUKOSHI, M.; NAGAOKA, S. (1998). Study on the shrinkage crack resistance of self-compacting concrete. In: FOURTH CANMET/ACI/JCI INTERNATIONAL CONFERENTE: Recent advances in concrete technology (SP-179), Tokushima, Japão, 7 a 11 de junho de 1998, Proceedings... Editores: V. M. Malhotra, publicado pelo ACI (E.U.A.), Tokushima, p. 651-670.

YOGENDRAN, V.; LANGRAN, B. W.; HAQUE, M. N.; WARD, M. A. (1987). Silica fume in highstrength concrete. ACI Materials Journal, Vol. 84, No. 2, Mar.-Apr., p. 124-129.

YOGENDRAN, V.; LANGRAN, B. W.; WARD, M. A. (1991). Hydration of cement and silica fume paste. Cement and Concrete Research, Vol. 21, No. 5, pp. 691-708.

ZENG, S.; HELA, R. (2002). Application of activated fly ash in mortar and concrete. In: CONCRETE STRUCTURES IN THE 21st CENTURY: Proceedings of the first FIB congress, Osaka, Japan, março de 2002, Proceedings..., Publicado por Japan prestressed concrete engineering association \& Japan concrete institute, Osaka, [CDROM].

ZHOR, J.; BREMNER, T. W. (1998). Advances in evaluation of lignosulphonates as concrete admixtures. In: FOURTH CANMET/ACI/JCI INTERNATIONAL CONFERENTE: Recent advances in concrete technology (SP-179), Tokushima, Japão, 7 a 11 de junho de 1998, Proceedings... Editores: V. M. Malhotra, publicado pelo ACI (E.U.A.), Tokushima, p. 1011-1042.

ZHU, W.; GIBBS, J. C.; BARTOS, P. J. M. (2001). Uniformity of in situ properties of selfcompacting concrete in full scale structural elements. Cement \& Concrete Composites, Vol. 23, p. 57-64. 